Universidad de Lima

Facultad de Arquitectura

Carrera de Arquitectura

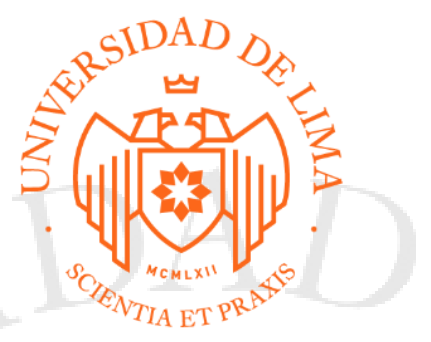

\title{
RESIDENCIA Y CENTRO DE DÍA PARA EL ADULTO MAYOR DE CHORRILLOS Y ALTO PERÚ
}

Trabajo de Suficiencia Profesional.Proyecto de Fin de Carrera para optar el título profesional en Arquitectura

\section{Stephanie Gael Alcalá Reyes}

Código 20111498

\section{Asesor}

Valerie More

$$
\text { Lima - Perú }
$$

Agosto de 2019 


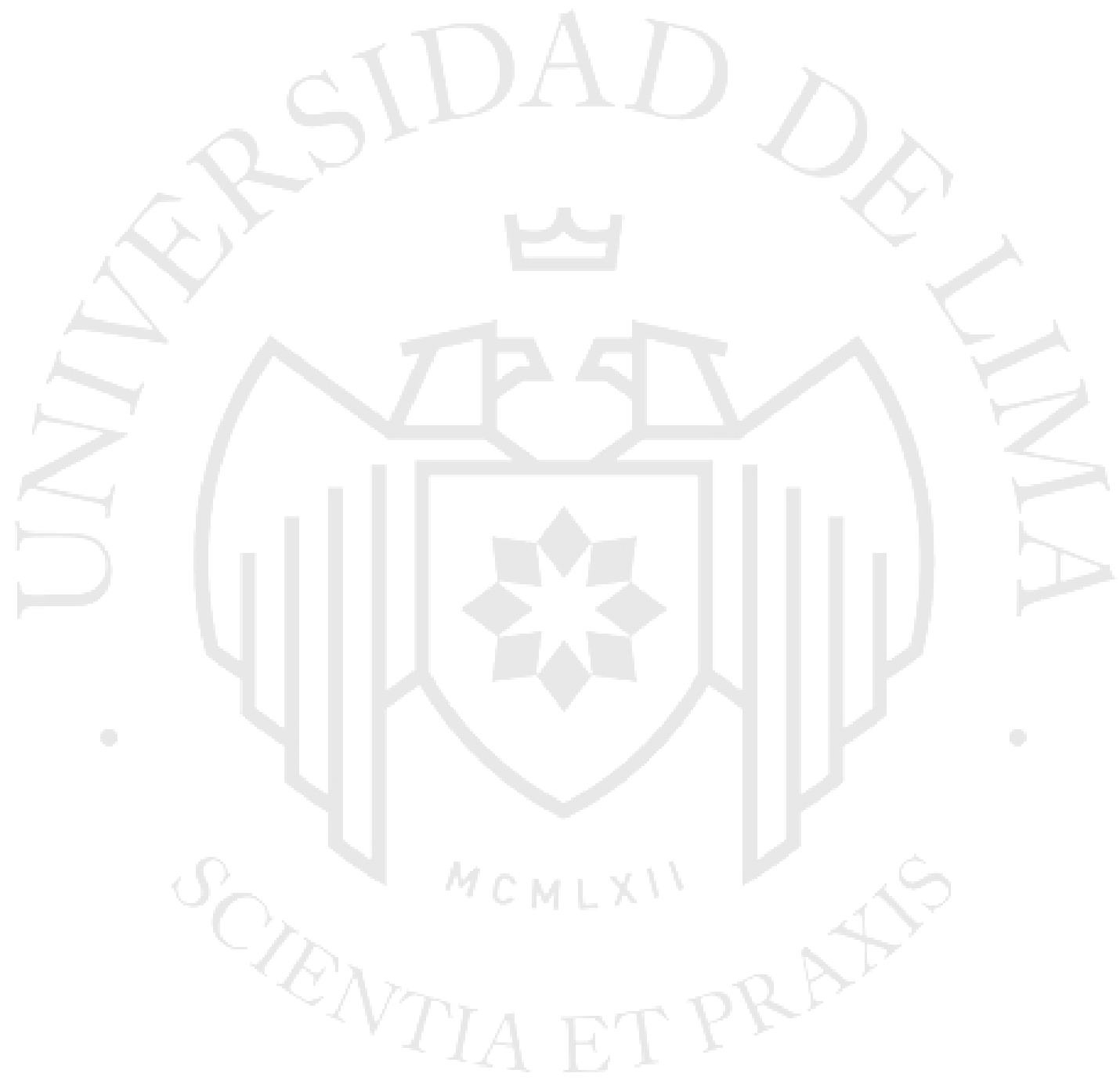




\section{RESIDENCIA Y CENTRO DE DÍA PARA EL ADULTO MAYOR DE CHORRILLOS Y ALTO PERÚ}




\section{TABLA DE CONTENIDO}

CAPITULO I: GENERALIDADES....................................................3

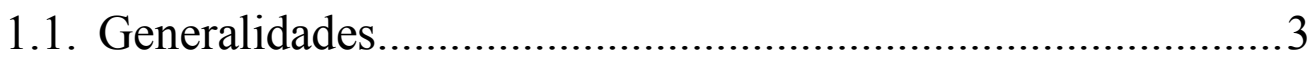

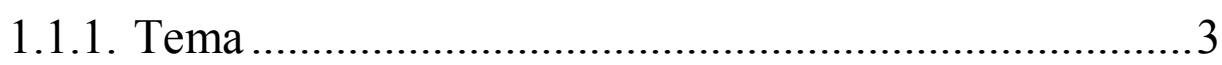

1.1.2. Justificación de tema..................................................... 4

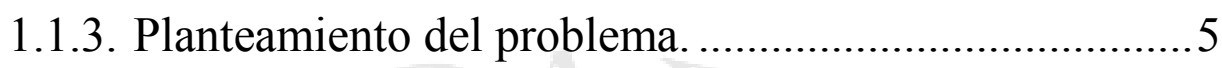

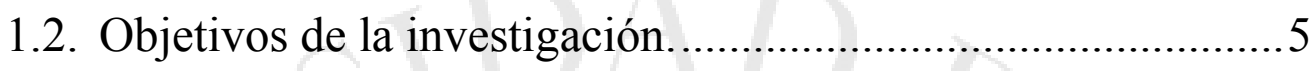

1.2.1. Objetivos generales. .................................................... 5

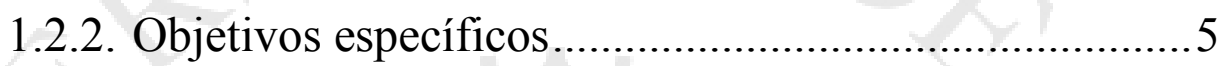

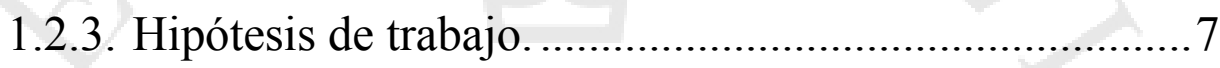

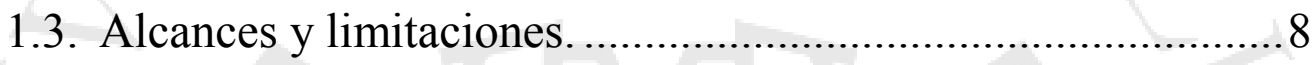

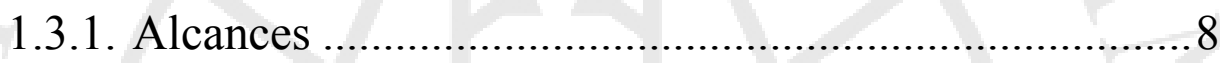

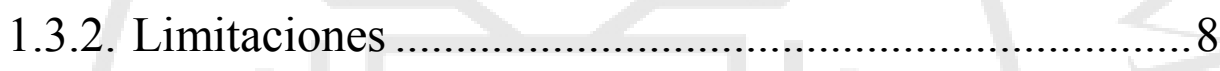

CAPITULO II: MARCO REFERENCIAL _..................................9

2.1. El adulto mayor en la historia y la evolución de los centros de

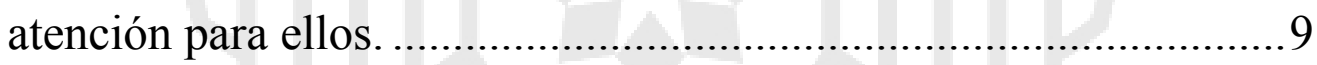

2.2. Evolución de la atención del adulto mayor en el Perú.............14

2.3. Crecimiento demográfico del adulto mayor a nivel mundial y en

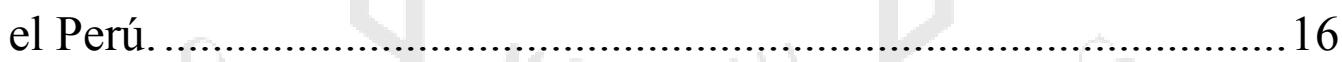

2.4. Centros de atención para el adulto mayor en Lima ...................22

2.5. El adulto mayor de bajos recursos y en estado de abandono. . 25

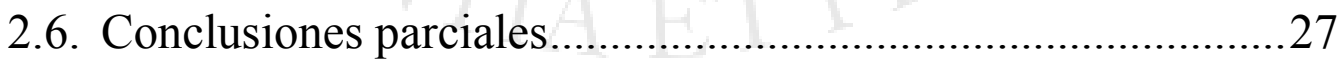

CAPITULO III: MARCO TEÓRICO ...........................................28

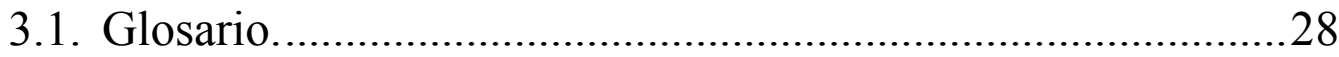

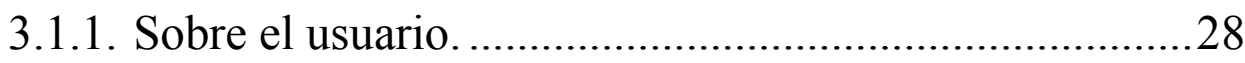

3.1.2. Términos relacionados con los adultos mayores............30

3.1.3. Sobre los centros de asistencia para el adulto mayor....31 
3.1.4. Cuadro comparativo de los centros de asistencia para el adulto mayor

3.2. Consecuencias del envejecimiento en relación con los centros para el adulto mayor.

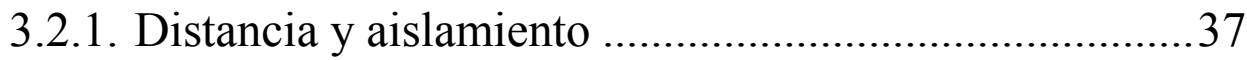

3.2.2. Cambio de vida: de dinámico a pasivo............................39

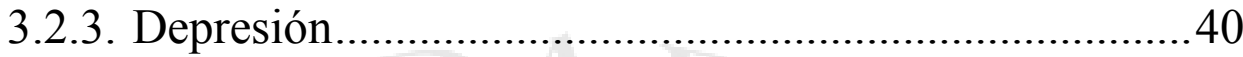

3.2.4. Cambio de vida: de hogar a asilo ...................................41

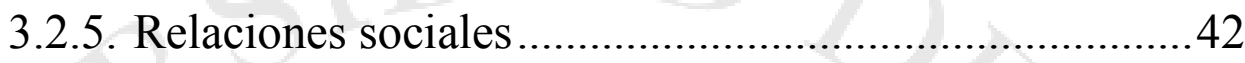

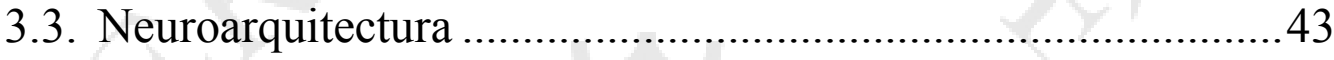

3.4. Arquitectura y permeabilidad como elemento de articulación e

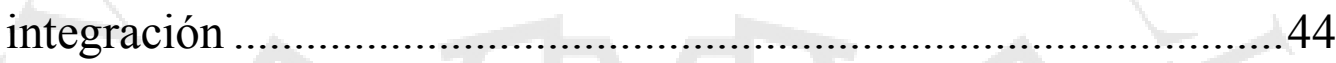

3.5. Características de diseño de los centros de asistencia para

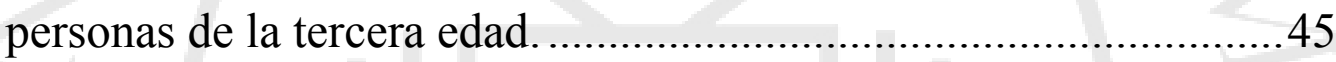

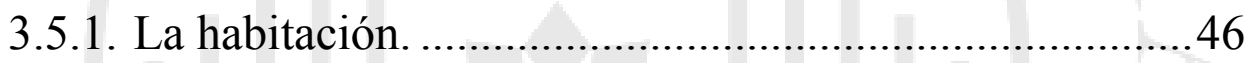

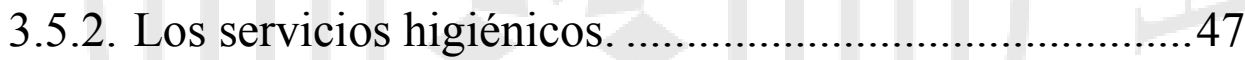

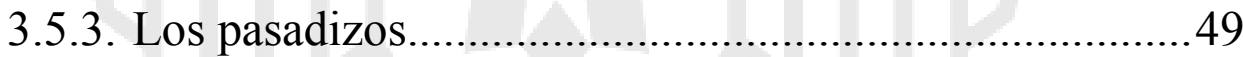

3.6. Leyes y normas a favor de las personas de la tercera edad.....50

3.6.1. Día del adulto mayor. ......................................................50

3.6.2. Otras acciones internacionales para las personas de la tercera edad .............................................................50

3.6.3. Ley de protección del Adulto Mayor $\mathrm{N}^{\circ} 4339$..............52

3.6.4. Ley del adulto mayor $\mathrm{N}^{\circ} 28803$....................................53

3.6.5. Ayuda económica y sistemas de pensiones.....................54

3.7. Programas de asistencia para el adulto mayor...........................58

3.7.1. Programas de asistencia pública.....................................59

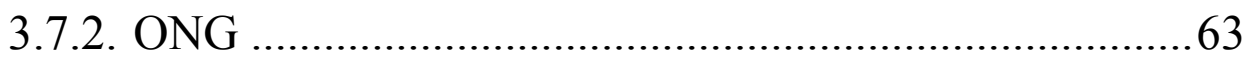

3.7.3. Comunidades religiosas..................................................63

3.8. Parámetros nacionales e internacionales. ................................64 
3.8.1. Reglamento Nacional de Edificaciones (RNE) 64

3.8.2. Organización Iberoamericana de Seguridad Social (OISS).

3.8.3. Cuadro comparativo entre las normas peruanas y las establecidas por la OISS. .65

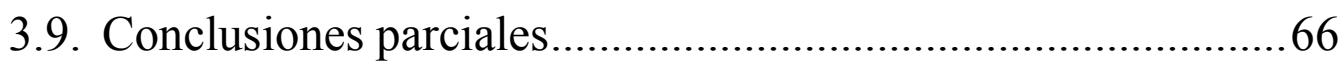

CAPITULO IV: MARCO OPERATIVO ...........................................667

4.1 Instituto Benéfico Social Padre Rubinos...................................68

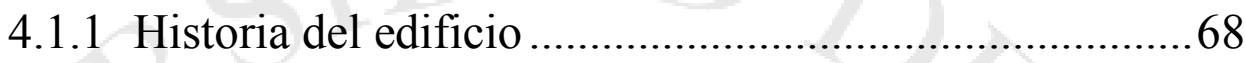

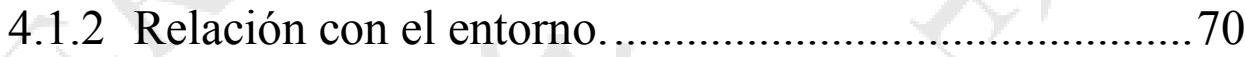

4.1.3 Programas y relaciones programáticas..........................72

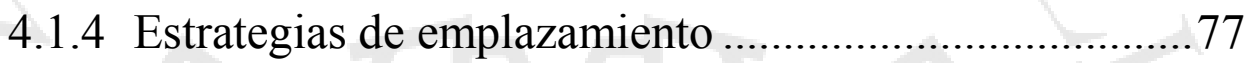

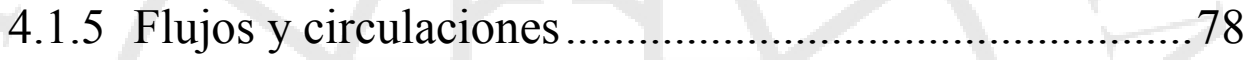

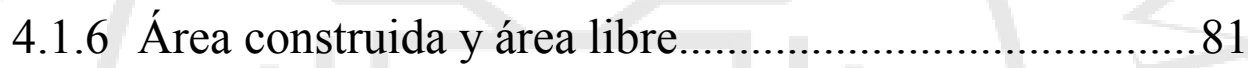

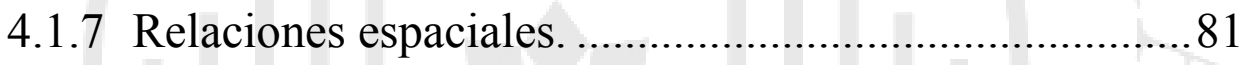

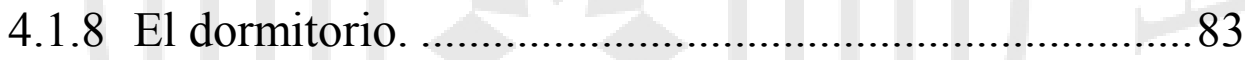

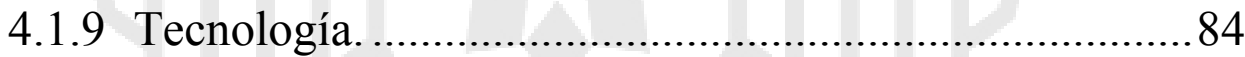

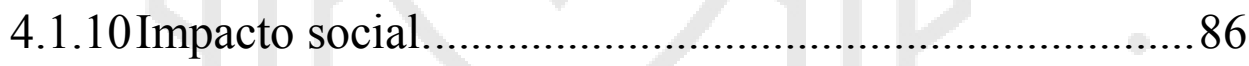

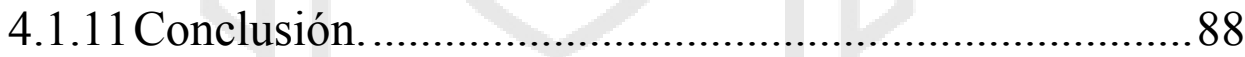

4.2 Residencia para personas mayores "El Molino" ......................8 88

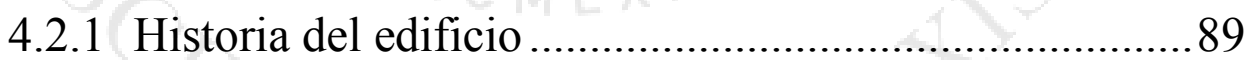

4.2.2 Relación con el entorno..................................................91

4.2.3 Programa y relaciones programáticas. ...........................94

4.2.4 Estrategias de emplazamiento ........................................97

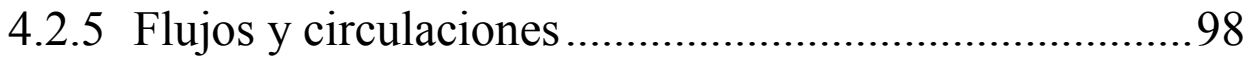

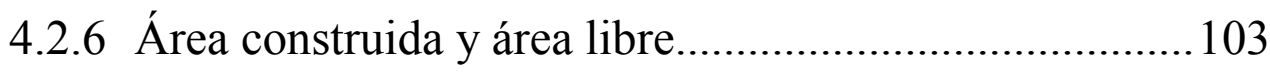

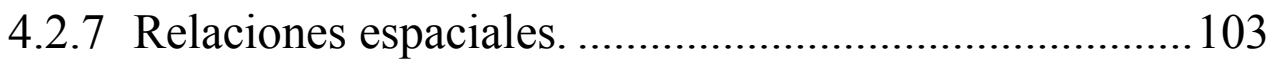

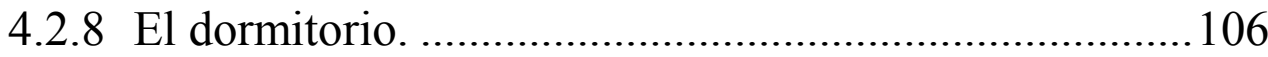

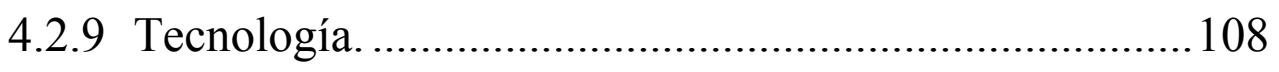




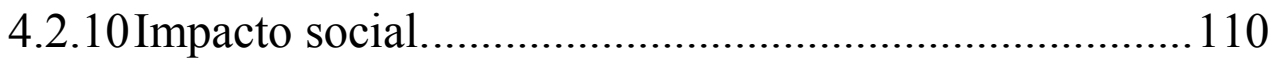

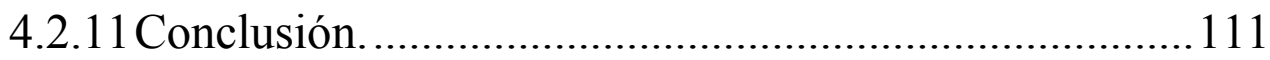

4.3. Guardería y Residencia de la tercera edad...............................112

4.3.1. Historia del edificio....................................................... 112

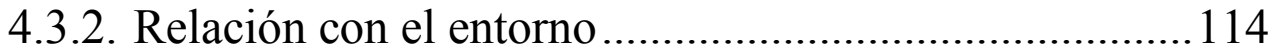

4.3.3. Programas y relaciones programáticas.......................... 117

4.3.4. Estrategias de emplazamiento. ...................................... 122

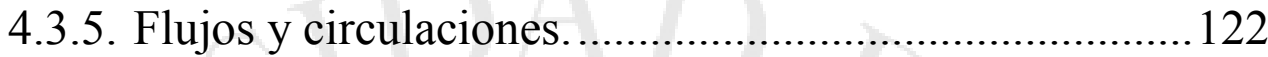

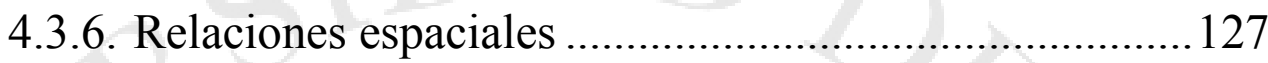

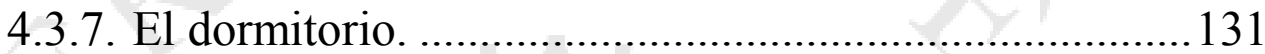

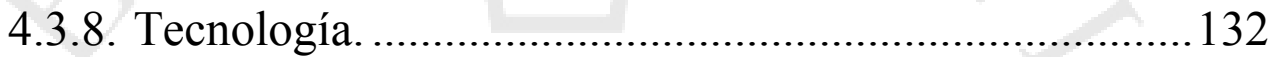

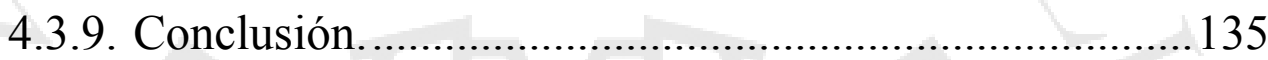

4.4. Hogar Para Personas Mayores Dulce Estancia........................136

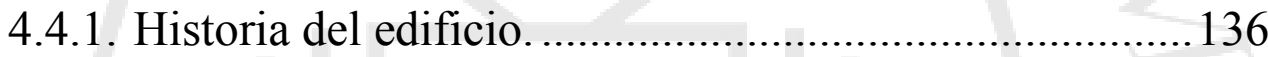

4.4.2. Relación con el entorno................................................... 138

4.4.3. Programa y relaciones programáticas. ........................... 141

4.4.4. Estrategias de emplazamiento....................................... 144

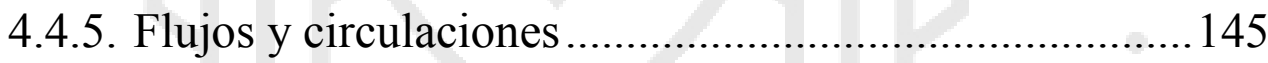

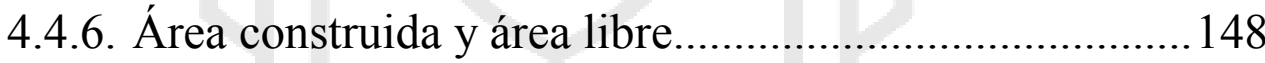

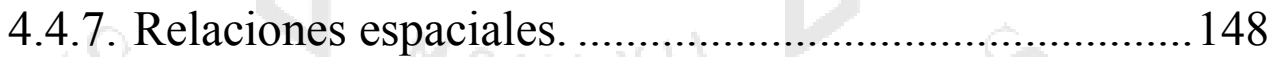

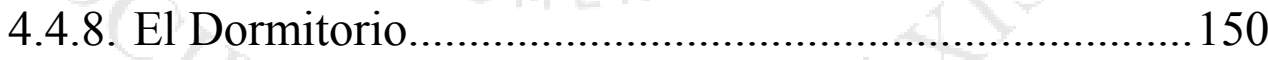

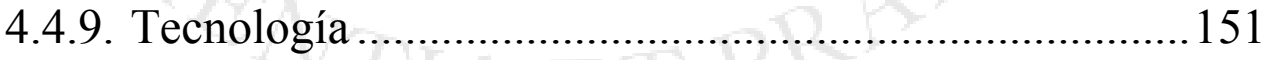

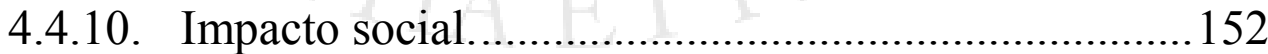

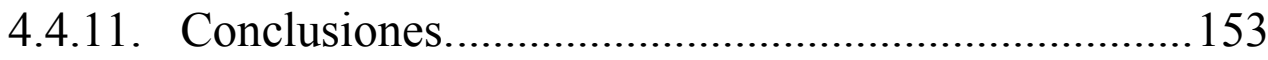

4.5. Casa Hogar "La Piedad"............................................................ 154

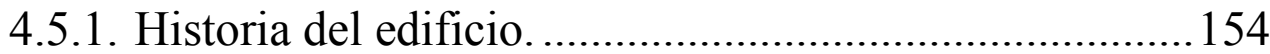

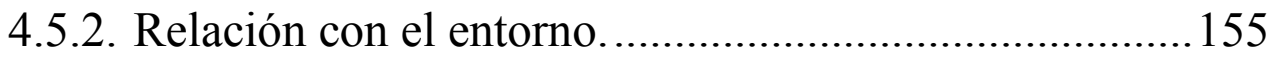

4.5.3. Programa y relaciones programáticas. ........................... 157

4.5.4. Estrategias de emplazamiento........................................ 161 


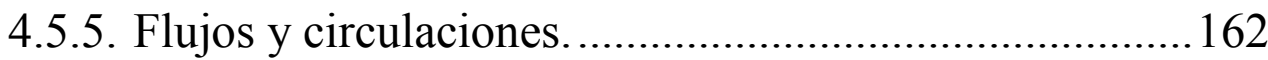

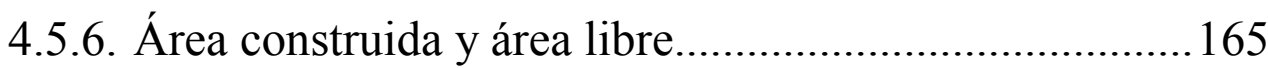

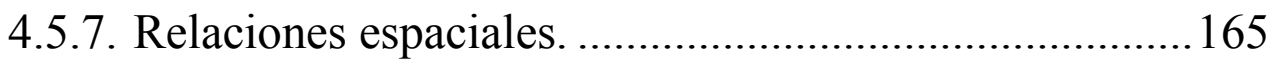

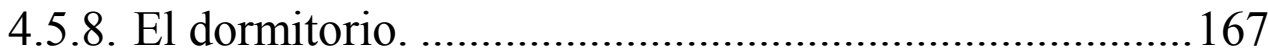

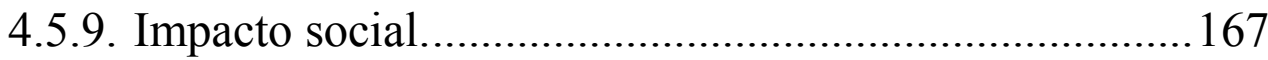

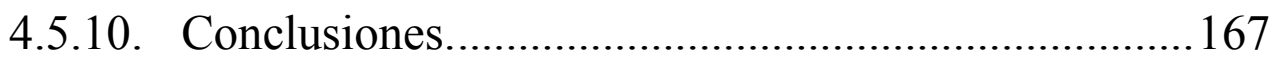

4.6. Conclusiones Parciales ............................................................. 167

CAPÍTULO V: MARCO CONTEXTUAL...........................................169

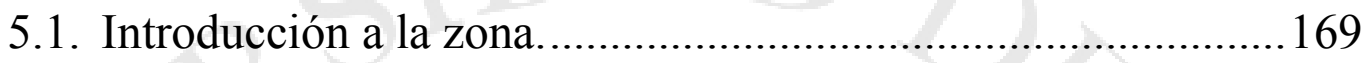

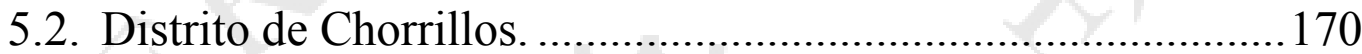

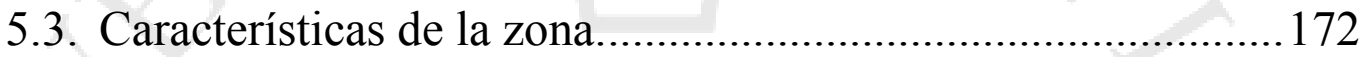

5.4. Asentamiento Humano Alto Perú.............................................. 175

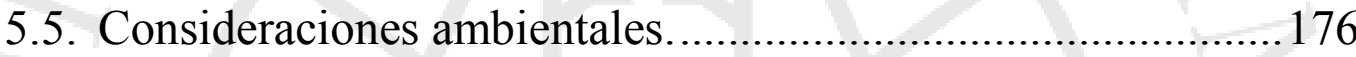

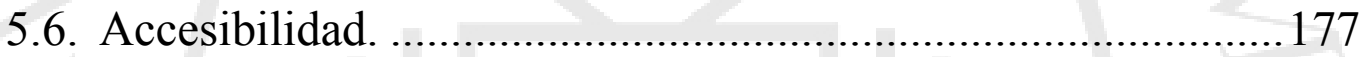

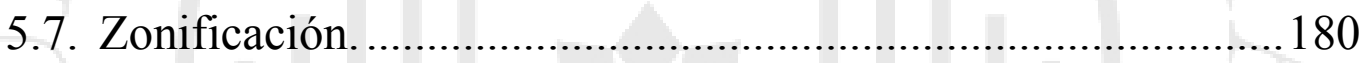

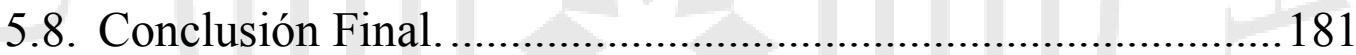

CAPÍTULO VI: ANÁLISIS DE CONTEXTO. ....................................182

CAPITULO VII: PROYECTO.................................................184

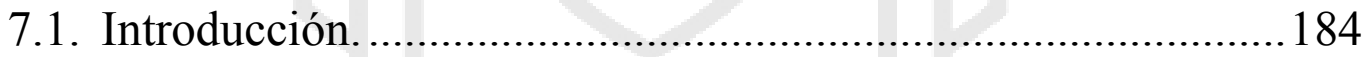

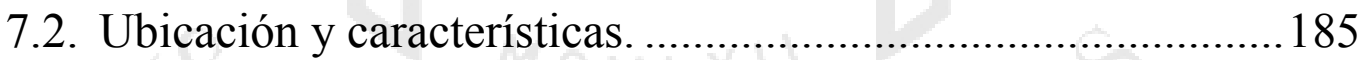

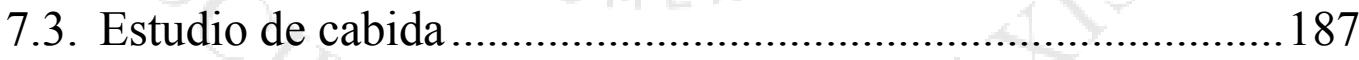

7.4. Programa arquitectónico......................................................... 189

7.5. Usuario y aforo permitido......................................................... 198

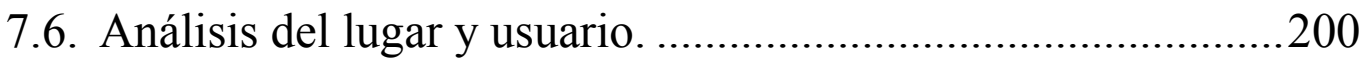

7.7. Panorama general del proyecto................................................201

7.8. Viabilidad, sostenibilidad y tecnología del proyecto. ..............203

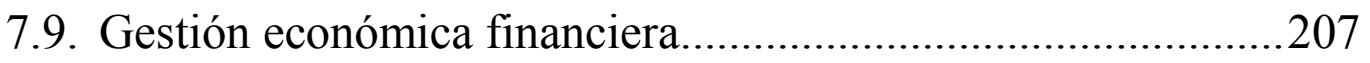

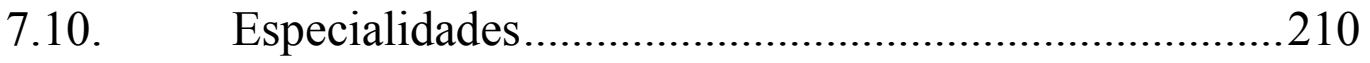

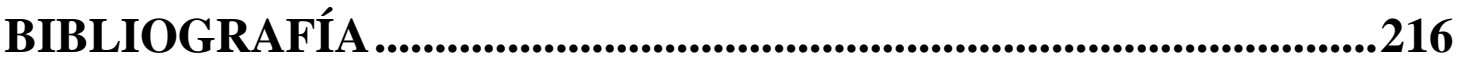




\section{INDICE DE FIGURAS}

Figura 2.3.1 (Crecimiento de la población mundial mayor de 60 años)................16

Figura 2.3.2 (Crecimiento de la población mayor de 60 años en el Perú)................17

Figura 2.3.3 (Esperanza de vida al nacer desde 1950 proyectada a 2100 - Mujeres).....19

Figura 2.3.4 (Esperanza de vida al nacer desde 1950 proyectada a 2100 - Hombres)....19

Figura 2.3.5 (Población adulta mayor en el Perú según sexo)......................20

Figura 2.3.5 (Adultos mayores por condición de actividad y sexo)..................21

Figura 2.4.1 (Mapeo de Centros de Atención Residencial actuales en Lima

Metropolitana.)..............................................................24

Figura 2.5.1 (Aprueban programa para rescatar a adultos mayores en abandono).......26

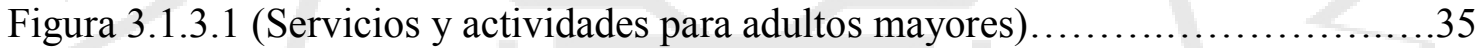

Figura 3.1.3.2 (Servicios y actividades para adultos mayores) $. \ldots \ldots \ldots \ldots \ldots \ldots \ldots \ldots . \ldots \ldots$

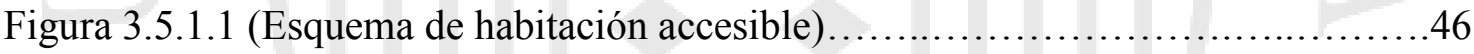

Figura 3.5.1.2 (Esquema de habitación accesible) ................................47

Figura 3.5.2.1 (Esquema de baño accesible)..................................48

Figura 3.5.3.1 (Esquema de pasadizo accesible) $\ldots \ldots \ldots \ldots \ldots \ldots \ldots \ldots \ldots \ldots \ldots \ldots \ldots \ldots$

Figura 3.6.5.4.1 (Pensión 65) ..................................................58

Figura 3.7.1.1.1 (Actividades CIAM de La Molina) ..............................60

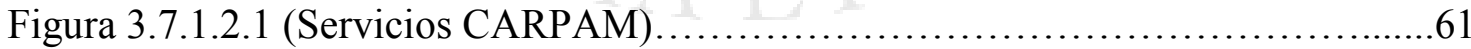

Figura 3.7.1.3.1 (Actividades CAM) .......................................62

Figura 3.7.3.1.1 (Adultos Mayores en Cáritas del Perú) ..........................64

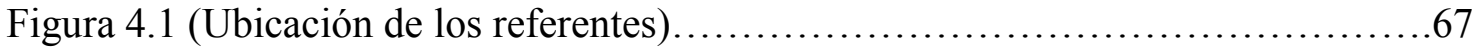

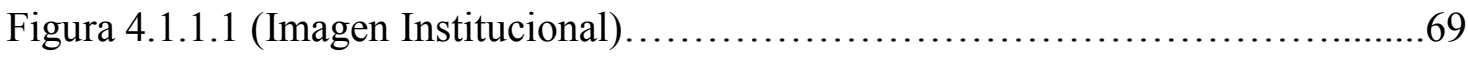

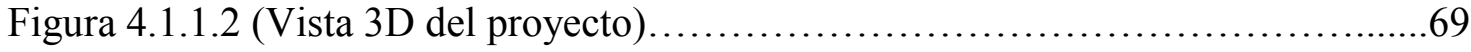


Figura 4.1.2.1 (Ubicación del proyecto en A Coruña)............................ 70

Figura 4.1.2.2 (Ubicación Macro del proyecto en A Coruña).........................70

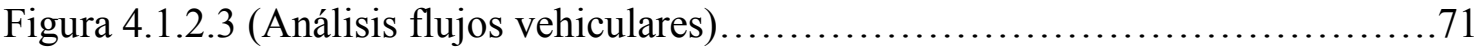

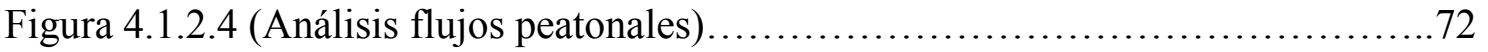

Figura 4.1.3.1 (Planta dividida por áreas) ..................................... 73

Figura 4.1.3.2 (Porcentaje de Áreas Instituto Benéfico Social Padre Rubinos)..........76

Figura 4.1.4.1 (Estrategias de emplazamiento)..................................77

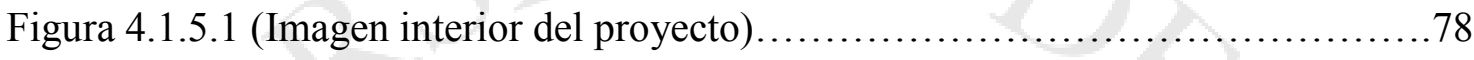

Figura 4.1.5.2 (Imagen interior del proyecto) ..................................79

Figura 4.1.5.3 (Imagen interior del proyecto) ....................................79

Figura 4.1.5.4 (Análisis de flujo peatonal en el proyecto).........................80

Figura 4.1.7.1 (Análisis relaciones espaciales) $\ldots \ldots \ldots \ldots \ldots \ldots \ldots \ldots \ldots \ldots \ldots \ldots \ldots \ldots . . \ldots 1$

Figura 4.1.8.1 (Habitación en Padre Rubinos) ....................................... 83

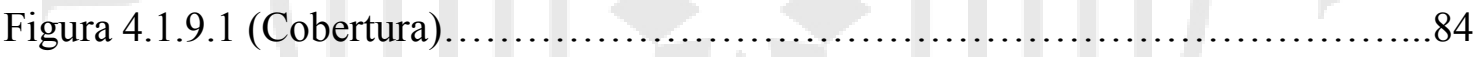

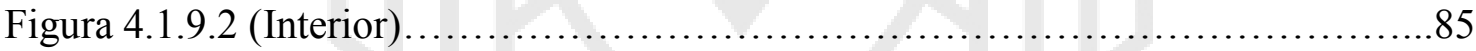

Figura 4.1.9.3 (Exterior)................................................ 85

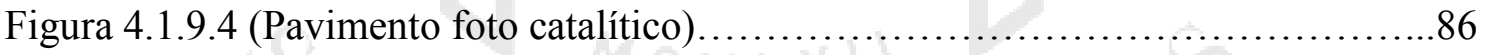

Figura 4.1.10.1 (Artículo sobre Instituto Benéfico Social Padre Rubinos)..............87

Figura 4.1.10.2 (Artículo sobre Instituto Benéfico Social Padre Rubinos)..............87

Figura 4.2.1.1 (Afiche de presentación de Los Molinos)..........................90

Figura 4.2.1.2 (Imágenes del interior de proyecto) .............................90

Figura 4.2.2.1 (Ubicación del distrito de Mota del Cuervo)........................91

Figura 4.2.2.2 (Ubicación de la residencia en el distrito de Mota del Cuervo)...........91

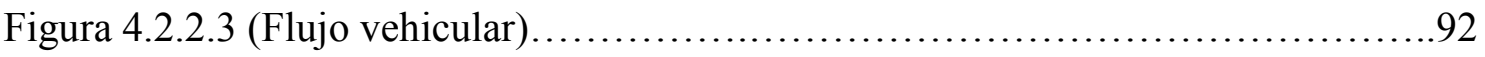


Figura 4.2.2.4 (Flujo peatonal).............................................93

Figura 4.2.2.5 (Corte A-A') .................................................. 93

Figura 4.2.3.1 (Planta dividida por áreas - nivel -1$) \ldots \ldots \ldots \ldots \ldots \ldots \ldots \ldots \ldots \ldots \ldots \ldots \ldots$

Figura 4.2.3.2 (Planta dividida por áreas - nivel 1) .............................95

Figura 4.2.3.3 (Planta dividida por áreas - nivel 2).............................95

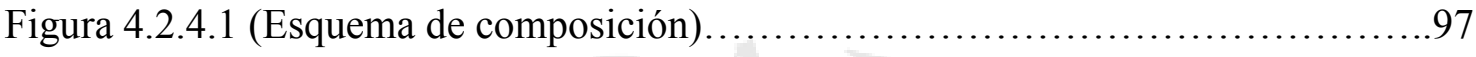

Figura 4.2.5.1 (Imagen interior de la Residencia)..................................98

Figura 4.2.5.2 (Imagen interior de la Residencia)...............................99

Figura 4.2.5.3 (Imagen interior de la Residencia).................................99

Figura 4.2.5.4 (Análisis de flujo peatonal en el proyecto).........................100

Figura 4.2.5.5 (Análisis de flujo peatonal en el proyecto).........................101

Figura 4.2.5.6 (Análisis de flujo peatonal en el proyecto)........................102

Figura 4.2.7.1 (Análisis relaciones espaciales) ................................. 103

Figura 4.2.7.2 (Análisis relaciones espaciales)................................ 104

Figura 4.2.7.3 (Análisis relaciones espaciales)................................... 104

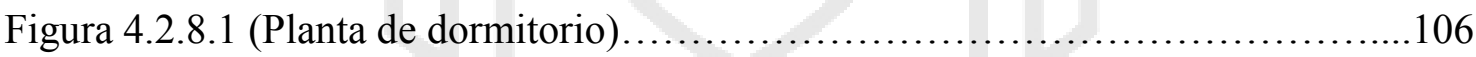

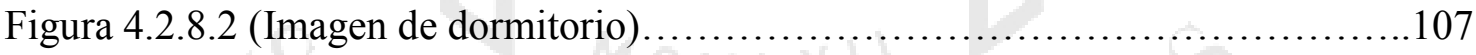

Figura 4.2.8.3 (Vista del baño al interior del dormitorio)..........................107

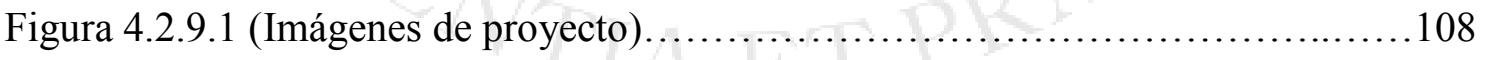

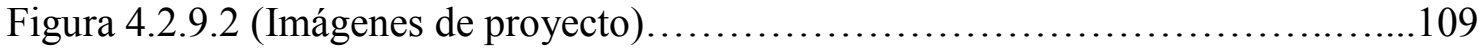

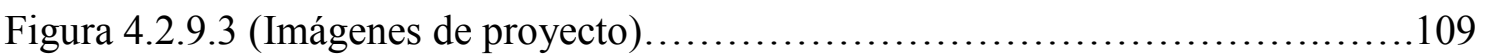

Figura 4.2.10.1 (Imágenes de artículo) .................................... 110

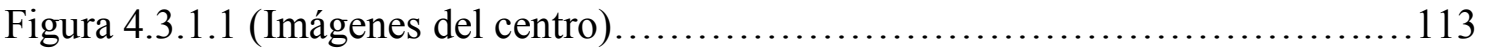

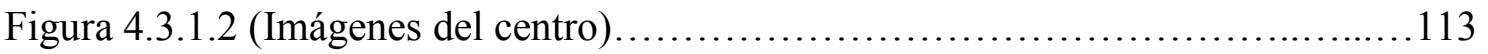


Figura 4.3.2.1 (Ubicación Macro del proyecto en Rennes)..........................114

Figura 4.3.2.2 (Ubicación Macro del proyecto en Rennes)...........................114

Figura 4.3.2.1 (Análisis de flujo vehicular de vías cercanas) $\ldots \ldots \ldots \ldots \ldots \ldots \ldots \ldots \ldots 115$

Figura 4.3.2.2 (Análisis de flujo peatonal de vías cercanas)......................116

Figura 4.3.3.1 (Planta dividida por áreas) ................................... 117

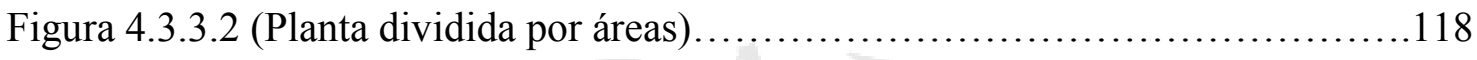

Figura 4.3.3.3 (Planta dividida por áreas) ....................................118

Figura 4.3.3.4 (Planta dividida por áreas) .................................. 119

Figura 4.3.3.5 (Planta dividida por áreas) .....................................119

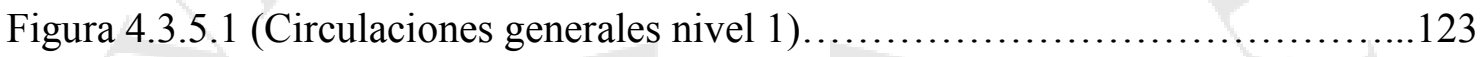

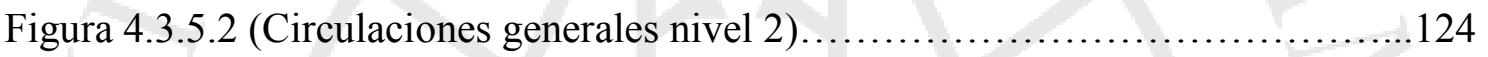

Figura 4.3.5.3 (Circulaciones generales nivel 3,4,5) ............................. 125

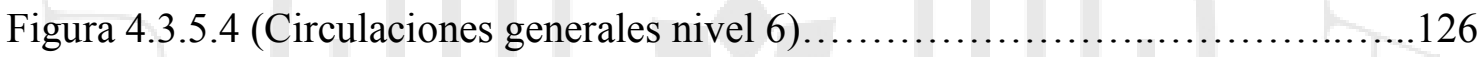

Figura 4.3.6.1 (Análisis relaciones espaciales nivel -1)..........................127

Figura 4.3.6.2 (Análisis relaciones espaciales nivel 1)............................ 128

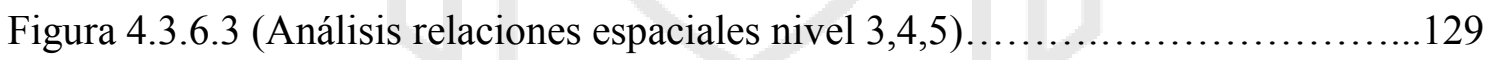

Figura 4.3.6.4 (Análisis relaciones espaciales nivel 6).......................... 130

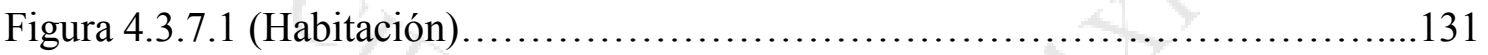

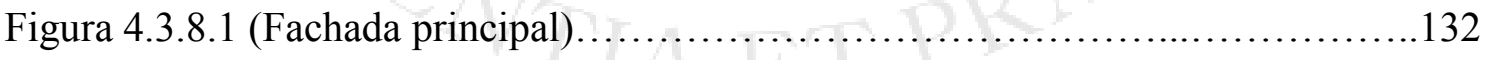

Figura 4.3.8.2 (Fachada lateral)..............................................

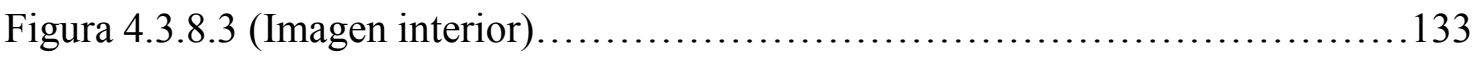

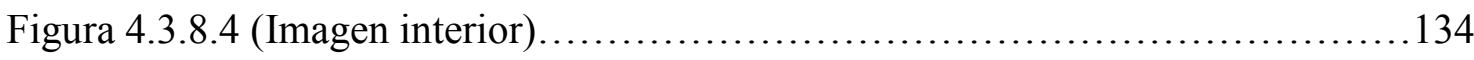

Figura 4.3.8.5 (Imagen interior)........................................... 134

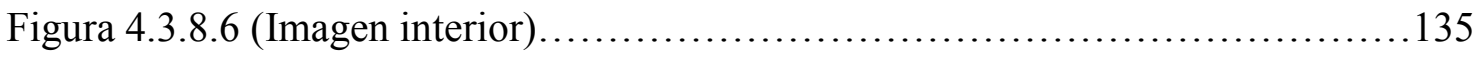


Figura 4.4.1.1 (Fachada Hogar para personas mayores Dulce Estancia)..............137

Figura 4.4.1.2 (Fachada Hogar para personas mayores Dulce Estancia)................138

Figura 4.4.2.1 (Ubicación Guadalajara)....................................... 138

Figura 4.4.2.2 (Ubicación de proyecto en ciudad de Guadalajara)...................139

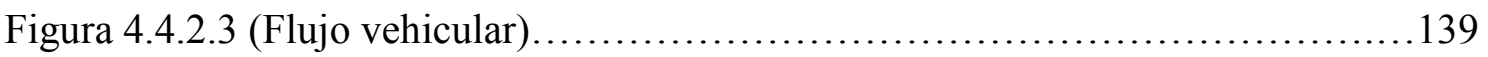

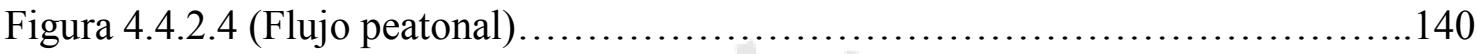

Figura 4.4.3.1 (Planta dividida por áreas - nivel 1) .............................141

Figura 4.4.3.1 (Planta dividida por áreas - nivel 2) ............................. 142

Figura 4.4.4.1 (Esquema de composición)....................................144

Figura 4.4.5.1 (Adultos mayores en actividades)................................. 145

Figura 4.4.5.2 (Circulaciones generales primera planta)..........................146

Figura 4.4.5.3 (Circulaciones generales primera planta)...........................147

Figura 4.4.7.1 (Esquema de área construida y área libre)............................148

Figura 4.4.7.2 (Esquema de área construida y área libre)............................149

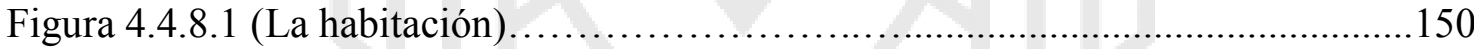

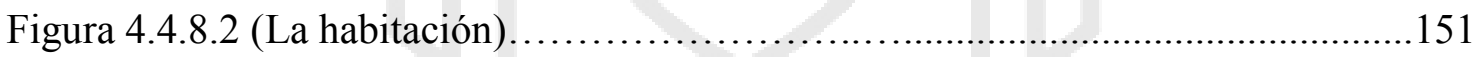

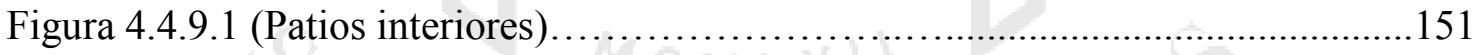

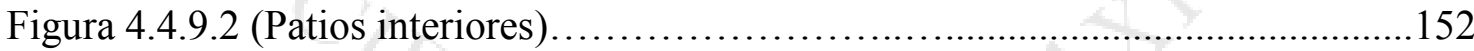

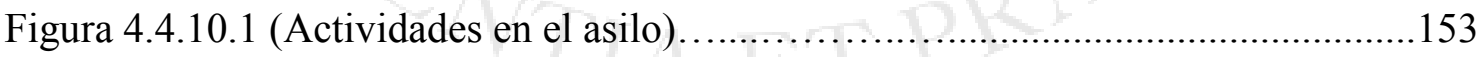

Figura 4.5.1.1 (Fachada Casa Hogar La Piedad)...................................................155

Figura 4.5.1.1 (Ubicación de la ciudad de Lima)..................................................155

Figura 4.5.2.2 (Ubicación del proyecto en la ciudad de Lima)..................................156

Figura 4.5.2.3 (Ubicación del proyecto en la ciudad de Lima)..................................156

Figura 4.5.2.4 (Ubicación del proyecto en la ciudad de Lima)....................................156 
Figura 4.5.2.4 (Planta dividida por áreas - nivel 1) ................................................158

Figura 4.5.2.4 (Planta dividida por áreas - nivel 2)...............................................159

Figura 4.5.4.1 (Estrategias de emplazamiento)..................................................161

Figura 4.5.5.1 (Plano de flujos y circulaciones)......................................................163

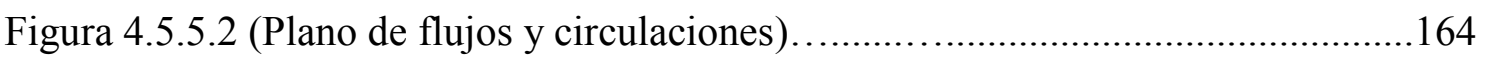

Figura 4.5.7.1 (Esquema de área construida y área libre)....................................165

Figura 4.5.7.2 (Esquema de área construida y área libre).......................................166

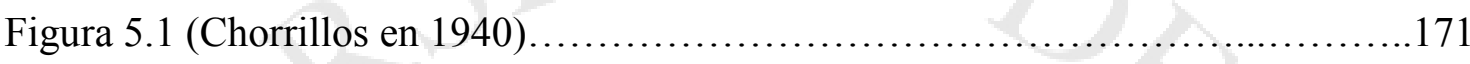

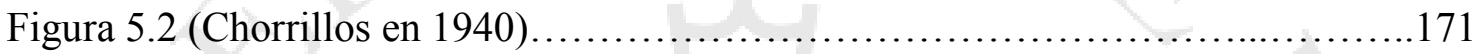

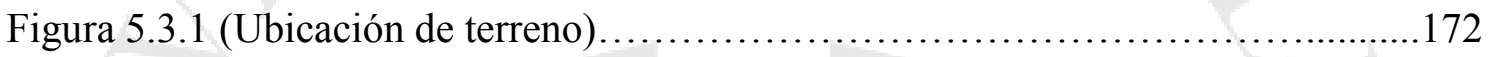

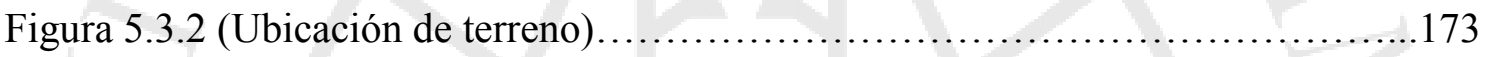

Figura 5.3 .3 (Cortes)....................................................... 174

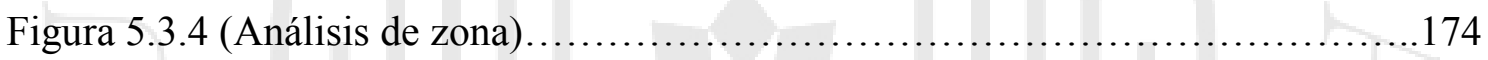

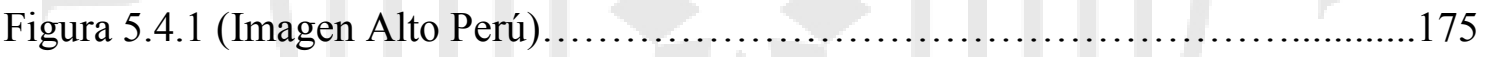

Figura 5.5.1 (Niveles de contaminación ambiental).............................176

Figura 5.6.1.1 (Flujo peatonal Av. Defensores del Morro).........................177

Figura 5.6.1.2 (Flujo peatonal Malecón Grau.)...............................178

Figura 5.6.2.1 (Congestión vehicular Av. Defensores del Morro)....................179

Figura 5.6.2.2 (Congestión vehicular Av. Malecón Grau).........................179

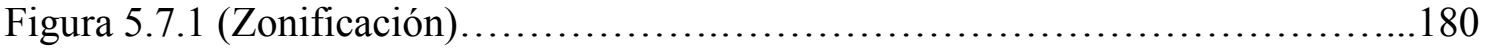

Figura 7.3.1 (Conexión entre ambas calles)................................... 187

Figura 7.3.2 (Diagonales para optimizar espacio y generar patios) $\ldots \ldots \ldots \ldots \ldots \ldots \ldots . \ldots 188$

Figura 7.4.1 (Análisis programa en planta).................................... 189

Figura 7.4.2 (Elevación principal del proyecto - Calle Malecón Grau)...............192 
Figura 7.4.3 (Elevación posterior del proyecto - Calle Santa Teresa)................192

Figura 7.4 .4 (Corte del proyecto) .......................................... 193

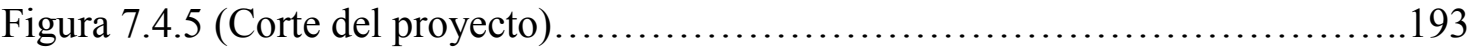

Figura 7.4.6 (Corte del proyecto)........................................... 194

Figura 7.4.7(Planta de habitación típica) ......................................... 194

Figura 7.6.1 (Centro del Adulto Mayor - Poder Judicial) .........................200

Figura 7.6.2 (Centro del Adulto Mayor - Poder Judicial).........................201

Figura 7.7.1 (Pirámide de Maslow) .........................................202 


\section{INDICE DE TABLAS}

Tabla 2.4.1 (Primeros Centros de Asistencia para Adultos Mayores en Lima

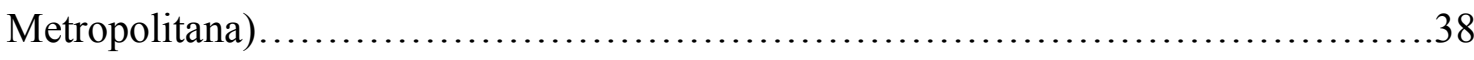

Tabla 3.1.4.1 (Cuadro comparativo de centros de asistencia para el adulto mayor)......52

Tabla 3.6.2.2.1 (Principios de las Naciones Unidas a favor de las Persona de Edad)...68

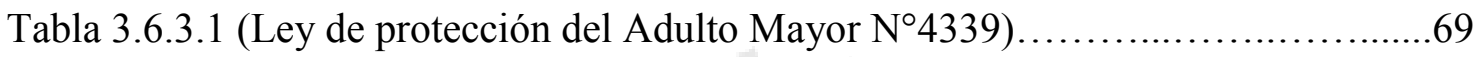

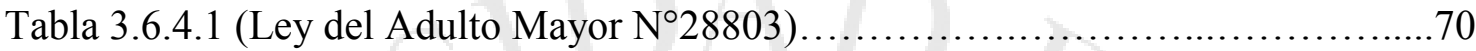

Tabla 3.6.5.2.1 (Requisitos para solicitar pensión de jubilación)......................71

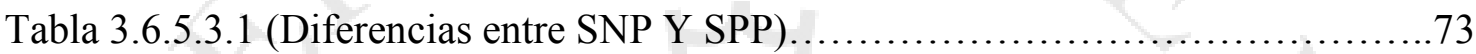

Tabla 3.8.3.1 (Comparación de temas entre normativas).......................... 81

Tabla 4.1.3.1 (Cuadro de áreas) ..............................................90

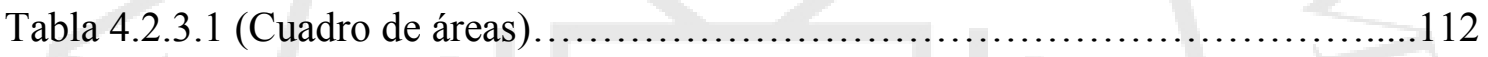

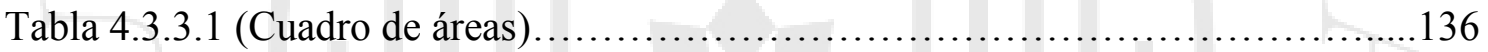

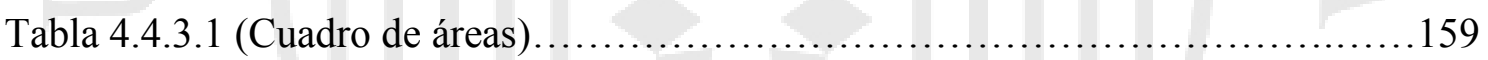

Tabla 4.5.3.1 (Cuadro de áreas)............................................... 176

Tabla 7.2 .1 (Análisis FODA) .................................................202

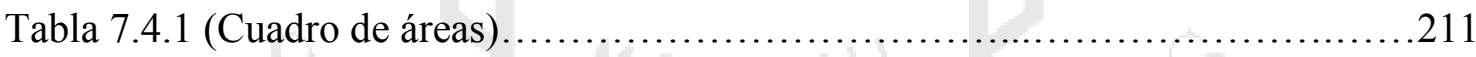

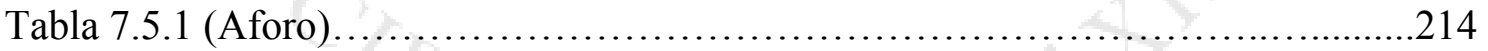

Tabla 7.8.1 (Cuadro de ingresos mensuales y anuales) ............................221

Tabla 7.8.2 (Cuadro de presupuesto de operación y mantenimiento)....................222

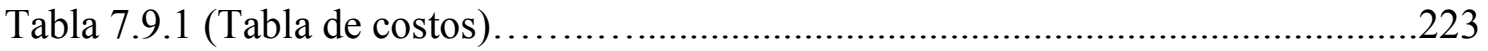

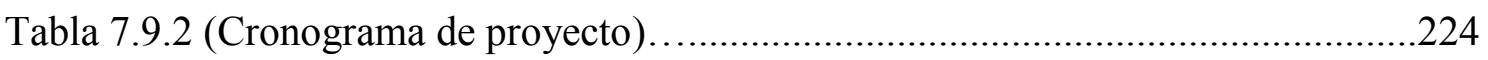




\section{INTRODUCCIÓN}

El adulto mayor es una persona de edad avanzada que con el transcurrir de la vida ha adquirido capacidad y conocimientos a través de la experiencia; por esta razón, deberían ser parte vital en la articulación de una sociedad que los acepte e incluya para tener la importante labor de transmitir lo vivido a las nuevas generaciones. Por otro lado, el proceso natural de envejecer, por el cual pasan todas las personas una vez terminada la etapa de adultez, llega con características particulares que requieren cuidado y atención.

Los centros de atención para personas de la tercera edad son lugares de gran ayuda para acompañar este proceso, puesto que están acondicionados para albergar a personas mayores salvaguardando su salud, deben estar adaptados para su fácil desplazamiento, y deberían estar enfocados en realizar actividades que generen el desarrollo de sus potencialidades, mejore la calidad de vida de los usuarios y contribuya a que la última etapa de su vida sea placentera y digna. Existen diversos medios para poder lograr que estos establecimientos cuenten y cumplan con los parámetros recomendados, los cuales son explicados en la investigación realizada.

En nuestro país, los censos de los últimos años revelan una tendencia de crecimiento demográfico en la población adulta mayor. En razón de ello, el Gobierno tiene en marcha proyectos sociales que buscan brindar ayuda económica, de salud y asilo, sin embargo, nos encontramos en un panorama aún distante de ser un programa social óptimo, debido a que el funcionamiento de estos es deficiente y la población atendida es baja en relación al universo.

Vivimos en una ciudad que crece sin planificación y en la que la población más vulnerable se ve afectada. La improvisación de establecimientos, la falta de espacios de recreación y la desatención que se les da a las personas de la tercera edad, nos sugiere evaluar de qué manera se puede contribuir para ayudar a este sector de la población. Por esta razón, se propone como proyecto una residencia y centro de día para adultos mayores que, a manera de simbiosis, ayude a generar un impacto positivo en la población y su entorno.

La ubicación del proyecto será en la zona monumental del distrito de Chorrillos, la cual es parte del borde costero del departamento de Lima. Este cuenta con un fácil acceso a través del Circuito de Playas y tiene una ubicación estratégica frente al malecón 
del distrito, manteniendo en todo momento una conexión visual con el mar, logrando así un vínculo directo con la naturaleza que es favorable para los adultos mayores. Además, las características arquitectónicas del proyecto estarán pensadas para facilitar y hacer confortable la estancia del adulto mayor en el mismo.

Así mismo, el terreno se encuentra cerca de centros de asistencia de emergencia y de servicios al ciudadano, los cuales complementan las funciones de la residencia y centro de día, generando así un entorno propicio y seguro para el desarrollo del adulto mayor sin incurrir en mayor costo directo para el proyecto. También, en las avenidas cercanas hay alto movimiento comercial lo cual podría resultar positivo para el proyecto.

La residencia y centro de día es un establecimiento que estará dirigido para atender a los adultos mayores del distrito de Chorrillos con la ayuda de los jóvenes voluntarios del asentamiento humano Alto Perú, el cual se ubica cerca al proyecto, fomentando de esta manera el trabajo comunitario y brindando oportunidades de desarrollo a estos jóvenes que viven en una situación vulnerable debido al entorno en el que se desarrollan. 


\section{CAPITULO I: GENERALIDADES}

1.1. Generalidades.

\subsubsection{Tema}

La Residencia y Centro de día, es un proyecto dirigido a los adultos mayores del distrito de Chorrillos, los cuales contarán con un nuevo lugar en el cual se desarrollarán actividades y se brindarán servicios que contribuirán a mejorar su calidad de vida.

Esta propuesta se encuentra en un terreno ubicado entre dos zonas de contraste; la frontal, es la que tiene vista al malecón y es parte del borde de la ciudad, tiene carácter más urbano con grandes vías, algunas edificaciones modernas de mediana y gran altura; la cara posterior del terreno es una zona barrial con pequeñas vías, menor movimiento vehicular y peatonal, con edificaciones pequeñas y antiguas.

El terreno con frente al malecón de Chorrillos pertenece al Arzobispado de Lima, institución que vela por el bien de las personas más necesitadas, por lo cual, se trabajará conjuntamente en el desarrollo y posterior funcionamiento del proyecto, así como, las actividades que realizarán los usuarios.

El proyecto pretende lograr un impacto positivo en la zona, desarrollando el espacio público y fomentando la interacción de los residentes. Así mismo, el diseño arquitectónico de la Residencia y Centro de Día será estudiado y analizado en base a las necesidades físicas y fisiológicas de las personas de la tercera edad, generando espacios de confort y bienestar para contribuir con mejorar la calidad de vida de estos.

Este centro tendrá dos funciones principales dirigidas a los adultos mayores, éstas se complementan entre sí y generan una interacción entre dos grupos de ancianos que buscan servicios similares. El centro de día contará con una zona del proyecto en la cual se brindará atención y se desarrollarán actividades adaptadas a sus características, a este programa podrán asistir todos los adultos mayores que viven en el distrito de Chorrillos. Además, se contará con una zona de residencia para ancianos, el cual tendrá acceso limitado debido al aforo del lugar. 
Como tercera función complementaria, se buscará fomentar un voluntariado que vincule directamente a los adolescentes y jóvenes que viven en el asentamiento humano Alto Perú, para así incentivarlos a desarrollar actividades positivas y recreativas que contribuyan a combatir la situación de vulnerabilidad de muchos de ellos.

\subsubsection{Justificación de tema.}

A nivel mundial y en las últimas décadas, la población de adultos mayores ha crecido en relación directa con el aumento de esperanza de vida mundial (OMS - Organización Mundial de la Salud, 2016). Este incremento se debe a los avances de la medicina y tecnología que constantemente buscan mejorar la calidad de vida de las personas.

En nuestro país, se considera que una persona forma parte de este grupo de habitantes cuando alcanzan los 60 años de edad. Según el Instituto Nacional de Estadísticas e Informática (INEI, 2015), 1 de cada 10 peruanos es un adulto mayor, y en Lima representan el 11\% de la población total de la ciudad, cifra que según las estadísticas seguirá en aumento.

Según el censo del 2011, 4 de cada 10 hogares tiene al menos una persona adulta mayor como miembro, de estos, el $18 \%$ se encarga del cuidado de menores de edad mientras los padres no están en casa. Estos hogares deberían estar adaptados para la fácil convivencia de los ancianos, por lo cual, es necesario resaltar la importancia de generar normativas que ayuden a la elaboración de lugares óptimos para el desarrollo seguro de las personas mayores, así como, fomentar centros en buenas condiciones que brinden servicios, atención y promuevan actividades para ellos.

El Ministerio de la Mujer y Poblaciones Vulnerables (MIMP) tiene mapeadas 500 instituciones para personas mayores de las cuales sólo 160 cuentan con licencia de funcionamiento, esta cifra alarmante nos da un panorama de la situación irregular de los establecimientos que ofrecen servicios a las personas de edad avanzada. Además, el Estado cuenta con programas de ayuda y seguimiento que son promovimos por el MIMP, sin embargo, falta que estos sean eficientes para que puedan llegar a la mayoría de la población adulta mayor. 
1.1.3. Planteamiento del problema.

1.1.3.1. ¿En qué condiciones se encuentran los centros de asistencia para el adulto mayor en Lima Metropolitana y cuáles son los puntos a mejorar para brindarles una calidad de vida óptima?

1.1.3.2. ¿Si se ubica el centro de asistencia para mayores en una zona urbana dinámica, se podrá lograr un equilibro favorable para la salud del adulto mayor entre buscar la privacidad y el contacto con la naturaleza?

1.1.3.3. ¿Es positivo integrar a la comunidad de Chorrillos con la Residencia y centro de día?

1.2. Objetivos de la investigación.

1.2.1. Objetivos generales.

Desarrollar un proyecto arquitectónico para los adultos mayores del distrito de Chorrillos que cumpla con características de diseño que aseguren una estancia de confort y promueva actividades que permitan el desarrollo sus capacidades, a fin de mejorar su calidad de vida.

Este planteamiento se realizará en base a la siguiente investigación que nos permitirá entender más sobre este sector de la población, cómo la situación actual de los usuarios y de los centros de asistencia que hay en Lima.

\subsubsection{Objetivos específicos}

\subsubsection{Referencial.}

- Investigar la importancia del cuidado de los adultos mayores.

- Investigar la aparición de los centros de asistencia para adultos mayores más emblemáticos de Lima.

- Identificar la ubicación de centros que hay en la actualidad. 


\subsubsection{Teórico.}

- Investigar sobre la terminología relacionada con los adultos mayores y los centros de asistencia para ellos.

- Identificar cuáles son las características físicas y físiológicas que ligadas a una persona que llega a la tercera edad.

- Investigar e identificar teorías relacionadas a la arquitectura y el trabajo con los adultos mayores que puedan servir de base para el diseño del proyecto.

- Investigar e identificar teorías en la arquitectura que sean adecuadas para el proyecto y que puedan aportar al desarrollo del mismo.

- Identificar los programas, leyes y normas de ayuda que existen en la actualidad para los centros de cuidado del adulto mayor

- Encontrar información sobre los estándares internacionales para los centros de asistencia de adultos mayores, que complemente la normativa vigente de nuestro país.

- Investigar sobre la situación actual de los jóvenes en el asentamiento humano Alto Perú y proponer las características del tipo de trabajo que se realizaría con el voluntariado.

\subsubsection{Operativo.}

- Realizar el análisis arquitectónico de proyectos con diversas características que puedan servir como referencia para la futura propuesta.

- Realizar, a modo de resumen, un cuadro comparativo de los casos de estudio en base al cual se pueda determinar las características más importantes que se deberá aplicar en el proyecto para poder garantizar una estadía confortable para el adulto mayor.

\subsubsection{Contexto.}

- Demostrar que el distrito de Chorrillos tiene características climatológicas favorables para la calidad de vida los adultos mayores.

- Identificar donde se encuentran los centros de servicio al ciudadano, asistencia de emergencia y comercio que complementen positivamente al proyecto. 
- Realizar una intervención que genere conexión entre dos zonas de contraste del distrito de Chorrillos, para así lograr la integración entre los pobladores cercanos a la zona y que sea positivo para el usuario y el entorno.

\subsubsection{Proyecto.}

- Desarrollar un proyecto dirigido a los adultos mayores en el distrito de Chorrillos, que tenga un diseño que sea acorde con el programa y los servicios requeridos para hacer que este sector de la población pueda desarrollar sus capacidades y mejorar su calidad de vida.

- Procurar un impacto positivo en las personas adultas mayores que residan y acudan al proyecto, así como en los voluntarios del A.H. Alto Perú.

- Generar espacios de encuentro y actividades que permitan la interacción entre los pobladores.

\subsubsection{Hipótesis de trabajo.}

- Si se desarrollan centros de residencia en zonas consolidadas y dinámicas, se evitará el aislamiento de los adultos mayores, reduciendo así los niveles de depresión y soledad que son comunes en esa etapa de vida.

- Al estudiar las características del adulto mayor e identificar sus necesidades, se podrá crear un proyecto en el que puedan mejorar sus facultades y calidad de vida.

- Al generar un proyecto que integre a los adultos mayores de la residencia con los del centro de día, se podrá generar nuevos lazos dinámicos sociales. Así mismo, al integrar a los residentes de la zona con los adultos mayores del proyecto, se logrará una mejor relación y trabajo comunitario beneficioso para la sociedad. 
1.3. Alcances y limitaciones.

\subsubsection{Alcances}

- Se analizará la situación actual de los centros para el adulto mayor en Lima Metropolitana.

- Se identificará modelos de proyectos nacionales e internacionales existentes para usar como referentes.

- Se desarrollará un cuadro comparativo de las funciones que ofrecen los centros analizados.

- Se analizará estándares propuestos por organizaciones para poder generar un listado con las características esenciales que requiere un centro para adultos mayores.

- Se diseñará una residencia y centro de día para personas mayores con las características ya mencionadas hasta nivel de proyecto.

\subsubsection{Limitaciones}

- La normativa y los requerimientos para el diseño son básicos, por lo tanto, se complementará con las indicaciones que se encuentren en estándares internacionales e investigaciones previas.

- El terreno en el que se ubica el proyecto pertenece a la zona monumental del distrito de Chorrillos, por lo cual, el diseño del proyecto tiene mayores requisitos y menor densidad poblacional.

- Actualmente el terreno se encuentra en estado de abandono. 


\section{CAPITULO II: MARCO REFERENCIAL}

2.1. El adulto mayor en la historia y la evolución de los centros de atención para ellos.

Desde el inicio de la humanidad, la importancia que se la ha dado al adulto mayor ha ido variando debido a múltiples factores como costumbres culturales, lugar de residencia, desarrollo tecnológico, etc. En algunos momentos han sido venerados y asociados con sabiduría y experiencia, sin embargo, también eran criticados y aislados por la pérdida de habilidades y decadencia. "El envejecimiento, la muerte, la atención a ancianos o la forma de luchar contra la vejez, la aceptación o su rechazo, ha sufrido muchas vicisitudes a lo largo de los tiempos" (Inmaculada de la Serna, 2003)

Así mismo, a través de la historia han aparecido espacios llamados de diversas maneras y que ofrecen servicios de estancia, acojo y residencia para los ancianos. "Uno de los primeros pensamientos sobre estos lugares lo da Platón señalando que los adultos mayores debían tener un lugar de reposo, descanso y cuidado." (Quintanar Olguín, 2000)

Antes del sedentarismo se consideraba que las personas mayores era una carga, por tal motivo, eran abandonados y en la mayoría de casos asesinados. Después de esta época, y varios siglos antes de Cristo (A.C), debido al desarrollo de la agricultura, que originó asentamiento de población y una mayor estabilidad, los antiguos pobladores comenzaron a aceptar e integrar a los adultos mayores en la sociedad, sin embargo, el valor que cada comunidad les daba a las personas mayores era distinto y variaba según la clase social y jerarquía.

Fue en Egipto donde surgió el vocablo anciano, resultante de la voz egipcia “an” (manifestación divina) y Heh (suma de años). (González, 2014). Para esta sociedad, al igual que para la cultura oriental, las personas mayores representaban un papel muy importante ya que ellos eran los que mantenían la historia viva entre las generaciones de sus comunidades. Por lo cual, eran venerados y se les trataba con respeto. 
En la época griega, los ancianos tuvieron múltiples valoraciones. Al inicio se les seguía atribuyendo la imagen de sabiduría, por lo cual, en las familias tenían la función de educar a los más jóvenes quienes consultaban a los mayores antes de tomar grandes decisiones. Esta práctica de asesoramiento, en una escala mayor, llevó a la formación de una institución conformada por adultos mayores aristócratas, en la que los ancianos tenían poder para tomar grandes decisiones. Sin embargo, con el pasar de los años, el poder de decisión en los mayores se fue debilitando y logró ser reemplazado por la formación de grupos integrados por personas más jóvenes. Si bien los adultos mayores perdieron este poder, seguían siendo considerados los más aptos para la formación de los menores del hogar

La pérdida de importancia en las determinaciones se hizo más fuerte durante la época de Roma debido a la autoridad ejercida por el páter familias, que era el jefe con capacidad de completo control sobre todos los miembros de una familia. Esta situación de injusticia al interior de los hogares causó un conflicto generacional y originó sentimiento de rechazo contra los ancianos. (Inmaculada de la Serna, 2003, pág. 5)

En la edad media debido a los constantes conflictos territoriales entre los bárbaros y romanos, era necesaria la presencia de personas con buenas condiciones físicas, fortaleza y habilidades. En consecuencia, la población joven ganó mayor protagonismo en esta época, generando así, el olvido hacia los adultos mayores; quienes, por las propias características de la edad, ya dejaban de contar con la energía y vitalidad para realizar múltiples actividades. El valor de la decisión y autoridad de los ancianos en las familias y sociedad de la época, se siguen perdiendo, sin embargo, se mantiene el pensamiento y consideración de que sus conocimientos son importantes de transmitir. "Conservan el papel de archivos vivientes e incluso aconsejan a los príncipes. A los ancianos los cuida la comunidad, y a tal fin se crea un tributo especial que los libera de los impuestos" (Inmaculada de la Serna, 2003).

Como consecuencia de lo explicado anteriormente es que se origina la idea de "retiro" para las personas mayores. Este pensamiento, resultó favorecedor para los ancianos de sectores sociales altos, quienes tenían la posibilidad de elegir apartarse de las ciudades y vivir sus últimos años en monasterios con un estilo de 
vida confortable. Sin embargo, fue un hecho perjudicial para los que eran de bajos recursos y/o solitarios, ya que, se veían obligados a exponer su salud trabajando en lo que encontraban para poder obtener algún ingreso económico, y así evitar la mendicidad.

Con el tiempo esta idea cobra importancia y los monasterios que podían ser financiados comienzan a recibir adultos mayores necesitados a los que se les brinda comida y hogar de manera benéfica. Es aquí donde surgen dos ideas que dan inicio a las que se tienen en la actualidad: desconexión entre el adulto mayor y la sociedad que es parecida a la que existe actualmente, y el asilo como lugar de acogida para necesitados. (Inmaculada de la Serna, 2003, págs. 6,7)

Algunos años más tarde, debido a los grandes avances que hacía la medicina, aparecieron diversos estudios sobre el envejecimiento y los ancianos que actualmente se denomina geriatría, una rama especializada en los estudios de prevención, tratamientos y cura de enfermedades para este sector de la población.

A finales de la edad media existía gran cantidad de indigentes que eran personas adultas mayores abandonadas, ello evidenciaba la necesidad de fundar centros de atención para personas longevas de todas las clases sociales. Este problema generó preocupación por este sector de la población, por esta razón, se comenzaron a tomar medidas como la solicitud a los monasterios para que cuenten con el equipamiento necesario para atender a los ancianos que albergaban. Así mismo, surgió la idea de que en las casas pequeñas se podía brindar alojamiento a las mujeres viudas. (Inmaculada de la Serna, 2003, págs. 6,7).

Durante los siglos XV y XVIII surgen nuevos conflictos entre jóvenes y ancianos por poder y autoridad. Una razón es la elevada tasa de mortalidad de las mujeres durante la maternidad, esto generaba que aumenten los matrimonios entre personas de edad avanzada, que volvían a contraer nupcias con mujeres jóvenes. Por otro lado, continúa la idea de retiro al llegar a una edad avanzada, lo que lleva a que proliferen casas que acogían a las personas mayores para que estas puedan gozar de una vejez segura, sin embargo, éstas continúan siendo accesibles sólo para la clase acomodada, dejando - una vez más - al anciano pobre en mendicidad 
y sin la posibilidad de ingresar a algún monasterio. (Inmaculada de la Serna, 2003)

Durante la revolución industrial, la ciencia dio grandes avances que profundizaban en temas de salud, por lo cual, los ancianos se vieron favorecidos debido a los descubrimientos para tratar, evitar enfermedades y mejorar su calidad de vida. A pesar de esto, surgió un efecto negativo en la época, ya que las personas de edad avanzada fueron apartadas de varias actividades laborales debido a que demandaban un ritmo físico fuerte que fue cubierto por los jóvenes. Además, la industrialización originó desplazamiento de las personas de una ciudad a otra, estas nuevas formas de vivir no se adaptaban al ritmo de los adultos mayores por lo que muchas veces escogían quedarse en sus lugares natales, en consecuencia, originaba el desprendimiento de sus familias, aislamiento y desconexión.

En 1351 Jean le Bon crea la orden de caballería de la Estrella y manda a construir una casa de retiro para los viejos caballeros. Algunos historiadores consideran que este proyecto tiene un valor simbólico, pues es fuente de inspiración para otras iniciativas y además es la primera vez que el poder político aporta la idea de que es necesario mantener y corresponder a sus viejos servidores. (Quintanar Olguín, 2000)

En esta etapa se asiste al desarrollo de las órdenes religiosas cuyo objetivo principal era el cuidado de las personas mayores, destacando la de San Juan de Dios y las Hijas de la Caridad, esta última fundada por San Vicente de Paul (15781660) y Santa Luisa de Marillac (1591-1660), o la de las Hermanitas de los Ancianos, fundada por Santa Teresa de Jornet en 1873. (Milan Celenti, 2006)

La mayor parte de los asilos, hospitales, casas de retiro y pensiones eran atendidos básicamente por personas religiosas que, en cumplimiento con sus principios, creían en la necesidad de cuidar y ayudar a los ancianos, esta fue su idea central y motivo de origen, los ancianos activos era las excepciones y no la finalidad de dichos centros" (Quintanar Olguín, 2000)

Esto demuestra la importancia de las agrupaciones religiosas para los ancianos de la época, especialmente los que no tenían influencias sociales ni económicas, 
ya que se veían esperanzados por la atención, servicios y hogar que ofrecían los grupos religiosos, quienes destinaban parte de los bienes de la iglesia a la atención de los más necesitados, teniendo como intermediarios a organizaciones benéficas.

Finalmente, en esta época se logra captar la atención del sistema político y se le exige mayor interés por el cuidado y atención de las poblaciones vulnerables, entre ellas la población adulta mayor.

Por otro lado, apareció una nueva tipología de centro de acojo, especialmente dirigido para mujeres viudas de la tercera edad. Estos lugares eran casas adaptadas para brindarles alojamiento y atención a un grupo de personas que tenían una situación en común; por estas características, se puede decir que este nuevo tipo de centro se asemeja a la tipología que encontramos en la actualidad.

Conforme se fueron legislando las condiciones de estos espacios, el nombre de asilo se identificó como una Institución Social en la que se proporcionaba protección, amparo y medios de subsistencia a los desvalidos, incapacitados, indigentes o menesterosos que no pudieran ejercer por sí mismo sus derechos humanos. Es así como se llega a asumir que la función social del asilo es la de ser una institución de protección y amparo para las personas imposibilitadas de ejercer sus derechos humanos y que necesitan del auxilio de otros (Quintanar Olguín, 2000)

En la actualidad existen centros de atención al adulto mayor con diversas caracteristicas que en su mayoría varían dependiendo del estado de salud en el que se encuentran los usuarios que son atendidos y acojidos. Estos lugares, además de auxiliar a las peronas de la tercera edad, deberían incluir entre sus funciones principales el ayudar a que este sector de la población siga desarrollando sus capacidades.

Pero de cualquier forma casi todos han razonado con la misma lógica, quedando atrapados en su discurso y en las buenas intenciones, como si las condiciones no cambiaran y los nuevos tiempos no requieran otras estrategias para la atención a la salud de nuestros viejos. (Quintanar Olguín, 2000) 
Como conclusión del capitulo se puede señalar que históricamente, y en especial desde la revolución industrial, la sociedad le ha restado importancia al papel de los adultos mayores. Desde el inicio de la historia, los adultos mayores han sido vistos como obstáculo debido a los cambios físicos que se dan al llegar a dicha edad, si bien en algunas sociedades se tomaba en cuenta sus opiniones y les daban algunas funciones para realizar, siempre se recalca que ya no son capaces de realizar las mismas actividades que sus congéneres más jóvenes ni de tomar grandes decisiones. Esta visión negativa del adulto mayor, tiene como consecuencia que hasta la actualidad sean vistos como una sociedad vulnerable mas no importante.

\subsection{Evolución de la atención del adulto mayor en el Perú.}

En el Perú, el interés y el cuidado que se le ha brindado al adulto mayor ha tenido variaciones y ha ido evolucionando a través de los años. En principio, en las culturas Pre-Incas se consideraba al anciano como una carga para la sociedad debido a que se vivía en una época de constante guerra y conquista entre diferentes culturas, lo cual generaba un ambiente de inestabilidad y vulnerabilidad a la que los ancianos no podían adaptarse con facilidad. (Inmaculada de la Serna, 2003)

A partir de la época Incaica, se estableció una nueva organización en la cual toda la comunidad participaba en trabajos que beneficiaban a la cultura. El adulto mayor era considerado y tomado en cuenta para apoyar en trabajos agrícolas y realizar tareas domésticas como estar a cargo de la educación de los menores, también, realizaban actividades que estaban acorde con las habilidades que tenía para garantizar el éxito y eficacia de las labores. (Inmaculada de la Serna, 2003)

Los ancianos, eran considerados sabios, distinción que le daba el aprendizaje de la vida y la capacidad de resolver problemas; no eran aislados del núcleo familiar ni de la comunidad, por el contrario, el llegar a edad adulta los hacía merecedor del reconocimiento y el respeto. Era signo de haber vivido y cumplido todas sus obligaciones a cabalidad en las diferentes etapas de la vida que le tocó vivir.

Es más, el llegar a la edad de adulto mayor, era un regalo de los dioses, que le permitía poder compartir con los suyos, todos sus conocimientos y 
saberes. (Montibeller, La situación del adulto mayor en el Perú prehispánico y en el Perú moderno., 2010)

Por costumbre, en nuestro país y en los países latinoamericanos, los adultos mayores forman parte de los nuevos núcleos de familia formados por los hijos para que ellos puedan tener un mayor control y cuidado de salud de sus padres. "En el Perú, 4 de cada 10 hogares, cuenta con al menos un adulto mayor en casa.” (INEI, 2015)

Según un informe del Ministerio de la Mujer y Poblaciones Vulnerables: La familia ha sido por siglos el medio natural para el desarrollo de sus miembros y para la persona adulto mayor, además representa la posibilidad de relaciones y permanencia en un grupo, por ausencia de otros que ya han desaparecido. (MIMP, 2005)

De esta manera, los adultos mayores suelen formar parte de los nuevos núcleos de familia formados por los hijos, para así poder tener un mayor control y cuidado de la salud de estos. En muchas familias, los nietos quedan bajo el cuidado de los abuelos de la casa cuando los padres están fuera de esta. Sin embargo, esta práctica no se puede llevar a cabo en todos los hogares debido a que algunos adultos mayores, por las propias características de la edad, no poseen la totalidad facultad de sus capacidades físicas y metales.

Así mismo, existen situaciones que son resultado de una sociedad globalizada y moderna, en la cual, debido a los constantes cambios y las largas jornadas laborables de las cabezas de familia, se percibe alejamiento físico y falta de comunicación entre los miembros de la familia, afectando las relaciones intrafamiliares y especialmente a los ancianos, quienes no se ven involucrados en la familia ni reciben el cuidado ni atención necesaria que ellos requieren; por lo que las familias terminan apartándolos de sus núcleos familiares enviándolos a casas de reposo. (MIMP, 2005)

"El concepto de la familia moderna, solo considera la convivencia de la pareja y los hijos, mas no, la presencia de los padres, por considerarlos una carga económica y una molestia para la educación y crianza moderna de 
los hijos". (Montibeller, La situación del adulto mayor en el Perú prehispánico y en el Perú moderno., 2010)

2.3. Crecimiento demográfico del adulto mayor a nivel mundial y en el Perú.

En los últimos años, la población mundial se ha incrementado en grandes proporciones y una de las causas es que la esperanza de vida va aumentando cada vez más y ha pasado de ser 52.5 años en 1960 a 72 años en el 2016. Esto se debe a los avances de la medicina y tecnología, que constantemente están en búsqueda de encontrar cura para enfermedades y así prolongar la edad esperada de vida de las personas.

Figura 2.3.1: Crecimiento de la población mundial mayor de 60 años

\section{POBLACIÓN MUNDIAL $(60+$ AÑOS)}

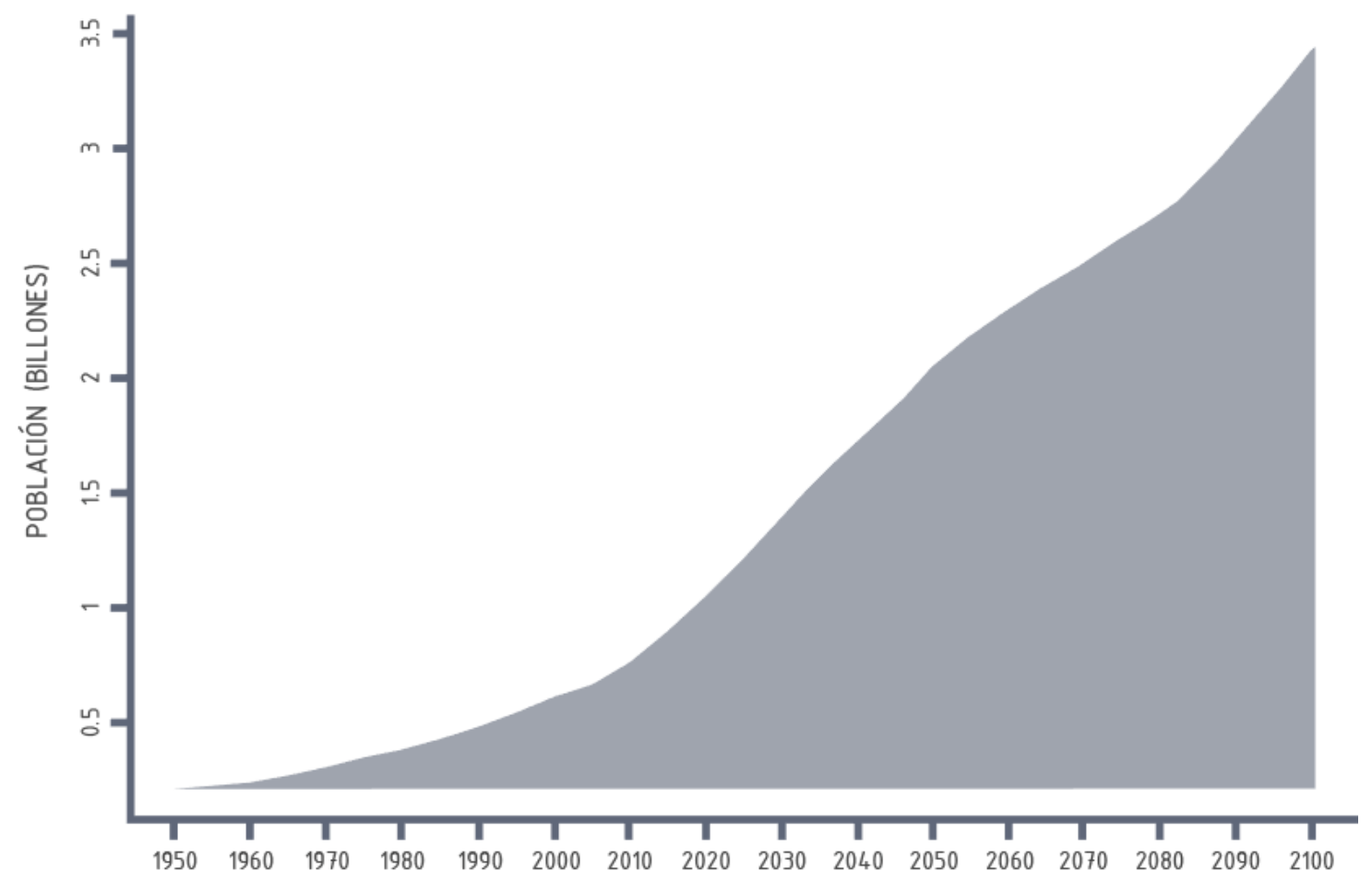

Fuente: (ONU, 2019) Figura elaborada por autor 
Figura 2.3.2: Crecimiento de la población mayor de 60 años en el Perú

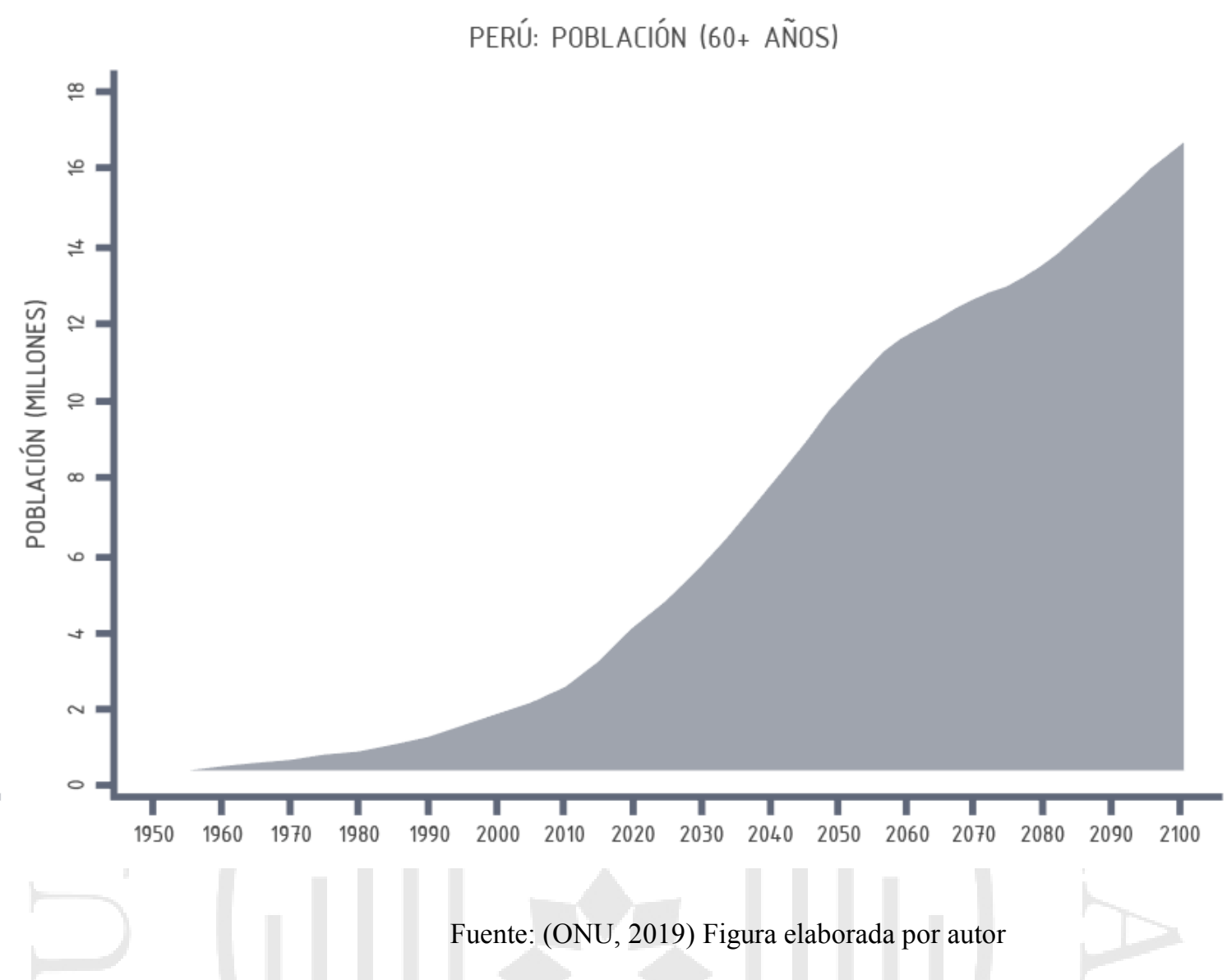

Según la Organización Mundial de la Salud entre 2000 y 2050, la proporción de los habitantes del planeta mayores de 60 años se duplicará, pasando de $11 \%$ a 22\%. En números absolutos, este grupo pasará de 605 millones a 2000 millones en el transcurso de medio siglo. (OMS Organización Mundial de la Salud, 2016)

Debido al incremento porcentual de los adultos mayores durante medio siglo, es de gran importancia generar medidas sobre los servicios de salud, cuidado y apoyo que se brinda actualmente a este gran sector de la población que con el transcurrir de los años seguirá necesitando de los servicios ofrecidos en mejor condición y mayor porcentaje.

Es necesario resaltar que aun así los avances de la medicina y tecnología logren incrementar la esperanza de vida, las personas mayores presentarán dificultades a raíz del deterioro natural de la salud, por lo cual, debemos estar 
preparados y trabajar para que esta etapa sea placentera y se adapte a sus necesidades.

Hay estudios que indican que existe un vínculo entre el desarrollo de la población y la economía, hablan de una diferencia en el crecimiento de población de personas de la tercera edad entre países desarrollados y los que se encuentran en vías de desarrollo. "Se calcula que en el año 2050 el $80 \%$ de las personas de edad vivirán en países que hoy se consideran de ingresos bajos o medianos..." (OMS, 2016)

El envejecimiento de la población en esos países se está produciendo con mucha más rapidez que en las regiones actualmente desarrolladas del mundo. Por lo tanto, tendrán mucho menos tiempo para preparase a fin de afrontarlas. (OMS, 2016)

Estas afirmaciones nos afectan directamente debido a que el Perú es un país en vías de desarrollo en el que en los últimos años se ha incrementado los programas de ayuda al adulto mayor, sin embargo, los centros que operan este tipo de ayuda no son los más apropiados. Como se señalaba en párrafos anteriores, no en todos los casos se ha tomado en cuenta la evolución y cambios en las costumbres de los adultos mayores para generar ambientes que ayuden a una mejor integración y calidad de vida para las personas de la tercera edad.

En nuestro país, los estudios hechos por el Instituto Nacional de Estadísticas e Informática (INEI), en el que se considera mayores de edad a las personas mayores de 60 años, afirma que las estimaciones de la ONU son una realidad en nuestro país. En el informe técnico "La Situación de la Población Adulta Mayor de marzo 2016" se indica que la población de personas de la tercera edad ha crecido en aproximadamente $4 \%$ en los últimos 60 años, y que actualmente son 3'011'050 personas, que representa a un 9.7\% de la población actual, y que la tendencia de aquí al 2050 es de un alza mucho mayor. (INEI, 2015)

Un dato importante es que la esperanza de vida en nuestro país se ha incrementado en 15 años en las cuatro últimas décadas. Por lo cual, actualmente la expectativa de vida de un hombre es de 72 años y para una mujer es de 76,4 
años, dando como resultado un promedio de 77,3 años. Además, se debe mencionar que en proyección se estima que este promedio aumente a 79 años de edad para el año 2050. (INEI, 2015)

Figura 2.3.3: Esperanza de vida al nacer desde 1950 proyectada a 2100 (Mujeres)

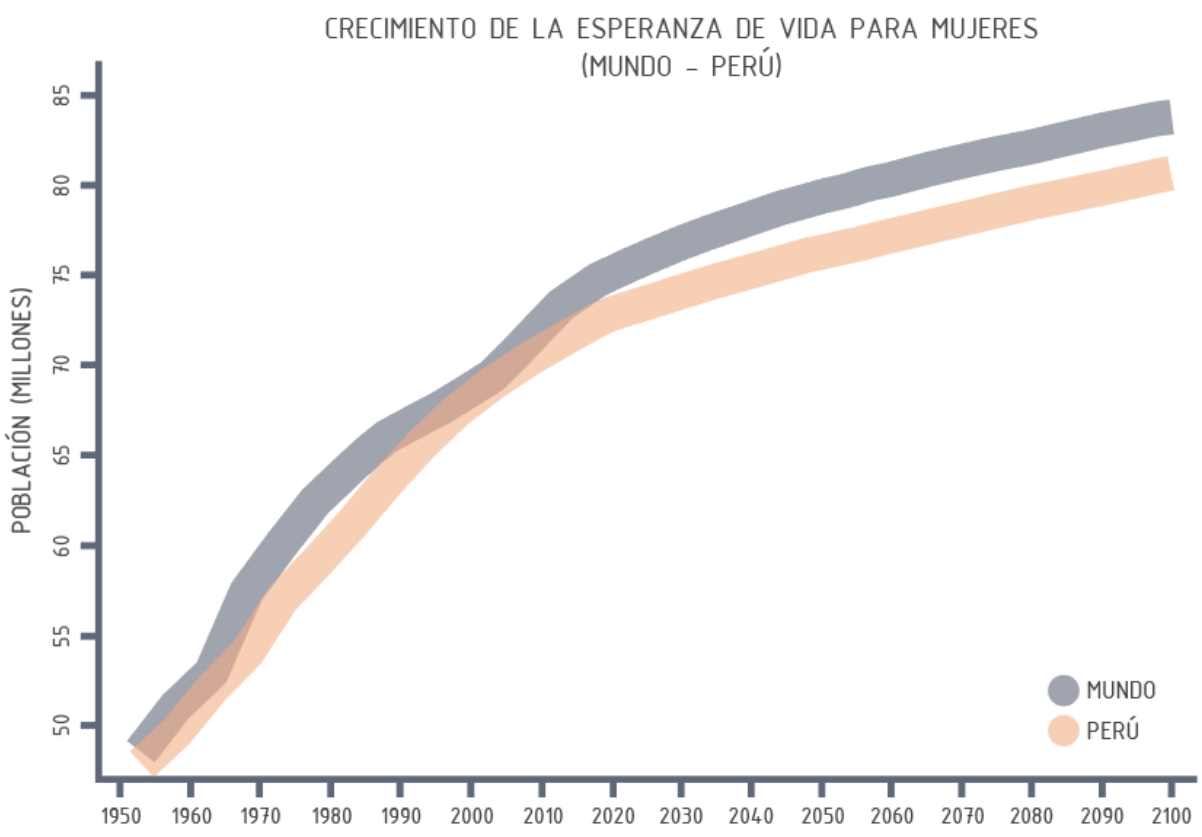

Fuente: (ONU, 2019) Figura elaborada por autor

Figura 2.3.4: Esperanza de vida al nacer desde 1950 proyectada a 2100 (Hombres)

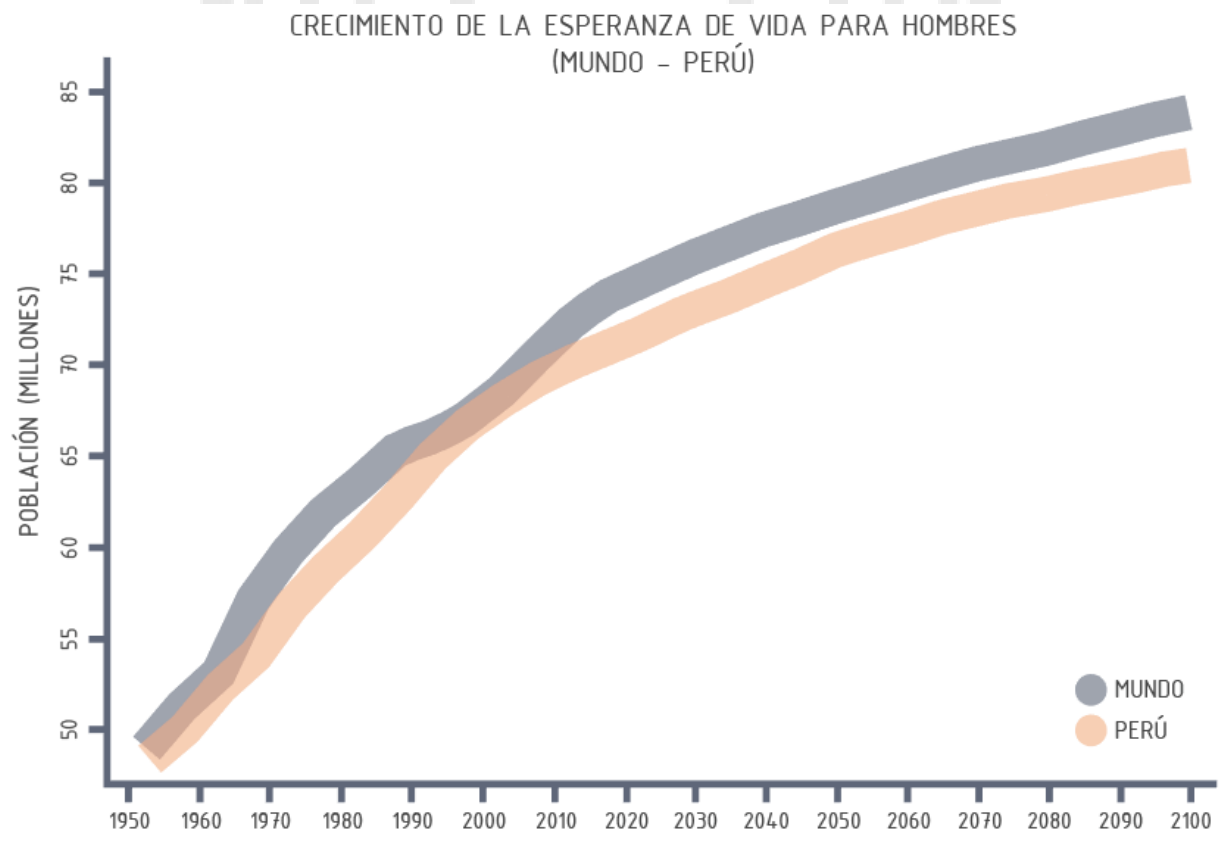

Fuente: (ONU, 2019) Figura elaborada por autor 
Según los resultados de la Encuesta Nacional de Hogares (ENAHO) del año 2014, el 39,1\% de los hogares lo integra algún adulto mayor de 60 a más, además, en el 8,1\% de los hogares vive algún anciano de 80 a más. (INEI, 2015)

Figura 2.3.5: Población adulta mayor en el Perú y por sexo. (\%)

\section{POBLACIÓN EN EL PERÚ}

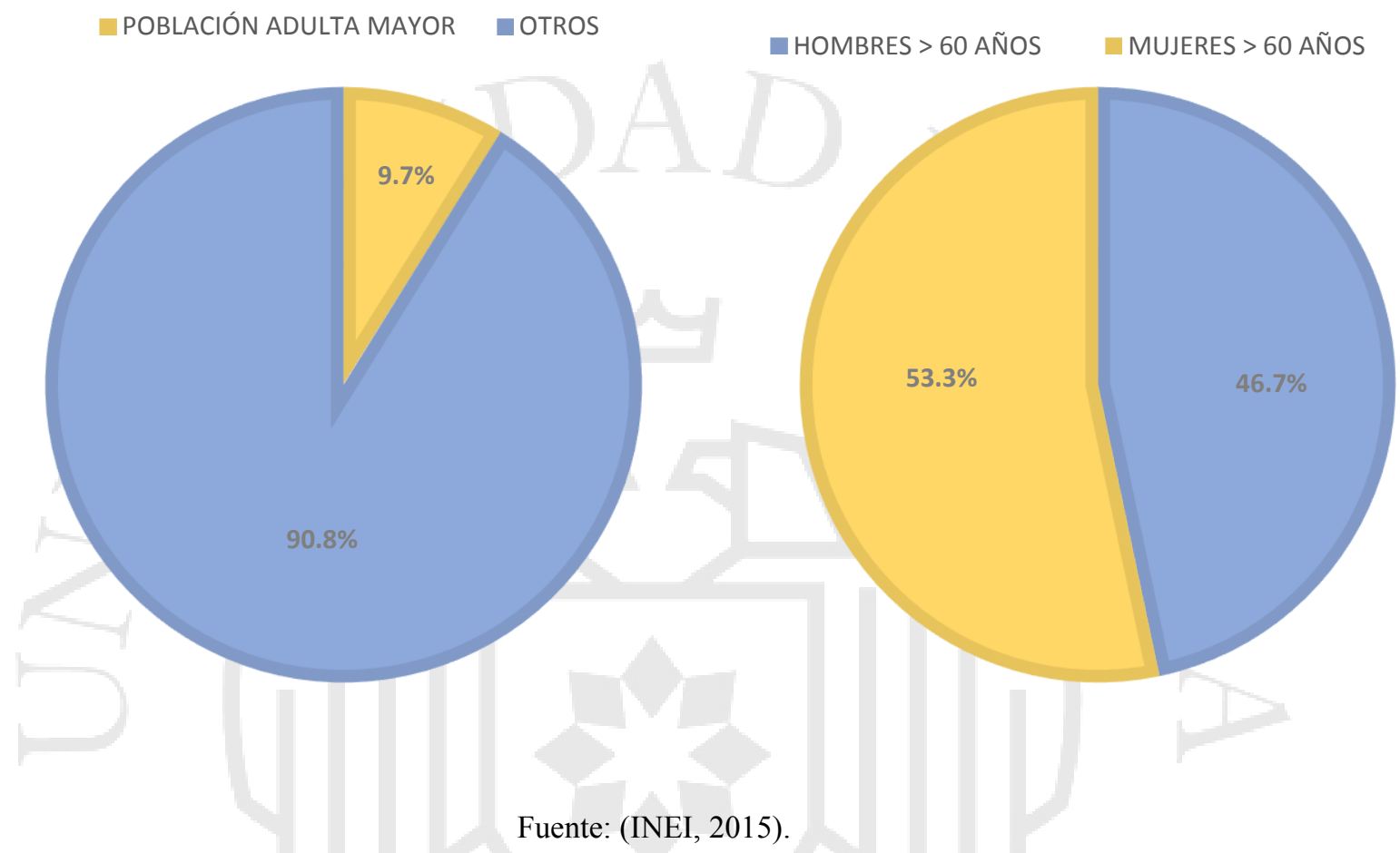

POBLACIÓN ADULTA MAYOR

Según el lugar de residencia, se aprecia que en Lima Metropolitana los hogares con adultos mayores alcanzaron el 40,6\%, en el área urbana 36,4\% y en la zona rural $42,0 \%$. (INEI, 2015)

Es necesario destacar que, en muchos hogares los adultos mayores constituyen una pieza fundamental para su funcionamiento. De acuerdo con la ENAHO del 2014, el 33,4\% de los hogares peruanos son conducidos por un adulto mayor. En Lima Metropolitana este porcentaje alcanzó el 34,3\% y en el área rural el porcentaje de familias con un jefe adulto mayor se incrementó a 37,0\%. (INEI, 2015)

En el aspecto económico, los adultos mayores pueden optar por el retiro de actividades laborales e ingresar a un sistema de pensión o jubilación que se les es retribuido desde los 65 años, sin embargo, hay personas que al pasar esta edad 
siguen ejerciendo actividades laborales. La figura 6.3 muestra que más de la mitad de los adultos mayores (58.3\%) sigue siendo económicamente activos pese a que no es una obligación que sigan trabajando, además, dentro de este grupo, son los hombres quienes tienen un mayor porcentaje de trabajo que las mujeres.

Figura 2.3.6: Adultos mayores por condición de actividad y sexo (\%)

\section{POBLACIÓN ADULTA MAYOR POR CONDICIÓN DE ACTIVIDAD Y SEXO}

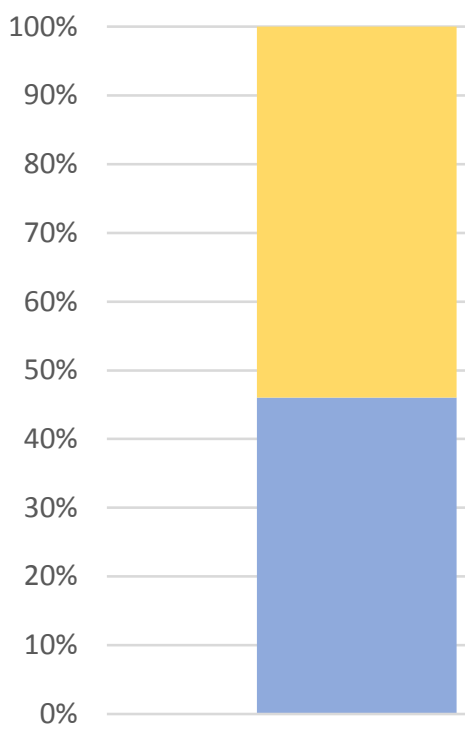

MUJERES
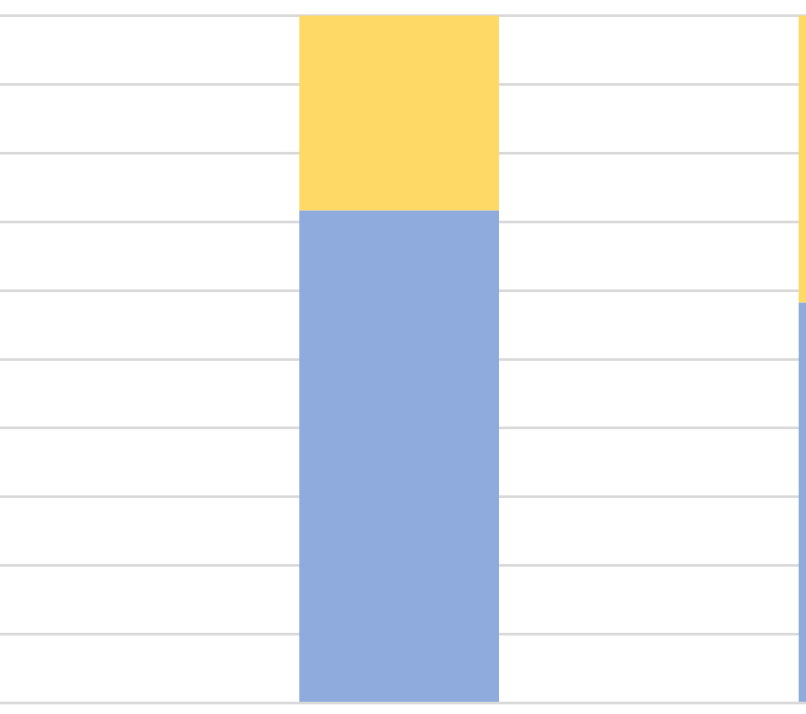

HOMBRES

TOTAL

$\square$ PEA NO PEA

Fuente: (INEI, 2016)

Por otro lado, el 41.7\% de adultos mayores, equivalente a 1'255'608 individuos, no cuentan con trabajo estable y muchas veces son ellos los que tienen la jefatura de sus hogares, por lo cual, se ven en obligación de realizar actividades de subempleo para poder subsistir sin importar que sean situaciones no favorables para su salud. Por lo tanto, este último grupo de adultos mayores pertenecen al grupo de adultos mayores con más vulnerabilidad debido a la dependencia en la que viven. 
2.4. Centros de atención para el adulto mayor en Lima

Los datos sobre los centros que brindaban atención a las personas de la tercera edad de Lima hacen referencia a casonas y propiedades que fueron donadas y adaptadas para albergar a los ancianos. Así mismo, de acuerdo con la importancia que se les va dando a los adultos mayores, aparece en los hospitales más emblemáticos de la ciudad, la geriatría, la especialidad médica al servicio de los ancianos.

Tabla 2.4.1

Primeros Centros de Asistencia para Adultos mayores en Lima Metropolitana.

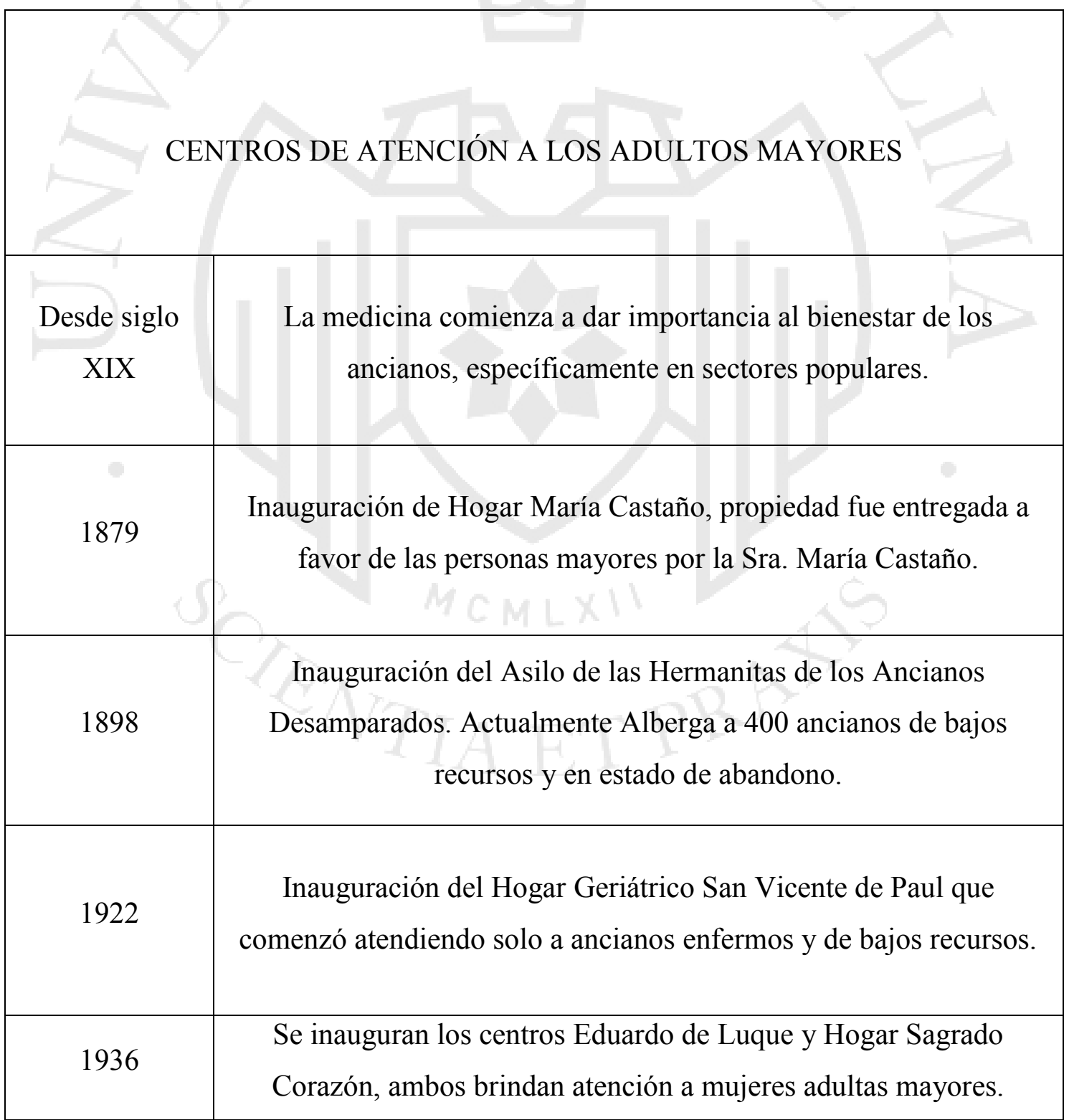




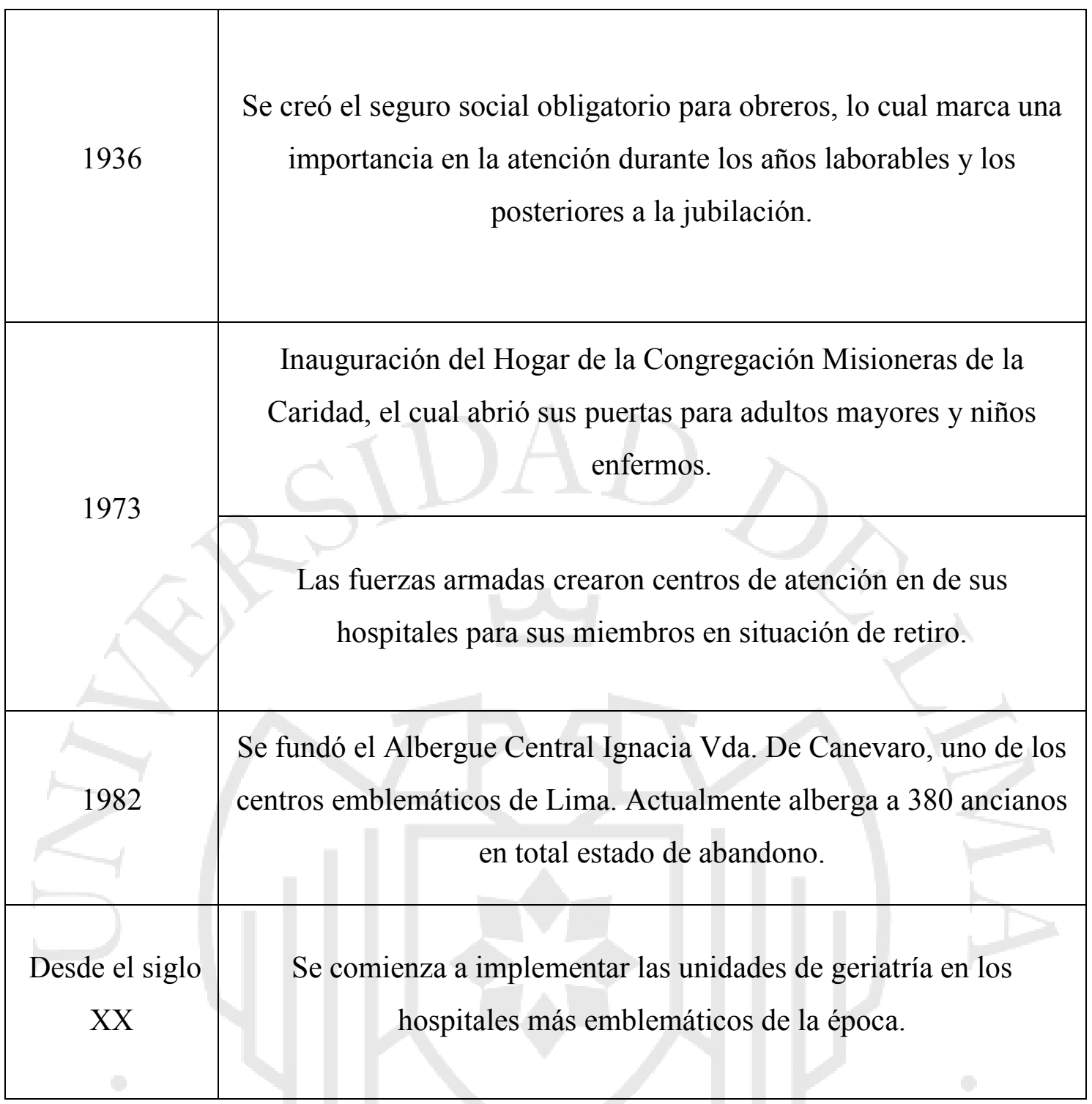

Elaborado por autor.

Según un análisis realizado con los datos del MINSA por la Comisión Económica para América Latina y el Caribe (CEPAL, 2016) en el Perú existen 1,840 centros que brindan atención a 43,885 de los 3,011,050 de adultos mayores que tenemos como población, es decir menos del 2\% del universo. Así mismo, según el ministerio de la Mujer y la Municipalidad de Lima, existen 500 residencias de tipo geriátricas, de las cuales 340 no cuentan con licencia para funcional como tales. (Diario Gestión, 2013). Estos datos muestran la gran falta de atención que hay para los adultos mayores de nuestro país y deja claro que es urgente realizar un plan para generar espacios que ayuden a este sector de la población a gozar de una mejor calidad de vida. 
Figura 2.4.1:

Mapeo de Centros de Atención Residencial actuales en Lima Metropolitana.

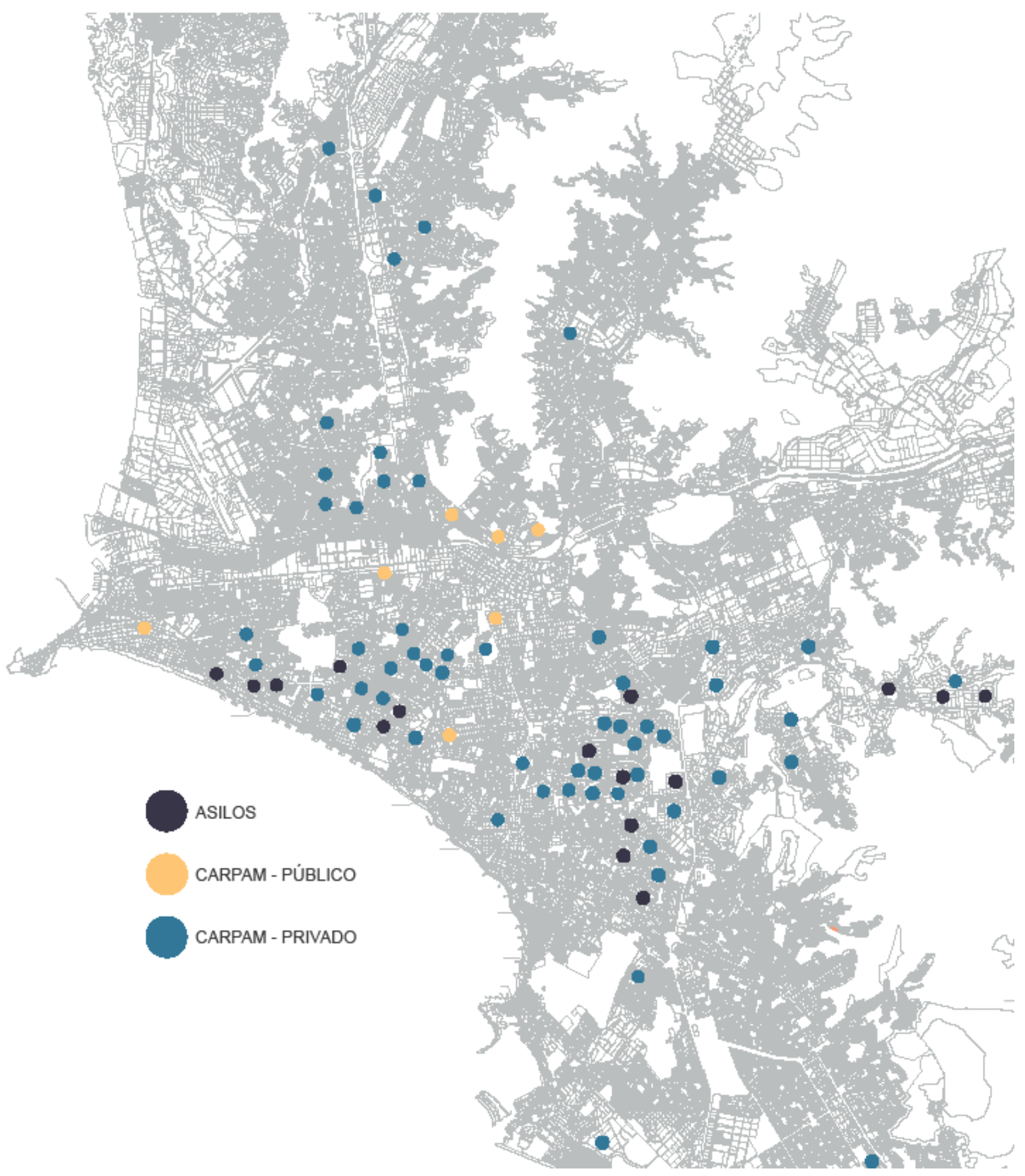

Fuente: (MIMP, s.f.) Elaborado por autor. 
La ubicación de los centros que sirven a los adultos mayores está concentrada en la zona central de Lima Metropolitana, lo que genera un desabastecimiento en los distritos más alejados de la ciudad, perjudicando directamente a la población adulta mayor que reside en esas zonas. Los centros de día de Lima son administrados por las municipalidades, quienes generalmente ofrecen servicios gratuitos a sus vecinos usuarios, por otro lado, dentro del grupo de los centros que brindan servicio de residencia se encuentran los casos más emblemáticos de Lima como el Hospital geriátrico San Vicente de Paul, el asilo Canevaro, asilo de las Hermanitas de los ancianos desamparados, entre otros, los cuales brindan ayuda de manera gratuita a las personas necesitadas. En contraste, otro grupo importante de centros de residencia son solventados por ONG, agrupaciones religiosas, etc., muchos de estos lugares, a excepción de los nombrados anteriormente, no brindan servicio gratuito, lo que deviene en limitar el acceso y excluir a los adultos mayores de bajos recursos.

2.5. El adulto mayor de bajos recursos y en estado de abandono.

Es importante resaltar que gran cantidad de adultos mayores no cuentan con las oportunidades de ingresar a algún centro de atención debido a la situación económica en la que se encuentran, ya que muchos de centros son de carácter privados.

Según una publicación del (INEI, 2013) que describe los niveles de pobreza en Perú dice que, en la zona urbana del país, el porcentaje de pobreza con respecto a cada grupo de edad en el año 2013 es el siguiente:

- De 60 - 64 años: $9,7 \%$

- De 65 - 69 años: $12,6 \%$

- De 70 años a más: $14 \%$

Para este sector de la población se han creado programas de ayuda que se explicarán más detalle en el siguiente capítulo. 
Figura 2.5.1: Aprueban programa para rescatar a adultos mayores en abandono

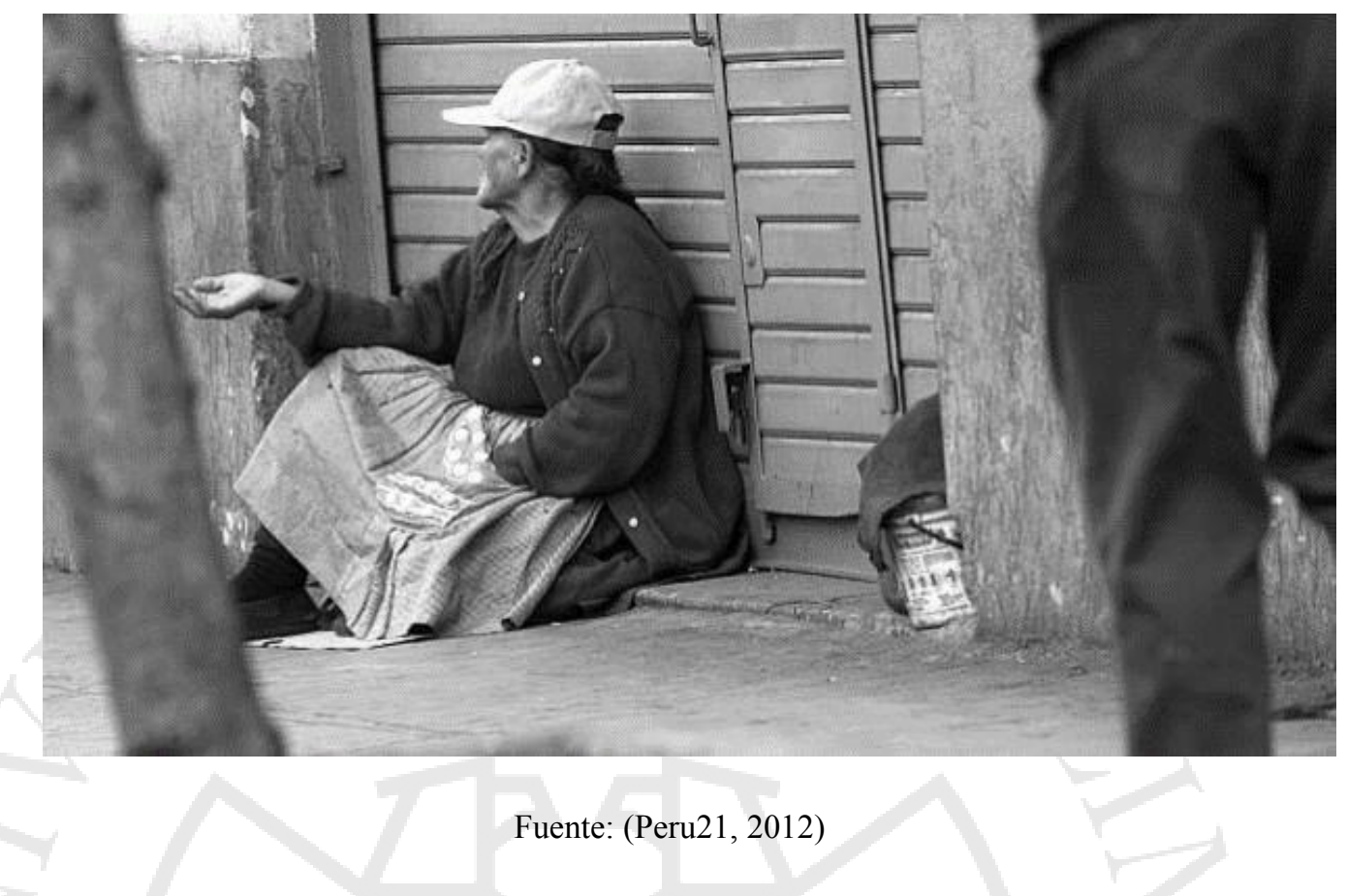

Por otro lado, un gran problema son las familias que dejan a los adultos mayores en estado de abandono, lo cual es considerado una agresión psicológica fuerte y se podría castigar hasta con una pena de privación de la libertad. Sin embargo, las estimaciones porcentuales de estos hechos no son exactas debido a que no todos los casos son denunciados. Por último, existen programas de gobierno y ONG que brindan ayuda y asesoramiento para los ancianos que se ven afectados por estas situaciones. 


\subsection{Conclusiones parciales}

El capítulo explica la importancia del adulto mayor desarrollando un recorrido en la historia universal, desde las culturas más antiguas, para así entender el valor que actualmente se le da como sociedad a este sector de la población. Así mismo, se explica la aparición de centros de asistencia para adultos de la tercera edad en nuestro país y como han ido evolucionando los servicios de atención para ello de acuerdo con los cambios en la sociedad, costumbres, etc.

Al conocer las proyecciones del crecimiento poblacional de las personas mayores, justificamos el interés por desarrollar un proyecto para este sector de la población que aún no logra ser atendida de forma adecuada. Por otro lado, el mapeo de los centros que brindan atención a los adultos mayores deja como conclusión que hay un núcleo ubicado en la zona de Lima centro, por lo cual, el proyecto busca no ser parte del foco, sino encontrar una zona con características adecuadas y que logre atender a un sector de la población objetivo que se encuentra a las afueras de este.

Finalmente, el entender la situación actual de nuestro usuario principal nos acerca al problema por resolver. De lo cual se concluye que es importante que como sociedad tomemos en mayor consideración las necesidades y características de los ancianos, para de este modo poder contribuir con el desarrollo de planes dirigidos para su bienestar. 


\section{CAPITULO III: MARCO TEÓRICO}

El siguiente capítulo nos ayuda a ampliar el conocimiento sobre las personas de la tercera edad. Comienza con un glosario en el que se explican los términos relacionados al usuario, tema de investigación y el proyecto. Además, se explican las necesidades y consecuencias que conlleva esta etapa de la vida como conclusión a una investigación basada en libros, reportes, artículos, etc.

Asimismo, se detallan las características que se deberán aplicar en el proyecto que tiene como usuario principal a los adultos mayores. De esta manera se logrará un impacto positivo en ellos, ayudándolos a que puedan seguir desarrollando sus capacidades en los últimos años de vida.

Finalmente, se desarrollará un resumen de las leyes, normas, programas nacionales e internacionales que influyen directamente con el proyecto, para así tener un mayor conocimiento de las acciones que se están tomando y las que faltan promover en favor de los ancianos.

\subsection{Glosario.}

Para entender los temas vinculados a los adultos mayores, es necesario tener en cuenta los siguientes términos definidos por la RAE y como resultado de la investigación.

\subsubsection{Sobre el usuario.}

\subsubsection{Adulto mayor:}

Persona de 60 años o más, de acuerdo a la Ley de los Derechos de las Personas Adultas Mayores. En los países desarrollados (en su mayoría miembros de la OCDE) se denomina así a las personas de 65 a más.

\subsubsection{Anciano:}

Una persona de mucha edad y que se encuentra en el último periodo de la vida. 


\subsubsection{Envejecimiento:}

Proceso biológico de hacerse viejo, incluye cambios físicos y funcionales que aparecen en la persona con el paso del tiempo.

\subsubsection{Jubilado:}

Dicho de una persona que ha cumplido con el ciclo laboral establecido para ello. En nuestro país una persona se puede jubilar desde los 65 años, a partir de esta se comienza a recibir una pensión por parte del SPP (Servicio privado de pensiones) o SNP (Servicio nacional de pensiones).

\subsubsection{Longevo:}

Cuando se alcanza una edad muy avanzada.

\subsubsection{Sabio:}

Dicho de una persona que posee sabiduría, es decir, grado más amplio de conocimientos en una materia, ciencia o arte.

\subsubsection{Vetusto:}

Muy antiguo o persona de mucha edad.

\subsubsection{Abuelo/a:}

Respecto al padre o madre, de su padre o madre, quien generalmente es una persona de edad avanzada.

\subsubsection{Senil:}

Persona de edad avanzada que presenta decadencia física o psíquica.

\subsubsection{Tercera edad:}

Etapa de la vida humana que comienza a los 60 años de edad. (INEI, 2015) Periodo avanzado de la vida de las personas en el que normalmente disminuye la vida laboral activa. 


\subsubsection{Vejez:}

Cualidad de ser viejo. Último periodo de la vida de una persona en el cual se tiene edad avanzada.

\subsubsection{Sexagenario:}

Que tiene de 60 a más años, pero no llega a los 70.

\subsubsection{Septuagenario:}

Que tiene de 70 a más años, pero no llega a los 80 .

\subsubsection{Octogenario:}

Que tiene de 80 a más años, pero no llega a los 90.

\subsubsection{Nonagenario:}

Que tiene de 90 a más años, pero no llega a los 100.

3.1.2. Términos relacionados con los adultos mayores.

\subsubsection{Geriatría:}

Rama de la medicina interna que estudia los aspectos clínicos, preventivos, terapéuticos y sociales de las enfermedades de los adultos mayores. Tiene como principal función diagnosticar las dificultades que se presentan en las personas en esta etapa de su vida. La creación del post grado en esta especialidad se creó en 1992 debido al interés que se tenía en estudiar a este grupo de población que estaba incrementando de forma muy acelerada.

\subsubsection{Gerontología:}

Es la ciencia que estudia el envejecimiento y sus conductas. Es desarrollada por científicos y médicos. La gerontología es parte de la Geriatría.

\subsubsection{Jubilación:}

Acto en el cual un trabajador activo pasa a una situación no activa o pasiva, es decir, no labora. Esto se da tras alcanzar la edad de 65, 
por enfermedad crónica o por incapacidad. En cada país la normativa es distinta para este acto.

\subsubsection{PAM:}

Población Adulta Mayor.

3.1.3. Sobre los centros de asistencia para el adulto mayor.

Es importante conocer los tipos de centros de asistencia que brindan servicios a los adultos mayores, para así entender el funcionamiento de cada uno de estos y diferenciar cual es el más favorable para cada adulto mayor según sus habilidades y necesidades.

Según sus características, el proyecto a desarrollar aplica las definiciones de los siguientes términos: Centro de día y Residencia asistida.

\subsubsection{Residencia de larga estadía:}

Estas instituciones tienen como característica principal brindar alojamiento temporal o permanente a personas de la tercera edad. Así mismo, ofrecen servicios complementarios para una buena estadía como servicio de salud, seguridad y supervisión continua.

\subsubsection{Asilos:}

Lugar de tipo benéfico que brinda asistencias a las personas necesitadas, en este caso, otorga apoyo a los ancianos que no pueden cubrir sus necesidades básicas.

La mayoría de estos cuentan con atención medica básica las 24 horas a disposición de los usuarios. Sin embargo, existen asilos en los que hay equipamiento y personal médico más especializado debido a que asisten a personas mayores que padecen enfermedades que necesitan un mayor control.

\subsubsection{Casa de reposo:}

Lugar en el que se brindan atención especializada, cuidado y residencia a los adultos mayores que presentan dificultades en la 
salud que necesitan ser atendidas de forma constante, pero que no sea necesario el traslado a un hospital o clínica.

\subsubsection{Vivienda Protegida:}

Según (Di Véroli \& Schmunis, 2008), Este tipo de vivienda es una opción en la que, mediante características residenciales y adaptadas para los adultos mayores, se les da independencia a los residentes que generalmente son personas mayores que aún pueden realizar actividades por ellos mismos. Estas comunidades tienen como fin mejorar la calidad de vida facilitando el acceso de atención y ayuda domiciliaria, servicio de seguridad, etc., sin acceder a medios institucionales, por lo cual, los usuarios de estas viviendas puedes mantener vínculo directo con sus familiares, amigos y comunidad.

Los programas que ofrecen las viviendas protegidas son de libre elección y están adecuadas para satisfacer las necesidades físicas y psicológicas.

- Viviendas: de 1 a más ambientes que cuente con baño, lavadero, moderna tecnología de atención, medios para evacuar de forma segura que estén señalizados, y de ser posible, espacio para cocinar.

- Servicios generales: Salas de estar, bibliotecas, salón de usos múltiples, acceso a teléfonos públicos, comedores, cocina central (para los residentes que obtén por este servicio), áreas para deporte, acceso inmediato a obtener una atención primaria de salud, jardines, cultivos, amplios estacionamientos, etc.

\subsubsection{Residencia asistida:}

Lugar que ofrece alojamiento para adultos mayores que no pueden vivir solos debido a que presentan cierta dependencia, sin embargo, tampoco necesitan servicios médicos especializados. Lo servicios que generalmente se ofrece puede incluir aseo, comidas, vigilancia y enfermería. 
Estos centros deben contar con actividades que estimulen las relaciones sociales entre los usuarios y la comunidad, respetando la intimidad individual de estos. Generalmente cuentan con controles de acceso, recepción, áreas administrativas, dirección, sala de reuniones para el personal que brinda atención, áreas de asistencia social y sanitaria, áreas deportivas, áreas de recreación y talleres, espacios de descanso y grandes patios, jardines y parques. (Di Véroli \& Schmunis, 2008)

\subsubsection{Centro de día:}

Como su nombre lo dice, son establecimientos que sólo funcionan de día, lo cual permite que los ancianos sigan viviendo con sus familias. Tiene como finalidad contribuir con el desarrollo de las capacidades de los ancianos mediante actividades recreativas y atención básica de prevención. Así mismo, trabajan para la reconstrucción de las redes sociales de las personas de la tercera edad en tres aspectos: educación, trabajo con la comunidad y asistencia integral. El personal de estos lugares son profesionales capacitados para el cuidado, supervisión y atención de los adultos mayores.

El programa general de estos centros cuenta con: un control de acceso, servicios sanitarios completos, salón de usos múltiples, salas para actividades recreativas, salas de descanso, consultorios médicos de atención básica, comedor, cocina, depósitos, estacionamiento y áreas para el personal. (Di Véroli \& Schmunis, 2008)

\subsubsection{Clínica y hospital de día geriátrico:}

Establecimiento especializado e integrado en un hospital en el cual se brinda atención a los adultos mayores con dificultades de mediana y menor gravedad, ayudándolos en consultas $\mathrm{y}$ tratamientos que los ayuden a mejorar sus capacidades físicas y cognitivas. Estos lugares no brindan residencia. 


\subsubsection{Club día:}

Estos centros buscan promover interrelaciones entre los adultos mayores asistentes. No brinda residencia.

\subsubsection{Hotel para la tercera edad:}

Son hoteles especialmente diseñados para que las personas de tercera edad puedan tener una estancia gratificante. Así mismo ofrecen servicios que no puedan perjudicar la salud de los adultos mayores.

\subsubsection{Centro Geriátrico:}

Destinado a los adultos mayores más vulnerables, que padecen de enfermedades crónicas metales y/o físicas, por lo cual requiere apoyo y supervisión permanente del personar para realizar las actividades básicas de la vida diaria.

\subsubsection{Centro Gerontológico:}

Centros en los cuales los pacientes adultos mayores tienen la capacidad de realizar actividades básicas de la vida cotidiana como: vestirse, bañarse, comer, etc. Sin embargo, es preferible que cuenten con apoyo cercano. 
Figura 3.1.3.1: "Servicios y actividades para adultos mayores"

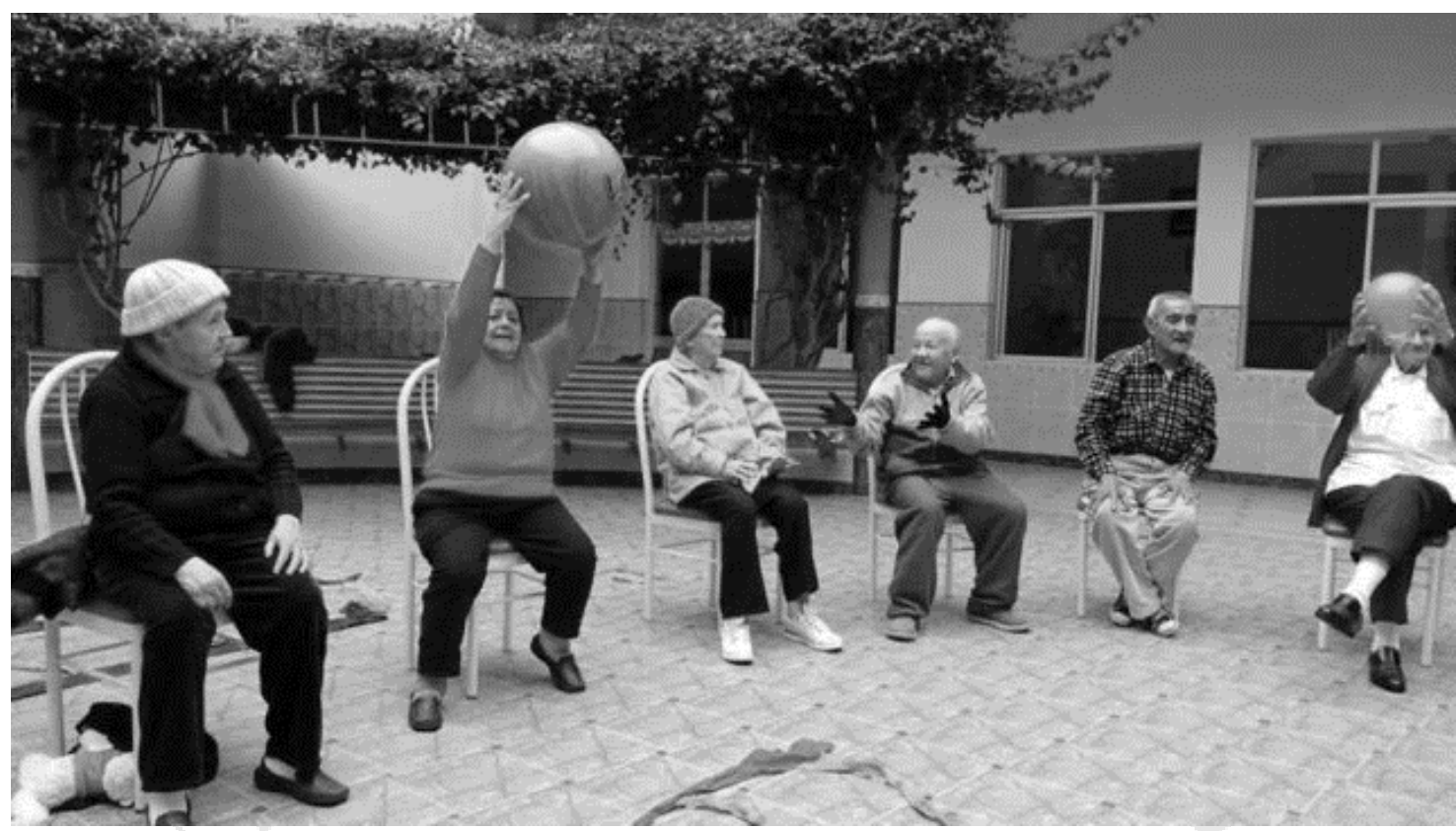

Fuente: (Central Informativa del Adulto Mayor, 2016)

Figura 3.1.3.2: "Servicios y actividades para adultos mayores"

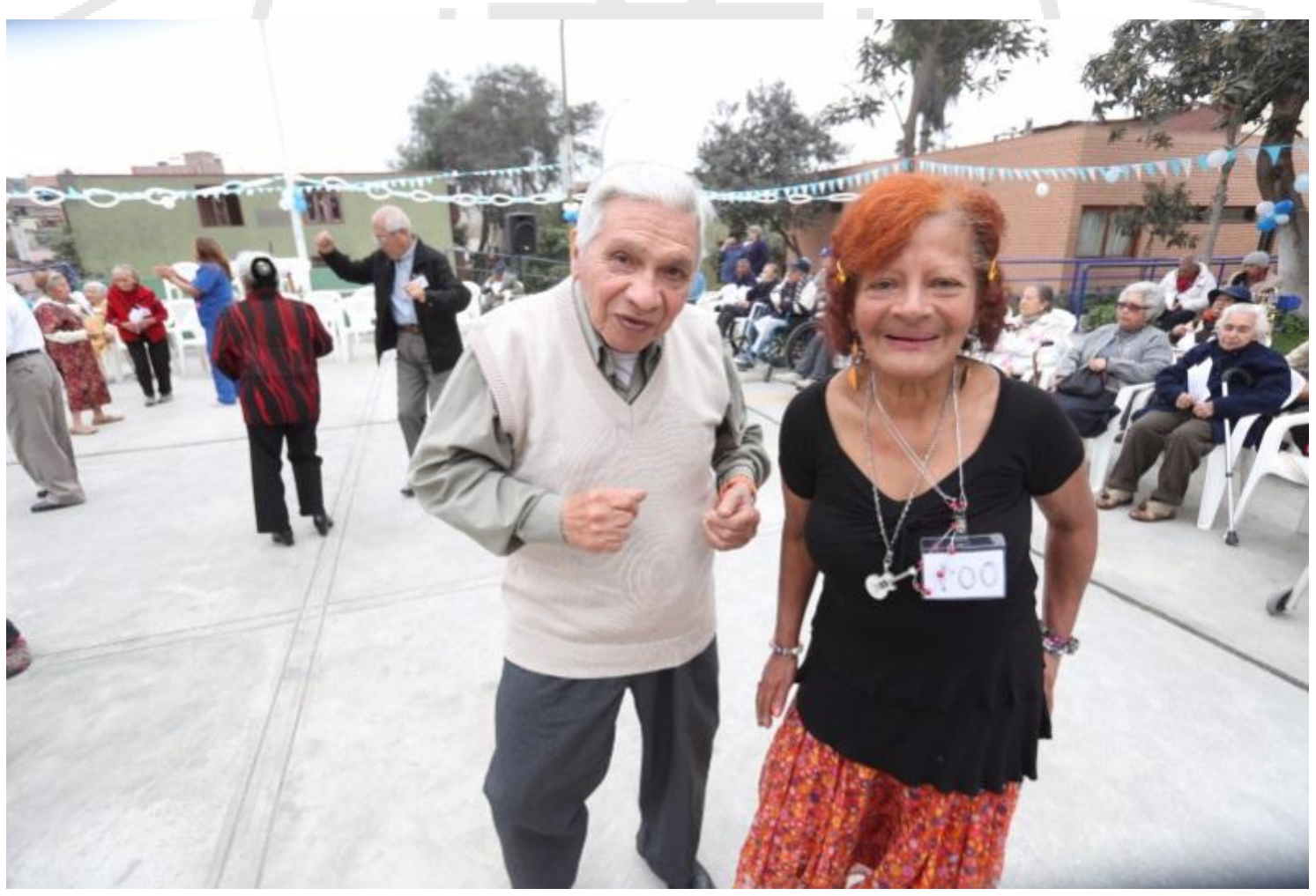

Fuente: (Municipalidad de Lima, 2017) 
3.1.4. Cuadro comparativo de los centros de asistencia para el adulto mayor

Tabla 3.1.4.1.

Cuadro comparativo de centros de asistencia para el adulto mayor

\begin{tabular}{|c|c|c|c|c|c|c|c|c|c|}
\hline & \multicolumn{8}{|c|}{ TIPOS DE CENTRO DE ASISTENCIA } \\
\hline & & $\frac{0}{\sqrt[5]{4}}$ & $\begin{array}{l}0 \\
0 \\
0 \\
0 \\
0 \\
0 \\
0 \\
0 \\
\tilde{0} \\
0 \\
0 \\
0\end{array}$ & 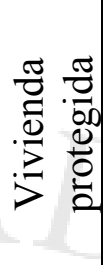 & 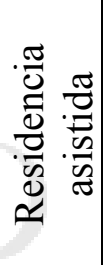 & $\begin{array}{l}\frac{\pi}{0} \\
0 \\
0 \\
0 \\
0 \\
0 \\
0 \\
0\end{array}$ & 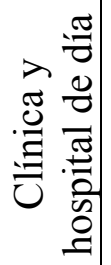 & $\begin{array}{l}\frac{\pi}{3} \\
0 \\
0 \\
0 \\
\Xi\end{array}$ & 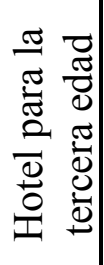 \\
\hline \multirow{12}{*}{ 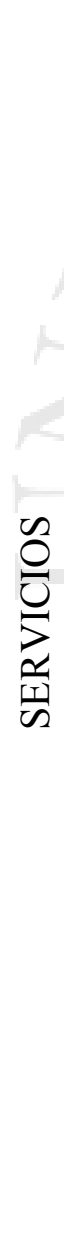 } & Benéfico & 2 & 0 & 0 & 0 & 0 & 2 & 0 & 0 \\
\hline & Vivienda & 3 & 3 & 3 & 3 & 0 & 0 & 0 & 3 \\
\hline & $\begin{array}{l}\text { Atención } \\
\text { personalizada }\end{array}$ & 3 & 3 & 3 & 3 & 2 & 3 & 2 & 3 \\
\hline & Servicio médico & 1 & 2 & 1 & 2 & 1 & 3 & 1 & 1 \\
\hline & Áreas recreativas & 3 & 3 & 3 & 3 & 3 & 1 & 3 & 3 \\
\hline & Jardines y patios & 3 & 3 & 3 & 3 & 3 & 1 & 3 & 3 \\
\hline & $\begin{array}{l}\text { Actividades } \\
\text { deportivas. }\end{array}$ & 2 & 3 & 3 & 2 & 3 & 1 & 3 & 3 \\
\hline & $\begin{array}{l}\text { Servicio de } \\
\text { rehabilitación }\end{array}$ & 2 & 3 & 0 & 1 & 1 & 3 & 0 & 1 \\
\hline & Comedor y cocina & 3 & 3 & 3 & 3 & 2 & 3 & 3 & 3 \\
\hline & Asistencia social & 0 & 0 & 0 & 0 & 3 & 0 & 0 & 0 \\
\hline & Supervisión 24 horas & 3 & 3 & 3 & 2 & 0 & 3 & 0 & 3 \\
\hline & Estacionamiento & 3 & 3 & 3 & 3 & 3 & 3 & 3 & 3 \\
\hline
\end{tabular}

Fuente: Autor.

\begin{tabular}{|c|c|}
\hline \multicolumn{2}{|c|}{ LEYENDA } \\
\hline 0 & No cuenta \\
\hline 1 & Importante \\
\hline 2 & Muy importante \\
\hline \hline 3 & Indispensable \\
\hline
\end{tabular}


3.2. Consecuencias del envejecimiento en relación con los centros para el adulto mayor.

Cuando una persona llega a la longevidad, se vuelve más vulnerable a los cambios y es más complicado que se adapte a nuevas situaciones. En las siguientes páginas se explicará 5 situaciones que aparecen en esta etapa y las cuales se han agrupado de la siguiente manera: distancia y aislamiento, se explica haciendo referencia al desprendimiento de los adultos mayores con sus actividades cotidianas. En cuanto al cambio de estilo de vida: de dinámico a pasivo, esto sucede cuando una persona mayor se jubila y detiene sus actividades laborales, situación que muchas veces es impuesta por la sociedad. Luego se desarrolla el tema de la depresión, enfermedad que aparece con mucha frecuencia en esta etapa de la vida debido a los constantes cambios y pérdidas que se generan; posteriormente, se explica sobre el proceso de adaptación de los ancianos cuando pasan de vivir en sus hogares a un asilo o centro de atención; finalmente, se hace énfasis en la importancia y los beneficios de mantener las relaciones sociales y familiares activas en las personas de la tercera edad.

\subsubsection{Distancia y aislamiento}

Las personas de tercera edad son conscientes de que a medida que pasan los años se vuelven más vulnerables a enfermedades y accidentes. Por tal motivo, desaceleran el ritmo de vida que llevaron durante sus años de juventud, y en algunas situaciones comienzan a perder el interés por actividades, relaciones, salud, objetos, etc. Según (Herrera S., Romero A., Gonzales J., \& Guillen Q., 2008) con el pasar de los años los adultos mayores tienden a refugiarse en la privacidad, se alejan de las actividades sociales y de las personas.

La participación de la población adulta mayor se ha caracterizado históricamente por ser más bien pasiva, marcada por la recepción de acciones más que por la gestión de sus propias tareas, lo que la sitúa más cerca de la marginación social que de la participación... (Zapata Frías, 2001, pág. 193) 
El origen de esta reacción en las personas de edad puede que esté estrechamente relacionada con la perspectiva que se tiene de estas en la sociedad actual, que, si bien hay un mayor interés por ellos, al mismo tiempo son apartados debido a la competitividad actual que pone a la juventud como actores principales. Además, existen factores personales y experiencias a lo largo de sus vidas que origina que los ancianos parezcan de un grado mucho mayor de aislamiento; y por consecuencia, en algunos casos resulta más difícil lograr que estos desarrollen relaciones con la comunidad, entorno y hasta con los familiares.

Por otro lado, es importante resaltar la relación con el exterior. Los lugares de asistencia para los adultos mayores que están ubicados en nuestra ciudad deberían integrarse al entorno, sin embargo, las características actuales de estos generan lo opuesto de lo óptimo, generando barreras arquitectónicas y urbanas en su contexto.

Según Stephen Verderber, las ubicaciones de los hogares de ancianos se colocan con frecuencia fuera de una ciudad. Con una mentalidad negativa acerca de estas instalaciones, las sitúan aisladas de las zonas más concurridas. Puede ser tranquilizador para las personas que no quieren enfrentar el envejecimiento y la muerte, sin embargo, esta separación de los vecinos puede causar gran tensión sobre los residentes y el personal quien vive y trabaja en el centro de ancianos. Estas instalaciones de áreas en contacto con las comunidades existentes podrían mejorar la calidad de vida y crea el sentido del lugar. Cómo se citó en (Jones T.-M. , 2015)

Mediante el aislamiento de los ancianos y la visualización de estas instalaciones como lugares de morir, este estigma se reforzará. El estilo de vida moderno de las personas de edad avanzada necesita mostrar cómo un hogar de ancianos puede ser una extensión de la vida, y no un lugar para la muerte inminente. (Jones T. , 2015)

El aislamiento psicológico por parte de la sociedad y el físico que se da en los lugares de asistencia son perjudiciales para el adulto mayor. Debido que además de contribuir con el efecto de rechazo y distanciamiento del adulto mayor con la 
comunidad, familia y contexto, puede generar que esta última etapa de vida no sea gratificante.

\subsubsection{Cambio de vida: de dinámico a pasivo}

Esto generalmente comienza con el retiro de las personas de sus actividades laborales y pasan de generar ingresos a ser dependientes, lo que causa un trastorno en la persona acostumbrada a su independencia y a tener un ritmo de vida activo. A este proceso la sociedad le ha impuesto el término de jubilación, y es la etapa que erróneamente se asocia con el envejecimiento y marca un límite en la edad productiva de las personas.

Teoría de la actividad: Sugiere que la continuación de un estilo de vida activo tiene un efecto positivo sobre la sensación de bienestar y satisfacción de los viejos. (Herrera S., Romero A., Gonzales J., \& Guillen Q., 2008)

En la actualidad esta limitación es impuesta artificialmente por las obligaciones de la sociedad y no por la edad real. Esto se debe al modo actual de vida que llevamos, el entorno cultural, las situaciones sociales, que tienden a introducir a las personas a la vejez en diversas edades. (Quintanar Olguín, 2000)

Existen diversas teorías sobre el efecto directo que surge en la persona que experimenta esta situación. Dos de estas son: "Teoría de la crisis" definida por Miller y Guillermard, en la que resaltan la importancia del trabajo como factor integrador de la persona y hacen énfasis en los efectos que tiene la jubilación en los adultos mayores. Definen tres consecuencias socio-psicológicas: desvalorización social, acceso a un tiempo libre vacío de contenido y ausencia de civilización, así como, consecuencias en la salud como depresión o ansiedad. (Jiménez, 1992)

Por otra parte, existe la "Teoría de la continuidad" por Atchley que hace énfasis en la crisis de identidad como parte de la realidad y menciona la posible satisfacción al tener un buen uso del tiempo libre y generando una mejor sensación de vida. (Sirlin, 2007). 


\subsubsection{Depresión}

Es una enfermedad muy común en los adultos mayores debido a la serie de cambios que genera esta etapa de la vida. Existen muchos tipos de depresión y también una variedad de causas que muchas veces son generadas por la sociedad, experiencia o por el propio ciclo de la vida.

El destacado psicoanalista estadounidense, Eric Erikson, divide la vida de las personas en 8 fases o crisis psicosociales, en la última se refiere a los adultos mayores como una fase de reposo exhaustivo y señala que el individuo en la última etapa analiza su vida y realiza un balance. El resultado de todo este proceso será satisfactorio si es positivo o desesperanzador si es negativo. (Ibeas, 2006)

Una de las causas frecuentes por la que las personas mayores son afectadas por la depresión es el experimentar constantes pérdida de familiares y amigos cercanos. Este desprendimiento eterno genera episodios de pena y pesar que afecta directamente la estabilidad emocional de los ancianos. Debido a que el comportamiento de los ancianos es el resultado de las experiencias lo largo de su vida, no se puede vincular que la depresión sea una característica exclusiva de esta etapa de la vida. (Herrera S., Romero A., Gonzales J., \& Guillen Q., 2008)

Los adultos mayores también son vulnerables al maltrato, sea físico, sexual, psicológico, emocional, económico o material; al abandono, a la falta de atención y a graves pérdidas de dignidad y respeto. El maltrato de las personas mayores no se limita a causar lesiones físicas sino también graves problemas psíquicos de carácter crónico, como la depresión y ansiedad. (Organización Mundial de la Salud (OMS), 2016)

El deterioro de la salud psíquica y mental de las personas mayores es vista de forma negativa por la sociedad que tiene como actor principal a la juventud, esta visión prejuiciosa y excluyente que experimentan actualmente los ancianos debe cambiar a tener una perspectiva positiva en la que se enfatice la sabiduría y experiencia que este sector de la población nos puede transmitir.

Entonces, se puede llegar a la conclusión de que los trastornos que sufren los adultos mayores, en especial la depresión, no son solo originados por experiencias, falta de motivación y situaciones naturales, sino que muchas de las características 
que la generan son ocasionadas por las presiones sociales, y en algunos casos por la falta de consideración y el abuso de aquellas personas que se aprovechan de las características vulnerables que los ancianos puedan presentar.

\subsubsection{Cambio de vida: de hogar a asilo}

Las actitudes de los adultos mayores que pasan de vivir a un asilo son diversas y dependen de la perspectiva que tenga y de situación en la que se hayan encontrado. Así mismo, la actitud inicial puede variar conforme pasa el tiempo de estadía en los asilos.

Es indispensable fomentar en los adultos mayores espacios donde puedan recrearse y estimular sus habilidades sociales y creativas, para volver a incluir dentro del ámbito social a aquellos que se encuentren aislados y para seguir estimulando a aquellos que han seguido con su actividad laboral hasta su jubilación (Herrera S., Romero A., Gonzales J., \& Guillen Q., 2008)

Según el libro "Gerontología: actualización, innovación y propuestas" de Pinazo y Sánchez, es común en las personas de edad avanzada que se muestren evasivos al realizar nuevas relaciones con otras personas, ya que en esta etapa las personas adultas mayores tienen a ser más conservadores y cerrados con los vínculos que ya han establecido con sus amigos y familiares cercanos. (Pinazo \& Sanchez, 2005)

Por tal motivo, es necesario hacer sentir a los adultos mayores que pasan de sus hogares a un centro residencial de asistencia, la mayor comodidad y bienestar posible. Asimismo, se debe trabajar en actividades que ayuden a que crezca un buen vínculo entre el nuevo usuario con los otros residentes de estos centros, las personas que trabajan en el lugar y la comunidad cercana. Estas nuevas relaciones pueden ayudar a que la nueva experiencia sea placentera y evitar enfermedades como depresión, ansiedad, estrés, etc.

Finalmente, se cree en la relación que existe entre el cambio de residencia con algunos problemas psicológicos en los adultos mayores, por ejemplo, la depresión y la baja autoestima. Debido a que, se tiene la idea que los ancianos que viven en sus hogares son más felices que los que residen en centros de asistencia. 
Sin embargo, según reportes de Canto y Castro en (Orosco, 2015), indican que esta relación entre las variables no es significativa, es decir, que la depresión y la autoestima en los adultos mayores no tiene un vínculo con respecto al lugar en el que se encuentra.

\subsubsection{Relaciones sociales}

Tener buenas relaciones sociales, contacto con familiares, amigos de toda la vida, relaciones con la comunidad y conocer a personas, permite que el adulto mayor desarrolle potencialidades y habilidades de integración que ayudan a mejorar su calidad de vida.

Se denomina redes de apoyo a las relaciones que el adulto mayor ha establecido a lo largo de toda su vida, y que tiene un papel importante debido a que en esta etapa de la vida son un sustento emocional que puede ayudar a superar adversidades. (Acevedo Alemán, Trujillo Perez, \& López Saucedo, 2012)

Según los doctores Couso, Zamora, Puron y Pino (1998), las relaciones que influyen en los adultos mayores se dividen en cuatro grupos en los que se dan situaciones diferentes: la relación anciano-anciano, puede generar ciertos conflictos debido a que cada adulto mayor envejecen con distinta percepción de vida y mientras más fortalecida estén a su personalidad, puede que resulte con más incertidumbre; la relación anciano - familia, señalan que hay distintas situaciones que van desde la sobreprotección hasta el maltrato físico y psicológico; la relación anciano - grupo social, ha sufrido diversas variaciones en la historia debido a que cada cultura y época le daba un trato distinto de acuerdo al contexto en el que se desarrollaban; finalmente, la relación anciano - trabajador de la salud, la cual requiere una debida preparación por parte del trabajador. Como se indica en (Acevedo Alemán, Trujillo Perez, \& López Saucedo, 2012)

La red social personal cumple funciones importantes para el bienestar psico-social del individuo, como es la de posibilitar la inserción social de la persona, y es básico el desarrollo de su 
identidad, por lo tanto, no solo es relevante en situaciones de crisis. (Zapata Frías, 2001, pág. 192)

Es importante mantener estables y fuertes las relaciones familiares, así mismo, las formadas con el trascurrir de los años. Debido a que, por la alta vulnerabilidad de la edad, los ancianos buscan apoyo en los seres queridos y conocidos, así como, ellos pueden genera la confianza para que los mayores puedan seguir agrandando las relaciones sociales.

\subsection{Neuroarquitectura}

La Neuroarquitectura es la unión científica entre la neurociencia y la arquitectura, esto nace a raíz de las investigaciones de Fred H. Gage y Peter Ericksson, en las cuales concluyen que el cerebro humano es capaz de fabricar nuevas células nerviosas (neuronas) a lo largo de su vida, de forma particular si el individuo se desarrolla en un entorno que lo estimule.

"Aunque la Neuroarquitectura es un concepto bastante novedoso, que los arquitectos tomen en cuenta principios de salud a la hora de diseñar inmuebles no lo es. Y es lógico que sea así, porque más del $90 \%$ del tiempo que estamos despiertos al día lo pasamos dentro de edificios, y lamentablemente muchos de los cuales no están pensados y construidos para hacernos sentir bien” . (Sáez, 2014)

La arquitectura es un arte que puede generar un impacto positivo en personas de todas las edades, quienes, por motivos de estudio o trabajo, pasan grandes horas al interior de edificaciones. Es decir, esta constante experiencia en las personas es un factor importante a tomar en cuenta al diseñar un proyecto debido a que las decisiones tomadas afectan directamente a las experiencias de las personas que ocupan el interior de las edificaciones.

En los adultos mayores, el desarrollo de la Neuroarquitectura es importante, ya que, por lo general, este grupo de población sufre de un deterioro constante de sus facultades físicas y mentales, sin embargo, si se desarrolla de manera óptima los lugares a los que ellos recurren constantemente, se podría generar un cambio positivo en la salud y confort de ellos. 
Aplicar la Neuroarquitectura como estrategias de diseño para el desarrollo de un centro de atención para adultos mayores es esencial para su buen funcionamiento y el cumplimiento de su objetivo. En principio se debe tener en cuenta que los adultos mayores son personas que han acumulado y desarrollado diversas experiencias y emociones a lo largo de su vida, por lo cual, llevarlas a experimentar con cambios drásticos podrían generar un efecto negativos en ellos.

Por lo tanto, la estimulación espacial se puede trabajar considerando las experiencias generales de los seres humanos y teniendo encuentra los sentidos; es decir, visión, tacto, audio, etc. Cada una de estas se puede desarrollar generando sensaciones térmicas y espaciales, trabajo con texturas y colores en los ambientes, estudiando la acústica y los sonidos que producen los diversos espacios; esto, es lo que va a generar un recorrido sensorial en los adultos mayores, y que, además, puedan reconocer con mayor facilidad los diversos ambientes al interior de un proyecto y relacionarlos con sus funciones.

3.4. Arquitectura y permeabilidad como elemento de articulación e integración

Según la RAE, permeabilidad viene de la palabra permear, que tiene como significado lo siguiente "Dicho de un líquido: Penetrar en un cuerpo o traspasarlo".

En arquitectura el significado de permeabilidad es similar, se refiere a la cualidad que hace referencia a la relación entre un espacio o geometría y la capacidad de atravesarlo de manera física, visual y acústica. Es decir, cuantifica la relación interior-exterior de un cuerpo.

"La permeabilidad de un material o de un cuerpo permite el traspaso, intercambio y gradación de un fluido, de un lugar a otro, en modo apreciable y conveniente. Gracias a esta capacidad, arquitecturas muy variadas posibilitan diversos efectos ambientales." (Mansilla \& Tuñon, 2013) 
Resaltar el término permeabilidad en el proyecto Residencia y Centro de día para el Adulto Mayor es importante debido a que se busca relacionar e integrar las actividades desarrolladas en los múltiples ambientes y de esta manera atravesar el proyecto generando recorridos fluidos. Asimismo, se busca una relación con la naturaleza del entorno que complemente las cualidades del centro.

"La arquitectura no se enfrenta a la naturaleza como una entidad independiente, sino que se incorpora a ella" (Ito, 2000)

Para los adultos mayores, por sus propias cualidades, es fundamental mantener una relación con elementos naturales. Por tal motivo, es importante encontrar una ubicación para el centro que permita que el proyecto se complemente con el exterior y que no sea una barrera. Así mismo, se busca integrar a las personas del entorno con el proyecto sin que las actividades de este sean interrumpidas, por lo cual, las conexiones visuales son importantes al interior del centro.

"Esta arquitectura permite la visibilidad de las situaciones cotidianas interiores y exteriores; acoge e invita al desplazamiento: antes que ocultar, amplifica nuestras relaciones afectivas y por eso hace de ellas un asunto de la estética social, relevante y singular” (Mansilla \& Tuñon, 2013).

3.5. Características de diseño de los centros de asistencia para personas de la tercera edad.

Los centros de residencia y asistencia para adultos mayores requieren de un programa espacial para el desarrollo de actividades de los ancianos, así mismo, estos deben contar con características que faciliten el desplazamiento de los usuarios, brinden comodidad y seguridad. Entre los ambientes con mayores requerimientos para facilitar el recorrido, seguridad y confort de los ancianos se encuentra: la habitación del adulto mayor, los servicios higiénicos y los pasadizos. A continuación, se explicarán las características de cada uno de los ambientes mencionados. 


\subsubsection{La habitación.}

Es el lugar de descanso, privacidad y confort dentro de un hogar. Las características en cuanto dimensiones e implementación para este espacio son variadas, sin embargo, cuando el usuario es un adulto mayor se debe cumplir con ciertos requisitos con el fin de hacerlas accesibles.

- Las puertas y pasillos deberán tener un ancho mínimo de $0.90 \mathrm{~m}$. y una altura mínima de $2.10 \mathrm{~m}$. (RNE, 2006)

- El dormitorio amoblado deberá dejar un espacio libre de $1.5 \mathrm{~m}$ de diámetro para el uso de silla de ruedas.

- Es importante enfatizar el uso de pisos antideslizantes que eviten accidentes al transitar. (RNE, 2006)

- Las cerraduras de puertas deberán estar a un máximo de $1.20 \mathrm{~m}$ de altura. (RNE, 2006)

- La cama debe estar levantada entre $45 \mathrm{~cm}$ y $50 \mathrm{~cm}$ del suelo.

Figura 3.5.1.1: Esquema de habitación accesible.

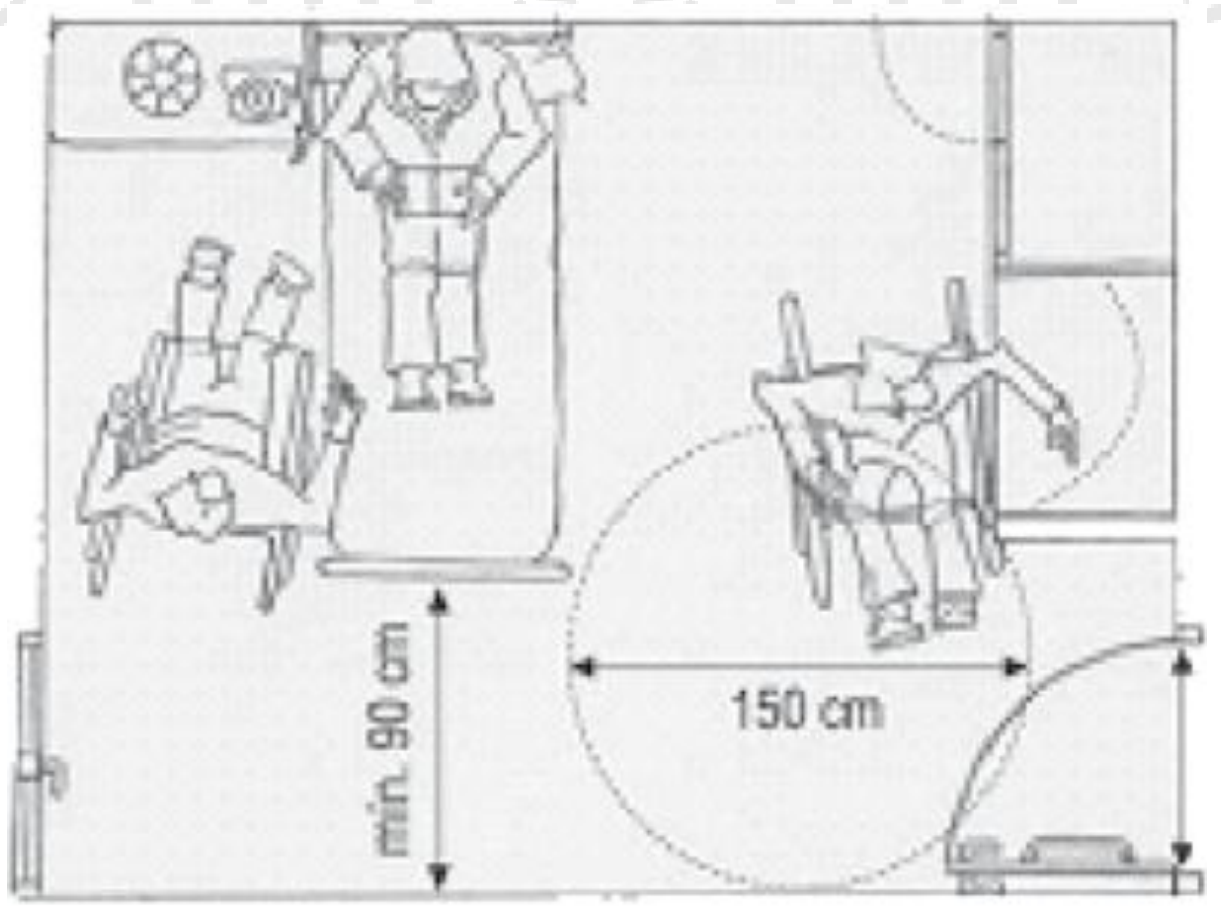

Fuente: (For Handicap Travelers, 2018) 
Figura 3.5.1.2: Esquema de habitación accesible.
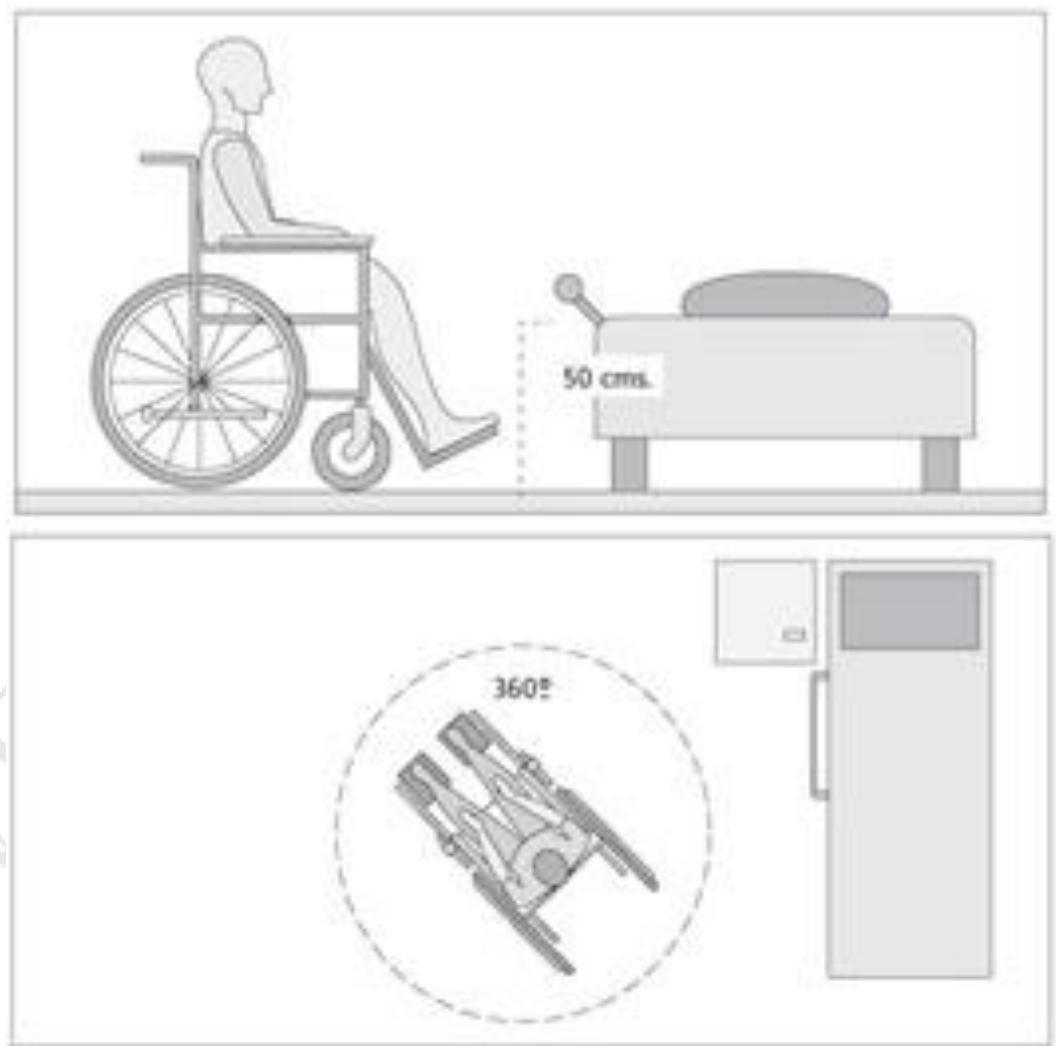

Fuente: (Mayores de hoy, 2013)

\subsubsection{Los servicios higiénicos.}

Ambientes destinados a la higiene y cuidado. Los servicios higiénicos para adultos mayores deben contar con implementos que ayuden a disminuir el riesgo el riesgo de uso como se detallará a continuación:

- La puerta de ingreso debe tener mínimo 0.90m (RNE, 2006)

- Deberá contar con barras de apoyo instaladas en las paredes necesarias para ayudar a la movilización del usuario.

- Los servicios higiénicos deberán tener un espacio libre de $1.5 \mathrm{~m}$ de diámetro para el uso de silla de ruedas. (RNE, 2006)

- El espacio inferior al lavatorio deberá tener una distancia libre de $0.75 \mathrm{~m}$ que permita que una persona en silla de ruedas se acomode para hacer uso de este. (RNE, 2006)

- Las duchas tendrán una dimensión mínima de 0.90x0.90m. (RNE, 2006)

- Las duchas deberán contar con un asiento rebatible o removible de $0.45 \mathrm{~m} \times 0.50 \mathrm{~m}$. (RNE, 2006) 
- Los accesorios deberán colocarse entre $0.50 \mathrm{~m}$ y $1.00 \mathrm{~m}$ de altura. (RNE, 2006)

- Los espejos se instalarán a una altura no superior de 1.00m (RNE, 2006)

Figura 3.5.2.1: Esquema de baño accesible

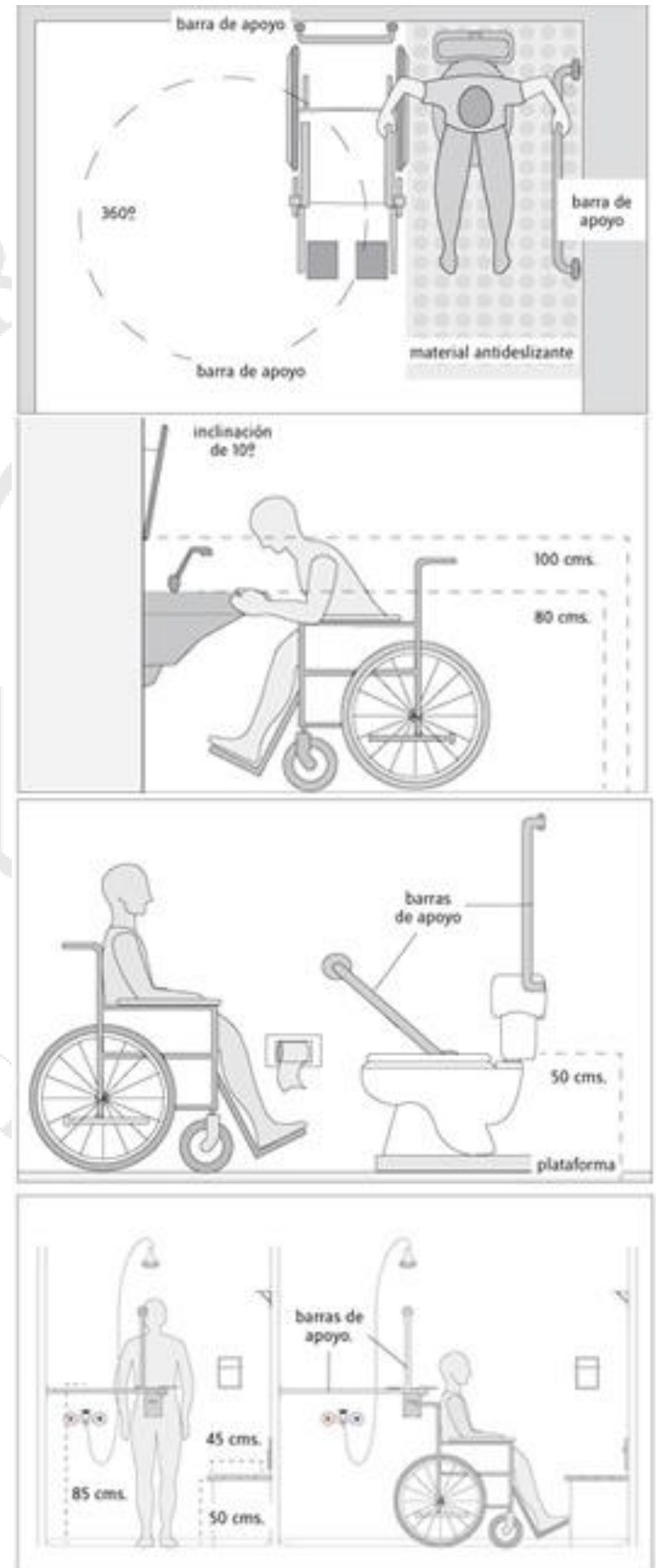

Fuente: (Mayores de hoy, 2013) 


\subsubsection{Los pasadizos.}

Los pasadizos son ambientes de transito constante, por lo tanto, para resguardar la seguridad de los adultos mayores, deberá contar con las siguientes características.

- Los pasadizos de ancho menor a 1.50m., deberán contar con espacios de giro de sillas de rueda de $1.50 \times 1.50 \mathrm{~m}$. cada $25 \mathrm{~m}$. En pasadizos con longitudes menores debe existir un espacio de giro. (RNE, 2006)

- Los pasadizos deben contar con barandas de seguridad para los adultos mayores.

- Deberán ser de un material antideslizante que evite los accidentes al transitar.

Figura 3.5.3.1: Esquema pasadizo accesible

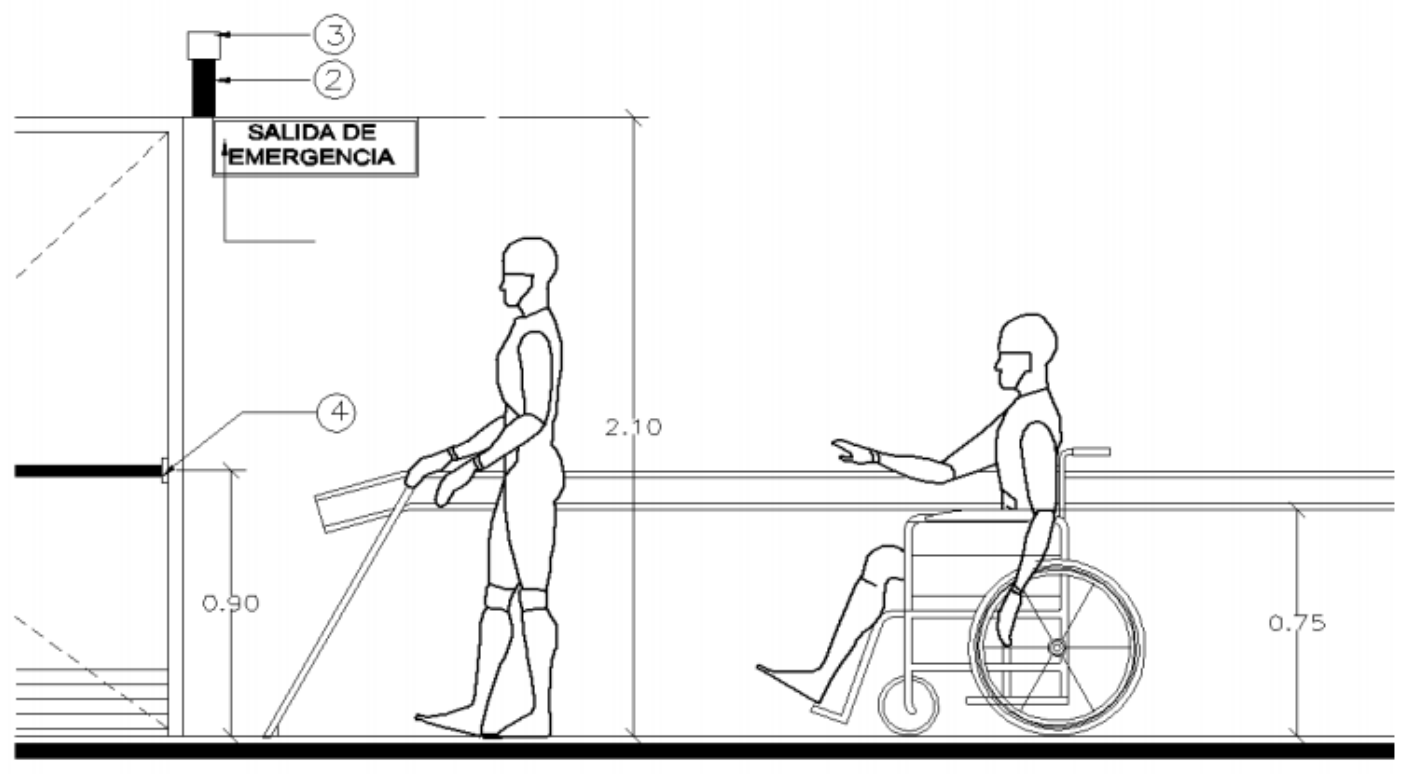


3.6. Leyes y normas a favor de las personas de la tercera edad.

3.6.1. Día del adulto mayor.

Uno de los eventos más importantes realizados en honor y reconocimiento a los ancianos es el Día Internacional de las Personas de Edad, establecida por la Organización de las Naciones Unidas (ONU) y que se celebra cada 1 de octubre desde 1991. Esta conmemoración tiene un tema distinto cada año que alienta a los países de todo el mundo a implementar servicios y programas que garanticen la seguridad y salud de las personas de tercera edad. "Lograr ciudades inclusivas para las personas de edad significa crear oportunidades para su participación económica y social en entornos accesibles y seguros." (Organización Mundial de la Salud (OMS), 2016)

En nuestro país, el gobierno del expresidente Fernando Belaunde Terry decretó que los 26 de agosto desde 1976, se celebra el día del anciano en Perú, este reconocimiento se da en honor a Santa Teresa de Jornet, quien fue fundadora de la congregación "Hermanitas de los Ancianos Desamparados". Esta congregación cuenta con un hogar para adultos mayores en Breña

3.6.2. Otras acciones internacionales para las personas de la tercera edad

3.6.2.1. Plan de acción Internacional de Viena sobre el Envejecimiento. (1982)

Planteaba recomendaciones en relación con la vivienda, salud, nutrición, entorno, familia, etc. De los adultos mayores. El plan siguió las necesidades de los países de "primer mundo" en aquella época y significo un avance puntual en el desarrollo de infraestructura en la que se tenga en cuenta al adulto mayor, creación de programas especiales de vivienda o residencias para ancianos, mayor seguridad y participación en la sociedad. (Santa Cruz, 2007) 
3.6.2.2. Asamblea General de los Principios de las Naciones Unidas a favor de las Personas de Edad (1991).

Se reconocieron los aportes que hacen los adultos mayores a la sociedad y se hizo un llamado a los gobiernos para que incluyan a estos en programas sociales. Así mismo, se coordinan principios a favor de los adultos mayores. (Santa Cruz, 2007)

Tabla 3.6.2.2.1

Principios de las Naciones Unidas a favor de las Personas de Edad

\begin{tabular}{|l|l|}
\hline \multirow{4}{*}{ Independencia } & $\begin{array}{l}\text { - Acceso adecuado a la alimentación, agua, vivienda, } \\
\text { vestido, seguridad, atención de salud adecuada con apoyo } \\
\text { de familiar y de la comunidad. } \\
\text { - Oportunidad de trabajo. } \\
\text { - Derecho a decidir hasta qué momento trabajan. }\end{array}$ \\
\hline - Las personas de edad deberán participar activamente en la \\
aplicación de políticas que pueda afectarnos directamente. \\
- Podrá prestar servicio a la comunidad y trabajar como \\
voluntarios en lugares apropiados a sus capacidades. \\
- Podrá formar movimientos o asociaciones de personas de \\
edad avanzadas.
\end{tabular}

Fuente: Principios de las Naciones Unidas a favor de las Personas Adultas Mayores. 
3.6.3. Ley de protección del Adulto Mayor $\mathrm{N}^{\circ} 4339$.

Tabla 3.6.3.1: Ley de protección del Adulto Mayor $\mathrm{N}^{\circ} 4339$

\begin{tabular}{|l|l|}
\hline Fecha & 20 de Marzo del 2015 \\
\hline Objetivo & $\begin{array}{l}\text { - Regular protección al adulto mayor. } \\
\text { - Garantizar que se cumplan los derechos reconocidos por la } \\
\text { Constitución Política del Perú y Tratados Internacionales. }\end{array}$ \\
\hline Alcance & $\begin{array}{l}\text { - Garantiza que los adultos mayores disfruten de una vida } \\
\text { plena en la que puedan participar activamente. } \\
\text { - Reconocimiento de la dignidad e igualdad de condiciones. } \\
\text { Elimina cualquier forma de discriminación, abandono o } \\
\text { violencia. }\end{array}$ \\
\hline
\end{tabular}

Fuente: Congreso de la República. (Congreso de la República, 2015)

En esta ley se señalan otras dieciséis leyes a favor de los adultos mayores, de su integridad y calidad de vida. Además, de once beneficios y ocho deberes. Así mismo señala el rol que debe tener el gobierno frente a la situación actual de los adultos mayores y la actitud que debemos adoptar los ciudadanos. 
3.6.4. Ley del adulto mayor $\mathrm{N}^{\circ} 28803$

Tabla 3.6.4.1: Ley del Adulto Mayor Nº 28803

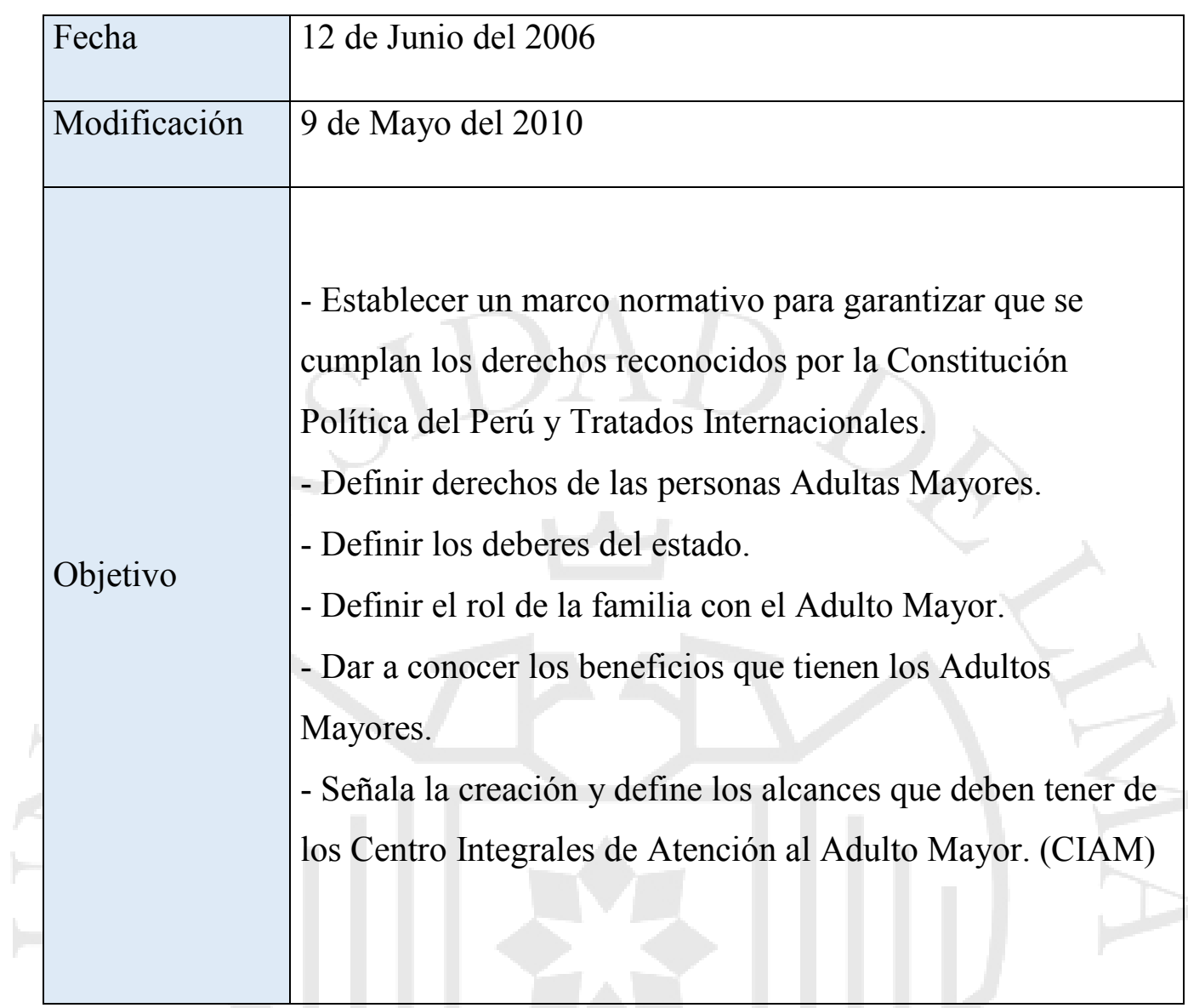

Fuente: Congreso de la República. (Congreso de la República, 2006) (Congreso de la República, 2010)

Uno de los puntos más importantes de esta ley es que incorpora los Centros Integrales de Atención al Adulto Mayor (CIAM), dirigidos por el Ministerio de la Mujer y Poblaciones Vulnerables (MIMP) y define las pautas que debe seguir para obtener un resultado a favor de una buena calidad de vida para el Adulto Mayor. 
3.6.5. Ayuda económica y sistemas de pensiones.

\subsubsection{SPP}

El Sistema Privado de Pensiones (SPP) es un régimen que ofrece pensiones de jubilación, invalidez y sobrevivencia, así como reembolso en caso de sepelio. Esto a través de un fondo personal al que se pueden afiliar las personas que ejercen laboralmente. La administración de estos fondos está a cargo de las empresas privadas Administradoras de Fondos de Pensiones (AFP), por otro lado, la supervisión de estás está a cargo de la Superintendencia de Banca y Seguros y AFP (SBS)

El resultado de la pensión se da del total de aportes que acumula el usuario más la rentabilidad obtenida. Además, los afiliados pueden realizar aportes adicionales a los obligatorios para poder tener mayor retribución al momento de jubilarse, por lo cual, no existen montos limitados de pago.

\subsubsection{SNP}

El Sistema Nacional de Pensiones (SNP), como sus siglas lo dicen, es un sistema pensionario administrado por el Estado, este fue creado el 1 de mayo de 1973 por el decreto de Ley N¹9990. A este régimen se pueden afiliar las personas que por primera vez ingresan a laborar y los trabajadores independientes que no estén afiliados a otro sistema de pensiones. A estos se les ofrece una pensión de jubilación por un monto mínimo de S/. 415.00 y máximo de $\mathrm{S} / .857 .36$. Esta pensión debe tener como condiciones que el afiliado usuario aporte del $13 \%$ de su remuneración por un mínimo de 20 años, el cual ingresa a un fondo común, además, debe tener 65 años edad para poder solicitarla.

Existen casos excepción a la regla los cuales están determinados por lo siguiente:

- Jubilación adelantada: Se puede obtener este beneficio antes de los 65 años. Los hombres deberán tener mínimo 55 años y 30 años de aportes al SNP, por otro lado, las mujeres deberán tener mínimo 50 años y haber aportado por 25 años.

- Pensión invalidez: El asegurado que se encuentra en incapacidad física o mental prolongada o presumida permanente, que le impida ganar más de la 
tercera parte de la remuneración o ingreso asegurable que percibía otro trabajador de la misma categoría, en un trabajo igual, podrá solicitar una pensión de invalidez, la cual equivale al $50 \%$ de la remuneración o ingreso de referencia. Si al producirse la invalidez el asegurado tuviera cónyuge a su cargo y/o hijos en edad de percibir pensión de orfandad, el monto de la pensión de invalidez se incrementará en un porcentaje comprendido entre el 2 y $10 \%$ de la remuneración o ingreso de referencia por el cónyuge, y entre el 2 y 5\% por cada hijo. (Oficina de Normalización Previsional)

- Régimen Especiales del SNP: Existen algunos casos orientados a trabajadores que realizan actividades especiales.

Tabla 3.6.5.2.1: Requisitos para solicitar pensión de jubilación.

Requisitos para solicitar pensión de jubilación - Regímenes Especiales

\begin{tabular}{|c|c|c|c|c|}
\hline \multirow{2}{*}{ Modalidad } & \multicolumn{2}{|c|}{ Edad } & D.L. $N^{\circ} 19990$ (1) & D.L. N²5967 (2) \\
\hline & Hombres & Mujeres & Aportes requeridos para pensión & Aportes requeridos para pensión \\
\hline $\begin{array}{l}\text { Construcción } \\
\text { civil (3) }\end{array}$ & 55 años & & $\begin{array}{l}15 \text { años de aportación en } \\
\text { modalidad o } 05 \text { años en la } \\
\text { modalidad efectuados en } \\
\text { los últimos } 10 \text { años } \\
\text { anteriores a la fecha de } \\
\text { cese. }\end{array}$ & $\begin{array}{l}20 \text { años de aportación de } \\
\text { los } 15 \text { años deben haberse } \\
\text { efectuado en la modalidad } \\
\text { o } 05 \text { años en los últimos } 10 \\
\text { años anteriores a la fecha } \\
\text { de cese. }\end{array}$ \\
\hline Marítimos & 55 años & & $\begin{array}{l}15 \text { años de aportación, de } \\
\text { los cuales } 05 \text { años deben } \\
\text { haberse efectuado en la } \\
\text { modalidad. }\end{array}$ & $\begin{array}{l}\text { Mínimo } 20 \text { años de } \\
\text { aportación de los cuales } 05 \\
\text { años deben haberse } \\
\text { efectuado en la modalidad. }\end{array}$ \\
\hline Periodistas & $\begin{array}{l}55 \\
\text { años }\end{array}$ & $\begin{array}{l}50 \\
\text { años }\end{array}$ & $\begin{array}{l}15 \text { o } 13 \text { años de aportación } \\
\text { en la modalidad o } 05 \text { años } \\
\text { en la modalidad efectuados } \\
\text { en los últimos } 10 \text { años } \\
\text { anteriores a la fecha de } \\
\text { cese. }\end{array}$ & $\begin{array}{l}20 \text { años de aportación, de } \\
\text { los cuales } 15 \text { o } 13 \text { años } \\
\text { deben haberse efectuado en } \\
\text { la modalidad o } 05 \text { años en } \\
\text { la modalidad en los últimos } \\
10 \text { años anteriores a la } \\
\text { fecha de cese. }\end{array}$ \\
\hline $\begin{array}{l}\text { Industrias del } \\
\text { cuero }\end{array}$ & $\begin{array}{l}55 \\
\text { años }\end{array}$ & $\begin{array}{l}50 \\
\text { años }\end{array}$ & $\begin{array}{l}15 \text { o } 13 \text { años de aportación } \\
\text { en la modalidad, de los } \\
\text { cuales por lo menos } 05 \\
\text { años deben haberse } \\
\text { efectuado en la modalidad. }\end{array}$ & $\begin{array}{l}20 \text { años de aportación de } \\
\text { los cuales por lo menos } 05 \\
\text { años deben haberse } \\
\text { efectuado en la modalidad. }\end{array}$ \\
\hline
\end{tabular}




\begin{tabular}{|c|c|c|c|c|}
\hline \multirow{5}{*}{$\begin{array}{l}\text { Pilotos y } \\
\text { copilotos }\end{array}$} & 55 años & & $\begin{array}{l}15 \text { años de aportación de } \\
\text { los cuales } 05 \text { años deben } \\
\text { haberse efectuado en la } \\
\text { modalidad }\end{array}$ & $\begin{array}{l}20 \text { años de aportación } \\
\text { debiéndose incluir los } \\
\text { requisitos señalados para el } \\
\text { D.L N} 19990\end{array}$ \\
\hline & 56 años & & $\begin{array}{l}15 \text { años de aportación de } \\
\text { los cuales } 04 \text { años deben } \\
\text { haberse efectuado en la } \\
\text { modalidad }\end{array}$ & $\begin{array}{l}20 \text { años de aportación } \\
\text { debiéndose incluir los } \\
\text { requisitos señalados para el } \\
\text { D.L N } 19990\end{array}$ \\
\hline & & & $\begin{array}{l}15 \text { años de aportación de } \\
\text { los cuales } 03 \text { años deben } \\
\text { haberse efectuado en la } \\
\text { modalidad }\end{array}$ & $\begin{array}{l}20 \text { años de aportación } \\
\text { debiéndose incluir los } \\
\text { requisitos señalados para el } \\
\text { D.L N} 19990\end{array}$ \\
\hline & 58 años & & $\begin{array}{l}15 \text { años de aportación de } \\
\text { los cuales } 02 \text { años deben } \\
\text { haberse efectuado en la } \\
\text { modalidad }\end{array}$ & $\begin{array}{l}20 \text { años de aportación } \\
\text { debiéndose incluir los } \\
\text { requisitos señalados para el } \\
\text { D.L N } 19990\end{array}$ \\
\hline & 59 años & & $\begin{array}{l}15 \text { años de aportación de } \\
\text { los cuales } 01 \text { año deben } \\
\text { haberse efectuado en la } \\
\text { modalidad }\end{array}$ & $\begin{array}{l}20 \text { años de aportación } \\
\text { debiéndose incluir los } \\
\text { requisitos señalados para el } \\
\text { D.L N } 19990\end{array}$ \\
\hline Amas de casa. & N.A. & $\begin{array}{l}55 \\
\text { años }\end{array}$ & 5 años de portación & $\begin{array}{l}20 \text { años de aportación } \\
\text { debiéndose incluir los } \\
\text { requisitos señalados para el } \\
\text { D.L N¹9990 }\end{array}$ \\
\hline
\end{tabular}

(1) Solo de aplicación para aquellos asegurados que hasta el 18.12.92 reúnan los requisitos de edad y aportaciones señalados.

(2) Será de aplicación para aquellas personas que a partir del 19.12.92 reúnan los requisitos de edad y aportaciones mencionados en el cuadro.

(3) El cálculo de la pensión para estas modalidades no está sujeto al descuento por años de adelanto. (art. 44 del D.L. $\left.\mathrm{N}^{\circ} 19990\right)$

(4) Las amas de casa aportan como facultativos independientes, pero se consideran como aseguradas obligatorias y como excepción, tienen derecho a pensión del Régimen Especial de las nacidas antes del 1 de julio de 1936, por lo que no procede otorgar pensión reducida. Es necesario que existan los cinco años de aporte en la modalidad al 18 
de diciembre de 1992, la acumulación de distintas modalidades de aporte es para efectos de incrementar el monto de pensión.

Fuente. (Oficina de Normalización Previsional)

Fuente: (Congreso de la República, 1973)

\subsubsection{Diferencias entre SNP Y SPP.}

El siguiente cuadro explica las diferencias entre los dos sistemas de pensiones que hay en nuestro país.

Tabla 3.6.5.3.1: Cuadro resumen de diferencias entre SNP y SPP

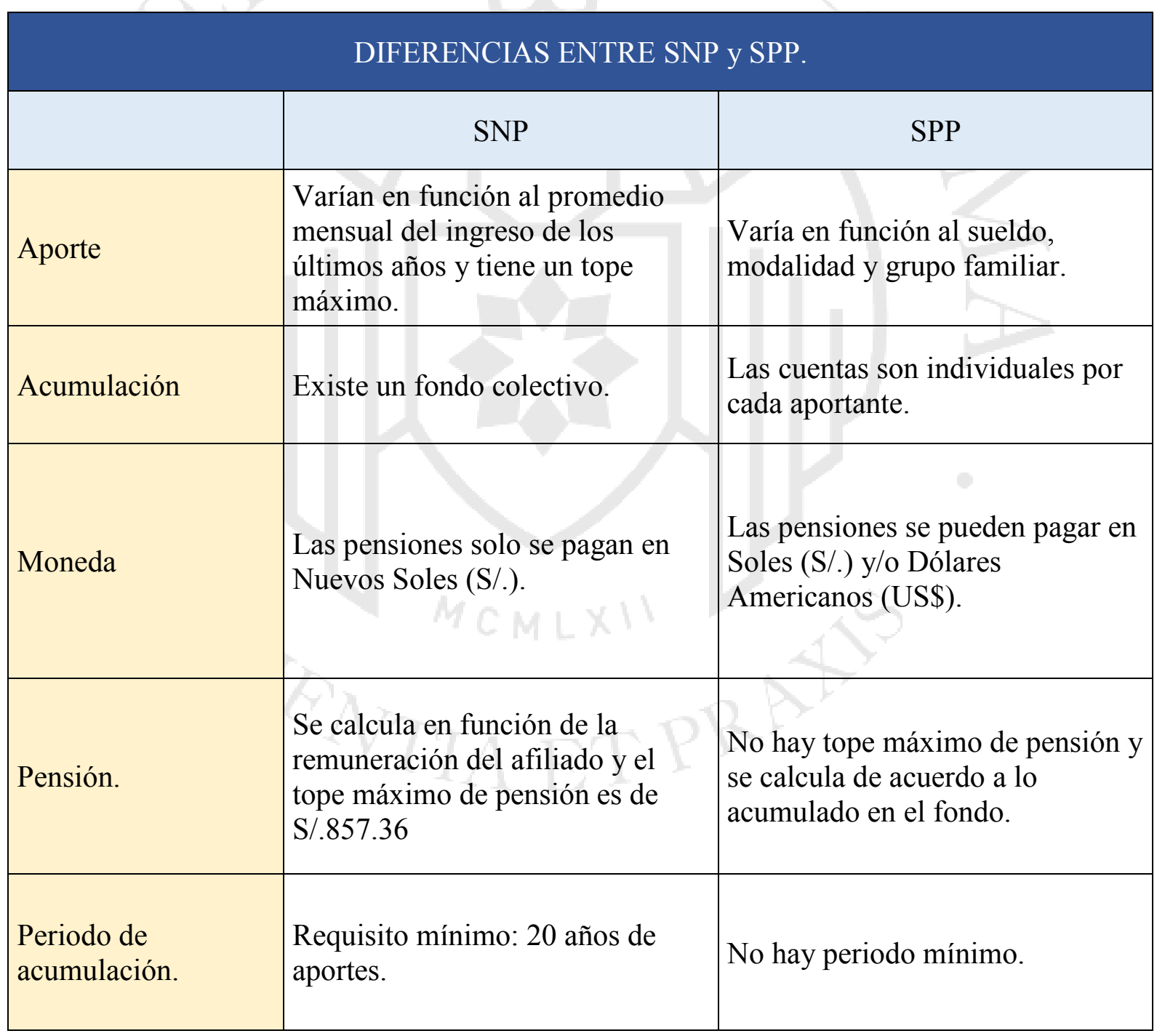

Fuente: Ver cuadro completo en anexos. (PROFUTURO, s.f.) 


\subsubsection{Pensión 65}

Pensión 65 es un programa de asistencia solidaria se creó con la finalidad de brindar ayuda y protección a las personas vulnerables mayores de 65 años que viven en la extrema pobreza y carecen de las condiciones básicas para subsistir.

Se creó el 19 de octubre del 2001 bajo el Gobierno del Ex Presidente Ollanta Humala Tasso, actualmente se encuentran inscritos 10'665 usuarios y se encuentra adscrito al Ministerio de Desarrollo e Inclusión Social (MIDIS).

La ayuda consta de un depósito de $\mathrm{S} / 265.00$ soles cada dos meses que abona el MIDIS en diversos puntos del Banco de la Nación. Para formar parte de este programa es necesario tener más de 65 años, contar con DNI, encontrarse en condición de pobreza extrema y no recibir pensión proveniente del sector público o privado. (Pensión 65, 2015)

Figura 3.6.5.4.1: Pensión 65

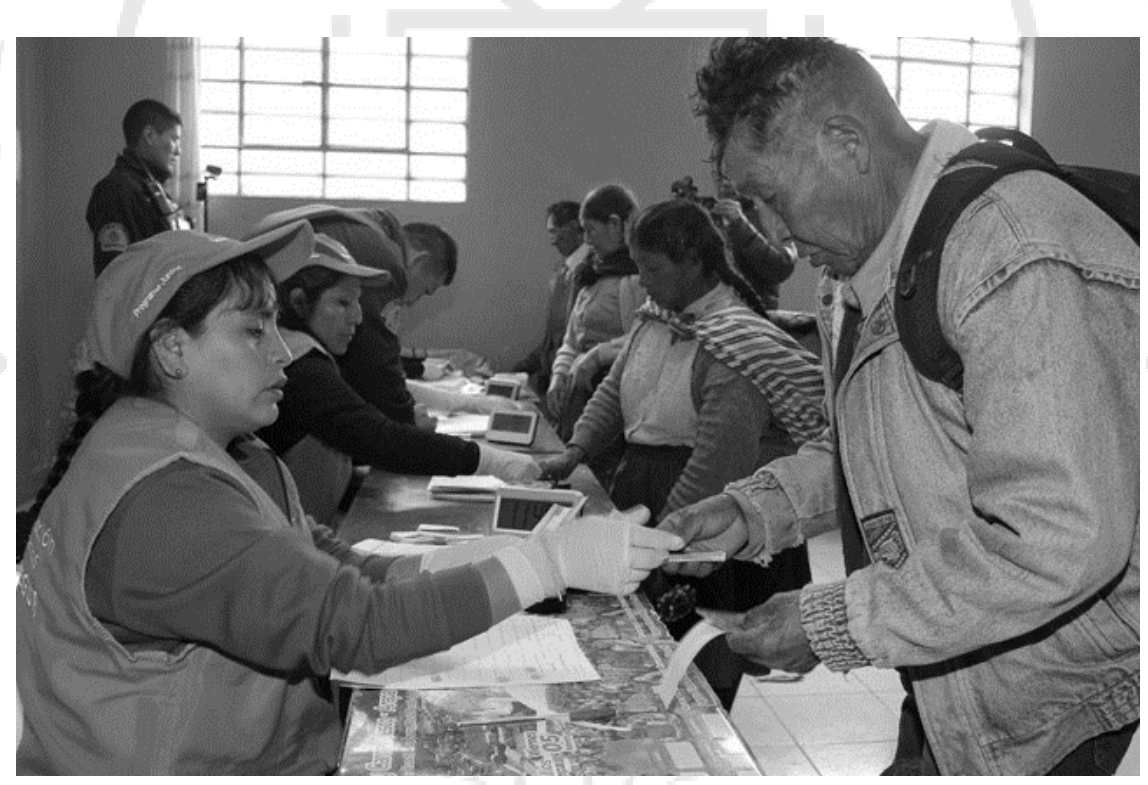

Fuente: (Pensión 65, 2015)

3.7. Programas de asistencia para el adulto mayor.

En nuestro país, desde hace algunos años, existen ciertos programas de asistencia para el adulto mayor que son manejados por diferentes instituciones del gobierno con ayuda de las municipalidades. Cada uno de estos programas tiene 
características, funciones y objetivos distintos pero que en su conjunto buscan la integridad de las personas de tercera edad.

3.7.1. Programas de asistencia pública.

\subsubsection{CIAM:}

Centro Integral de atención para el Adulto Mayor (CIAM) fue creado por la Ley No 28803 - Ley de Personas Adultas Mayores, artículo 8 y está dirigido para personas mayores de 60 años las cuales deberán inscribirse en el registro de cada CIAM para obtener los servicios gratuitos de estos lugares.

Son espacios municipales de prestación, coordinación y articulación, intra e interinstitucional, de servicios básicos integrales y multidisciplinarios, para el bienestar y promoción social de las personas adultas mayores, en un contexto de cogestión y participación de la persona adulta mayor y la familia. (Ministerio de la Mujer y Desarrollo Social, 2009)

Entre las finalidades de los CIAM estaba:

- Desarrollar lazos de mutuo conocimiento y amistad

- Realizar actividades y organizar talleres de autoestima, prevención de maltrato y enfermedades crónicas.

- Combatir y prevenir problemas de salud comunes.

- Talleres para desarrollar conocimiento y habilidades que influyan de manera positiva a los adultos mayores.

- Identificar problemas individuales, familiares o locales.

Entre sus enfoques:

- Enfoque de personas adultas mayores con sujetos de derecho.

- Enfoque intergeneracional de la familia y la comunidad.

- Enfoque intercultural con valoración positiva del envejecimiento.

- Enfoque de desarrollo de capacidades de las personas adultas mayores. 
Se debe resaltar que los servicios que ofrecen los CIAM se pueden efectuar de manera progresiva, es decir, se recomienda priorizar los que se consideran más importantes de acuerdo con la diversidad en la que se desarrollará cada CIAM. Entre los servicios se encuentran los siguientes:

- Servicios educativos, recreativos y deportivos.

- Servicios de participación ciudadana.

- Servicios para el desarrollo de las capacidades de las personas adultas mayores.

- Servicios de salud básicos.

Sobre el financiamiento y sostenibilidad se dispone que las Municipalidades Provinciales y Distritales deben ser las encargadas de gestionar recursos económicos para los CIAM con cargos en sus respectivos presupuestos. Así mismo, pueden establecer alianzas estratégicas con gobiernos regionales, entidades públicas y privadas.

Figura 3.7.1.1.1: Actividades en CIAM de La Molina

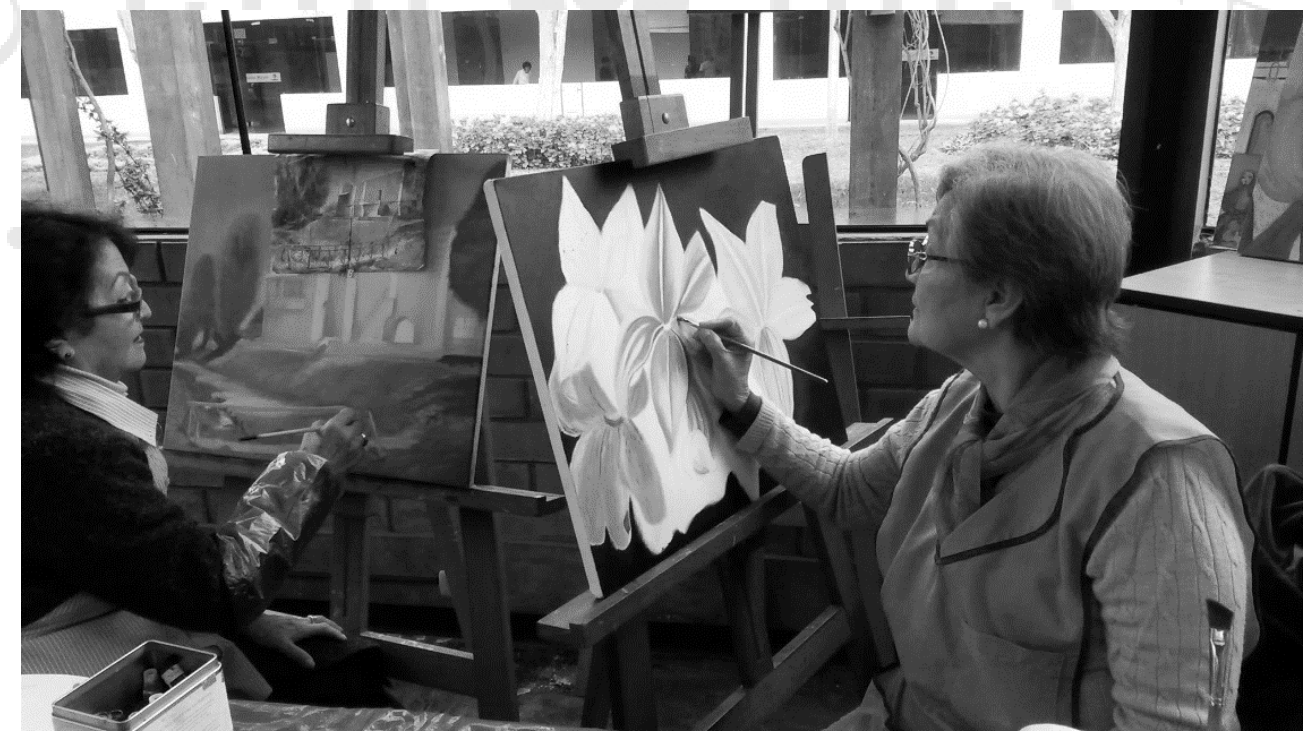

Fuente: (Municipalidad de La Molina, 2018)

\subsubsection{CARPAM (Ministerio de la Mujer)}

Los Centro de Atención Residencial para Personas Adultas Mayores, son lugares de reposo, privados o públicos, destinados para brindar atención a 
las personas adultas mayores, garantizándoles vivienda, salud, alimentación, recreación y otros servicios dependiendo de las características de los usuarios de cada CARPAM.

Los CARPAM deben garantizar una óptima atención y cuidado para los adultos mayores que, por voluntad, decidan ingresar a estos centros. Los servicios que se les ofrece a los residentes deberán ser supervisados las 24 horas del día por un personal especializado bajo el mando de algún especialista en gerontología, de esta manera, se garantiza una eficiente atención a los usuarios.

Entre los requisitos de infraestructura para estos centros, se encuentran los siguientes puntos:

- Un solo piso o se deberá contar con rampas o ascensor.

- Buena iluminación y ventilación.

- Áreas condicionadas para garantizar la comodidad de los adultos mayores.

- Áreas destinadas a funciones que desarrollen íntegramente a los adultos mayores.

Figura 3.7.1.2.1: Servicios en CARPAM.

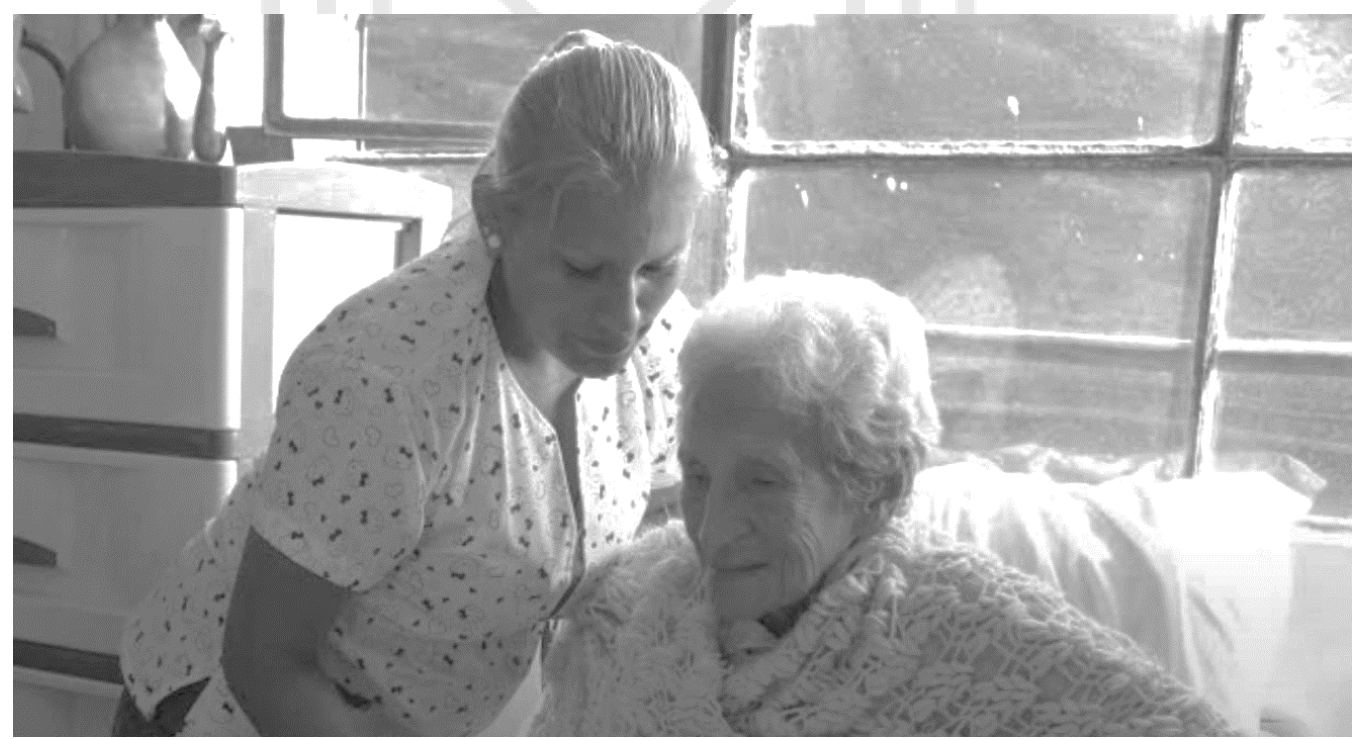

Fuente: (Ronie Bautista Gonzales, 2015) 


\subsubsection{CAM (ESSALUD).}

Centros del Adulto Mayor, son espacios de encuentro dirigido para personas de 60 años a más que están aseguradas en ESSALUD, y que tiene como finalidad mejorar la etapa de envejecimiento mediante el desarrollo de programas y actividades socioculturales, recreativas y de recreación donde se pueda lograr mejorar el estilo de vida.

Dentro del CAM existe el programa de Unidad Básica de Atención al Adulto Mayor (UBAAM), el cual brinda atención medica de prevención, mantenimiento y control de enfermedades, y otorga medicina básica a sus usuarios. (ESSALUD)

Entre las actividades que realizan los CAM:

- Talleres recreativos (Memoria, artístico, cultural, social, etc.)

- Eventos deportivos.

- Eventos para fomentar integraciones.

- Campañas de salud.

- Capacitación para proyectos de micro emprendimiento.

- Fisioterapia, podología, gimnasio, etc.

Figura 3.7.1.3.1: Actividades CAM

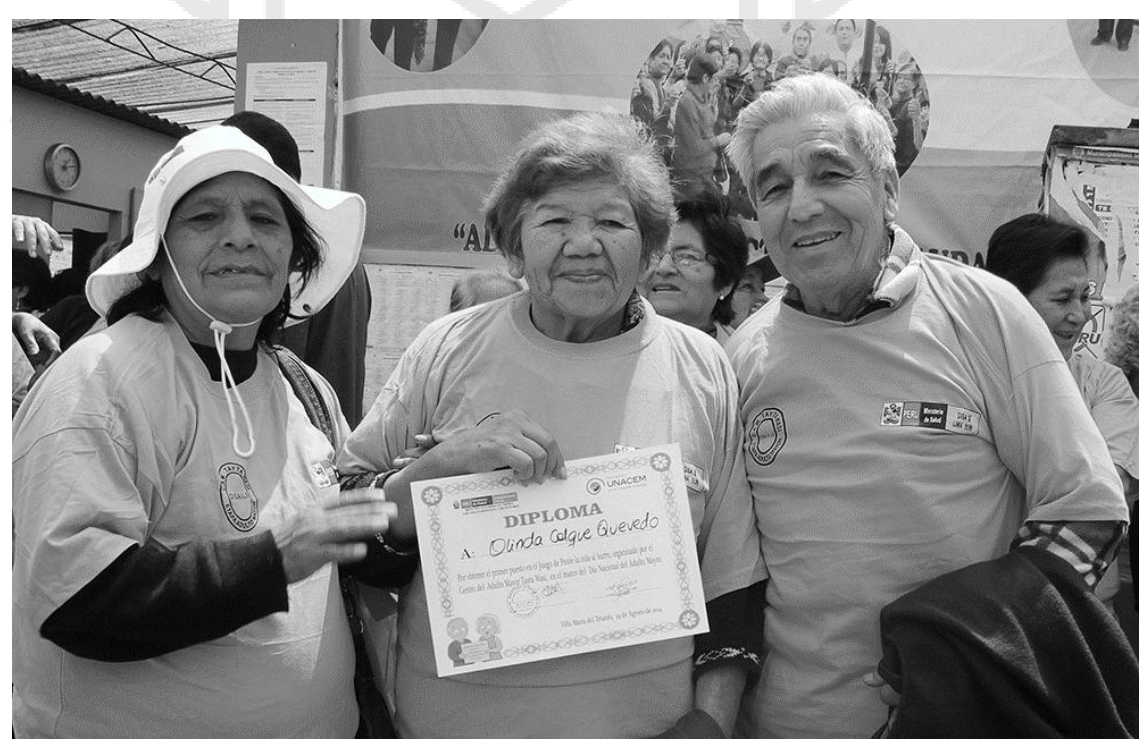

Fuente: (Asociación UNACEM, 2014) 


\subsection{2. $\mathrm{ONG}$}

\subsubsection{Fundación Canevaro.}

La fundación se crea gracias a la peruana Doña Ignacia Rodulfo Vda. De Canevaro quien se dedicó a ayudar a niños y ancianos en estado de abandono y que dejó en testamento la continuación de estos proyectos de ayuda.

La fundación se autofinancia administrando bienes de su propiedad y con donaciones. Busca contribuir al mejoramiento de la calidad de vida de las personas beneficiarias de la fundación.

\subsubsection{Asociación Benéfica María Echevarría Saona}

Es una asociación sin fines de lucro que busca ayudar al rescate de ancianos desamparados y con Alzheimer. No dan ayuda residencial, pero si brindan alimento, asistencia y ayuda médica a todos los ancianos que puedan.

3.7.3. Comunidades religiosas.

Hay diversas congregaciones religiosas que se dedican a la atención de adultos mayores en estado de abandono o de bajos recursos. Estos centros generalmente se financian de donaciones.

\subsubsection{Cáritas del Perú}

Es un organismo de la Iglesia Católica fundado en el año 1955 por la Conferencia Episcopal Peruana, actualmente tiene 48 centros en todo el país que brindan ayuda.

Cáritas tiene como fin el promover programas que favorezcan a las poblaciones vulnerables en su desarrollo humano integral, que esté basado en principios cristianos: justicia, solidaridad y respeto a la dignidad humana. Asimismo, fomentan la participación de la población como 
agentes de desarrollo, impulsando el conocimiento de sus propias capacidades y autoestima.

Figura 3.7.3.1.1: Adultos Mayores en Caritas del Perú

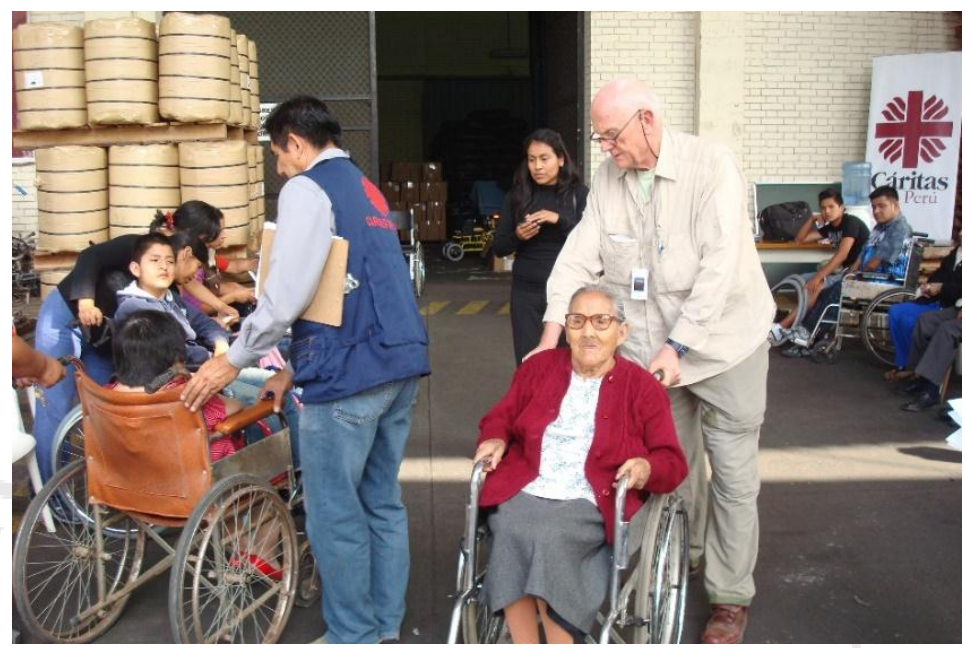

Fuente: (Conferencia Episcopal Peruana, 2009)

3.8. Parámetros nacionales e internacionales.

3.8.1. Reglamento Nacional de Edificaciones (RNE)

3.8.1.1. Servicios comunales A.090

Esta norma hace énfasis en las características de construcción y diseño que debe tener un centro de adultos mayores para garantizar un lugar con espacios de buena calidad.

3.8.1.2. Accesibilidad para personas con discapacidad y de personas adultas mayores A.120

La presente norma hace referencia a las características y diseño de espacios accesibilidad, circulación, áreas privadas y de actividades. Así mismo define minuciosamente los detalles que deben tener los niveles, dimensiones de objetos, etc. 
3.8.1.3. Requisitos de seguridad A. 130

Esta norma señala los requisitos que deben tener todo establecimiento público y privado de acuerdo a su uso y al aforo, para poder garantizar la seguridad de los usuarios en diversas circunstancias de emergencia.

3.8.2. Organización Iberoamericana de Seguridad Social (OISS).

La OISS con ayuda de la Secretaria General Iberoamericana (SGIB), establecen una guía en cuanto a los centros residenciales para personas adultas mayores en la que se puede encontrar características de ubicación, construcción, diseño y funciones que debe tener un centro de asistencia para personas de la tercera edad con el fin de garantizar una estancia óptima.

Esta guía fue acordada y aprobada por la cumbre Iberoamericana de Jefes de Estado y de Gobierno en el año 2011, en la cual participaron los siguientes países: Argentina, Brasil, Chile, Ecuador, España, México, Uruguay y Paraguay.

3.8.3. Cuadro comparativo entre las normas peruanas y las establecidas por la OISS.

Tabla 3.8.3.1: Comparación de temas entre normativas)

\begin{tabular}{|c|c|c|}
\hline Especificaciones & Perú & OISS \\
\hline Servicios & & \\
\hline Funciones & & \\
\hline Personal & & \\
\hline Ubicación & & \\
\hline Medio ambiente & & \\
\hline Entorno & & \\
\hline
\end{tabular}




\begin{tabular}{|c|l|l|}
\hline Arquitectura & & \\
\hline Seguridad & & \\
\hline Materialidad & & \\
\hline
\end{tabular}

Fuente: Autor

\subsection{Conclusiones parciales}

El capítulo de marco teórico nos ayuda a ampliar el conocimiento de palabras y expresiones que tienen relación con las personas de la tercera edad, además, se hace una referencia especial al significado de residencia asistida y centro de día; principales términos que - por sus características - están vinculados al proyecto que se desarrollará.

Por otro lado, se concluye que, al llegar a la etapa de vejez, los adultos mayores pasan por grandes cambios personales y sociales que pueden afectar el estado emocional y físico como: la variación de ritmo de vida, la jubilación, la perdida de seres queridos, el aislamiento que sufren en sus hogares, y el adaptarse a vivir en un centro de atención para personas longevas. Por lo cual, es importante tomar en cuenta las posibles secuelas al realizar un proyecto de atención para este sector de la población. Asimismo, se entiende que cada anciano tiene un estado de salud y emocional distinto, lo que genera múltiples opciones a tomar en cuenta al escoger el lugar adecuado de estancia.

Finalmente, se explican las existentes normas, leyes y diversas acciones realizadas por el gobierno y entidades privadas para respaldar a este sector de la población. Sin embargo, falta mayor trabajo en dichos sistemas debido a que aún existen miles de adultos mayores que no cuentan con ningún tipo de beneficio público ni privado. 


\section{CAPITULO IV: MARCO OPERATIVO}

Como parte de la investigación se analizarán cinco referentes de diversas partes del mundo. Los tres primeros casos están ubicados en Europa y son seleccionados debido a la importancia que tienen en sus ciudades, además por contar con características similares a los que se propondrán en el nuevo proyecto. Por otro lado, de los otros dos casos analizados, uno está ubicado en México, el cual es un claro ejemplo de la perspectiva que se tuvo en el pasado sobre los centros de residencia para adultos mayores; finalmente, el último caso está ubicado en nuestro país, este referente contiene características similares a los otros centros ubicados en Lima, esto permitirá tener un enfoque más claro de la realidad en nuestra ciudad.

Se realizará un cuadro resumen de todos los casos con el fin de hacer una comparación y concluir cuales son las mejores características de cada uno de estos centros, las cuales serán de ayuda para el diseño del proyecto a proponer.

Figura: 4.1

Ubicación de los referentes

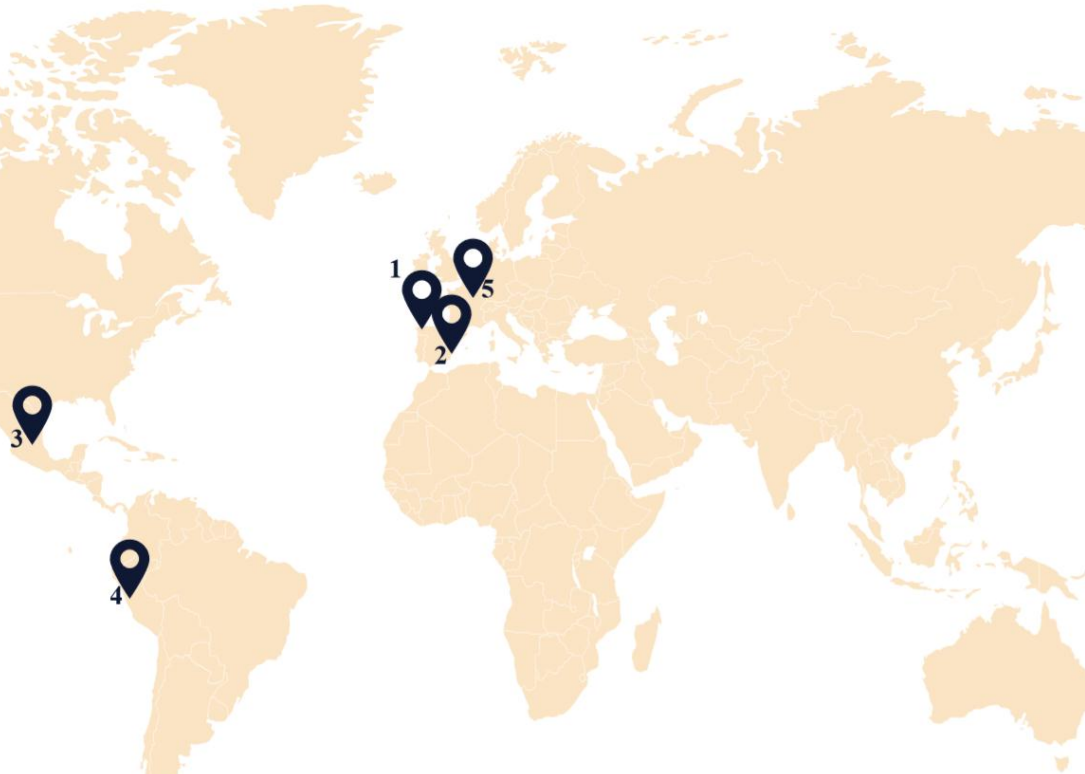

Ubicación de los referentes.

Fuente: The Noun Project. Modificado por autor. 
El siguiente proyecto es un referente en España debido al impacto que tiene en los usurarios beneficiados: adultos mayores, personas en mendicidad y los niños asistentes a la guardería. El Instituto Benéfico Social Padre Rubinos, ha sido diseñado priorizando la accesibilidad y cercanía en el centro de la ciudad, hasta sus más mínimos detalles pensados para resguardar el bienestar, seguridad y mejorar la calidad de vida de los usuarios.

\subsubsection{Historia del edificio}

\begin{tabular}{|l|l|}
\hline Nombre & Institución Benéfico Social Padre Rubinos \\
\hline Arquitectos & Elsa Urquijo Arquitectos \\
\hline Ciudad & La Coruña \\
\hline País & España \\
\hline Área techada & $15882 \mathrm{~m} 2$ \\
\hline Año Proyecto & 2014 \\
\hline
\end{tabular}

Esta Institución Benéfico Social Padre Rubinos está ubicada en la ciudad de La Coruña, España, que tiene una superficie de $37.83 \mathrm{~km} 2$ y una población de 243'978 personas. El Instituto cuenta con un terreno de 34’201 m2 y un área techada de 15'882 m2, el nuevo centro fue inaugurado en setiembre del 2014 tras 2 años de construcción, y tuvo una inversión de 25 millones de euros que financió la Fundación Amancio Ortega.

Esta institución nace hace casi un siglo con la finalidad de atender a los adultos mayores en necesidad. Con el pasar de los años, las actividades al interior del centro fueron aumentando, por lo cual, era necesario realizar una remodelación para poder atender la demanda de la ciudadanía. En consecuencia, el proyecto actual cuenta con ambientes dedicados al servicio de residencia y centro de día para ancianos, albergue temporal para personas en la mendicidad, un área de 
educación para niños de hasta tres años, y un ambiente de residencia para la comunidad de religiosos encargada del instituto. El diseño del centro estuvo a cargo de Elsa Urquijo Arquitectos quien señala sobre el tema "Será una casa abierta, punto de defensa y abrigo para los necesitados" y sobre el diseño "La arquitectura silenciosa, en la que el espacio habla por sí mismo".

La nueva institución ha generado gran impacto en la población y en la ciudad de La Coruña, ya que, desde el día de la inauguración, el centro tenía todas las vacantes ocupadas en todos los servicios que brinda, así mismo, actualmente se han visto en la necesidad de implementar dobles turnos en las asistencias diarias debido a la cantidad de personas que requieren este tipo de ayuda social.

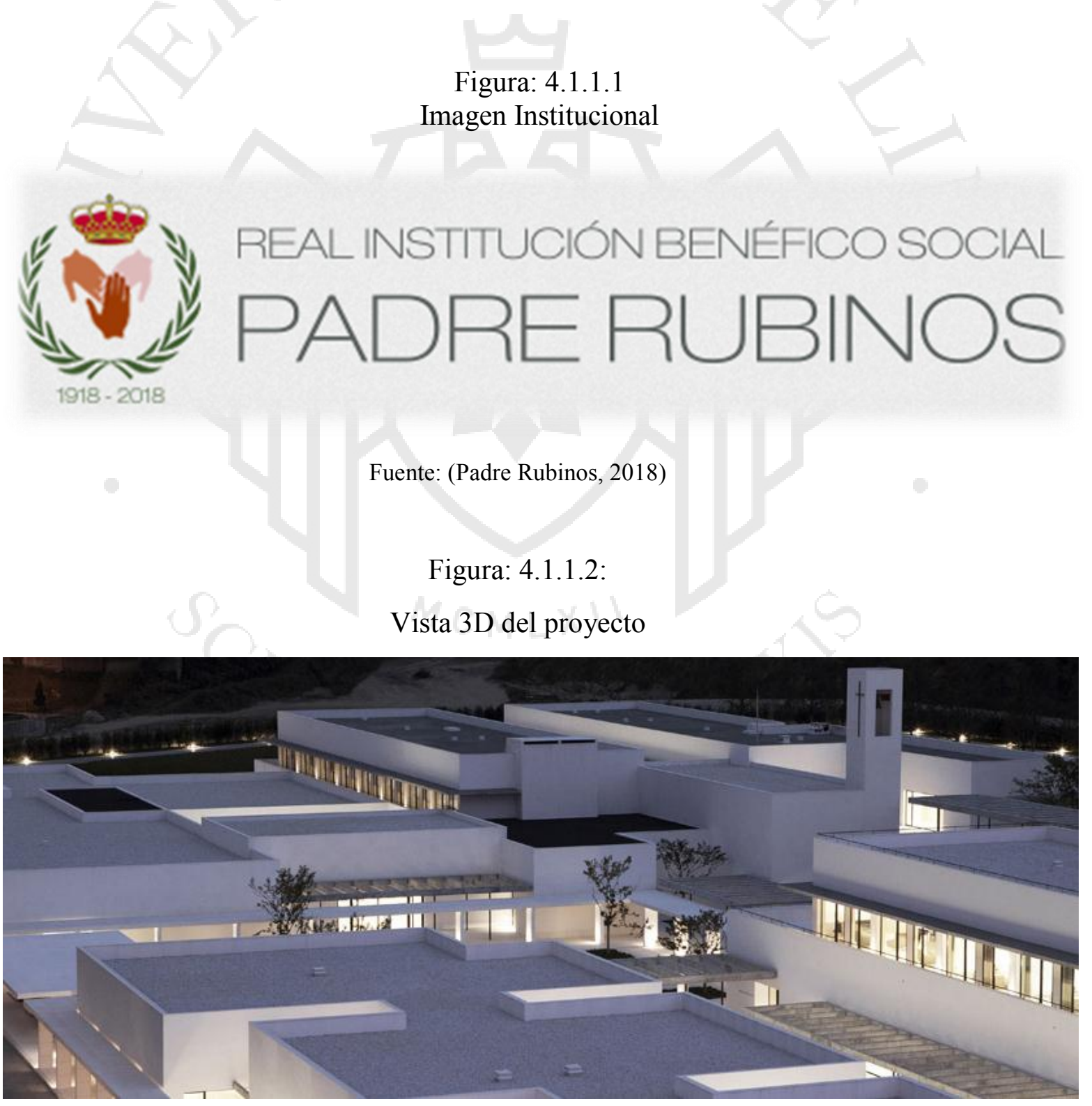

Fuente: (Padre Rubinos, 2018) 


\subsubsection{Relación con el entorno.}

La Institución Padre Rubinos se encuentra casi en la periferia este y muy cerca al malecón de la ciudad. Está exactamente en el cruce de las calles "Estrada os Fortes" y "Ronda Outeiro y que dista aproximadamente a $1.6 \mathrm{~km}$ del centro de la ciudad.

Figura: 4.1.2.1

Ubicación Macro del proyecto en La Coruña

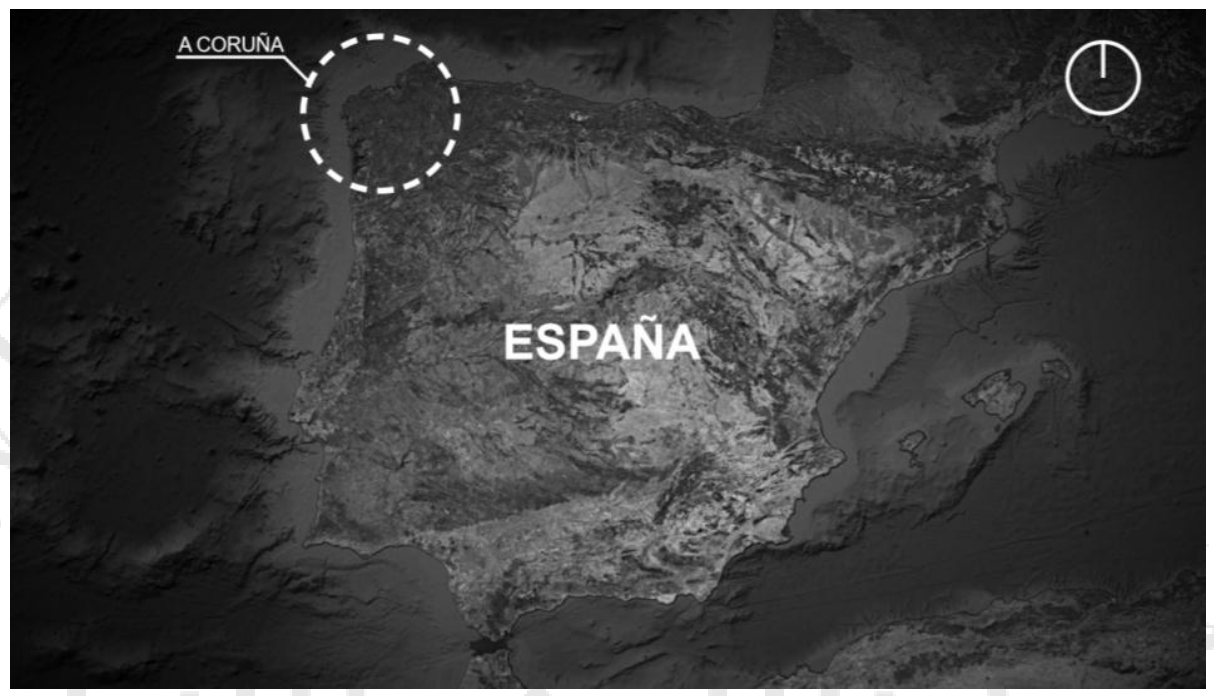

Fuente: Google Earth. Modificado por autor.

Figura: 4.1.2.2

Ubicación Macro del proyecto en La Coruña

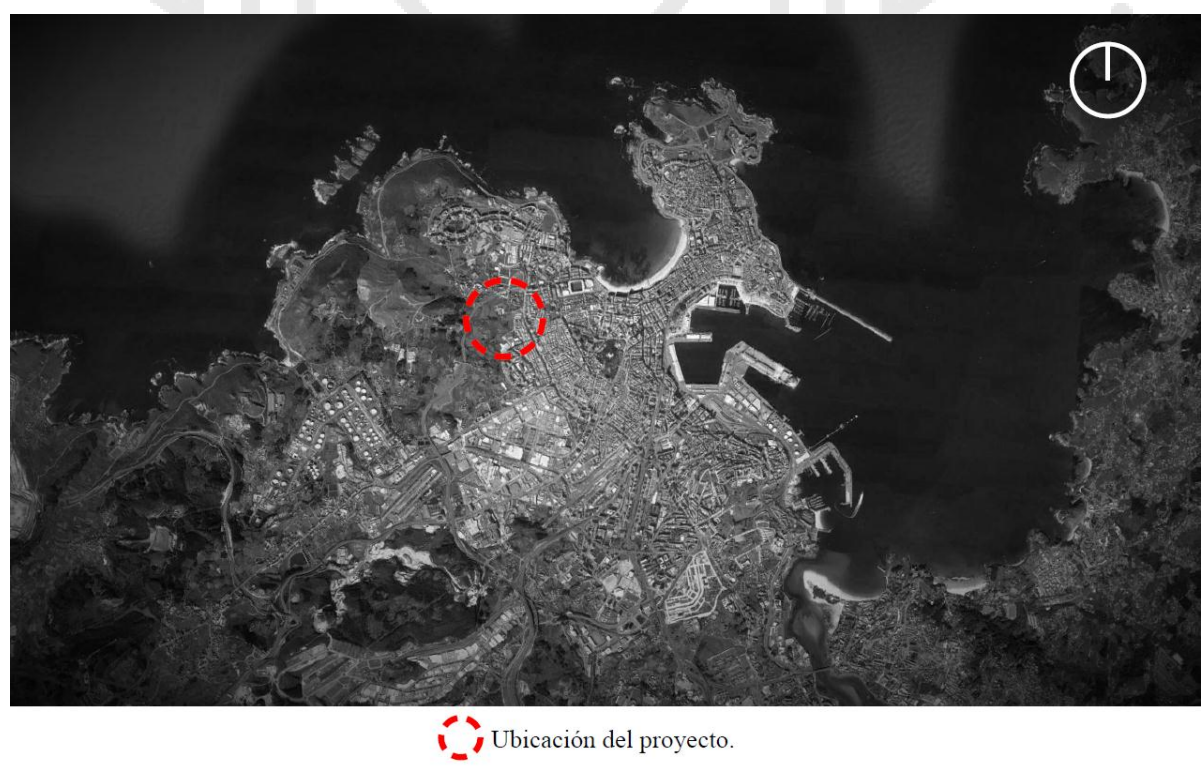

Fuente: Google Earth. Modificado por autor. 
Las vías de transporte principales cercanas a la institución son la Av. San Roque de Afuera, la cual, bordea el malecón que se ubica a pocos metros de la Institución; la Av. Manuel Murguía junto a la Av. Ronda Outeiro cruzan en un ovalo muy cercano del centro y ayudan a que el acceso sea mucho más eficiente. El siguiente gráfico muestra las diferentes vías que se encuentran en la zona, las cuales están categorizadas por su nivel de flujos e importancia.

Figura: 4.1.2.3

Análisis flujos vehiculares

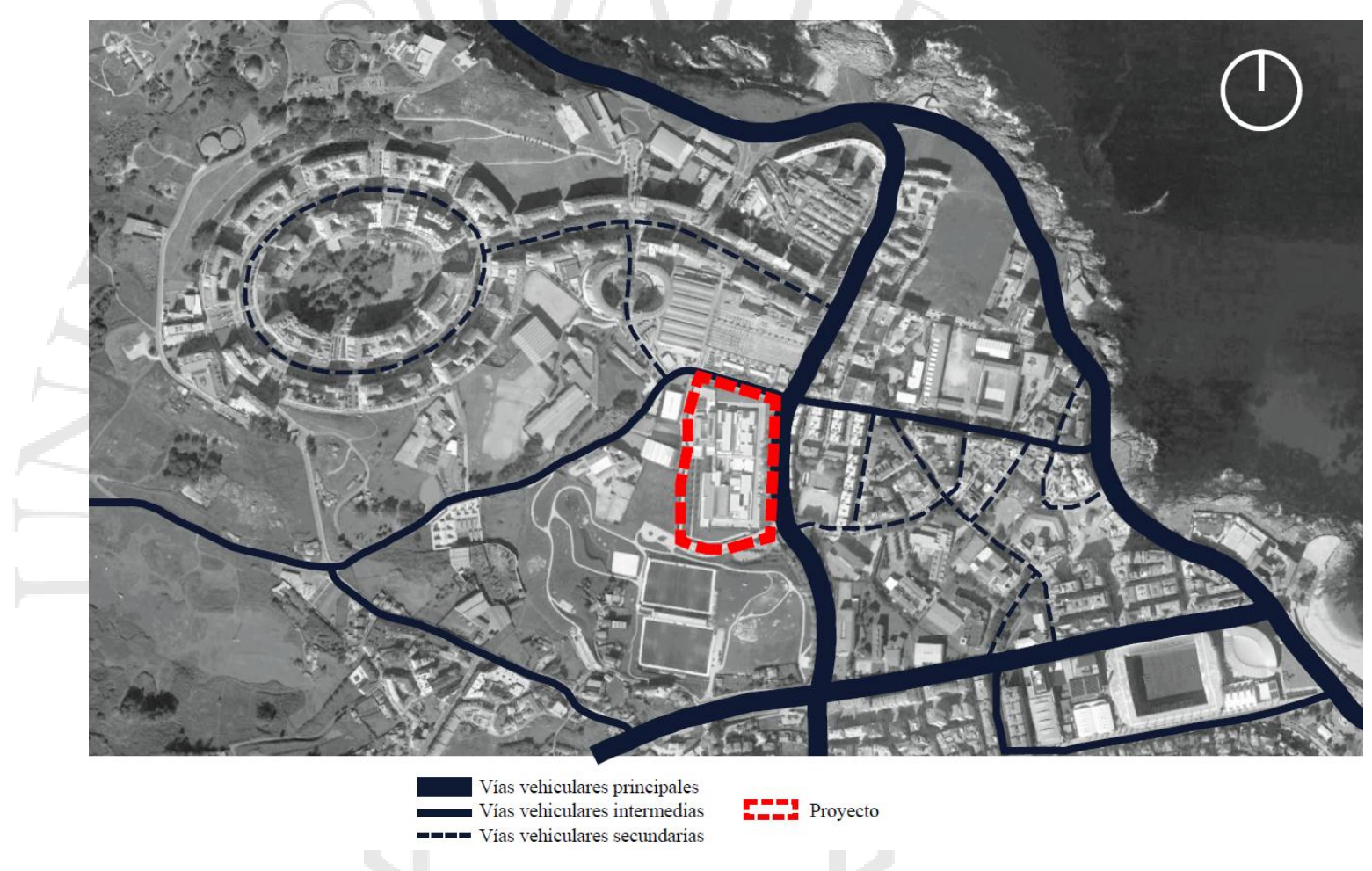

Fuente: Google Earth. Modificado por autor.

A pocos metros del ingreso principal de la Institución Benéfico Social Padre Rubinos, específicamente en la Calle Estrada os Fortes, y su continuación, la Av. Gran Canaria, se ubican 3 paraderos de transporte público, el cual es más conocido como tranvía. Estos tres puntos importantes de intercambio generan alto movimiento peatonal en la zona.

Además, existe equipamiento variado a los alrededores, la mayoría de las calles son viviendas de uso mixto destinado a un comercio zonal que funcionan a diversas horas del día y que generan que esta sea una zona concurrida y dinámica. 
Figura: 4.1.2.4

Análisis flujos peatonales

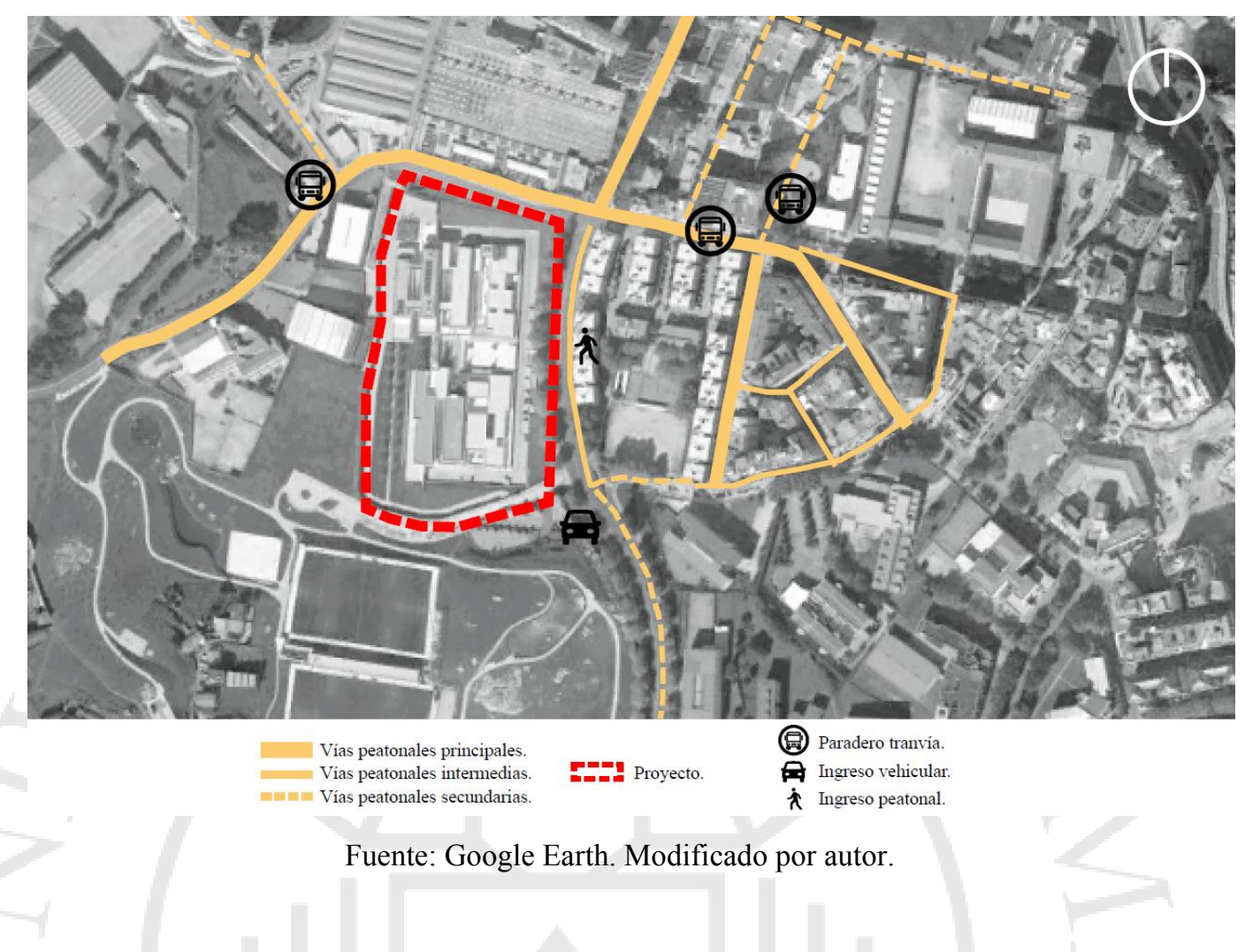

El proyecto se encuentra en una zona rodeada de construcciones de entre 5 y o pisos de altura, excepto el centro educativo y médico de la zona que cuentan con 2 niveles. Además, en la parte sur del proyecto hay un gran terreno vacío con una vertiente de aproximadamente entre $6-8$ metros de altura. Por tal motivo, este proyecto no rompe con el perfil urbano, sin embargo, en la vista aérea se puede ver que es un elemento importante e imponente en el entorno, y que contribuye con gran cantidad de área verde a la zona.

\subsubsection{Programas y relaciones programáticas.}

El siguiente análisis muestra las medidas y el aporte porcentual de cada ambiente con respecto al área en el que se ubica dentro del Instituto. Cada área general está separada por las características de los servicios que ofrece: área administrativa, educación infantil, albergue y residencia para adultos mayores. 
Figura: 4.1.3.1: Planta divida por áreas.

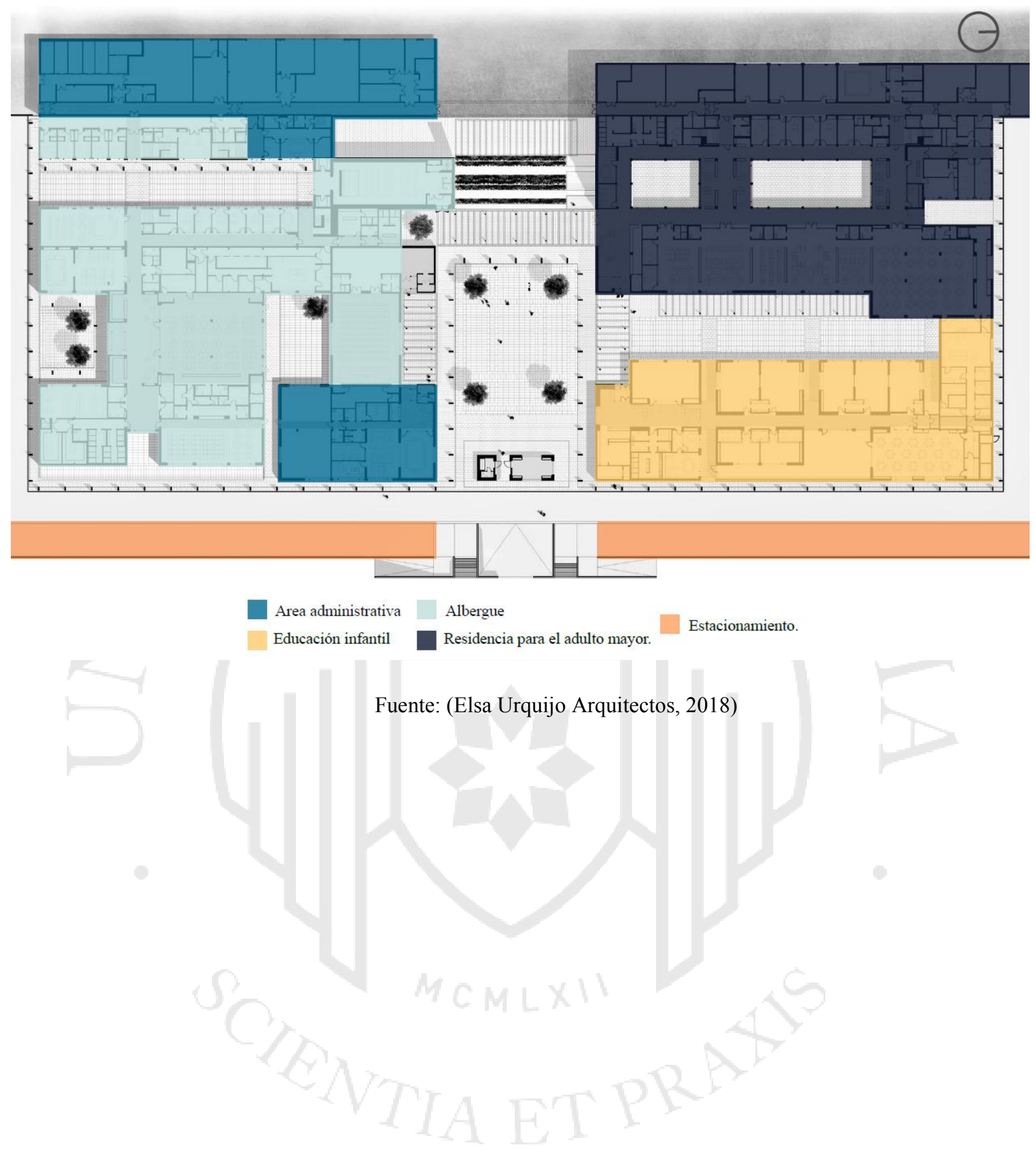


Tabla 4.1.3.1:

Cuadro de áreas

\begin{tabular}{|c|c|c|c|}
\hline \multicolumn{4}{|c|}{ AREA ADMINISTRATIVA / SOCIAL DEL INSTITUTO SOCIAL } \\
\hline AREA & DETALLE DE AREA & APORTE & $\%$ \\
\hline \multirow{6}{*}{ Área de atención } & Sala de espera & $19,6 \mathrm{~m} 2$ & 5,3 \\
\hline & Baño & $5,7 \mathrm{~m} 2$ & 1,5 \\
\hline & Secretaría & $29,5 \mathrm{~m} 2$ & 8,0 \\
\hline & Oficinas & $22,1 \mathrm{~m} 2$ & 6,0 \\
\hline & Área de atención & $3,8 \mathrm{~m} 2$ & 1,0 \\
\hline & Sala de reuniones & $29,6 \mathrm{~m} 2$ & 8,0 \\
\hline Servicios & Archivo & $7,1 \mathrm{~m} 2$ & 1,9 \\
\hline & SSHH & $12,9 \mathrm{~m} 2$ & 3,5 \\
\hline \multirow{2}{*}{ Religioso } & Capilla & $146 \mathrm{~m} 2$ & 39,4 \\
\hline & Residencia Religiosos & $82,7 \mathrm{~m} 2$ & 22,3 \\
\hline & Pasadizos & $8,5 \mathrm{~m} 2$ & 2,3 \\
\hline
\end{tabular}

Total

$371 \mathrm{~m} 2 \quad 100,0$

EDUCACIÓN INFANTIL DETALLE DE AREA APORTE

Área administrativa

Área de servicios

Aulas

Área Recreativa

Baños

Circulación

Dirección
Sala de profesores
Enfermería
Cocina
Área de limpieza
Salones de clase
Salón multiusos
Comedor
Patio interior
Hall de ingreso
SSHH
Circulación

\begin{tabular}{rr|r}
15,4 & $\mathrm{~m} 2$ & 2,1 \\
20,5 & $\mathrm{~m} 2$ & 2,8 \\
30,4 & $\mathrm{~m} 2$ & 4,2 \\
37,7 & $\mathrm{~m} 2$ & 5,2 \\
7,7 & $\mathrm{~m} 2$ & 1,1 \\
235 & $\mathrm{~m} 2$ & 32,1 \\
54,7 & $\mathrm{~m} 2$ & 7,5 \\
84 & $\mathrm{~m} 2$ & 11,5 \\
77 & $\mathrm{~m} 2$ & 10,5 \\
48,8 & $\mathrm{~m} 2$ & 6,7 \\
34 & $\mathrm{~m} 2$ & 4,6 \\
86 & $\mathrm{~m} 2$ & 11,8
\end{tabular}

Total 731,2 m2 100,00

ALBERGUE

\section{AREA}

Área de atención

Área de servicios
DETALLE DE AREA

Consultorios

Dormitorios trabajadores

Tópico

Cocina

Roperos

Área de limpieza

\begin{tabular}{rlr} 
APORTE & \multicolumn{1}{l}{$\%$} \\
$146,6 \mathrm{~m} 2$ & 5,9 \\
$48,1 \mathrm{~m} 2$ & 1,9 \\
$41,8 \mathrm{~m} 2$ & 1,7 \\
$120 \mathrm{~m} 2$ & 4,8 \\
$66,1 \mathrm{~m} 2$ & 2,7 \\
$15 \mathrm{~m} 2$ & 0,6
\end{tabular}




$\begin{array}{llrrr}\text { Baños } & \text { Baños } & 84,2 & \mathrm{~m} 2 & 3,4 \\ & \text { Duchas } & 66 & \mathrm{~m} 2 & 2,7 \\ \text { Área recreativa } & \text { Vestidores } & 40 & \mathrm{~m} 2 & 1,6 \\ & \text { Aulas de talleres } & 274,2 & \mathrm{~m} 2 & 11,0 \\ & \text { Hall interior } & 97,6 & \mathrm{~m} 2 & 3,9 \\ & \text { Comedor } & 155,7 & \mathrm{~m} 2 & 6,3 \\ \text { Circulación } & \text { Patios } & 205,2 & \mathrm{~m} 2 & 8,3 \\ & \text { Escaleras y ascensor } & 255,2 & \mathrm{~m} 2 & 10,3 \\ \text { Habitaciones } & \text { Pasadizos } & 167 & \mathrm{~m} 2 & 6,7 \\ & \text { Mujeres } & 557,8 & \mathrm{~m} 2 & 22,5 \\ & \text { Baños } & 143,2 & \mathrm{~m} 2 & 5,8 \\ & & \mathbf{2 4 8 3 , 7} & \mathbf{m 2} & \mathbf{1 0 0 , 0}\end{array}$

\begin{tabular}{|c|c|c|c|c|}
\hline $\mathrm{E}$ & RA ADUL & DE DIA & & \\
\hline AREA & DETALLE DE AREA & APORTE & & $\%$ \\
\hline de atención & Consultorios & 115,7 & $\mathrm{~m} 2$ & 2,8 \\
\hline de atencion & Dormitorios trabajadores & 105,3 & $\mathrm{~m} 2$ & 2,6 \\
\hline & Tópico & 24,2 & $\mathrm{~m} 2$ & 0,6 \\
\hline & Cocina & 120,4 & $\mathrm{~m} 2$ & 3,0 \\
\hline Área de servicios & Baños & 62,1 & $\mathrm{~m} 2$ & 1,5 \\
\hline & Depósitos & 160,3 & $\mathrm{~m} 2$ & 3,9 \\
\hline & Otros servicios & 277 & $\mathrm{~m} 2$ & 6,8 \\
\hline & Comedor & 150 & $\mathrm{~m} 2$ & 3,7 \\
\hline Área recreativa & Salones recreativos & 400,6 & $\mathrm{~m} 2$ & 9,8 \\
\hline & Hall interior & 162 & $\mathrm{~m} 2$ & 4,0 \\
\hline & Patio interior & 188,1 & $\mathrm{~m} 2$ & 4,6 \\
\hline Habitaciones & Dormitorios & 1132 & $\mathrm{~m} 2$ & 27,8 \\
\hline & Baños & 271,3 & $\mathrm{~m} 2$ & 6,7 \\
\hline Circulación & Escaleras y ascensor & 36 & $\mathrm{~m} 2$ & 0,9 \\
\hline & Pasadizos & 870 & $\mathrm{~m} 2$ & 21,3 \\
\hline & & 4075 & $\mathbf{m} 2$ & 100,0 \\
\hline
\end{tabular}


Figura: 4.1.3.2:

Porcentaje de áreas en Instituto Benéfico Social Padre Rubinos
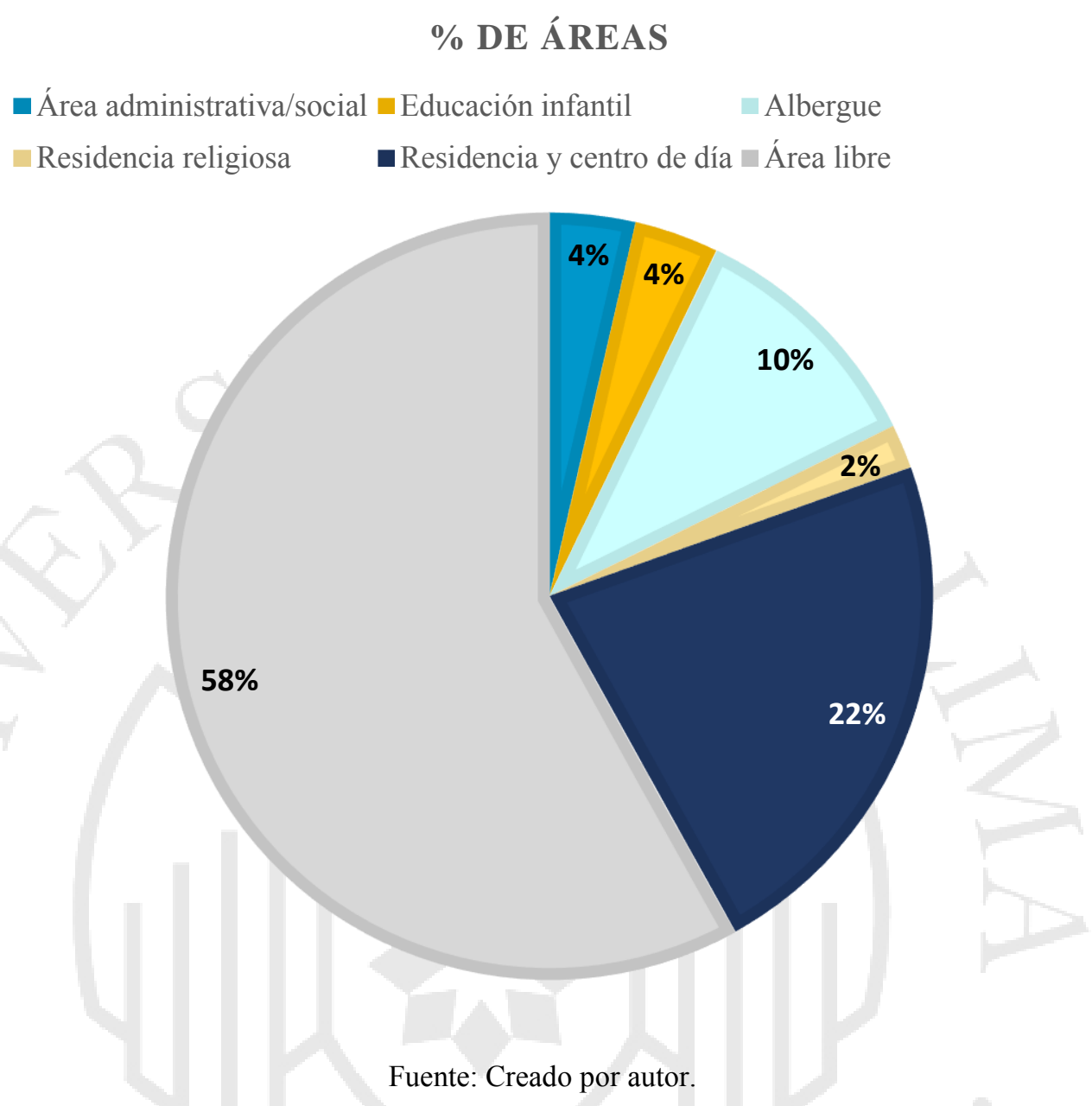

De la elaboración de los gráficos que demuestran el porcentaje que tiene cada espacio destinado a diversas funciones del Instituto Social Padre Rubinos se puede concluir:

- La mayor cantidad de área del terreno está destinada para áreas verdes y libres.

- La mayor área construida está destinada para la residencia de adultos mayores y centro de día.

- El establecimiento cuenta con grandes espacios de circulación, lo cual ayuda a que los usuarios se desplacen de forma ordenada a cada una de las áreas en las que son atendidos.

- El Instituto cuenta con diversas áreas recreativas al interior de sus volúmenes, así mismo, el conjunto de estos genera patios al aire libre. Estos espacios de encuentro son importantes para todos los servicios que 
se desarrollan en el Instituto, debido a que genera mayor interacción entre los usuarios.

\subsubsection{Estrategias de emplazamiento}

Figura: 4.1.4.1:

Estrategias de emplazamiento

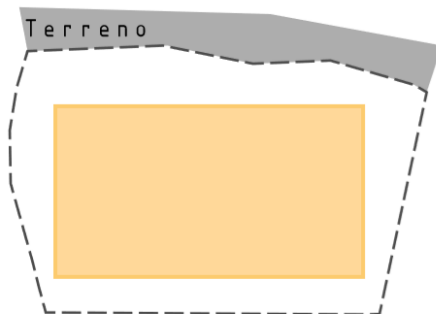

(1)

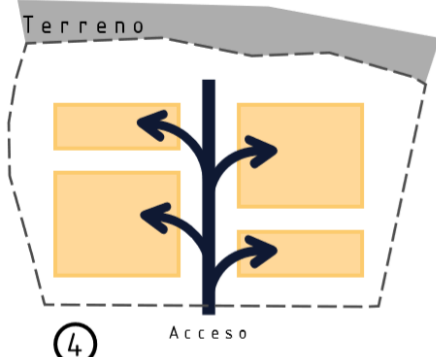

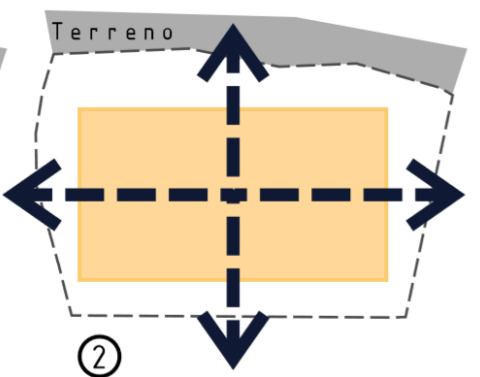

(2)

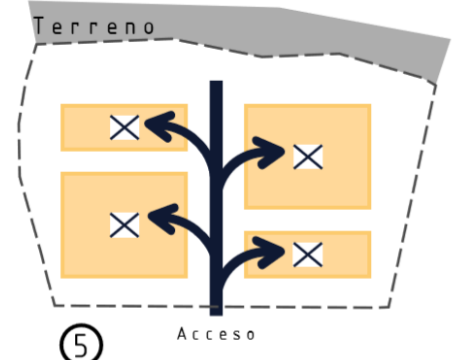

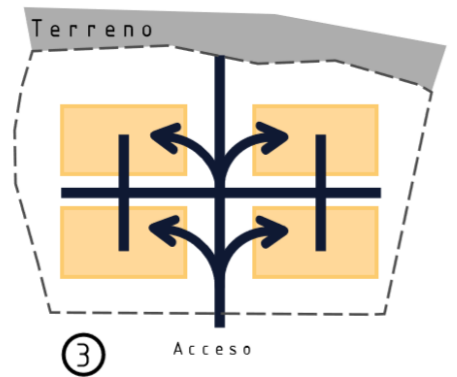

(3)

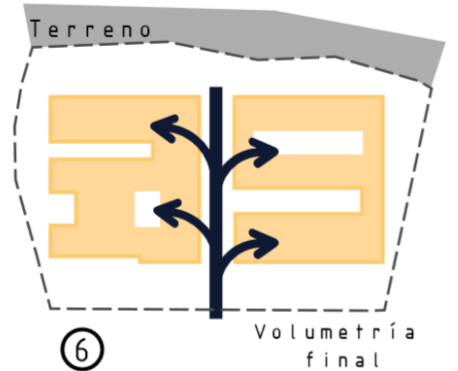

டーユLimite de terreno

Fuente: Por autor.

Como se puede observar en el gráfico, la idea del diseño del proyecto comienza direccionando posibles flujos de circulación importantes, lo cual origina una separación de volúmenes en los que se desarrollaran actividades del Instituto. En cada uno de estos se puede observar la formación de patios que generan espacios de interacción y conexión entre los diferentes servicios. Es así como la forma final del proyecto se lee como un gran volumen que resume todos los pasos anteriores.

Entonces, al ingresar al Instituto se encuentra el patio central más grande que sirve como articulación y que une a cada una de las zonas del centro: educación infantil, área administrativa, albergue y residencia para ancianos. En los laterales de este gran patio de ingreso se ven dos grandes volúmenes en los que se desarrollan los distintos servicios ofrecidos. Estas áreas cuentan en su interior con diversos patios de mediano tamaño que marca el límite de las zonas destinada para cada uso. 
Elsa Urquijo, arquitecta del proyecto, define lo siguiente "Se trata de un espacio arquitectónico que gira en torno al individuo renunciando a la composición académica de fachada y ofreciendo un pórtico de entrada que rodea y define una plaza abierta a la ciudad; retomamos -continúa Urquijo- el concepto de claustro, en sintonía con el carácter religioso y la labor social de la institución; la idea de patio se repite en todo el complejo como elemento articulador de los diferentes espacios buscando potenciar la diafanidad, la luz y la continuidad visual entre interior y exterior".

\subsubsection{Flujos y circulaciones}

El siguiente análisis muestra la intensidad de flujo peatonal en cada zona del instituto. Se puede observar cuales son las áreas más concurridas, públicas y dinámicas, así como las zonas que tienen un ingreso más limitado. Estas últimas generalmente son el área de servicio del personal y los dormitorios de los residentes del instituto.

\section{Figura: 4.1.5.1:}

Imagen interior

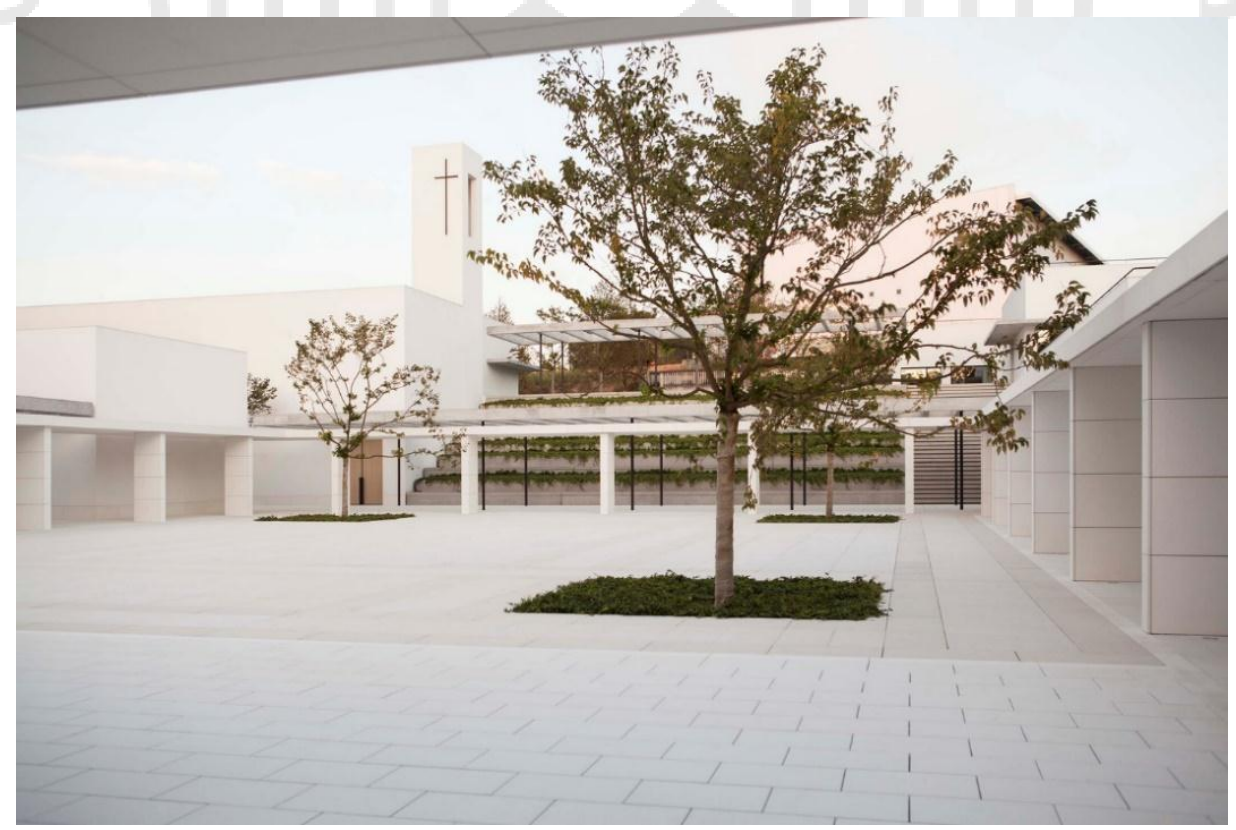

Fuente: (Archdaily, 2014) 
Figura: 4.1.5.2:

Imagen interior del proyecto.

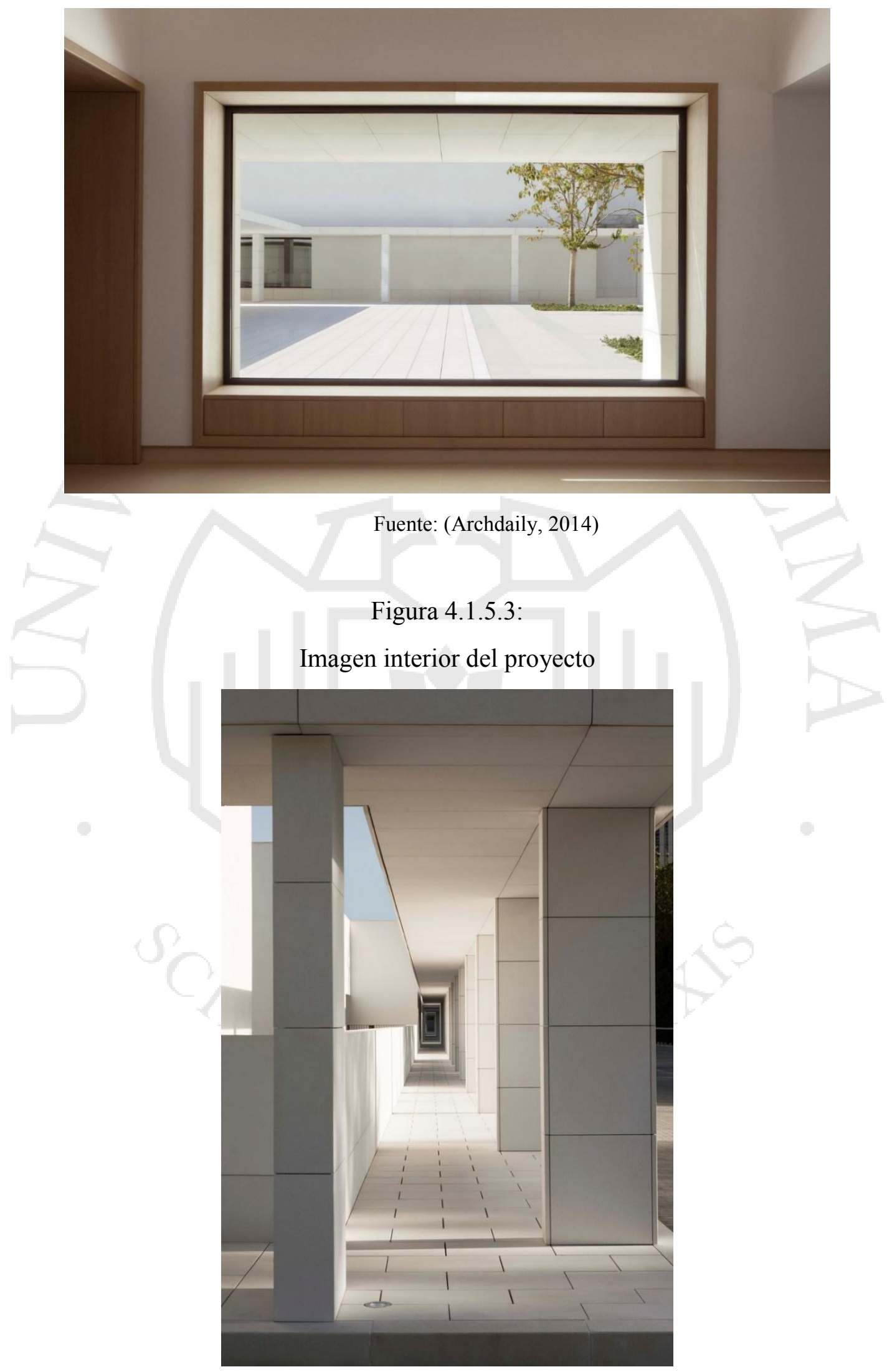

Fuente: (Archdaily, 2014) 
Figura 4.1.5.4:

Análisis de flujo petonal en el proyecto

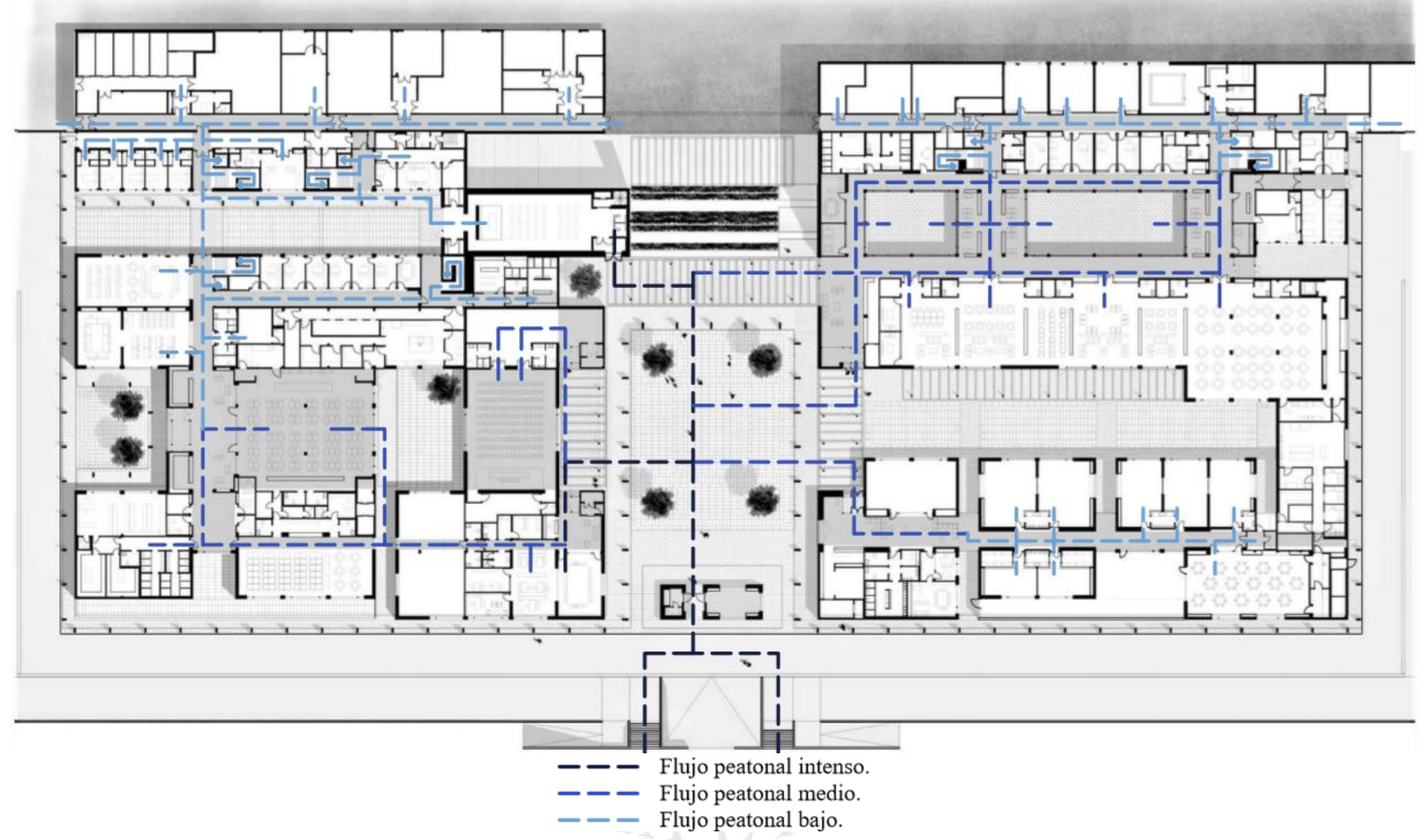

Fuente: (Archdaily, 2014) Análisis: Autor. 
4.1.6 Área construida y área libre.

El proyecto está ubicado en un terreno de 34'201 m2. De este total, el $42 \%$ está construido y el 58\% son áreas libres como patios, jardines, cochera, etc. Es importante resaltar el porcentaje de área libre destinada para espacios de recreación ya que es una característica importante para proyectos que tienen como usuarios a personas de la tercera edad, los cuales tienen la necesidad de estar en contacto con el aire libre y la naturaleza.

\subsubsection{Relaciones espaciales.}

Los espacios para las actividades y servicios que brinda el centro se pueden clasificar en 3 grupos dependiendo de la accesibilidad: privado, semi privado y público. Por lo cual, el siguiente gráfico muestra la planta principal zonificada en estos 3 grupos diferenciado por colores.

Figura 4.1.7.1. Análisis relaciones espaciales

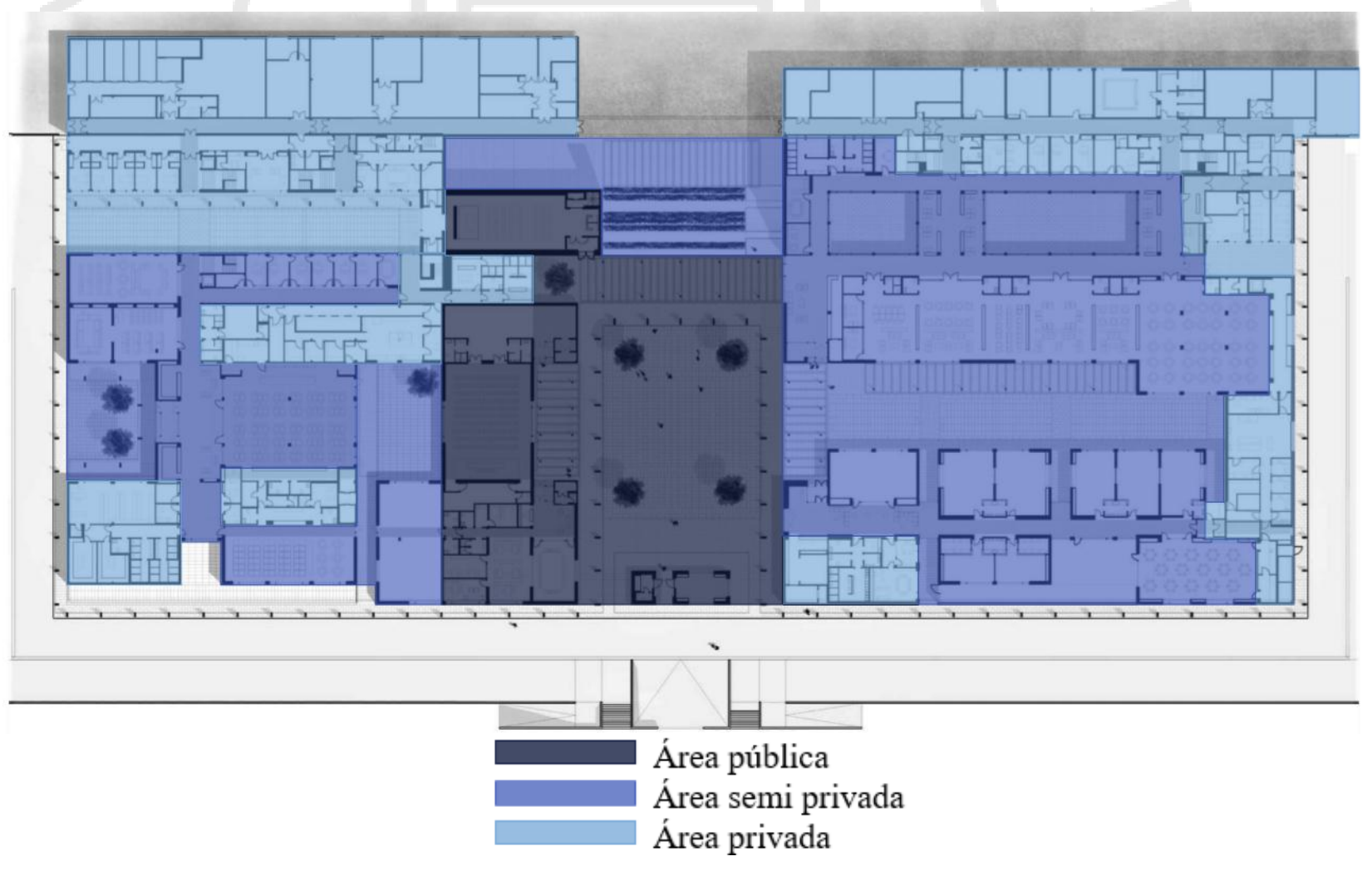

Fuente: (Archdaily, 2014) Análisis: Autor. 
- El ingreso y patio principal son los espacios con mayor conexión al público en general, por lo cual, están zonificados como área pública. Así mismo, en este grupo está la zona administrativa, en la cual se brinda atención y asesoramiento al público interesado en los servicios del Instituto. Finalmente, la capilla es un área de servicio público debido a que es un lugar al cual pueden acceder todas las personas atendidas en el centro y los trabajadores; además, los pobladores de la zona pueden ingresar a este lugar en los horarios de misa establecidos.

- La zona de educación infantil esta seleccionada como semi privada debido a que cualquier niño menor de tres años tiene la posibilidad de acceder a este centro, sin embargo, es necesaria la previa inscripción. Así mismo, el albergue se ubica en esta categoría por lo que es accesible para los pobladores, sin embargo, al igual que en la zona de educación infantil, es necesaria una previa inscripción para poder acceder a este lugar. Finalmente, los patios interiores también se encuentran en esta categoría debido a que son espacios de integración que pueden ser usados por los diferentes usurarios del Instituto.

- La zona de residencia es las más privada de todo el complejo por la función de descanso que cumple y por estar físicamente ubicada en la parte más lejana al ingreso del Instituto. 


\subsubsection{El dormitorio.}

Espacio que ha sido diseñado principalmente para el descanso de uno o más usuarios y se caracteriza por tener gran privacidad. El elemento más importante dentro de este espacio es la cama debido a que es el mobiliario en donde se desarrollará la actividad de dormir.

Es un espacio libre con las dimensiones necesarias para contener al menos una cama; es este sistema elemental el que puede complejizarse para mejorar las condiciones de un espacio privado que, en muchos casos, puede llegar a ser el más utilizado de la casa. (Franco, 2014)

El dormitorio para los adultos mayores tiene características particulares que se diferencian al resto en las medidas mínimas necesarias para asegurar una circulación segura y confortable para los ancianos. En la siguiente figura se puede apreciar el dormitorio del proyecto: Instituto Benéfico Social Padre Rubinos.

Figura 4.1.8.1: Habitación en Padre Rubinos

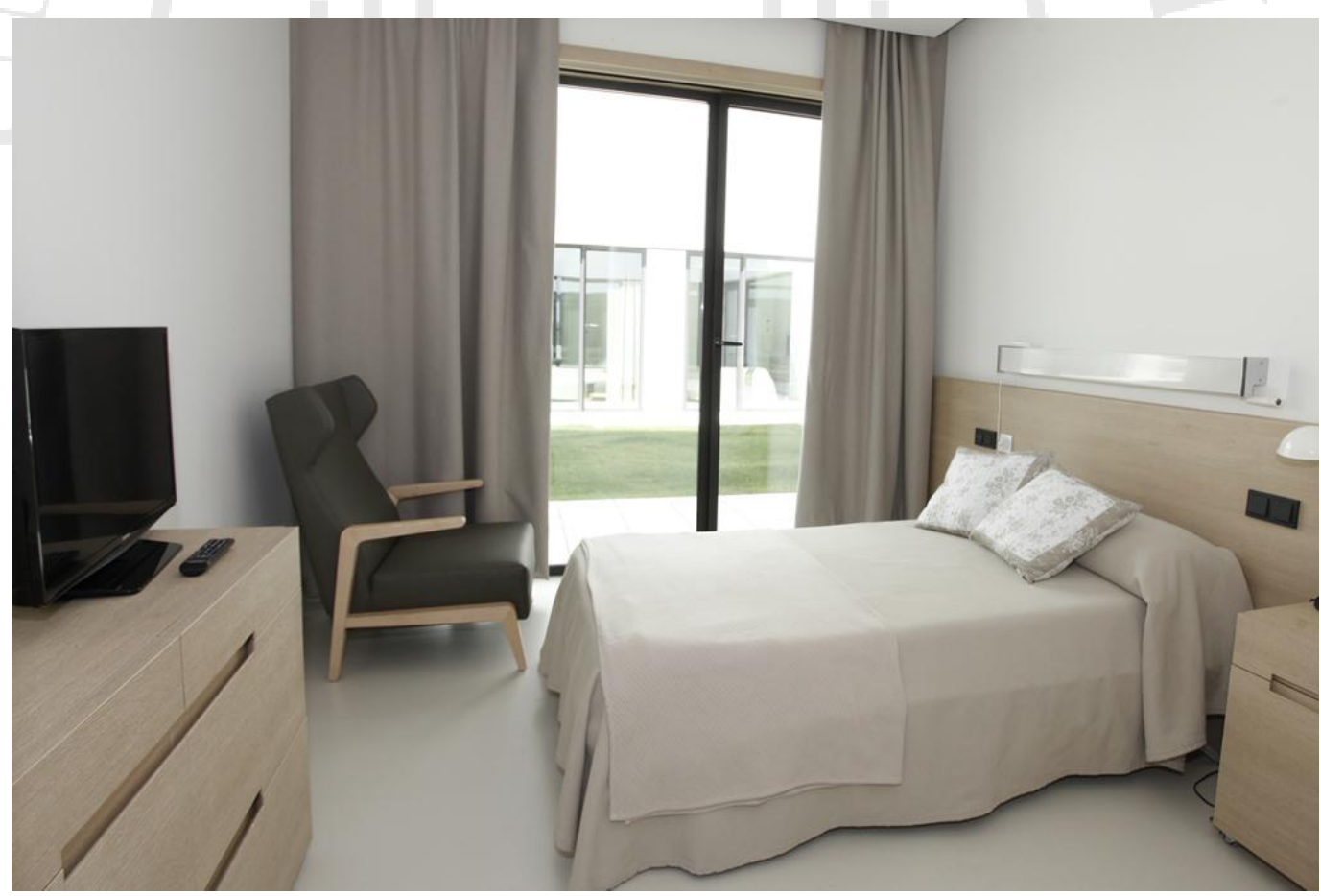

Fuente: (Acolle.org, 2018) 


\subsubsection{Tecnología.}

Este proyecto ha tenido un estudio minucioso que ha permitido aplicar un diseño eficiente, diversos materiales, estrategias y equipos que hacen posible un proyecto más amigable con el medio ambiente.

- Sobre el sistema constructivo se puede observar placas de concreto revestidas en los exteriores con materiales claros.

- Cubierta de techo en espacios libres con bloques de concreto prefabricado que se apoyan en columnas de acero.

- En algunas áreas libres se colocan celosías prefabricadas de concreto como techos, las cual se apoya en columnas de acero pintadas de color negro.

- El uso de grandes escalones de concreto los cuales son usados como jardineras.

Figura 4.1.9.1:

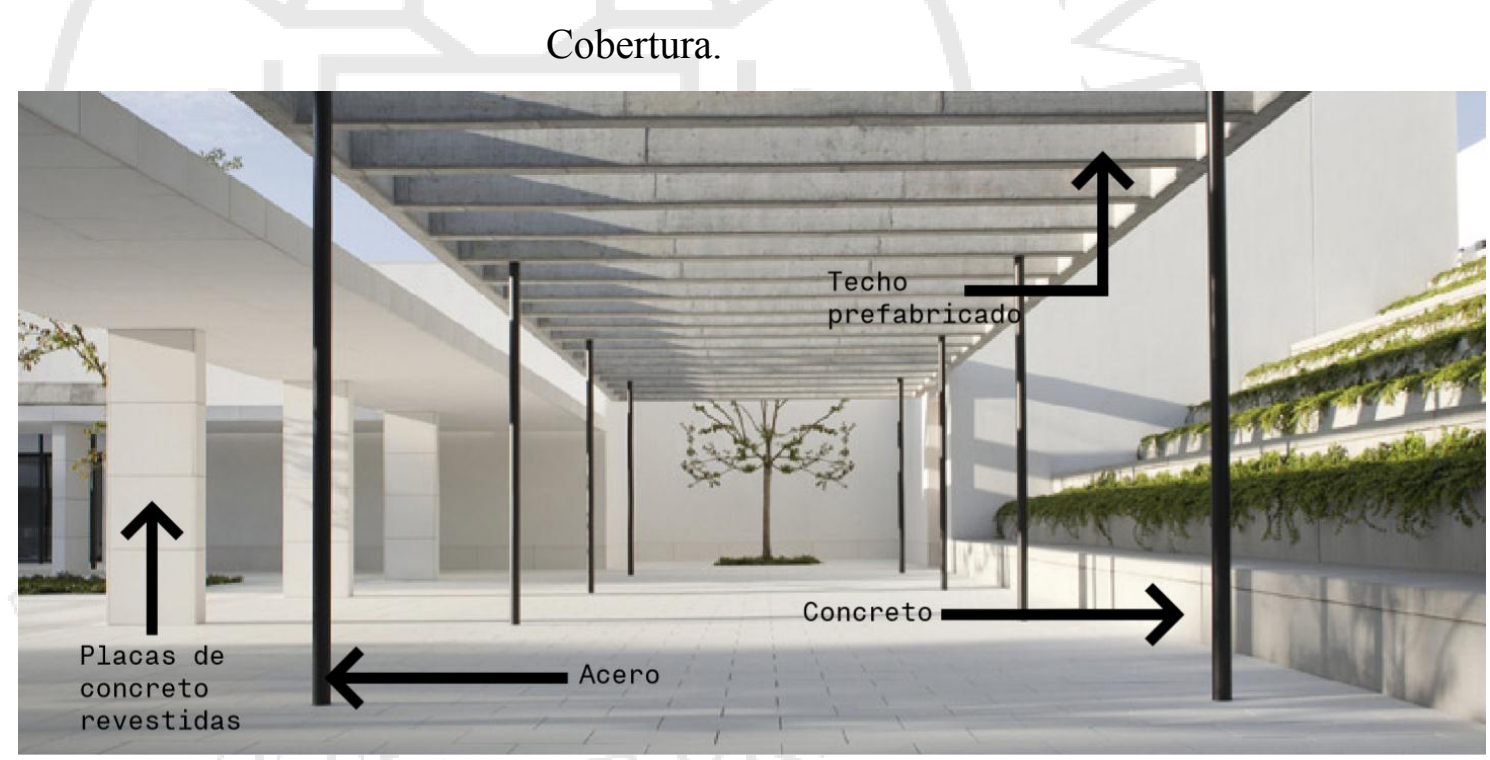

Fuente: (Archdaily, 2014) Análisis: Autor.

- La iluminación general se realiza con fluorescentes y se controla a través de sensores, así mismo, la emergencia utiliza la tecnología LED.

- Al interior del centro se observa el gran uso de revestimientos de madera en marcos de puertas, ventanas, y paredes. Así como falso techo.

- El uso de pintura blanca y vidrio como complemento genera amplitud en los ambientes. 
Figura 4.1.9.2: Interior.

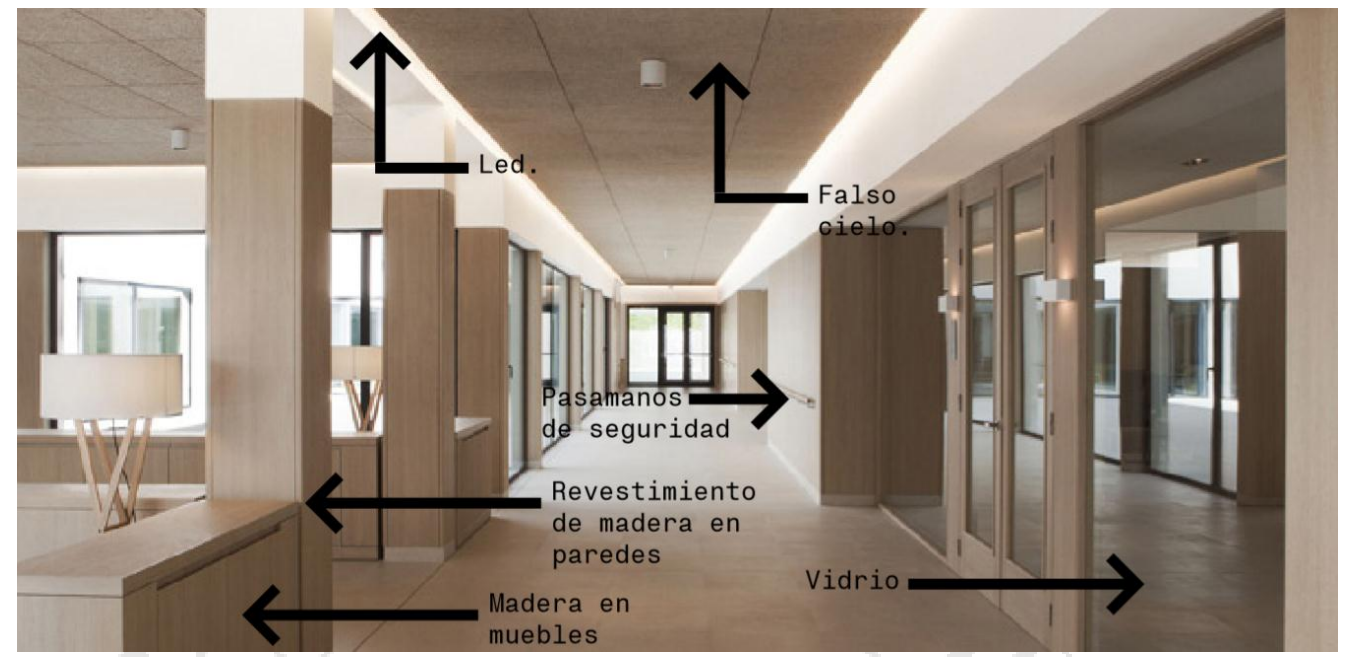

Fuente: (Archdaily, 2014) Análisis: Autor.

- El proyecto usa suelo radiante que permite climatizar los ambientes de manera ecológica y reduce hasta un $75 \%$ la factura de energía.

- El proyecto usa aguas subterráneas para recoger los jardines interiores.

- En los exteriores resalta el uso de materiales reciclables como fotocatalíticos para vías y plazas en el instituto, este material permite la descontaminación del aire, funciona de manera tal que se activa con la presencia de luz y humedad transformando el aire contaminado en inocuo.

Figura 4.1.9.3: Exterior.

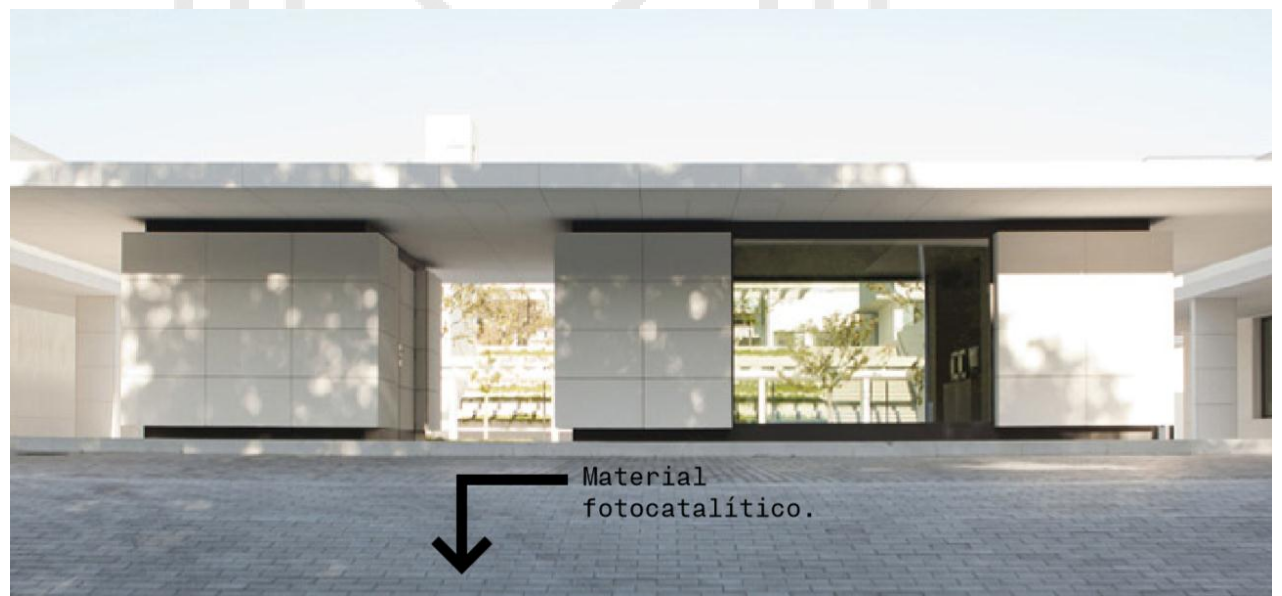

Fuente: (Archdaily, 2014) Análisis: Autor. 
Figura: 4.1.9.4:

Pavimento foto catalítico.

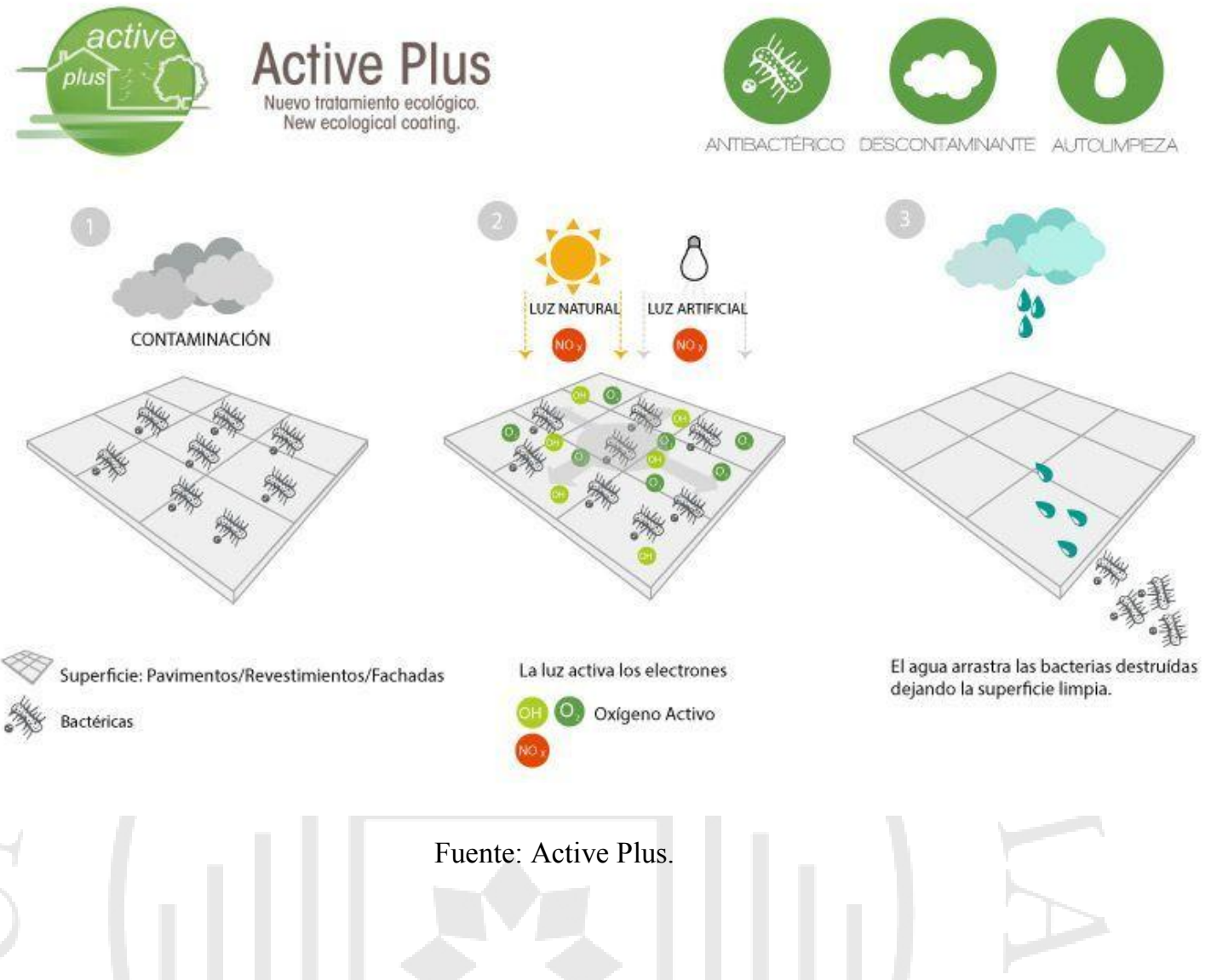

\subsubsection{Impacto social.}

El Instituto Benéfico Social Padre Rubinos, ha tenido un gran impacto en la ciudad y en la población, incluso antes de la inauguración de su nuevo centro. Durante años, la comunidad de los Padres Rubinos ha servido a los más necesitados y actualmente con el nuevo proyecto pueden llegar a muchas más personas. Sin embargo, pese a que el nuevo Instituto es de gran tamaño y tiene una gran capacidad de 146 plazas para adultos mayores residentes, 40 plazas para centro de día, 100 plazas para educación infantil y 200 usurarios en el albergue; la administración del instituto y los medios de prensa de la ciudad, aseguran que el lugar se encontraba completamente ocupado desde semanas previas a la inauguración, y actualmente, cuentan con un 50\% adicional de personas en espera de alguna plaza en el instituto, a comparación de años anteriores. 
Figura 4.1.10.1:

Artículo sobre Instituto Benéfico Social Padre Rubinos.

Instalaciones energéticamente eficientes y sostenibles

\section{Climatización radiante por energía} geotérmica en el Instituto Benéfico Social Padre Rubinos

División Building Solutions de REHAU

\begin{tabular}{l|l|l|l|l|l|l|}
\hline 616 & $D$ & $f$ & $y$ & 8 & in
\end{tabular}

$13 / 02 / 2018$

La división de Building Solutions de la empresa REHAU, especializada en soluciones basadas en polímeros para la construcción y otros sectores, ha participado en la realización de proyectos de obra tan emblemáticos e interesantes como la instalación de climatización radiante por geotermia en la nueva sede del Instituto Benéfico Social Padre Rubinos, en La Coruña.

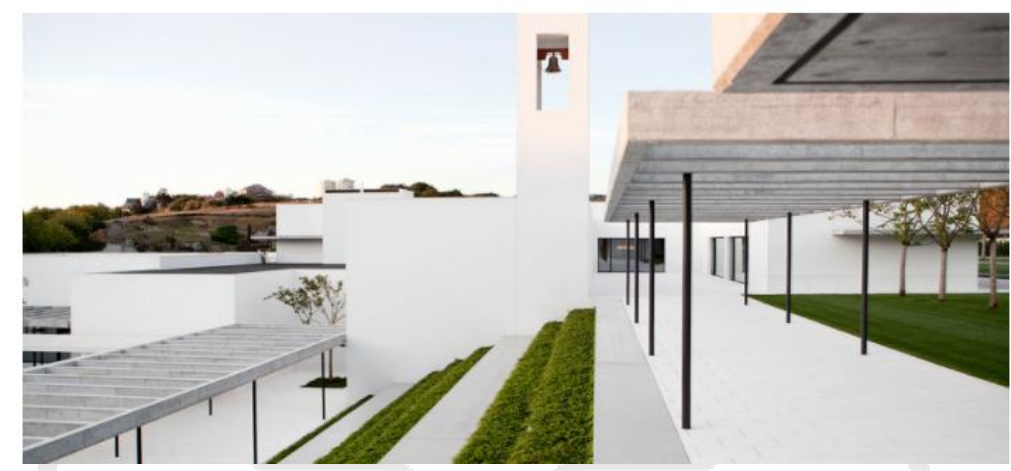

Fuente: (Interempresas.net, 2018)

Figura 4.1.10.2:

\section{courch}

\section{La Institución Padre Rubinos, "un ejemplo" en atención social}

La nueva sede coruñesa de esta entidad, un edificio de 16.000 metros cuadrados, abrió sus puertas tras la inversión de 25 millones de euros realizada por la Fundación Amancio Ortega

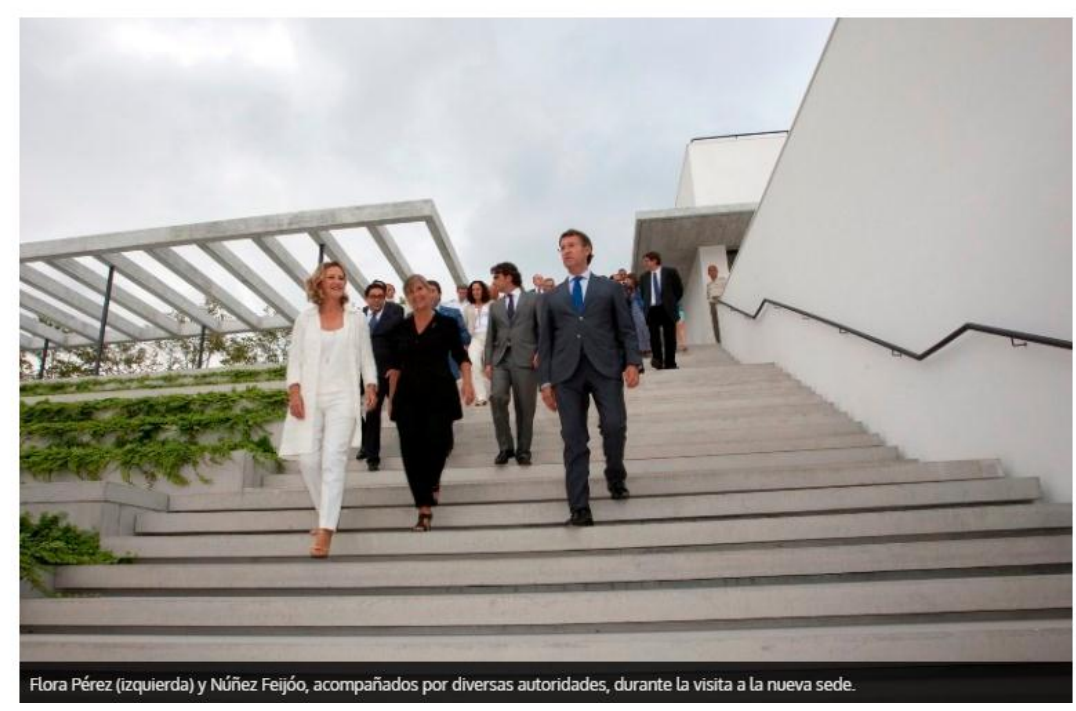

Fuente: (Atlantico.net, 2014) 


\subsubsection{Conclusión.}

En conclusión, el proyecto explicado es referente por tener características similares a la propuesta de Residencia y Centro de día en el distrito de Chorrillos. Desde su ubicación, al estar localizado en una zona céntrica de la ciudad de La Coruña en la cual se desarrollan actividades comerciales, educativas, laborales, etc.

Además, es un lugar en el que brindan diferentes tipos de atenciones para a distintos sectores de la población: cuenta con una zona de residencia y centro de día para adultos mayores, una zona para atender a personas en mendicidad y una zona de guardería infantil.

Por otro lado, el funcionamiento del Instituto Benéfico Social Padre Rubinos, es operado por la comunidad de religiosos Padre Rubinos y el gobierno de La Coruña. Finalmente, los ambientes diseñados y los acabados aplicados para este proyecto responden a las características que aseguren el bienestar y la seguridad de los adultos mayores que viven y realizan sus actividades en este centro.

\subsection{Residencia para personas mayores "El Molino"}

El siguiente proyecto que se explicará, al igual que nuestra propuesta, opera como centro de actividades diurnas (centro de día) y residencia para personas de la tercera edad, por lo cual, es importante entender el planteamiento arquitectónico y funcionamiento de este proyecto que beneficia a este sector de la población.

Se ubica en un distrito alejado del centro de la ciudad de Cuenca, por lo cual las actividades que se realizan cercanas al entorno del proyecto son de menor dinamismo. No obstante, se considera a este centro como punto de encuentro para las personas de la tercera edad y en el cual podrán realizar múltiples actividades que los ayuden a seguir desarrollando sus capacidades. 


\subsubsection{Historia del edificio}

\begin{tabular}{|l|l|}
\hline Nombre & Residencia para personas mayores "Los Molinos" \\
\hline Arquitectos & GEED arquitectos. \\
\hline Ciudad & Cuenca \\
\hline País & España \\
\hline Área construida & 7'700 m2. \\
\hline Año Proyecto & 2009 \\
\hline
\end{tabular}

Este centro que ofrece residencia para adultos mayores y servicio de estancias diurnas está ubicado en el distrito de Mota del Cuervo, España. El terreno del proyecto cuenta con un área total de 13 ' $750 \mathrm{~m} 2$ y se emplaza en una zona rodeada de pequeños montes. Esta residencia fue encargada por la Junta de Comunidades de Castilla - La Mancha, ciudad a la que pertenece el distrito de Mota del Cuervo. Los encargados del diseño fueron los arquitectos del estudio "GEED Arquitectos", y la construcción la realizó "Ortiz - Constructores y Proyectos S.A". Pese a que los distritos cercanos a Mota del Cuervo ya contaban con algunos proyectos sobre estancias para adultos mayores, la consejería de Bienestar Social de la Junta de Comunidades propuso este nuevo proyecto para generar un impacto en la zona y que los adultos mayores del lugar puedan tener acceso gratuito a establecimientos en los que se les pueda brindar servicio de calidad y confort, así como cuidado de la salud y el bienestar familiar de los residentes del establecimiento. 
Figura: 4.2.1.1:

Afiche de presentación de "Los Molinos"

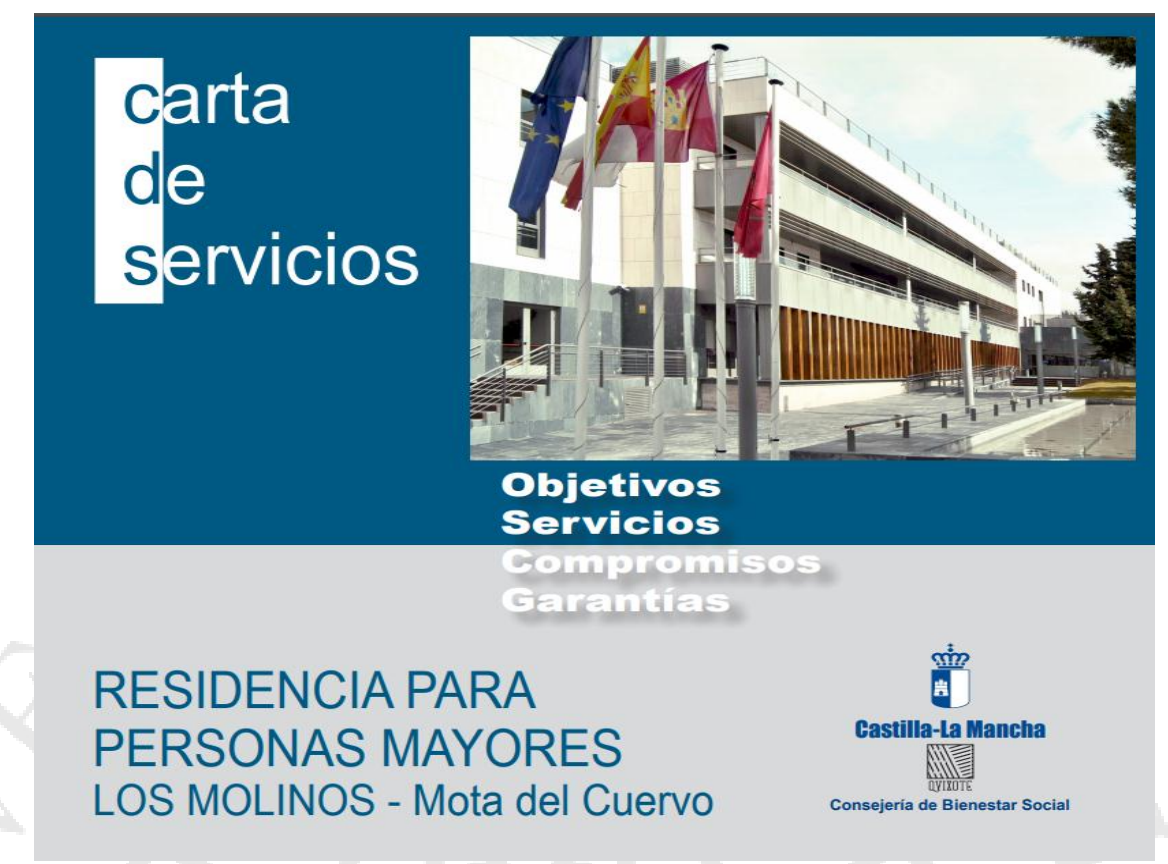

Fuente: (Castilla - La Mancha, 2016)

Figura: 4.2.1.2:

Imágenes del interior del proyecto

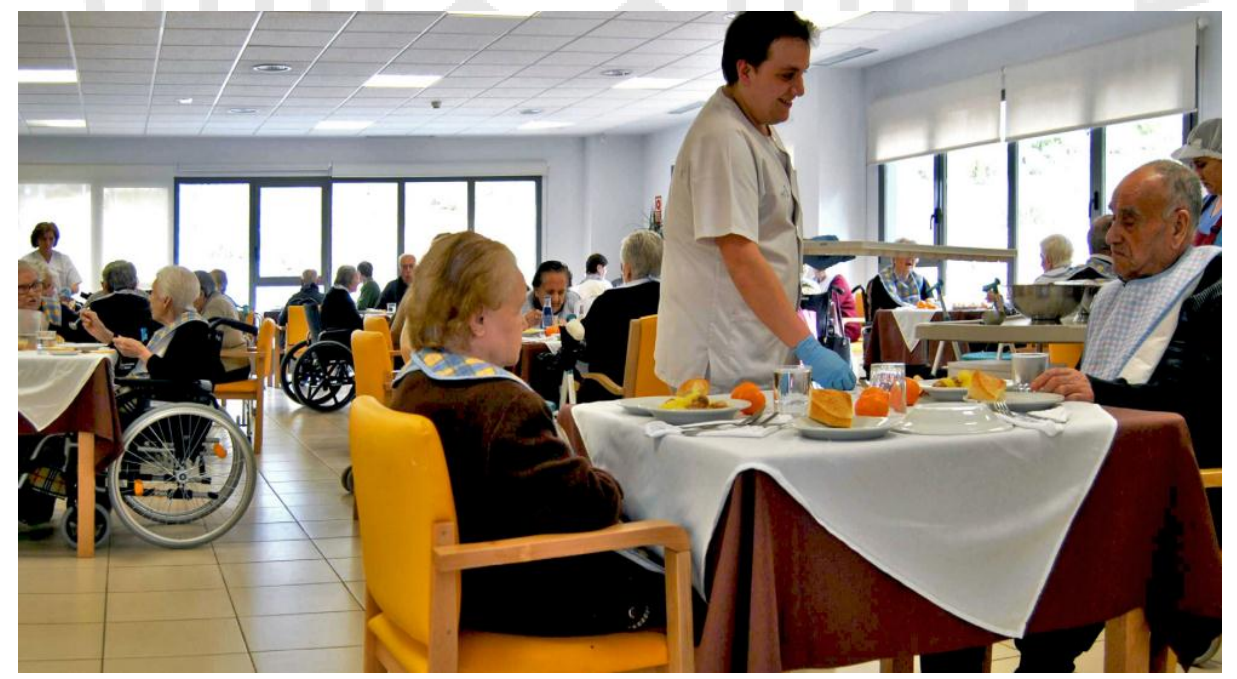

Fuente: (Castilla - La Mancha, 2016) 


\subsubsection{Relación con el entorno.}

La Residencia para Mayores "El Molino" se encuentra en los límites del distrito de Mota del cuervo - provincia de Cuenca, en una zona rural. Está exactamente en el cruce de la Calle Santa Rita y Calle Cuenca por donde se ubica el ingreso peatonal y vehicular de la residencia. El centro se encuentra aproximadamente a $0.49 \mathrm{~km}$ del centro del distrito.

Figura 4.2.2.1:

Ubicación del distrito de Mota del Cuervo.

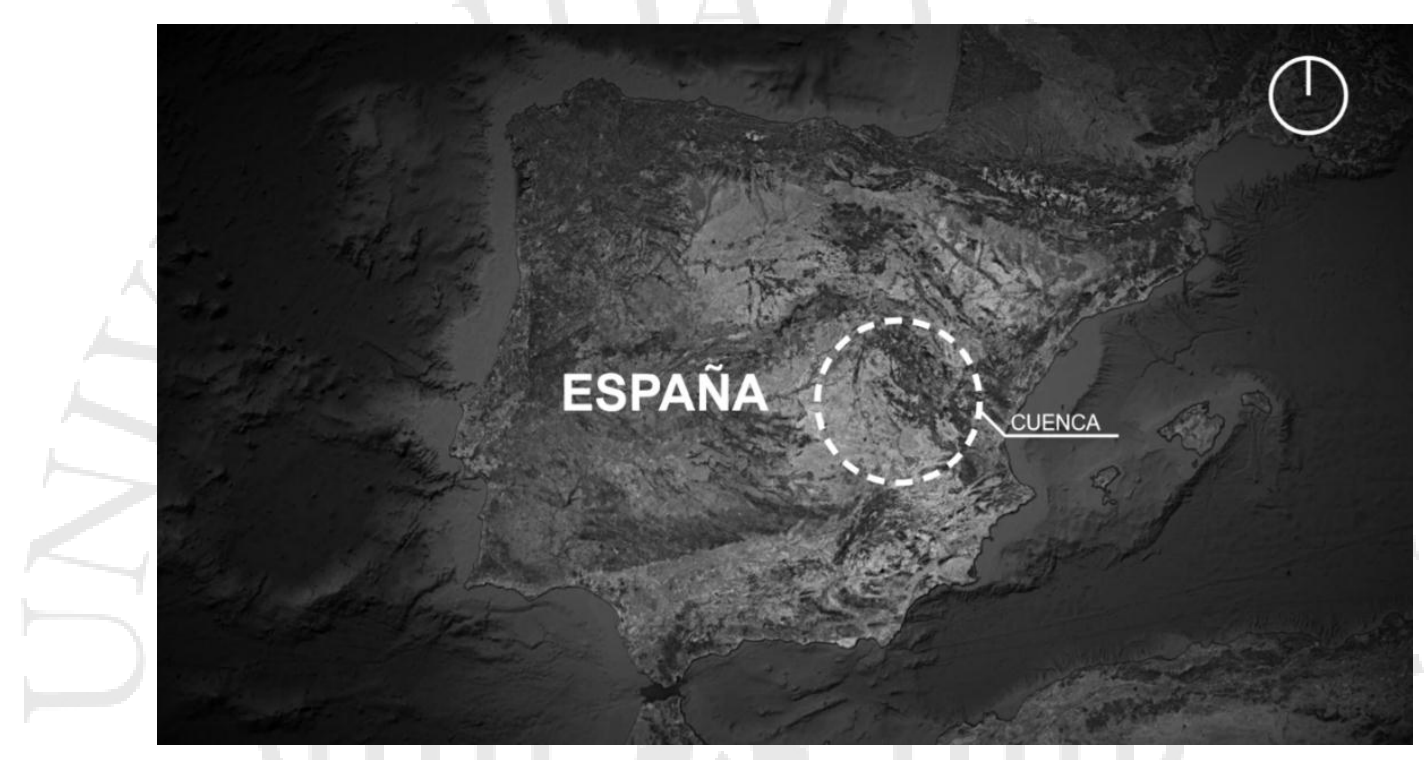

Fuente: Google Earth. Modificado por autor.

Figura 4.2.2.2:

Ubicación de la residencia en el distrito de Mota del Cuervo.

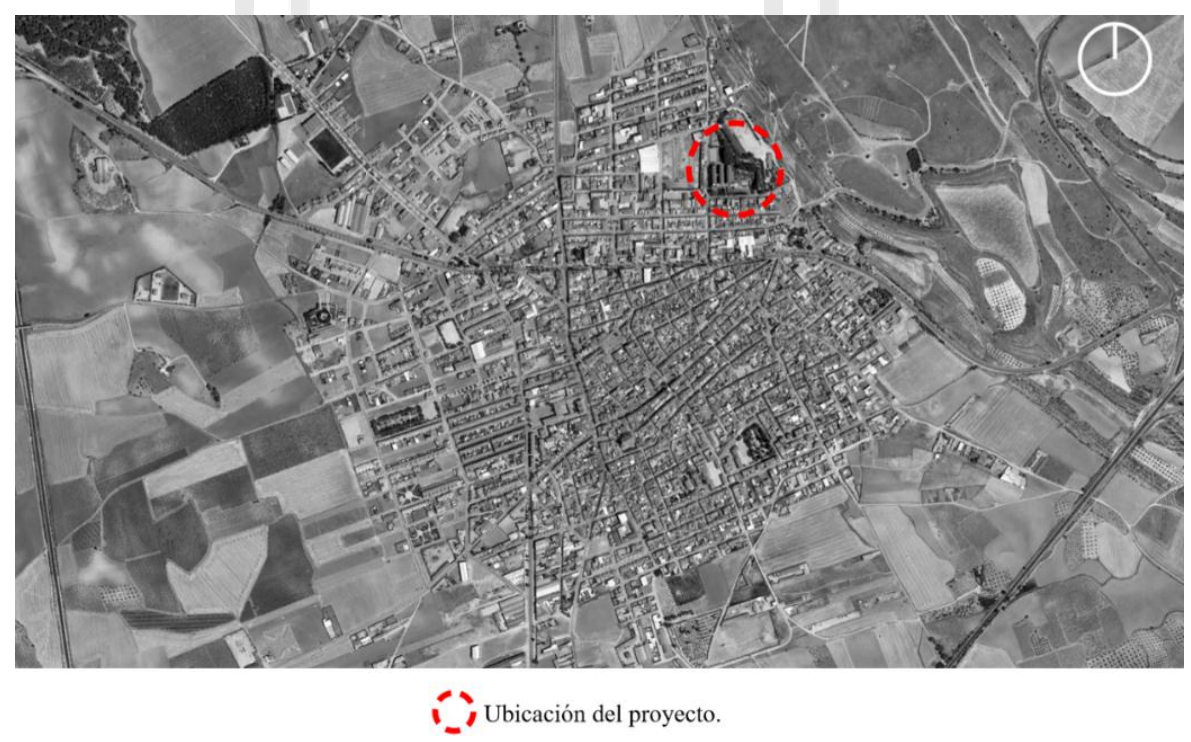

Fuente: Google Earth. Modificado por autor. 
La vía principal cercana a la Residencia es la continuación de la Carretera Belmonte, seguido de las calles Don Sabino y Camino Real Alta.

Debido a que es un distrito pequeño y poco activo, no cuenta con grandes líneas de transporte público y carece de paraderos. Las calles aledañas a la Residencia son secundarias, por tal motivo, el movimiento en la zona es regularmente activo.

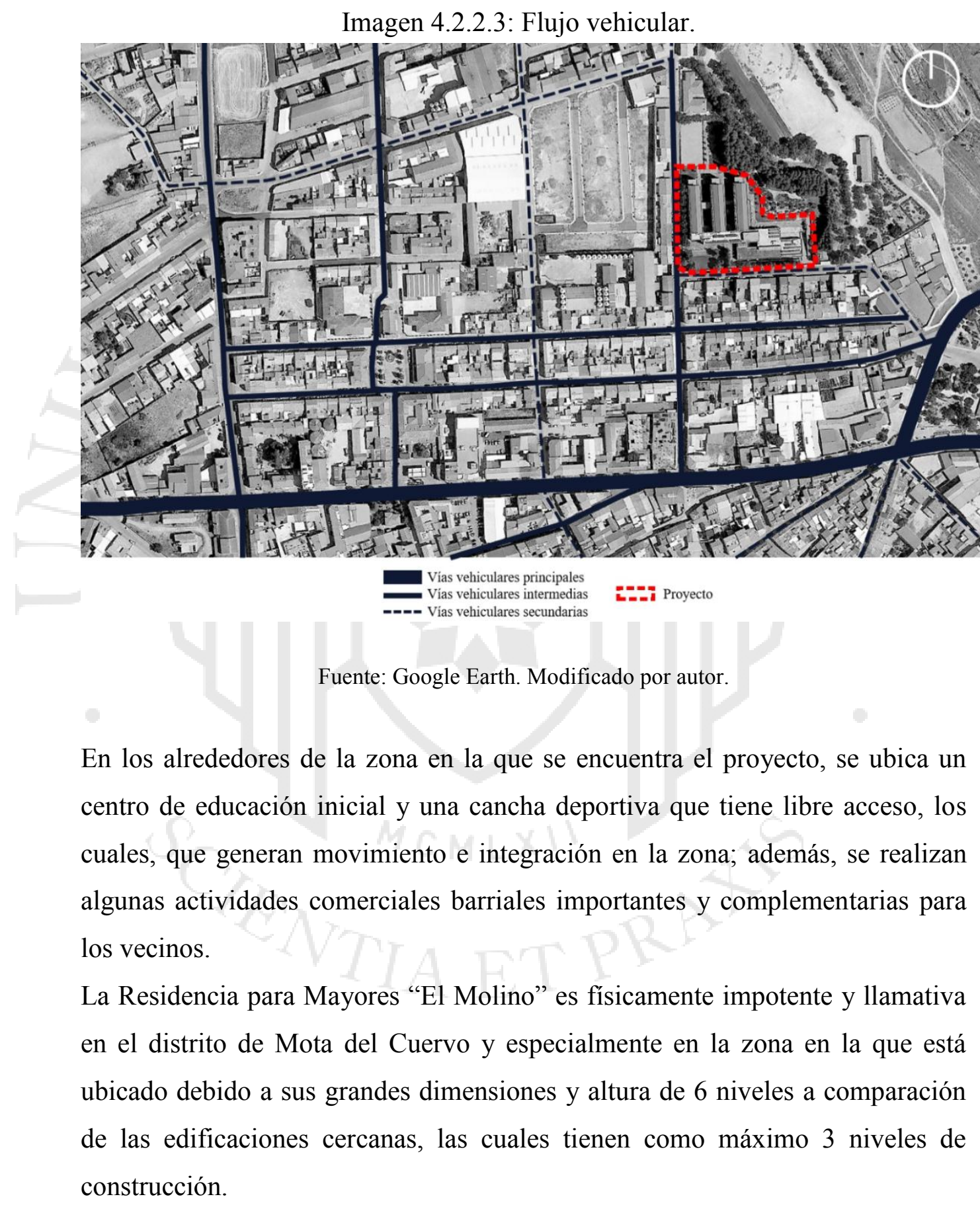


Imagen 4.2.2.4:

Flujo peatonal

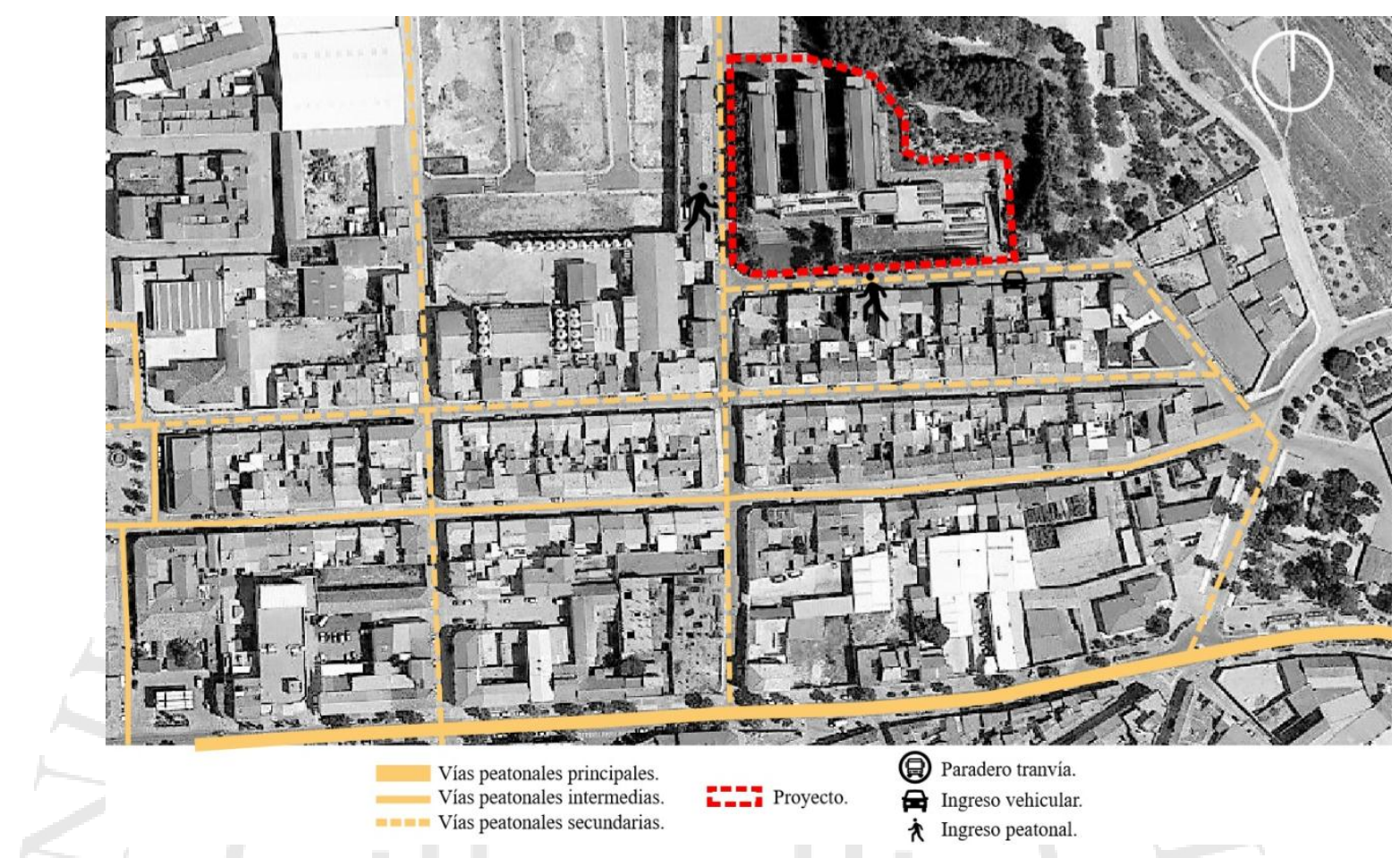

Fuente: Google Earth. Modificado por autor.

Figura 4.2.2.5: Corte A-A'.

Corte A-A'

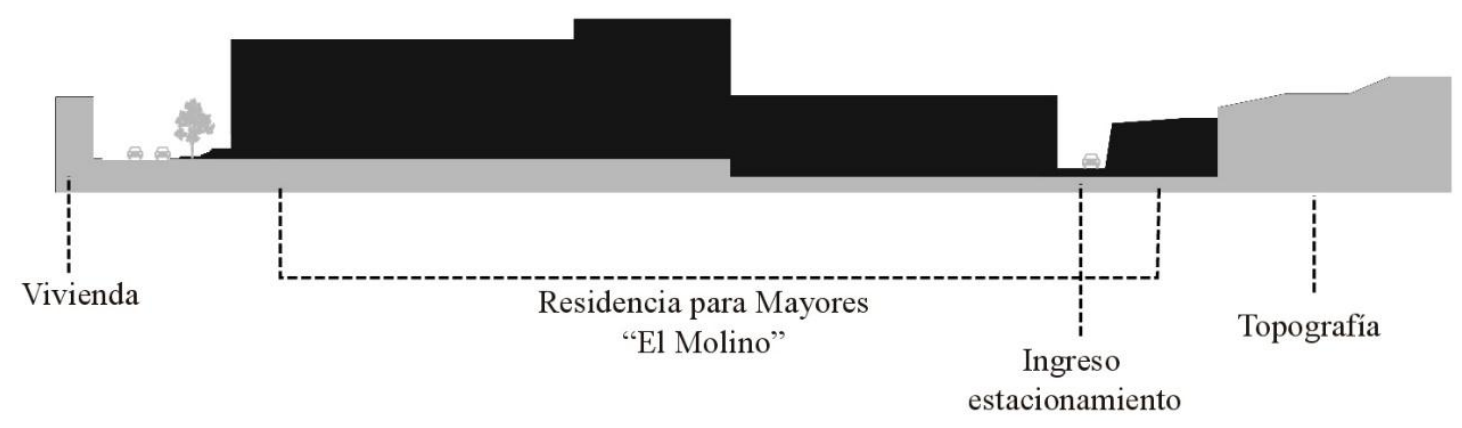

Fuente: Elaborado por autor. 


\subsubsection{Programa y relaciones programáticas.}

El siguiente análisis muestra las medidas y el aporte porcentual de cada ambiente con respecto al área en el que se ubica dentro de la Residencia para Adultos Mayores "El Molino". Cada área general está separada por las características de los servicios que ofrece: Área administrativa, área de servicios, área de actividades diurnas, área residencial, área libre y estacionamiento.

\section{Figura 4.2.3.1:}

Planta dividida por áreas - nivel -1 .

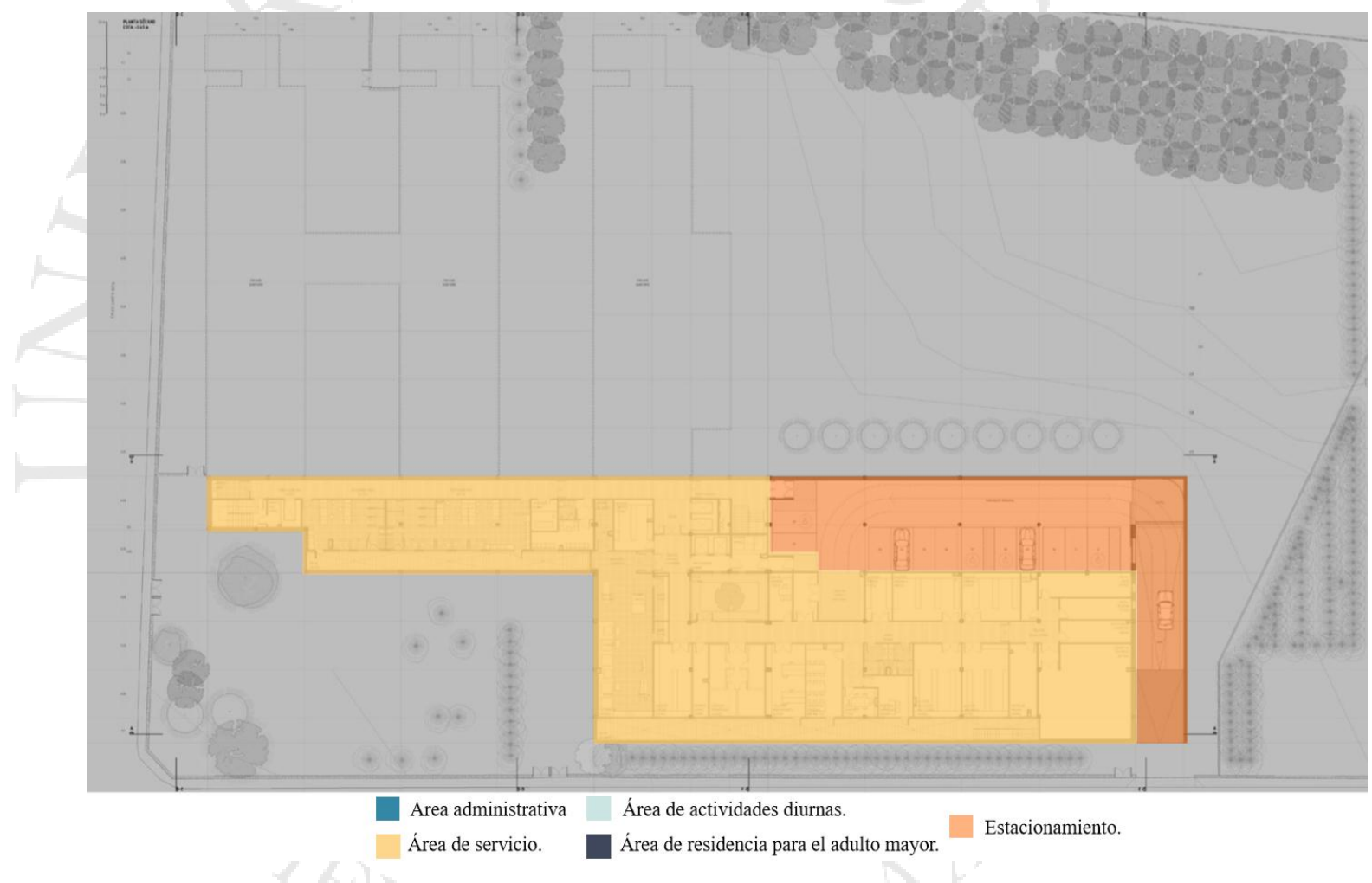

Fuente: (Archdaily, 2012). Modificado por autor. 
Figura 4.2.3.2:

Planta dividida por áreas - nivel 1

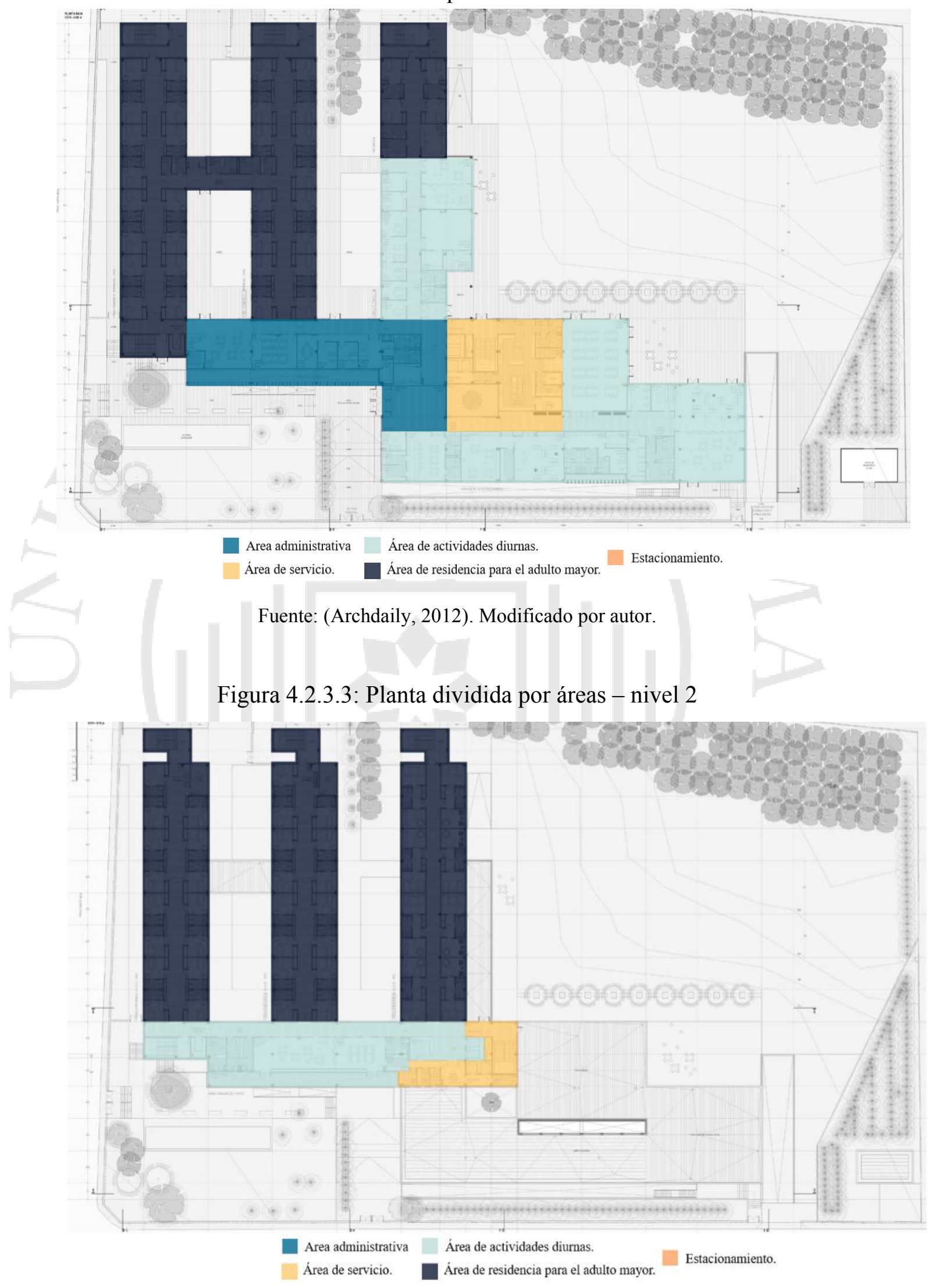

Fuente: (Archdaily, 2012). Modificado por autor. 
Tabla 4.2.3.1:

Área administrativa Los Molinos

\section{AREA ADMINISTRATIVA DE LA RESIDENCIA PARA MAYORES LOS MOLINOS}

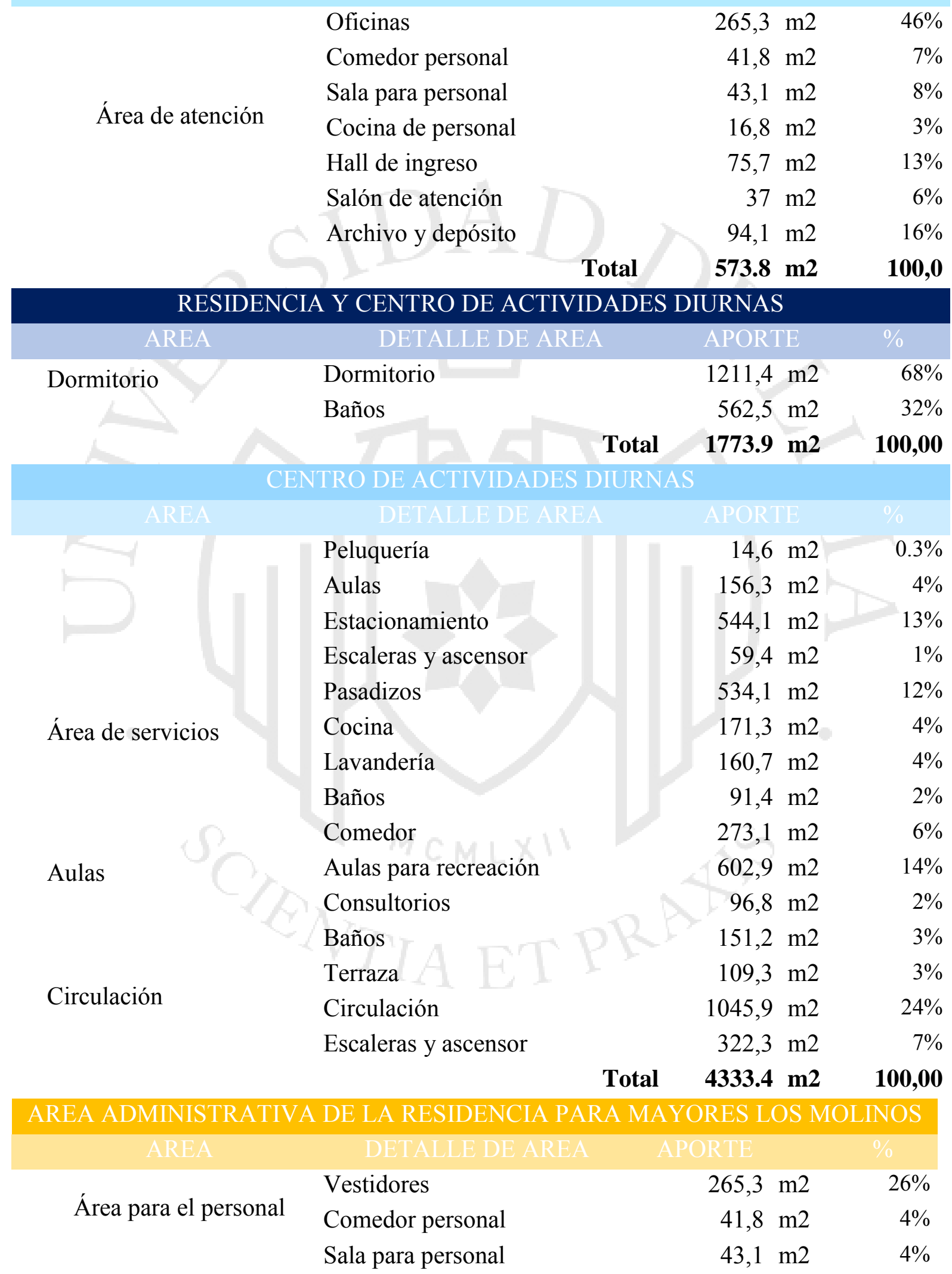


Cocina de personal

Hall de ingreso

Circulación

Escaleras y ascensor

Pasadizos

Total

$1036.2 \mathrm{~m} 2$

100,0

Análisis: Autor

\subsubsection{Estrategias de emplazamiento}

Figura 4.2.4.1:

Esquema de composición.
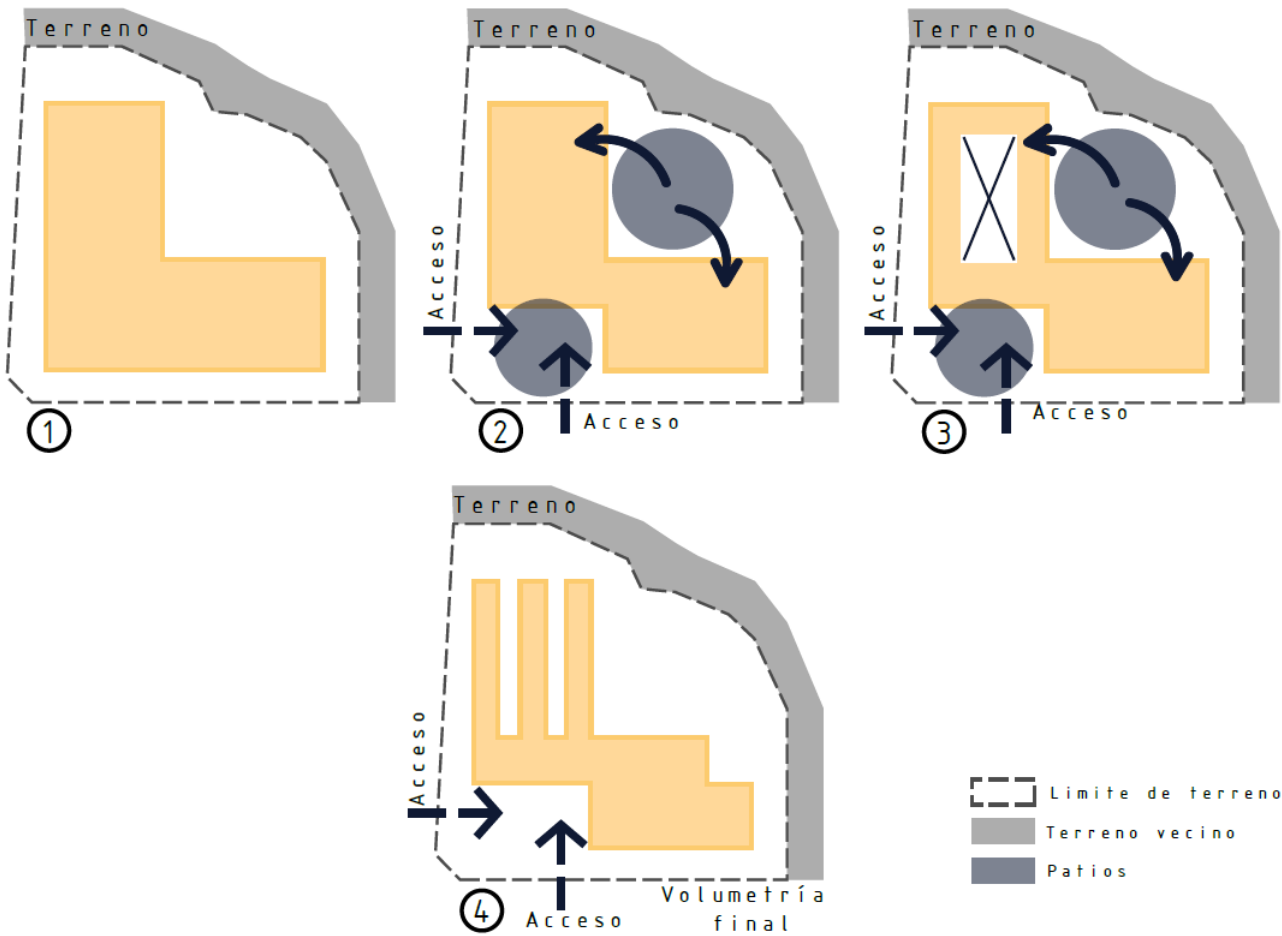

Fuente: Elaborado por autor.

El gráfico muestra las estrategias del emplazamiento del proyecto sobre el terreno. En el esquema, se puede visualizar un gran patio en la parte superior derecha el cual sirve como espacio de integración entre el área de actividades diurnas y la zona residencial, este tiene vista hacia los montes ubicados a la espalda del proyecto, lo que genera una conexión directa con la naturaliza.

En la esquina inferior izquierda, se forma un patio - jardín como complemento de los ingresos de las calles que dan a la esquina. Esta área tiene conexión directa con las calles Santa Rita y Cuenca. 
Por otro lado, en la zona norte del proyecto se visualizan 3 bloques paralelos similares separados por patios. Estos volúmenes que optimizan los ingresos de luz y ventilación son destinados para el área de residencia de los adultos mayores

\subsubsection{Flujos y circulaciones}

El siguiente análisis muestra los diferentes flujos que hay dentro de cada zona de la Residencia para Mayores "El Molino”. Estos flujos varían según las actividades realizadas en cada zona de la residencia, puesto que hay áreas para uso especial de los usuarios, otras exclusivamente para el personal que realiza las labores de ayuda y atención, etc.

Figura 4.2.5.1:

Imagen interior de la Residencia

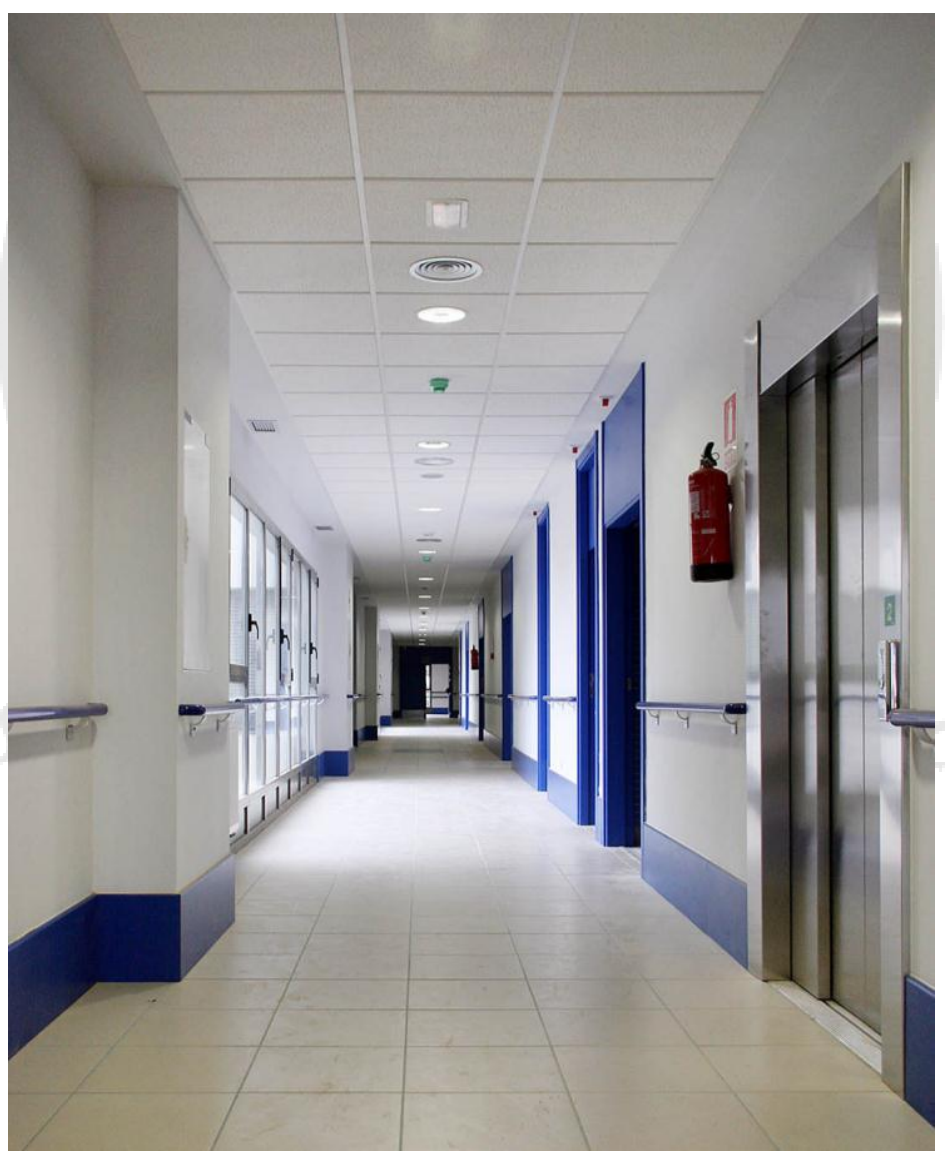

Fuente: (Archdaily, 2012). 
Figura 4.2.5.2:

Imagen interior de la Residencia

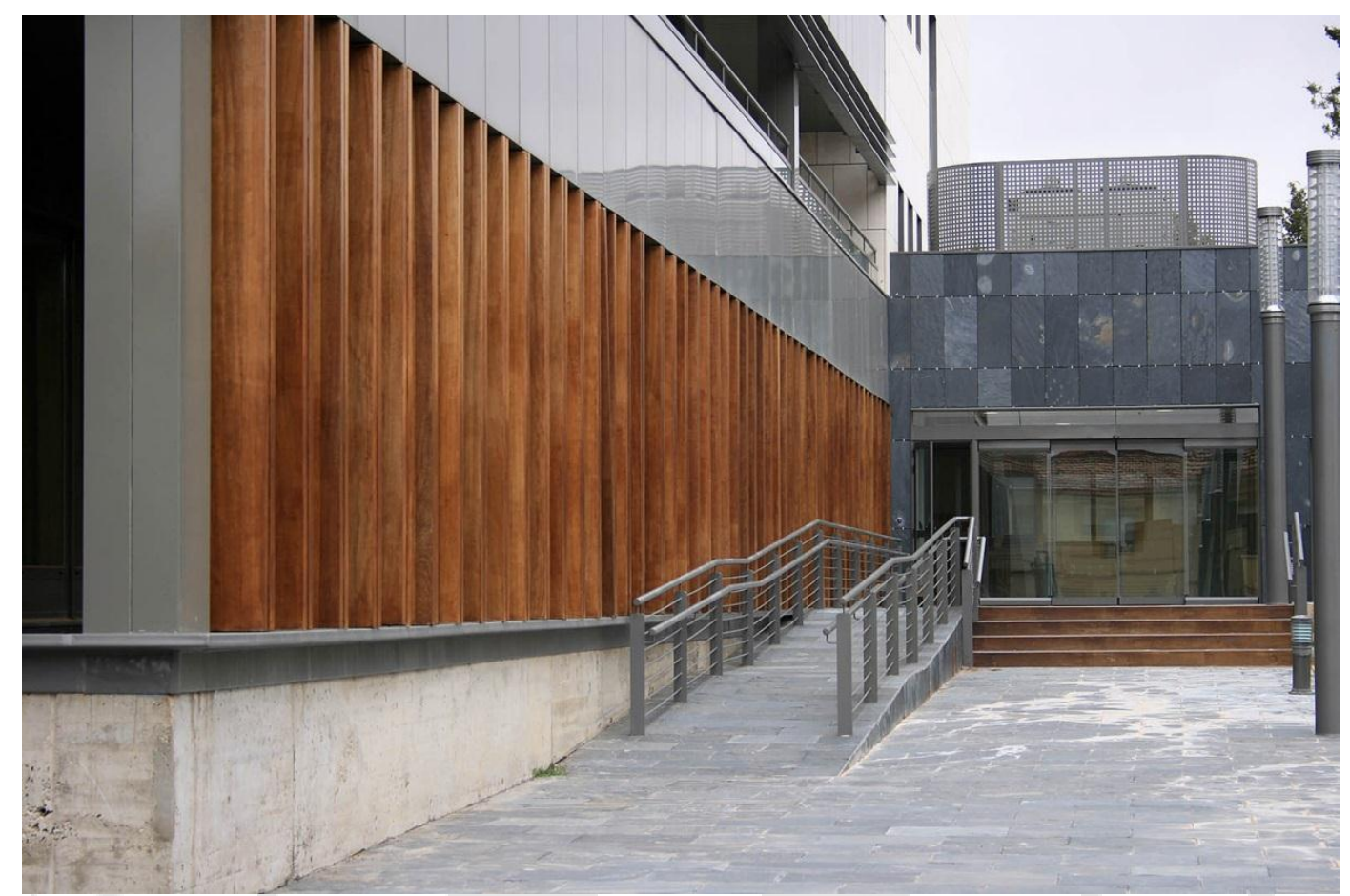

Fuente: (Archdaily, 2012).

Figura 4.2.5.3:

Imagen interior de la Residencia

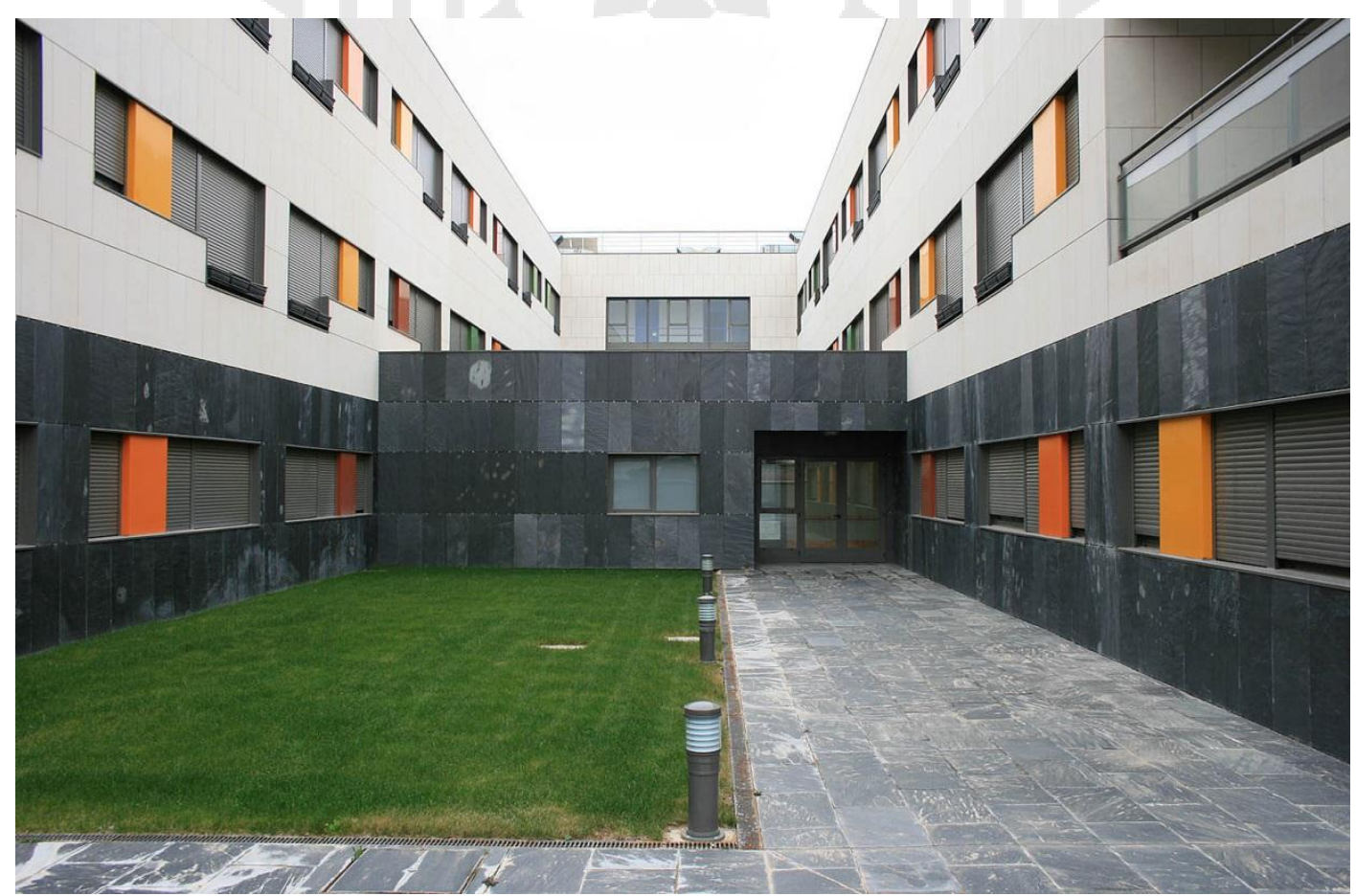

Fuente: (Archdaily, 2012). 
Figura 4.2.5.4: Análisis de flujo peatonal en el proyecto

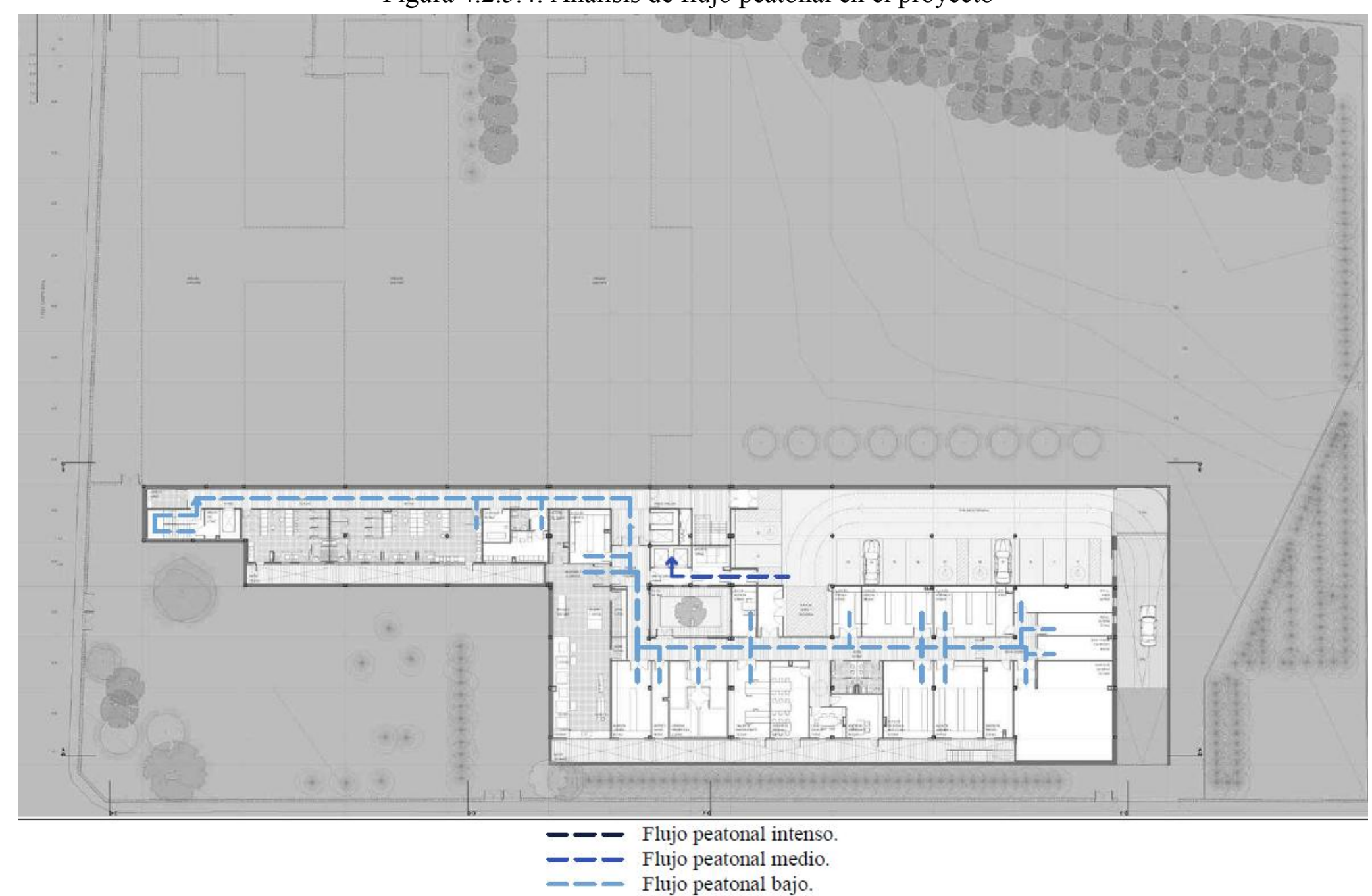

Fuente: (Archdaily, 2012). Modificado por autor. 
Figura 4.2.5.5: Análisis de flujo peatonal en el proyecto

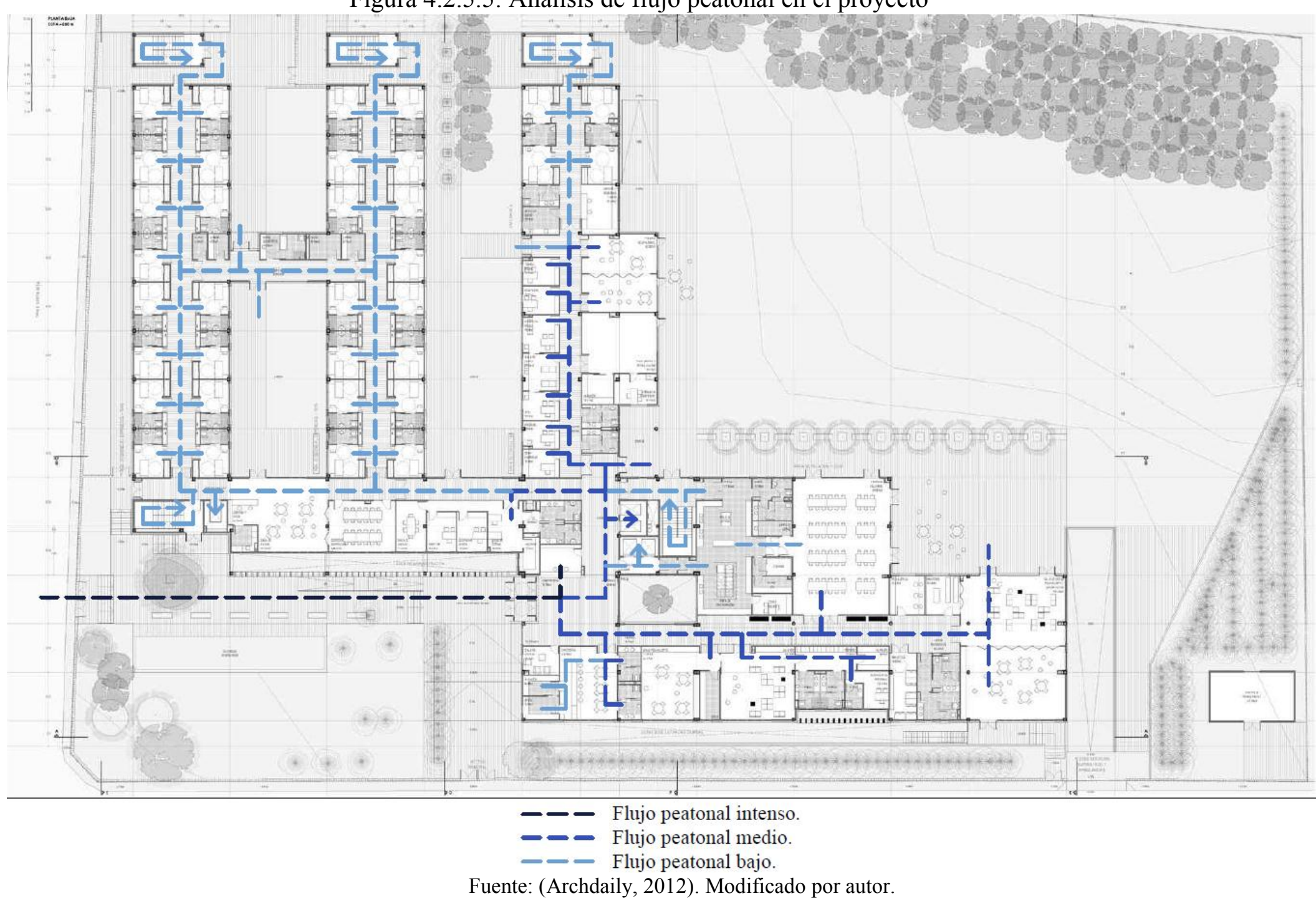


Figura 4.2.5.6: Análisis de flujo peatonal en el proyecto

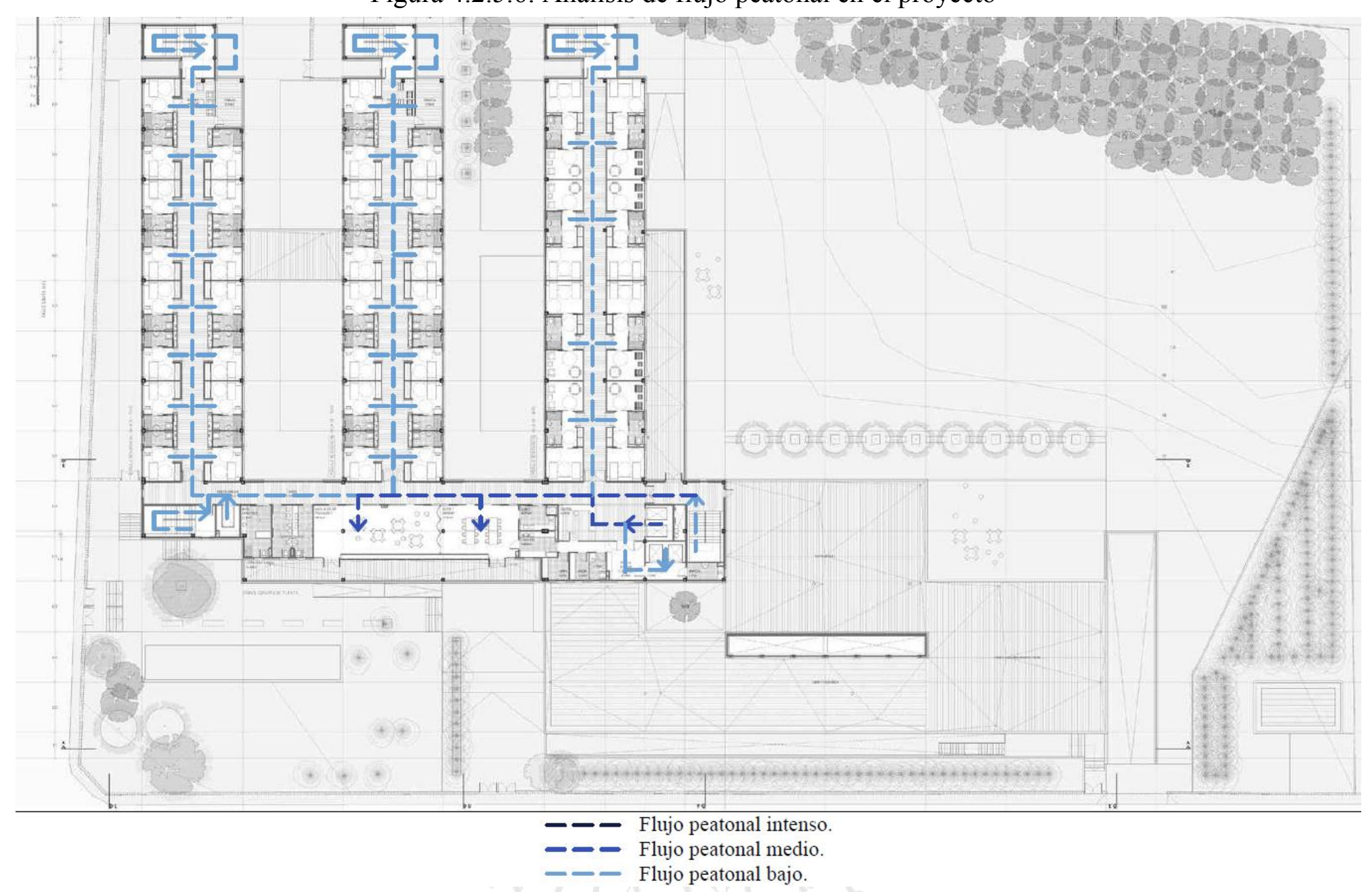

Fuente: (Archdaily, 2012). Modificado por autor 
4.2.6 Área construida y área libre.

El área libre, en este proyecto está compuesto de amplios jardines que contribuyen a dar una mejor calidad de vida a los residentes del centro. Además, el diseño permite que estas áreas libres ayuden a mejorar la iluminación y ventilación alrededor de todo el instituto.

El proyecto cuenta con el $44 \%$ de área libre y el 56\% de área techada, sin embargo, para que este sea eficiente y pueda tener mayor área para albergar a las personas de la tercera edad, el área techada se multiplica en 3 niveles de altura. Además, cuenta con un amplio sótano en el que se ubica las áreas de servicios complementarios y el estacionamiento del centro.

4.2.7 Relaciones espaciales.

Figura 4.2.7.1:

Análisis relaciones espaciales

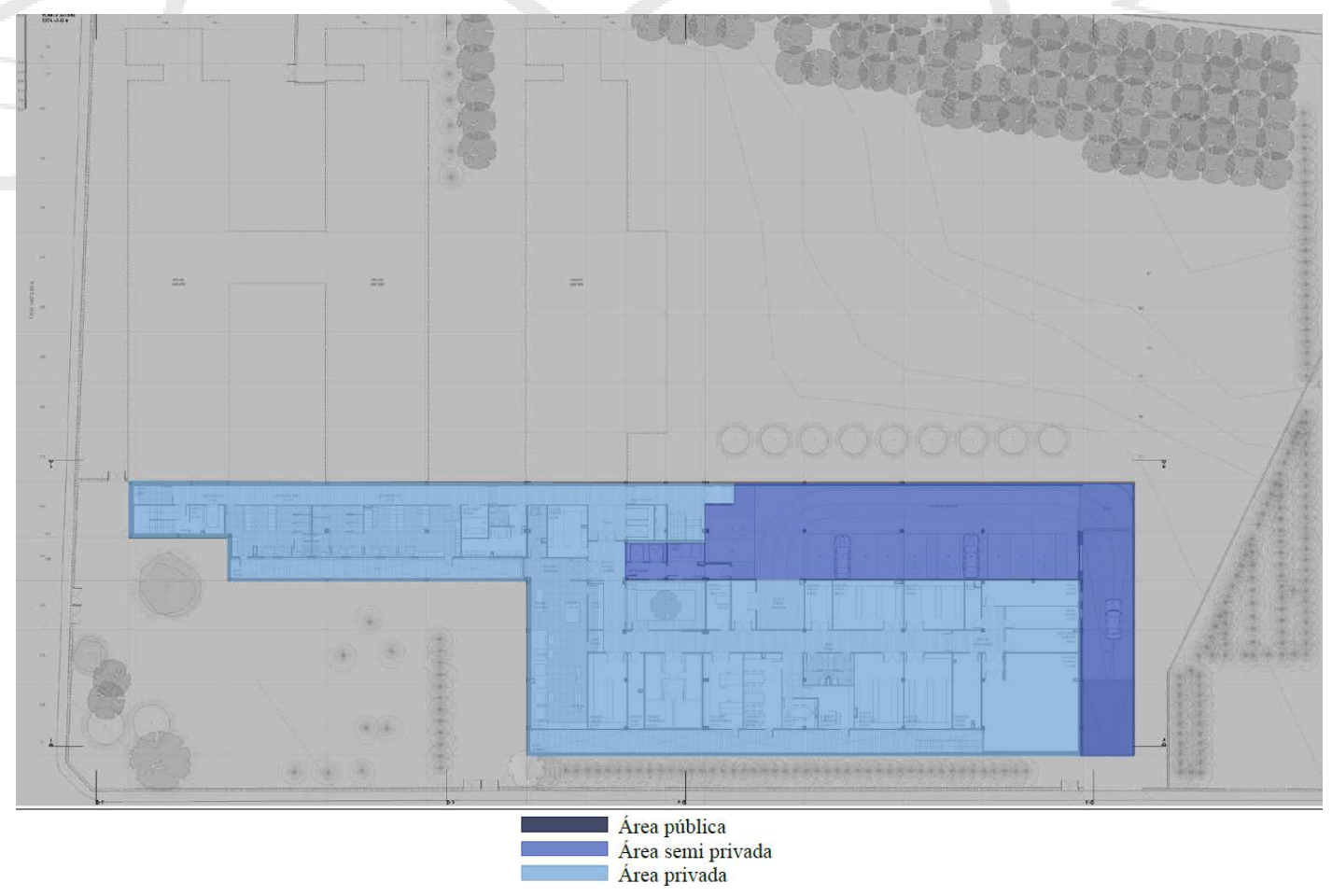

Fuente: (Archdaily, 2012). Modificado por autor. 
Figura 4.2.7.2:

Análisis relaciones espaciales

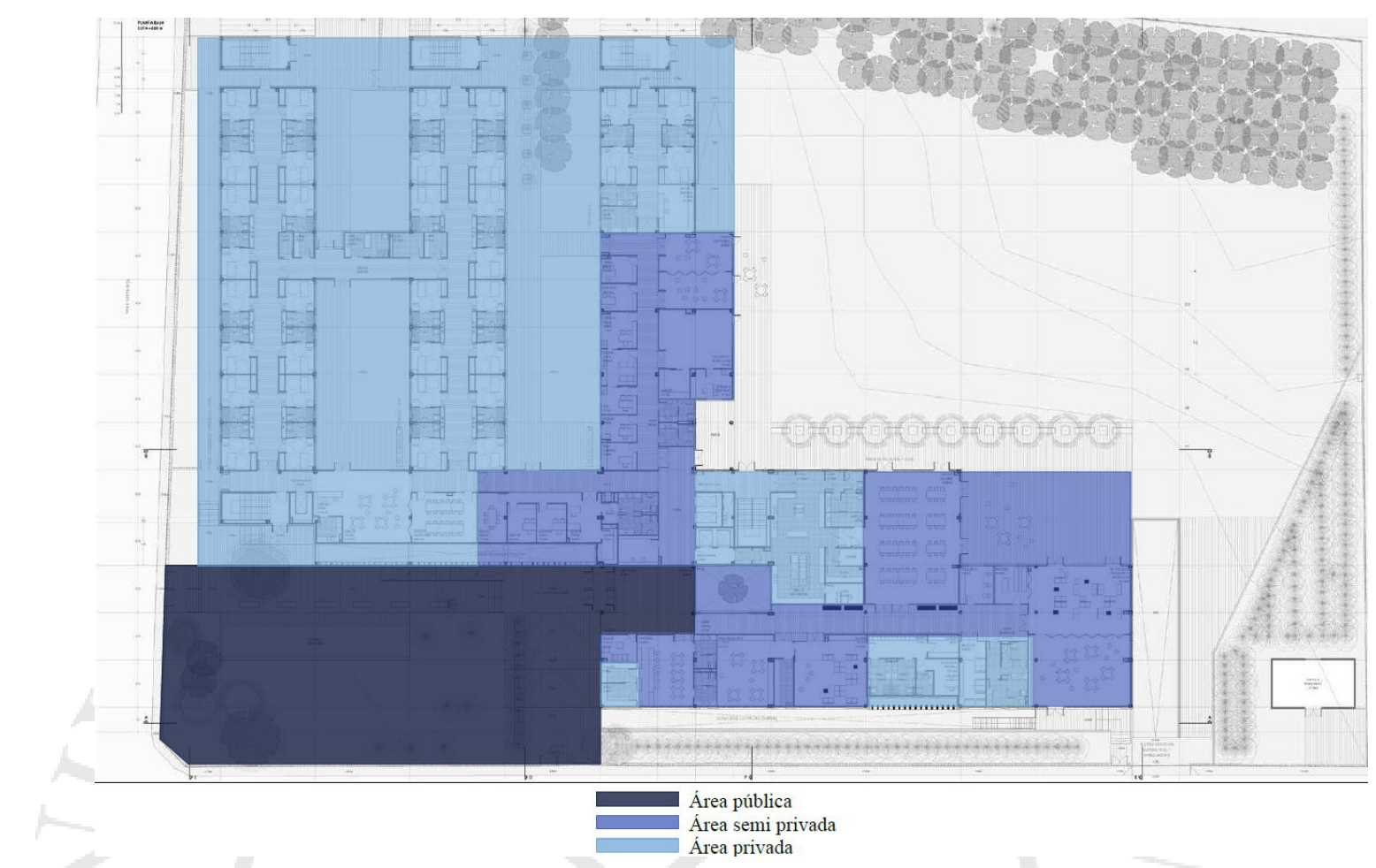

Fuente: (Archdaily, 2012). Modificado por autor.

Figura 4.2.7.3:

Análisis relaciones espaciales

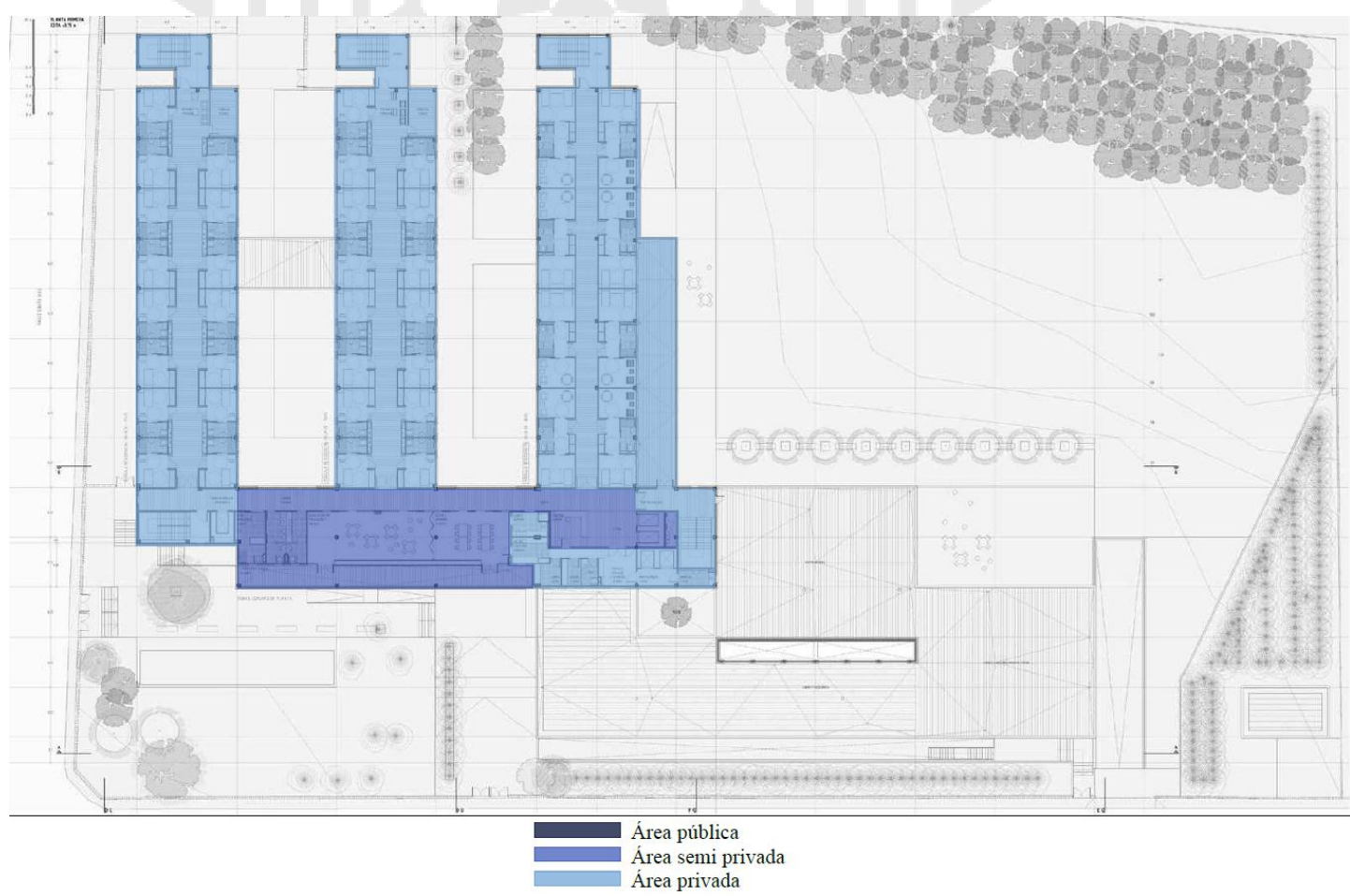

Fuente: (Archdaily, 2012). Modificado por autor. 
El análisis muestra los distintos niveles de accesibilidad y privacidad que tiene la Residencia para Adultos Mayores.

- La zona de mayor exposición a todo el público es en la parte sur del proyecto, en el cruce de la Calle Santa Rita y Calle Cuenca, el espacio que genera la esquina es el que está más relacionado con el exterior. Si bien hay una reja que divide el jardín de la calle, el aporte visual que genera en el paisaje es importante.

- La zona semipública es la que se encuentra al ingresar al centro, esta es el área administrativa en donde se puede consultar sobre los servicios que ofrece el instituto. El acceso es libre para todas las personas.

- En la parte este del proyecto se ubican zonas con actividades que pueden ser realizadas por los residentes y los adultos mayores que van a pasar el día. Por tal motivo, la privacidad en esta zona es mayor pero no en su totalidad debido a que existe una fuerte relación entre lo exterior e interior.

- Finalmente, la zona de residencia es la de mayor privacidad, se encuentra en la parte norte del proyecto, en una zona más cercana al área verde que se encuentra en la parte posterior del proyecto. 
Figura 4.2.8.1

Planta de dormitorio

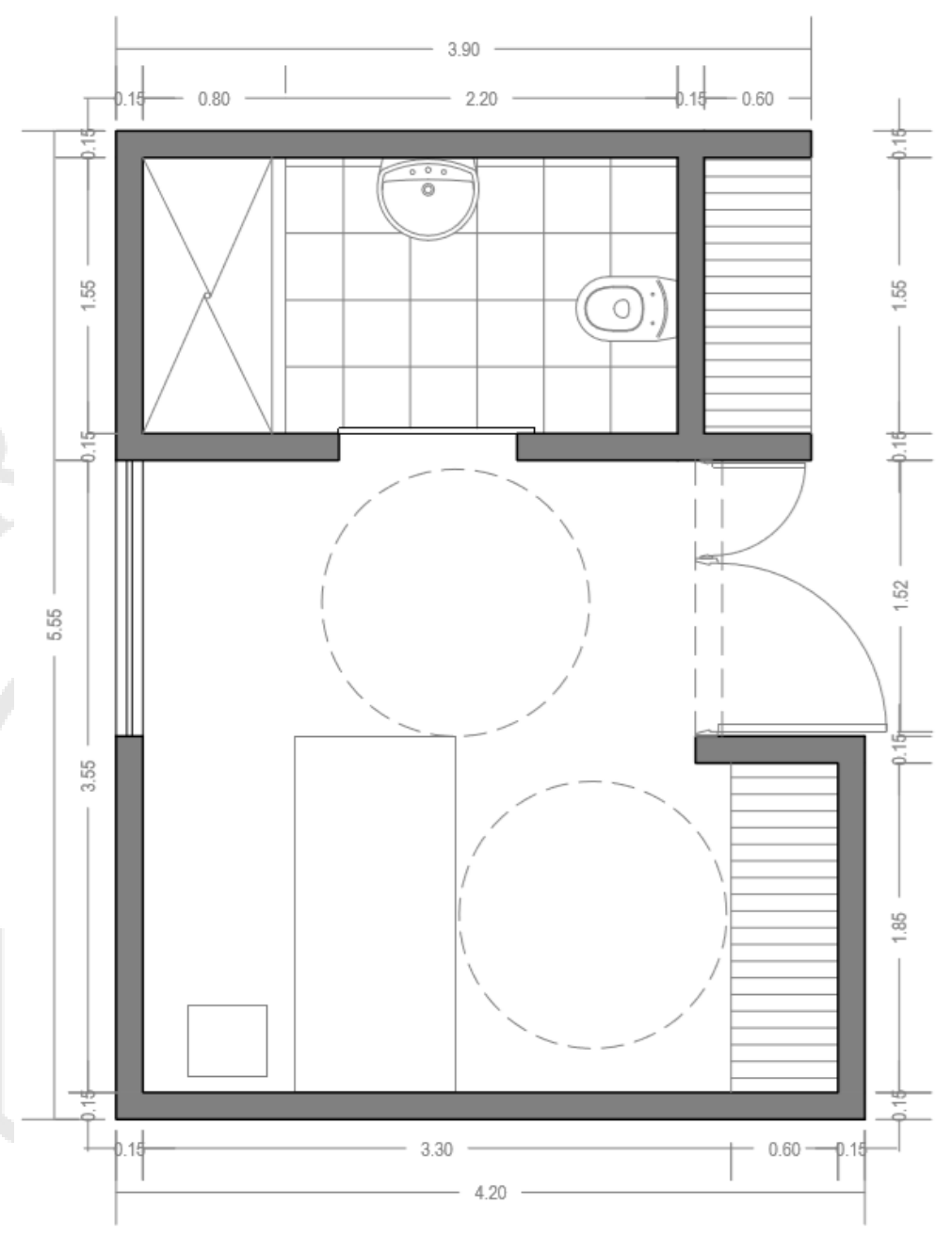

Fuente: Elaborado por autor.

En el caso de la Residencia para Personas Mayores "El Molino", los dormitorios son personales. Son módulos de $23.31 \mathrm{~m} 2$ que cuenta con las dimensiones reglamentarias para que sea accesible para ancianos en silla de ruedas. Además, cada dormitorio tiene un baño completo adaptado a las necesidades de los usuarios.

Se ingresa por una puerta de dos hojas que mide 1.52 metros a un pasadizo de la misma dimensión el cual divide el área del dormitorio y el ingreso al baño. Al lado izquierdo de esta se ubica la cama de $1 \frac{1}{2}$ plaza, a los lados de esta se ubican un velador de noche y closet de $0.60 \mathrm{~m}$ de profundidad, el pasadizo entre la cama y el armario tiene una dimensión de $1.50 \mathrm{~m}$ y es 
apto para que una persona en silla de ruedas pueda maniobrar en caso utilice este mobiliario.

Finalmente, la vista de los dormitorios está dirigida al patio que se extiende en la zona noroeste del proyecto, generando así una buena iluminación y ventilación a cada habitación.

Figura 4.2.8.2

Imágenes de dormitorios

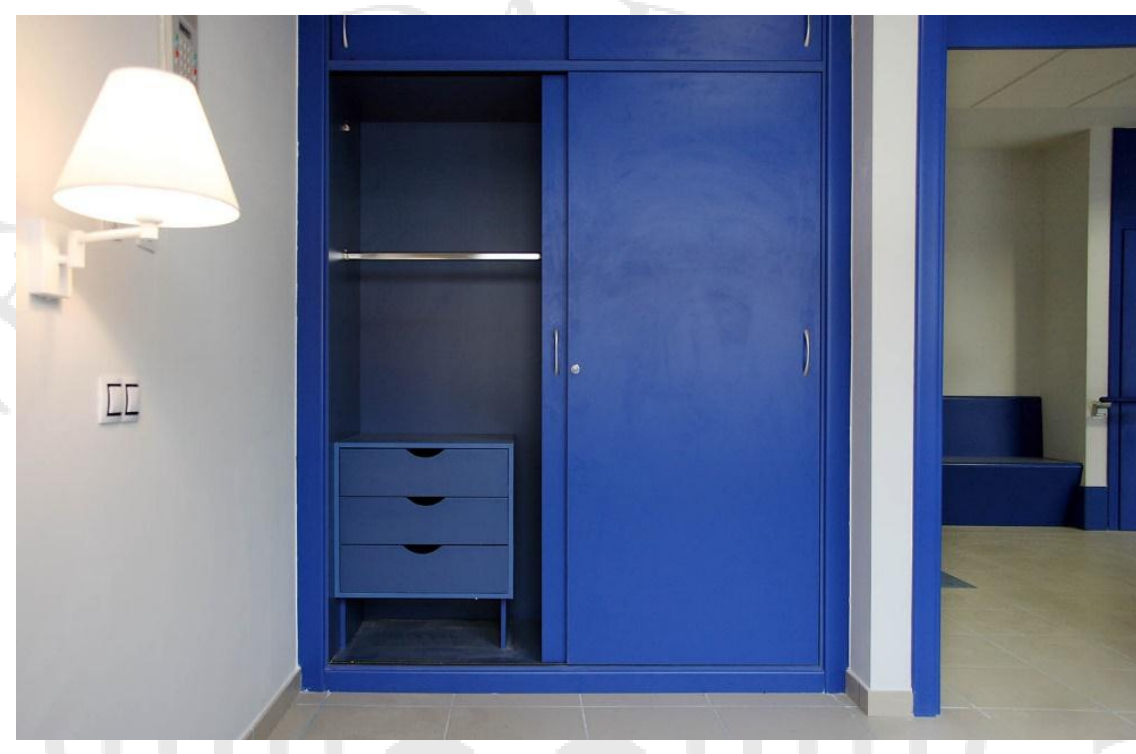

Fuente: (Archdaily, 2012).

Figura 4.2.8.3

Vista del baño al interior del dormitorio

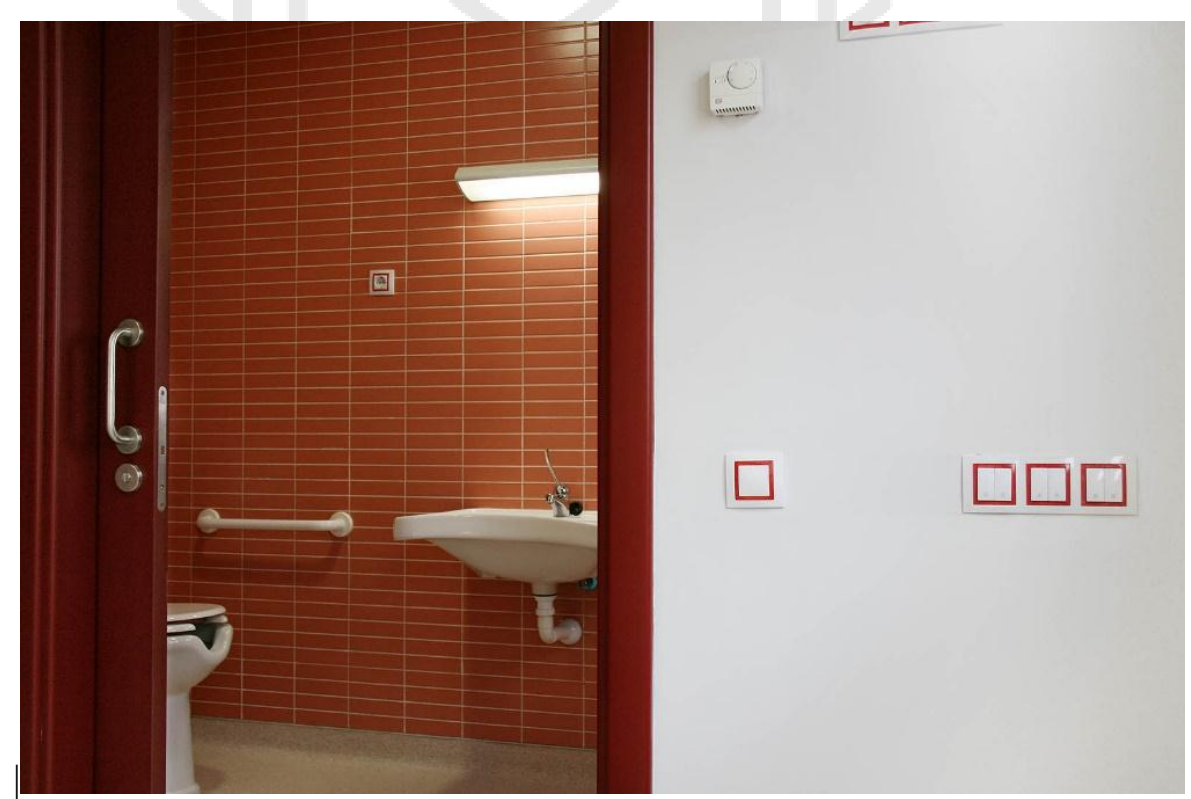

Fuente: (Archdaily, 2012). 


\subsubsection{Tecnología.}

Para que el proyecto sea más eficiente y amigable con el medio ambiente, tiene detallados estudios sobre la orientación de cada pabellón para hacer más eficiente los elementos naturales.

Por ejemplo, la crujía de la residencia es de $10.5 \mathrm{~m}$ x $10.5 \mathrm{~m}$, esta medida favorece los ingresos de luz y permite tener ventilación cruzada en los ambientes.

Además, cuenta con un sistema de captación que ayuda a cubrir una parte de la temperatura de agua caliente que requiere el lugar. Finalmente, hay partes de la fachada en las que se usa celosías de lamas verticales y que regula el ingreso controlado de luz y controla la temperatura interior con relación al clima de la zona.

\section{Figura 4.2.9.1:}

Imágenes del proyecto

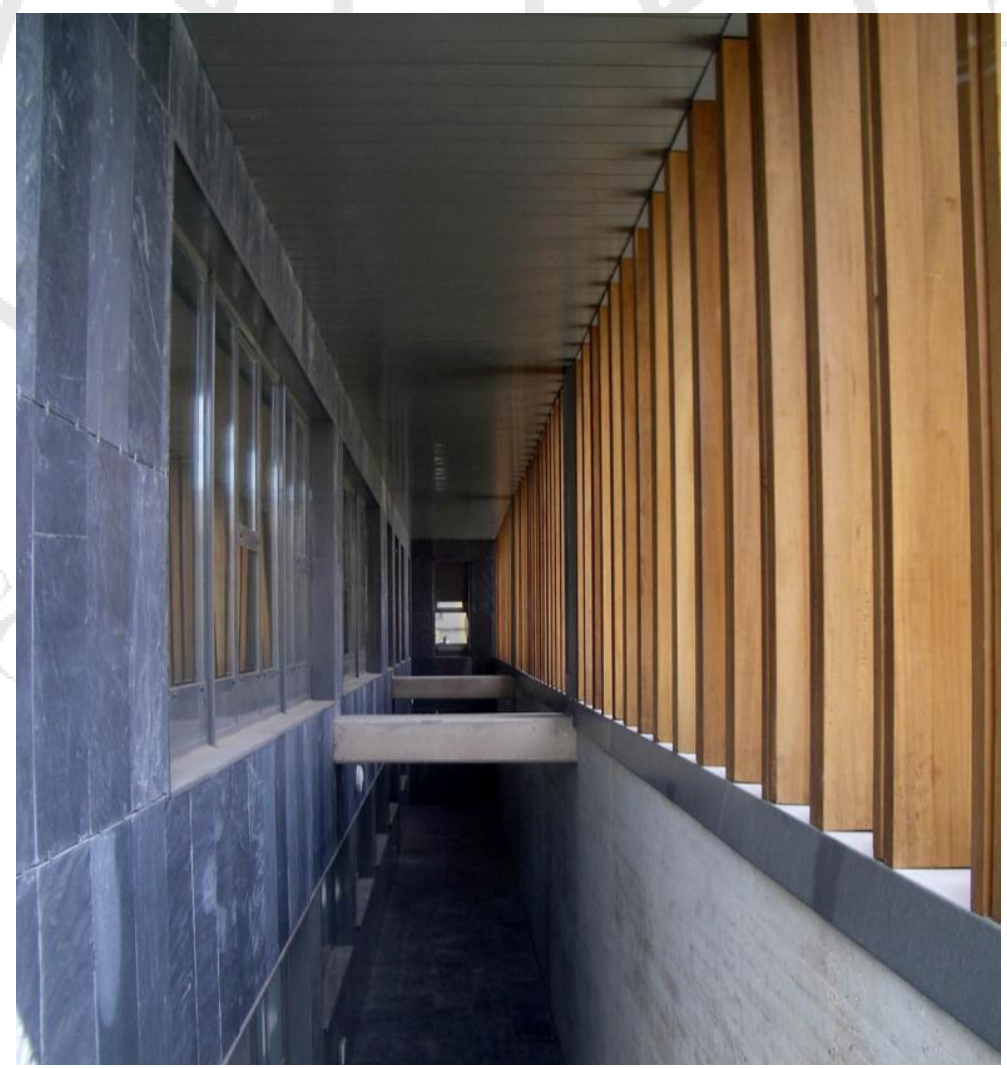

Fuente: (Archdaily, 2012). 
Figura 4.2.9.2:

Imágenes del proyecto

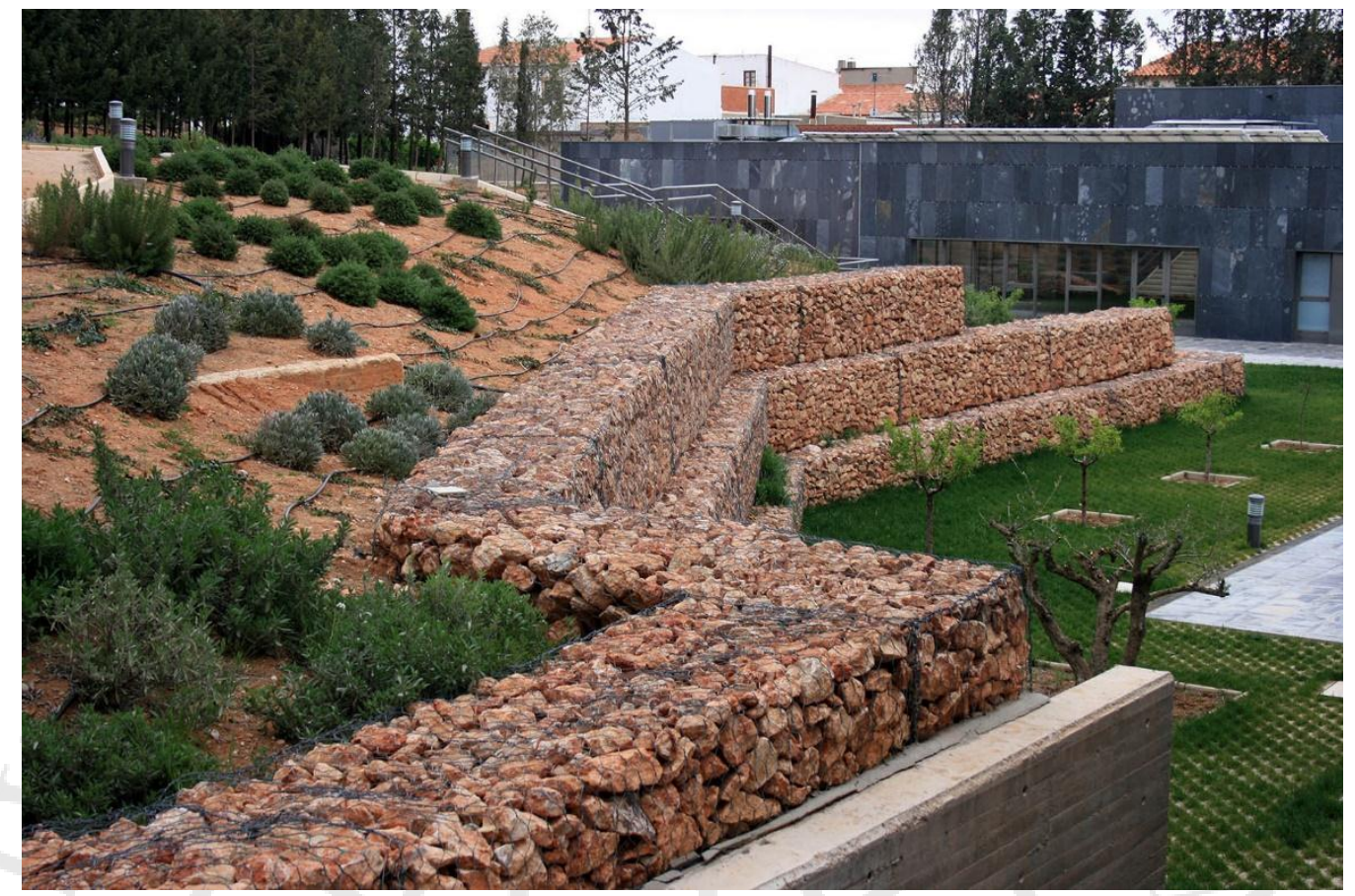

Fuente: (Archdaily, 2012).

Figura 4.2.9.3:

Imágenes del proyecto

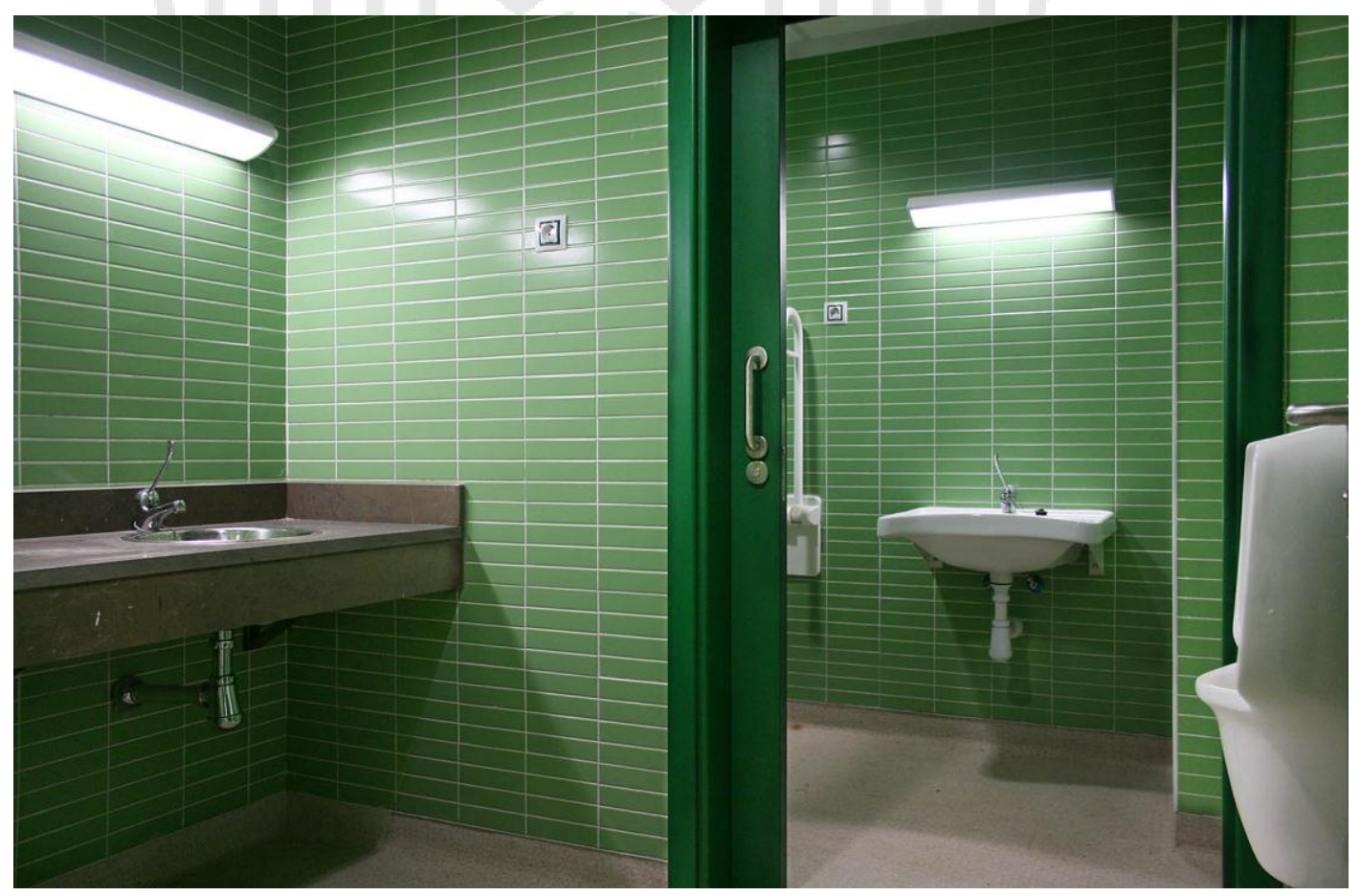

Fuente: (Archdaily, 2012). 


\subsubsection{Impacto social.}

La Residencia para Adultos Mayores "El Molino" es el segundo centro para adultos mayores ubicado en Mota del Cuervo, sin embargo, El Molino cuenta con ambientes y áreas más grandes, es así que el centro dispone de 120 plazas residenciales para adultos mayores, los cuales están divididos en 90 dormitorios y 15 dobles; así mismo, cuenta con 20 vacantes para estancias diurnas.

La meta del centro, según la directora del centro es mantener "El Molino" como uno de los referentes de centro de adultos mayores más completas de Castilla La Mancha, además de lograr el contar con instalaciones modernas y lograr una atención óptima para que ancianos se sientan como en casa.

Figura 4.2.10.1:

\section{Noticias Mota del Cuervo.}

El alcalde de Mota del Cuervo, Alfonso Escudero, y la concejala del área de mayores, Mónica Salido, han realizado una visita a la residencia de ancianos "Los Molinos" para dar la bienvenida a su nueva directora, María del Carmen Herraiz González.

Con esta visita el primer edil ha querido dar su apoyo a la nueva directora poniéndose a su entera disposición para cubrir cualquier necesidad que tengan desde el centro y que haya un contacto permanente entre ambas entidades, con el objetivo de conseguir un mayor bienestar para nuestros mayores.

Asimismo, la concejala, ha mostrado su intención de trabajar conjuntamente ayuntamiento y residencia, realizando proyectos y actividades con otros colectivos de la localidad para integrar a nuestros mayores en la sociedad y reconocer todo lo que nuestros antecesores han trabajado para dejarnos un mundo mejor.

La nueva directora ha agradecido la visita y ha explicado que pretende mantener la misma línea de trabajo que hasta ahora, "manteniéndose como uno de los referentes en residencias de ancianos más completas de Castilla La Mancha". Su principal reto será, según declara, "contar con las instalaciones más modernas y el trato más humano, para que los residentes se sientan como en casa".

La Residencia Los Molinos dispone de 120 plazas residenciales para personas mayores distribuidas en 90 habitaciones individuales y 15 dobles y un Servicio de Estancias Diurnas para 20 usuarios que pueden recibir los cuidados terapéuticos y asistenciales necesarios para mejorar su calidad de vida y su autonomia personal.

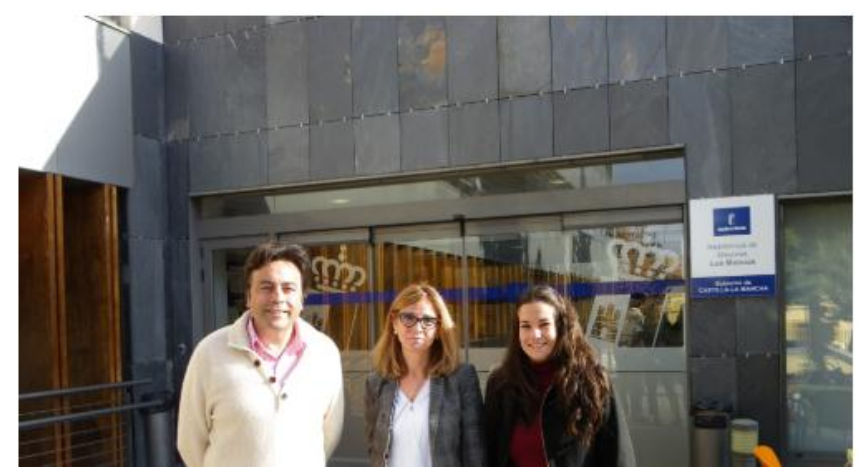

Fuente: (Ayundamiento Mota del Cuervo, 2015) 


\subsubsection{Conclusión.}

La Residencia para personas mayores "El Molino" es importante como referente debido a que nos ayuda a entender mejor el funcionamiento de un centro que cuenta opera como centro de día y residencia para personas de la tercera edad. Además, se entiende mejor el programa arquitectónico necesario y la ubicación de diversos ambientes que articulan el proyecto, lo cual permite hacer un análisis comparativo para generar una mejor propuesta.

Así mismo, nos muestra un ejemplo que a pesar de contar con un terreno de grandes dimensiones que permite realizar propuestas muy diversas, es importante diseñar manteniendo una relación con el entorno y optimizando el espacio y generar ambientes iluminados y ventilados que favorezcan la estancia de los adultos mayores. 
4.3. Guardería y Residencia de la tercera edad.

Al igual que los dos primeros ejemplos, este referente cumple más de una función debido que, además de ser residencia para personas adultas mayores, tiene una zona de guardería para bebés. Además, dos características importantes son la ubicación en el centro de la ciudad de Rennes y el tipo de emplazamiento en el terreno que se explicará más adelante.

4.3.1. Historia del edificio.

\begin{tabular}{|l|l|}
\hline Nombre & Residencia Saint Helier \\
\hline Arquitectos & $\mathrm{a} /$ LTA \\
\hline Ciudad & Rennes \\
\hline País & Francia \\
\hline Área & $5 ’ 000 \mathrm{~m} 2$ \\
\hline Año Proyecto & 2012 \\
\hline
\end{tabular}

La residencia de ancianos y guardería está ubicada en la ciudad de Rennes, Francia y cuenta con un terreno de aproximadamente 6'000m2 y área construida de 5’000 m2, cabe señalar que este centro es la extensión de la Clínica Saint Helier, y que está ubicado en la parte posterior de la residencia. El proyecto estuvo a cargo del estudio francés a/LTA y se invirtió 6800000 de euros en su ejecución.

Al interior del centro se atiende a dos grupos de adultos mayores con características particulares, en primer lugar, se encuentran los ancianos que padecen de Alzheimer, las habitaciones de estos se encuentran ubicadas en la primera planta; por otro lado, están los adultos mayores con capacidades aptas para poder desarrollarse por su propia autonomía, las habitaciones de este grupo de ancianos se distribuyen entre los pisos 3 y 5 del edificio.

Además, la residencia no solo tiene como usuario a los adultos mayores, sino, cuenta con un espacio para guardería abierta al público. Esta actividad particular al interior del centro genera una relación interesante entre dos sectores de 
población muy distinto, pero con algunas características similares, por ejemplo, ambos usuarios son vulnerables y necesitan constante vigilancia de personal capacitado. Por otro lado, ésta interesante relación podría repercutir de manera favorable especialmente en los ancianos, ya que, en algunas ocasiones se realizan actividades, especialmente artísticas, en las que ellos pueden contribuir con el entretenimiento de los niños.

Figura 4.3.1.1: Imágenes del centro

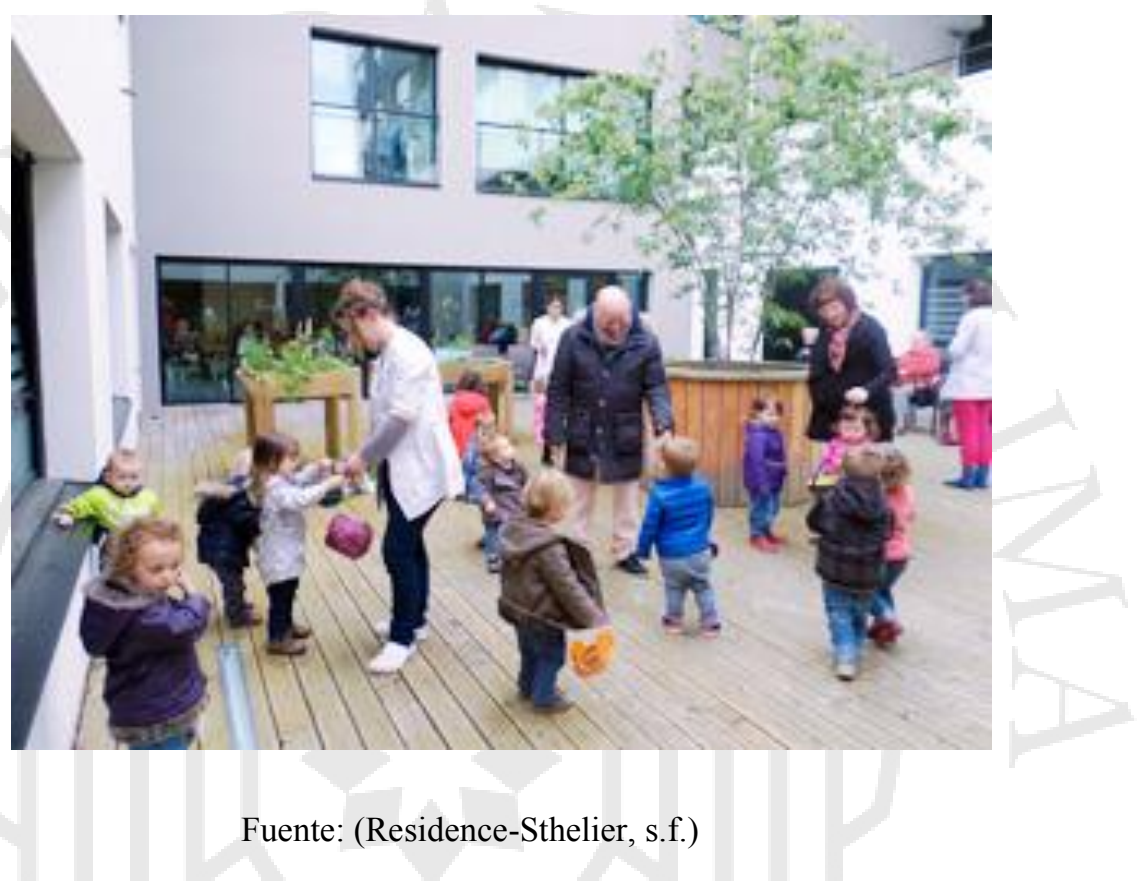

Figura 4.3.1.2: Imágenes del centro

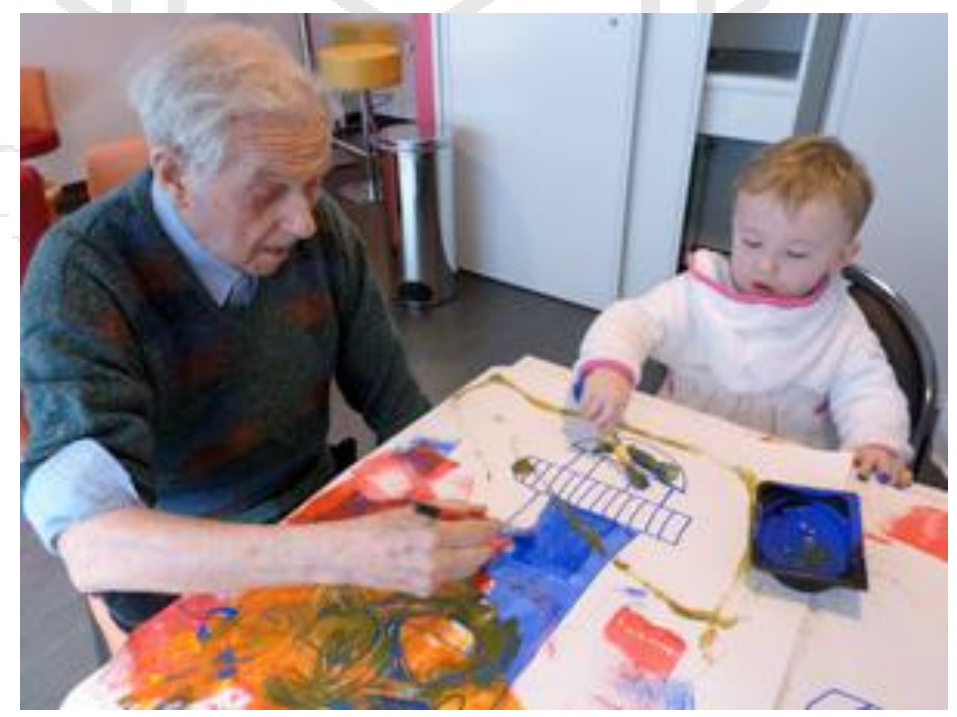

Fuente: (Residence-Sthelier, s.f.) 


\subsubsection{Relación con el entorno}

La ciudad de Rennes se encuentra en la parte noreste de Francia, a más de $300 \mathrm{kms}$ de la capital. Es una ciudad muy desarrollada por la cual pasan dos importantes ríos, lo cual la hace atractiva. La guardería y residencia para personas de la tercera edad está ubicada en la parte centro sur de la ciudad, exactamente en la calle "Avenue des Français Libres" a $1 \mathrm{~km}$ de la plaza central de esta ciudad

Figura 4.3.2.1 Ubicación Macro del proyecto en Rennes

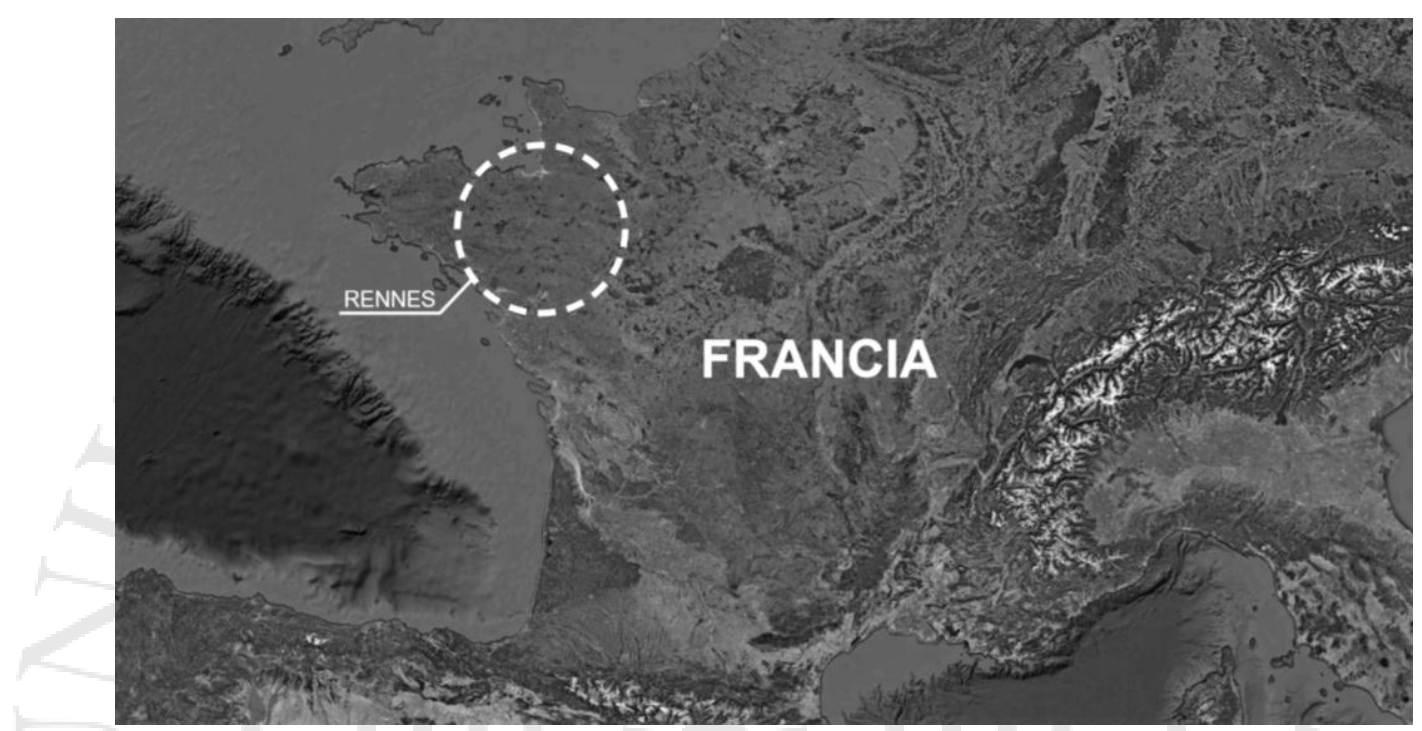

Fuente: Por autor.

Figura 4.3.2.2 Ubicación del proyecto en Rennes

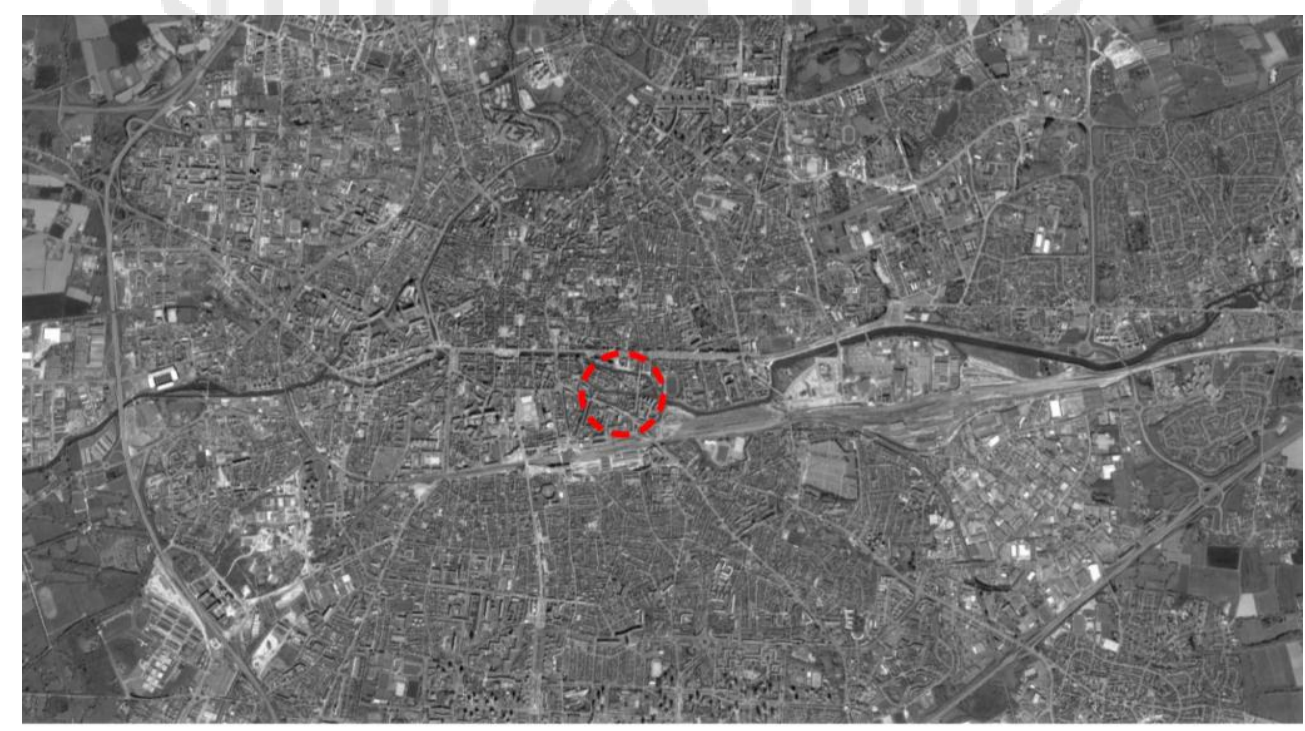

Ubicación del proyecto.

Fuente: Por autor 
Las vías principales cercanas al centro son la Av. Rue Saint-Hélier, la cual pasa por la clínica que lleva el mismo nombre, ésta se encuentra en la parte posterior del centro para ancianos y con el cual tiene una relación directa, ya que, funciona como nexo al centro de adulto mayor. Así mismo, las Avenidas “Jean Janvier” y "Boulevard René Laennec" conectan a través de puentes, sobre un río, a la parte norte de la ciudad con la zona en donde se encuentra el proyecto, lo cual evita que el río se vuelva una barrera en la ciudad y aporta a que se genere mayor conectividad.

El siguiente análisis muestra las diferentes vías que se encuentran en la zona, las cuales están categorizadas por su nivel de flujos e importancia.

Figura 4.3.2.1 Análisis de flujo vehicular de vías cercanas.

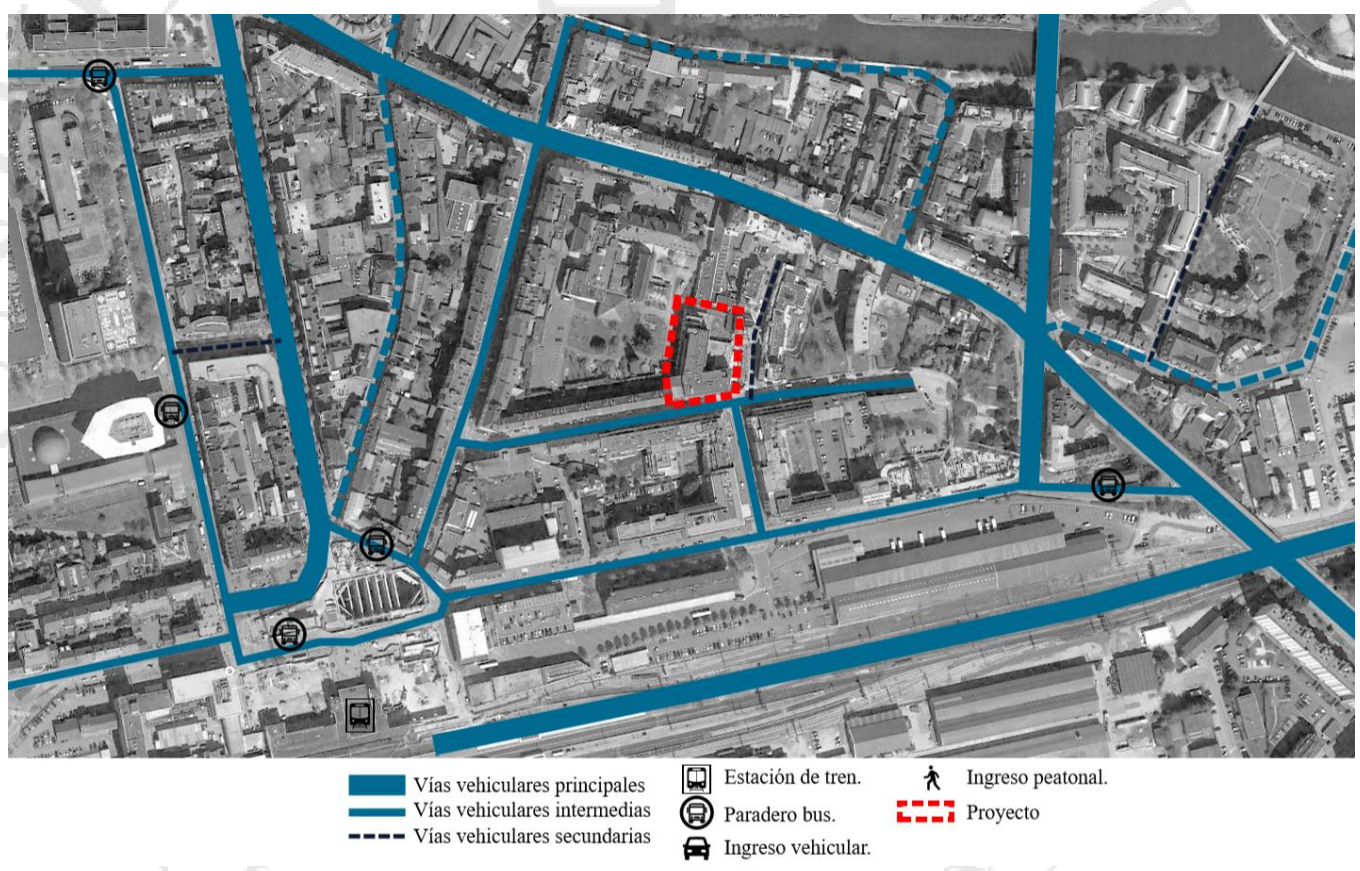

Fuente: Por autor.

Las calles a los alrededores del Centro para adultos mayores son de una sola vía y para vehículos particulares o taxis ya que es una zona de bajo flujo; lo cual, permite que el transito sea rápido y eficiente. Por otro lado, el paradero de transporte público más cercano se ubica en la avenida "Jean Javiere" que se encuentra a 3 calles del centro.

Sobre el tránsito peatonal en la zona, este es variado: en la mayoría de las calles aledañas hay mezcla de comercio donde predominan farmacias, hoteles, tiendas medianas y oficinas que se complementan con vivienda; lo cual, genera 
movimiento durante el día, y, por el contrario, durante la noche la zona es más calmada.

El siguiente gráfico muestra la importancia de las calles respecto a los flujos que se generan durante el día, siendo los de color más oscuro los lugares más transitados, y, por el contrario, los de color más claro son los lugares con menor actividad peatonal.

Figura 4.3.2.2 Análisis de flujo peatonal de vías cercanas.

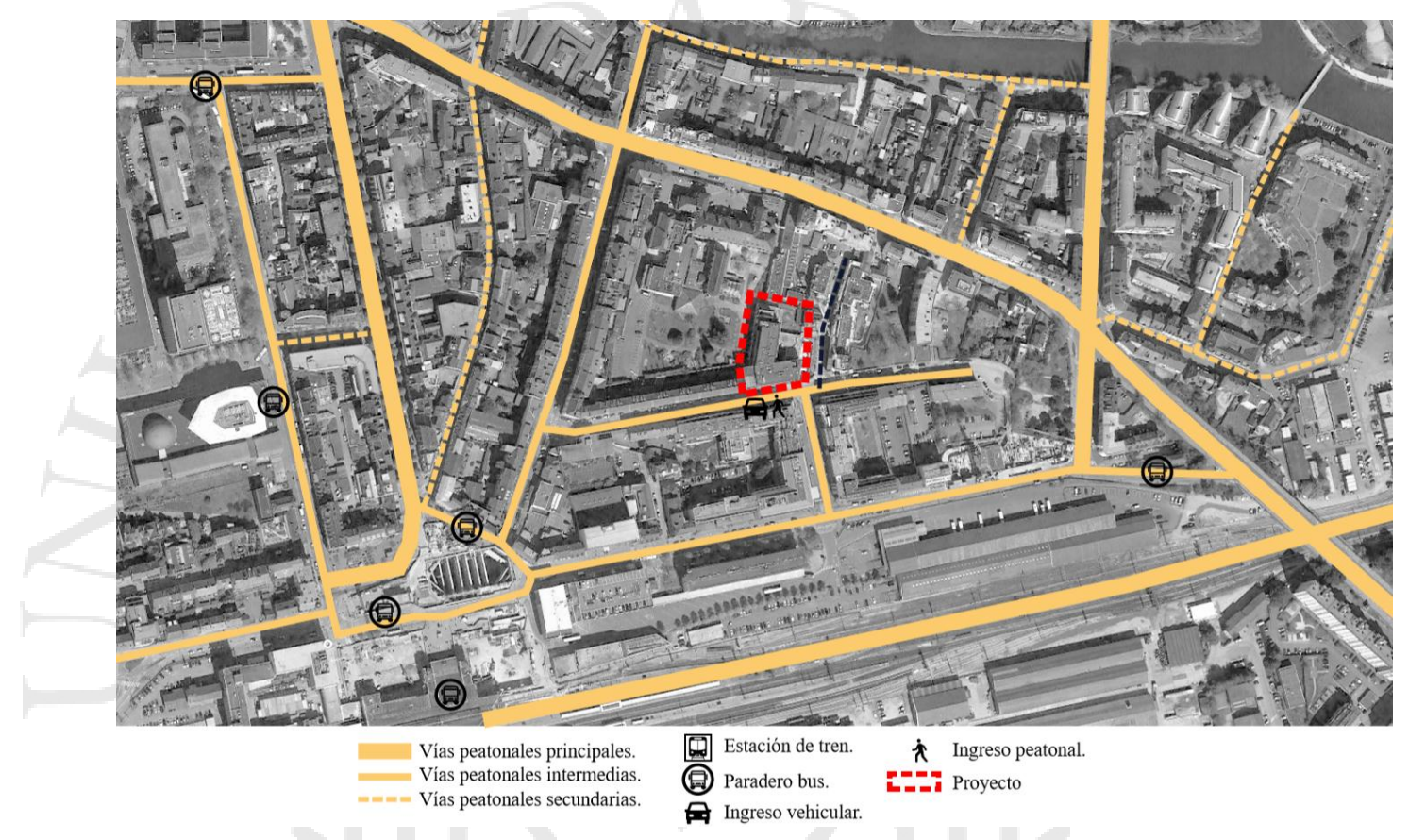

Fuente: Por autor. 
4.3.3. Programas y relaciones programáticas.

El siguiente análisis muestra las medidas y el aporte porcentual de cada ambiente con respecto al área en el que se ubica dentro del centro. Cada área general está separada por las características de los servicios que ofrece: área administrativa, servicios complementarios, residencia para adultos mayores y área de trabajadores.

Figura 4.3.3.1 Planta dividida por áreas.

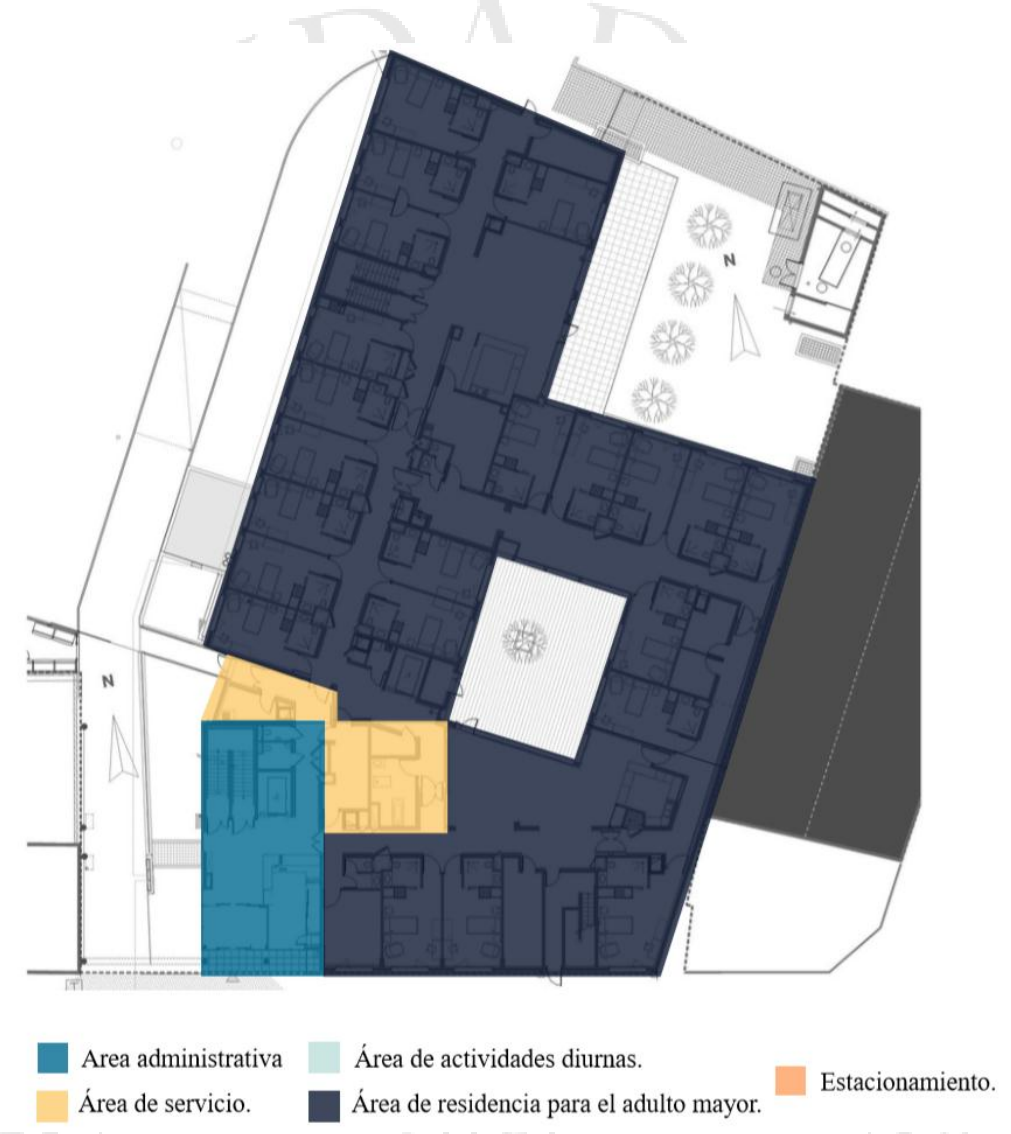

Fuente: A/lta architects. Análisis: Autor. 
Figura 4.3.3.2 Planta dividida por áreas.

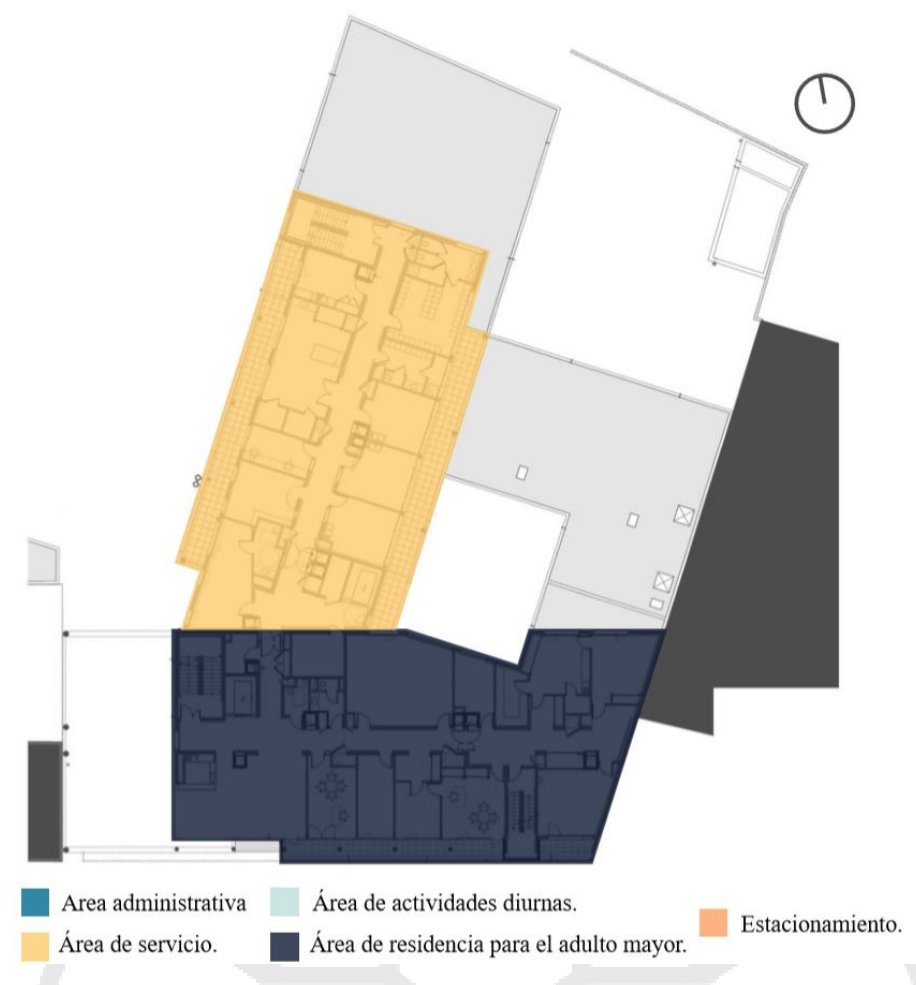

Fuente: A/lta architects. Análisis: Autor.

Figura 4.3.3.3 Planta dividida por áreas.

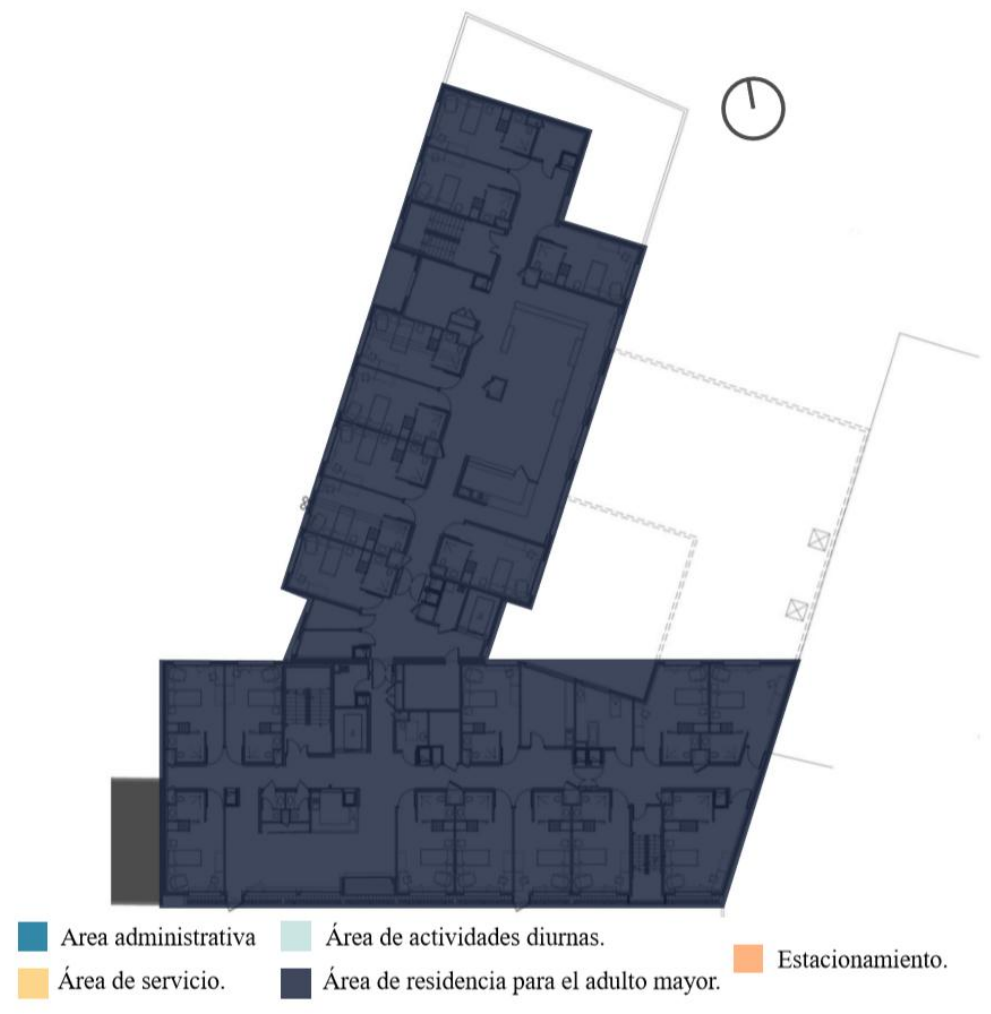

Fuente: A/lta architects. Análisis: Autor. 
Figura 4.3.3.4 Planta dividida por áreas.

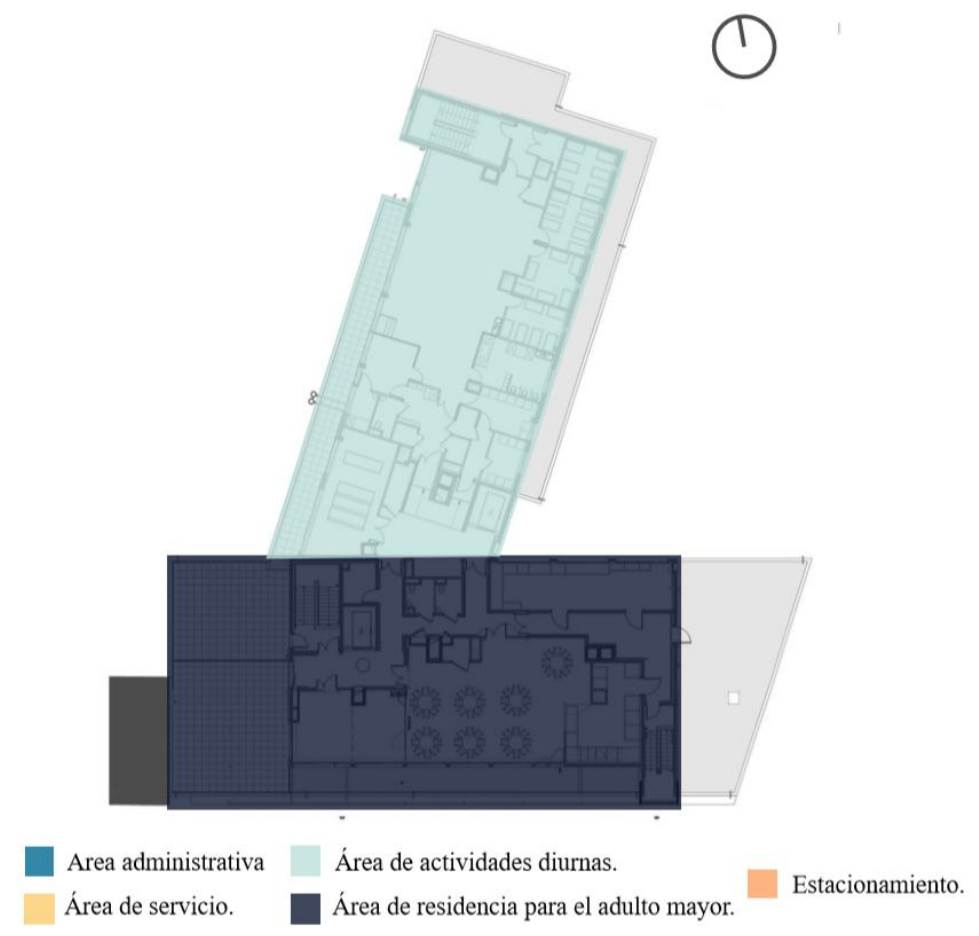

Fuente: A/lta architects. Análisis: Autor.

Figura 4.3.3.5 Planta dividida por áreas.

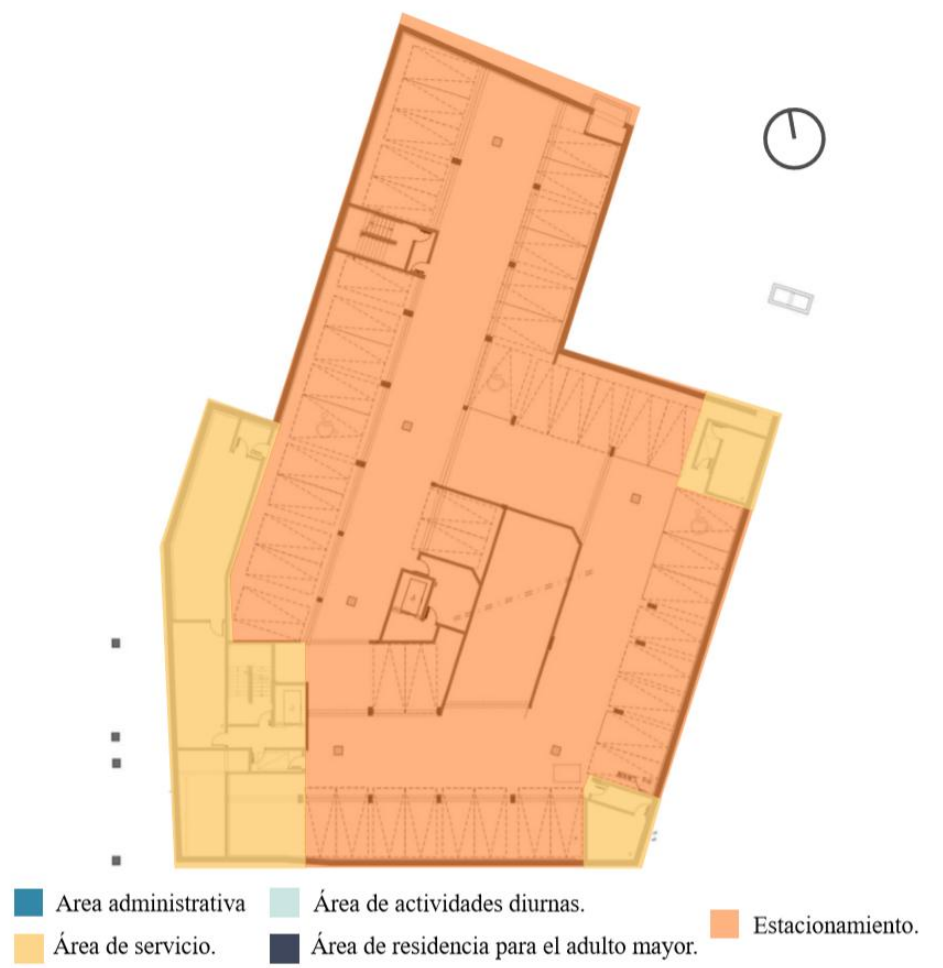

Fuente: A/lta architects. Análisis: Autor. 
Tabla 4.3.3.1: Porcentaje de área administrativa de la Residencia Los Molinos

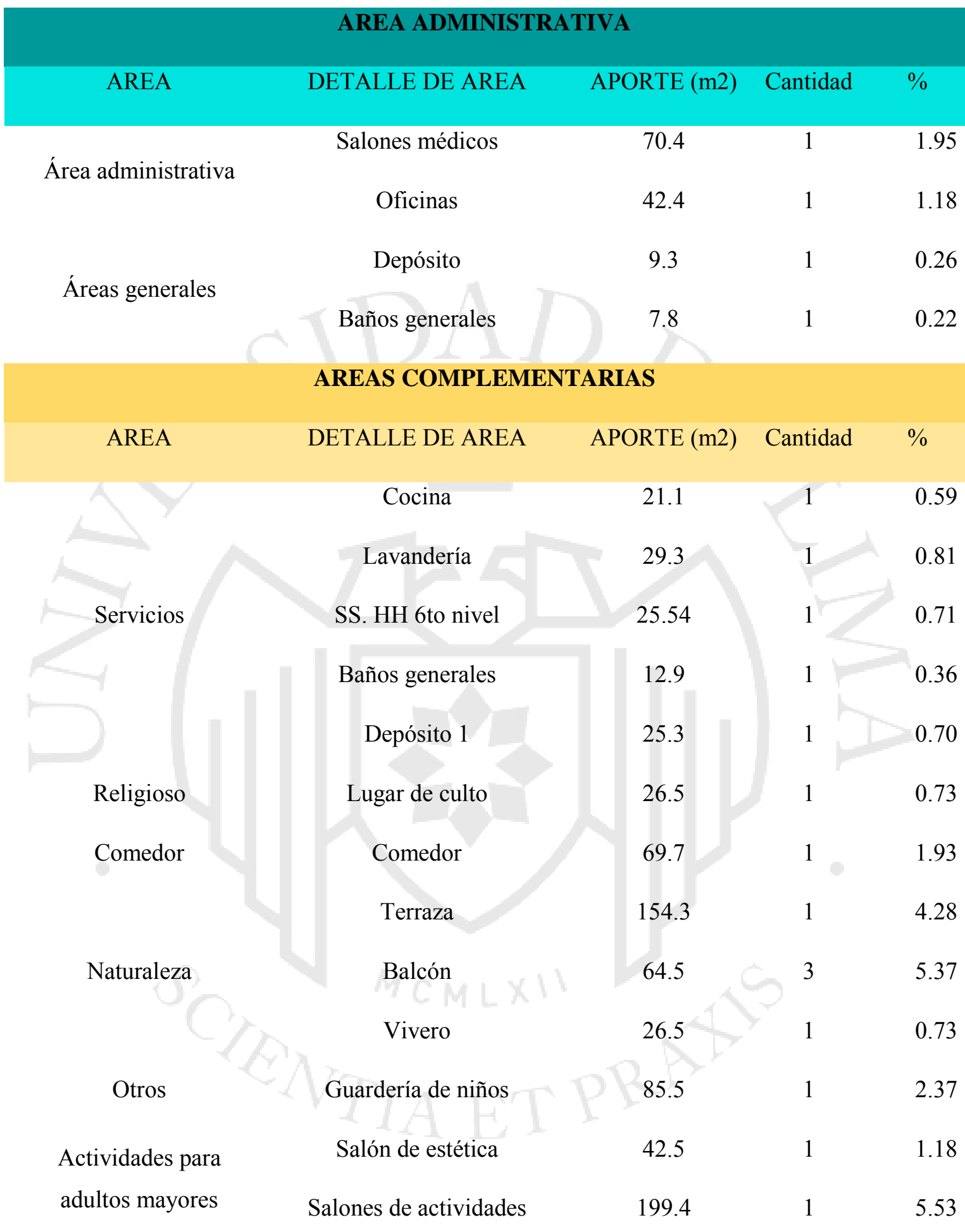




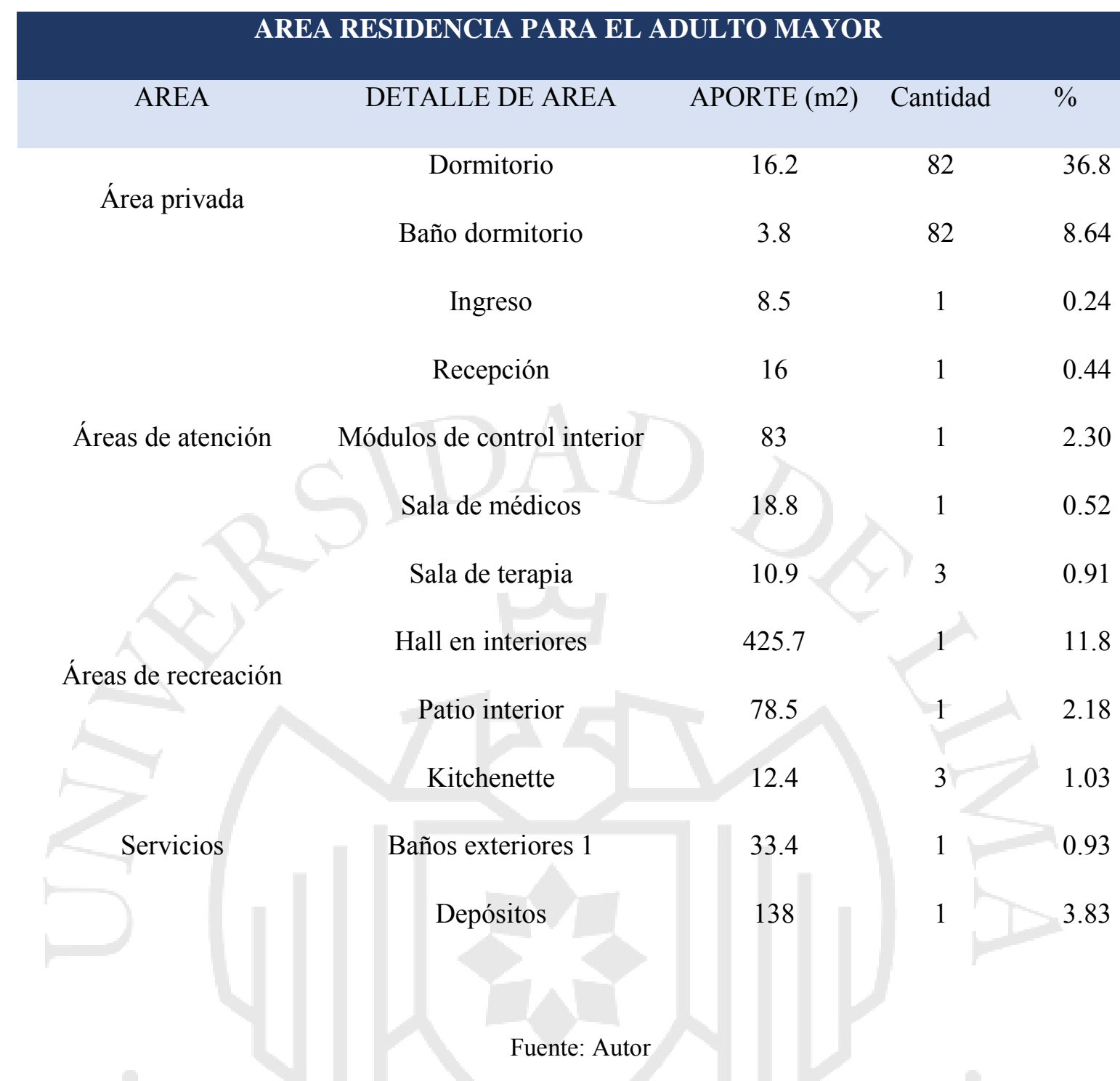

El mayor porcentaje de área construida es para los dormitorios de los adultos mayores, ya que es necesario que las habitaciones cuenten con dimensiones mayores a las de un dormitorio estándar debido a que se debe facilitar el desplazamiento de los 82 ancianos que acoge este establecimiento. Además, al igual que en los ejemplos anteriores, cada habitación cuenta con un baño propio que, así como los dormitorios, necesita de grandes dimensiones para asegurar el desplazamiento de los ancianos al usar los servicios.

Los lugares de encuentro al interior de cada piso también ocupan gran porcentaje del área construida del edificio, estos ambientes son importantes para un centro con este tipo de uso debido a que genera espacios para que los propios usurarios se relacionen. En el hall interior de cada piso hay mobiliario para descanso, tv, juegos de mesa. y cada uno con un módulo de control para las enfermeras desde el cual se puede tener en constante cuidado a los adultos mayores 
4.3.4. Estrategias de emplazamiento.

El proyecto guarda relación con el entorno, desde el exterior se puede observar que la fachada es moderna a comparación de las edificaciones adyacentes, sin embargo, al mantenerla de color plomo no genera que rompa con al entorno y desde el exterior se lee un orden en toda la manzana. Así mismo, la altura de 6 niveles en el edificio guarda relación con las edificaciones de la zona.

El terreno tiene forma regular y el proyecto tiene forma de "L" con pequeños quiebres que genera en la parte izquierda un gran patio que ayuda a iluminar y ventilar todos los ambientes al interior del edificio; por el lado derecho del proyecto hay un pequeño retiro como respuesta a un ingreso de doble altura que se genera al ingresar al recinto y que lo conecta con el hospital ubicado en la parte posterior. Este retiro es otra fuente de iluminación y ventilación importante que permite que uno de los brazos del edificio se ilumine por la mayoría de sus lados. Las 3 circulaciones están ubicadas en los extremos de cada brazo y en el punto de conexión entre ambos, esto es importante debido a que se tiene una cantidad óptima de puntos de evacuación en caso de emergencia, lo cual ayudaría a que sea de forma más inmediata, ya que, por sus características físicas, los usuarios del centro no pueden realizar movimiento con rapidez.

\subsubsection{Flujos y circulaciones.}

Los siguientes gráficos analizan los diferentes tipos de flujos que hay al interior de las zonas de la Residencia Saint Helier. Estos varían según las actividades realizadas en piso y ambiente. Se observa que se prioriza la seguridad de los adultos mayores más vulnerables debido a que las habitaciones de estos se ubican en el primer nivel. Así mismo, las actividades y servicios que brinda el centro se agrupan por pisos y zonas para evitar que los flujos generen nodos que sean obstáculos para los usuarios. 
Figura 4.3.5.1 Circulaciones generales nivel 1.

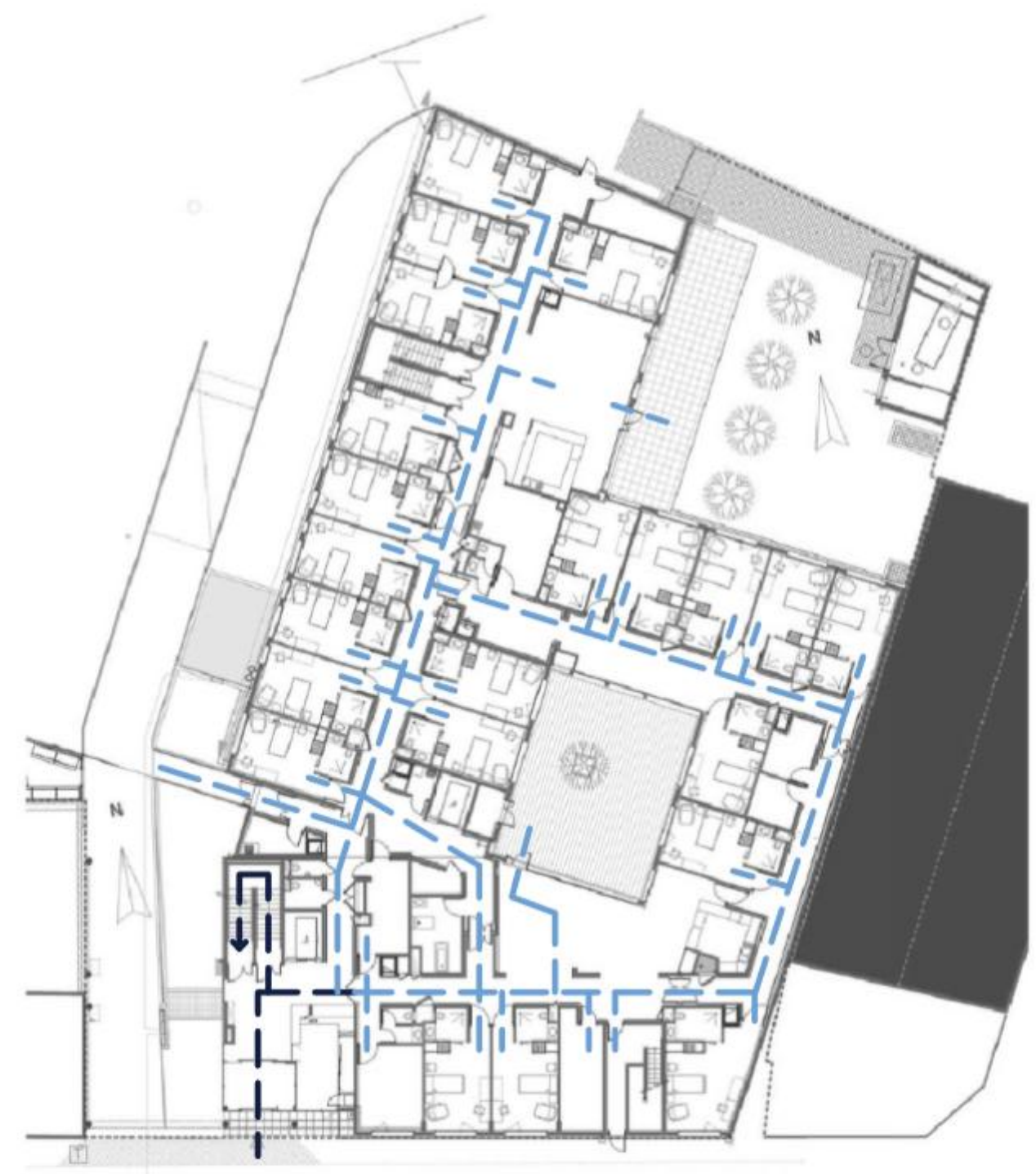

- - Flujo peatonal intenso.

- - Flujo peatonal medio.

- - - Flujo peatonal bajo.

Fuente: Elaborado por autor 
Figura 4.3.5.2 Circulaciones generales nivel 2.

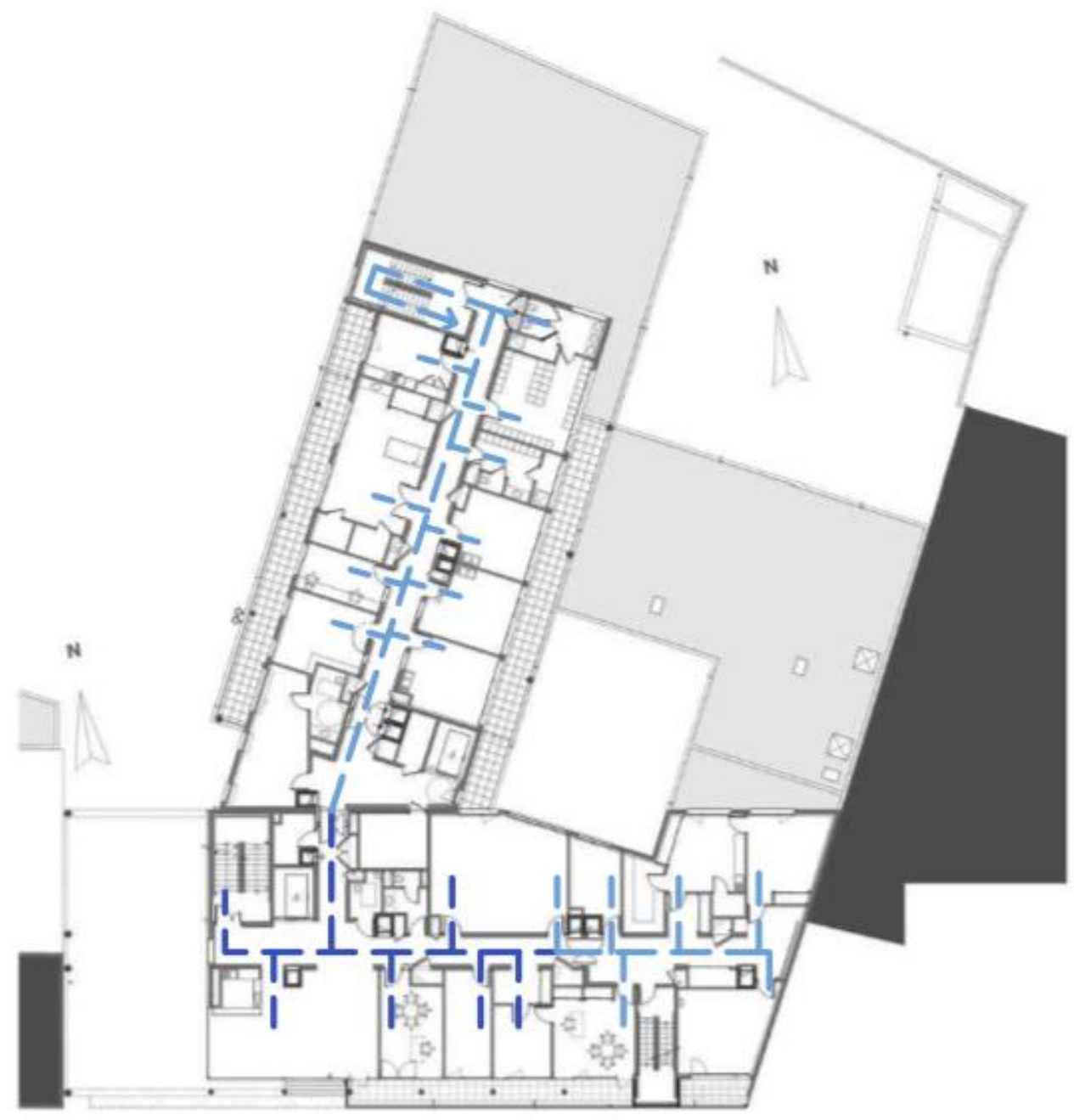

- - Flujo peatonal intenso.

- - Flujo peatonal medio.

- - - Flujo peatonal bajo.

Fuente: Elaborador por autor 
Figura 4.3.5.3 Circulaciones generales nivel 3,4,5.

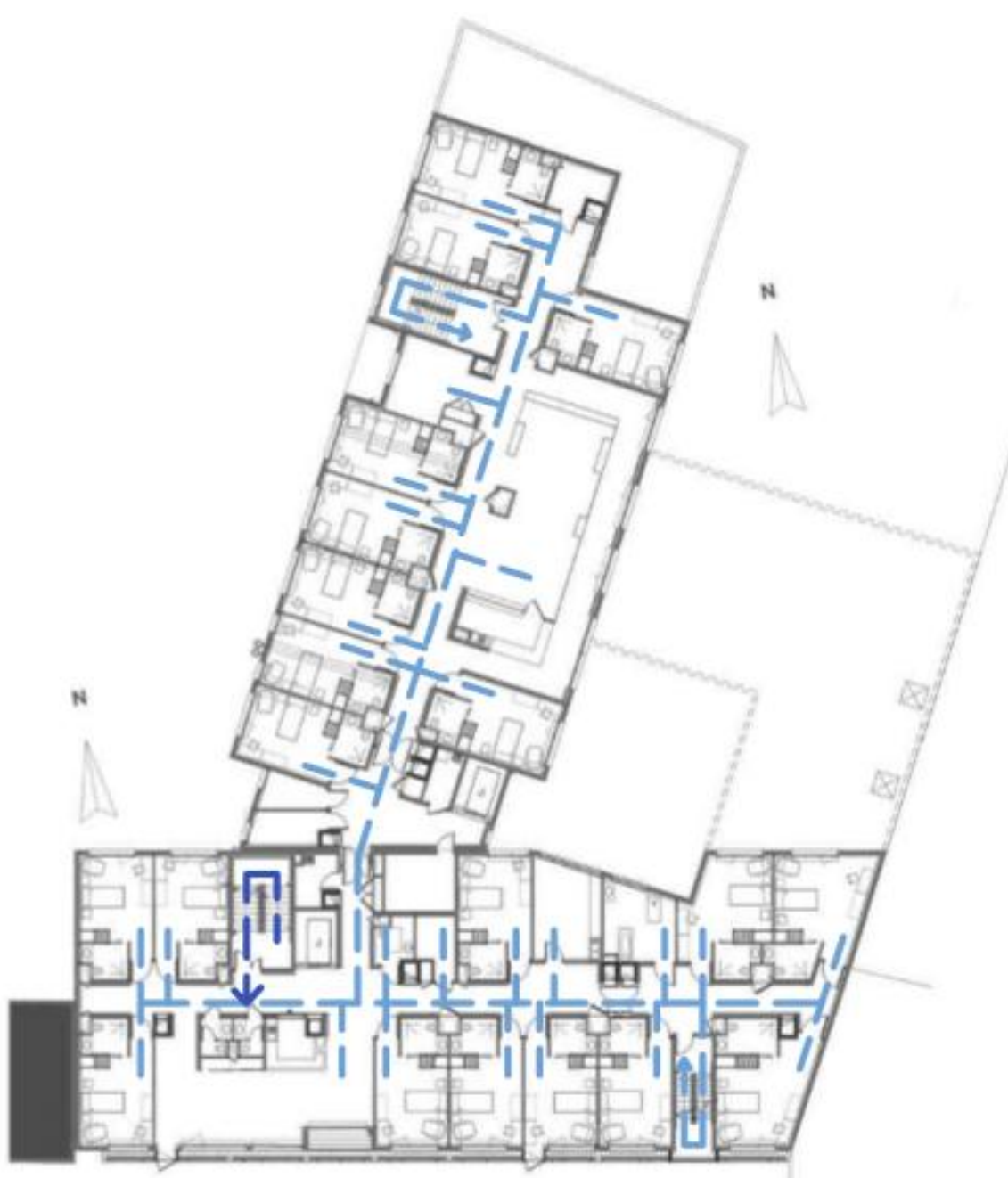

- - Flujo peatonal intenso.

- - Flujo peatonal medio.

- - Flujo peatonal bajo.

Fuente: Elaborador por autor 
Figura 4.3.5.4 Circulaciones generales nivel 6.

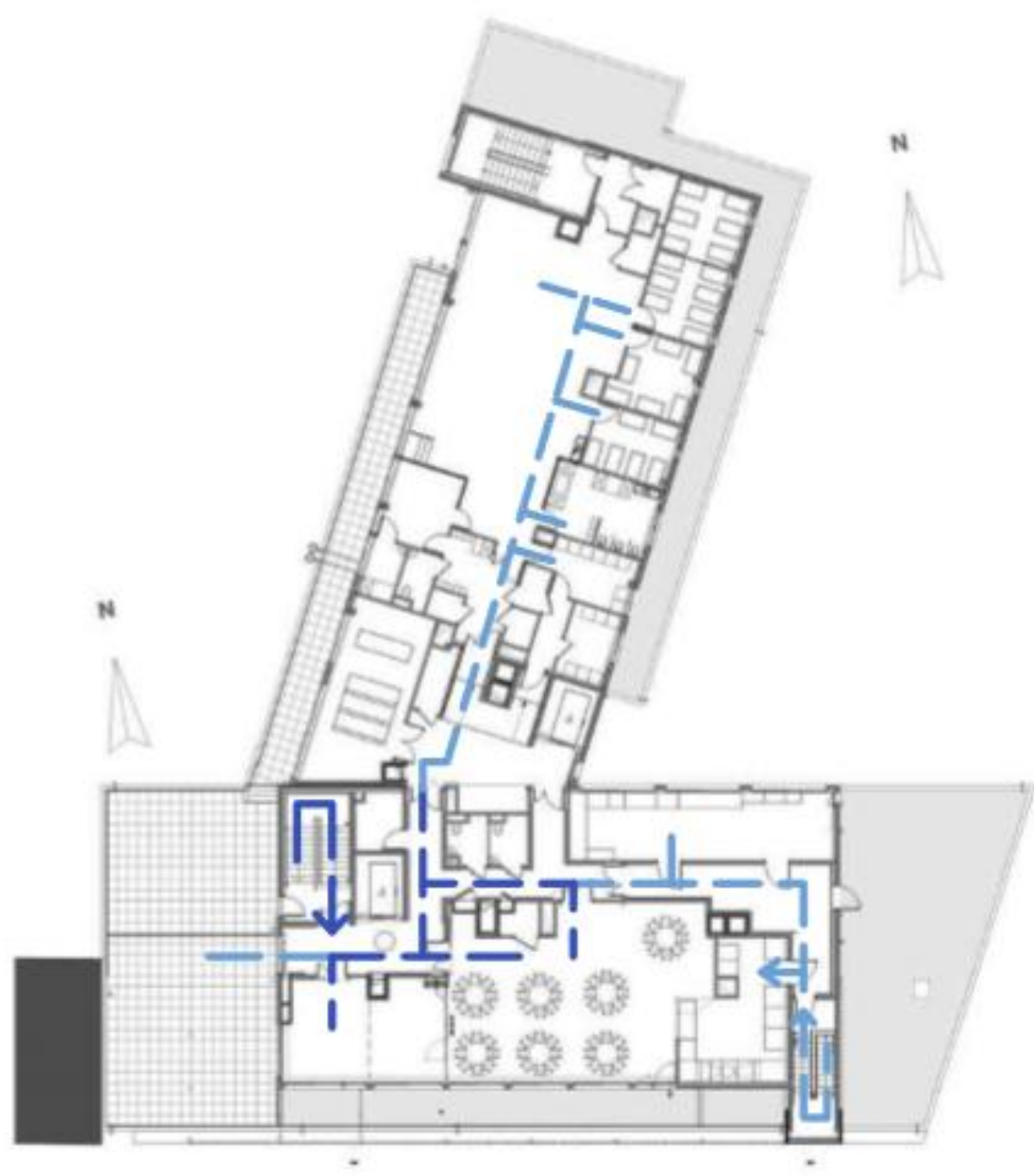

- - Flujo peatonal intenso.

- - Flujo peatonal medio.

- - Flujo peatonal bajo.

Fuente: Elaborador por autor 


\subsubsection{Relaciones espaciales}

Figura 4.3.6.1 Análisis relaciones espacialidades nivel -1.

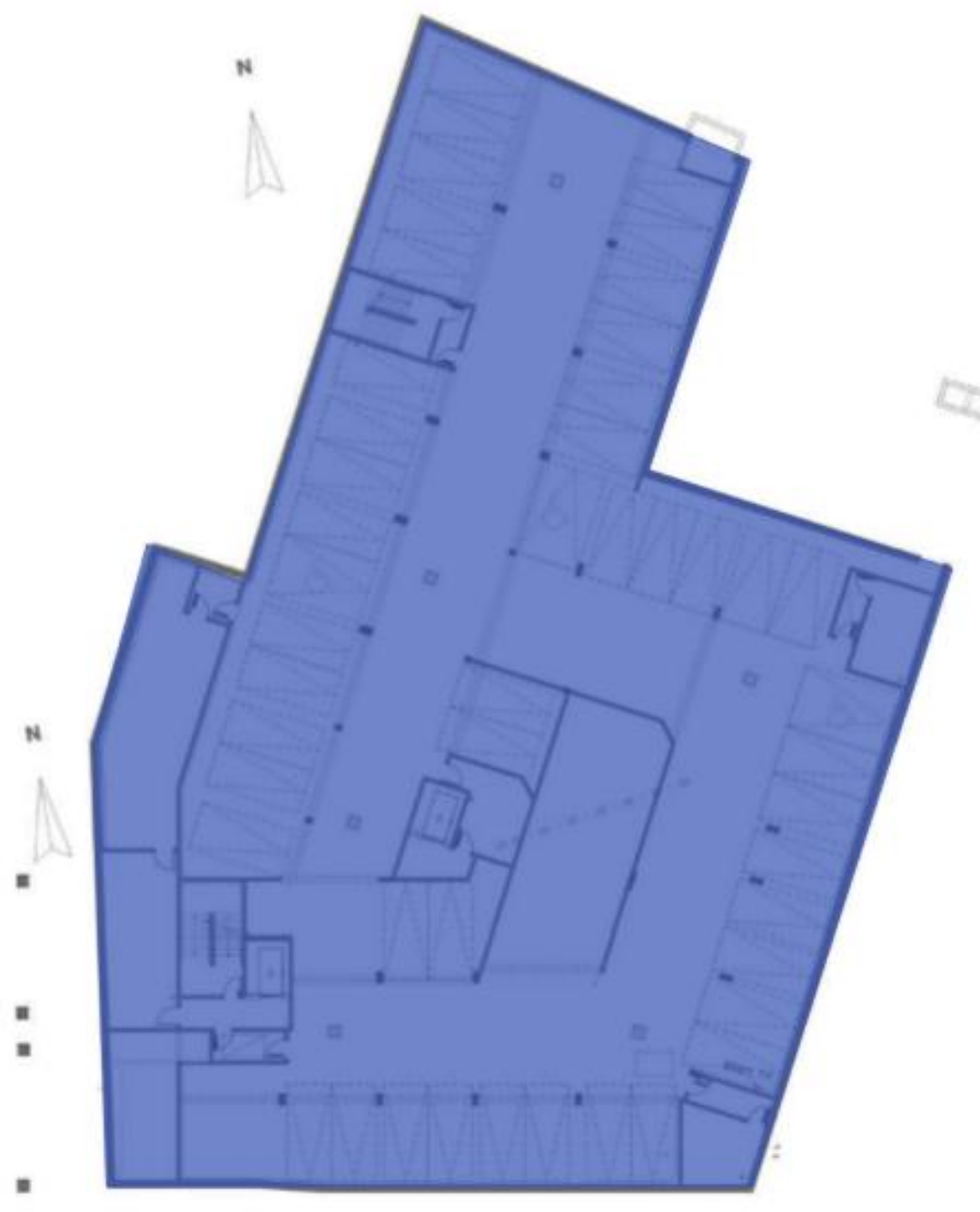

Área pública

Área semi privada

Área privada

Fuente: Elaborador por autor 
Figura 4.3.6.2 Análisis relaciones espacialidades nivel 1.

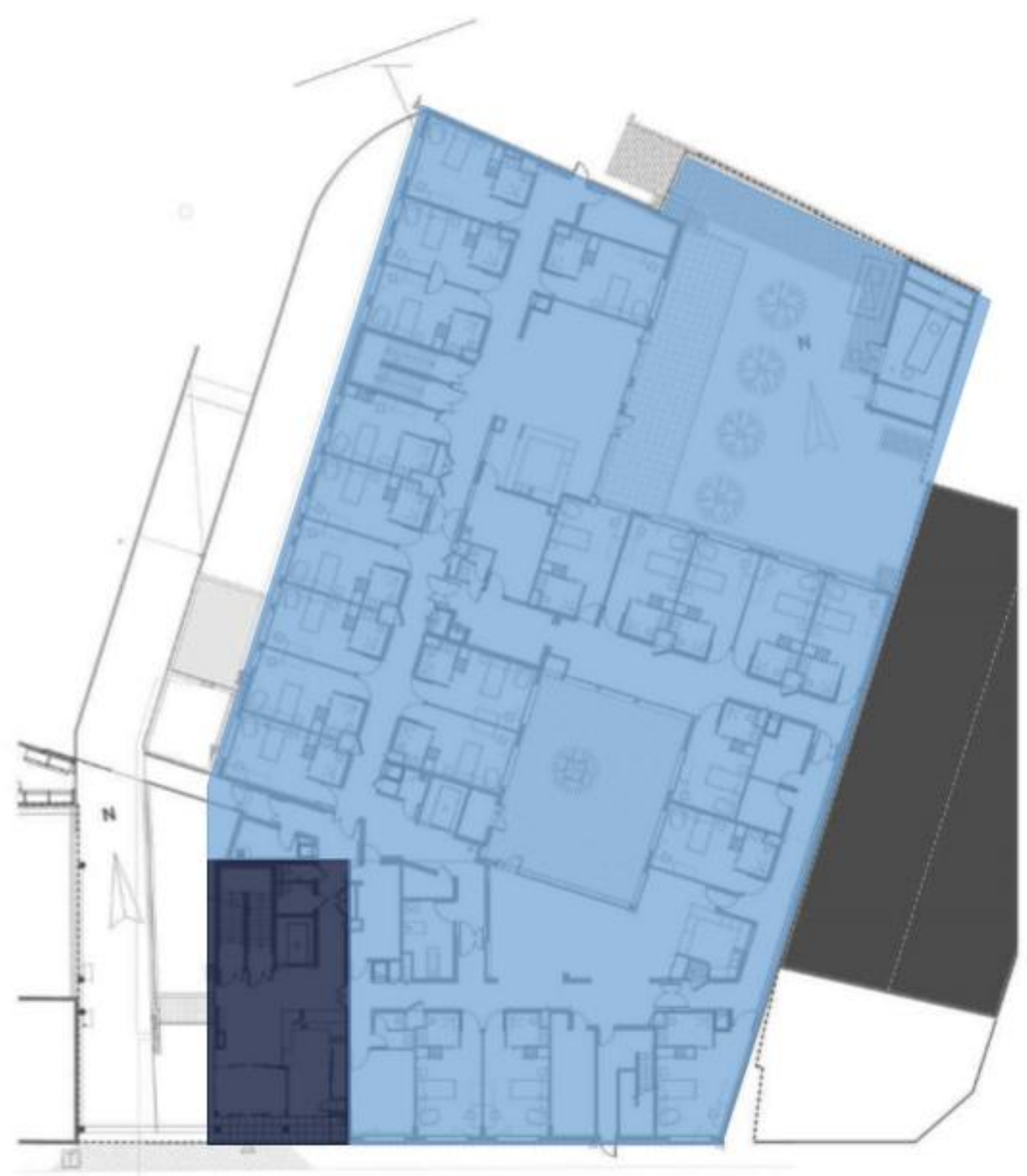

Área pública

Área semi privada

Área privada

Fuente: Elaborado por autor. 
Figura 4.3.6.3 Análisis relaciones espacialidades niveles 3,4,5.

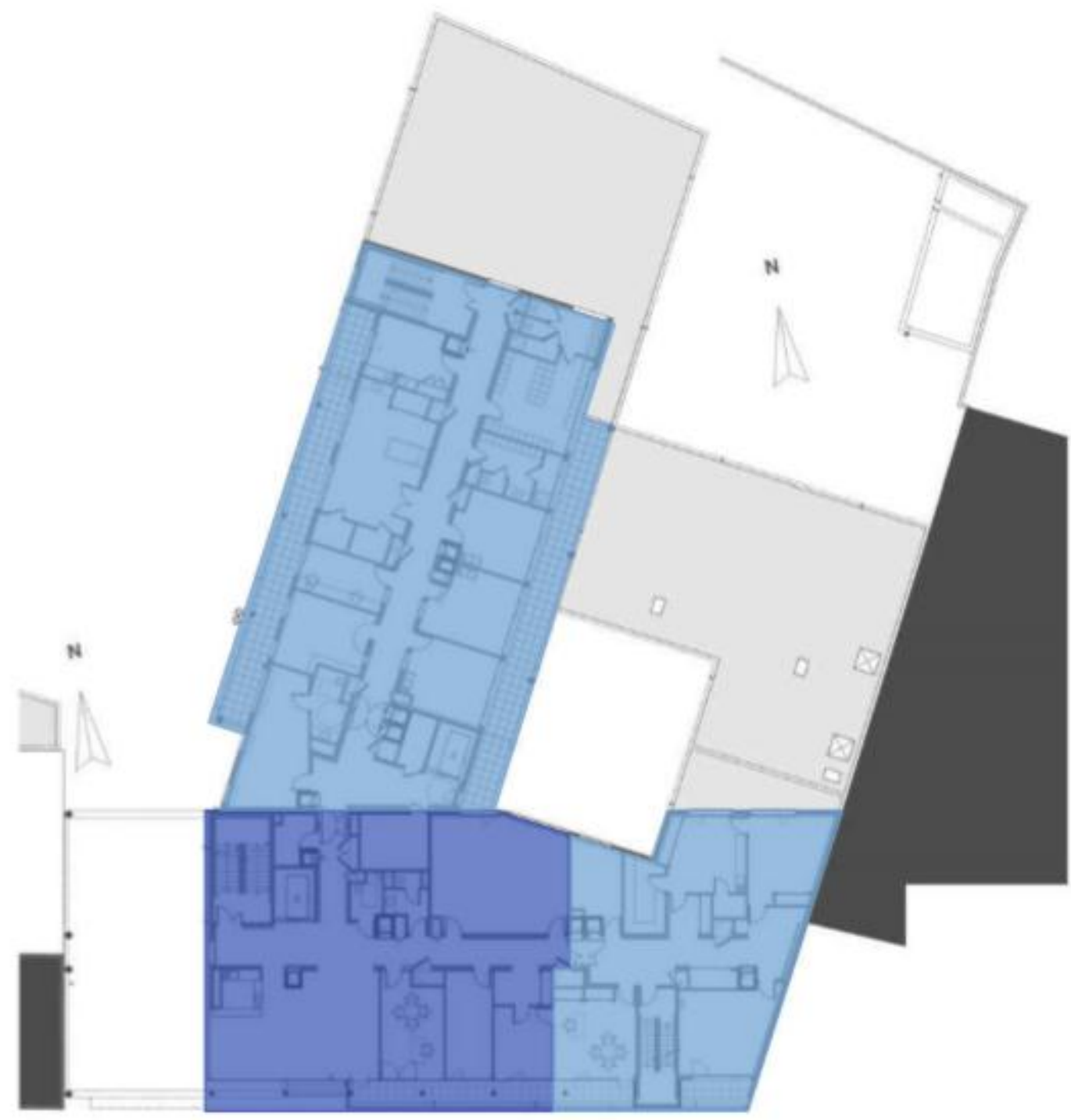

Área pública

Área semi privada

Área privada

Fuente: Elaborado por autor 
Figura 4.3.6.4 Análisis relaciones espacialidades nivel 6.

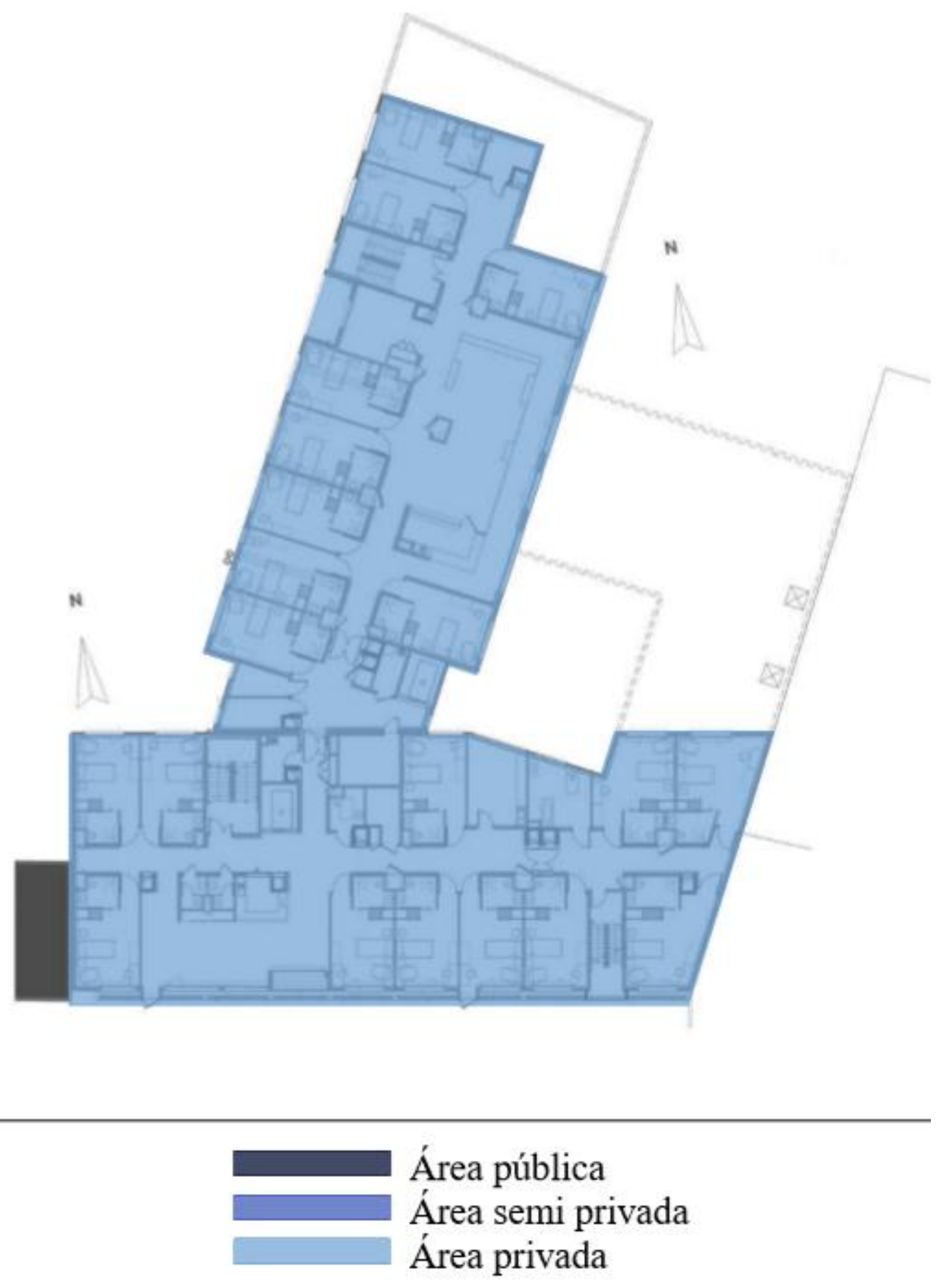

Fuente: Elaborador por autor 
4.3.7. El dormitorio.

Figura 4.3.7.1. Habitación

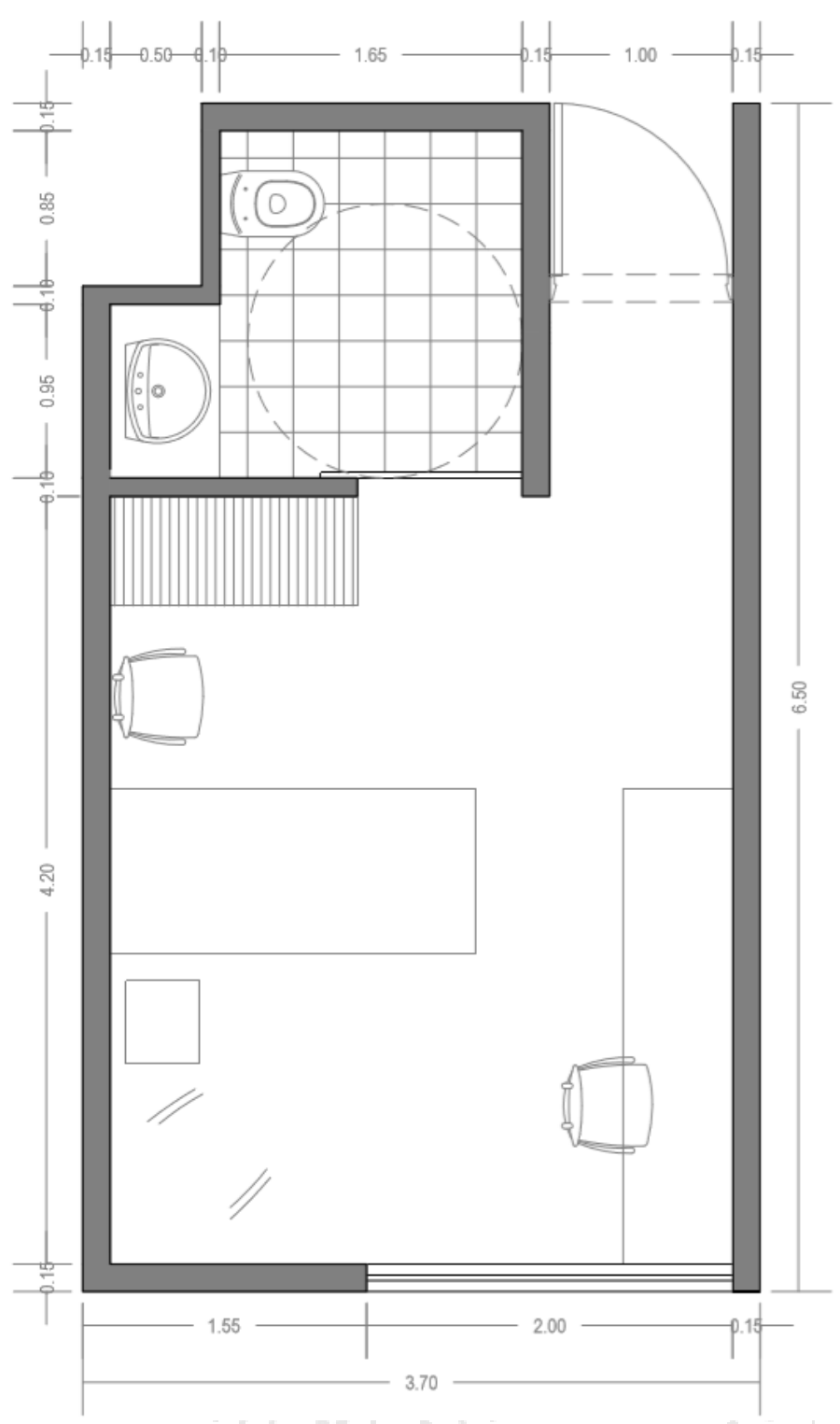

Fuente: Elaborado por autor 


\subsubsection{Tecnología.}

Es importante resaltar la forma de emplazamiento del proyecto en el terreno, debido a que genera amplias fuentes de ingreso de iluminación y ventilación; lo que permite que el edificio funcione durante la mayor parte del día con luz natural. De esta forma se reduce el consumo de energía eléctrica en luz y aire acondicionado. Un punto importante son los detalles interiores como los que se presentará a continuación:

- Sobre el sistema constructivo se puede observar placas de concreto revestidas en los exteriores con materiales claros.

- Cubierta de techo en espacios libres con bloques de concreto prefabricado que se apoyan en columnas de acero.

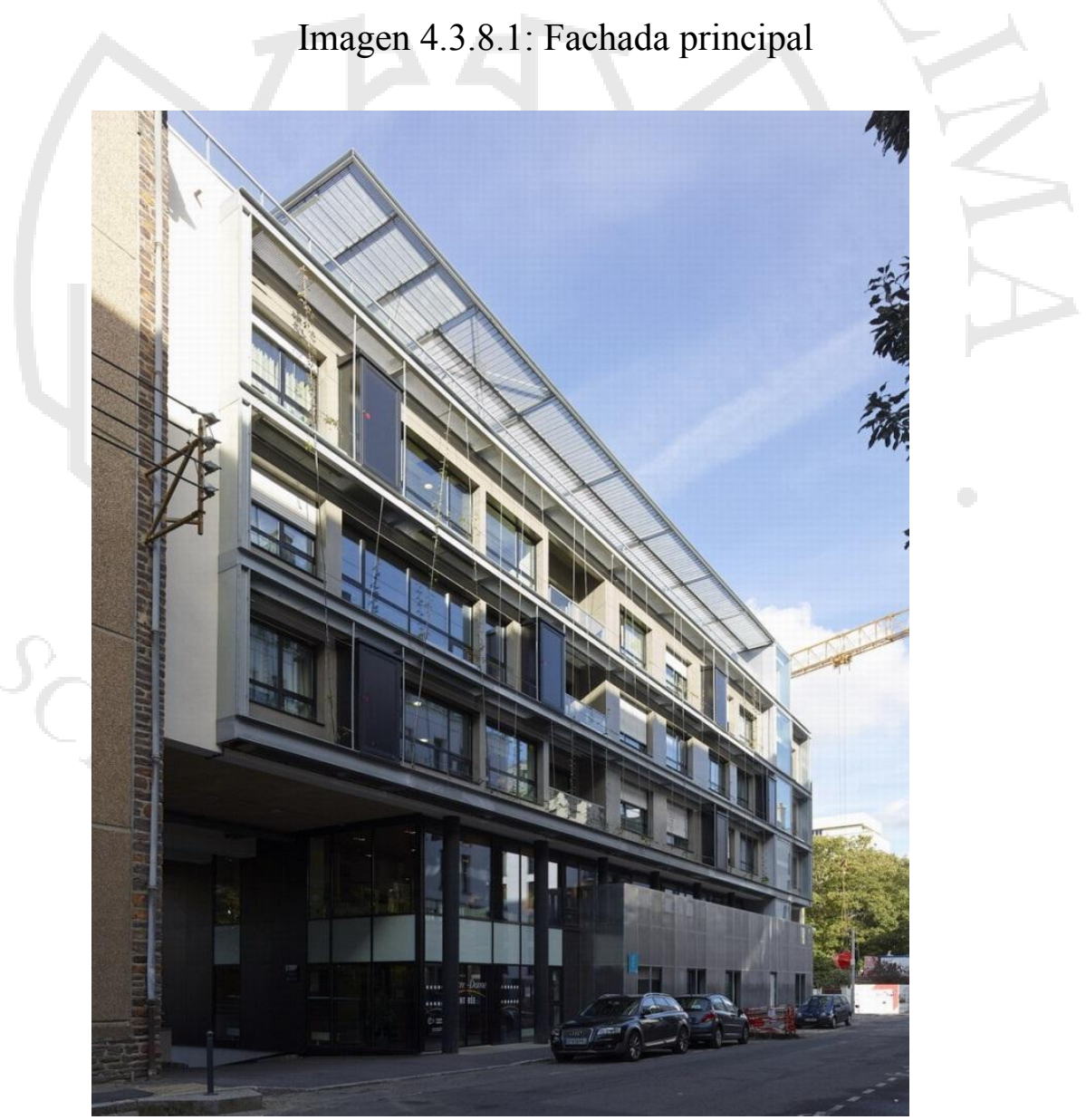

Fuente: (Residence-Sthelier, s.f.) 
Imagen 4.3.8.2: Fachada lateral

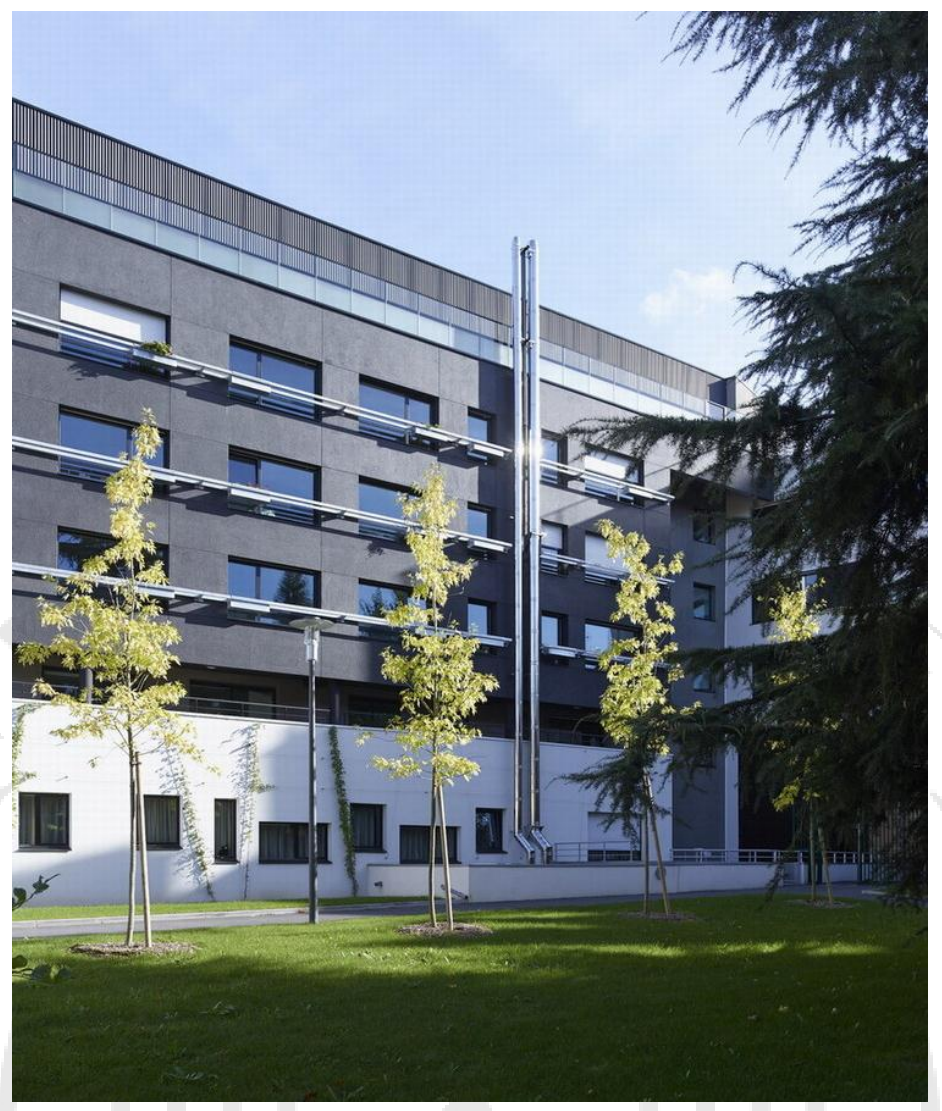

Fuente: (Residence-Sthelier, s.f.)

Imagen 4.3.8.3: Interior

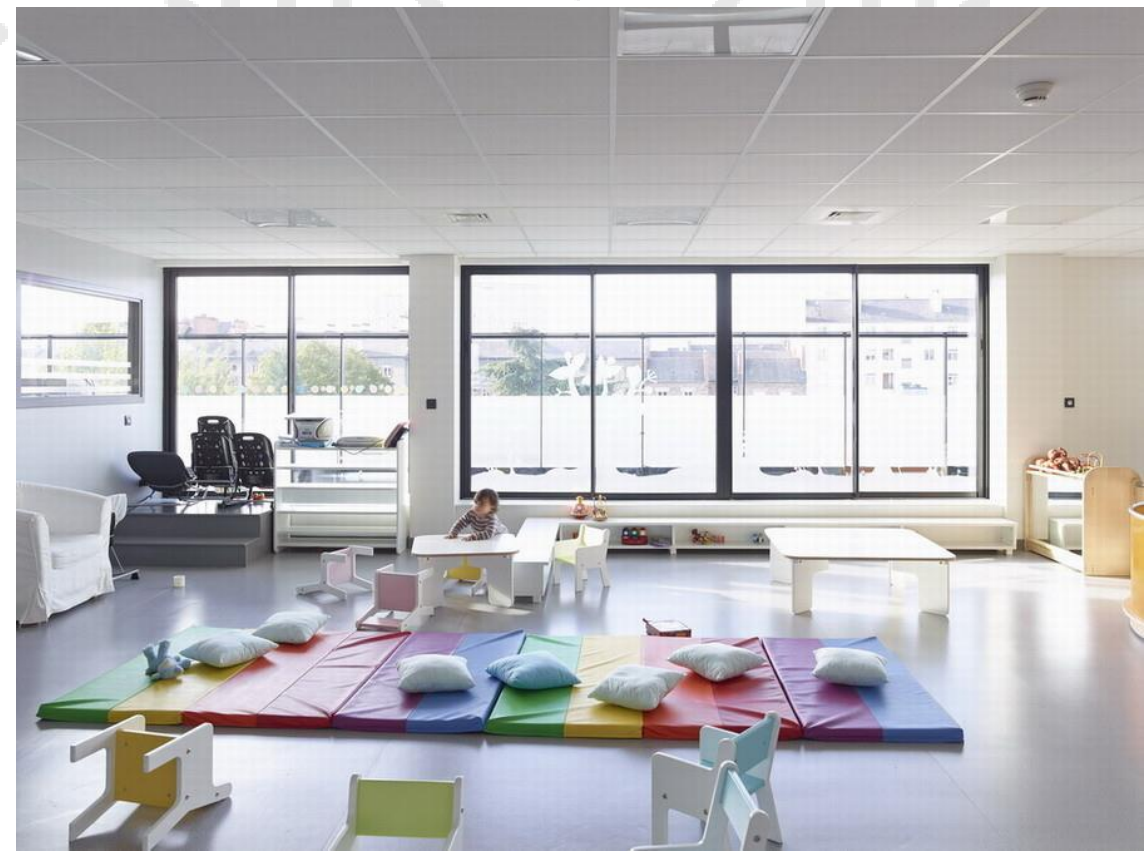

Fuente: (Residence-Sthelier, s.f.) 
Figura 4.3.8.4 Imagen interior.
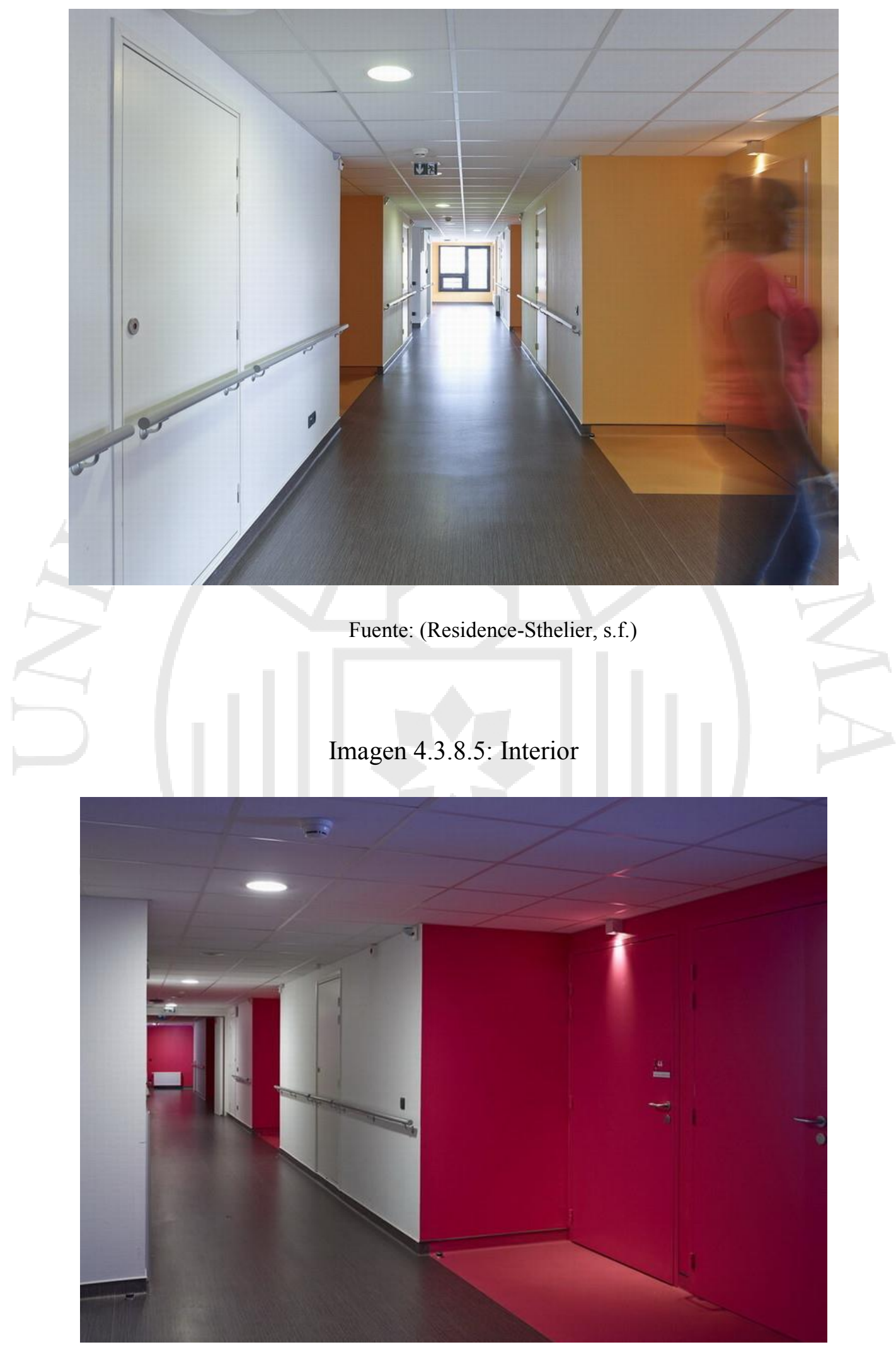

Fuente: (Residence-Sthelier, s.f.) 


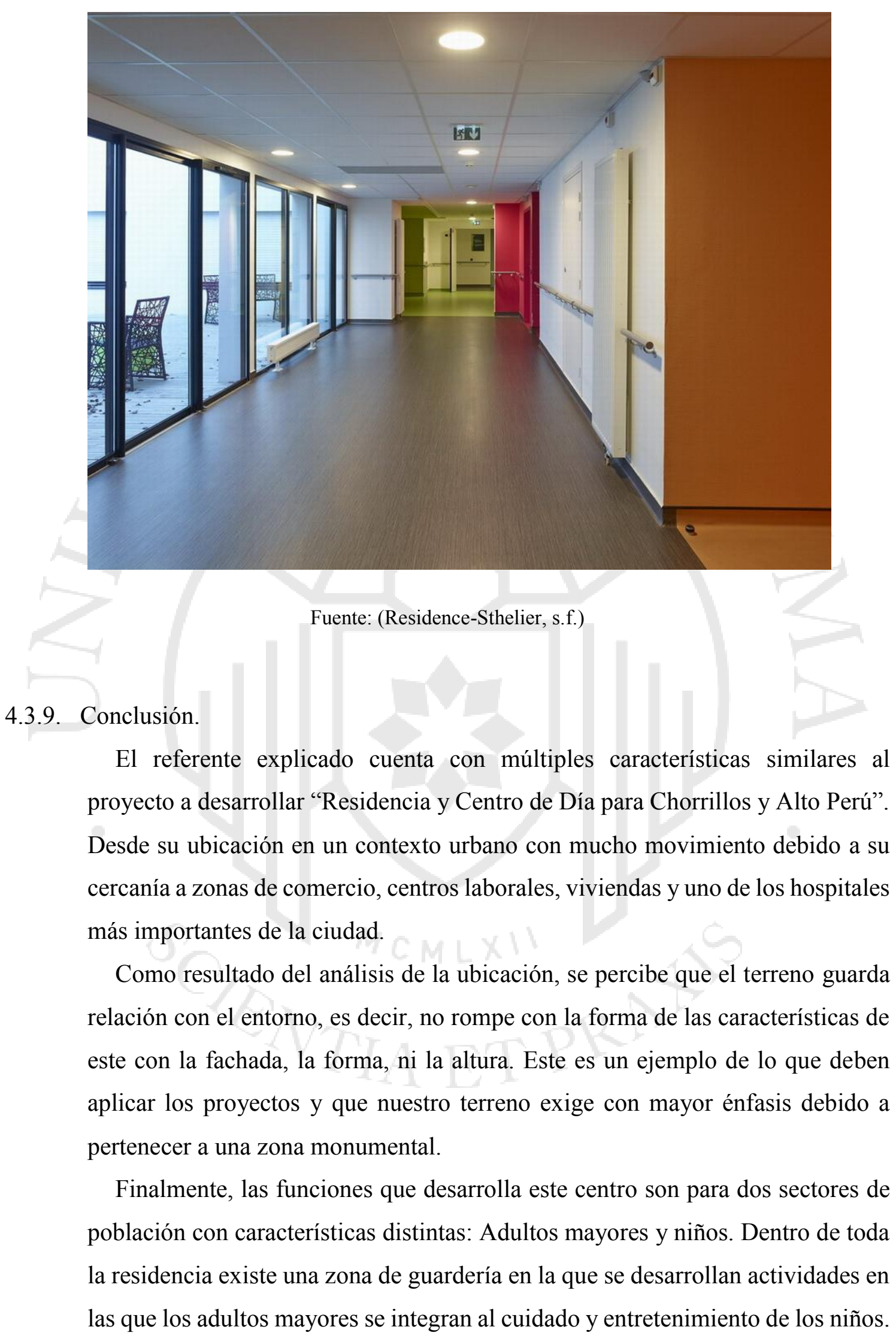


4.4.Hogar Para Personas Mayores Dulce Estancia.

A diferencia de los proyectos anteriores, el hogar "Dulce Estancia" solo funciona como residencia para personas de la tercera edad, por lo cual los adultos mayores tienen menor probabilidad de interactuar con gente nueva. Así mismo, debido a su antigüedad, el centro es ejemplo de las características que no se deberían emplear para este tipo de proyectos.

El siguiente referente

4.4.1. Historia del edificio.

\begin{tabular}{|l|l|}
\hline Nombre & Dulce Estancia Hogar para Personas Mayores \\
\hline Arquitectos & Julio de la Peña \\
\hline Ciudad & Guadalajara \\
\hline País & México \\
\hline Área & $3 ’ 314 \mathrm{~m} 2$ \\
\hline Año Proyecto & 1985 \\
\hline
\end{tabular}

El Hogar para Personas Mayores Dulce Estancia se encuentra en la ciudad de Guadalajara, México. Fue construido en 1992 por el Arquitecto Julio Peña. Este centro cuenta con un terreno de $3314 \mathrm{~m} 2$ de los cuales más del $50 \%$ es área techada, por lo cual, se considera un proyecto macizo.

El centro para personas mayores, de 26 años de antigüedad, es uno de los más emblemáticos en su ciudad. Del exterior se observa un proyecto que no es amigable con el entorno debido a que la fachada es completamente ciega y no genera relación entre el exterior y el interior del proyecto, por lo cual, aparenta ser un lugar poco atractivo y confortable. Sin embargo, en una vista aérea se observa que las áreas libres están ubicadas estratégicamente para poder generar luz, ventilación y visuales en la mayoría de los ambientes que se desarrollan al interior del volumen. 
El asilo cuenta con cuarenta dormitorios exclusivamente para los adultos mayores residentes, estos no son compartidos. Sin embargo, el área de aseo personal de los ancianos está ubicado en los extremos de las alas laterales, por lo cual, se genera distintos turnos de aseo para los usuarios. Además, este centro cuenta con áreas de recreación e integración como talleres, comedor, patios interiores y exteriores, salón de usos múltiples, etc. Esto se complementa con un área administrativa, residencia para religiosas y una pequeña capilla que está abierta al público en los horarios de misa establecidos.

\section{Figura 4.4.1.1:}

Fachada Hogar para personas mayores Dulce Estancia

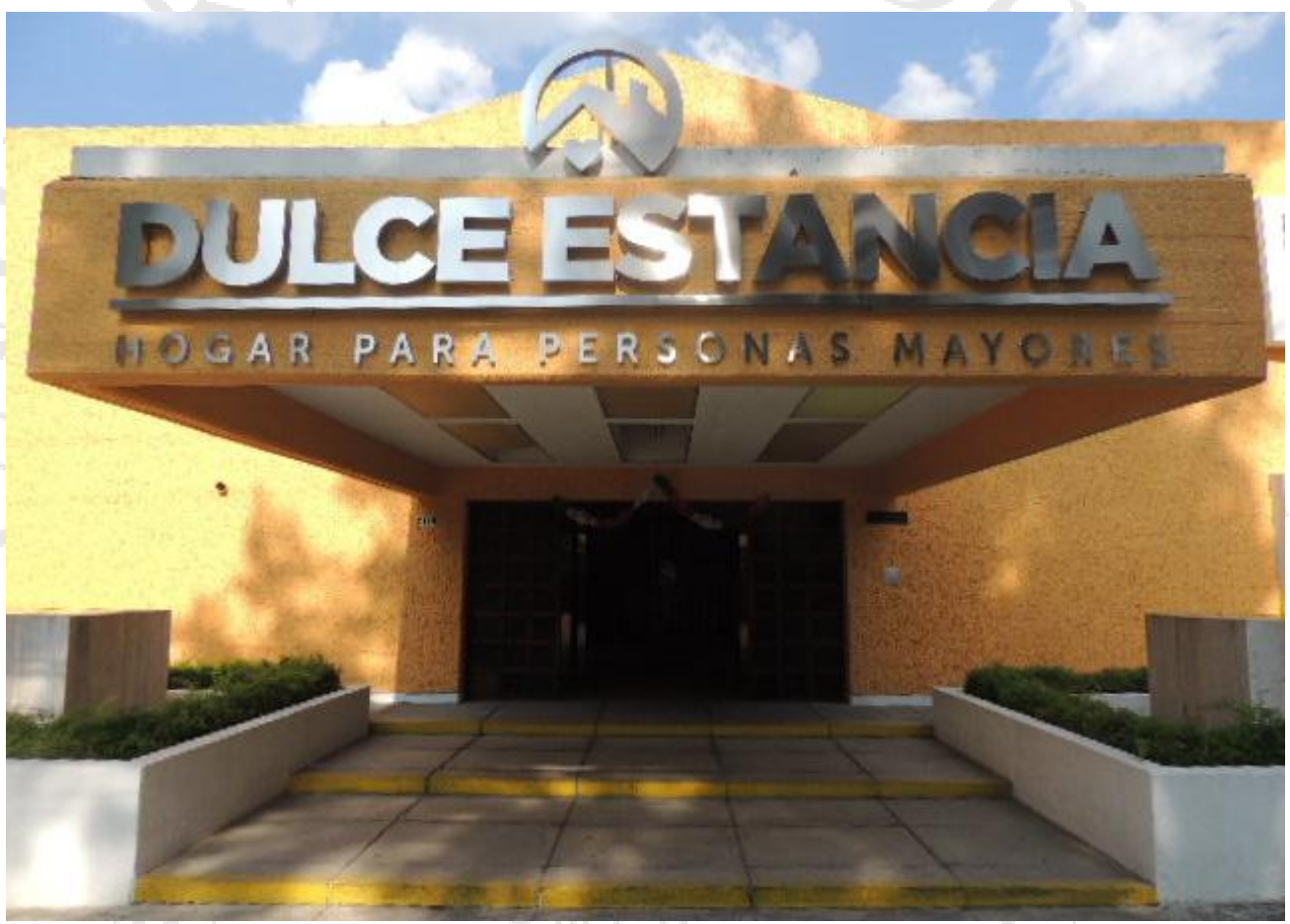

Fuente: (Dulce Estacia Hogar para Personas Mayores, 2018) 
Figura 4.4.1.2:

Fachada Hogar para personas mayores Dulce Estancia

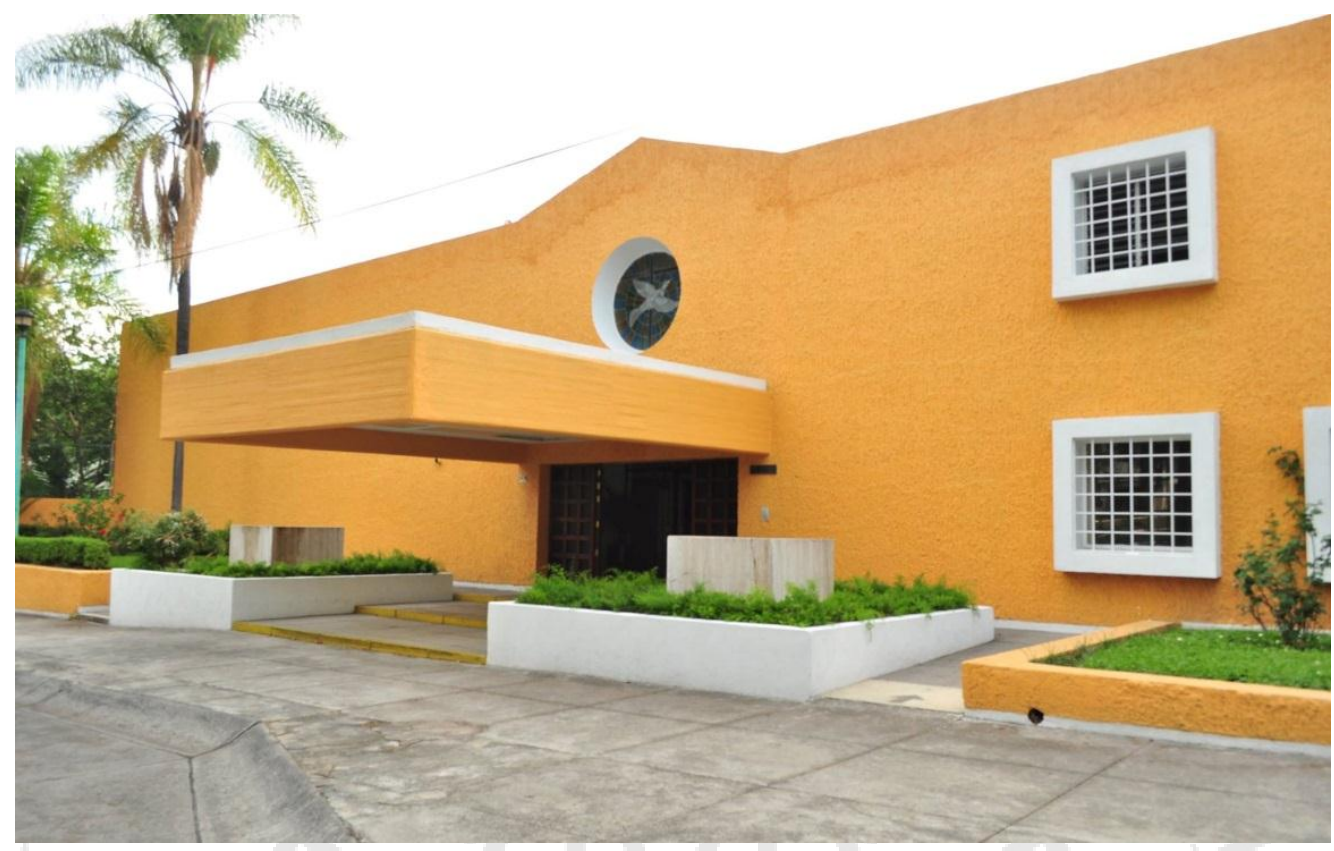

Fuente: (Dulce Estacia Hogar para Personas Mayores, 2018)

\subsubsection{Relación con el entorno.}

El hogar para personas mayores se encuentra casi al centro del tejido urbano de la Ciudad de Guadalajara, México. Está ubicada aproximadamente a $5.7 \mathrm{~km}$ del centro de la ciudad, en el cruce de la Calle Caballo Arete y Av. Topaccio, por la cual se ubica el ingreso principal al asilo.

Figura 4.4.2.1:

Ubicación de Guadalajara.

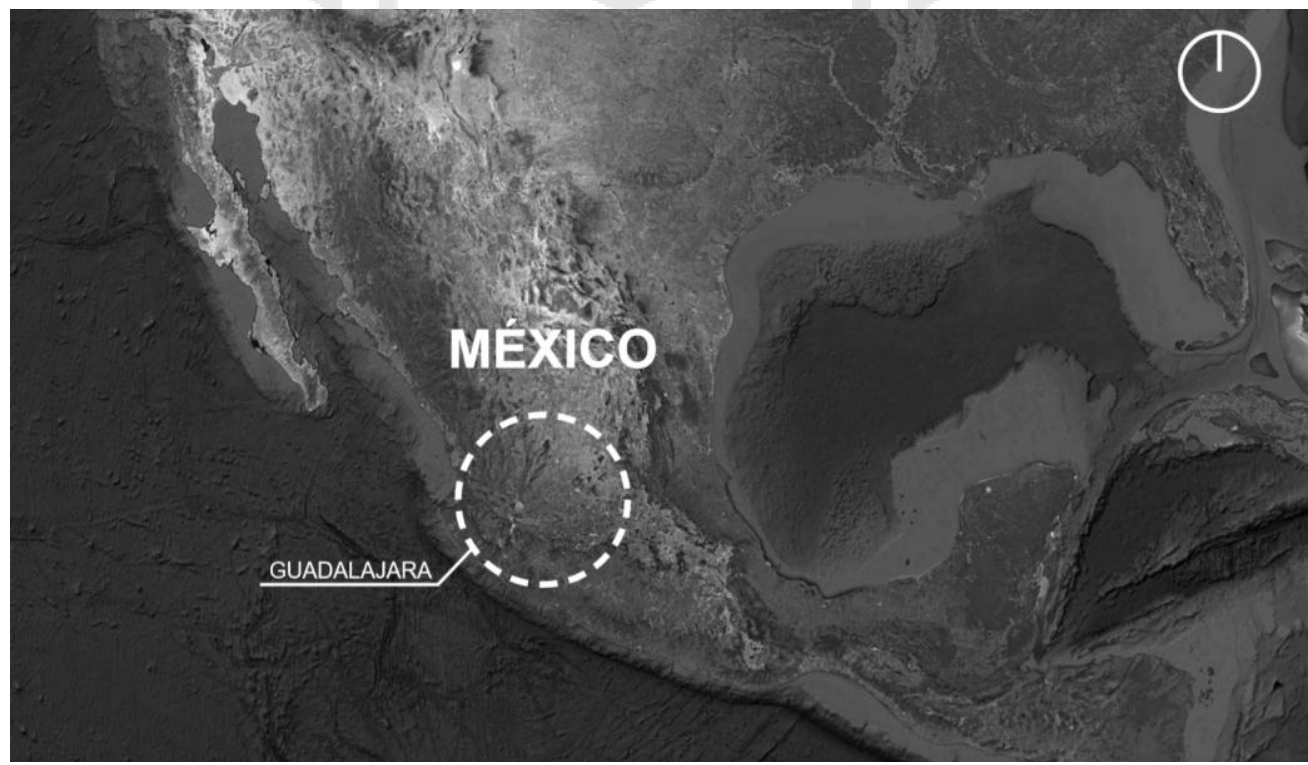

Fuente: Google Earth. Modificado por autor. 
Figura 4.4.2.2: Ubicación del proyecto en la ciudad de Guadalajara.

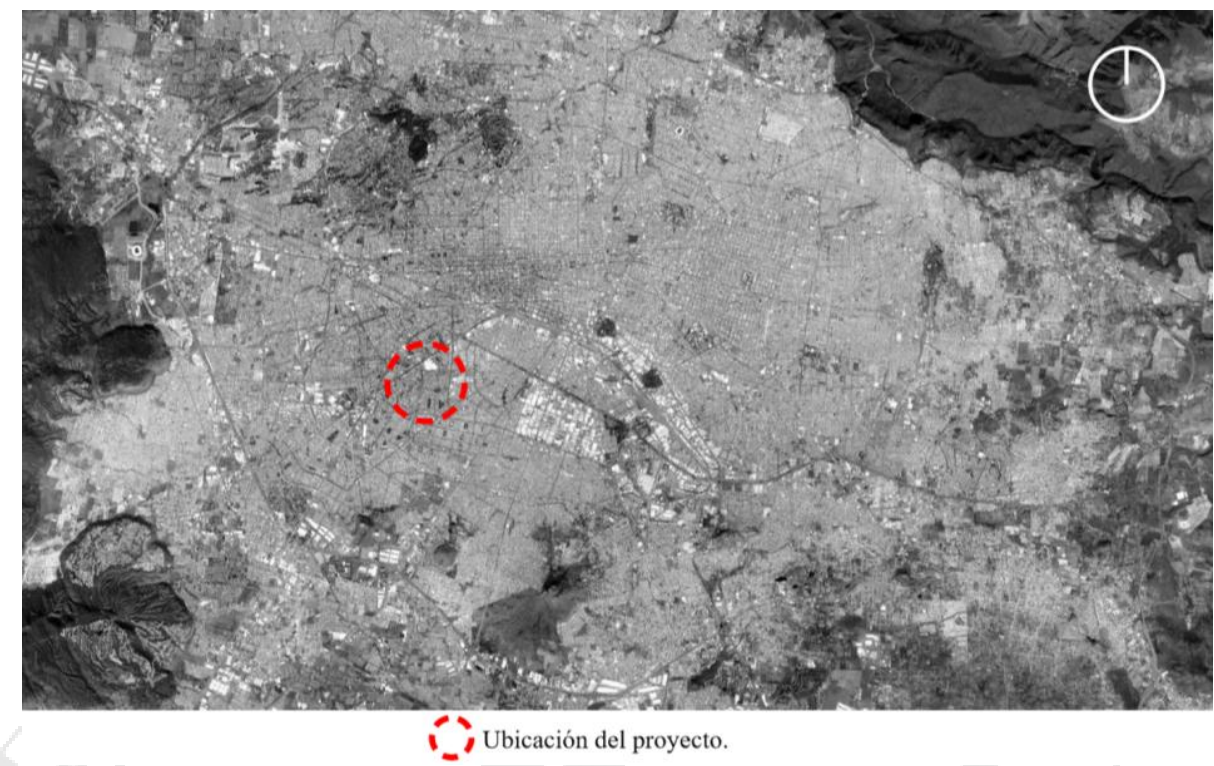

Fuente: Google Earth. Modificado por autor.

Las vías principales de transporte cercanas al asilo son la Av. Mariano Otero la cual tiene conexión con la Av. Calle Lázaro Cárdenas Pdte, este cruce de avenidas genera un nudo importante de intercambio vial en la ciudad. Otra de las calles más importantes de la zona es la Av. Topacio, por la cual se ubica el único ingreso con el que cuenta el asilo. Así mismo, este centro se encuentra rodeado en la zona posterior por la Calle Caballo Arete.

Figura 4.4.2.3:

Flujo vehicular

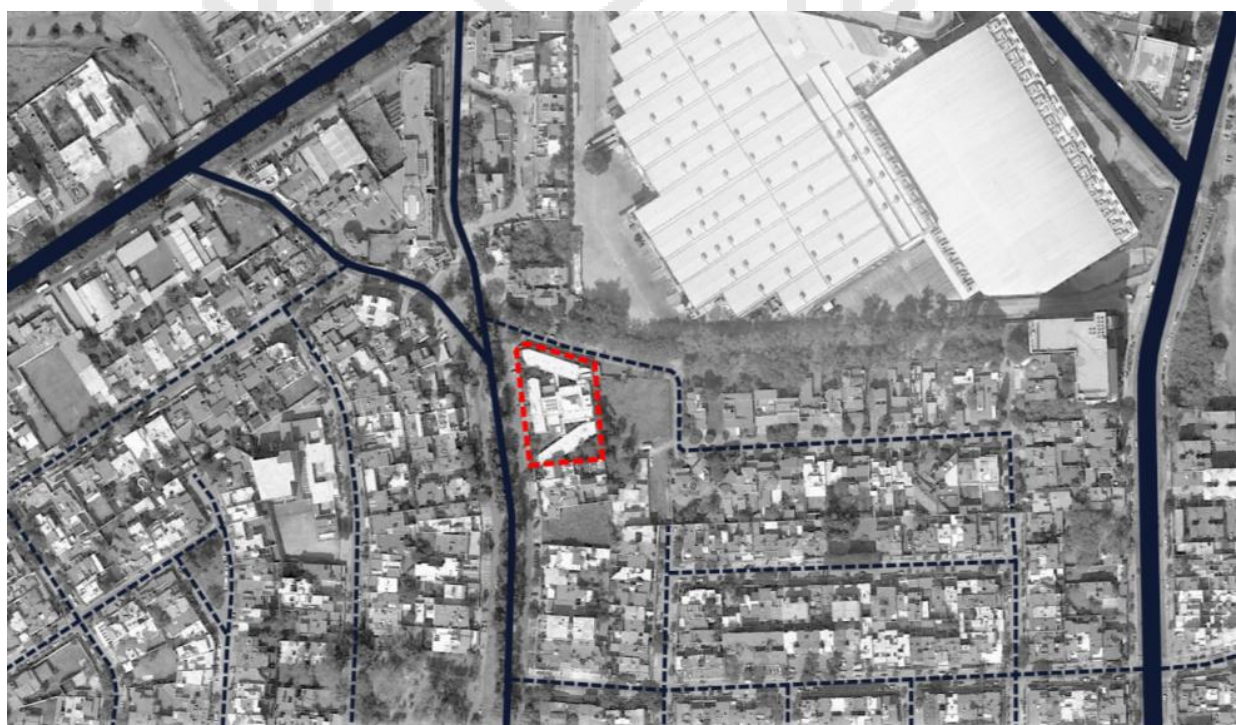

Vias vehiculares principales
--- Vias vehiculares intermedias vehiculares secundarias

Fuente: Google Earth. Modificado por autor. 
El centro se encuentra en una zona de la ciudad en la que predominan las construcciones de baja densidad, zona residencial en su mayoría, esto genera que el corte de perfil urbano no rompa con la escala del lugar. Sin embargo, es una zona que también cuenta con equipamientos de poca intensidad e impacto. En planta, la escala del asilo con respecto a los terrenos y construcciones aledañas es mayor, sin embargo, no es imponente debido a que muy cercano a la ubicación del asilo se ubica un gran centro de convenciones el cual es predominante en la zona.

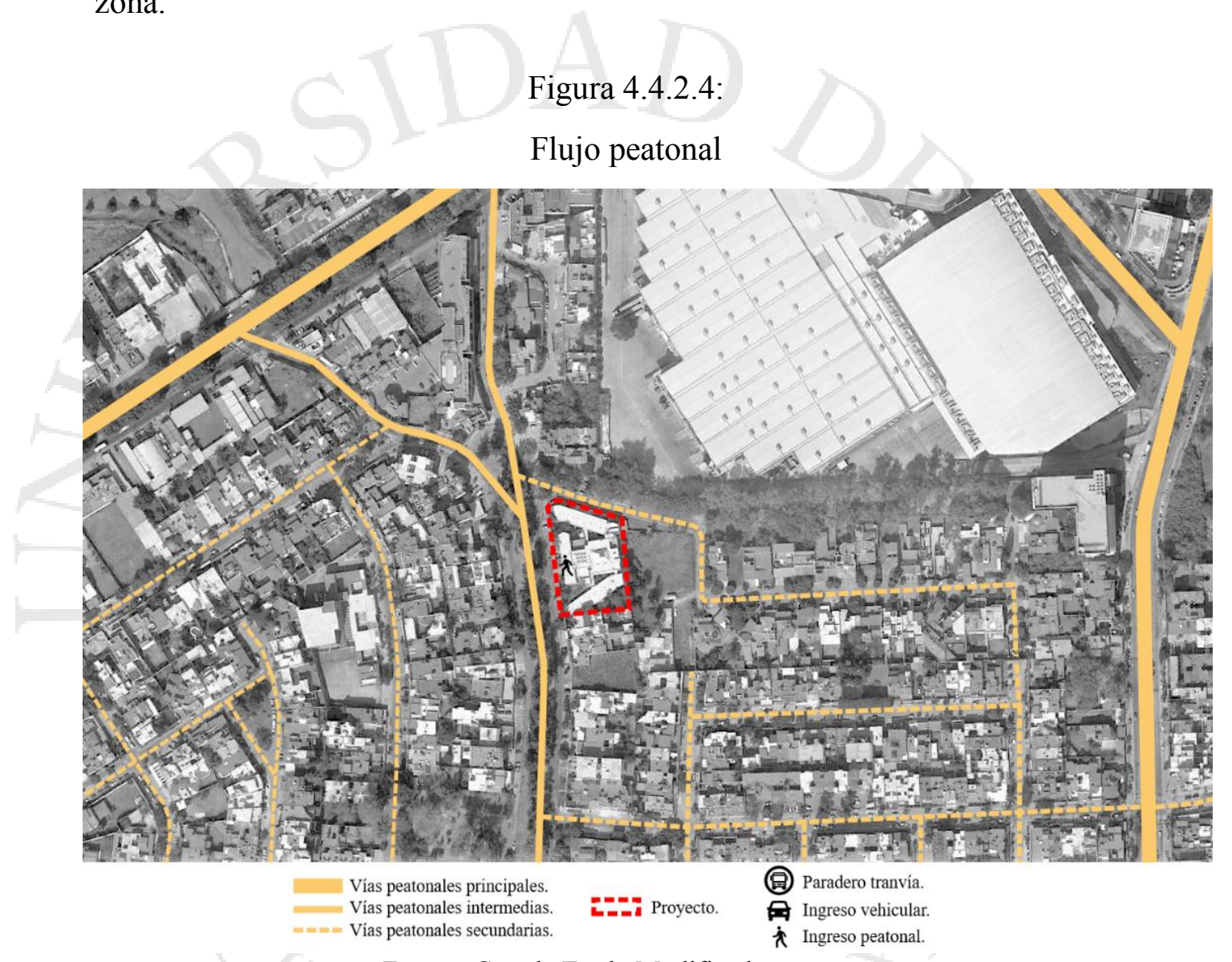

Fuente: Google Earth. Modificado por autor.

La zona en la que se ubica el Hogar para Personas Mayores es residencial, sin embargo, muy cerca a este hay una diversidad de locales entre los que predomina las actividades comerciales, talleres y algunos centros de educación. Esto genera un gran movimiento cerca al centro durante el día, en consecuencia de esto, el flujo de personas en las avenidas es entre medio y alta. 
4.4.3. Programa y relaciones programáticas.

A continuación, el siguiente análisis explica la importancia de cada ambiente con relación al área que ocupa en el Hogar Dulce Estancia. Cada área general está separada por las características de los servicios que ofrece: área administrativa, área de servicios, área de actividades diurnas, residencia para adultos mayores y estacionamiento.

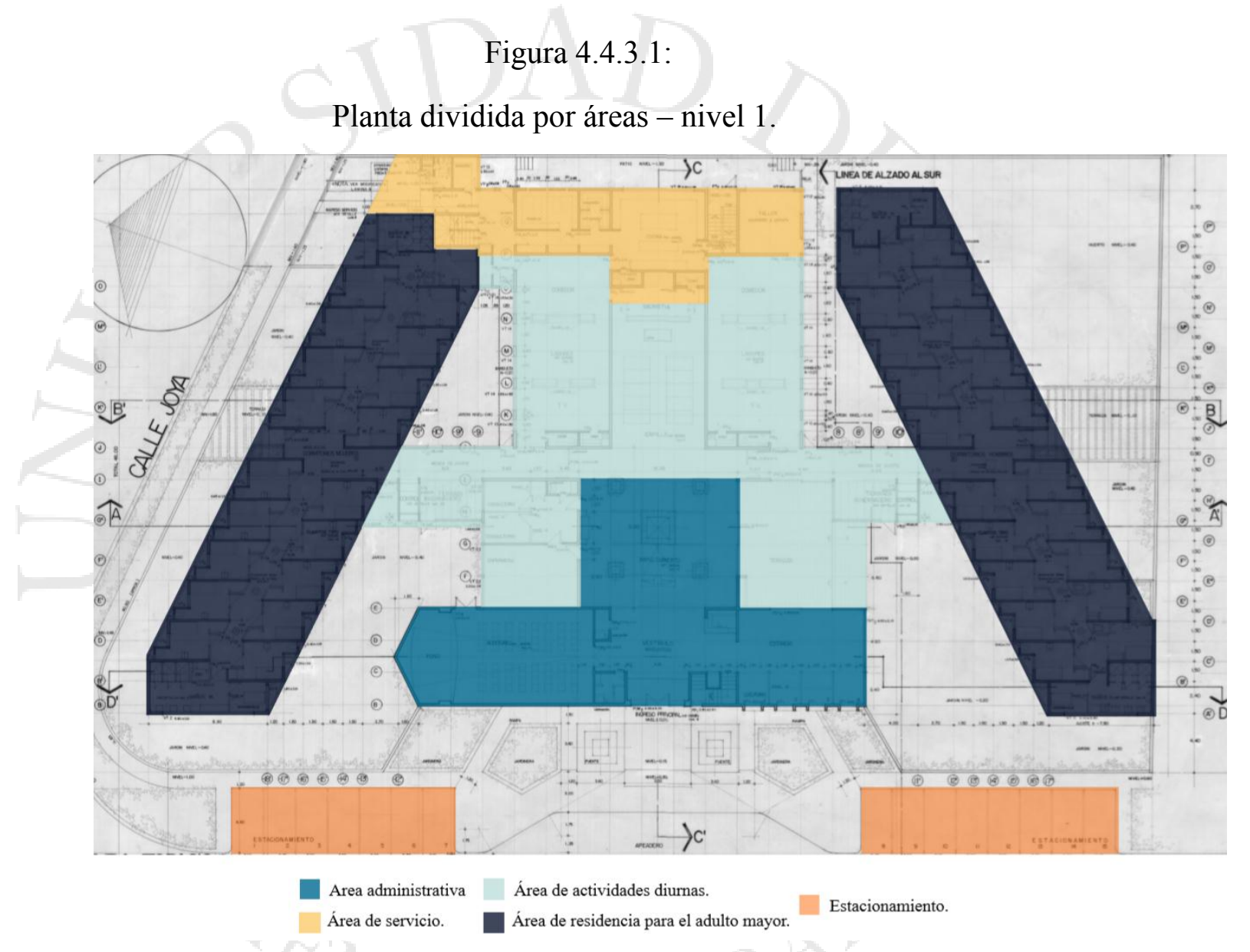

Fuente: (Arquitectos Jaliscienses., 2014). Modificado por autor. 
Figura 4.4.3.2:

Planta dividida por áreas - nivel 2.

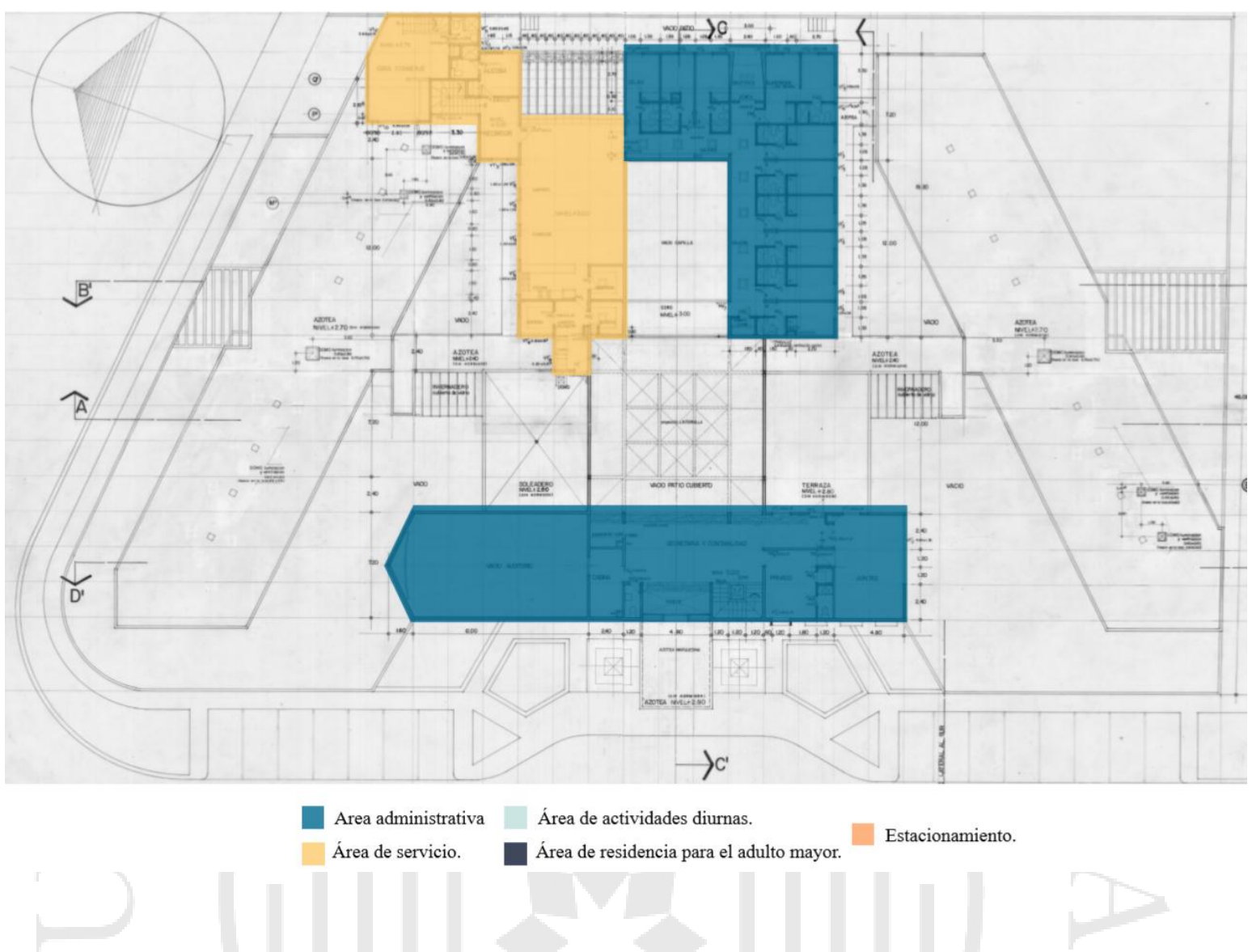

Fuente: (Arquitectos Jaliscienses., 2014). Modificado por autor. 
Tabla 4.4.3.1: Porcentaje de área administrativa de la Residencia Los Molinos

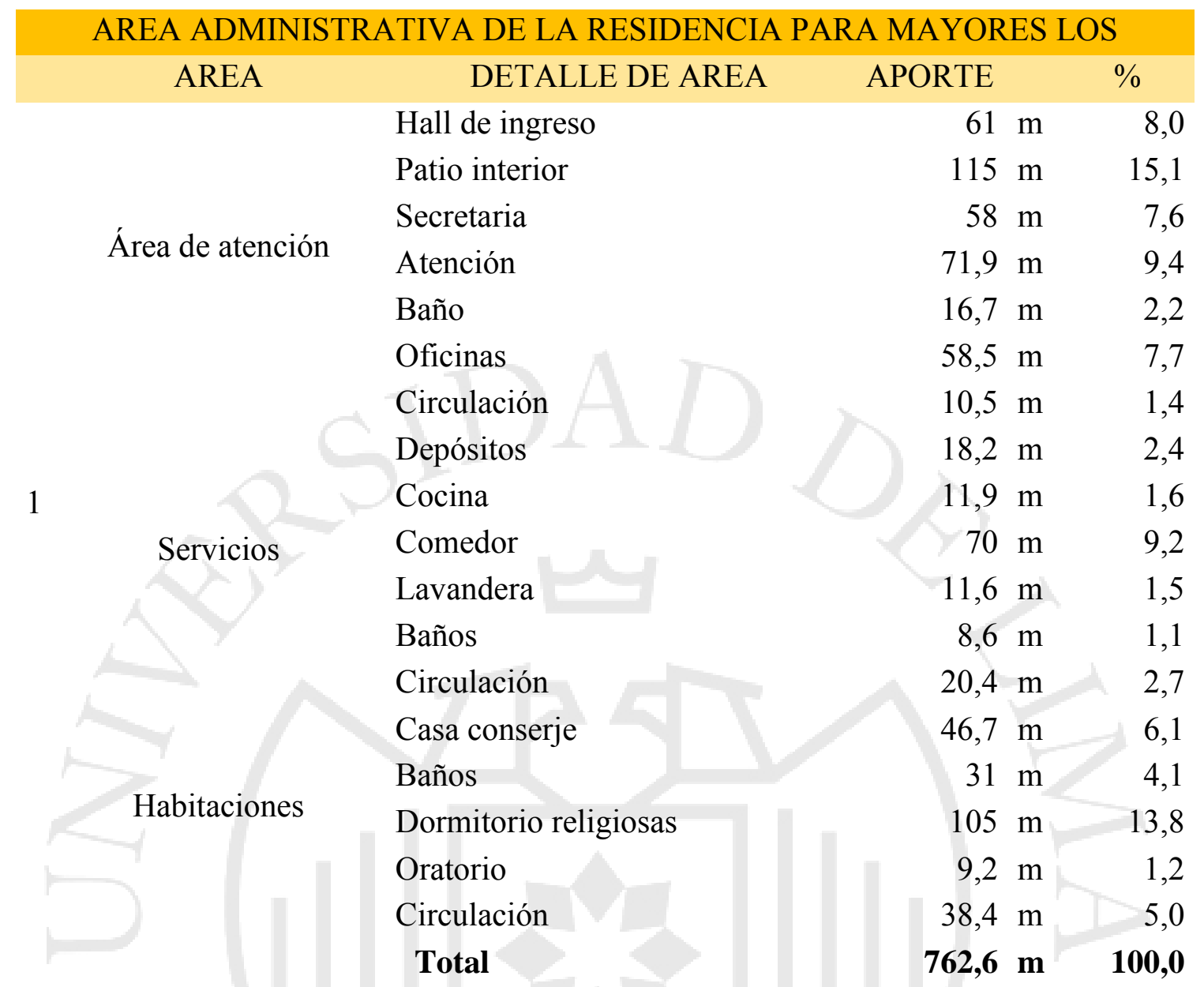

\begin{tabular}{|c|c|c|c|}
\hline \multicolumn{4}{|c|}{ AREA ADMINISTRATIVA DE LA RESIDENCIA PARA MAYORES LOS } \\
\hline AREA & DETALLE DE AREA & APORTE & $\%$ \\
\hline \multirow{6}{*}{ Servicios } & Cocina & $45,1 \mathrm{~m}$ & 3,3 \\
\hline & Depósitos & $34,2 \mathrm{~m}$ & 2,5 \\
\hline & Baño & $6,5 \mathrm{~m}$ & 0,5 \\
\hline & Enfermería & $34,5 \mathrm{~m}$ & 2,6 \\
\hline & Consultorios & $35,7 \mathrm{~m}$ & 2,6 \\
\hline & Circulación & $29,2 \mathrm{~m}$ & 2,2 \\
\hline \multirow{6}{*}{ Recreación } & Sala de tv & $57,5 \mathrm{~m}$ & 4,3 \\
\hline & Capilla & $96 \mathrm{~m}$ & 7,1 \\
\hline & Taller & $84,8 \mathrm{~m}$ & 6,3 \\
\hline & Comedor & $74 \mathrm{~m}$ & 5,5 \\
\hline & Baño & $18,6 \mathrm{~m}$ & 1,4 \\
\hline & Terraza & $85,5 \mathrm{~m}$ & 6,3 \\
\hline \multirow{5}{*}{ Habitaciones } & Circulación & $93,2 \mathrm{~m}$ & 6,9 \\
\hline & Habitaciones & $452,2 \mathrm{~m}$ & 33,4 \\
\hline & Baño & $105,6 \mathrm{~m}$ & 7,8 \\
\hline & Circulación & $100 \mathrm{~m}$ & 7,4 \\
\hline & Total & $1352,6 \mathrm{~m}$ & 100,0 \\
\hline
\end{tabular}

Fuente: Por autor 


\subsubsection{Estrategias de emplazamiento.}

Figura 4.4.4.1: Esquema de composición

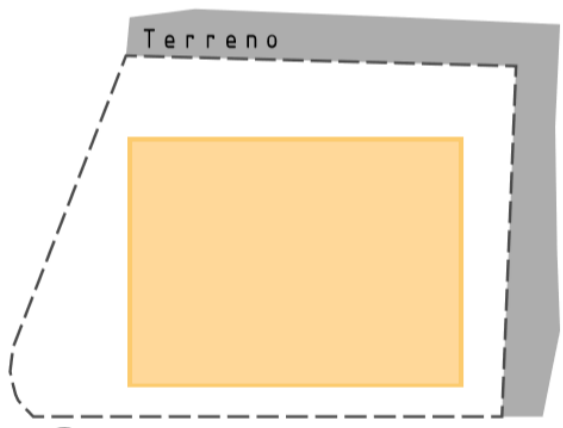

(1)

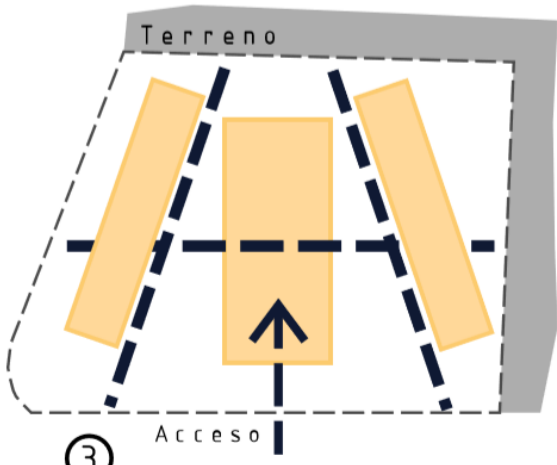

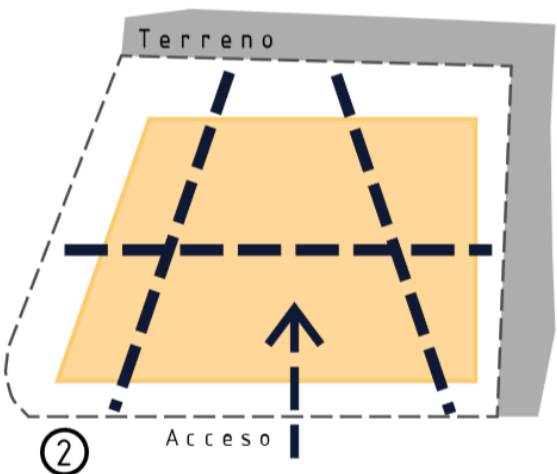

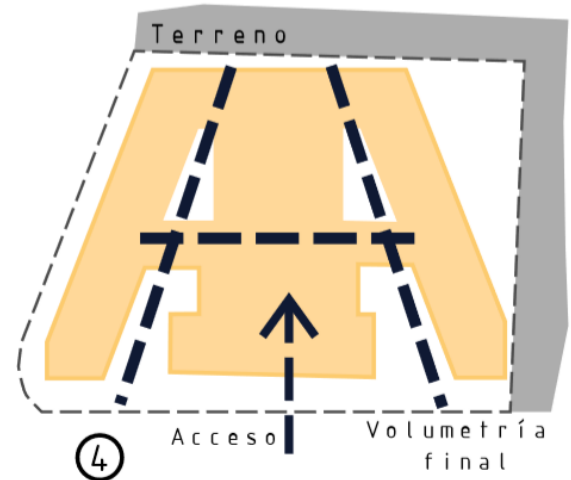

Fuente: Elaborado por autor.

Desde la fachada se puede percibir que el Hogar Dulce Estancia no es un centro que tiene intención de ser parte de la ciudad, sino, se aísla mediante la gran fachada que no permite observar del exterior absolutamente nada de lo que sucede en el asilo; así mismo, desde el interior no hay conexión visual al barrio a excepción de tres ventanales que dan al área administrativa del asilo.

En la planta se puede observar un gran bloque central del cual salen dos brazos en diagonal en donde se ubican las habitaciones de los residentes del asilo. Entre los espacios que dejan los volúmenes diagonales y la zona central se genera un patio que sirve de área de recreación para los usuarios y que además permite la ventilación e iluminación de las áreas más importantes del centro. 


\subsubsection{Flujos y circulaciones}

El siguiente análisis muestra la concurrencia que tienen los diversos ambientes del Hogar a consecuencia de las actividades que se desarrollan al interior de cada una de estas zonas. Existen algunos pases restringidos dependiendo la función del usuario al interior del establecimiento como puede ser: Residente, visita o trabajador.

En el ingreso se ubica la zona administrativa, un salón de usos múltiples y otros servicios de atención que pueden ser utilizados por los usuarios o visitantes, es por esto que es el área con mayor acceso. Así mismo, la capilla del Hogar es una de las zonas con más concurrencia debido a que es un lugar abierto al público sólo en horario de misa.

Seguido de esto, se ubican los lugares de actividades recreativas y de interacción, estas zonas son de flujo medio debido a que son los puntos de encuentro entre residentes o entre un residente y algún familiar/amigo.

Finalmente, la zona con mayor privacidad son los dormitorios y las áreas que brindan servicio a los ancianos (lavandería, cocina, limpieza, etc.)

Figura 4.4.5.1: Adultos mayores en actividades

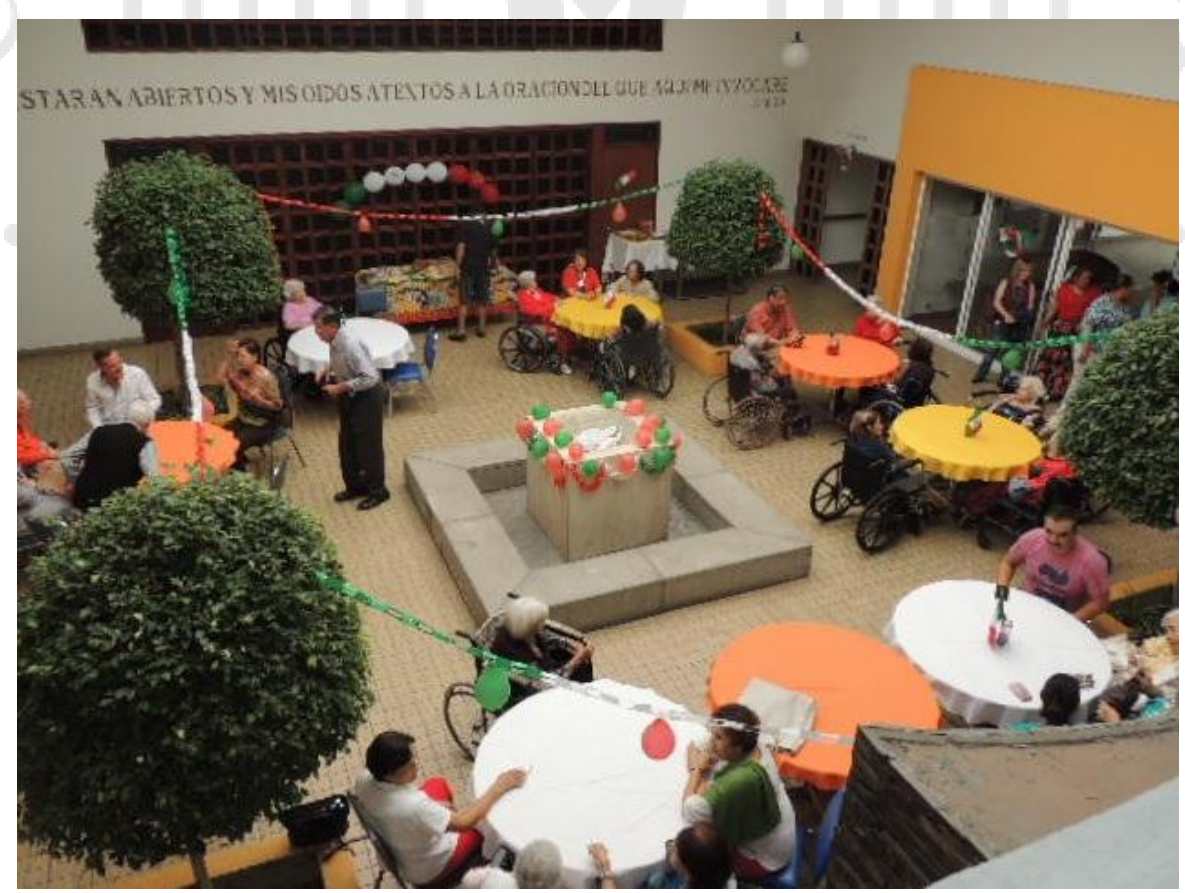

Fuente: (Dulce Estacia Hogar para Personas Mayores, 2018) 
Figura 4.4.5.2: Circulaciones generales primera planta.

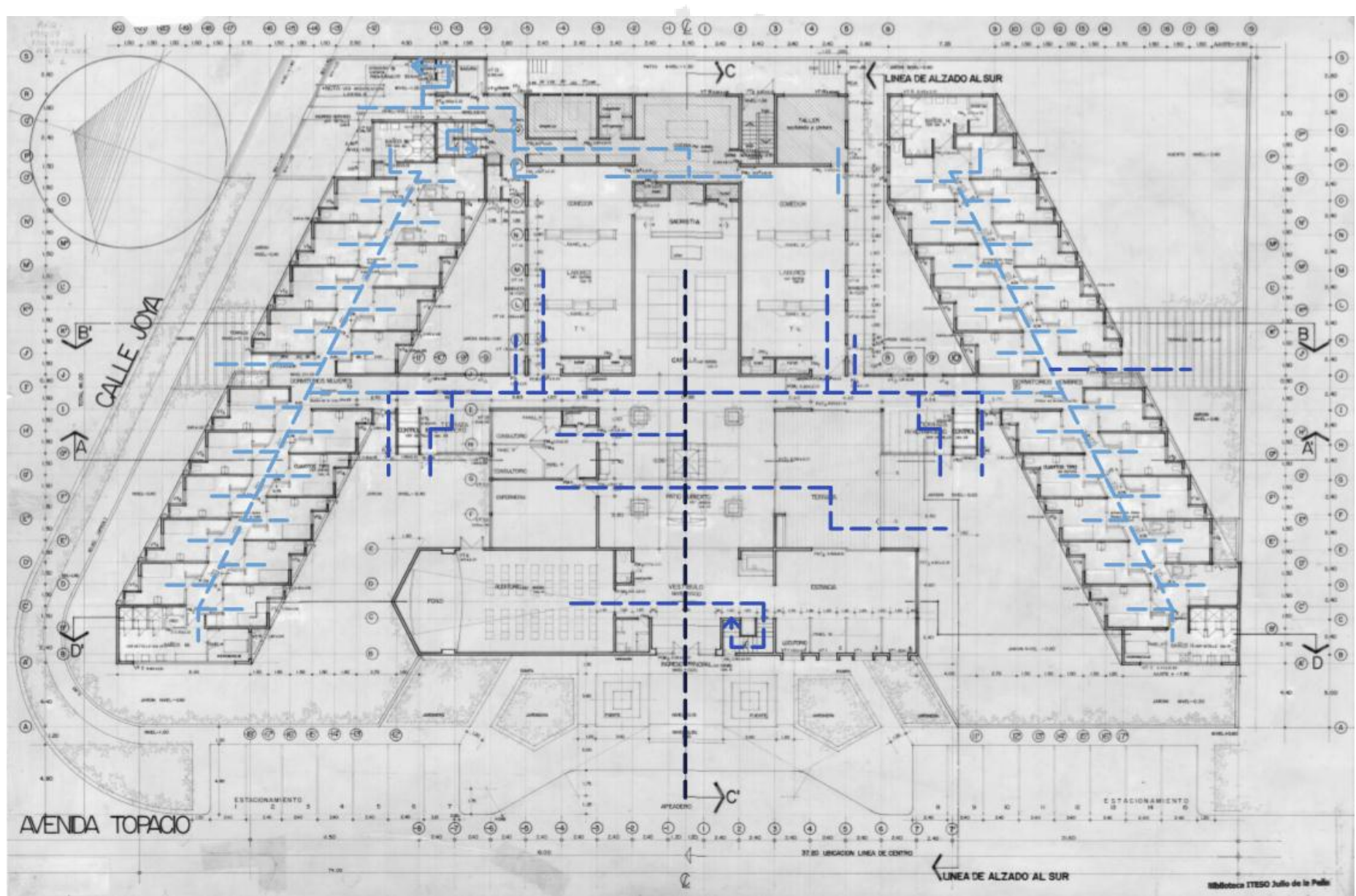

Fuente: (Arquitectos Jaliscienses., 2014). Modificado por autor. 
Figura 4.4.5.3: Circulaciones generales primera planta.

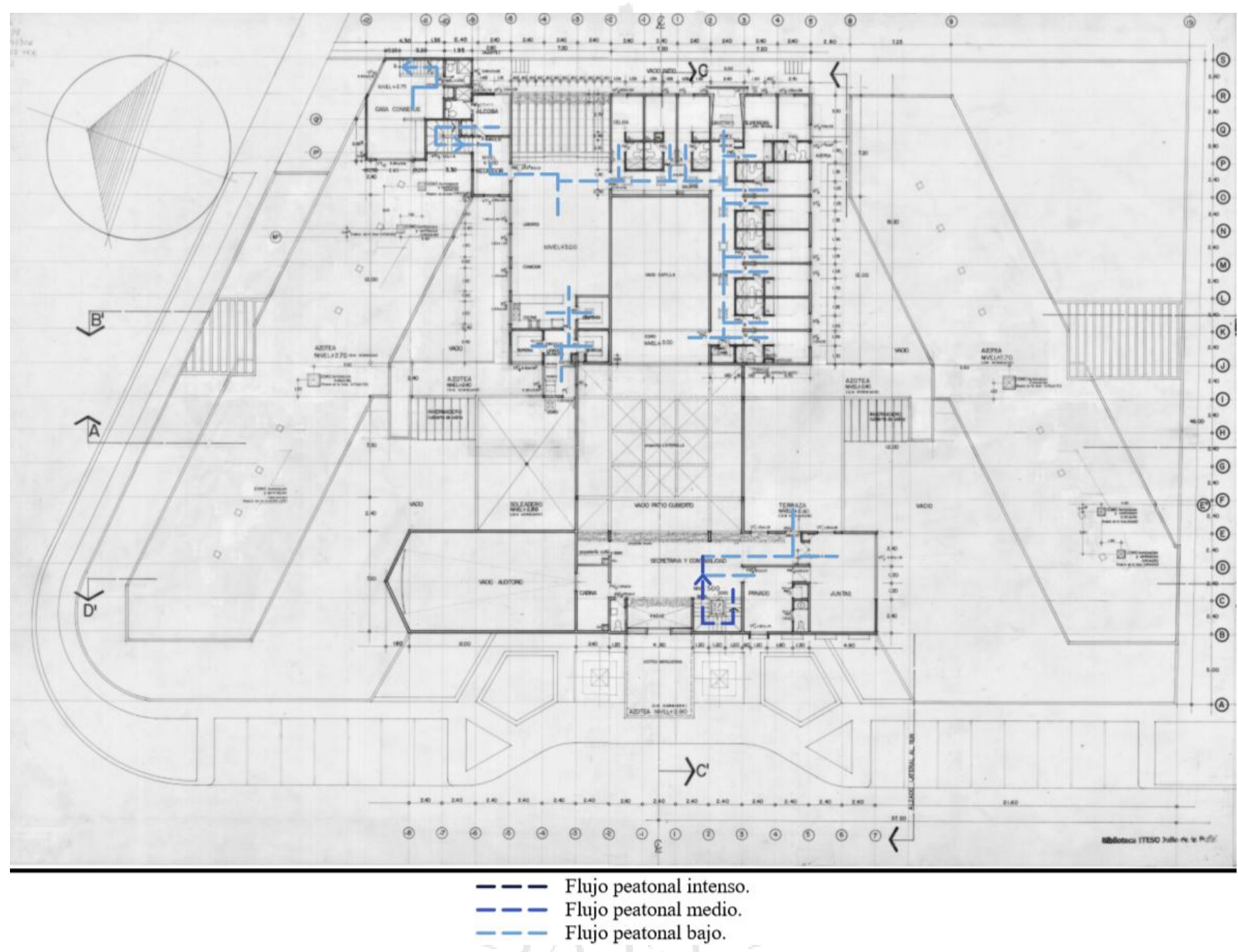

Fuente: (Arquitectos Jaliscienses., 2014). Modificado por autor. 
4.4.6. Área construida y área libre.

En este caso, la mayor parte del proyecto es construcción, por lo cual, el proyecto se percibe como una gran masa. Sin embargo, si bien las áreas libres son menores, se encuentran distribuidas de forma precisa al interior del proyecto y alrededor de todo el terreno de forma que todos los ambientes obtengan iluminación natural.

Los pequeños patios al interior de la edificación también cumplen con un rol de conector visual entre las áreas de recreación y el área de habitaciones.

\subsubsection{Relaciones espaciales.}

\section{Figura 4.4.7.1:}

Esquema de área construida y área libre.

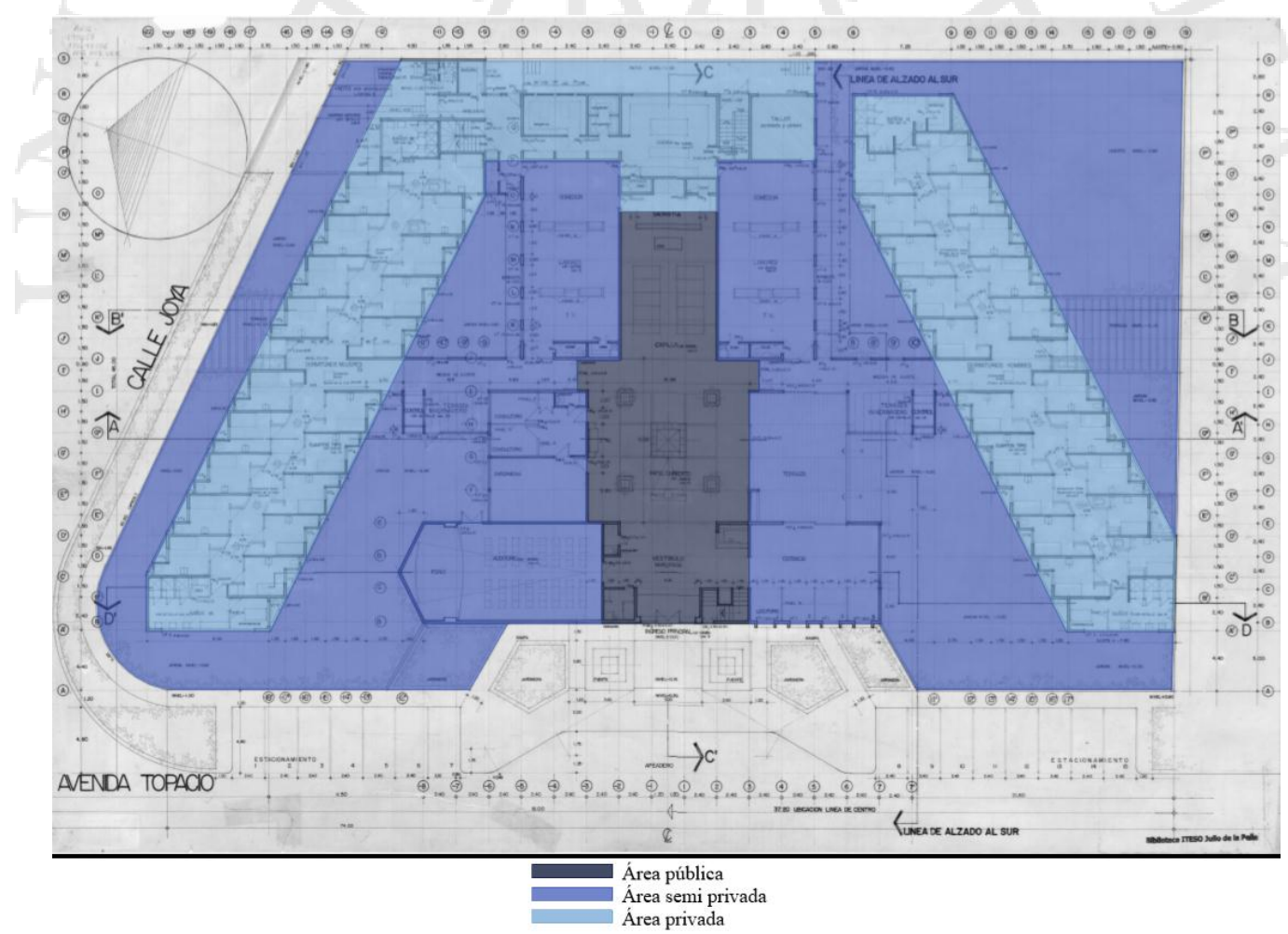

Fuente: (Arquitectos Jaliscienses., 2014). Modificado por autor. 
Figura 4.4.7.2:

Esquema de área construida y área libre.

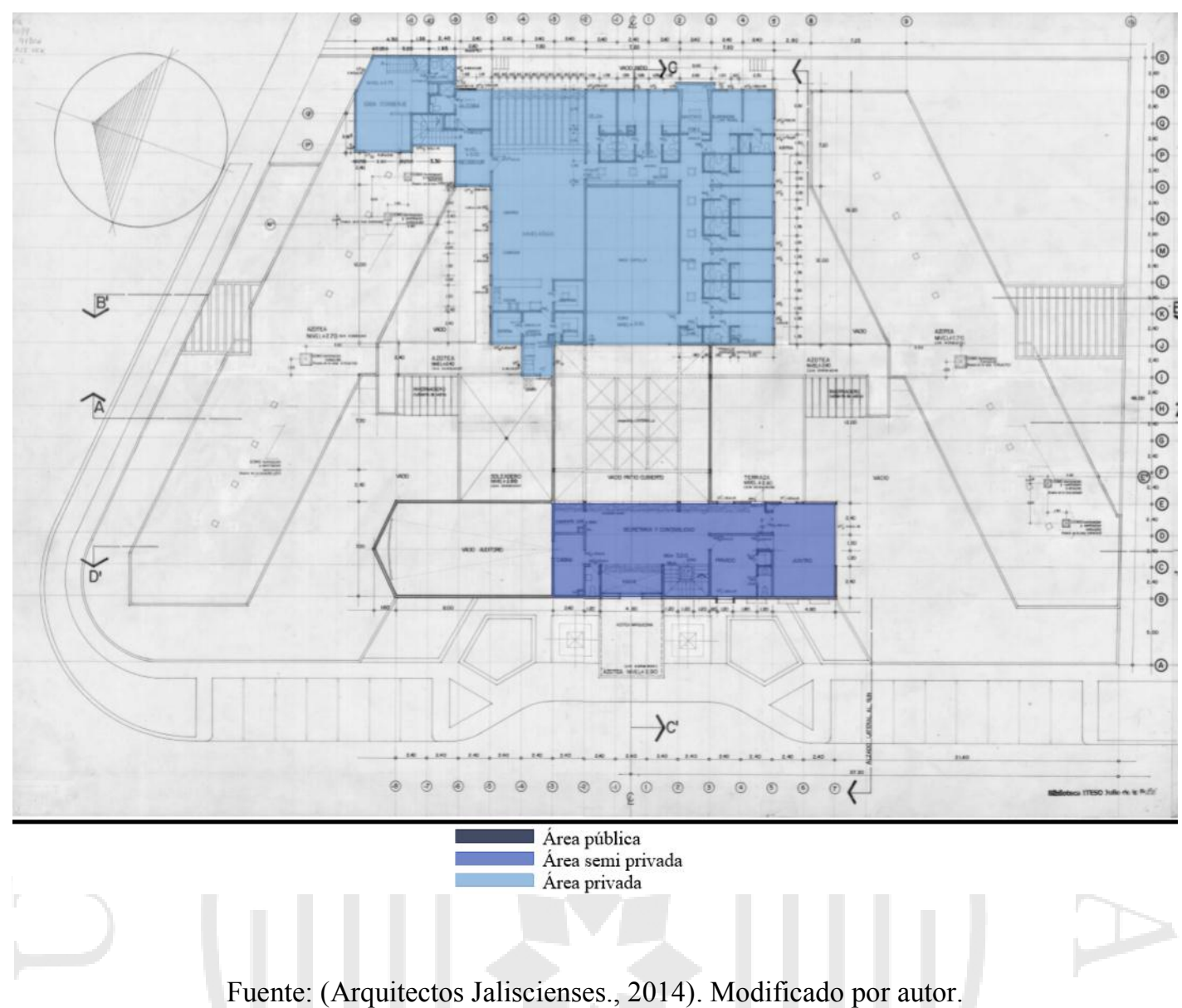

Este análisis muestra los distintos niveles de privacidad que hay en este asilo de ancianos.

- El pequeño jardín, que se encuentra previo al ingresar al centro, es el único espacio que se podría poner en la categoría de público.

- Las áreas administrativas de atención al público que están ubicadas en el primer nivel del asilo se podrían poner en la categoría de semiprivado. Esto debido a que en este ambiente se tiene gran contacto con el exterior a comparación de los otros espacios del centro.

- Los lugares en donde se encuentra el comedor, sala de tv y talleres están en el grupo de semipúblico debido a que pueden ser empleados por los residentes del asilo, sin embargo, no son ambientes abiertos al público en general.

- Finalmente, los volúmenes en donde se ubican las habitaciones son las zonas más privadas al interior del centro. 


\subsubsection{El Dormitorio}

Figura 4.4.8.1:

La habitación

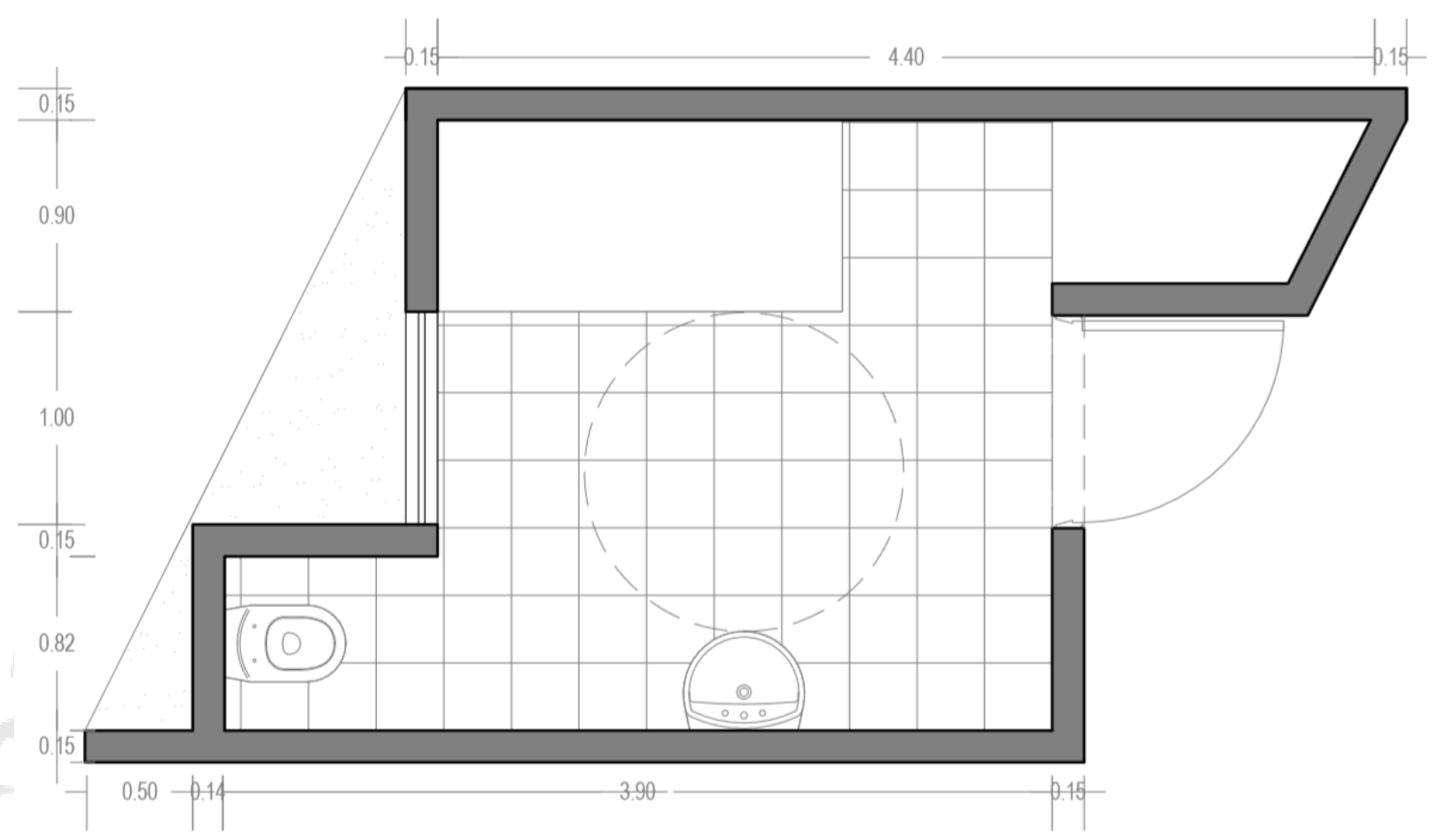

Fuente: Elaborado por autor.

Es importante resaltar que la construcción del Hogar Dulce Estancia es del año 1985, por lo tanto, la exigencia de normas y características para implementar una habitación para personas mayores era mínima.

En el Hogar las habitaciones para ancianos son personales, estás son módulos de $15 \mathrm{~m} 2$ aproximadamente en las que se encuentra una cama, un pequeño closet y un área de higiene. Las dimensiones de este y la distribución de los elementos al interior, permiten que se obtenga un espacio suficiente para el giro de una silla de ruedas. Sin embargo, el dormitorio no es lo suficientemente amplio para contar con un baño completo, por lo tanto, estos se ubican en los extremos de los pasillos y son de uso general para todos los adultos mayores. 
Figura 4.4.8.2: La habitación

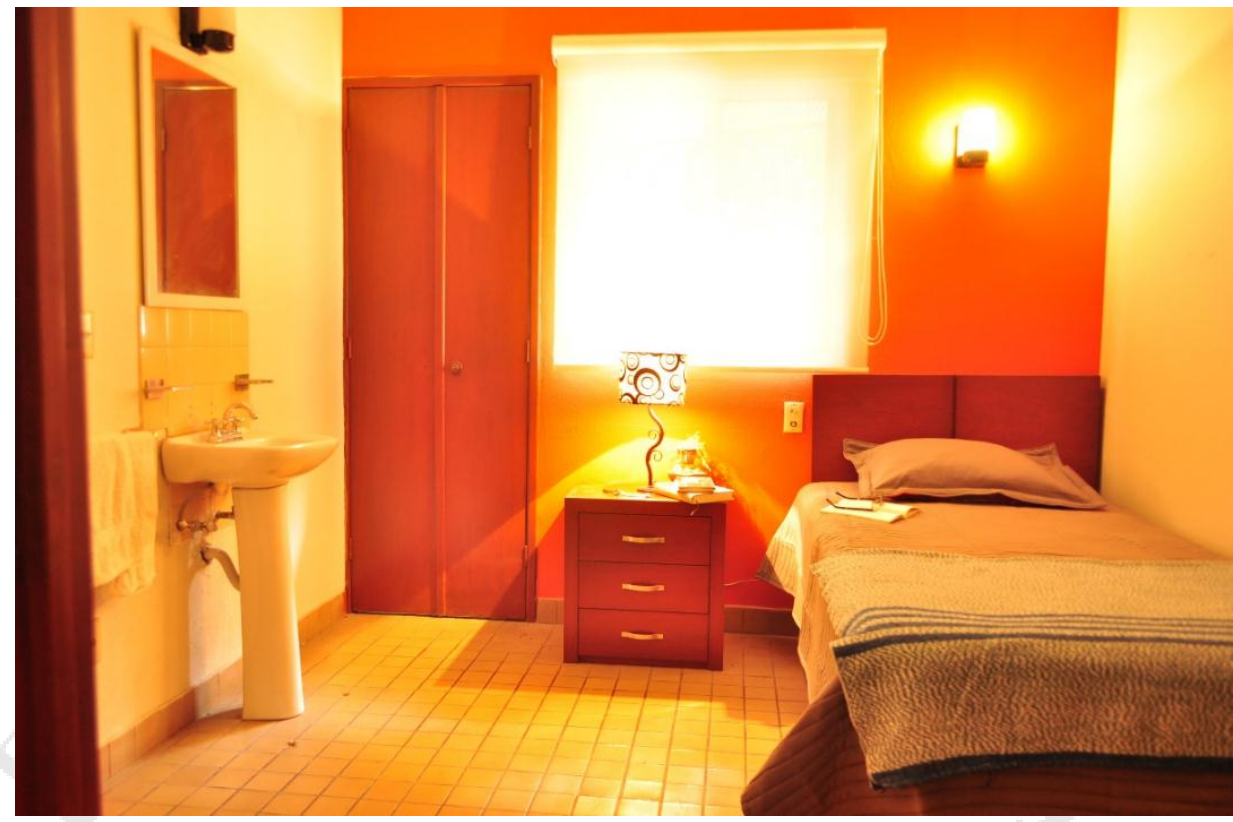

Fuente: (Dulce Estacia Hogar para Personas Mayores, 2018)

\subsubsection{Tecnología}

La fachada del Hogar Dulce Estancia tiene apariencia de ser un proyecto macizo y con poco ingreso de luz al interior. Sin embargo, al interior de este hay un mayor trabajo en la volumetría que logra que se optimice el uso de luz natural por medio de los patios, jardines, ventanas y aberturas en los techos.

Figura 4.4.9.1: Patios interiores

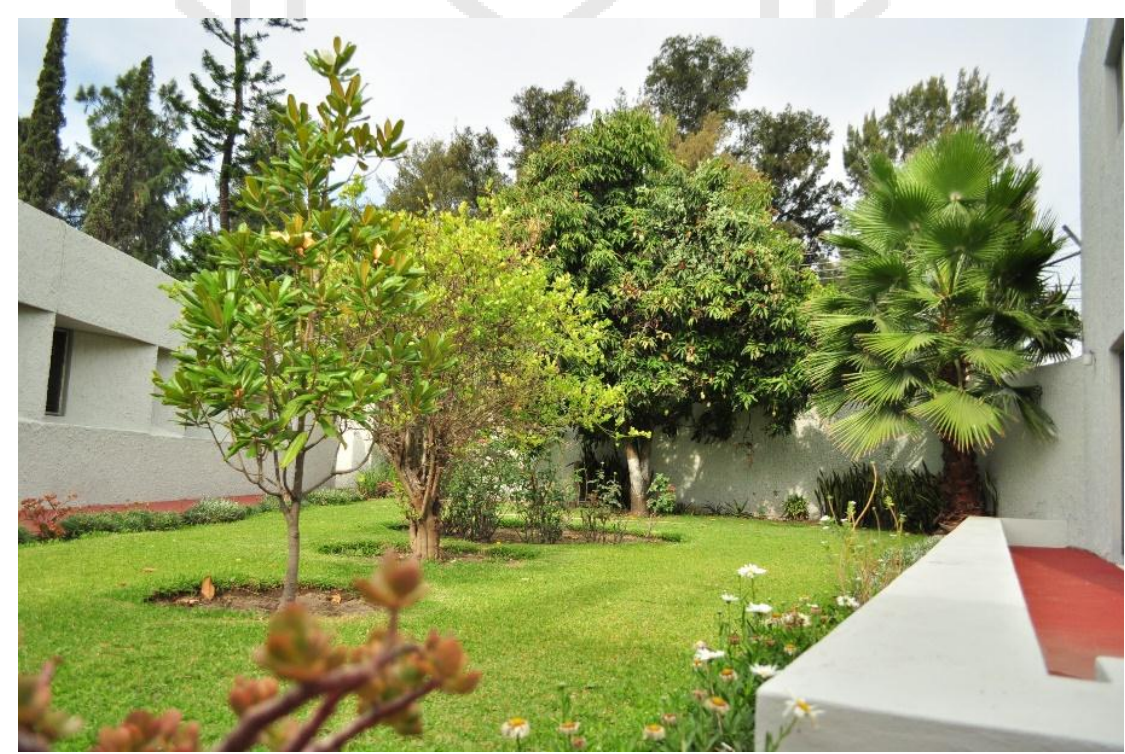

Fuente: (Dulce Estacia Hogar para Personas Mayores, 2018) 
Figura 4.4.9.2: Patios interiores

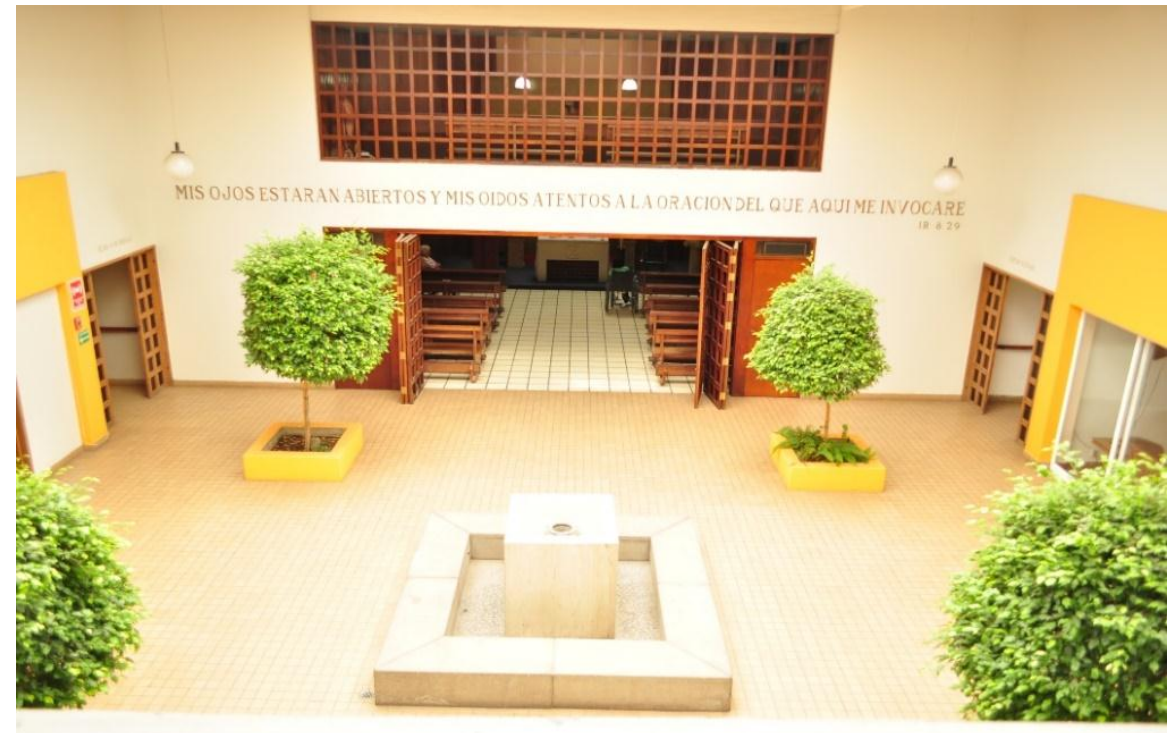

Fuente: (Dulce Estacia Hogar para Personas Mayores, 2018)

\subsubsection{Impacto social.}

En Guadalajara, el 9\% de la población son adultos mayores. Por tal motivo, es importante la existencia de grandes centros como el Asilo David Gutiérrez que permitan que las personas de tercera edad puedan encontrar un lugar en donde puedan vivir.

Sin embargo, debido a la antigüedad de la construcción del centro, es posible que hayan existido mejores maneras de lograr una óptima calidad de vida al interior del asilo que, si bien tiene características importantes como gran iluminación y ventilación, en la parte programática y de distribución de espacios es deficiente. 
Figura 4.4.10.1: Actividades en el asilo.

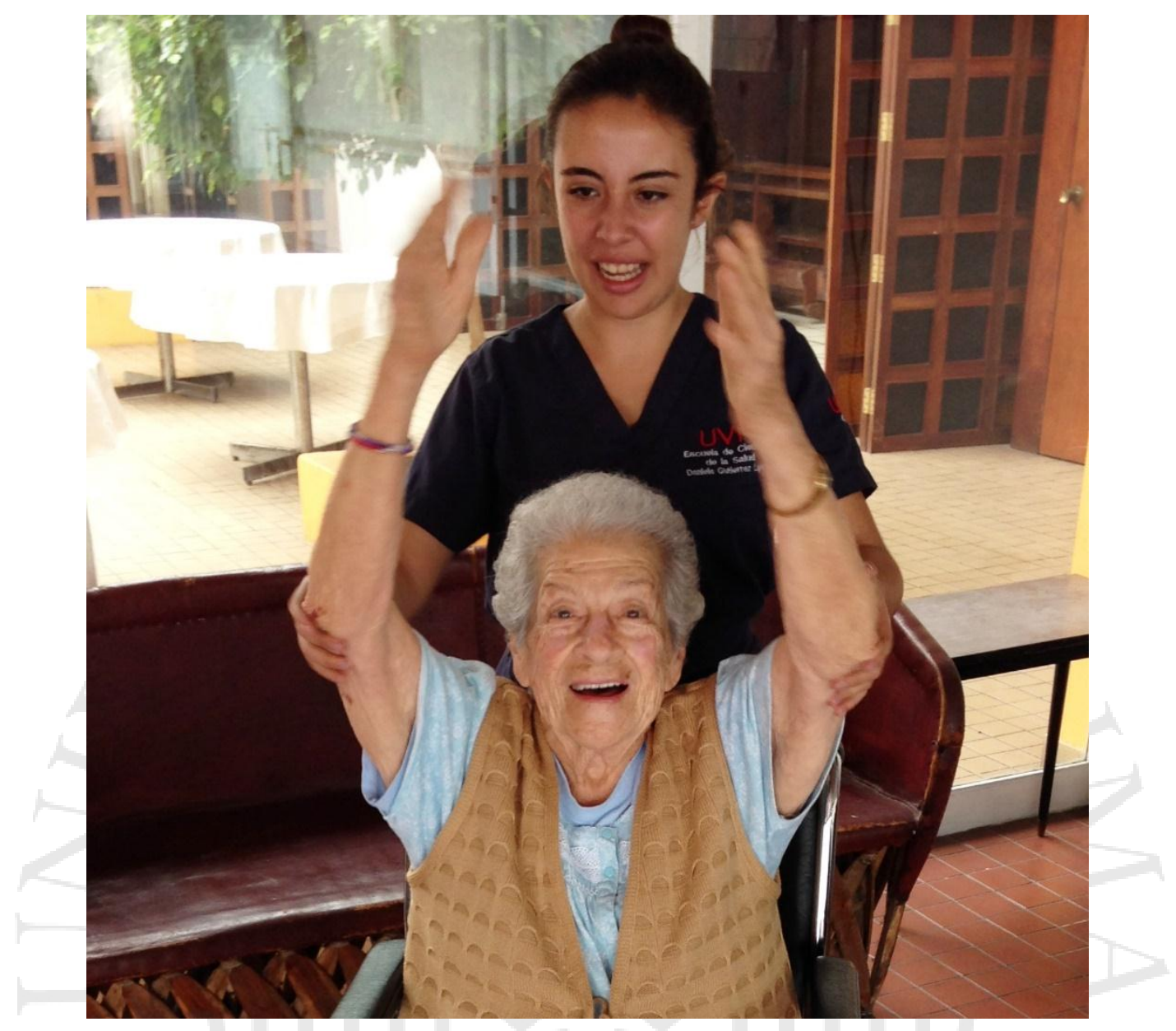

Fuente: (Dulce Estacia Hogar para Personas Mayores, 2018)

\subsubsection{Conclusiones.}

El hogar para personas mayores Dulce Estancia es un proyecto que beneficia a los adultos mayores debido a que brinda servicios de residencia y cuidado. Sin embargo, tiene características que pueden ser optimizadas. Desde el ingreso es un proyecto que se encierra drásticamente y le da la espalda a la calle, por lo cual, queda completamente aislado del exterior quitándole la oportunidad de generar una relación con su entorno.

Por la forma en la que el proyecto se emplaza en el terreno es posible decir que se ha pensado en referencia al sol. Por otro lado, se generan patios interiores que ayudan al ingreso de luz y ventilación de los ambientes, que, a su vez, cumplen la función de ser espacios de reunión e integración, lo cual favorece a los adultos mayores debido a que se fomenta la relación entre ellos. 
Finalmente, al interior de cada uno de los ambientes se desarrollan funciones que complementan la vida de los adultos mayores residentes. Uno de los ambientes principales es el de los servicios higiénicos y dormitorios, estos ambientes se encuentran separados y originan largos traslados para ser usados, esto no es una característica correcta en un centro para personas de la tercera edad debido a que aumenta la probabilidad de accidentes por el propio recorrido o por la propia salud de los adultos mayores.

4.5. Casa Hogar "La Piedad"

\subsubsection{Historia del edificio.}

\begin{tabular}{|l|l|}
\hline Nombre & Casa Hogar La Piedad \\
\hline Arquitectos & Isaac Libaque Saenz \\
\hline Ciudad & Lima \\
\hline País & Perú \\
\hline Área & $2050 \mathrm{~m} 2$ \\
\hline Año Proyecto & 2009 \\
\hline
\end{tabular}

El centro para adultos mayores "Casa Hogar La Piedad" se ubica en la ciudad de Lima - Perú, exactamente en el distrito de Breña. El terreno del proyecto cuenta con un área de 2050m2 los cuales fueron entregados a inicios del año 2006. En octubre de ese mismo año se iniciaron las coordinaciones y los trámites para llevar a cabo el proyecto que concluyó en mayo del año 2009. El centro ha sido financiado con el apoyo de diversas familias extranjeras, la Fundación Wilhel Oberle, y con el apoyo de empresas como Corporación Aceros Arequipa, Asociación Tocongo, Cementos Lima, Cerámica Lima y Ladrillos Forte.

El asilo fue inaugurado hace 10 años, es administrado por las hermanas de la Congregación Religiosas de Las Hijas de Nuestra Señora de la Piedad. Además, son ellas las encargadas de atender a los adultos mayores que residen en las 
instalaciones, los cuales tiene como característica el no necesitar atención médica constante debido a que el centro no cuenta con un cuerpo médico permanente.

Figura 4.5.1.1: Fachada Casa Hogar La Piedad.

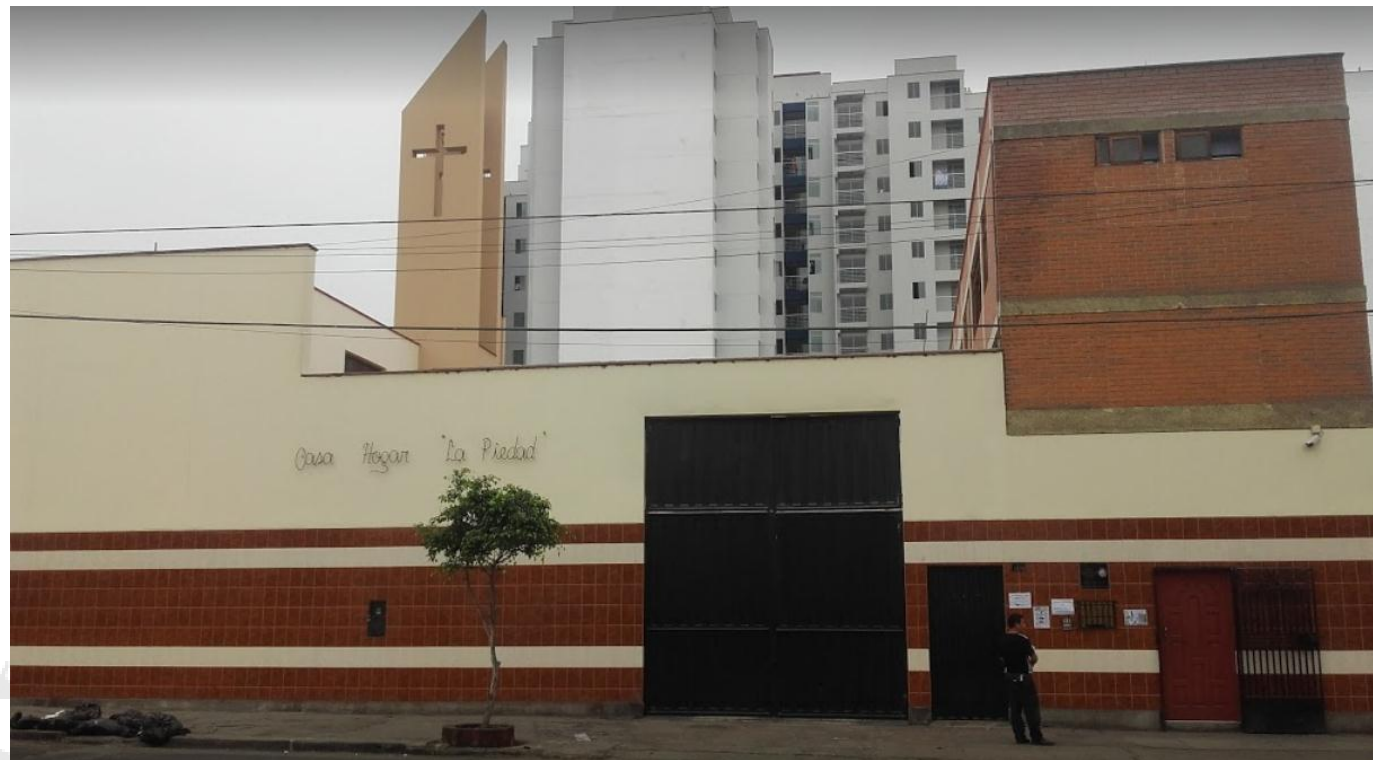

Fuente: (Google Maps , s.f.)

\subsubsection{Relación con el entorno.}

La Casa Hogar "La Piedad" se encuentra en una zona céntrica de la Ciudad de lima, a unos 2.9 kms del Centro Histórico y en una zona en la que los edificios multifamiliares comienzan a ser protagonistas. Este proyecto se encuentra muy cerca a la Av. Brasil, una de las más importantes de la ciudad, y exactamente en la cuadra 16 de la Av. General Varela.

Figura 4.5.2.1: Ubicación de la ciudad de Lima.

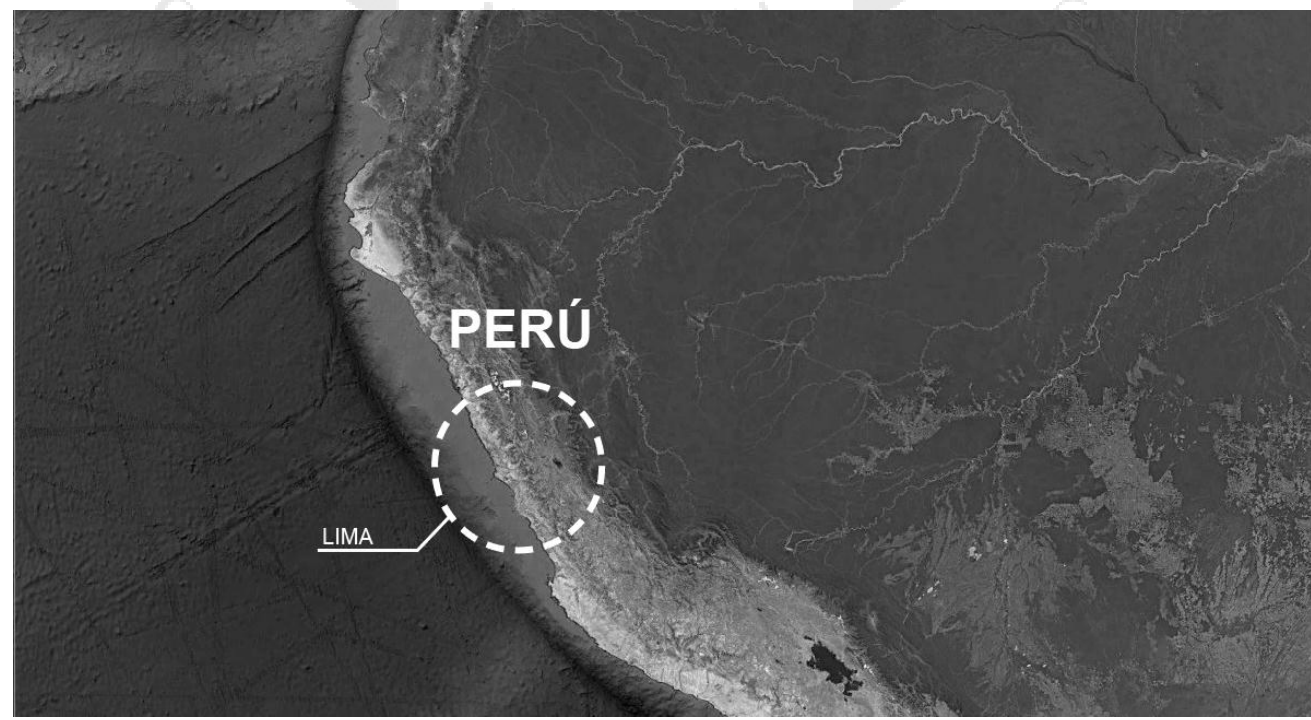

Fuente: Google Earth. Modificado por autor. 
Figura 4.5.2.2: Ubicación del proyecto en la ciudad de Lima.

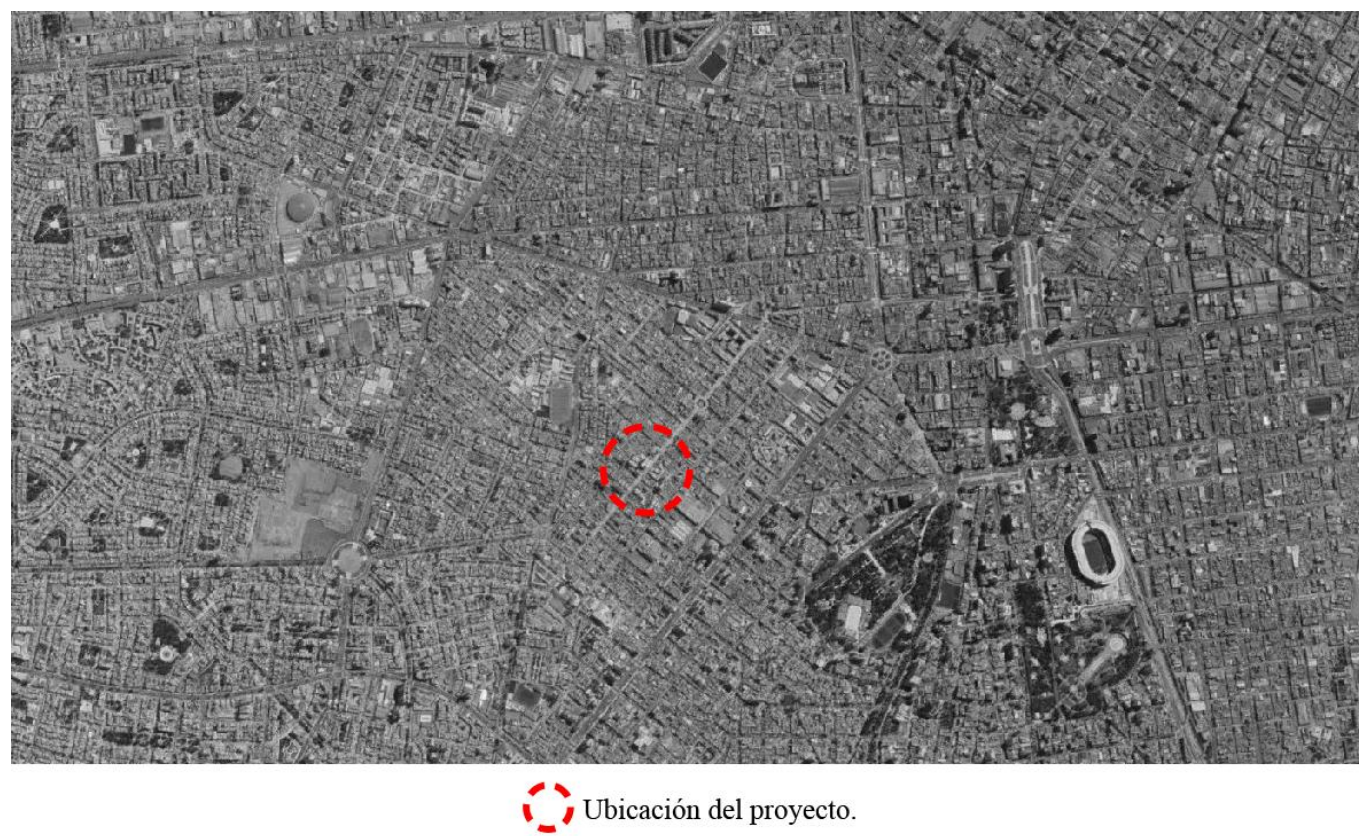

Fuente: Google Earth. Modificado por autor.

Las vías de transporte principales cercanas a la Casa Hogar son la Av. Brasil y Av. Aguarico, seguido de estas se encuentran la Calle Independencia y la Av. General Varela. En esta última se ubica el proyecto Casa Hogar La Piedad, por lo tanto, es por donde se da el ingreso peatonal y vehicular.

Figura 4.5.2.3: Ubicación del proyecto en la ciudad de Lima.

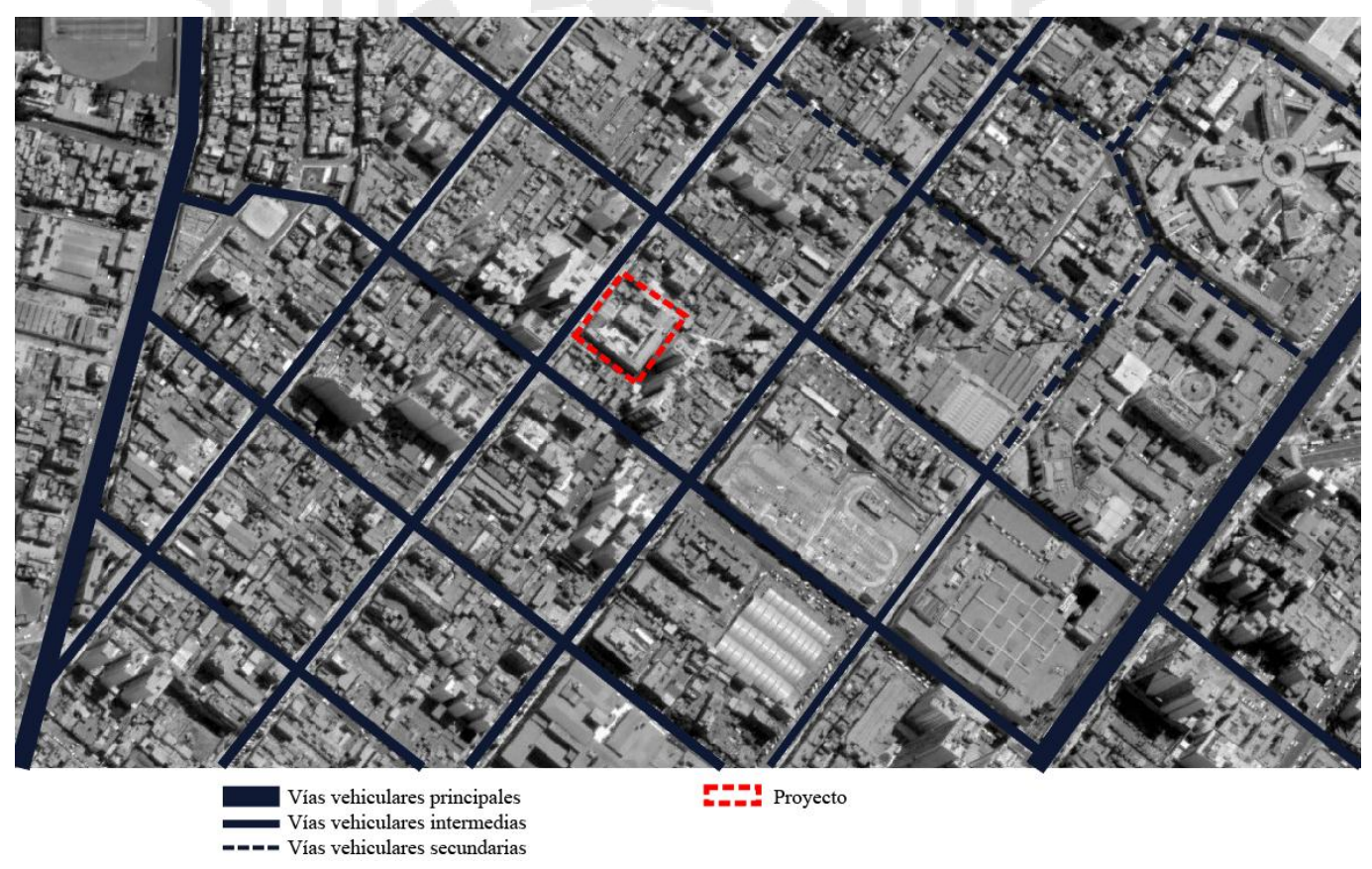

Fuente: Google Earth. Modificado por autor. 
La zona en la que se ubica, en promedio, es de tránsito peatonal medio debido a la cercanía con grandes avenidas, centro comercial y comercio zonal bajo. Además, cerca al proyecto existen vías de transporte público, por lo tanto, se ubican ciertos paraderos que permiten que la Casa Hogar sea accesible.

Figura 4.5.2.4: Ubicación del proyecto en la ciudad de Lima.

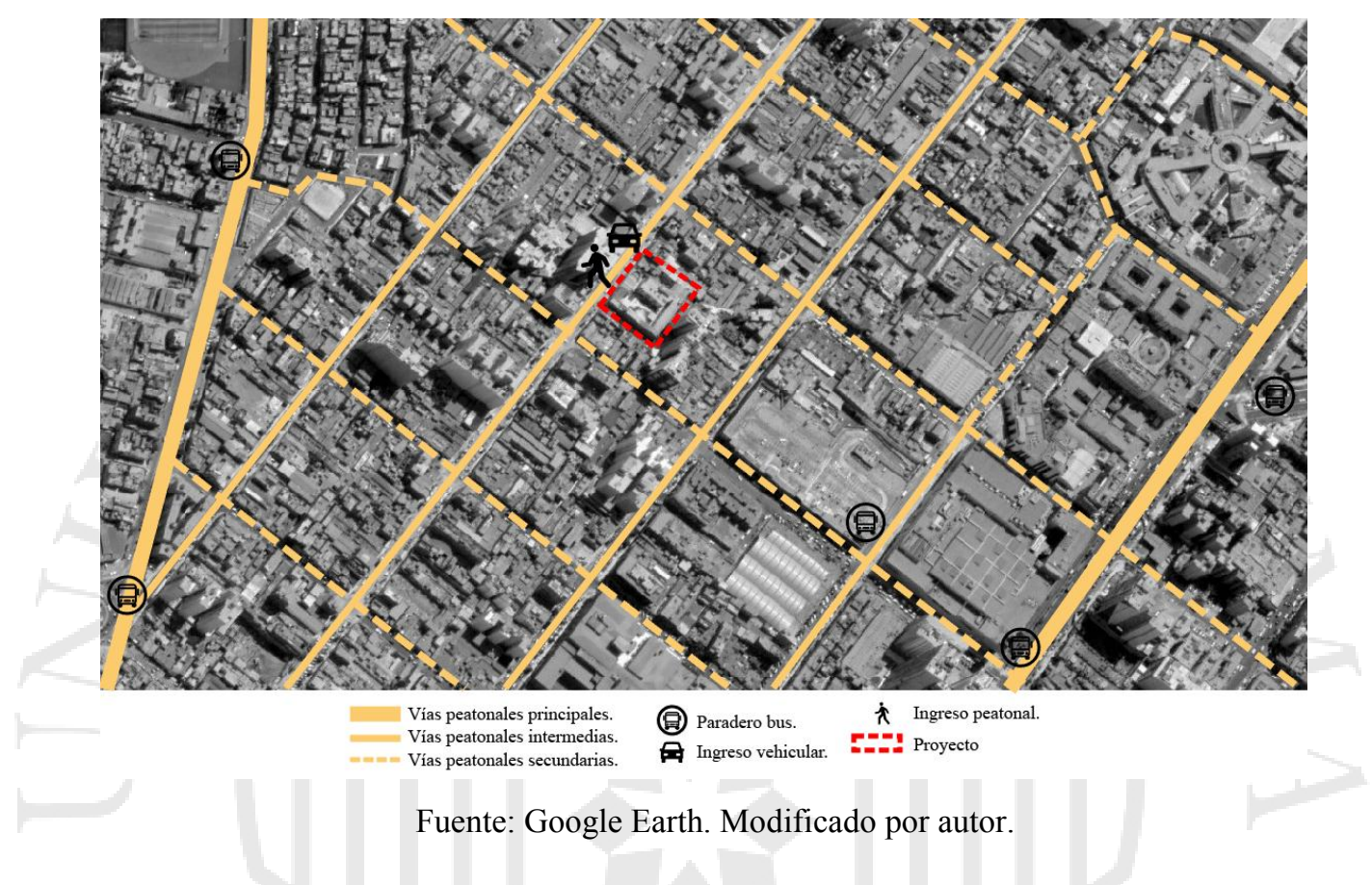

4.5.3. Programa y relaciones programáticas.

El siguiente análisis muestra el aporte porcentual de cada ambiente el centro. Las áreas generales se dividen por las características de los servicios que ofrece: área administrativa, servicios complementarios, residencia para adultos mayores y área de trabajadores. 
Figura 4.5.3.1:

Planta dividida por áreas - nivel 1.

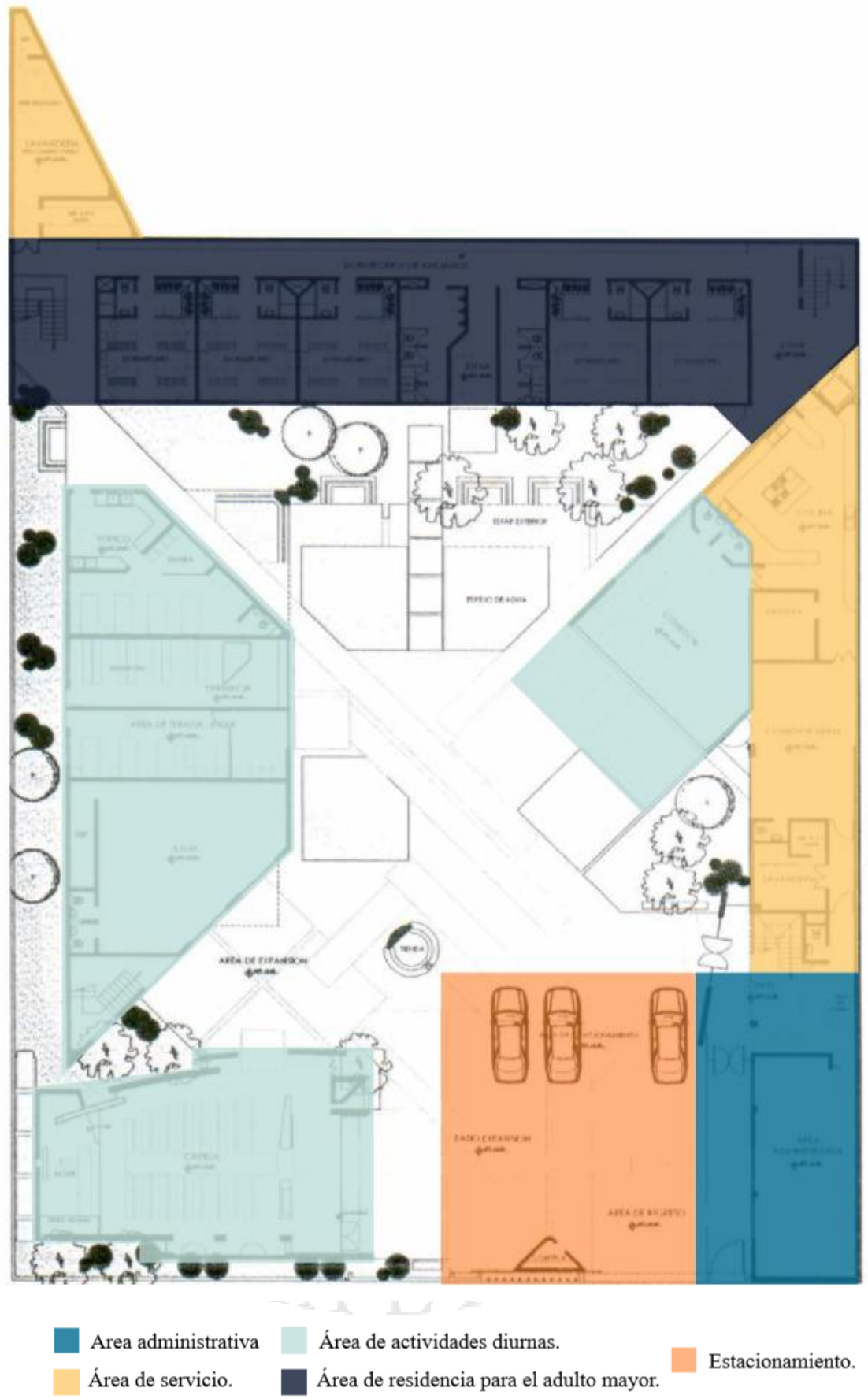

Fuente: (Congregación Religiosas de Las Hijas de Nuestra Señora de la Piedad, 2016).

Modificado por autor. 
Figura 4.5.3.2:

Planta dividida por áreas - nivel 2.

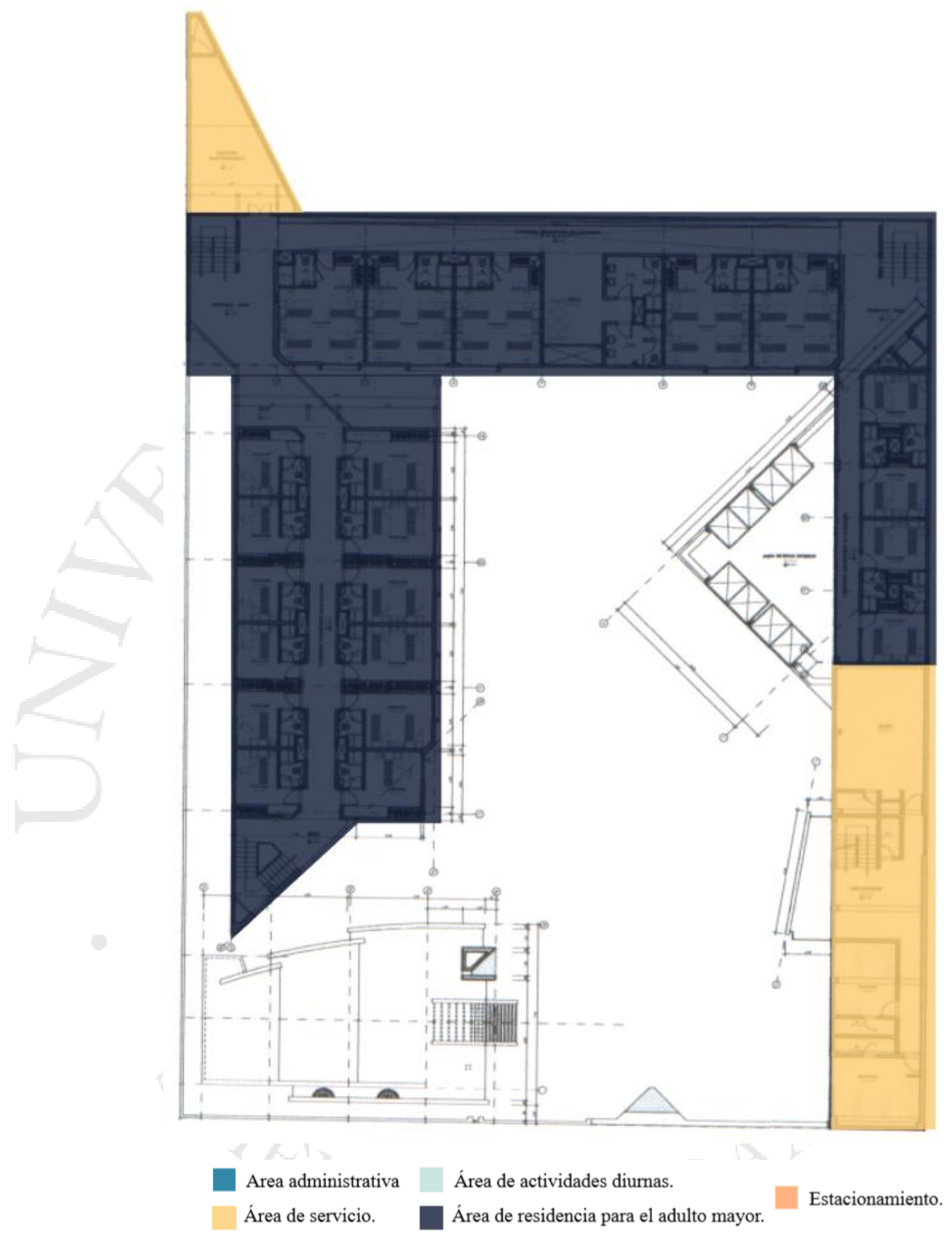

Fuente: (Congregación Religiosas de Las Hijas de Nuestra Señora de la Piedad, 2016). Modificado por autor. 
Tabla 4.5.3.1: Cuadro de áreas

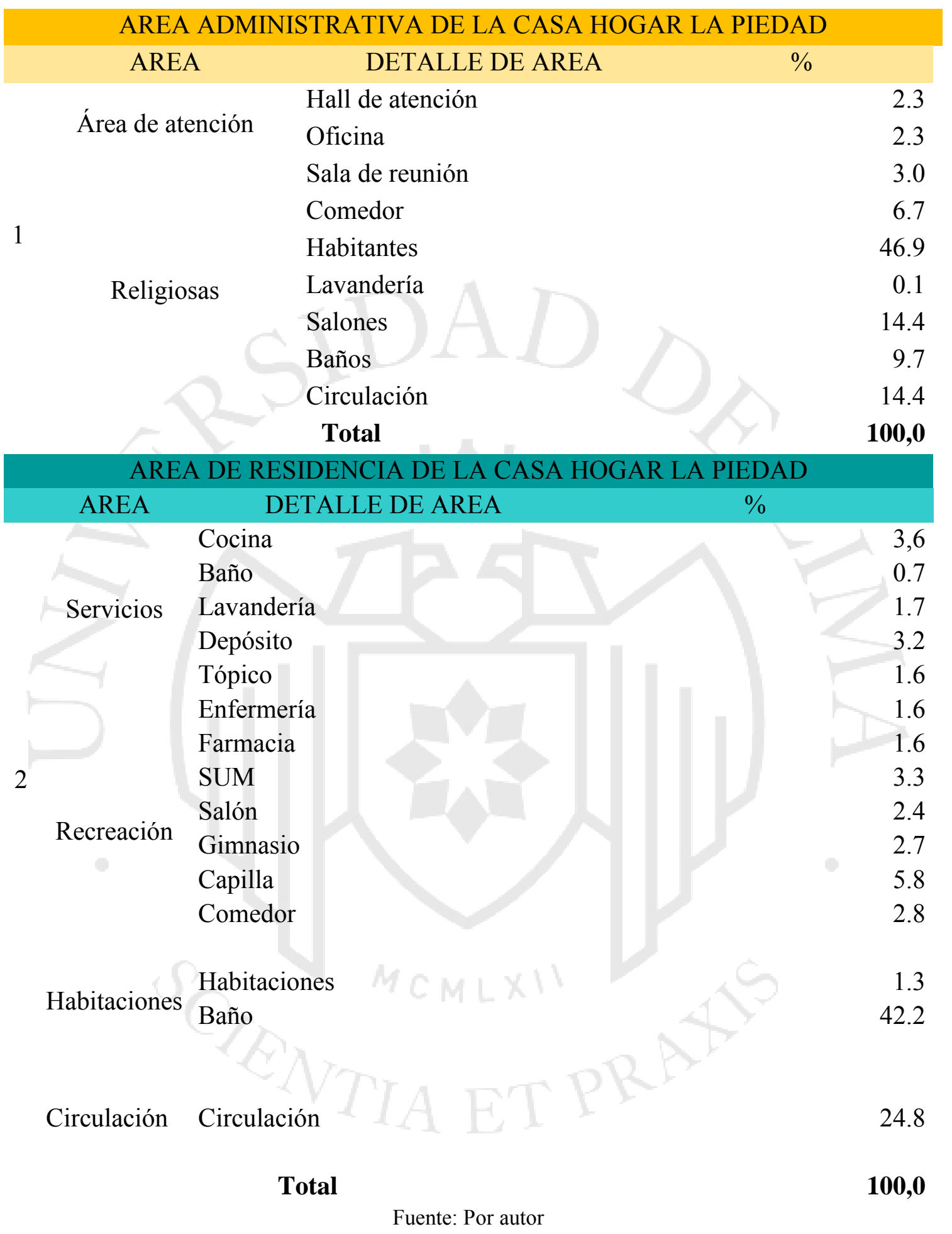


4.5.4. Estrategias de emplazamiento.

Figura 4.5.4.1: Estrategias de emplazamiento
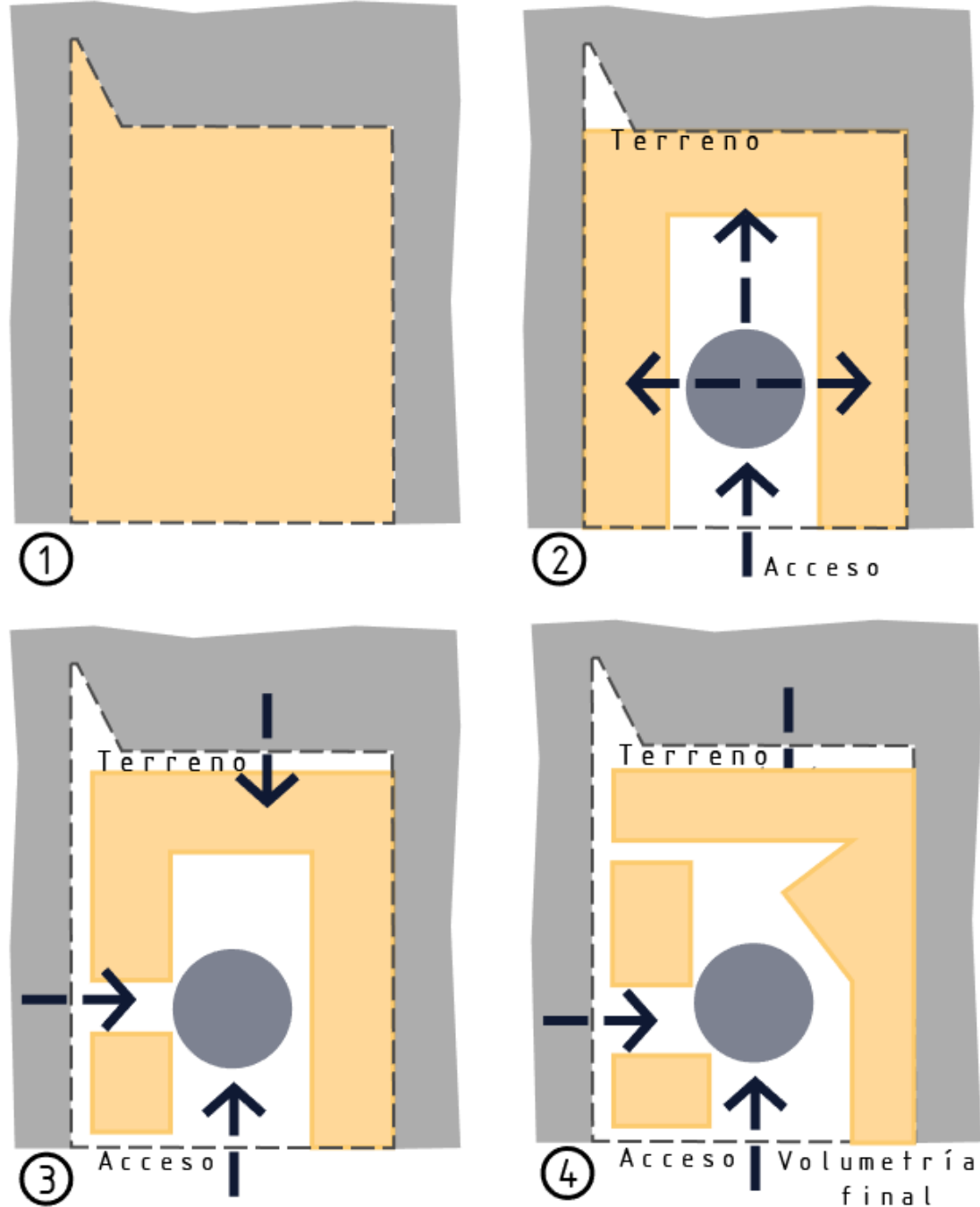

[-- Limite de terreno

Terreno vecino

Patios

Fuente: (Congregación Religiosas de Las Hijas de Nuestra Señora de la Piedad, 2016).

Modificado por autor.

La Casa Hogar "La Piedad", es un proyecto de forma casi regular ubicado entre linderos, por lo tanto, tiene el reto de optimizar el espacio ante esta limitante.

Desde el exterior se observa un proyecto que se aísla del entorno con un gran muro y dos puertas. Esto evita una conexión entre el centro y el entorno en el que se encuentra, rompiendo así una relación de integración. 
Al ingresar al proyecto, se observa un gran patio central rodeado de volúmenes 3 volúmenes que virtualmente forman una "U". Por otro lado, para ganar ingresos de luz y ventilación, el proyecto toma como estrategia el retirarse algunos metros de dos de sus linderos, de esta forma genera pequeños tragaluces en los que se ha utilizado la vegetación.

\subsubsection{Flujos y circulaciones.}

El siguiente análisis muestra la intensidad de flujo peatonal en cada zona de la Casa Hogar. Se puede observar cuales son las áreas con mayor acceso y las más privadas. Las áreas con mayor flujo de personas son en las que se desarrollan las actividades diurnas para los adultos mayores, además, es importante resaltar que el proyecto cuenta con una gran capilla a la que también pueden ingresar los vecinos de la zona en los horarios de misa, por lo tanto, es uno de los espacios más concurridos.

Por otro lado, las áreas de menor flujo de personas son el área de servicio del personal, los dormitorios de los residentes del instituto y el área en el que viven las religiosas. 
Figura 4.5.5.1: Plano de flujos y circulaciones

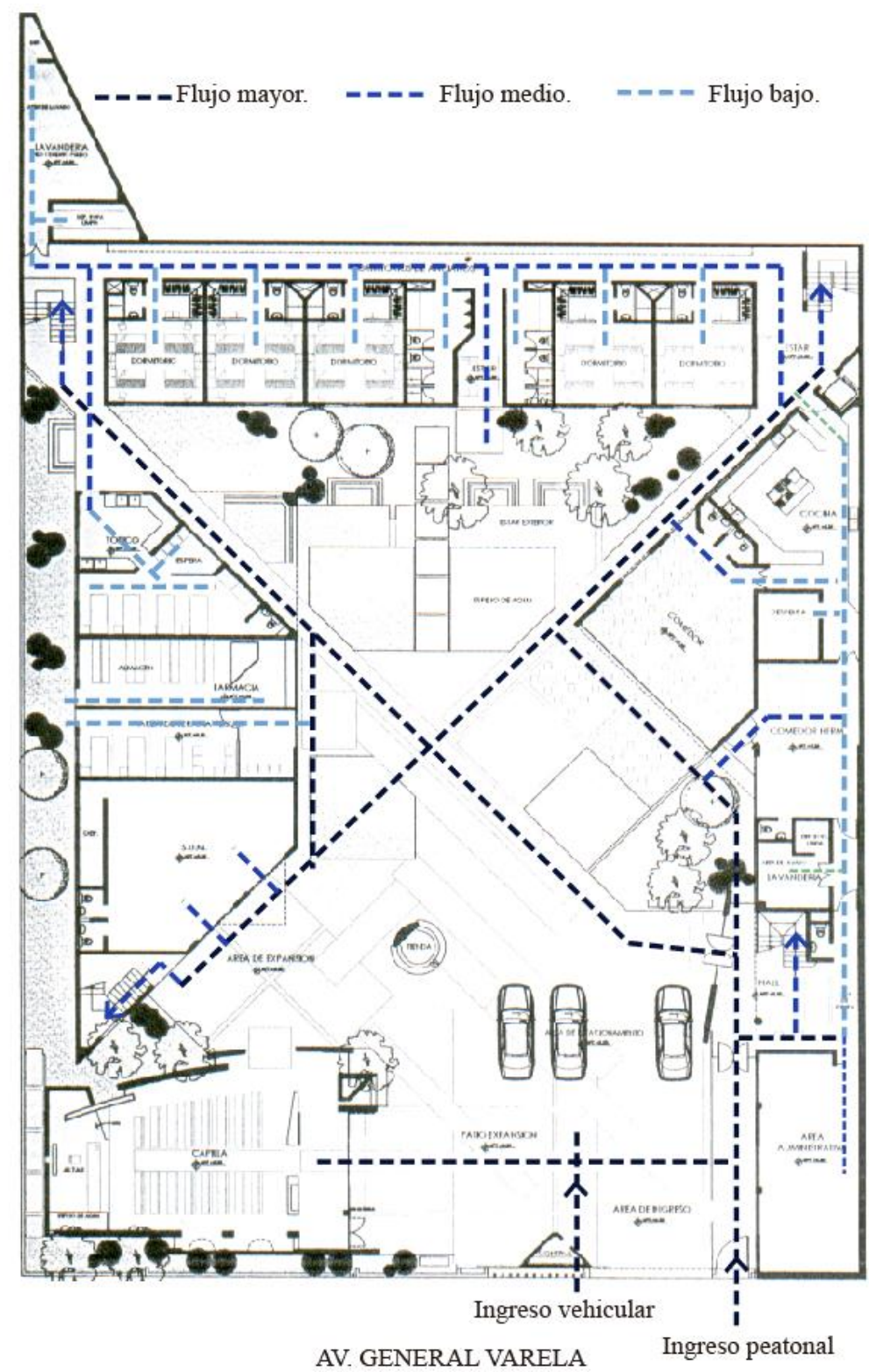

Fuente: (Congregación Religiosas de Las Hijas de Nuestra Señora de la Piedad, 2016).

Modificado por autor. 
Figura 4.5.5.2: Plano de flujos y circulaciones

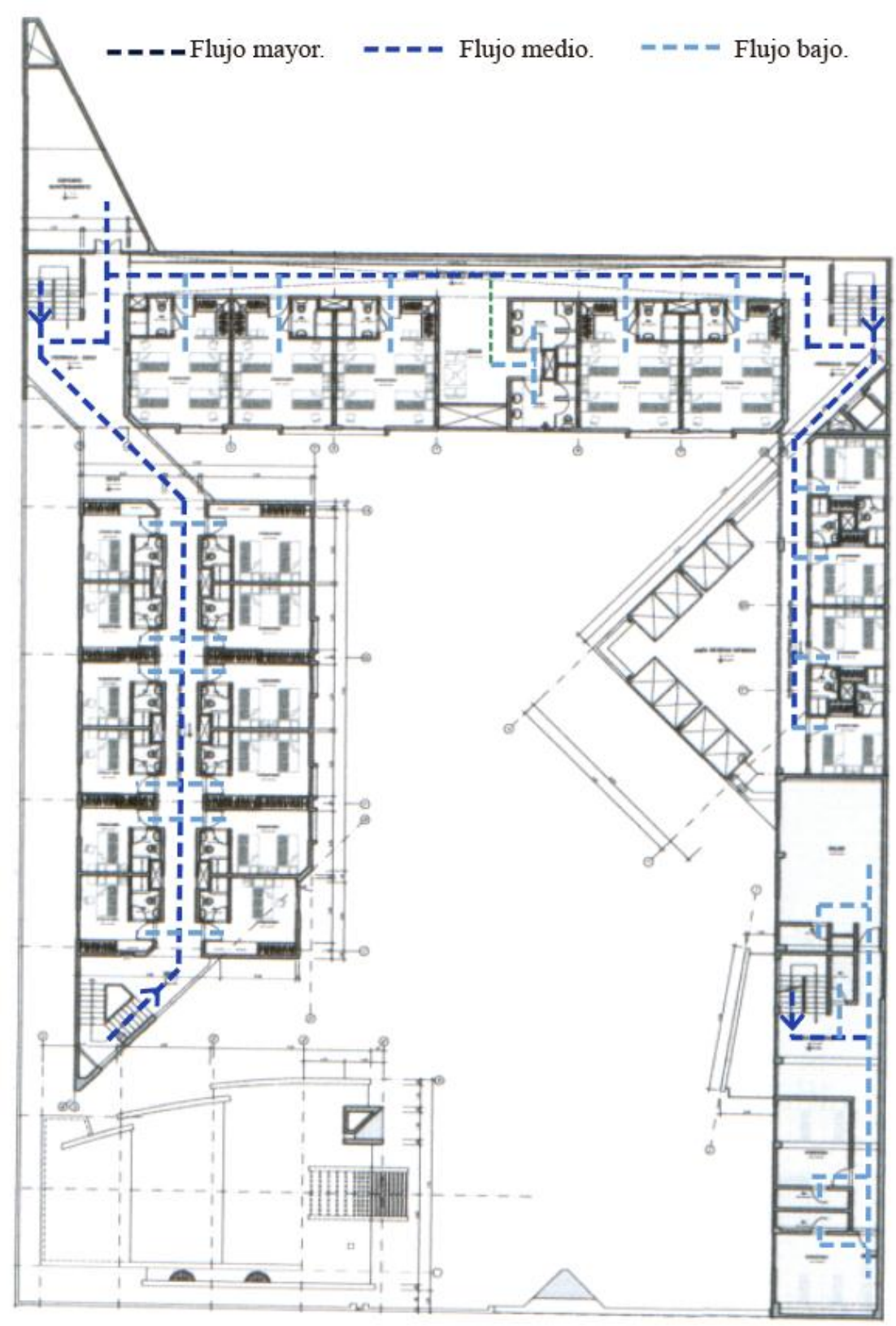

AV. GENERAL VARELA

Fuente: (Congregación Religiosas de Las Hijas de Nuestra Señora de la Piedad, 2016). Modificado por autor. 
4.5.6. Área construida y área libre.

Este proyecto tiene pequeñas áreas libres en sus bordes que tienen como función el retirarse de los linderos, estos espacios no cuentan con ningún tipo de actividad debido a sus mínimas dimensiones. Por otro lado, la Casa Hogar "La Piedad" ubica su área libre en el patio central que articula y une visualmente todo el proyecto.

4.5.7. Relaciones espaciales.

Figura 4.5.7.1: Esquema de área construida y área libre

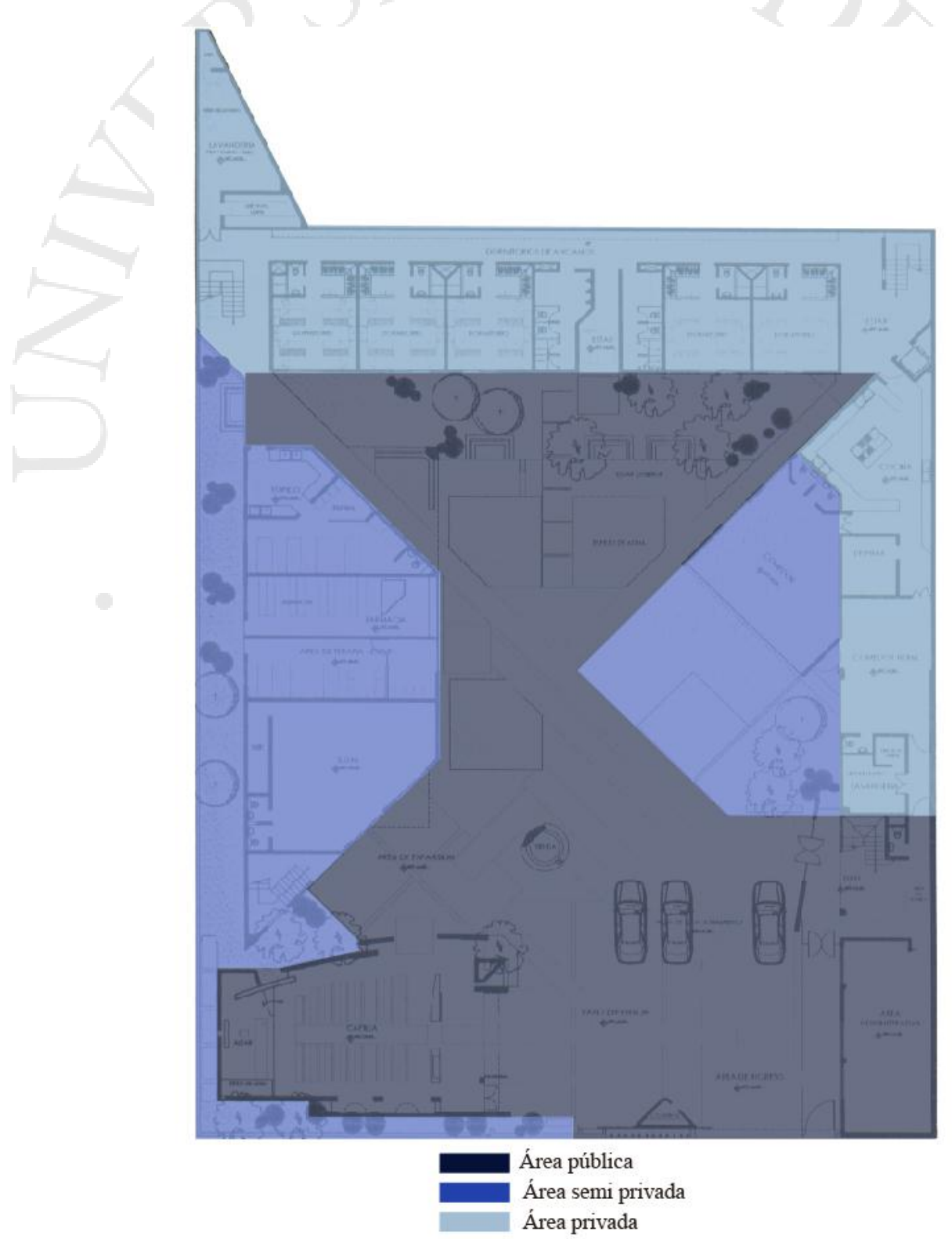

Fuente: (Congregación Religiosas de Las Hijas de Nuestra Señora de la Piedad, 2016). Modificado por autor. 
Figura 4.5.7.2: Esquema de área construida y área libre

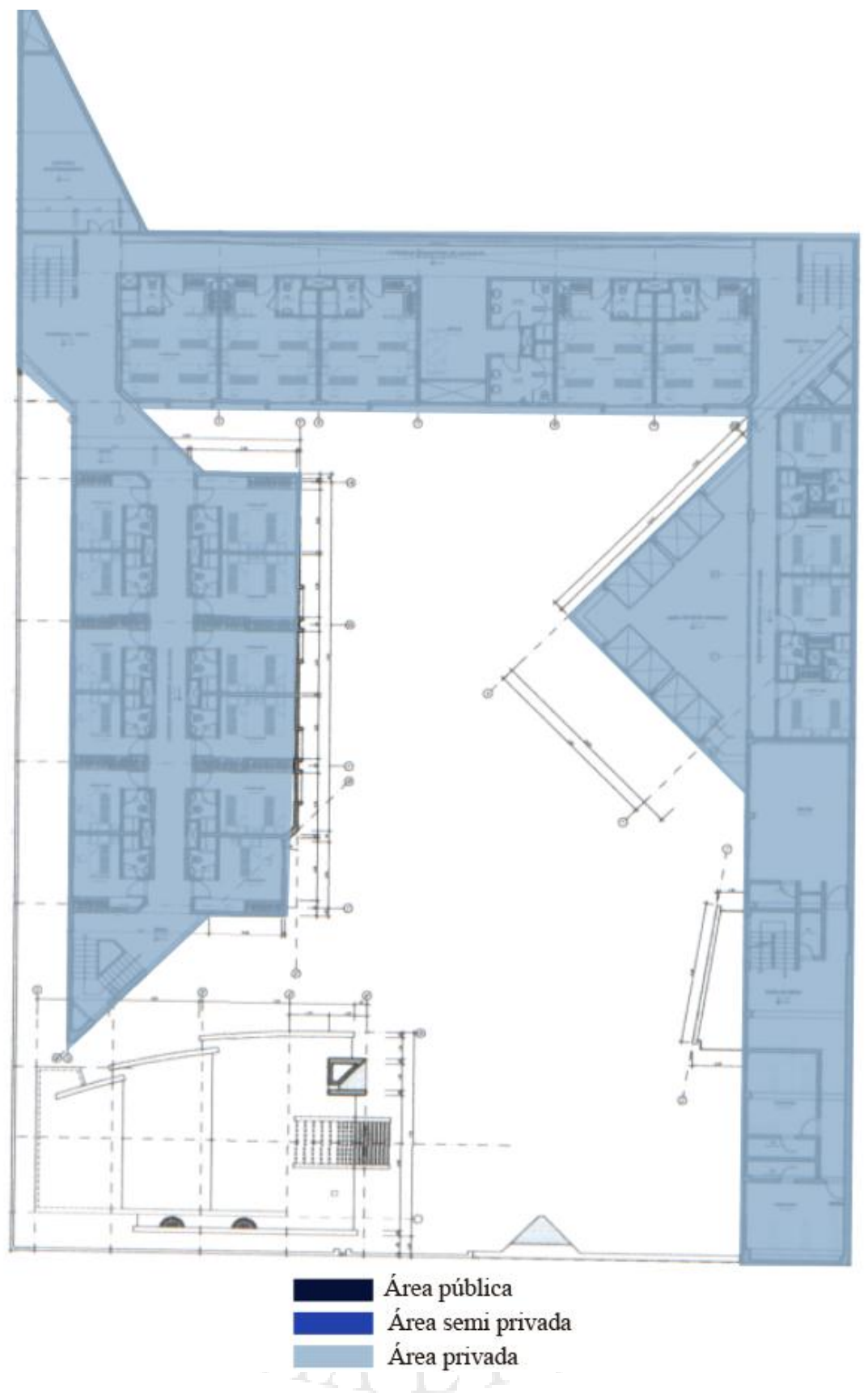

Fuente: (Congregación Religiosas de Las Hijas de Nuestra Señora de la Piedad, 2016). Modificado por autor. 


\subsubsection{El dormitorio.}

A diferencia de los proyectos anteriormente analizados, la Casa Hogar "La Piedad" tiene una propuesta de dormitorios compartidos de 2 y 4 adultos mayores, además, cada una de las habitaciones cuenta con un baño completo.

\subsubsection{Impacto social.}

La Casa Hogar "La Piedad" es uno de los 500 centros de atención para el adulto mayor que hay en Lima. Actualmente cuenta con un apoyo parcial de donaciones de alimentos e implementos algunas ONGs y empresas que se han sumado al compromiso de darles una mejor calidad de vida a las personas de la tercera edad.

\subsubsection{Conclusiones.}

\subsection{Conclusiones Parciales}

Este capítulo explica proyectos existentes con características referenciales que se deben aplicar en la "Residencia y Centro de Día para el Adulto Mayor de Chorrillos y Alto Perú".

De los ejemplos se concluye que los centros para personas de la tercera edad que se ubican en zonas urbanas pueden funcionan óptimamente, y que no es necesario tener que alejarse del entorno en el que el adulto mayor ha vivido a lo largo de su vida para crear un lugar en el que puedan encontrar tranquilidad, descanso y especialmente en el que sigan desarrollando sus capacidades físicas y mentales.

Asimismo, cada uno de estos cuenta con características que ayudan a que la estancia del adulto mayor sea placentera y segura. Basándonos en la definición de neuroarquitectura, se puede señalar que los proyectos desarrollados cumplen con la definición de este concepto. Por ejemplo, estos son tener en cuenta el orden y ubicación de los ambientes que se relacionan entre sí, las dimensiones necesarias de los espacios sociales y privados, el uso de diversos colores y materiales que le dan identidad a los espacios, el trabajo con los ingresos de iluminación y ventilación a los ambientes más concurridos, la conexión con los patios y áreas verdes, etc.

Finalmente, se concluye que son importantes los ambientes de reunión como actividad para que las personas de la tercera edad puedan seguir relacionándose entre ellos. Esto logra fomentar la integración del adulto mayor y también reduce la sensación de soledad y aislamiento que se puede padecer a esta edad. 
En el siguiente cuadro comparativo se resume cada uno de los casos estudiados.

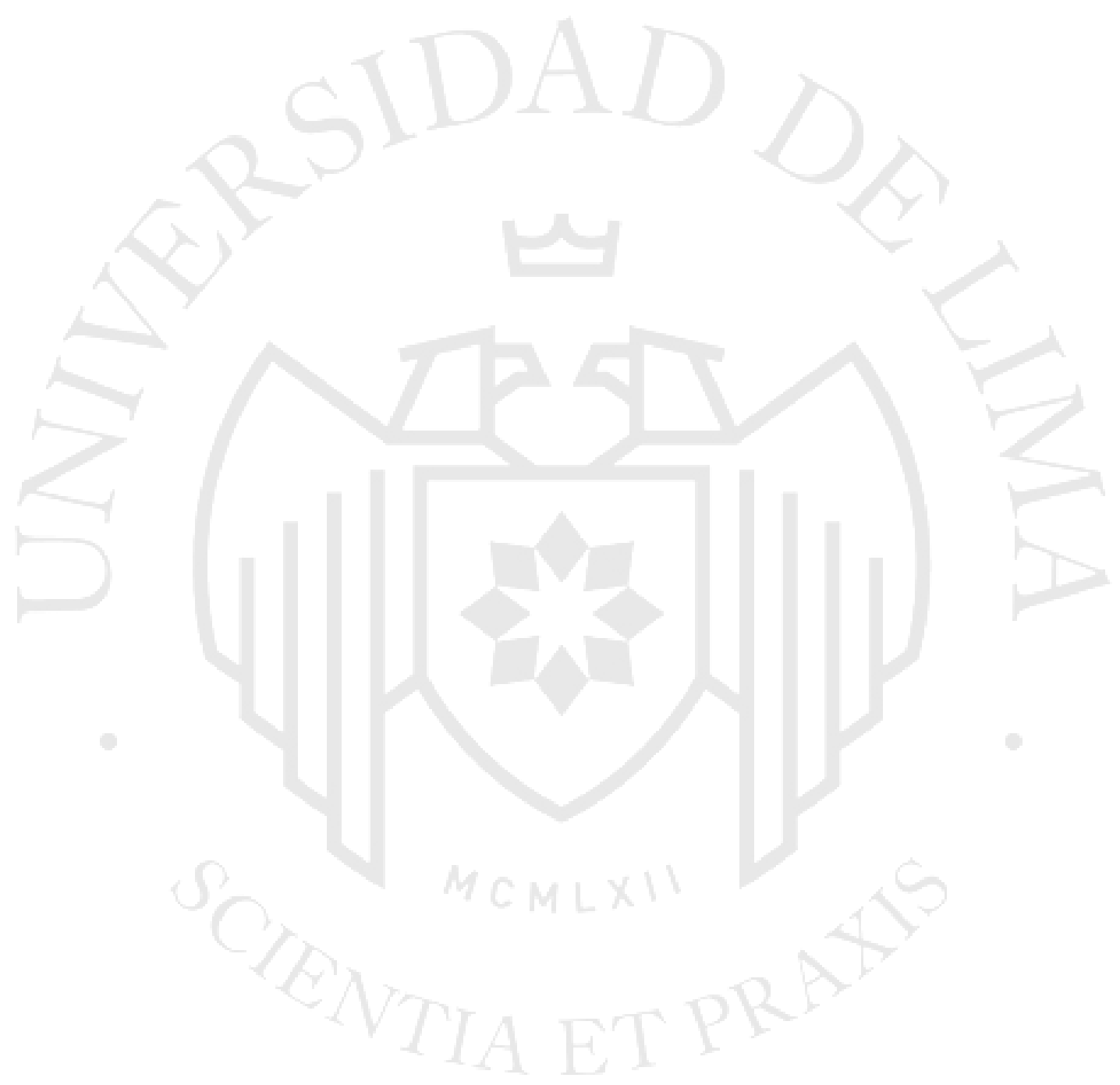


REFERENTES EJEMPLOS DE PROYECTOS PARA ADULTOS MAYORES

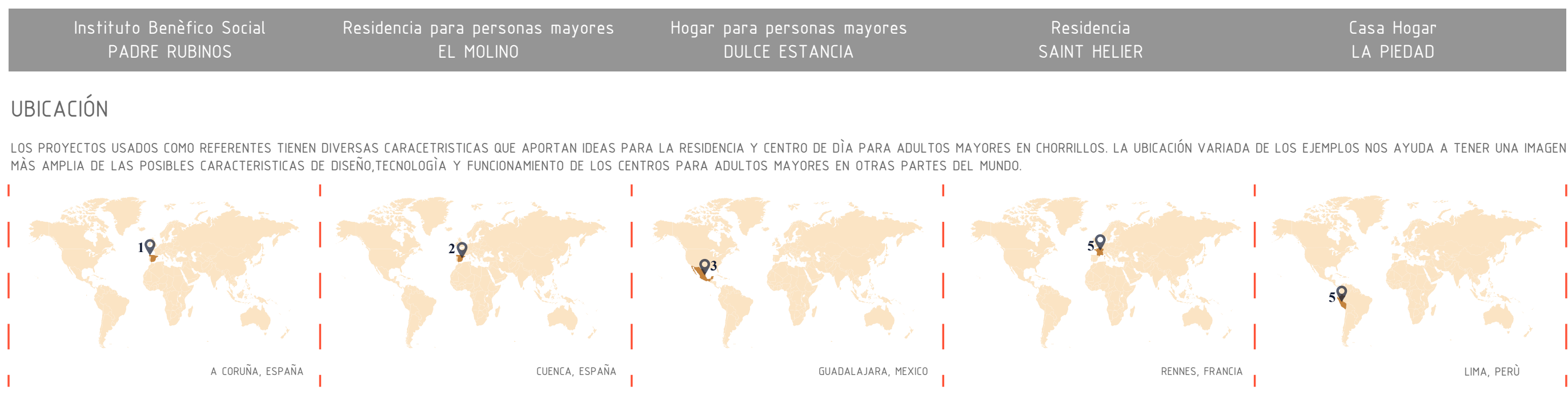

CONTEXTO Y ENTORNO

LOS PROYECTOS REFERENTES SE DESARROLLAN EN CONTEXTOS URBANOS CON ACTIVIDAD COMERCIAL MEDIA Y ALTA.
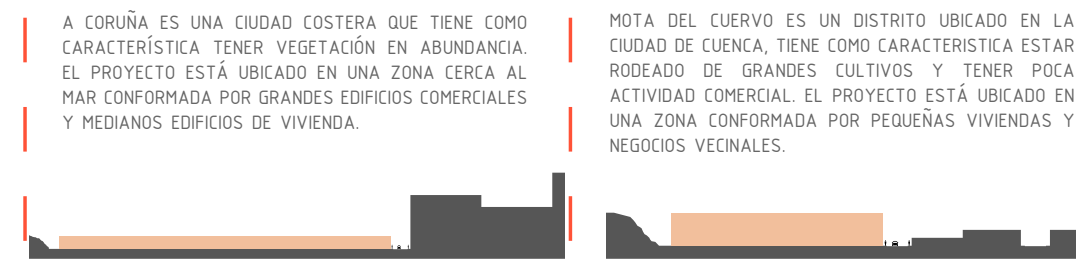

GUADALAJARA ES UNA GRAN CIUDAD AL OESTE DE
MEXXICO. EL PROYECTO ESTÁ UBICADO EN UNA ZONA
URBANA BASTANTE DESARROLLADA Y CON GRAN

aCtVIIDAD EN LAS AVENIDAS CERCANAS. LA MAYORÍA
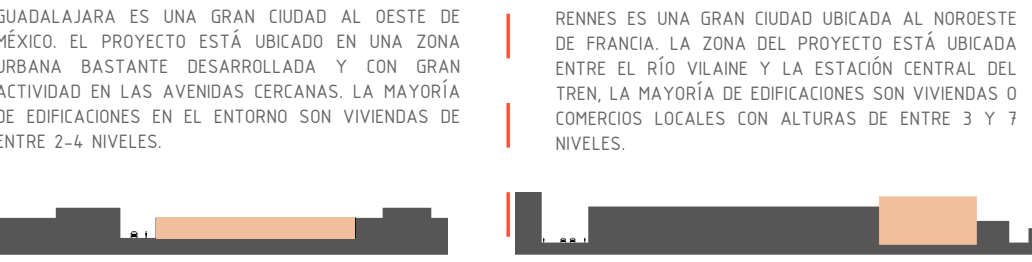

LIMA ES UNA GRAN CIUDAD UBICADA EN LA COSTA
PERUANA. LA ZONA DEL PROYECTO SE ENCUENTRA EN UN DISTRITO CON EDIFLCALIONES MEDIAAAS ENTRE

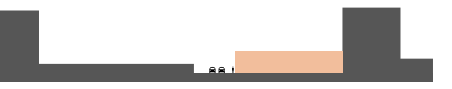

PLANTA GENERAL - ESQUEMA PATIOS

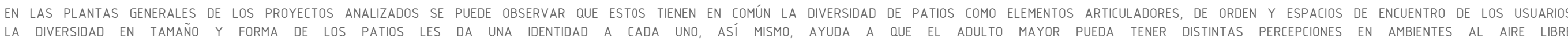

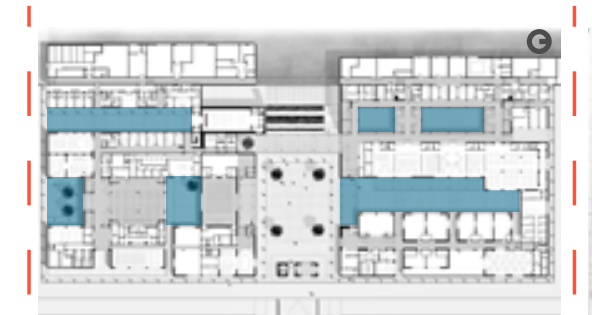

$=\mathrm{l}$

6 PATIOS

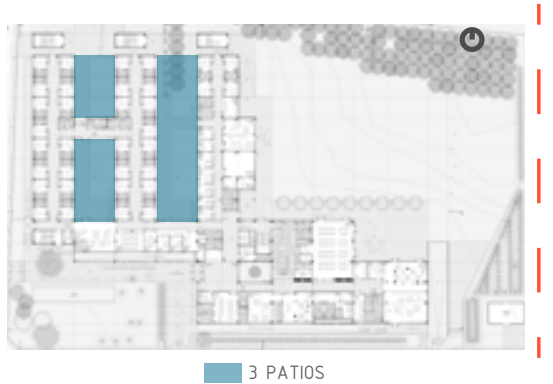

I PATIOS

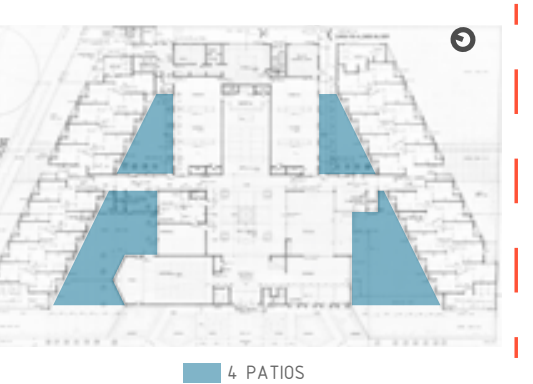

4 PATIOS

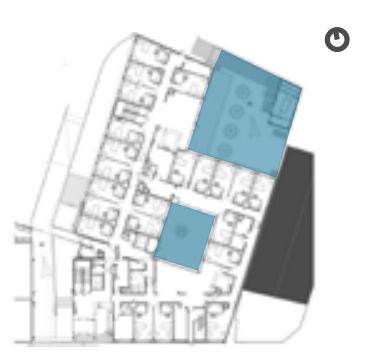

2 PATIOS

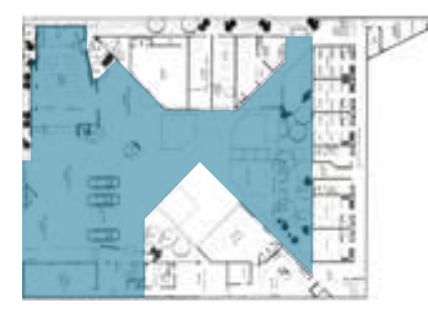

1 PATIO

FOTOGRAFÍA
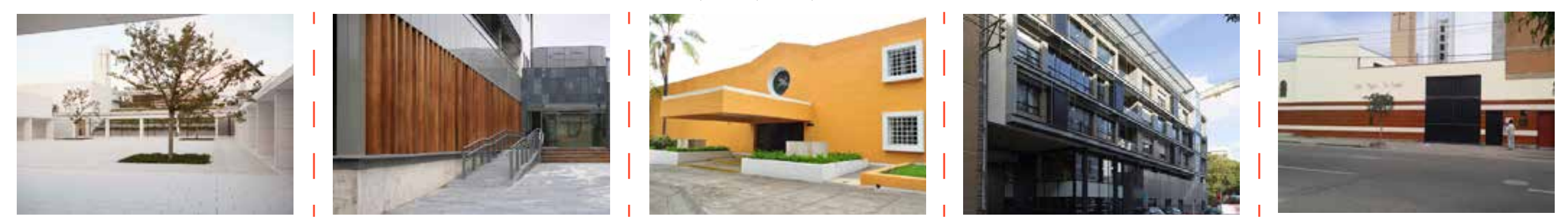

PROGRAMA

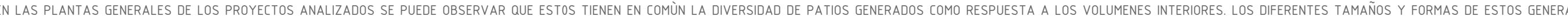
UNA IDENTIDAD A CADA UNO Y AYUDA A QUE EL ADULTO MAYOR PUEDA TENER DISTINTAS PERCEPCIONES EN AMBIENTES AL AIRE LIBRE.
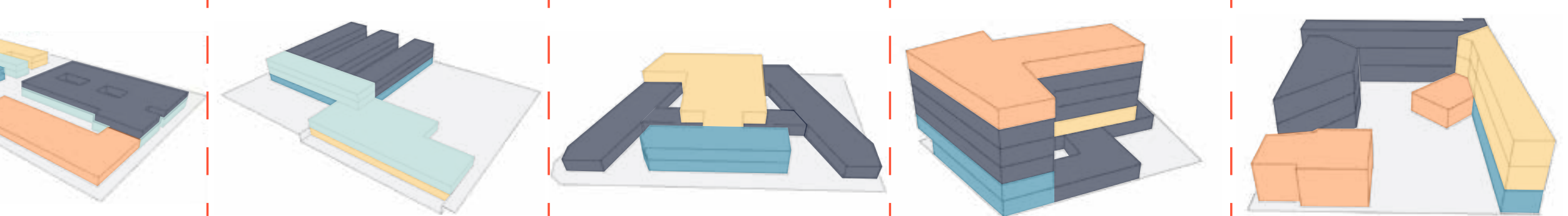

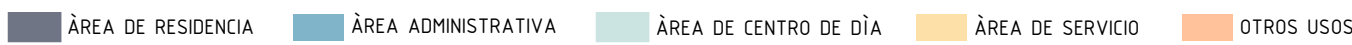

DORMITORIO

EL DORMITORIO PARA LOS ADULTOS MAYORES TIENE CARACTERÍSTICAS PARTICULARES QUE SE

$$
\text { । }
$$
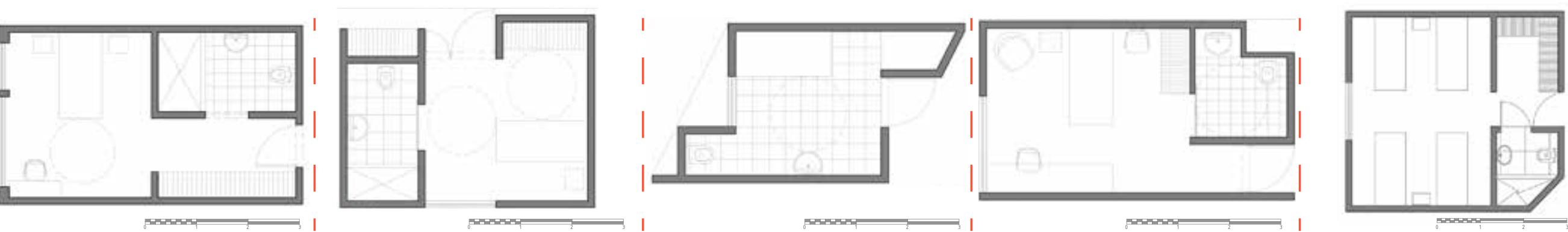


\section{CAPÍTULO V: MARCO CONTEXTUAL}

\subsection{Introducción a la zona.}

De la investigación se puede concluir que cuando una persona llega a la etapa de vejez es complejo que se adapte rápidamente a nuevas situaciones, a pesar de esto, los adultos mayores pasan por múltiples cambios que, de no ser tratados con cuidado, podrían ser perjudiciales para su salud física y mental. Estos cambios se explican en el capítulo III de la investigación y se dividen en 5 teorías que se tomarán en cuenta desde el inicio del desarrollo del proyecto.

En una de las teorías se explica que para los adultos mayores es perjudicial el cambio en las actividades cotidianas que inician o dejan de realizar, así como, el distanciamiento con sus seres queridos y el notar la aparición de ciertas dificultades físicas. Por lo tanto, se considera que los centros de atención al adulto mayor que se encuentran alejados del entorno cotidiano pueden generar impacto negativo en la relación entre los adultos mayores, familiares y trabajadores debido al quiebre de relación generada por la lejanía entre estos.

Por otro lado, según los estudios realizados por el Instituto Nacional de Estadísticas e Informática (INEI), se sabe que actualmente en nuestro país por cada 10 hogares hay 4 que tienen como miembro de familia un adulto mayor; además, es común que en las familias actuales los adultos del hogar salgan a trabajar para mantener la economía, de esta manera, dejan a los adultos mayores solos en casa, con la responsabilidad del cuidado de los nietos o viceversa.

Por esta razón, el proyecto busca emplazarse en una zona urbana para así mantener la conexión con el entorno del adulto mayor, además, como respuesta a la situación de las familias actuales, se creará un lugar para Centro de Día en donde los adultos mayores puedan pasar su tiempo en un espacio en el que encuentren actividades y cuidado acorde a sus características. 
Por otro lado, se concluye que la ubicación de los centros de asistencia para adultos mayores está focalizada en la zona central de Lima Metropolitana, en distritos como: San Borja, Surco, Miraflores, Pueblo Libre, Magdalena y San Miguel. A consecuencia de esto, en el mapa de análisis de ubicación (Figura 7.1), se observa que hay zonas en la ciudad que no están cubiertas por centros que brindan atención a los adultos mayores. Esto sucede debido al poco interés y falta de organización de los municipios y el gobierno nacional que no priorizan los proyectos dirigidos a este sector de la población.

Es importante resaltar que los factores a tener en cuenta para el desarrollo de un proyecto para personas de la tercera edad parte desde una buena ubicación, es decir, considerar las características ambientales, de seguridad, accesibilidad y que el equipamiento urbano cercano sea complementario con las actividades y la seguridad para los ancianos.

Por tal motivo, se considera que una ubicación favorable para el proyecto a desarrollar es en el distrito de Chorrillos, zona de Lima sur ubicada en el límite costero de la ciudad. Chorrillos, es un distrito con múltiples características positivas que responden a los requerimientos necesarios para hacer que la estancia de los adultos mayores sea placentera.

\subsection{Distrito de Chorrillos.}

Chorrillos es un distrito costero que está ubicado en la zona sur oeste de Lima Metropolitana, limita por el norte con Barranco y Surco, al este con Villa el Salvador y San Juan de Miraflores y al sur y oeste con el Océano Pacífico. Tiene un área aproximada de $38.94 \mathrm{~km} 2$ y se encuentra a 37m.s.n.m.

Su nombre oficial es San Pedro de Chorrillos y se origina debido a los chorrillos de agua dulce subterránea que caía del acantilado hacia la zona de la playa Agua Dulces (Peru.com, s.f.), y dado que desde un principio inicio como un pueblo de pescadores. La fundación se da en 1688, época en la que las primeras construcciones fueron chozas de caña, luego le sucedió el adobe, con lo que se fue consolidando el 
progreso urbano del distrito iniciando con una población de 581 hombres y 470 mujeres. (Mar del Sur, s.f.)

Chorrillos es un distrito con acontecimientos históricos importantes, fue protagonista durante la Guerra del Pacífico con Chile, además fue una de las zonas más golpeados durante el terremoto de 1940 en el que quedó casi en escombros. Sin embargo, es un distrito que con organización ha logrado ser reconstruido y que hoy refleja en edificaciones parte de la historia.

Figura 5.1.: Chorrillos en 1940

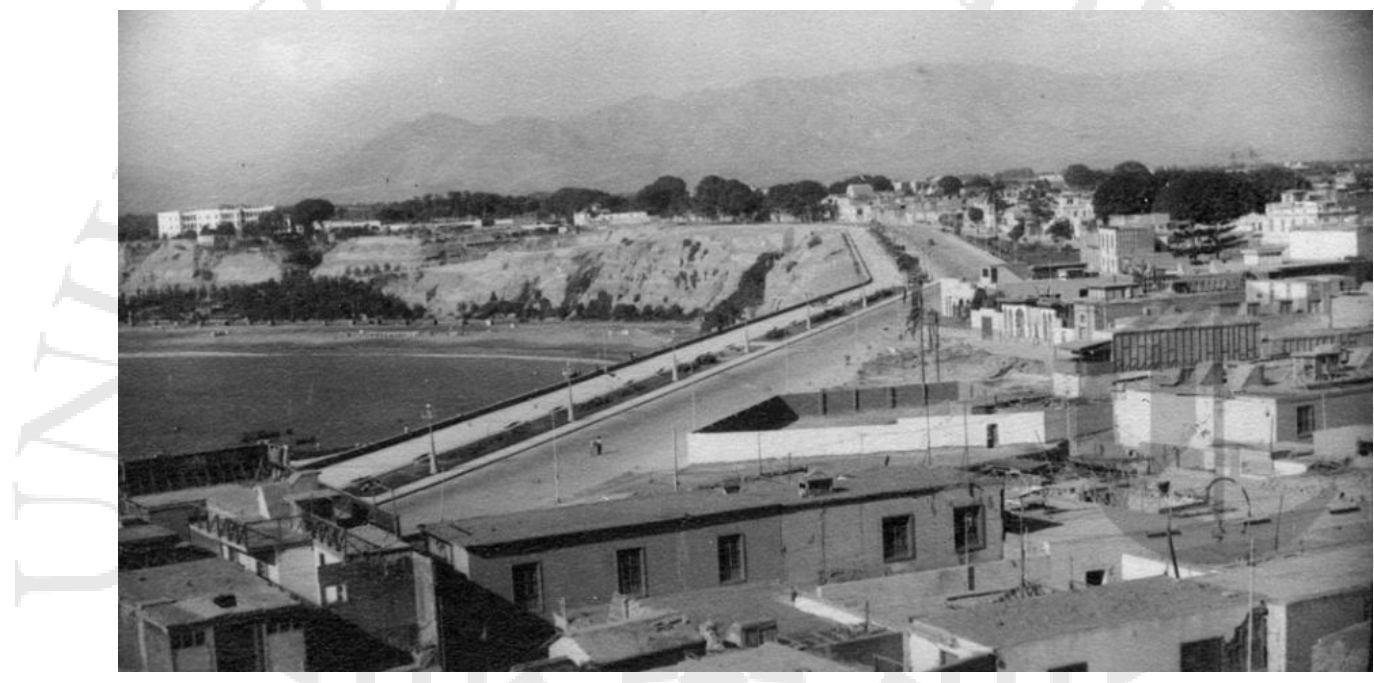

Fuente: (Peru.com, s.f.)

Figura 5.2: Chorrillos en 1940

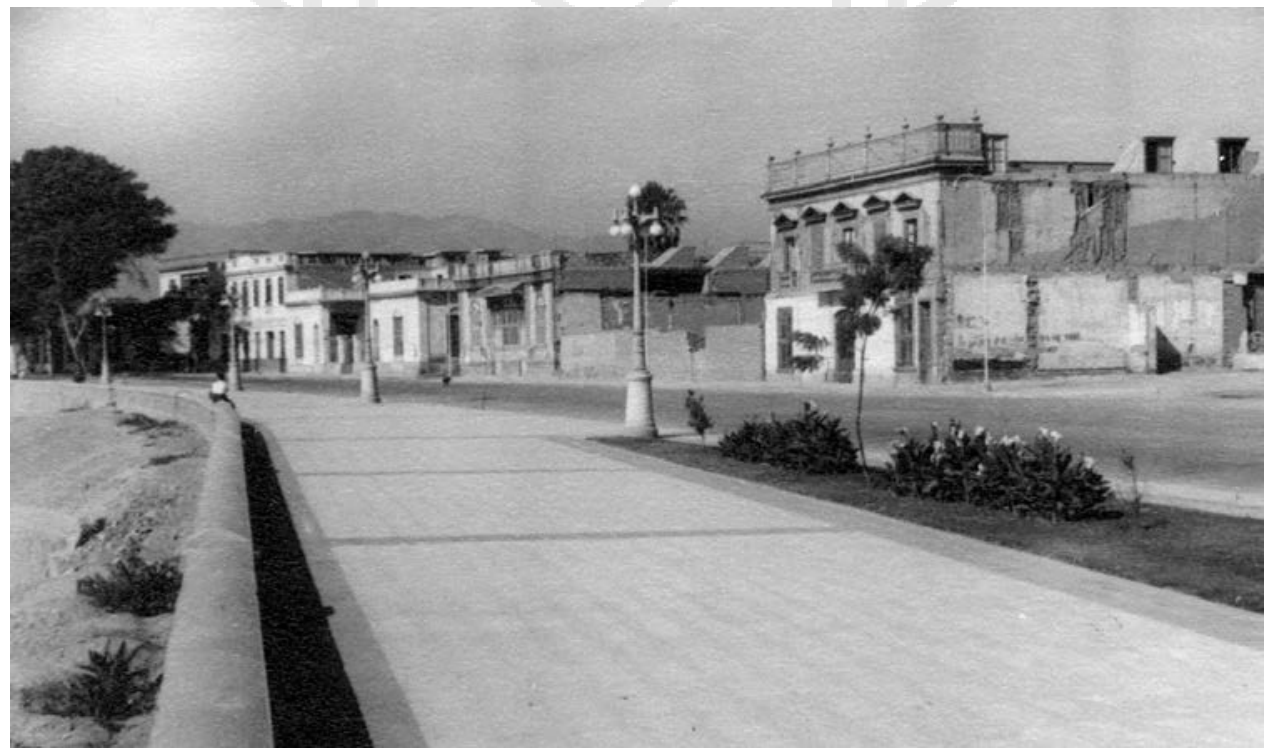

Fuente: (Peru.com, s.f.) 
El distrito se ubica a unos 20kms del centro de la Ciudad de Lima, y actualmente tiene un área de 44km2 aproximadamente y cuanta con una población de 325547 habitantes. (INEI, 2015). De los cuales 39 065, que representa el 12\% son personas de la tercera edad, por lo cual, es un distrito potencial para generar proyectos para este sector de la población.

Además, cuenta con hitos importante para la ciudad que enriquecen la importancia de este distrito. El morro solar es el más característico de este y desde el año 2010 cuenta con el planetario y observatorio más modernos del país, además, se ubica una gran Cruz que se puede observar desde cualquier punto de toda la costa verde. Chorrillos también es característico por sus playas, la más conocida de estas es la playa Agua Dulce, la cual es la más visitada por los limeños en época de verano.

5.3.Características de la zona.

Figura 5.3.1: Ubicación de terreno.

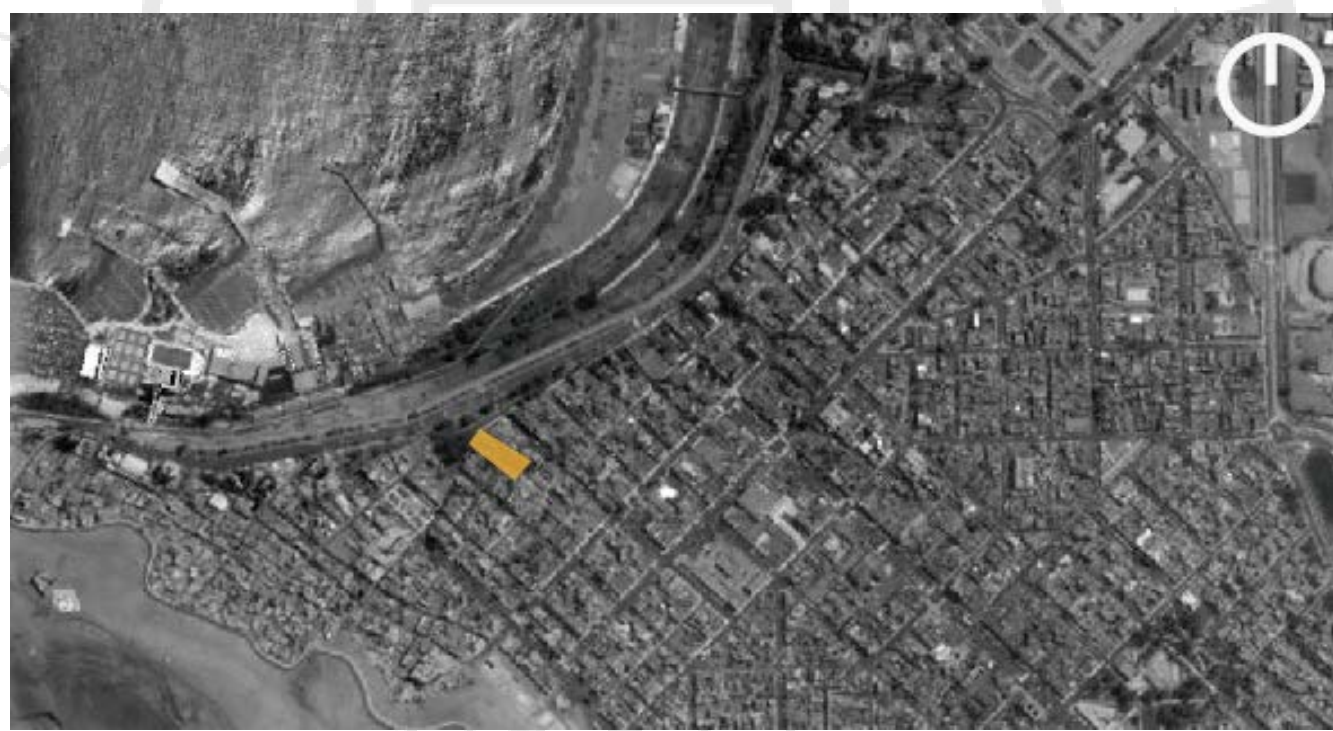

Fuente: Google Earth modificada por autor.

El proyecto está ubicado en la Zona Monumental del distrito, por lo cual, las construcciones tienen una densidad promedio entre 2 y 4 pisos, además, frente a este se encuentra el malecón de Chorrillos que cuenta con una vista privilegiada del mar y de toda la Costa Verde, así mismo, existen 3 plazas o parques en las que se podrán desarrollar diversas actividades complementarias a las del Centro de Día. 
El proyecto se ubica en una zona de fácil acceso, la avenida de mayor relevancia es la Av. Malecón Grau, la cual tiene conexión directa con el Circuito de Playas, vía que une a varios distritos de Lima que limitan con el mar; además, en la Av. Defensores del Morro, cercana al proyecto, se ubican paraderos de transporte público. El acceso peatonal y las otras vías que vuelven la zona accesible se detallarán más adelante.

Cerca de la ubicación del proyecto se desarrollan múltiples actividades que complementan el funcionamiento de la Residencia y Centro de día. Por ejemplo el Centro de Asistencia Chorrillos y Centro de Salud Lanatta Luján son de gran relevancia por si alguno de los adultos mayores requiere una atención especializada o de emergencia; los mercados y supermercados ayuda a evitar grandes desplazamientos del personal administrativo y operativo que realiza compras de alimentos e insumos necesarios para el funcionamiento del centro; la comisaría de Chorrillos y la estación de bomberos voluntarios estarán atentos ante cualquier eventualidad o emergencia y solo deberán recorrer pocos metros para llegar al proyecto; finalmente, la ubicación de la Municipalidad de Chorrillos es importante para realizar operaciones y coordinaciones con esa entidad.

Figura 5.3.2: Ubicación de terreno.

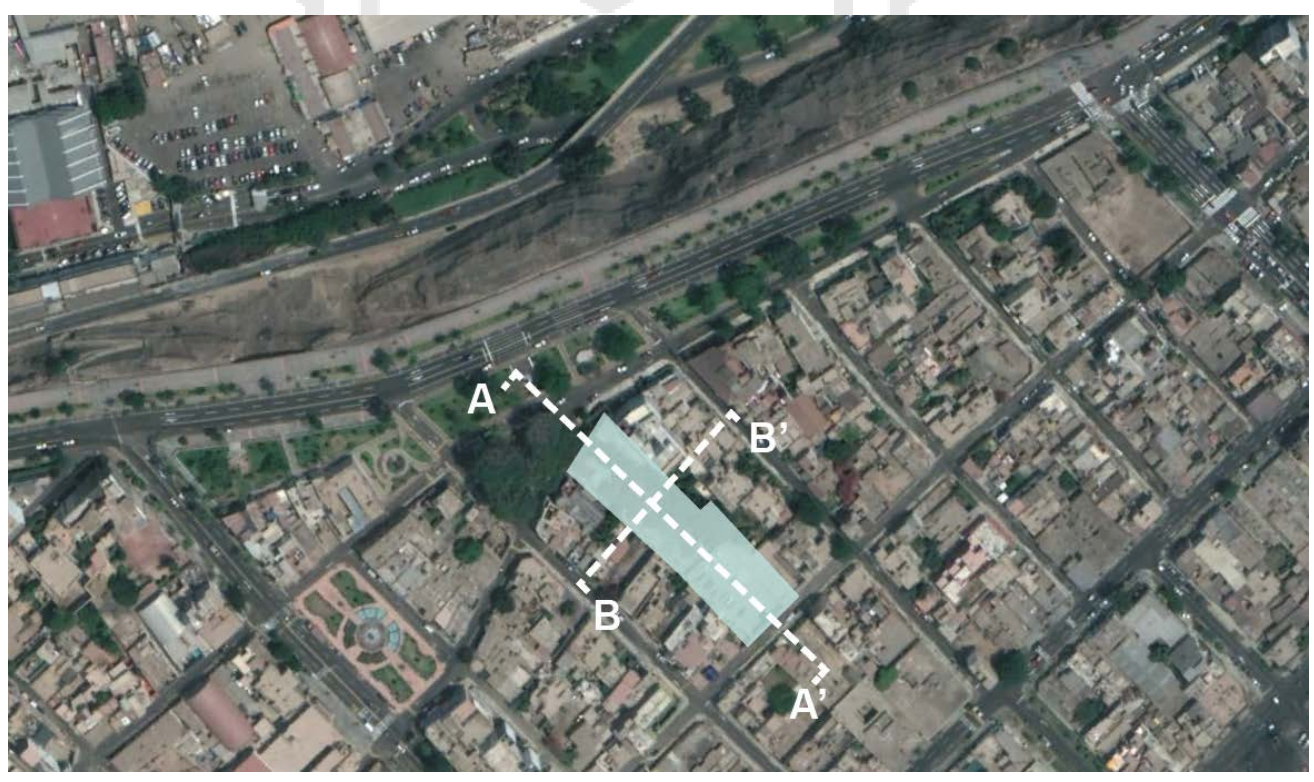

Fuente: Google Earth. Adaptado por autor. 
Figura 5.3.3: Cortes

CORTE A-A

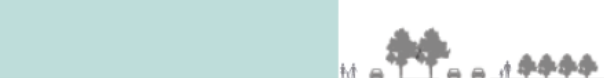

CORTE B-B'

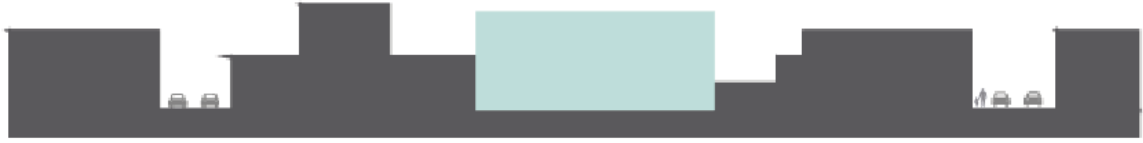

Fuente: Elaborado por autor.

Figura 5.3.4: Análisis de zona.

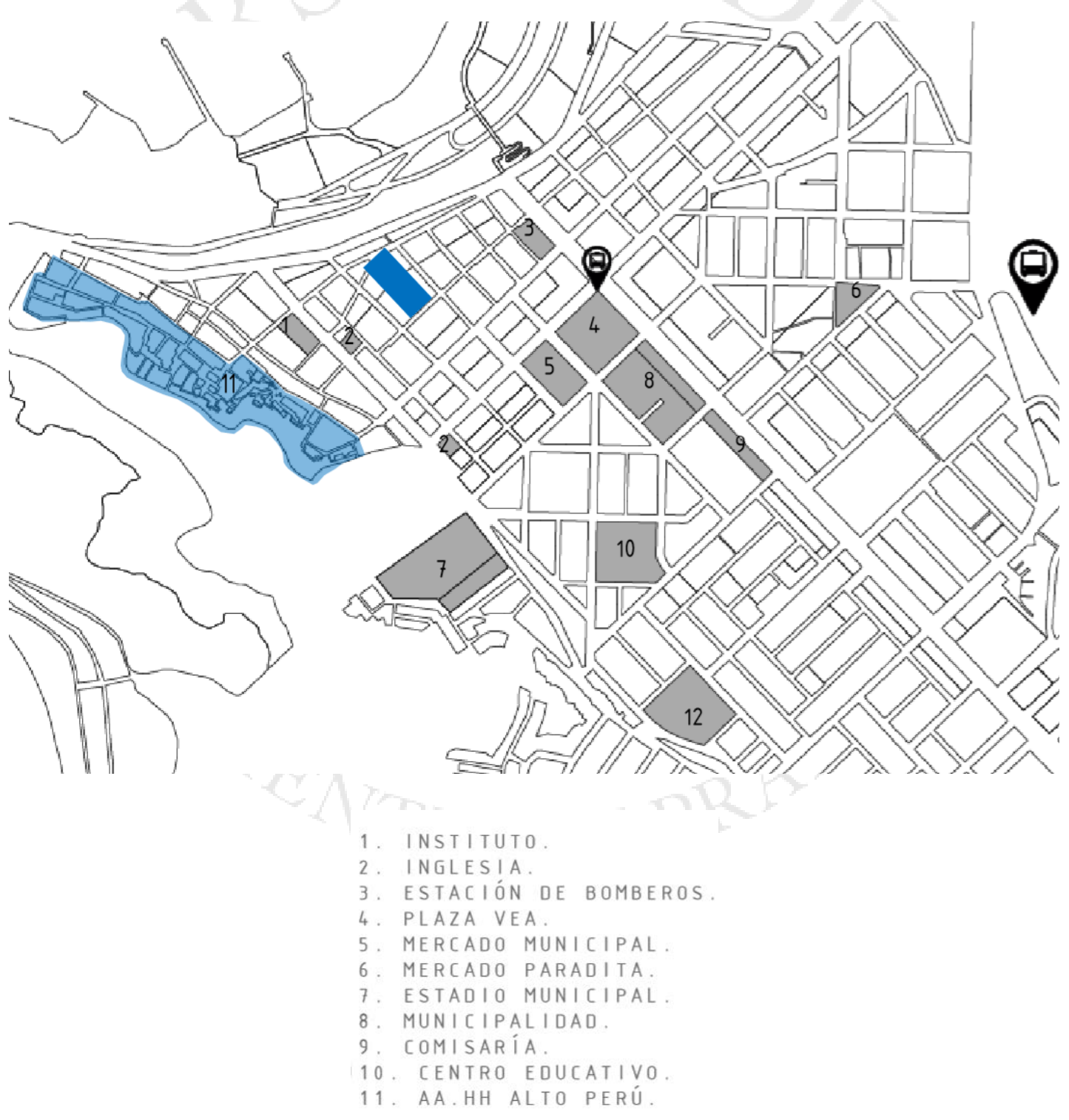

Fuente: Elaborado por autor. 
Alto Perú es un asentamiento humano ubicado en la falda del Morro Solar, a pocos metros del terreno, y es un lugar considerado peligroso debido a la informalidad y constantes actos de delincuencia que existe dentro de los límites de esta zona. Además, es una zona que no cuenta formalmente con los servicios básicos de agua, desagüe y luz, por lo que los pobladores tienen instalaciones ilegales.

Según los propios pobladores, actualmente en Alto Perú viven 47 adultos mayores en condiciones lamentables y con gran probabilidad de sufrir algún tipo de accidente en las viviendas precarias que hay en la zona. Además, los accesos a Alto Perú son deplorables debido a que aún existen calles que no están asfaltadas, lo que perjudica en tránsito peatonal de los vecinos e imposibilita el acceso vehicular en caso de accidentes. Esta información resalta la importancia de reubicar con urgencia a los adultos mayores de la zona que viven en constante peligro.

Por otro lado, desde hace 10 años existen ONG’s con diversos programas que están dirigidos a los jóvenes y niños que viven en este asentamiento humano, y que tienen como objetivo darles la oportunidad de pasar el tiempo realizando actividades positivas. Por tal motivo, la Residencia y Centro de día contará con un programa organizado de jóvenes voluntarios que ayude con las diversas actividades y labores que se desarrollaran en el proyecto.

Figura 5.4.1: Alto Perú

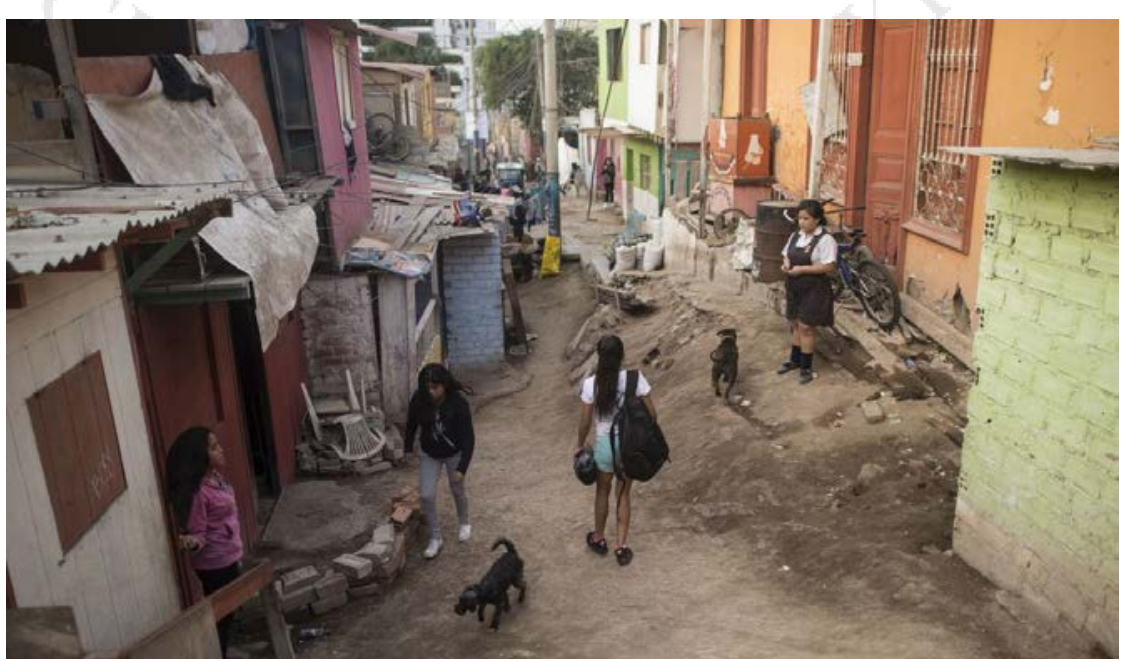

Fuente: (El Comercio, 2017) 
5.5.Consideraciones ambientales.

En el distrito de Chorrillos la temperatura promedio es de $17.0^{\circ} \mathrm{C}$, durante la temporada de verano la temperatura puede alcanzar hasta $23.0^{\circ} \mathrm{C}$ y durante el invierno la temperatura puede bajar hasta $10.7^{\circ} \mathrm{C}$. Por esta razón, el proyecto propone el uso de diversos patios para optimizar la iluminación y ventilación natural en cada ambiente, así mismo, se propone trabajar con materiales que ayuden a generar un ambiente cálido en cada espacio utilizado por los adultos mayores. Es importante resaltar que la ubicación del Morro Solar es una ventaja debido a que actúa como una barrera que ayuda a controlar los fuertes vientos que provienen del sur.

Por otro lado, el índice de contaminación es un factor importante al proponer un centro de atención al adulto mayor, debido a que, en caso el lugar no sea óptimo, puede traer consecuencias en la salud de los ancianos. Por tal motivo, el distrito de Chorrillos se adapta a este requerimiento ya que el nivel del ambiente está por debajo del límite permitido, además, es uno de los distritos con menor contaminación en la ciudad.

Figura 5.5.1: Niveles de contaminación ambiental.

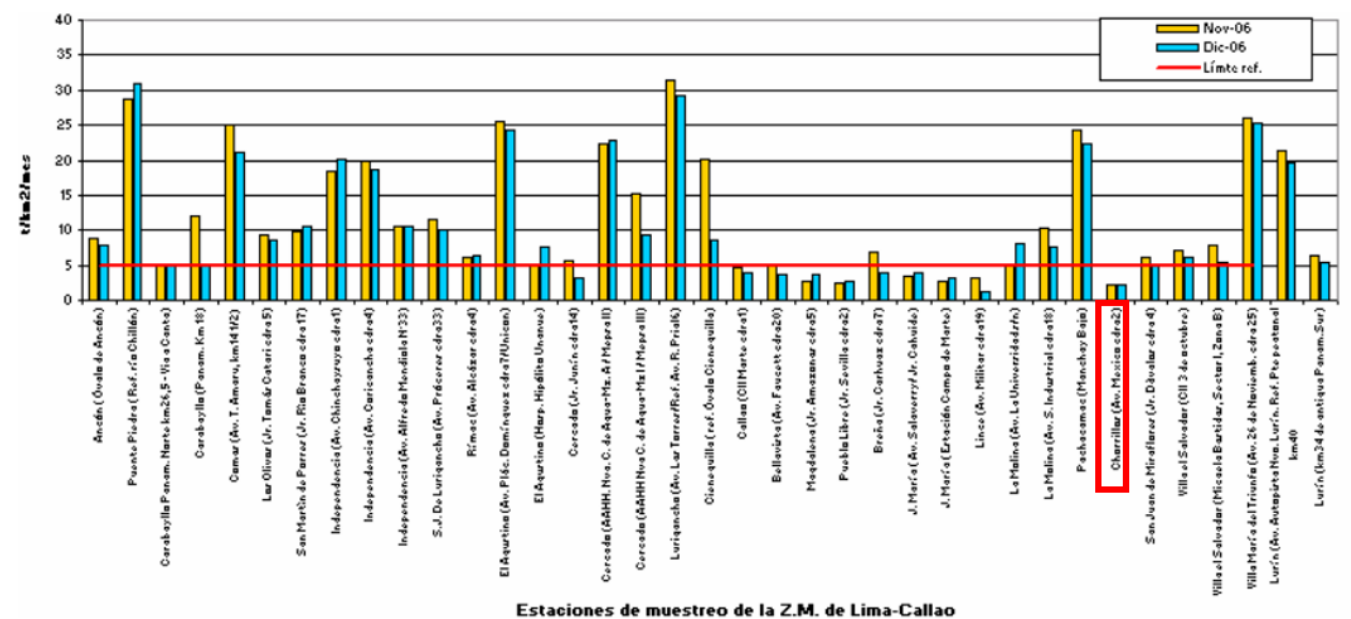

Fuente: Estación de muestro Lima - Callao 
5.6.Accesibilidad.

El proyecto está ubicado en una zona estratégica y accesible por diversos medios de transporte desde distintos puntos de la ciudad.

5.6.1. Vías peatonales.

El proyecto está ubicado en una zona con calles de flujo variado, frente a este se ubica la Av. Malecón Grau que se conecta directamente con una vía Metropolitana. El malecón, que se ubica en esta avenida, cuenta una vereda amplia en la que se desarrolla gran actividad peatonal de transito lento, las personas se dirigen a este lugar para poder tener una mejor vista del mar y la Costa Verde. Las calles auxiliares al proyecto son de menor dimensión y tienen un flujo bajo debido a la poca actividad en los terrenos adyacentes. Por otro lado, la Av. Defensores del Morro, se desarrolla un flujo peatonal intenso durante todo el día debido a la gran actividad económica que se desarrolla en este lugar, además, de ser una avenida con paraderos de transporte público.

Figura 5.6.1.1: Flujo peatonal Av. Defensores del Morro

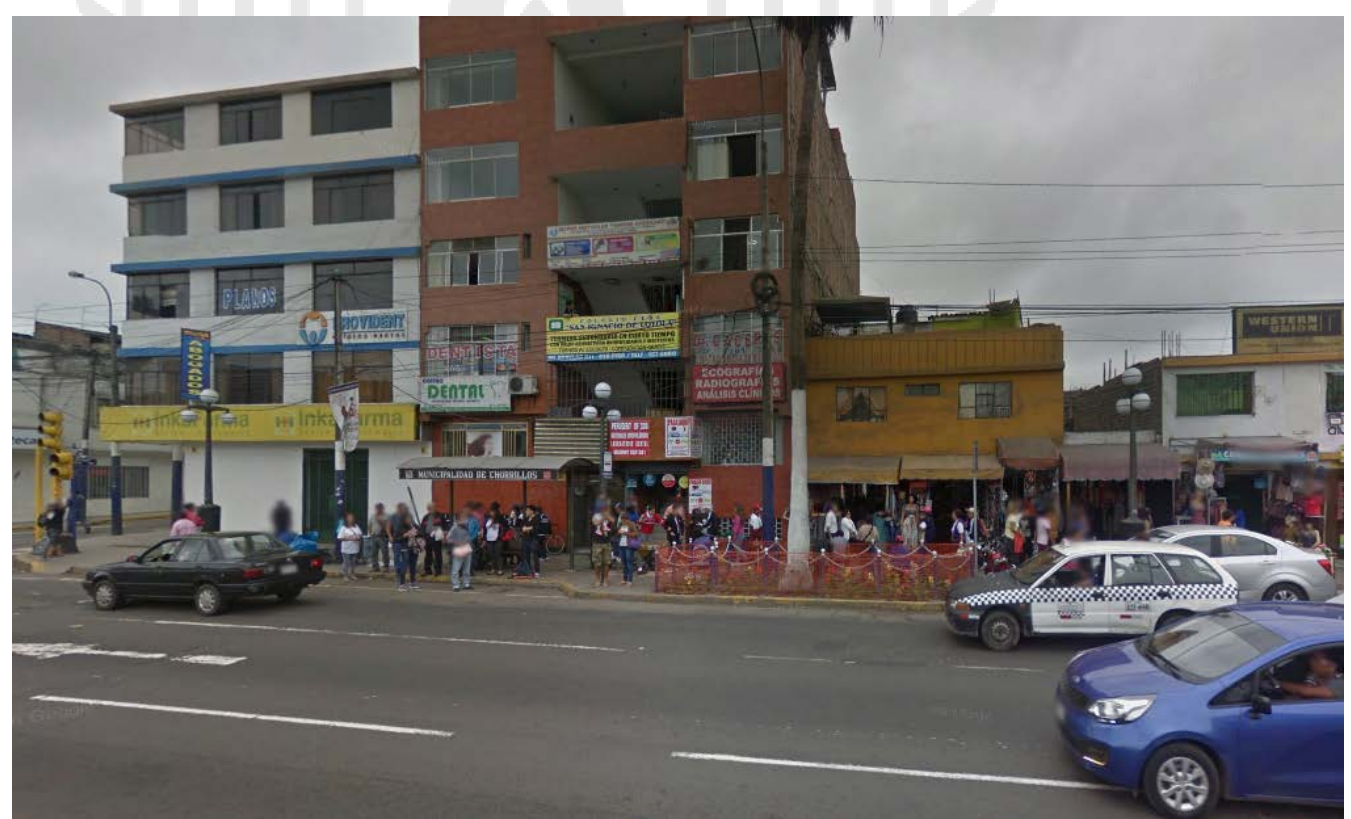

Fuente: Google Earth 
Figura 5.6.1.2: Flujo peatonal Malecón Grau.

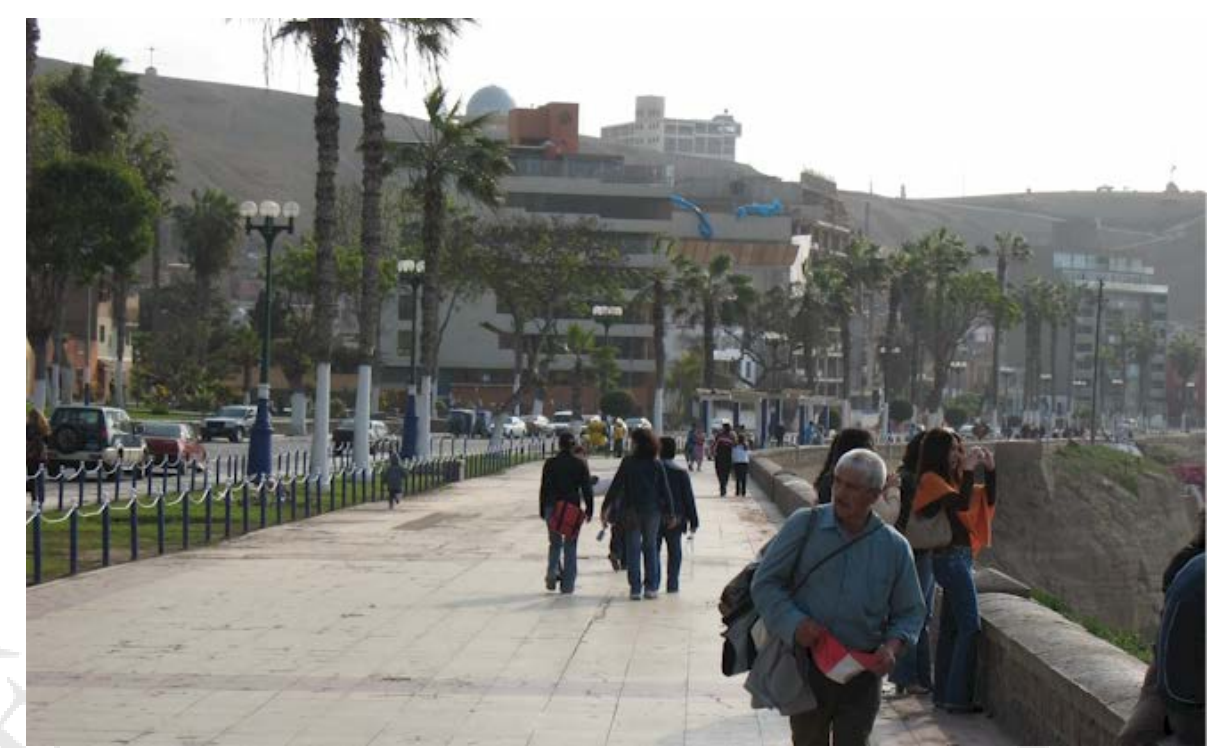

Fuente: (Salazar Sanches, s.f.)

5.6.2. Vías vehiculares.

El acceso vehicular al proyecto se puede dar en transporte privado y público.

El primero de estos tiene dos importantes avenidas por las cuales se puede acceder: La Avenida Malecón Grau que conecta todo el Circuito de Playas conformado por 7 distritos y la Avenida Defensores del Morro, las más importante del distrito. Por otro lado, es posible acceder al proyecto en transporte público como el Metropolitano, transporte que une dos extremos de la ciudad y que cuenta con una estación muy cercana a la Av. Defensores del Morro, el usuario que llegue a esta estación puede acceder a los buses que transitan por esta concurrida avenida y que se encuentra a escasos metros del lugar elegido para el proyecto. 
Figura 5.6.2.1: Congestión vehicular Av. Defensores del Morro
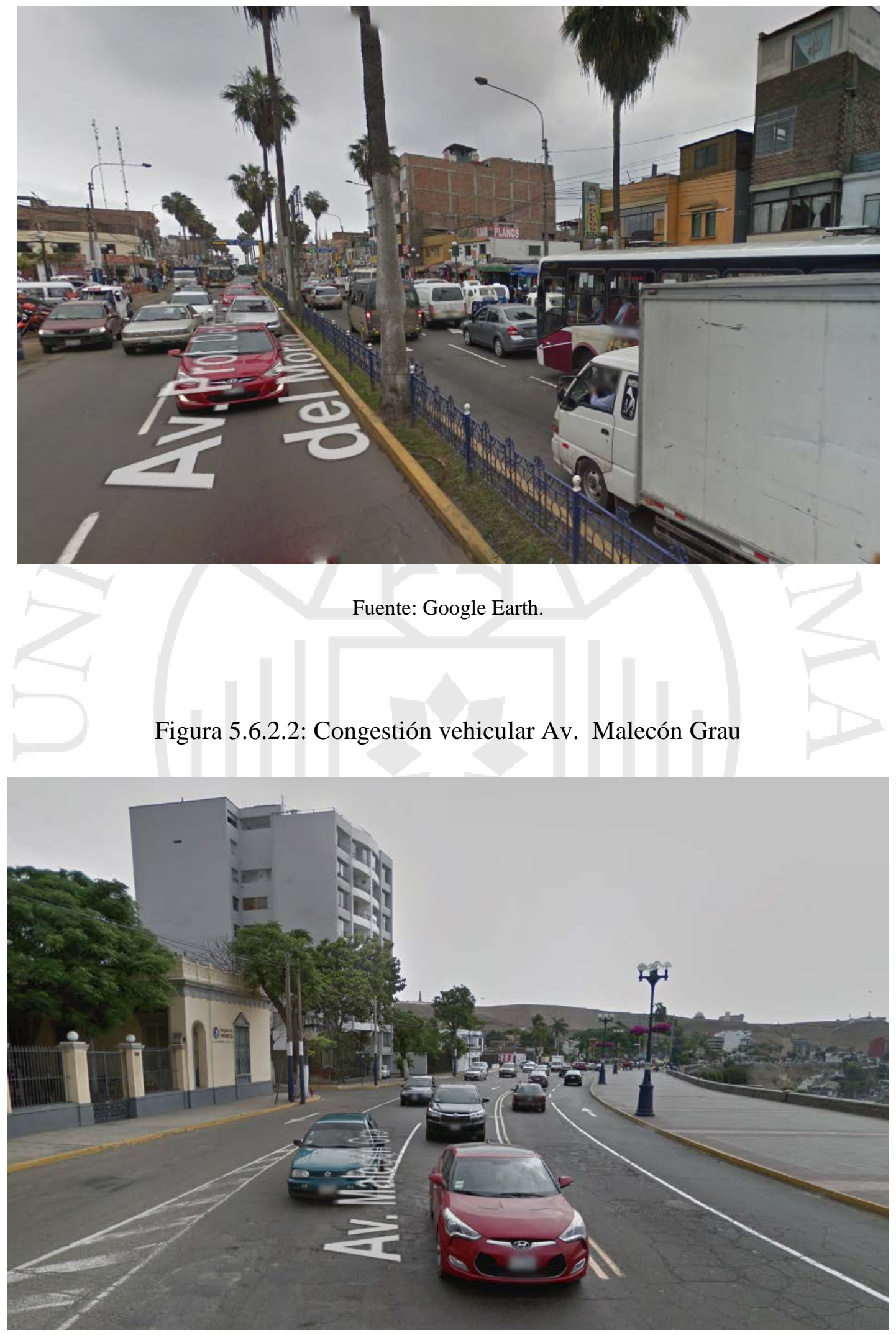

Fuente: Google Earth 


\subsection{Zonificación.}

Según el distrito de Chorrillos, el terreno está clasificado como RDA (Residencia de densidad Alta), y RDM (Residencia de densidad Media), en los parámetros generales del distrito esta zonificación permitiría alcanzar 8 niveles. Sin embargo, la zona en la que se ubicará el proyecto, que está entre las Avenidas Defensores del Morro y Mariscal Castilla, tiene características distintas por ser una Zona Monumental.

Esto limita el crecimiento vertical de proyecto debido a que, por norma del distrito, la altura en la fachada frontal es máximo 13m. y en la fachada posterior $9.75 \mathrm{~m}$.

Figura 5.7.1: Zonificación.

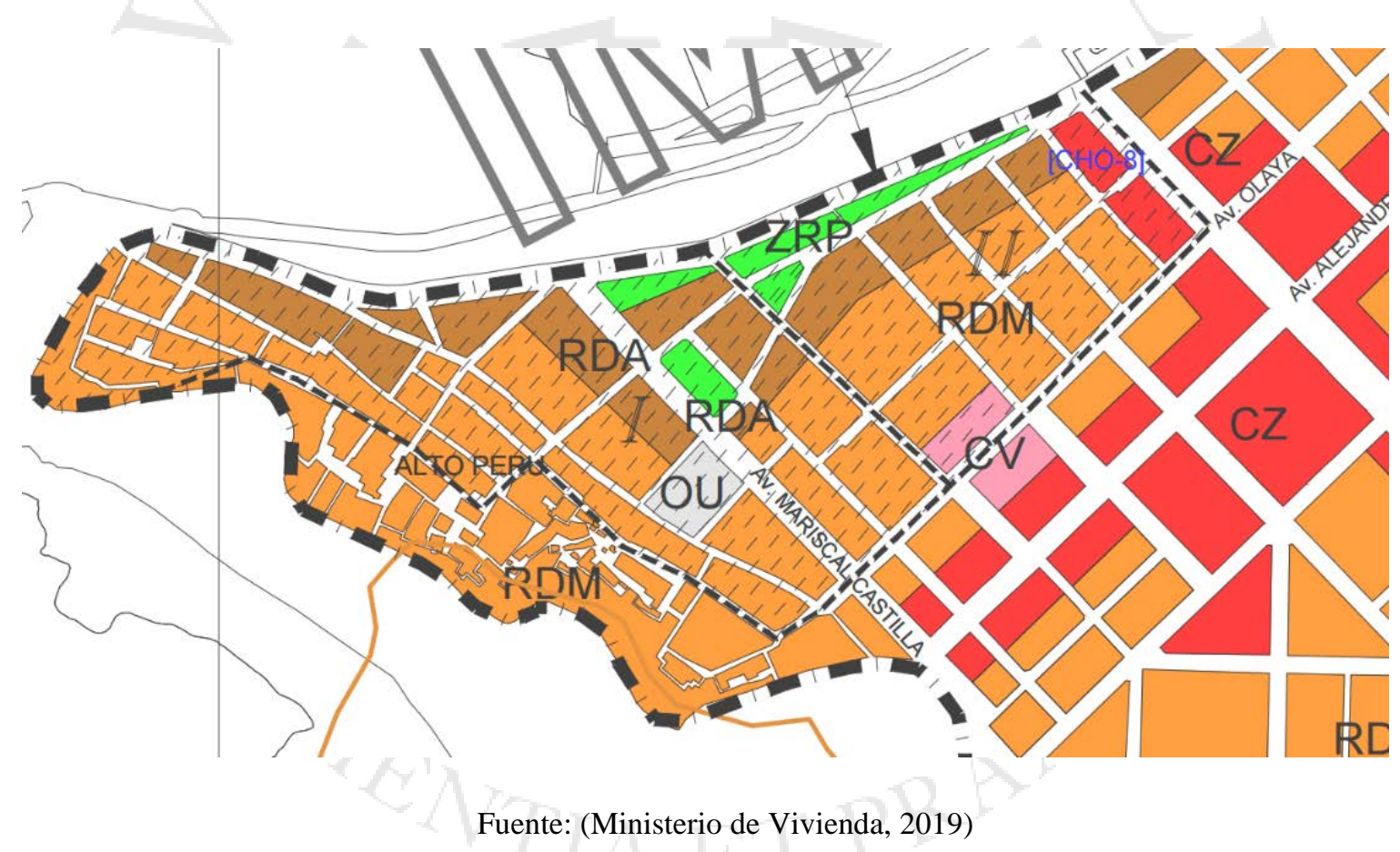




\subsection{Conclusión Final.}

El distrito de Chorrillos cuenta con las características antes mencionadas que lo hacen muy apropiado para la ubicación de un proyecto que busca mejorar la calidad de vida de las personas mayores, pero sin apartarlos del ritmo de vida que siempre han llevado.

La importancia de la accesibilidad a la zona es una de las características más importantes en una ciudad caótica y poco inclusiva, debido a que se le da oportunidad a la mayor cantidad de personas de acceder al proyecto. La cercanía al comercio e instituciones brinda una sensación de mayor seguridad y de constante actividad en la zona. Por otro lado, el clima y el ambiente poco contaminado es un gran punto a favor para la salud de los ancianos, así como la conexión que existe entre Chorrillos y el mar es un factor positivo para las personas adultas mayores que constantemente buscan tener contacto con la naturaleza.

Además, su ubicación permite generar una conexión entre dos zonas con características distintas del distrito de Chorrillos, una residencial y una más urbana, por lo cual, el proyecto pretende ser un espacio de integración para los adultos mayores con la participación de los vecinos de la zona.

Finalmente, una de las características más importantes del terreno es que le pertenece al Arzobispado de Lima, institución que vela por el bien de las personas y con la cual se trabajará para el desarrollo del proyecto como se explicará en el siguiente capítulo. 


\section{CAPÍTULO VI: ANÁLISIS DE CONTEXTO.}

6. Láminas de análisis de contexto.

El siguiente análisis nos ayuda a conocer mejor el contexto en el que está ubicado el terreno para el proyecto "Residencia y Centro de Día para el Adultos Mayores de Chorrillos y Alto Perú”. En cada lámina se desarrollarán los siguientes temas:

- L-6.1: Chorrillos

Esta lámina explica las características generales del distrito de Chorrillos y la cantidad de adultos mayores que actualmente habitan en él.

- L-6.2: Vulnerabilidad.

Es importante conocer el contexto en el que se encuentra el terreno, el tipo de piso, y la calidad de las construcciones aledañas.

- L-6.3: Condiciones Ambientales:

El nivel de contaminación en Chorrillos se encuentra muy por debajo del límite, por lo cual, se considera un distrito óptimo para la salud. Por otro lado, el clima en el distrito cuenta con una temperatura promedio de $23^{\circ} \mathrm{C}$ durante el verano y en invierno la sensación de frío ha llegado hasta los $10^{\circ} \mathrm{C}$ debido al porcentaje de humedad por tener una ubicación frente al mar, por tal motivo, en el capítulo de proyecto se explicará de qué manera se generará una solución.

- L-6.4: Áreas libres:

El conocer las áreas verdes y espacios públicos cercanos, se podrán organizar ciertas actividades variadas para los adultos mayores.

- L-6.5: Sistema de cuerpos edificatorios:

En esta lámina se explica el equipamiento cercano al proyecto que ayuda a entender mejor el contexto en el que se ubica y que puede contribuir al funcionamiento del mismo.

- L-6.6: Bordes - Barrios:

Esta lámina nos explica los límites geográficos del distrito de Chorrillos y de la zona del proyecto, los cuales le dan un plus a la ubicación. Así mismo, se explica un poco del A.A.H.H Alto Perú debido a que se trabajará con sus pobladores adultos mayores. 
- L-6.7: Hitos - Nodos - Sendas:

Los puntos de referencia y estratégicos cercanos al terreno le dan importancia al proyecto y ayudan a que este pueda ser identificado con mayor facilidad.

- L-6.8 y L-6.9: Flujos:

El análisis de los flujos vehiculares y peatonales de la zona nos ayuda a entender el movimiento de las personas y cuáles son los puntos más importantes y de conexión cercanos al proyecto.

- L-6.10: Zonificación:

Por la ubicación frente a una avenida, el terreno debería ser zonificación RDM, sin embargo, está ubicado dentro de una zona monumental, lo cual tiene parámetros distintos para ayudar a la conservación del entorno.

- L-6.11: Percepción:

La zona en la que se encuentra el proyecto es una de las más privilegiadas por estar ubicados en el límite de la Costa Verde y tener una vista privilegiada, sin embargo, muy cera al proyecto se encuentra el A.A.H.H Alto Perú, en el cual la realidad es completamente distinta. La percepción al interior de este lugar es completamente opuesta a la del proyecto, es una zona con altos índices de delincuencia e inseguridad, además, no cuenta con los servicios básicos para vivir, por lo cual, se considera que no es una zona favorable para que los adultos mayores residan.

- L-6.12:

Esta lámina resume todas las potencialidades del terreno en el que se desarrollará el Centro de Día y Residencia para el Adulto Mayor de Chorrillos y Alto Perú, así como las limitaciones a las que se intentará encontrar solución para favorecer al adulto mayor y la zona del proyecto. 


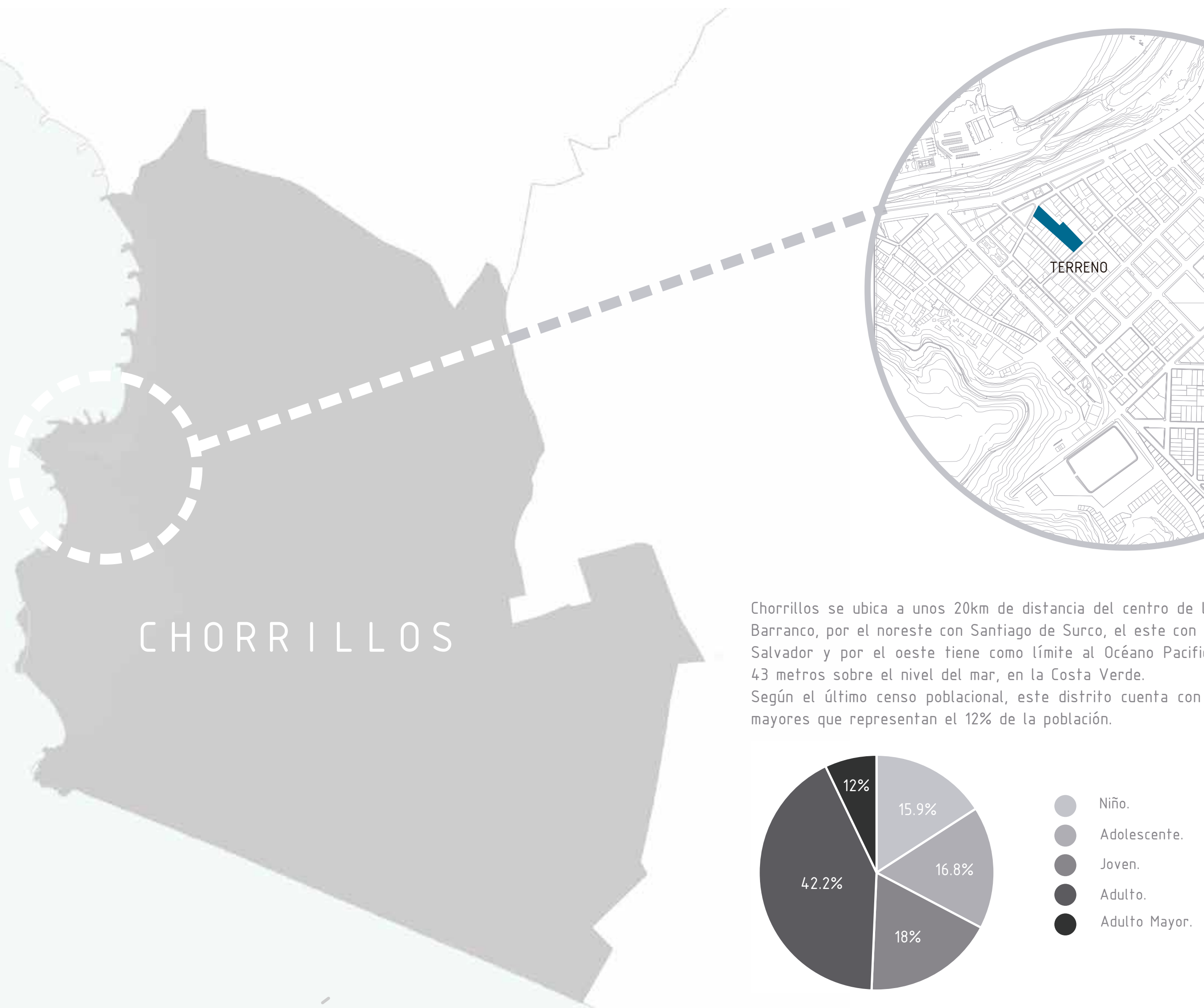

Chorrillos se ubica a unos $20 \mathrm{~km}$ de distancia del centro de la Ciudad de Lima. Por el norte limita con el distrito de

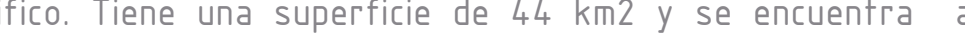

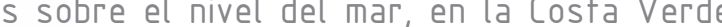

el último censo poblacional, este distrito cuenta con 325547 habitantes de los cuales 39065 son adultos mayores que гергеsentan el $12 \%$ de la población. 
VULNERABIBILIDAD POR MANZANA

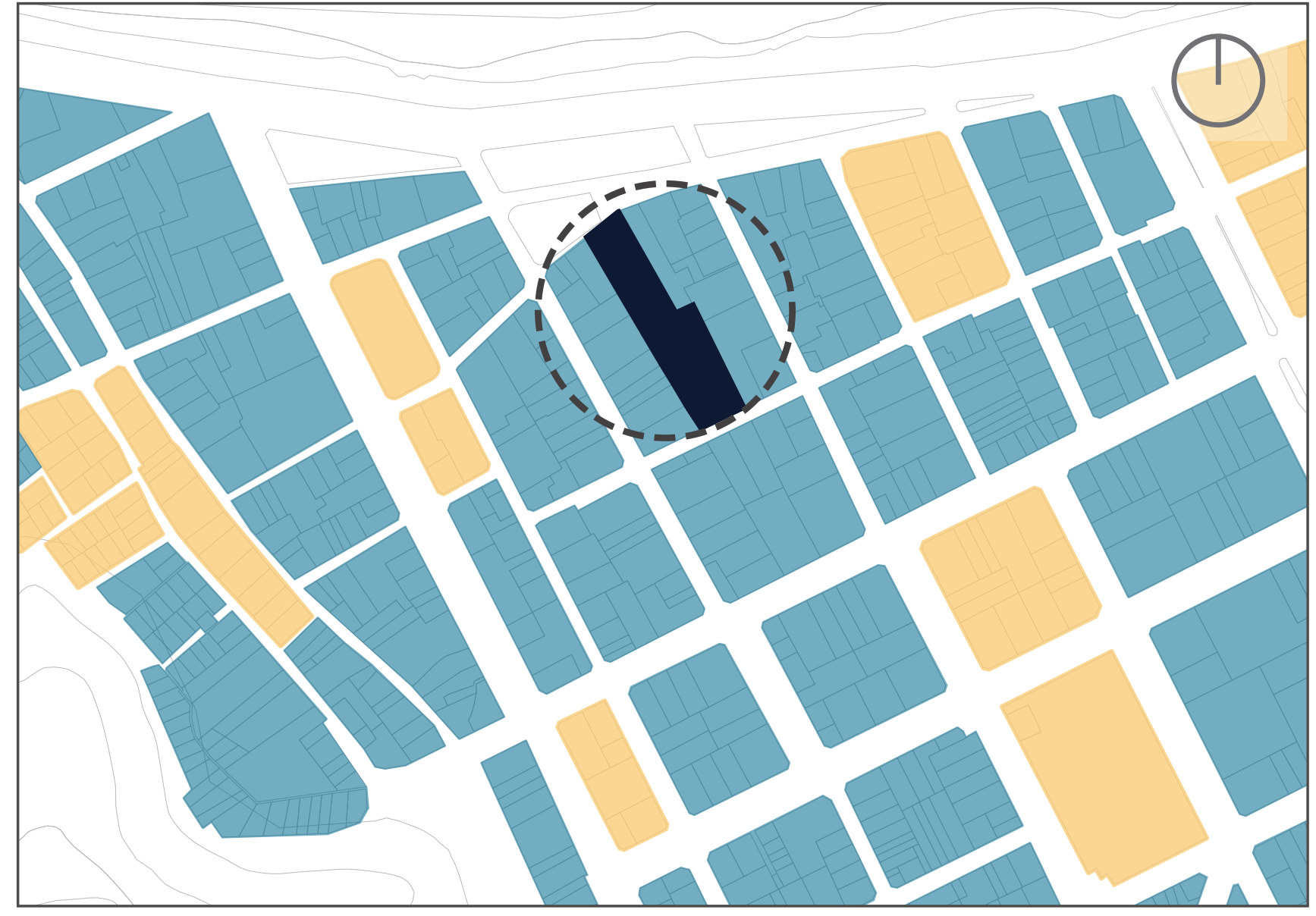

VULNERAB IBILIDAD DE LOTES

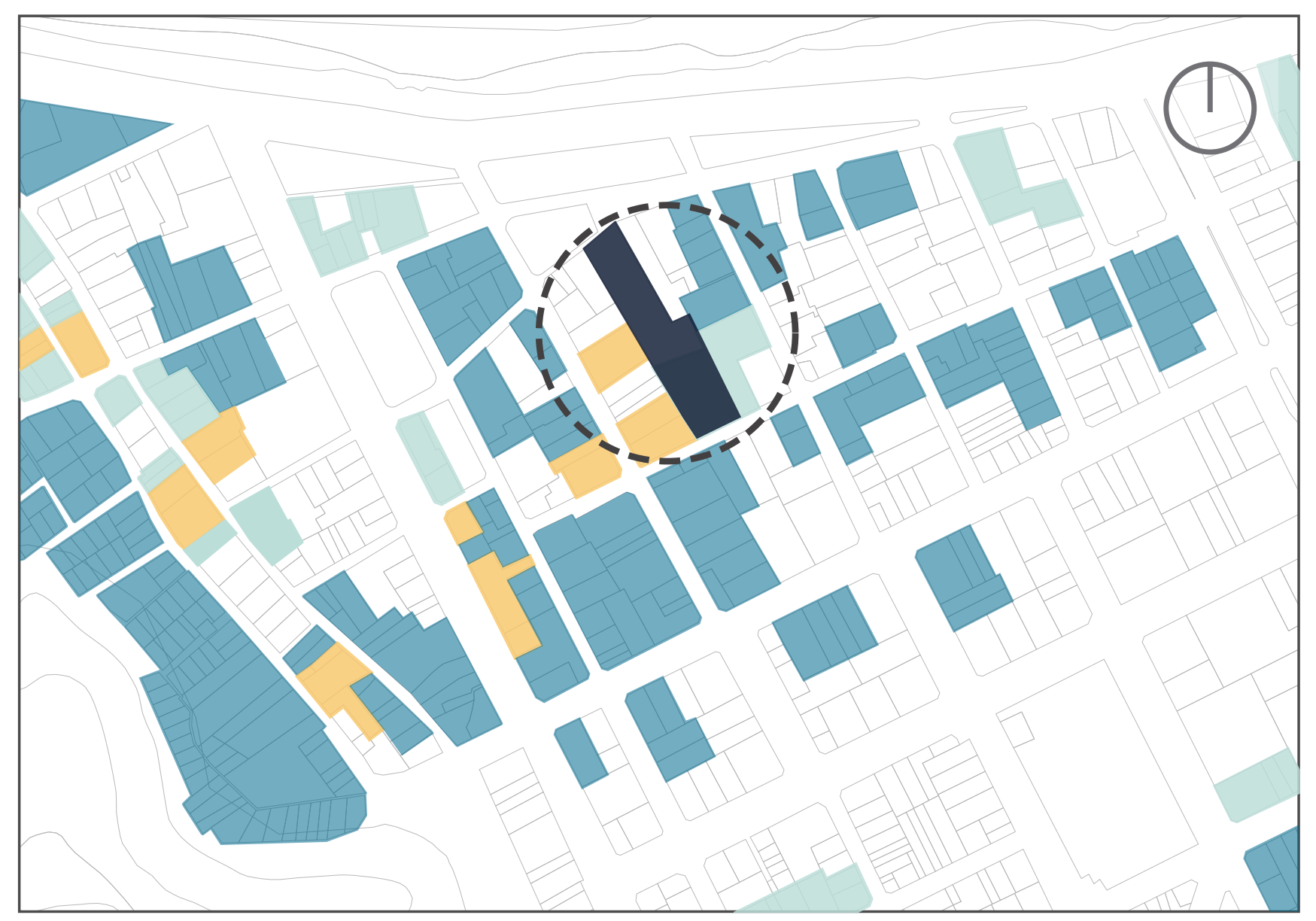

Según INDECI (2011), la vulnerabilidad ante un desastre natural en Chorrillos es medio y alta debido a las caracteristicas del suelo sobre el que se encuentra el distrito, es en su mayoría arena de gran espesor, sin embargo, hay medidas y recomendaciones por INDECI y la municipalidad para poder realizar una construcción en óptimas condiciones. La zona más vulnerable cerca al terreno del proyecto es el Asentamiento Humano Alto Perú, el cual se ubica sobre el Morro Solar, esta zona además de tener un suelo no óptimo рага la construcción, cuenta con viviendas de material ргеcario.

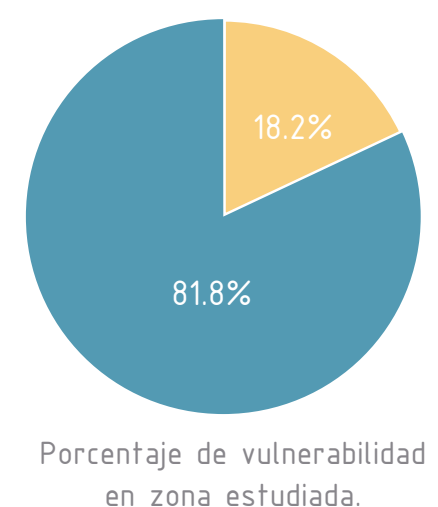

$$
\text { en zona estudiada. }
$$

Vulnerabilidad alta.

Vulnerabilidad media

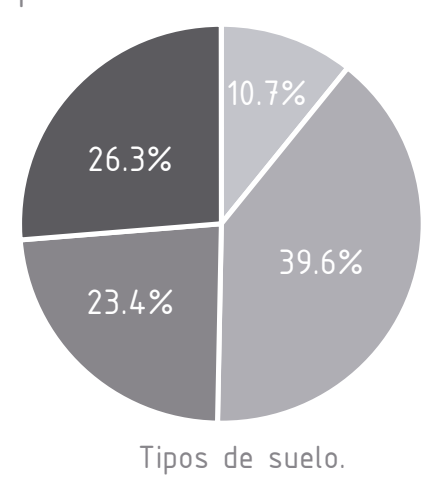

Rellenos

Arena de gran espesor.

Granular fino y arcilloso.

Suelos rocosos.

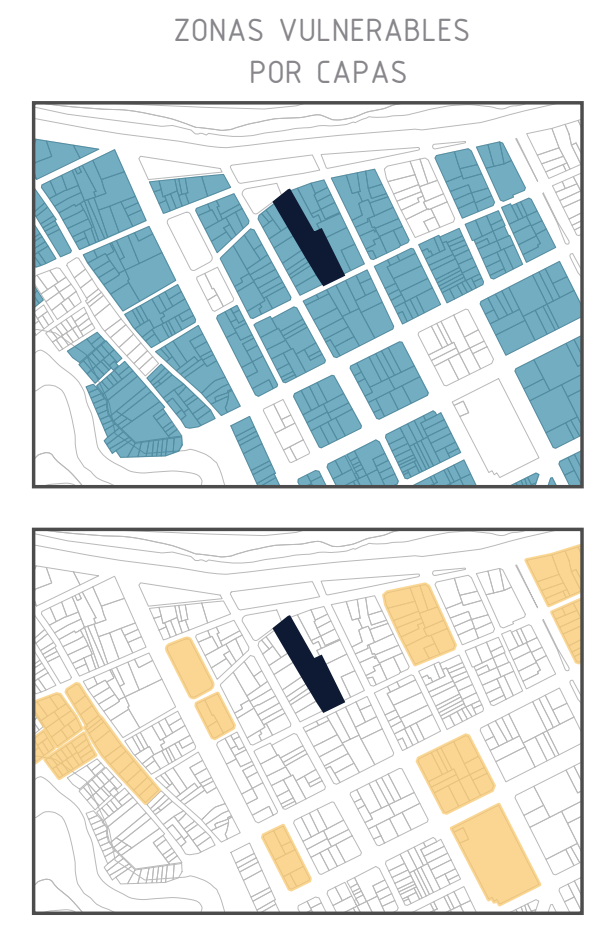

Un estudio realizado en el año 2010 por INDECI indica la vulnerabilidad de las edificaciones en el distrito de Chorrillos. Estas se agrupan de acuerdo al peligro en el que se encuentran tomando en cuenta el tipo de suelo y la calidad de la construcción. En los resultados se observa lo siguiente: $45,46 \%$ de las viviendas se encuentran en riesgo alto, $8 \%$ en riesgo medio, $21,2 \%$ de las viviendas son de bajo riesgo y el $25,5 \%$ de construcciones no se encuentran en peligro. Además, se indica que la mayor de las construcciones han sido realizadas de materiales como adobe, quincha y mampostería. Los siguientes gráficos explican el resultado del analizis realizado en la zona cercana a la ubicación del terreno a intervenir.

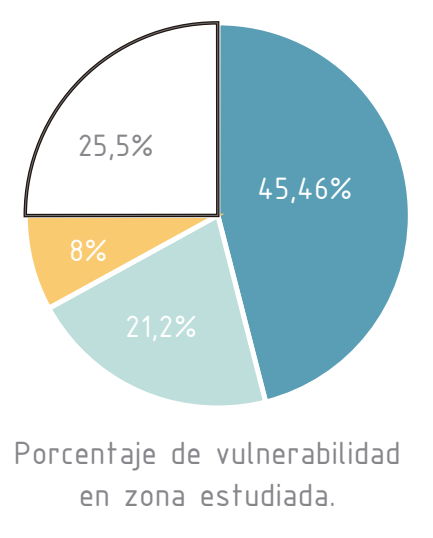

Edificaciones con peligro alto Edificaciones con peligro medio. Edificaciones con peligro bajo Edificaciones sin peligro.

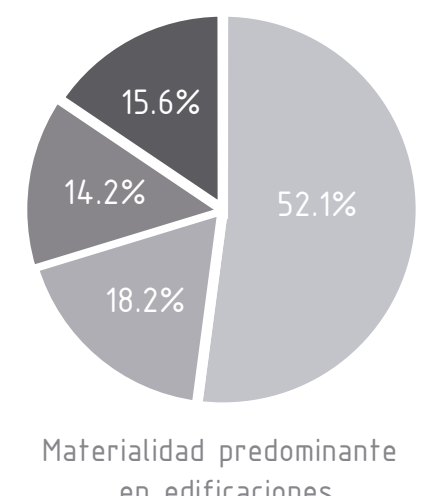
en edificaciones

Adoble, quincha, mamposterìa y otros màs precarios. Adobe reforzado y albañilerìa

Albañilerìa confinada.

Concreto armado, acero y otros.

El terreno en el que se ubicará la Residencia y Centro de Día para Adultos Mayores no está catalogado dentro de este estudio debido a que actualmente es un terreno vacío que se encuentra en estado de abandono.
EDIFICACIONES VULNERABLES POR CAPAS
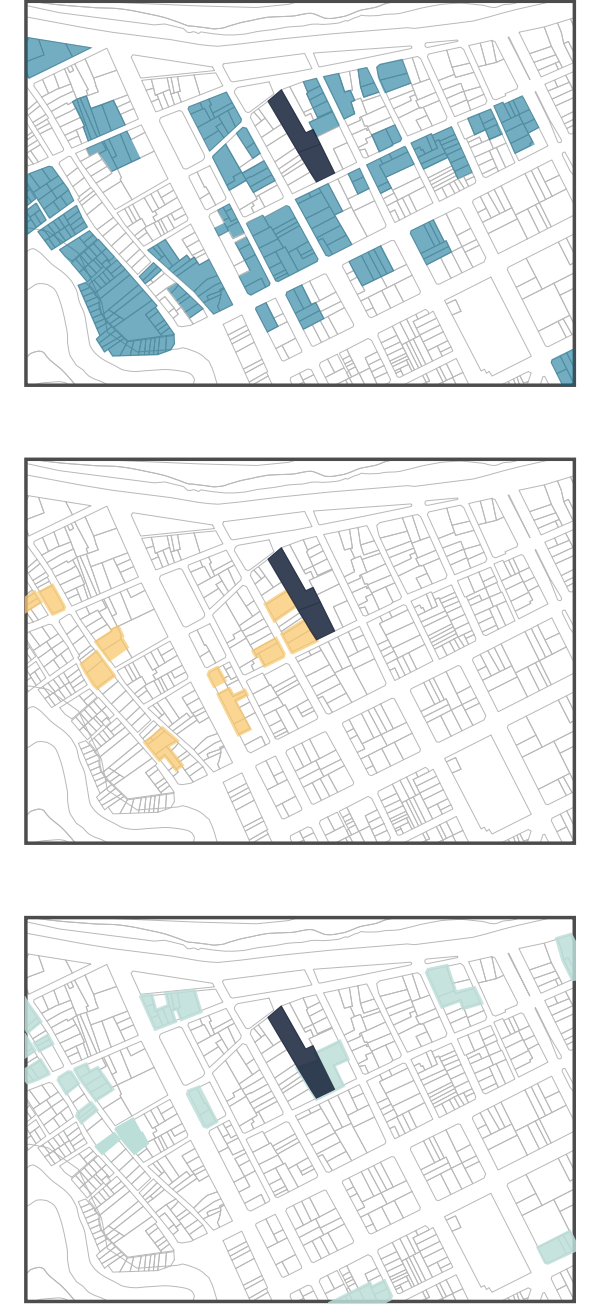

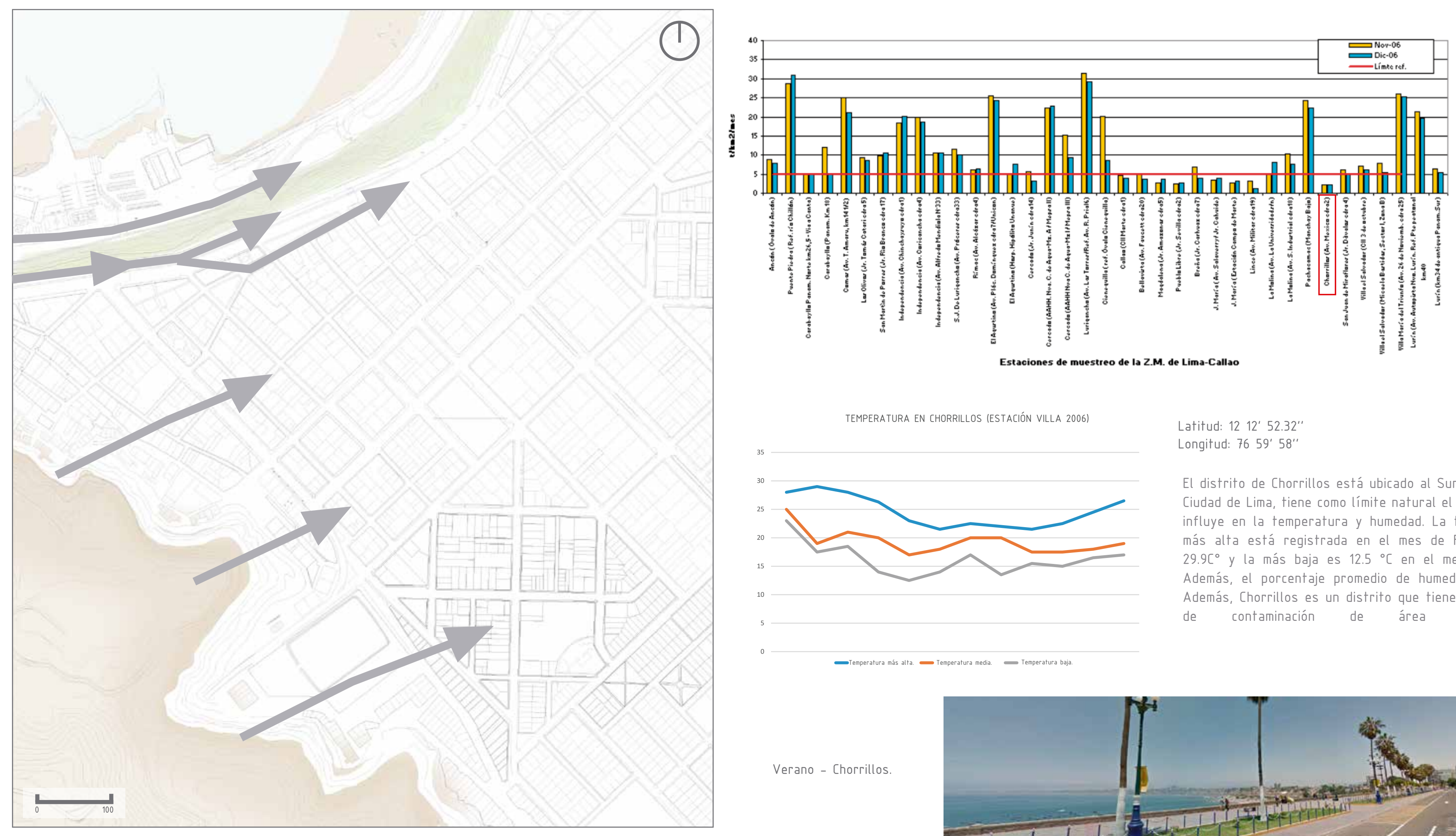

Latitud: $1212^{\prime} 52.32^{\prime \prime}$

Longitud: $7659^{\prime} 58^{\prime \prime}$

El distrito de Chorrillos está ubicado al Suroeste de la Ciudad de Lima, tiene como límite natural el mar, lo cual influye en la temperatura y humedad. La temperatura más alta está registrada en el mes de Febreго con $29.90^{\circ}$ y la más baja es $12.5^{\circ} \mathrm{C}$ en el mes de mayo. Además, el porcentaje promedio de humedad es $82 \%$ Adenás, Chorritos es un distrito que tiene tos nivetes Adenás, Chorrilos es un distrito que tiene los niveles

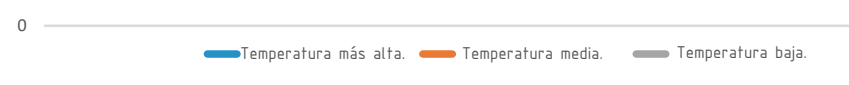

Verano - Chorrillos.

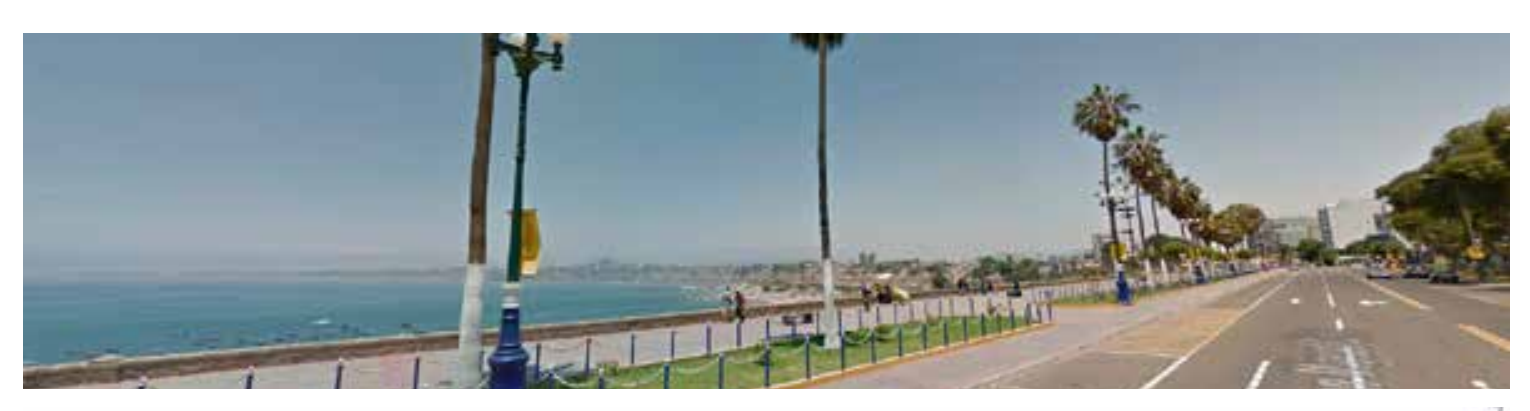

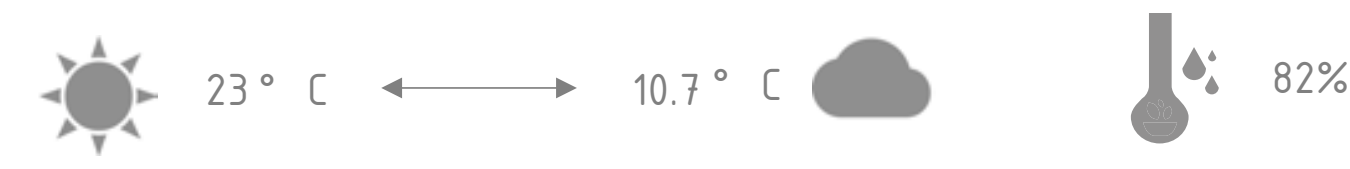

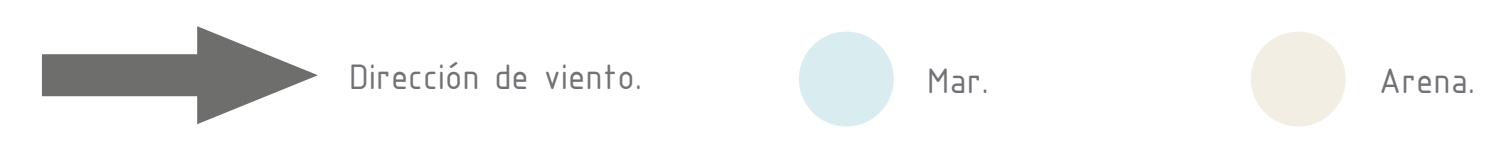




\section{AREAS L I BRES}

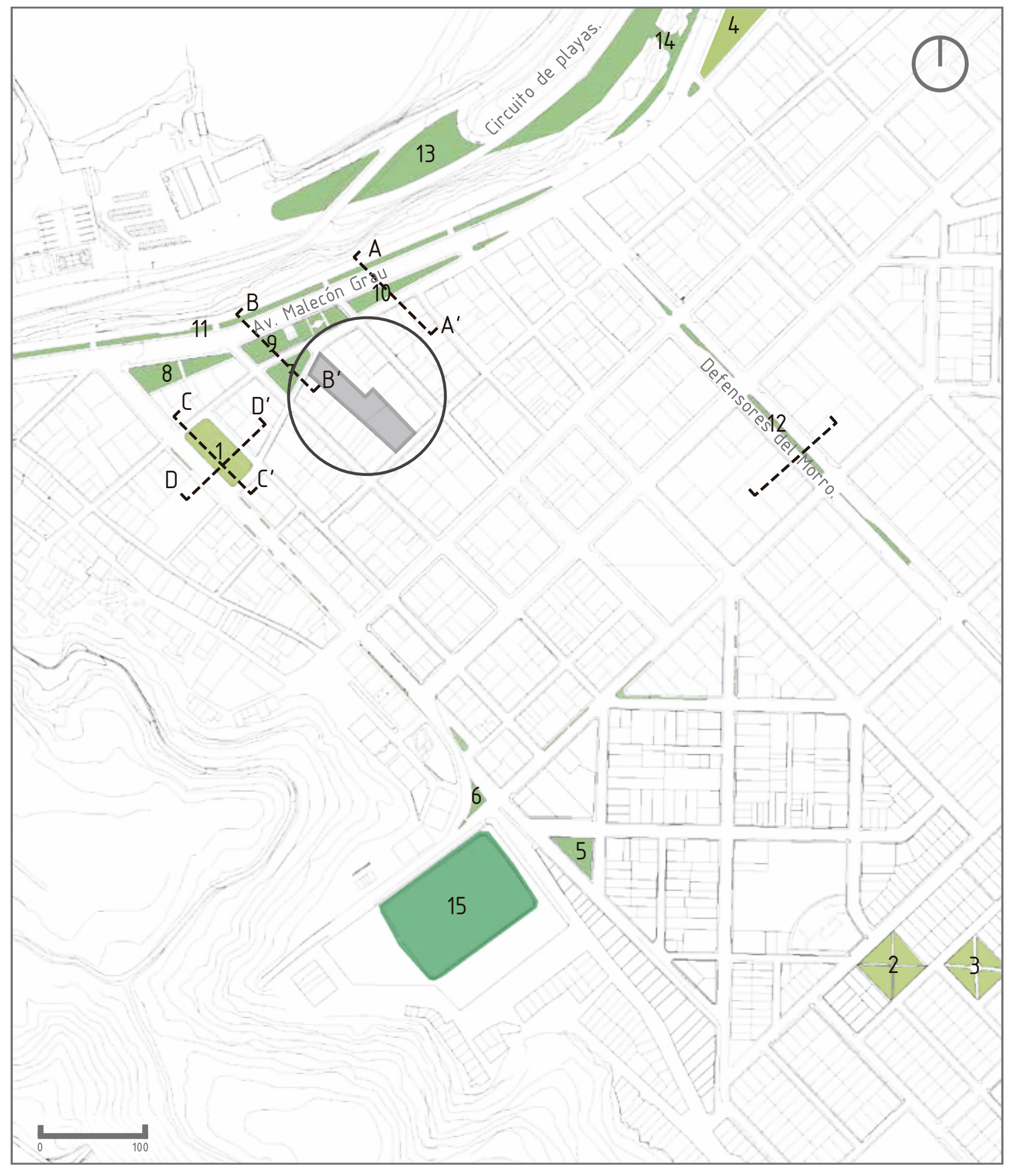

Area verde publica.
L----J Cortes.
Агеa verde privada
Chorrillos cuenta con $21 \mathrm{~m} 2$ de àrea verde por habitante, cifra muy por debajo de los $9 \mathrm{~m} 2$ recomendados por la Organización Mundial de la Salud (OMS). Debido a que el trabajo del municipio con estas áreas se limita a los bordes de calles y vermas centrales de algunas avenidas.

Esta situación se da pese a que el distrito cuenta con importantes áreas como Los Pantanos de Villa y la Costa Verde, los cuales deberían complementar la implementación de parques spacio público en el distrito.
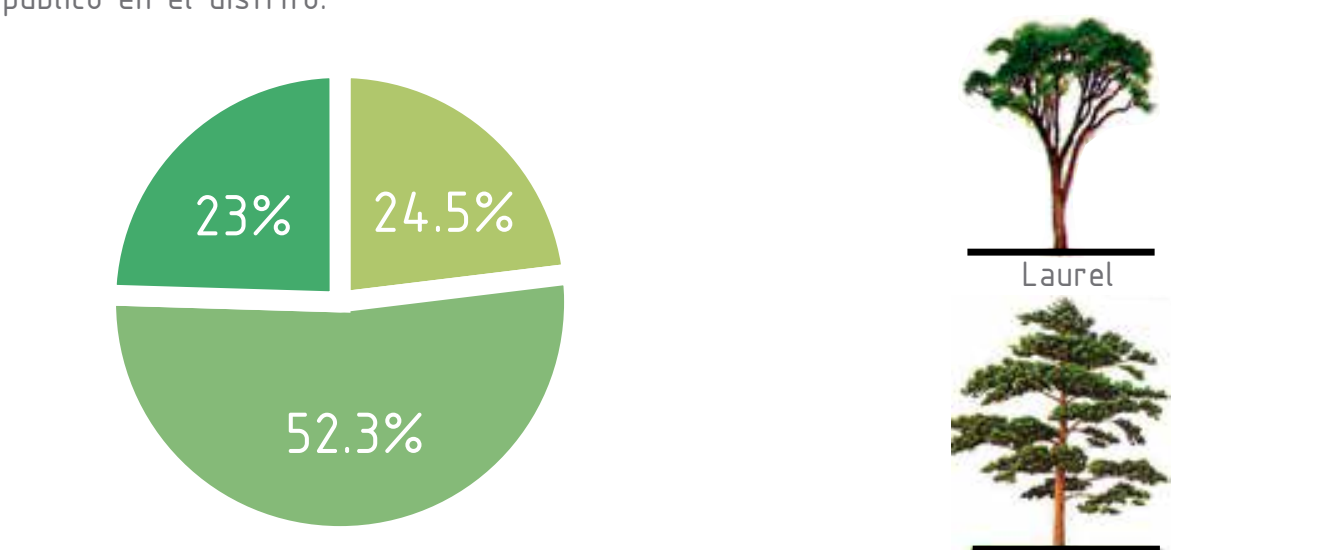

EArea verde publica mplaza y paroues mArea verde privada

\begin{tabular}{|r|l|r|r|}
\hline \multicolumn{3}{|c|}{ NOMBRE } & \multicolumn{1}{|c|}{ AREAS } \\
\hline 1 & Plaza San Pedro. & 1720 & $\mathrm{~m} 2$ \\
\hline 2 & Parque San Francisco. & 1930 & $\mathrm{~m} 2$ \\
\hline 3 & Parque Juan de Espinoza. & 1800 & $\mathrm{~m} 2$ \\
\hline 4 & Parque Rosario de Villa. & 2830 & $\mathrm{~m} 2$ \\
\hline 5 & Area verde Av. Seminario. & 740 & $\mathrm{~m} 2$ \\
\hline 6 & Area verde Av. Mariscal Castilla. & 350 & $\mathrm{~m} 2$ \\
\hline 7 & Area verde Jose Olaya & 780 & $\mathrm{~m} 2$ \\
\hline 8 & Area verde Av. Malecon Grau & 1340 & $\mathrm{~m} 2$ \\
\hline 9 & Area verde Av. Malecon Grau & 1780 & $\mathrm{~m} 2$ \\
\hline 10 & Area verde Av. Malecon Grau & 910 & $\mathrm{~m} 2$ \\
\hline 11 & Area verde Malecon Grau & 2400 & $\mathrm{~m} 2$ \\
\hline 12 & Area verde Defensores del Morro & 1720 & $\mathrm{~m} 2$ \\
\hline 13 & Area verde Circuito de Playas & 5600 & $\mathrm{~m} 2$ \\
\hline 14 & Area verde Costa Verde & 3170 & $\mathrm{~m} 2$ \\
\hline 15 & Area deportiva & 8800 & $\mathrm{~m} 2$ \\
\hline
\end{tabular}

\section{Cortes.}

$A-A^{\prime}$

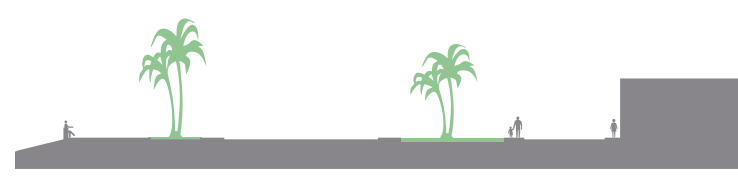

$B-B^{\prime}$

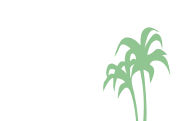

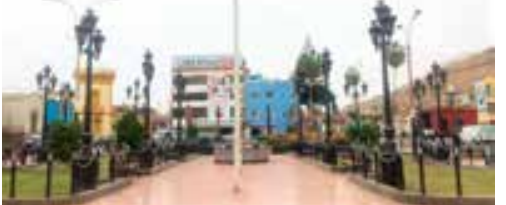
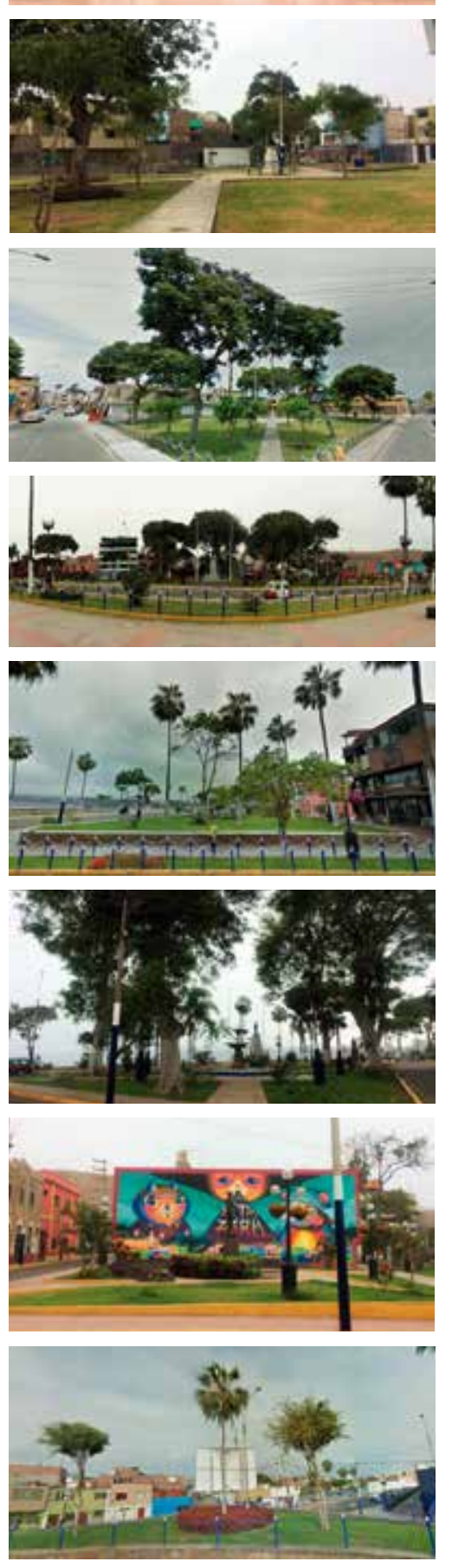

$z^{2}+x^{2}$ 


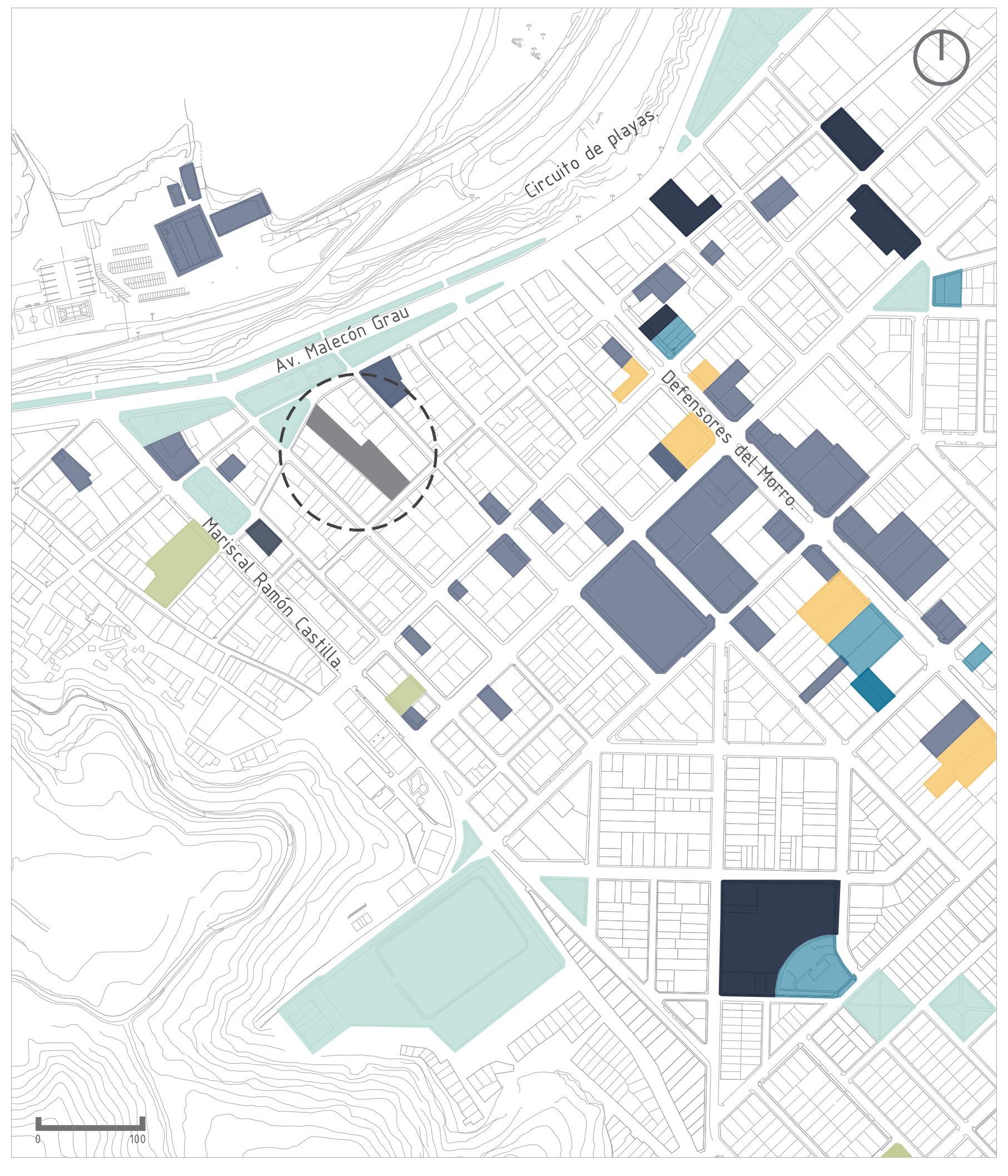

En Chorrillos, la zona ubicada cerca a las Avenidas Malecón Grau y Av. Defensores del Morro tiene el tipo de equipamiento que complementa a las grandes instituciones de la zona como: Municipalidad, Mercado y Centros de salud. El dinamismo que genera el comercio de diferentes escalas, hace que esta zona se identifique como economicamente activa.

Llegando a la Av. Mariscal Castilla, los lugares de comercio, educación y salud disminuyen debido a que deja de ser una zona tołalmente comercial para ser más residencial.

En los siguientes gráficos, se puede identificar los diversos usos y actividades que hay en zona cercana al proyecto, muchas de estas complementan el uso de la Residencia de Ancianos y centro de día.

- 重

Instituto Superior Tecnológico Libertador Escuela de música PUCP Colegio Av. Defensores del Morro. CETPRO piloto Jose Pardo .E.P Cristo Rey

0 Pornica Parroquial San Francisco de Asis. Posta Médica

Centro de Salud Lanatta Lujan.

Centro de asistencia Chorrillos.

Consultorios médicos Av. Defensores del Morro.

Mercado Municipal №1

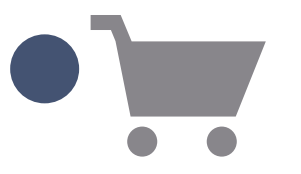

erminal pesquero de Chorrillos. Plaza Vea. Farmacias. Bodegas y tiendas zonales. Bancos.

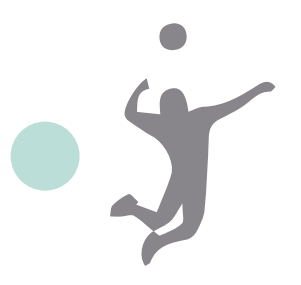

Estadio Municipal Chorrillos

Parque San Francisco.

Parque Juan de Espinoza Medrano

Áreas verdes en Av. Malecón Grau

Parque Angélica Recharte. Parque Rosario de Valle.

\section{IIII}

Municipalidad de Chorrillos

Bomberos Estación Gribaldi №6.

Comisaría Chorrillos.

Banco de la Nación

Dentro del $41.2 \%$ de comercio, se encuentra el mercado, terminar pesquero, farmacias y tiendas de comida; estas actividades comerciales tienen una relacion directa con el proyecto debido que constantemente se necesitará de estos. Así mismo, es importante resaltar la cercanía con las zonas de recreación debido a que se puede generar un relación entre las actividades realizadas al interiore del proyecto y los espacios que ofrece el distrito.

Otra caracteristica importante del proyecto, que brinda seguridad a los usuarios, es la cercanía con los grandes centros de salud las instifuciones que brindan ayuda y primeros auxilios como bomberos, comisaría y municipalidad.
Parroquia San Pedro. Iglesia con Castilla Iglesia Advientista del Séptimo día. Huaca La Lechuza

\section{Porcentaje de usos en zona}

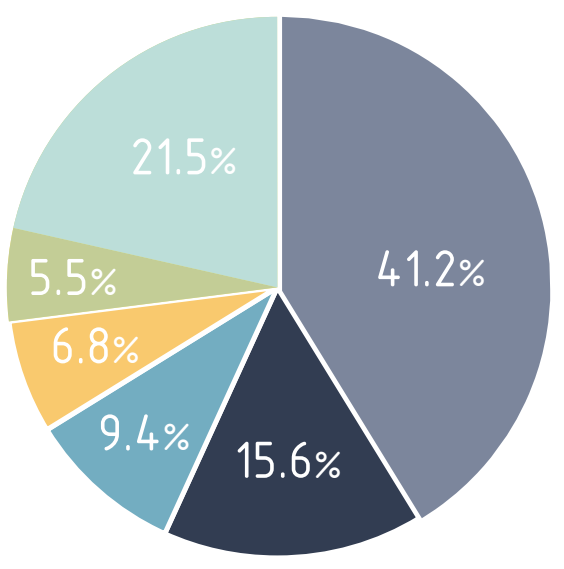

Educacion. Salud. $\bigcirc$ comercio. $\bigcirc$ Zona de Recreaciòn.

Institucional otros. Terreno. 


\section{BORDES - BARRIOS}
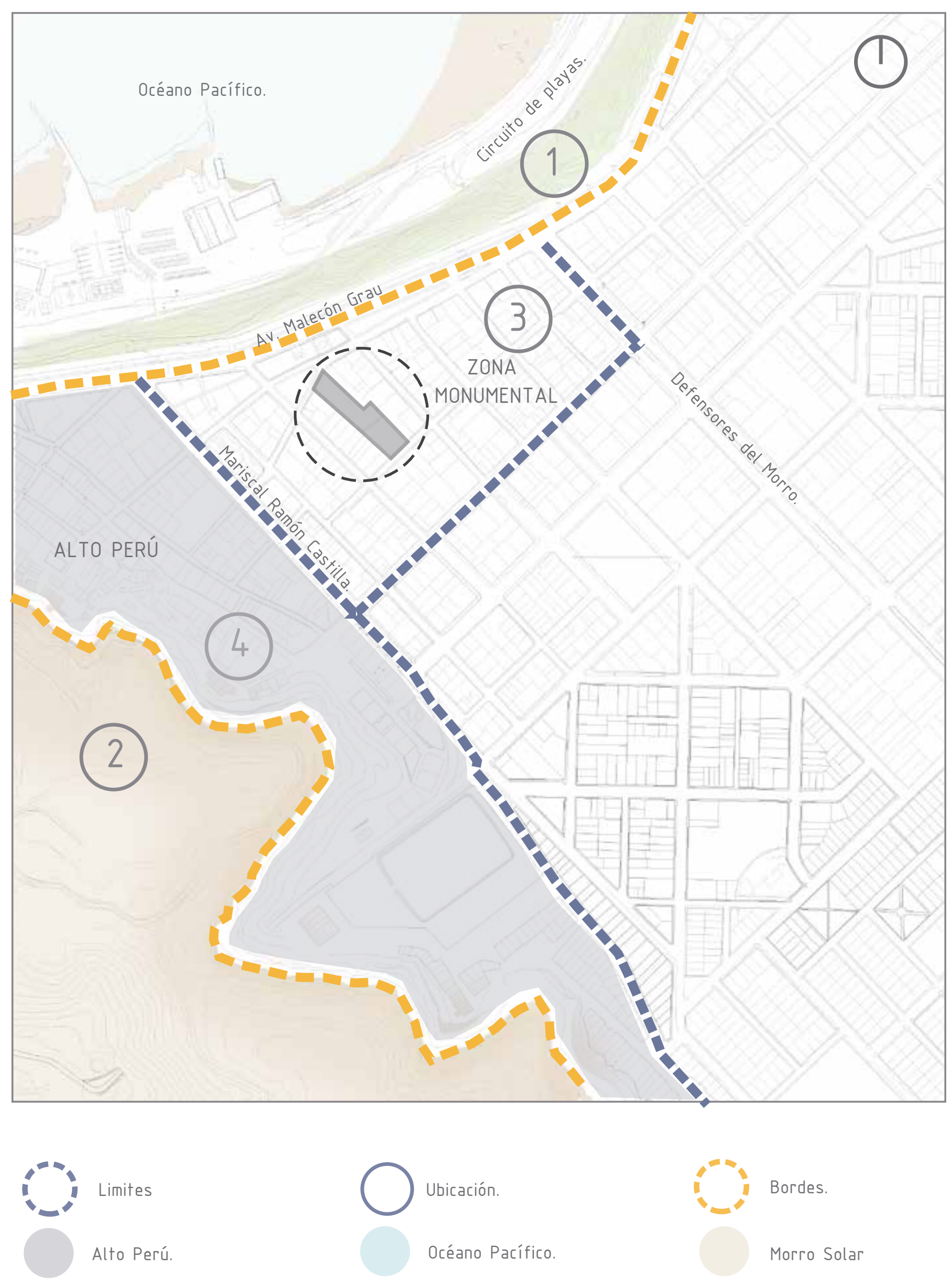

BORDES

Elementos lineales que no se consideran sendas. Son los límites entre dos fases que rompen con la continuidad, son referencias y no ejes coordinados. Los bordes pueden ser vallas que separan un sector de otro, y que tienen carácteristicas especiales en la función., por ejemplo el contorno de una ciudad por playas, ríos, murallas, montañas, etc.

1. Malecón de Chorrillos: Es el límite natural de Chorrilos y marca la diferencia entre el distrito y el már, además es un borde para la Ciudad de Lima. Aproximadamente hay una diferencia entre 44 metros de altura entre el distrito y el mar.

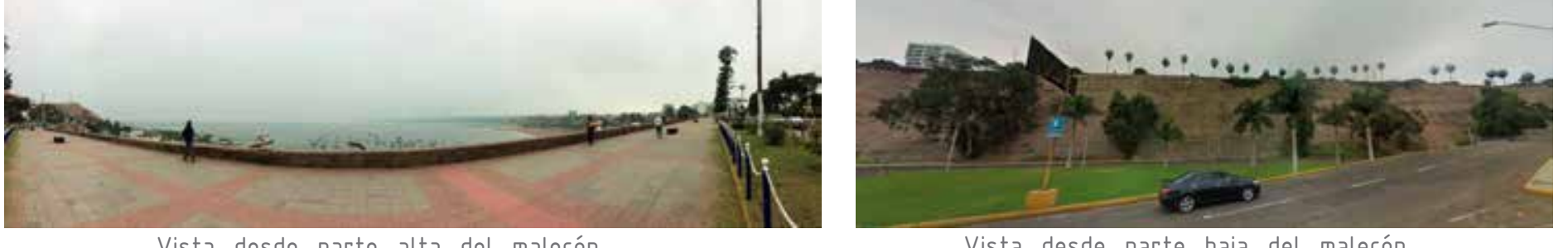

Vista desde parte alta del malecón.

Vista desde parte baja del malecón.

2. Morro solar: Conjunto de cerros del distrito de Chorrillos, este tiene una relación directa con el entorno estudiado debido a que marca un borde natural en el distrito, ademas de la zona de Alto Perú que esta ubicada a pocos metros del tеггеno elegido. Así mismo, el Могго Solar separa la conexión directa entre el mar y el distrito por el lado suroeste.

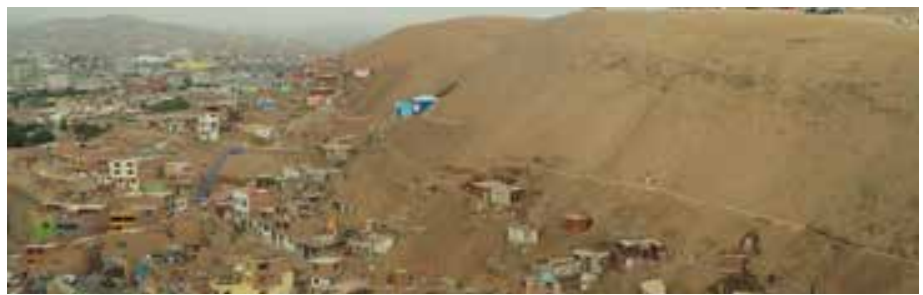

Vista desde parte alta del malecón.

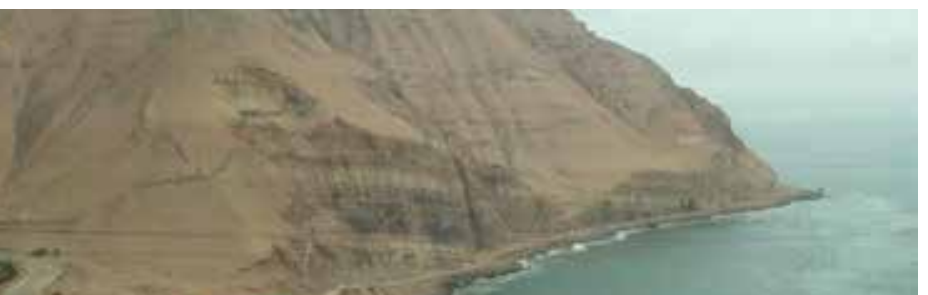

Vista desde parte baja del malecón.
BARRIOS

Son medianas o grandes secciones en la ciudad, en las cuales el usurario se siente parte de un grupo o lugar debido a las caracteristicas comunes que lo identifica como persona. Los barrios son reconocidos por su apariencia y son puntos referentes en la ciudad.

3. Alto Perú: Es un barrio formado por invaciones informales y que ubicado en la parte suroeste del distrito de Chorrillos, en la zona baja del Morro solar. Las características de las viviendas en Alto Perú contrastan a la de las otras calles de Chorrillos debido a la precariedad de estas. Alto Perú es barrio conocido por su peligrosidad. 4. Zona Monumental: Es una parte del distrito de Chorrillos que está conformada por edificaciones antiguas que son el reflejo de la historia del distrito y la ciudad.

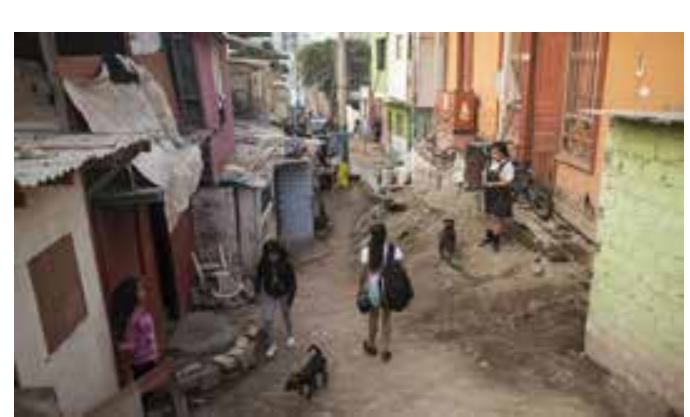

Vista de Alto Рeru.

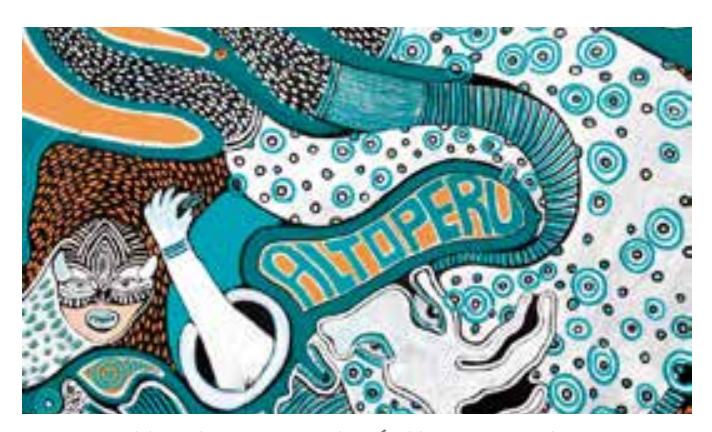

Murales c
Relaciones:

1-4: Zonas ubicadas en el límite del distrito, tiene como borde el maleción. Solo hay conexión visual, además, la zona 2 esta ubicada sobre otro borde, el morro solar.

1-3: Zonas ubicadas al límite del distrito, tiene como borde el gran malecón que solo permite una conexión visual directa.

3-4: La diferncia entre estas es que la zona 3, aun siendo antiguas, no son precarias a comparación con la zona 2 (Alto Perú). 


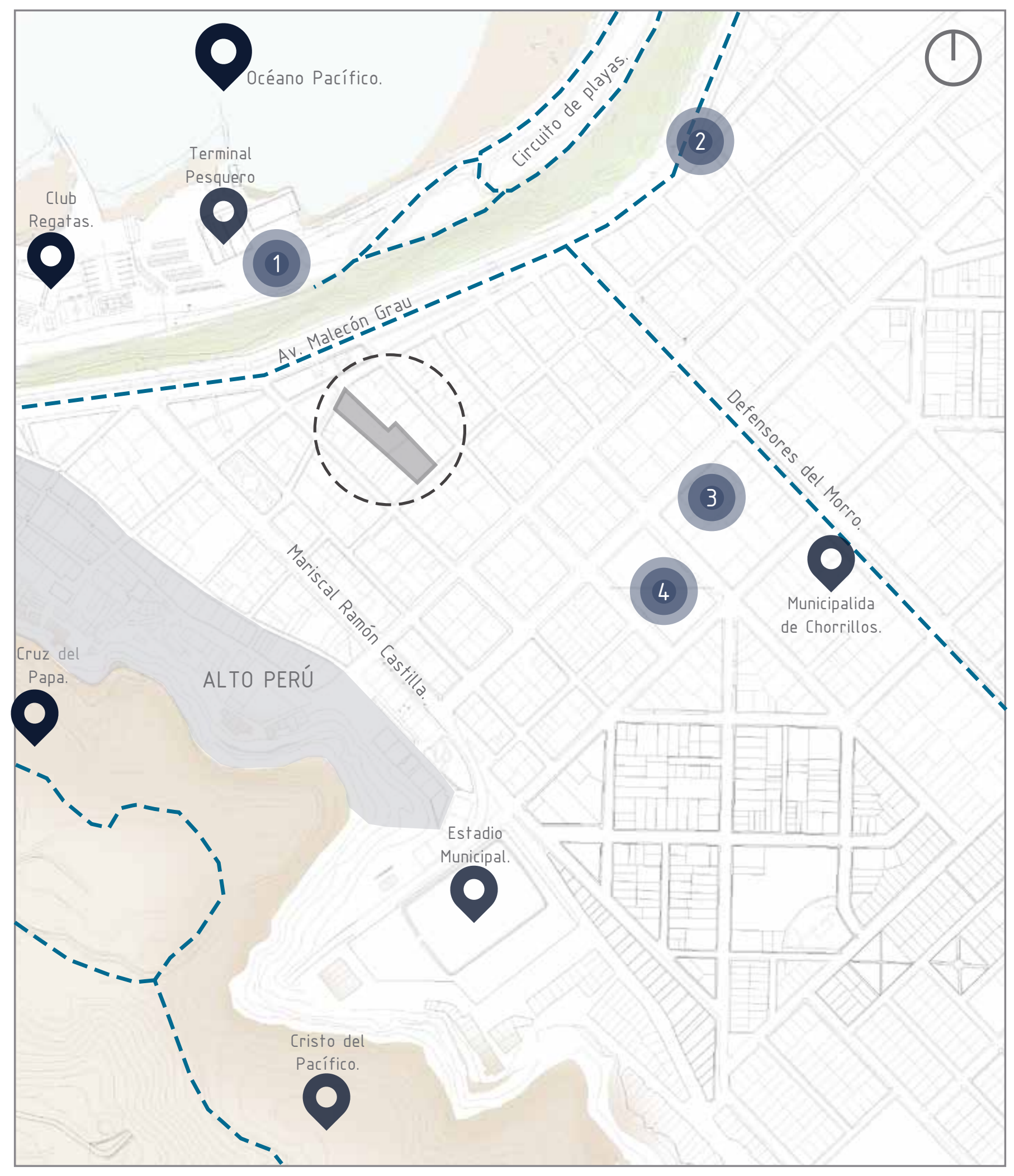

$\mathbf{P}$

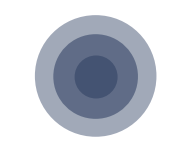

HITOS

Los hitos son puntos de referencia, por lo general se trata de un objeto físico que logra que el usurario pueda ubicarse con mayor facilidad en la ciudad. La zona cercana al proyecto tiene grandes hitos que pueden ser vistos a lo largo de todo el malecón, y otros puntos que son referentes al interior del distrito.
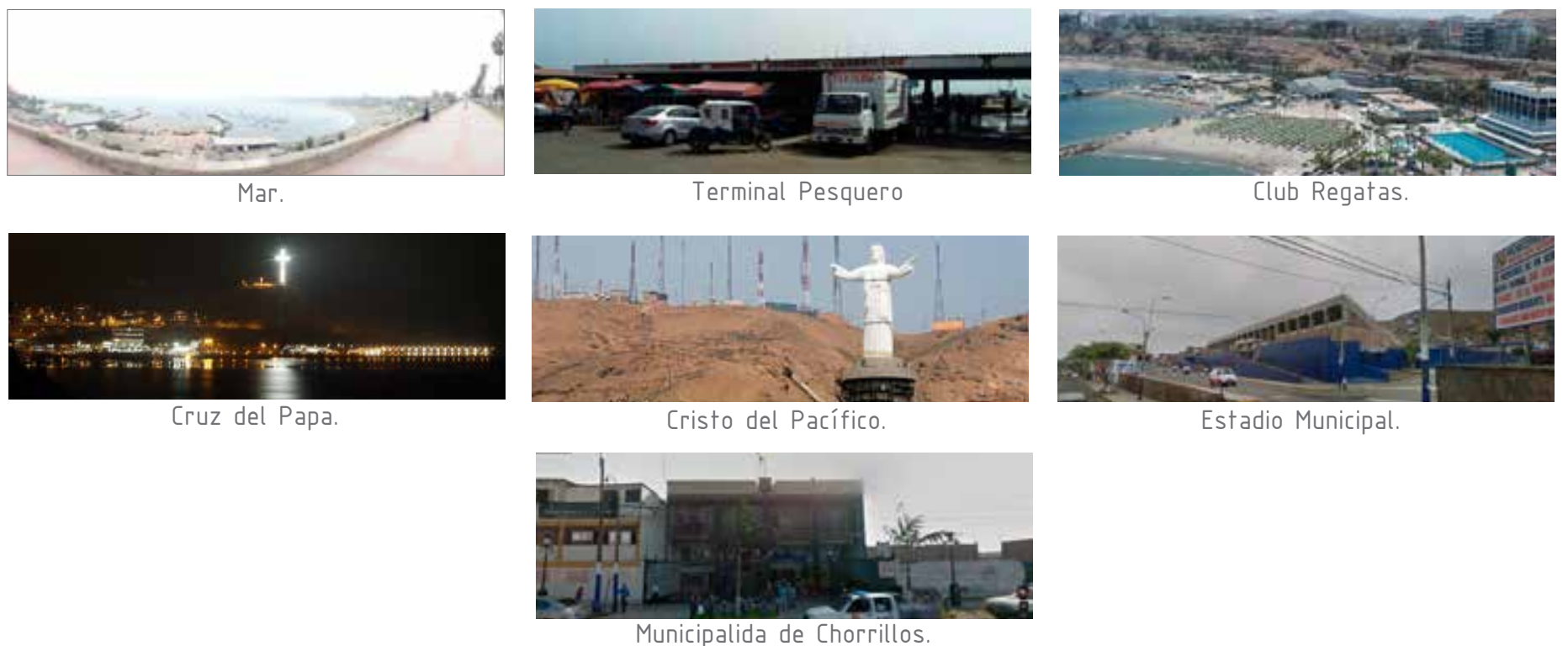

NODOS:

Son los puntos estratégicos y de grandes confluencias en una ciudad, los nodos estan relacionados con las sendas debido a que ambos elementos tienen como carácteristicas el movimiento de grandes masas, En el distrito de Chorrillos hay diversos nodos relacionados con el comercio y transporte-que

(1)

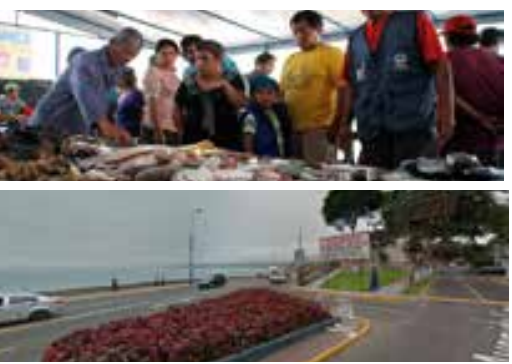

(2)

Terminal Pesquero: Gran actividad económica diaria. Radio de antención Lima Sur.

Acceso a circuito de playas.: lugar de intercambio víal.

(3)

Supermercado Plaza Vea.: Actividad económica en la zona. Radio de antención zonal.

(4. Mercado Municipal №1: Actividad económica en distrito. Radio de antención distrital.

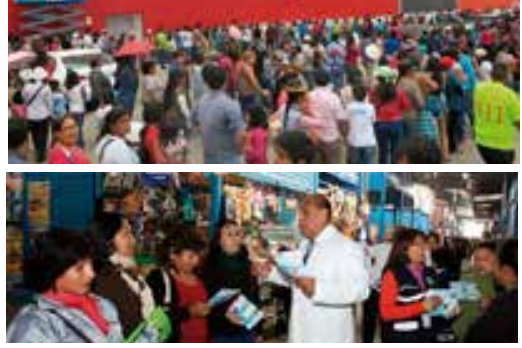

SENDAS:

at a 7 a calles y vías principales.

J Av. Defensores del Morro: Una de las avenidas principales del distrito. Conecta grandes edificos institucionales.

-

Av. Malecón Miguel Grau: Borde zonal, distrital y metropolitano. Vista a la Costa Verde.

1

J Vía que sube al Morro Solar, se puede observar todo el distrito. 


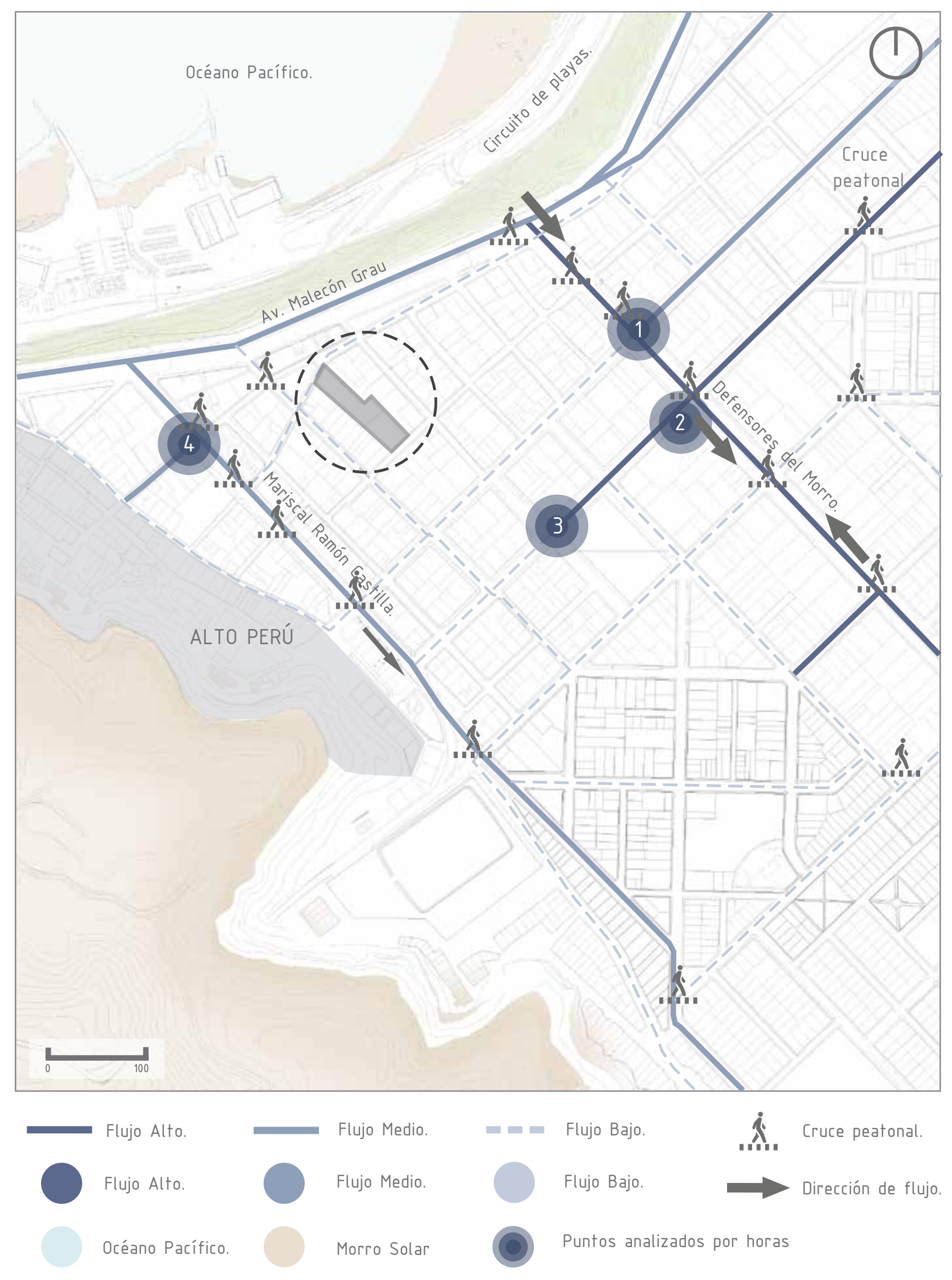

En la zona de análisis hay diferentes intensidades de flujos peatonales, las mayores y principales se dan a lo largo de la Av. Defensores del Morro debido a la gran cantidad de comercio y servicios que hay en esta. Las esquinas de mayor flujo peatonal son las que cruzan con las Av. José Olaya, Av. Alejandro Iglesias, Jr. Emilio Sandoval, debido a que en estas hay regular actividad comercial que complementa a la de la avenida principal, además, la ubicación de los paraderos de buses genera mayor concentración de personas.

(1)
7:00 AM
1:00 PM
7:00 PM

Cruce de Av. Defensores del Morro con Av. José Olaya.
Lun - Jue

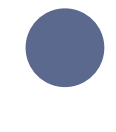
(1)
Vie - Dom

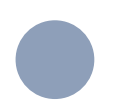

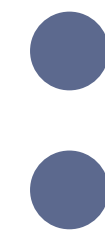

(2) Cruce de Av. Defensores del Morro con Av. Alejandro Iglesias.

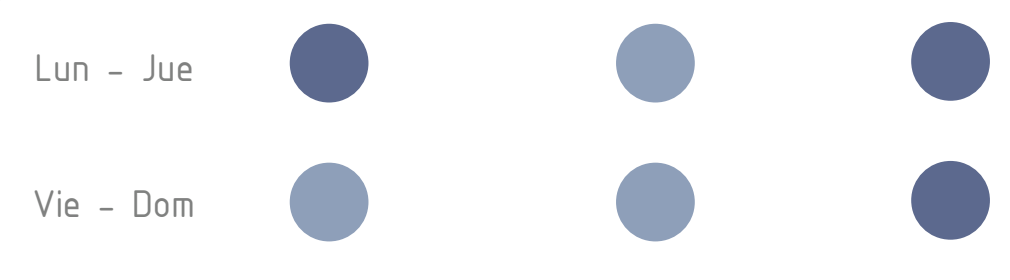

(3) Cruce de Av. Alejandro Iglesias con Саггега Ваггега (Mercado Municipal)
Lun - Jue
(
(
Vie - Dom
C
○
○
(

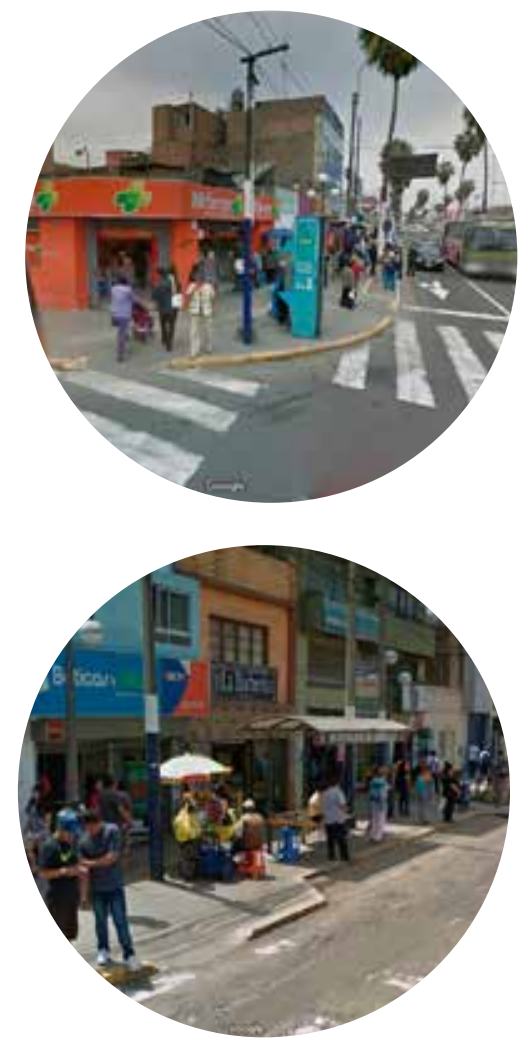

(4)

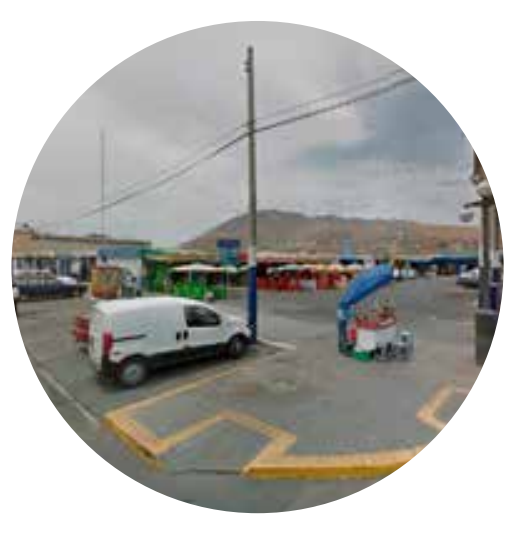

(4) Cruce de Av. Mariscal Castilla con Calle Luis Villarán.

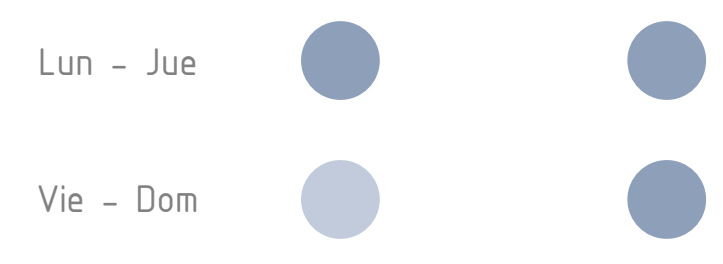

(

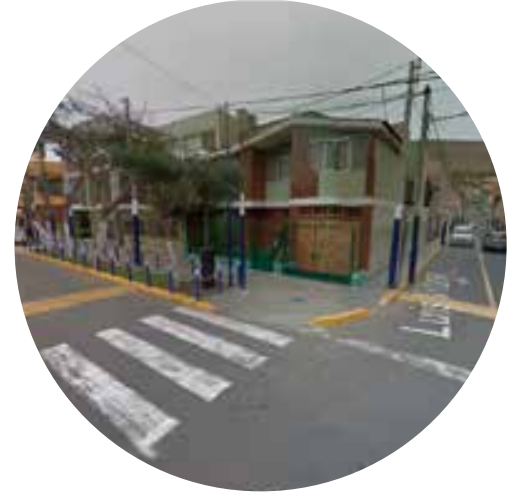




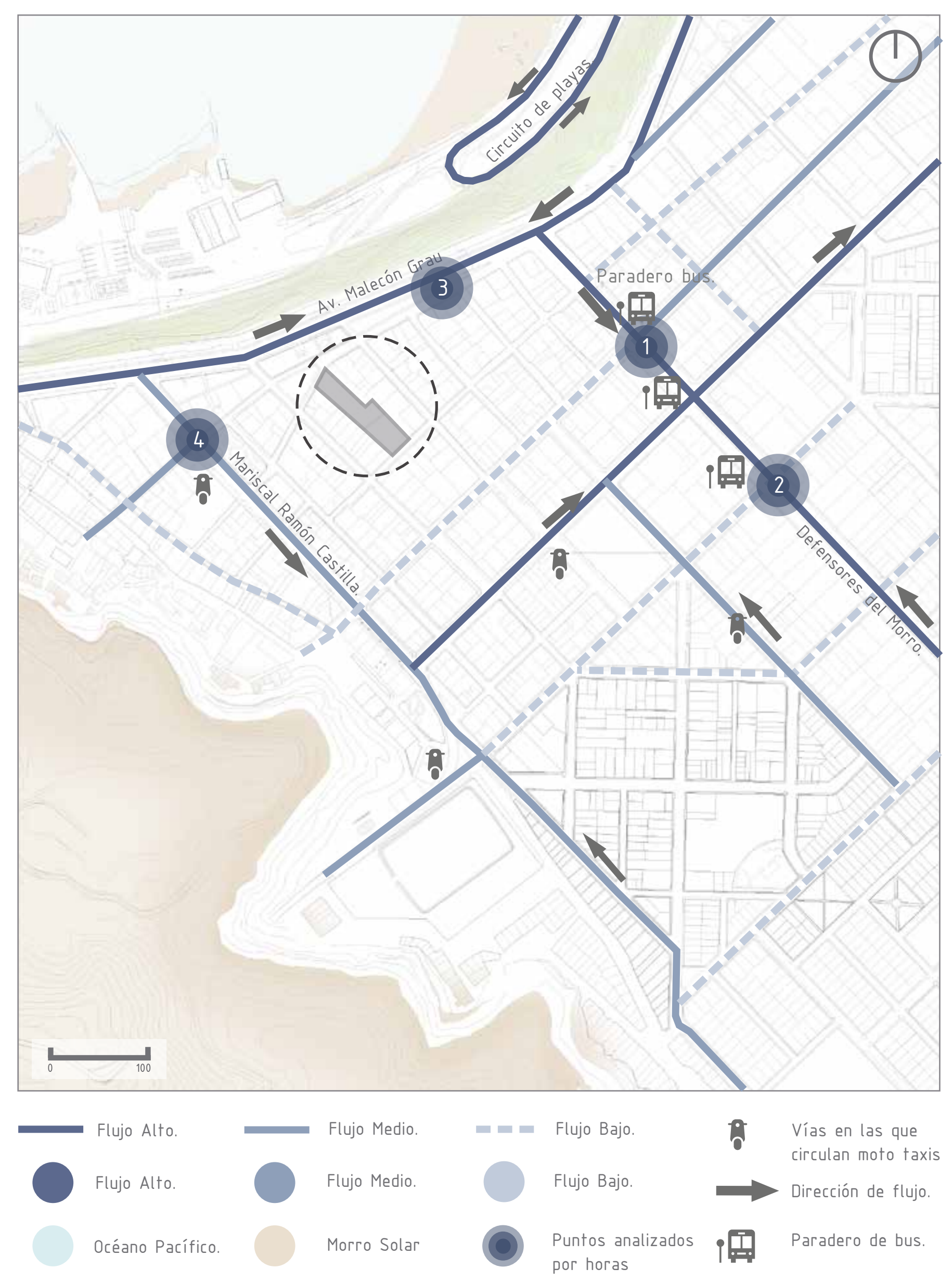

En la zona de análisis hay diferentes intensidades de flujos vehiculares, las mayores y principales se da a lo largo de la Av. Defensores del Morro debido a la gran cantidad de comercio y servicios que hay en esta. Av. Malecón Grau que recorre el malecón de Chorrillos y tiene acceso directo al Circuito de playas, que también es una vía con alto movimiento vehicular. A lo largo de la Av. Huaylas hay 3 paraderos, esto genera congestión vehicular y gran flujo de personas en dichos puntos. Otra vía importante es la Av. Ramón Castilla, en esta circula vehículo privado y moto taxis que bajan desde la zona de alto Perú.
7:00 AM
1:00 PM
7:00 PM

1. Cruce de Av. Defensores del Morro con Av. Alejandro Iglesias.

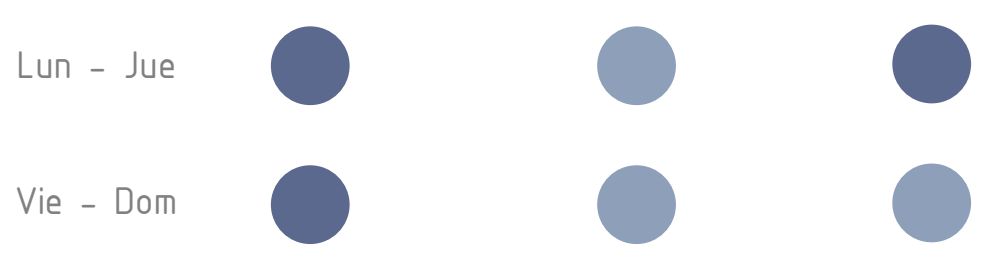

2. Cruce de Av. Defensores del Morro con Calle Urugay.
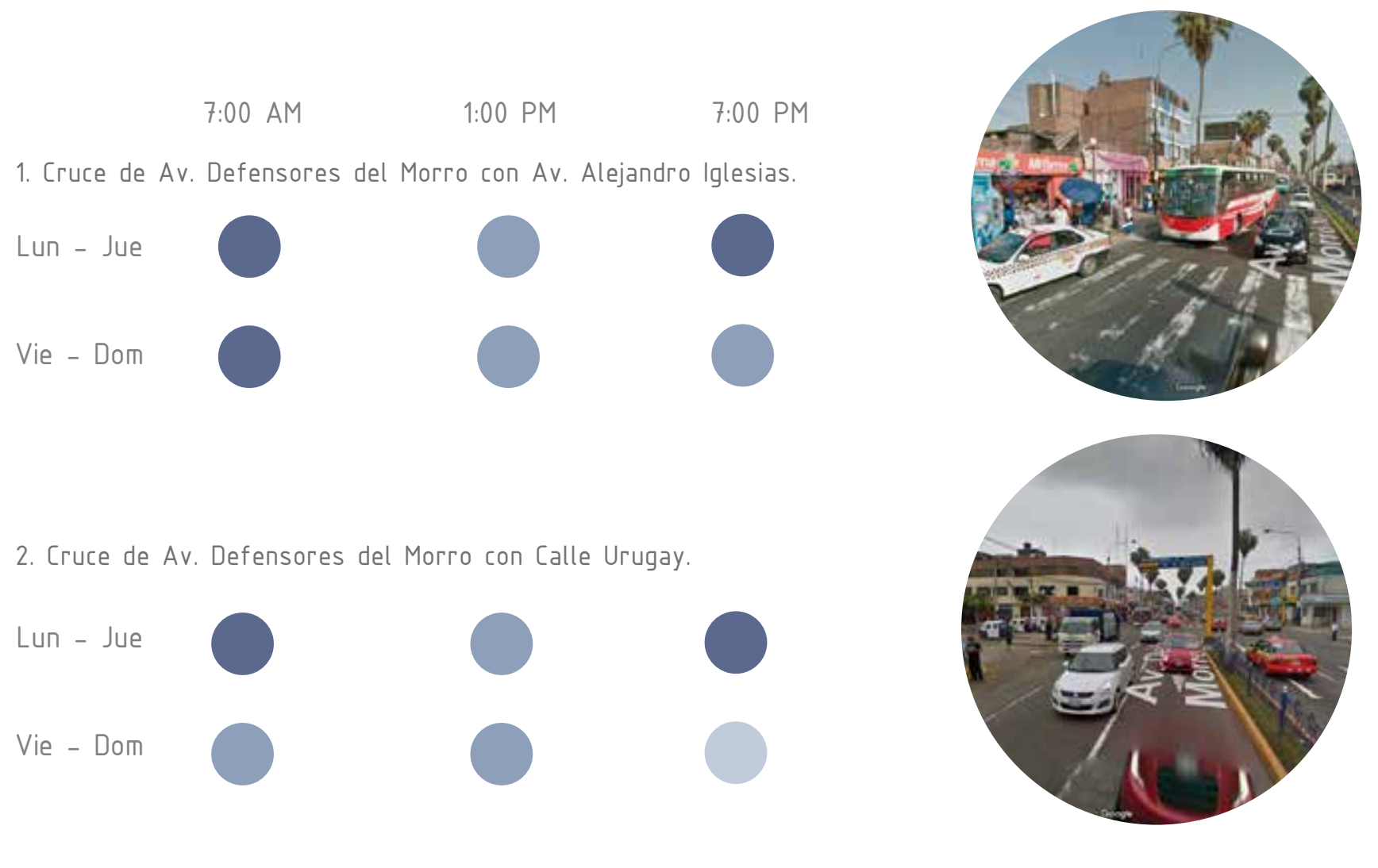

3. Av. Malecón Grau.
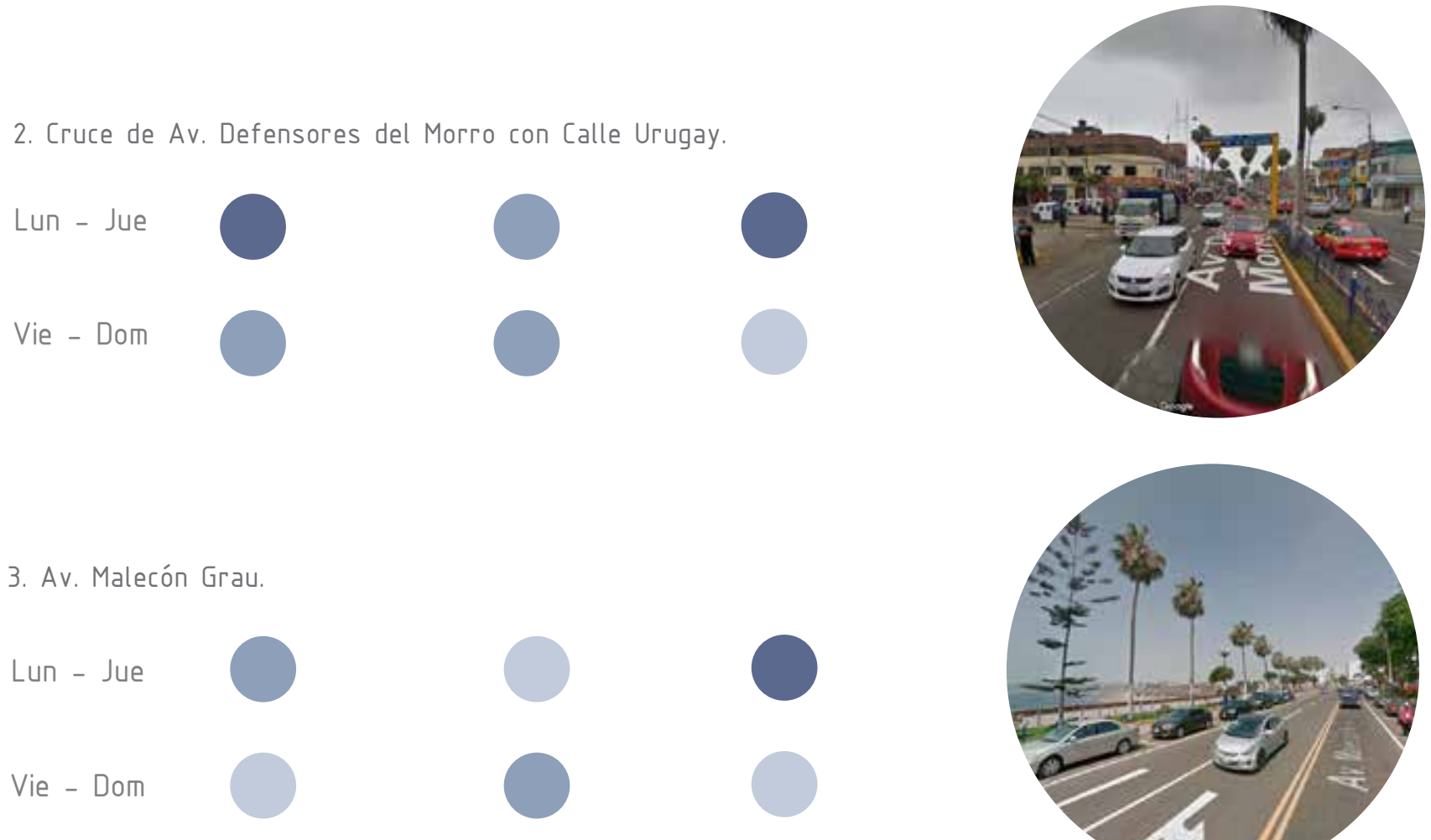

4. Cruce de Av. Mariscal Castilla con Calle Luis Villarán
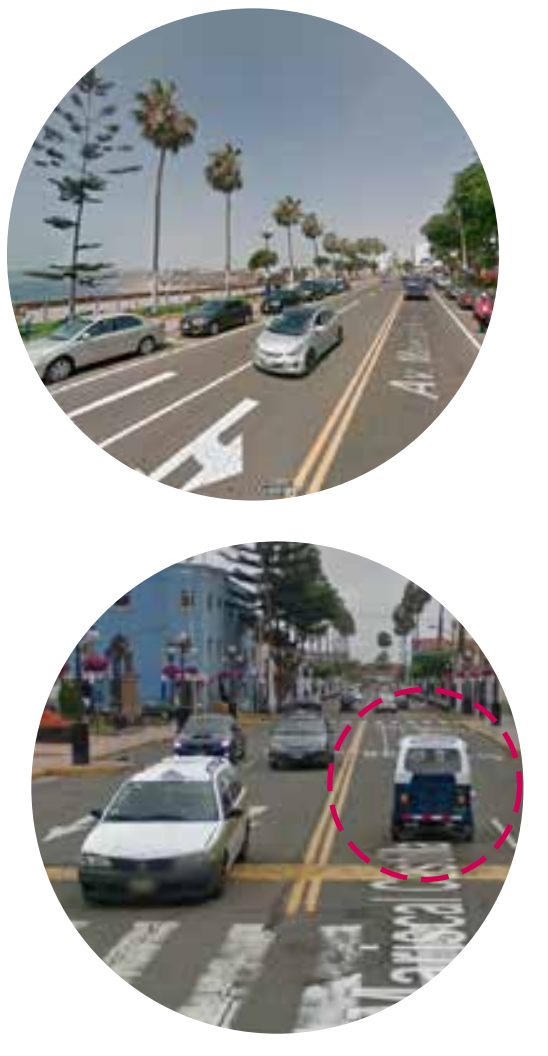


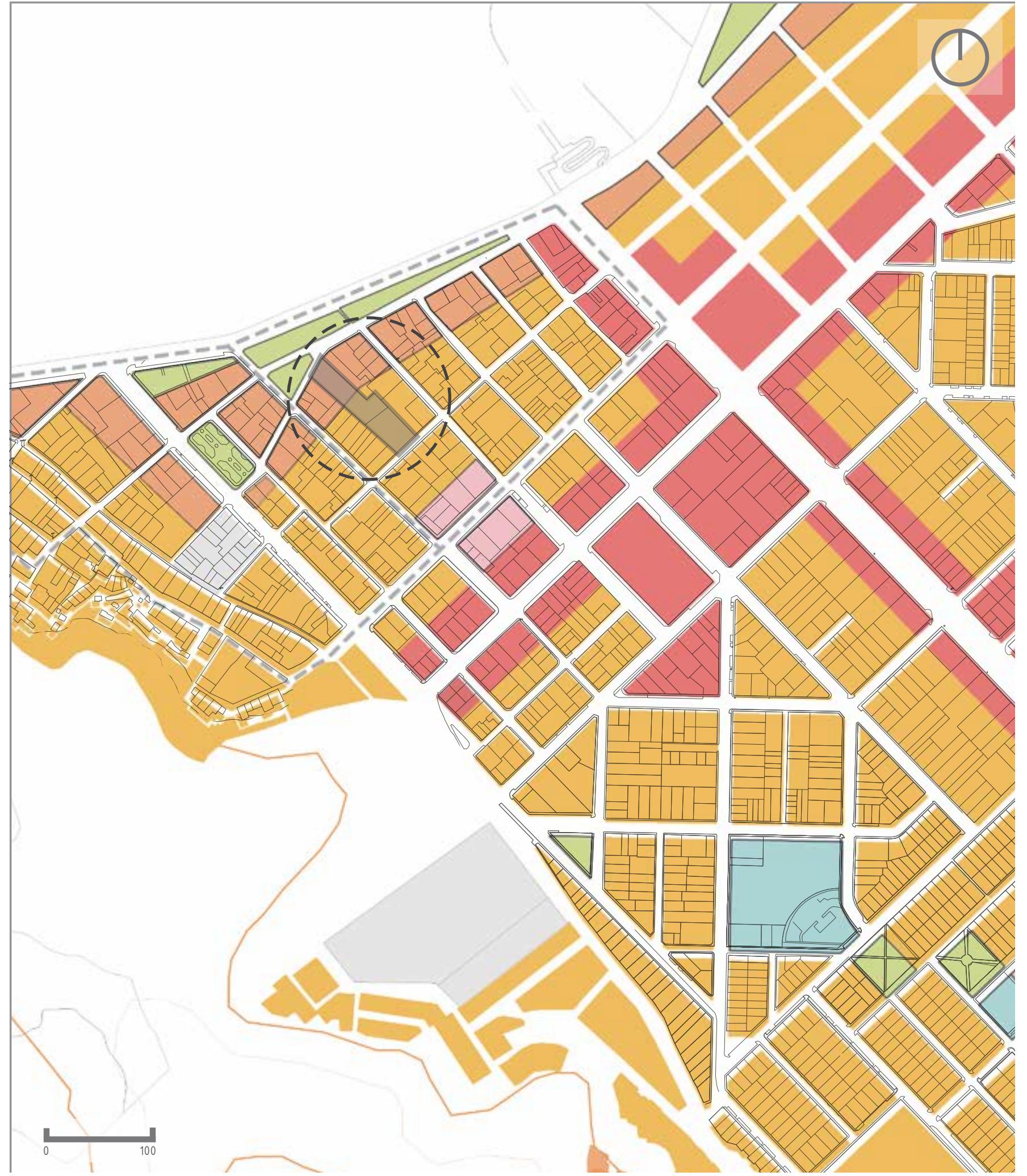

Residencial Densidad Alta (RDA) Residencial Densidad Media (RDM) Zona de Recreaciòn Pùblica (ZRP)

Comercio Zonal (CZ)

Comecio Vecinal (CV)
Educaciòn (E1)
En la zona estudiada, la mayoría de terrenos tiene zonificación como residencial densidad media, seguido de comercio zonal sobre odo en la avenida Defensores del Morro y la avenida Alejandro Iglesias. La primera de estas, Av. Defensores del Morro, tiene gran actividad debido a que es una de las vías principales del distrito, por lo cual, tienen gran flujo vehicular y es por esta avenida pasan los principales medios de transporte público urbano. Por otro lado, en la Av. Alejandro Iglesias se ubica el Mercado Municipal №1 de Chorrillos, lo que genera un flujo importante en la vía, por lo cual, se concentra una importante cantidad de negocios que complementan el mercado. Finalmente, como conclusión, la tendencia de la zona estudiada es de residencia de densidad media, рог lo łanto, las edificaciones construidas son de mediano tamaño.

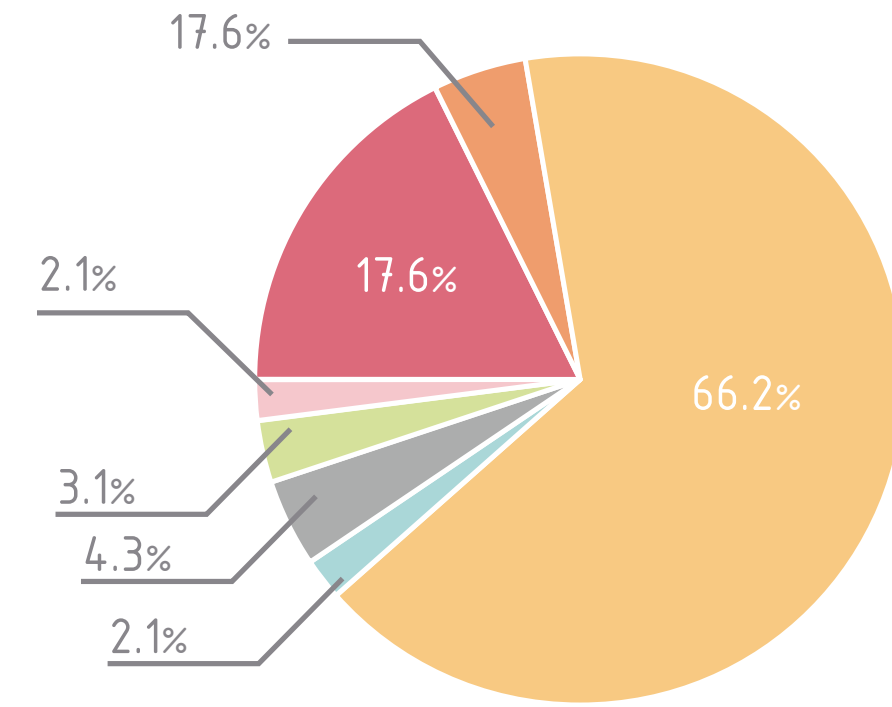

Zonificación de área de estudio por porcentaje. (\%)

Parámetros Generales del Distrito de Chorrillos.

\begin{tabular}{|c|c|c|c|c|c|c|}
\hline Zona & Altura & $\begin{array}{c}\text { Uso } \\
\text { compatible }\end{array}$ & $\begin{array}{l}\text { Lote mínimo } \\
\text { (m2) }\end{array}$ & $\begin{array}{c}\text { Frente } \\
\text { mínimo (ml) }\end{array}$ & $\begin{array}{l}\text { Area libre } \\
\text { mínima }\end{array}$ & Estacionamientos mínimos \\
\hline Comercio Metropolitano & $1.5(a+r)$ & RDA & \multirow{3}{*}{$\begin{array}{l}\text { Existente o } \\
\text { segun } \\
\text { proyecto. }\end{array}$} & & \multirow{3}{*}{$\begin{array}{c}\text { No exigible } \\
\text { para uso } \\
\text { comercial. Para } \\
\text { vivienda } \\
\text { revisar } \\
\text { requisitos. }\end{array}$} & 1 cada $50 \mathrm{~m} 2$ \\
\hline Comercio Zona & $1.5(a+r)$ & RDA/RDM & & & & 1 cada $50 \mathrm{~m} 2$ \\
\hline Comercio Vecinal & 5 pisos. & RDM & & & & 1 cada $50 \mathrm{~m} 2$ \\
\hline $\begin{array}{l}\text { Rresidencial de Densidad } \\
\text { Baja }\end{array}$ & $\begin{array}{l}\text { Uni: } 3 \text { pisos. } \\
\text { Multi: } 4 / 5 \mathrm{p} \text {. }\end{array}$ & $\begin{array}{l}\text { Unifamiliar. } \\
\text { Multifamiliar. }\end{array}$ & $200 \mathrm{~m} 2$. & $10 \mathrm{ml}$. & $30 / 35 \%$ & 1 cada 1.5 viv. \\
\hline $\begin{array}{l}\text { Residencial de Densidad } \\
\text { Media }\end{array}$ & $\begin{array}{l}\text { Uni: } 3 \text { pisos. } \\
\text { Multi: } 4 / 7 \mathrm{p} \text {. } \\
\text { CR: } 8 \text { pisos. }\end{array}$ & $\begin{array}{l}\text { Unifamiliar. } \\
\text { Multifamiliar. } \\
\text { C Residen. }\end{array}$ & $\begin{array}{l}\text { Uni: } 120 \mathrm{~m} 2 . \\
\text { Multi: } 150 / 300 \\
\text { CR: } 1600 \mathrm{~m} 2 .\end{array}$ & $\begin{array}{l}\text { Uni: } 6 \mathrm{ml} . \\
\text { Multi: } 6 / 10 \mathrm{ml} . \\
\text { CR: } 20 \mathrm{ml} .\end{array}$ & $\begin{array}{l}\text { Uni: } 30 \% \\
\text { Multi: } 35 \% \\
\text { CR: } 40 \%\end{array}$ & 1 cada 1.5 viv. \\
\hline $\begin{array}{l}\text { Residencial de Densidad } \\
\text { Alta }\end{array}$ & $\begin{array}{c}\text { Multi: } 8 \\
\text { CR: } 1.5(\mathrm{a}+\Gamma) 3\end{array}$ & $\begin{array}{l}\text { Multifamiliar } \\
\text { C Residen. }\end{array}$ & $\begin{array}{l}\text { Multi: } 300 / 450 \\
\text { CR: } 2500 \mathrm{~m} 2 .\end{array}$ & $\begin{array}{l}\text { Multi: } 10 \mathrm{ml} . \\
\text { CR: } 10 / 25 \mathrm{ml} .\end{array}$ & $\begin{array}{l}\text { Multi:35/40\% } \\
\text { CR: } 50 \%\end{array}$ & 1 cada 1.5 viv. \\
\hline
\end{tabular}

Sin embargo, el proyecto tiene unos parametros especiales debido a que está ubicado dentro de la Zona Monumental del distrito de Chorrillos. Esta parte del distrito es la más conservadora y sus edificaciones aún tienen características de la Lima Antugua, por lo tanto, la altura de las constrcciones no puede pasar los $13 \mathrm{ml}$ en las calle principal paralela a la Av. Malecón Grau, y de $9.75 \mathrm{ml}$ en las calles secundarias. 


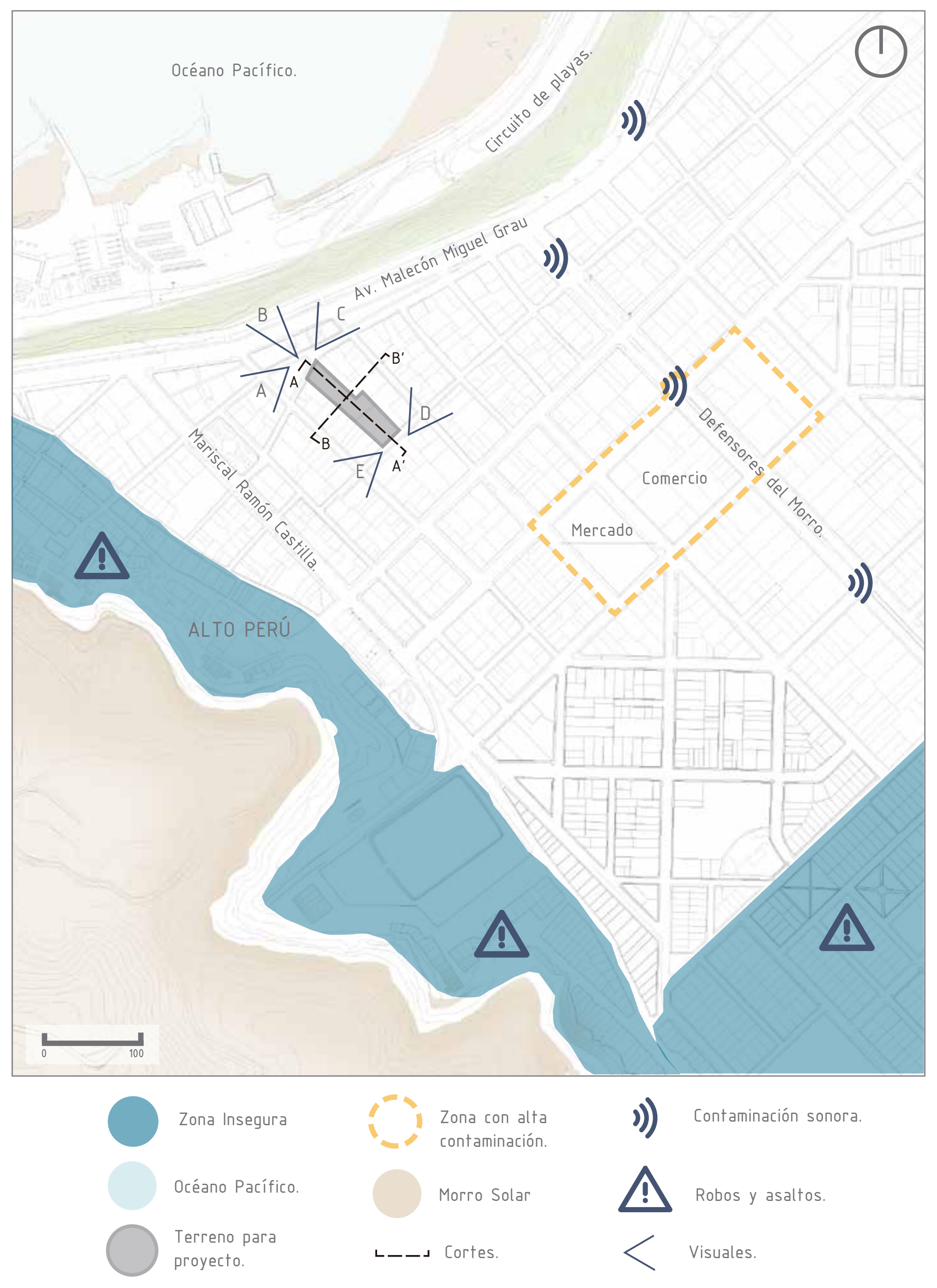

VISUAL.
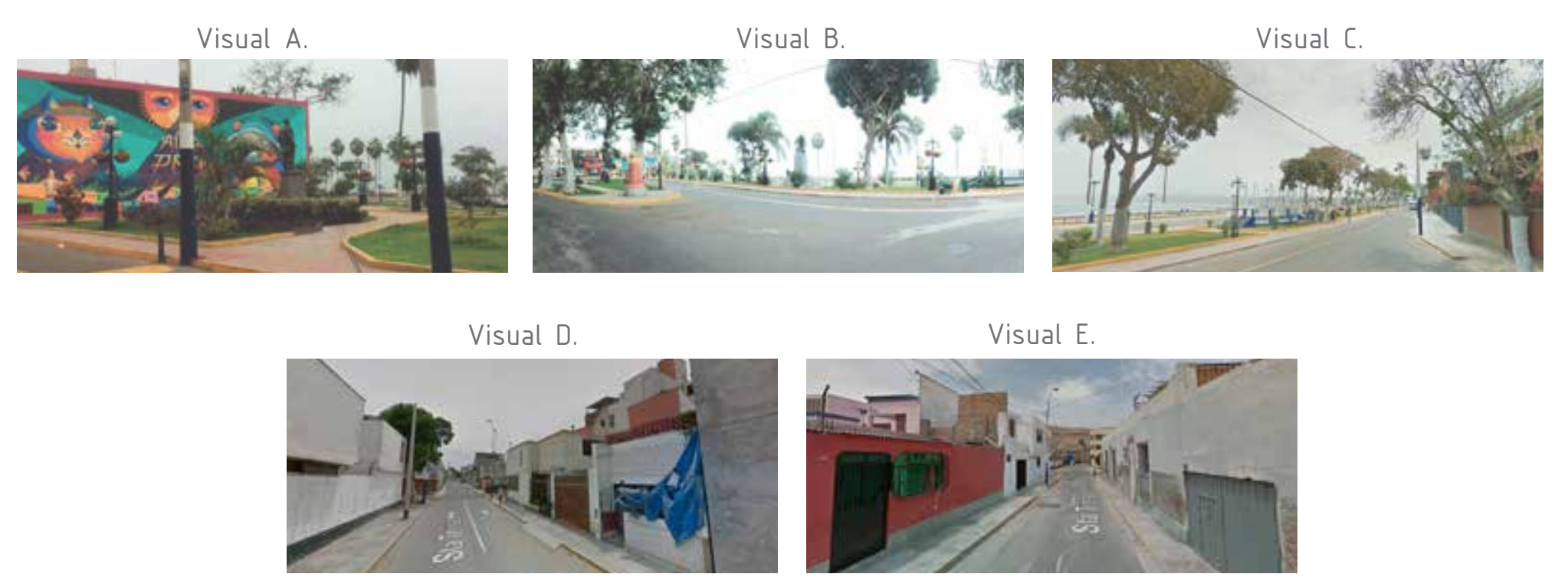

ESPACIALIDAD.

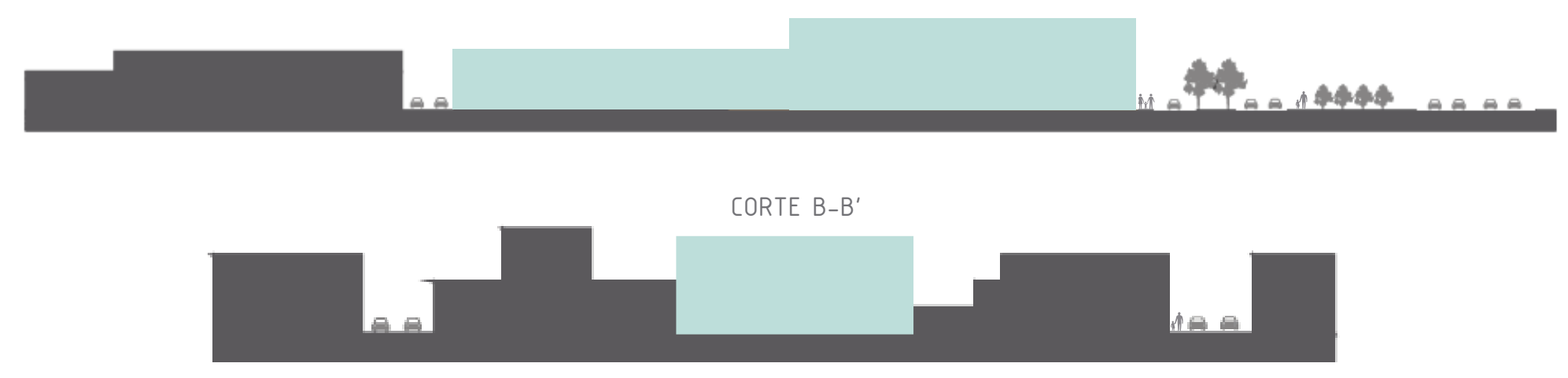

CONTAMINACIÓN.

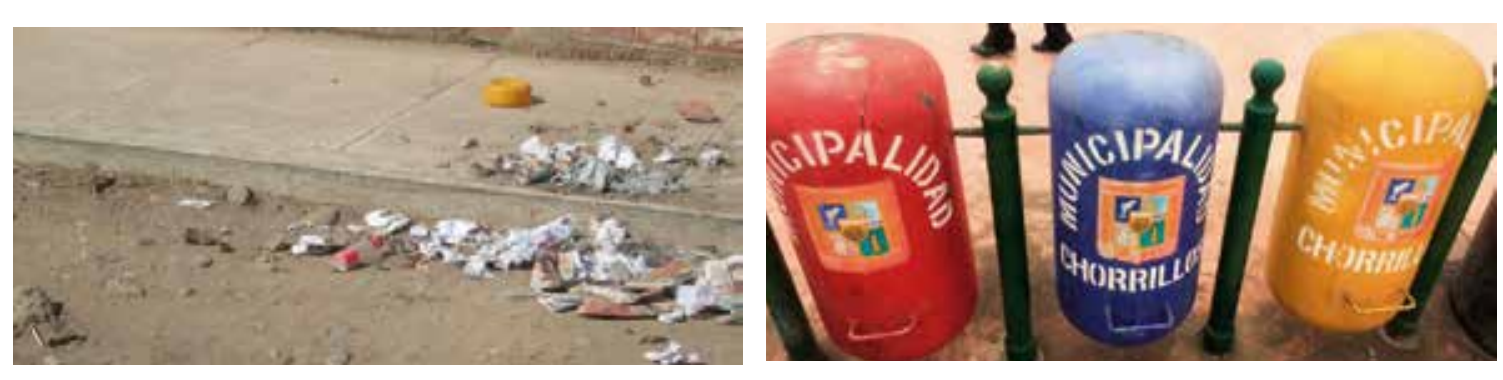

La zona investigada tiene variadas características, por tal motivo, la percepción de cada lugar es distinta e influye mucho de acuerdo a cada contexto. En la zona colindante al cerro, A.A.H.H Alto Perú, es donde se percibe mayor inseguridad debido a que es en donde se encuentra la mayor cantidad de delincuencia y pandillaje, además, no cuenta con los servicios básicos de agua, luz ni desahue, las conexiones que tienen con ilegales.

A los alrededores del Mercado Municipal no hay buena limpieza, al salir del mercado hay muchos desechos y bolsas de basura, por lo cual esa zona da la sensación de ser la más contaminada. Sobre contaminación sonora, la Av. Defensores del Morro es la que cuenta con mayor porcentaje de este tipo de contaminación, debido 

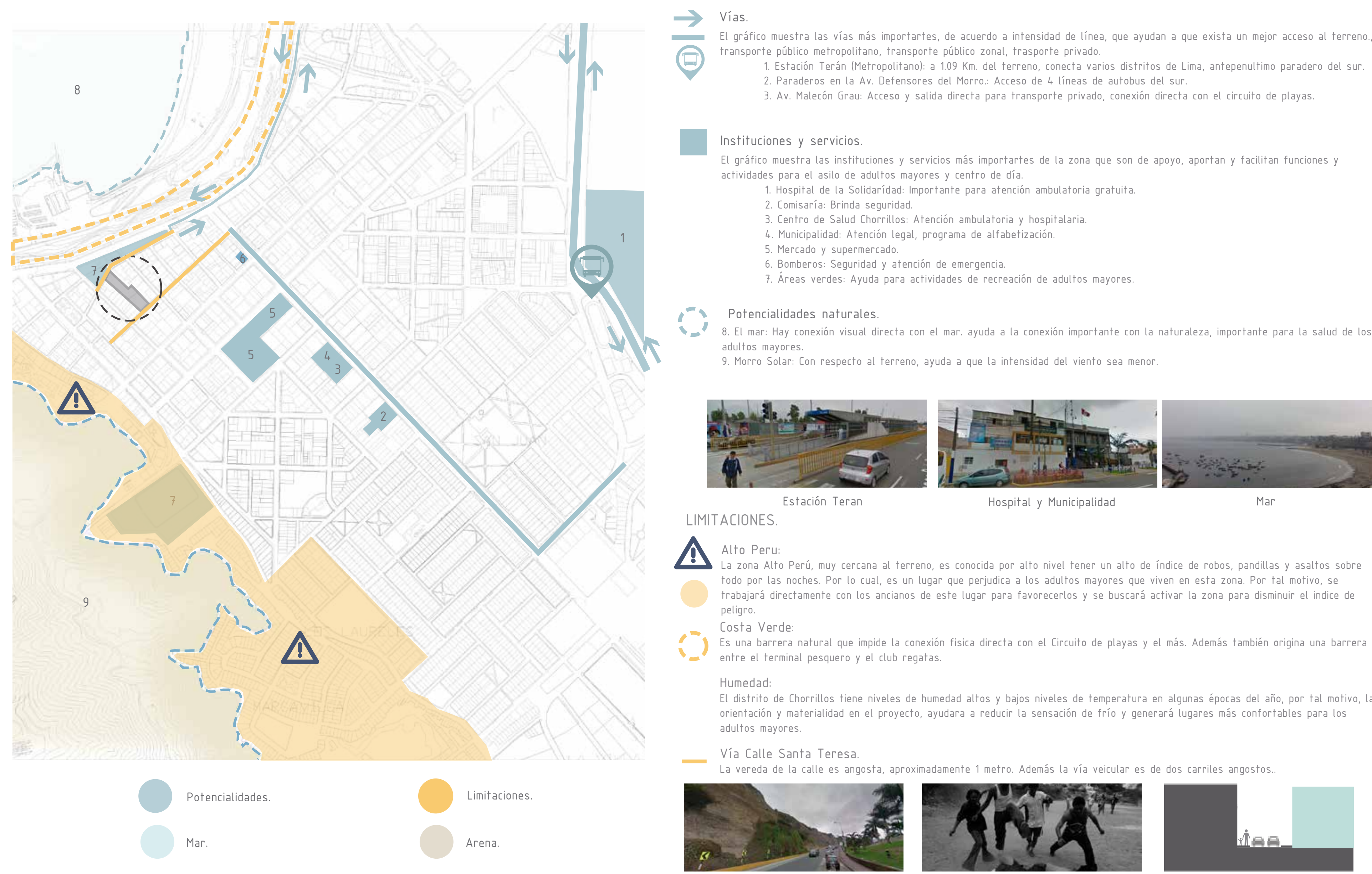

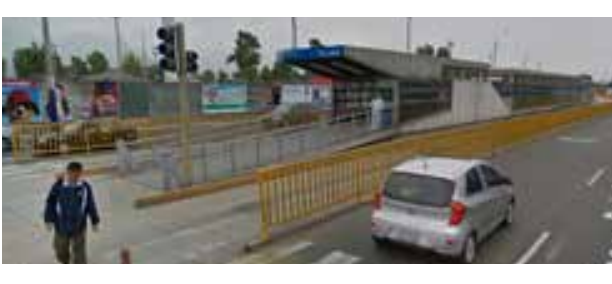

Estación Teran

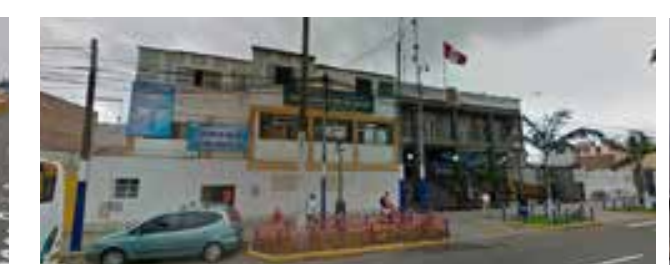

Hospital y Municipalidad

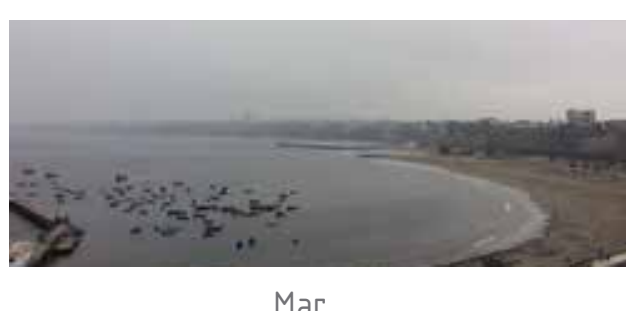
LIMITACIONES

A. Alto Peru:

La zona Alto Perú, muy cercana al terreno, es conocida por alto nivel tener un alto de índice de robos, pandillas y asaltos sobre todo por las noches. Por lo cual, es un lugar que perjudica a los adultos mayores que viven en esta zona. Por tal motivo, se trabajará directamente con los ancianos de este lugar para favorecerlos y se buscará activar la zona para disminuir el indice de peligro.

- Costa Verde:

Es una barrera natural que impide la conexión fisica directa con el Circuito de playas y el más. Además también origina una barrera entre el terminal pesquero y el club regatas.

Humedad:

El distrito de Chorrillos tiene niveles de humedad altos y bajos niveles de temperatura en algunas épocas del año, por tal motivo, la orientación y materialidad en el proyecto, ayudara a reducir la sensación de frío y generará lugares más confortables para los adultos mayores.

- Via Lalle Santa Teresa.

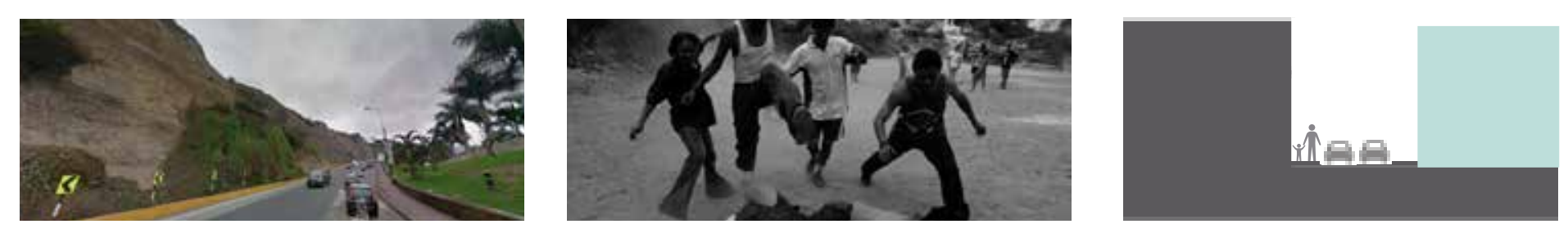




\section{CAPITULO VII: PROYECTO}

7. Panorama general del proyecto.

\subsection{Introducción.}

“La Residencia y Centro de Día para el Adulto Mayor de Chorrillos y Alto Perú" es un proyecto dirigido a las personas de la tercera edad para que gocen de sus facultades físicas y mentales. Tiene como objetivo mejorar su calidad de vida y contribuir a que sigan desarrollando sus capacidades en un espacio y ambiente adecuado a sus necesidades.

El terreno, ubicado en la calle José Olaya frente a la Av. Malecón Grau del distrito de Chorrillos, le pertenece al Arzobispado de Lima, institución que realiza labores pastorales y sociales a favor de las personas necesitadas, y la cual será una de las colaboradoras para el desarrollo y funcionamiento de este proyecto. Además, la localización del terreno pertenece a la zona monumental del distrito, por tal motivo, las alturas máximas de los dos volúmenes del proyecto son de 3 y 4 niveles respectivamente, los cuales son unidos por un puente central en un terreno de $2336.37 \mathrm{~m} 2$.

El proyecto cuenta con un área construida de 4939.85m2 en la que se realizan ambas funciones. La zona de Centro de Día ocupa el 70\% del proyecto y son áreas a las que pueden acceder todos los ancianos inscritos en las actividades que se brindan en este lugar; por otro lado, la zona de residencia se distingue por ser el área utilizada para las habitaciones de los 58 usuarios que viven en el proyecto, quienes también pueden acceder a todas las actividades realizadas en el centro de día e integrarse con más de 1260 adultos mayores divididos en 3 grupos de 420 asistentes diarios.

El proyecto considera las teorías desarrolladas en el capítulo III las cuales hablan de los diferentes estados y percepciones del adulto mayor al llegar a la etapa de vejez. Además, se explican teorías arquitectónicas que se han considerado desde la toma de partida del diseño del proyecto. La permeabilidad, es de las principales características porque se busca generar un proyecto que no se aísle del entorno y que invite al vecino de Chorrillos a participar de este. Por otro lado, se explica la importancia de la Neuroarquitectura que se aplicará a cada 
ambiente del proyecto generando distintas percepciones que ayuden a que el adulto mayor pueda lograr identificar y encontrar ambientes con diversas características y que le generen sensaciones utilizando elementos como agua, vegetación, mobiliario, texturas, etc.

Por otro lado, todas las actividades del centro de día están pensadas para ayudar a que el adulto mayor siga manteniéndose activo, e involucra, por un lado, el trabajo físico con actividades deportivas adecuadas; y, por otro lado. el mental, con manualidades, jardinería, lecturas, aprendizaje, etc.

Finalmente, el proyecto busca ser una ayuda para integrar mejor las zonas aledañas, por tal motivo, se podrán realizar actividades programadas con vecinos y familiares con el fin de sensibilizar y dar a conocer la importancia y el cuidado que merece el adulto mayor, además de exponer los trabajos realizados en los talleres del centro de día.

\subsection{Ubicación y características.}

"La Residencia y Centro de Día para el Adulto Mayor de Chorrillos y Alto Perú” es un proyecto ubicado en la zona monumental del distrito de Chorrillos en un terreno con doble frente que le pertenece al Arzobispado de Lima.

Es un terreno de $2336.37 \mathrm{~m} 2$ que se encuentra entre medianeras y tiene una forma longitudinal con 103.47 metros de profundidad, 19.90 metros en su fachada principal, y 22.85 metros en la fachada posterior. Este logra conectar dos calles paralelas que caracterizan a dos zonas distintas, una con cualidades más urbanas y la otra con rasgos más barriales. Este contraste nos da la oportunidad de realizar un proyecto que genere integrar ambos frentes.

El contexto urbano en el que se encuentra el proyecto es morfológicamente heterogéneo, la fachada principal está ubicada en el cruce de la Calle José Olaya con la Calle Malecón Grau, estas son paralelas a la Av. Malecón Grau la cual conecta directamente al distrito con todo el borde costero de Lima conocido como La Costa Verde. Además, por su ubicación, el proyecto tiene una vista privilegiada del malecón de Chorrillos lo que genera una conexión visual directa con el mar. 
Por otro lado, la fachada posterior del proyecto está ubicada en la Calle José Olaya, zona residencial con edificaciones que tienen como máximo 3 niveles altura y con calles angostas de flujos vehiculares y peatonales bajos.

Por otro lado, es importante resaltar la cercanía con la Av. Defensores del Morro, esta tiene actividad económica importante y se ubican los centros de asistencia en casos de emergencia que le dan mayor seguridad al proyecto; así como la cercanía con el Morro Solar como hito de la ciudad, y el asentamiento humano Alto Perú, barrio de población vulnerable con la que se desea trabajar en el proyecto.

Tabla 7.2.1:Análisis FODA

FORTALEZA

\begin{tabular}{|c|c|}
\hline $\begin{array}{l}\text { - Tendencia de crecimiento en } \\
\text { el grupo de la población } \\
\text { objetiva. } \\
\text { - Bajo índice de contaminación } \\
\text { en el distrito. } \\
\text { - Cercanía con equipamiento y } \\
\text { asistencia complementaria de } \\
\text { otras entidades. } \\
\text { - Accesibilidad. }\end{array}$ & 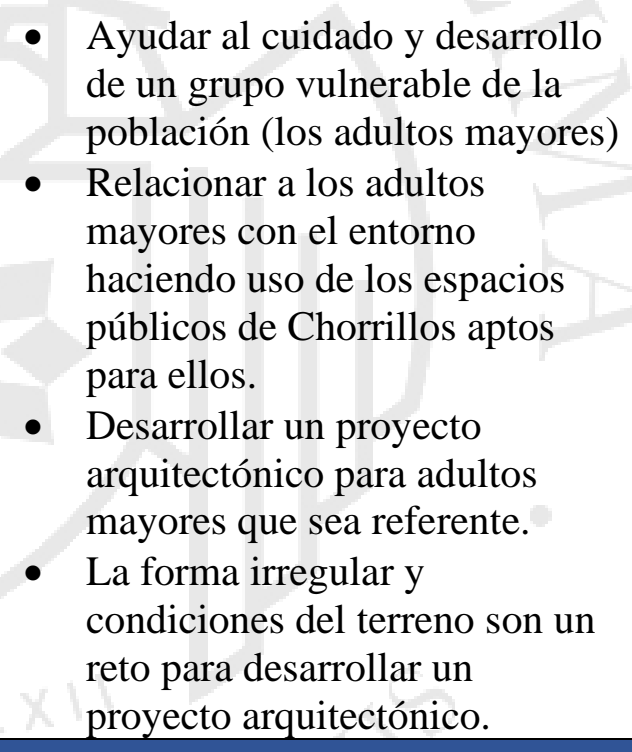 \\
\hline DEBILIDADES & AMENAZAS \\
\hline $\begin{array}{l}\text { - Límite de altura para el } \\
\text { desarrollo del proyecto. } \\
\text { - Terreno entre medianeras. } \\
\text { - El ruido producido por los } \\
\text { autos en los días de mayor } \\
\text { congestión vehicular en la Av. } \\
\text { Malecón Grau. }\end{array}$ & $\begin{array}{l}\text { El proyecto se encuentra } \\
\text { regularmente cerca de una } \\
\text { zona peligrosa del distrito de } \\
\text { Chorrillos. } \\
\text { - En un eventual movimiento } \\
\text { sísmico de gran intensidad que } \\
\text { desencadene una alerta de } \\
\text { tsunami, los adultos mayores y } \\
\text { el personal que se encuentre } \\
\text { en el proyecto deberá evacuar. }\end{array}$ \\
\hline
\end{tabular}

Fuente: Elaborado por autor. 


\subsection{Estudio de cabida}

El terreno de forma irregular y alargada tiene $2335.37 \mathrm{~m} 2$, mide 19.90m en su fachada principal, en la fachada posterior: 22.85, y 103.47 metros en su profundidad. Se desea optimizar la forma del terreno y optimizar la importancia del mar, sin perjudicar la idea principal de generar recorridos que direccionen a diversos ambientes de encuentro que incentiven las relaciones entre los adultos mayores.

Figura 7.3.1: Conexión entre ambas calles.

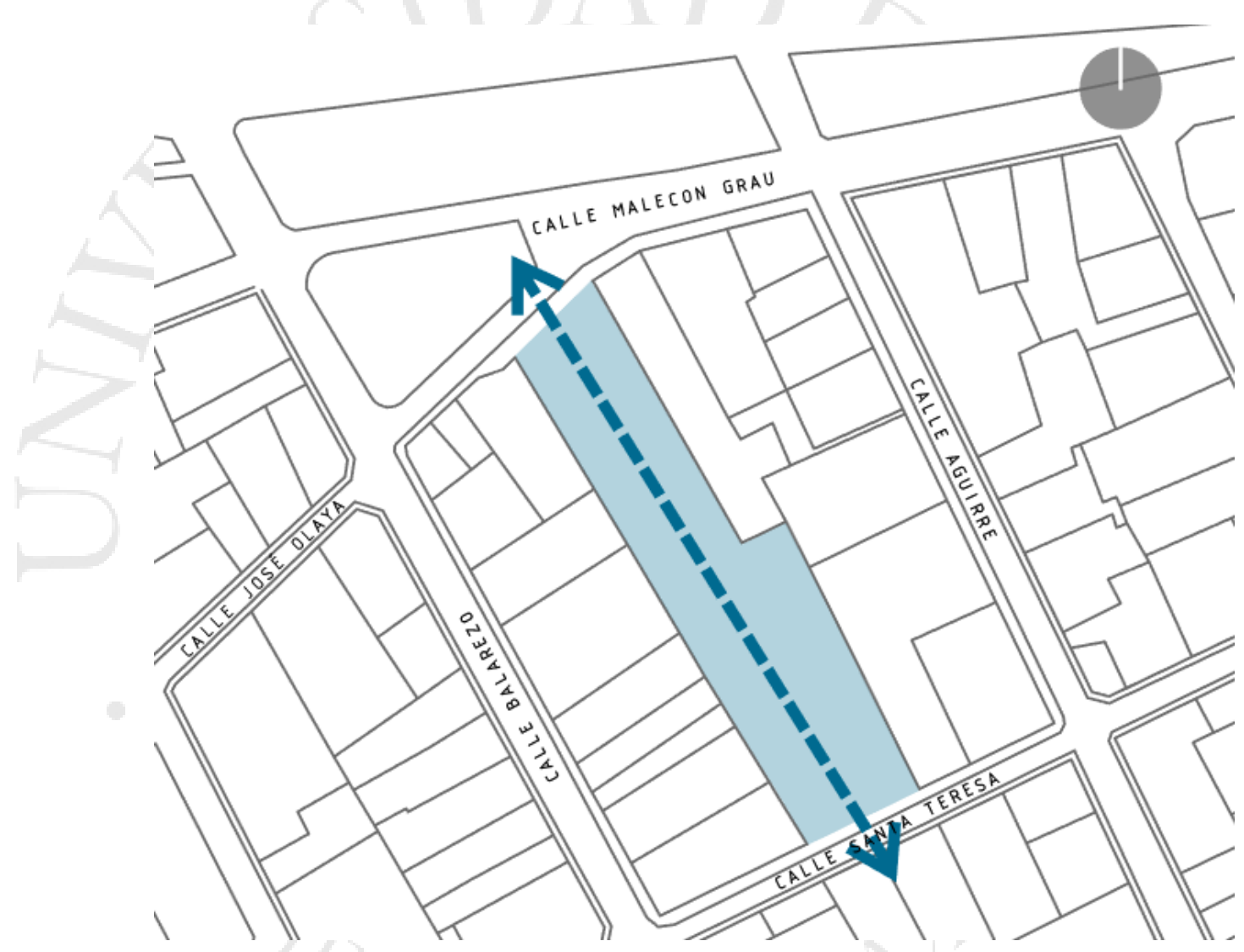

Fuente: Elaborado por autor.

En primer lugar, se realiza el retiro de las medianeras para poder generar ambientes con mayor iluminación y ventilación. Como resultado de esto, se considera que las diagonales son la mejor opción pues se generan espacios intermedios, mayor recorrido y se logra optimizar el uso de los ambientes. 
Figura 7.3.2: Diagonales para optimizar espacio y generar patios.

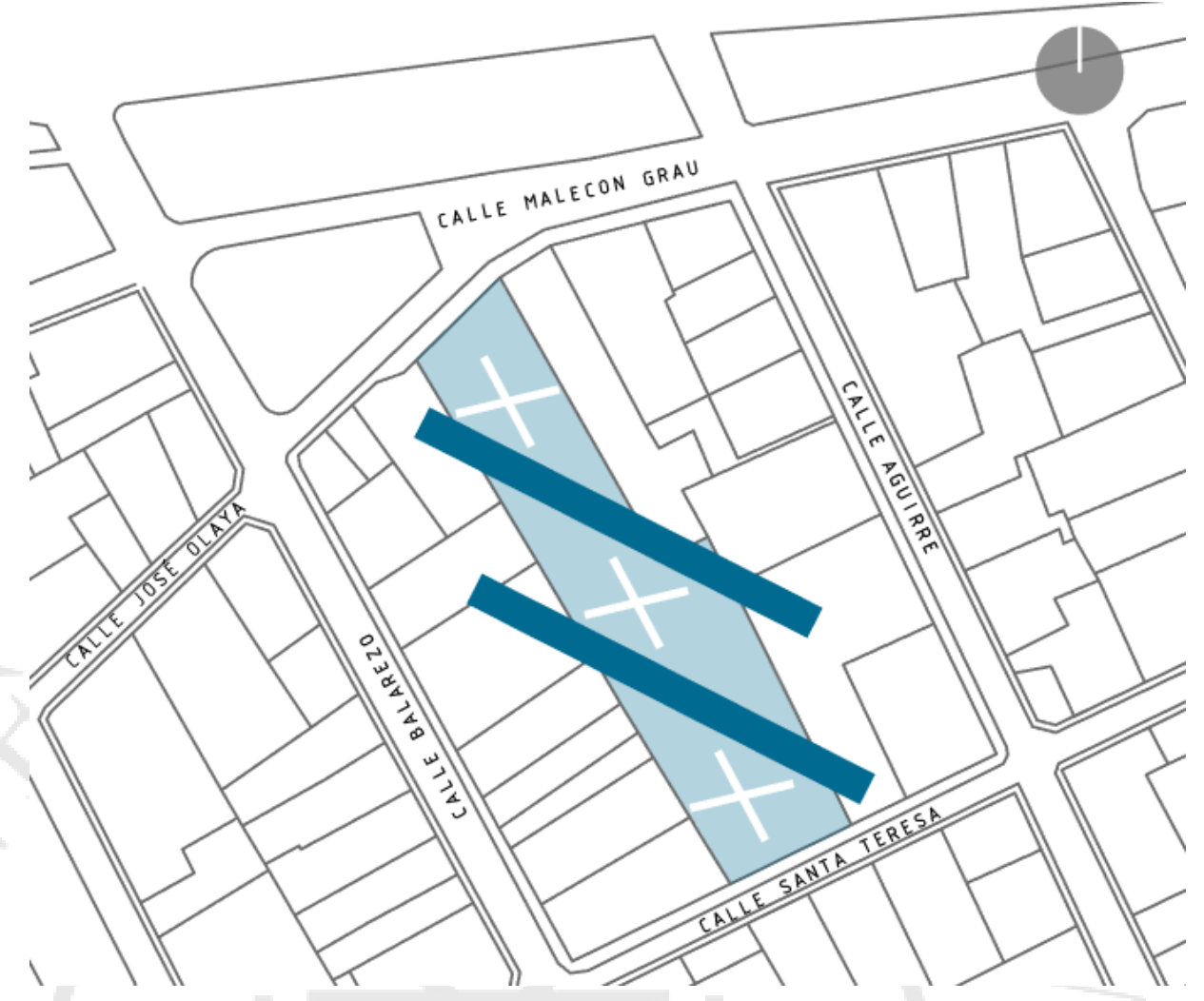

Fuente: Elaborado por autor.

Para lograr contener los ambientes de encuentro, se cierran siguiendo la forma del propio terreno, de esta manera se generan 3 patios paralelos a lo largo del terreno que serán rodeados por los volúmenes del proyecto. Además, como requisito de los parámetros del proyecto, en ambos frentes es necesario que no existan los retiros y, por el contrario, las edificaciones estén a plomo con las de toda la cuadra.

La forma responde a la necesidad de desarrollar dos funciones con características distintas pero que se complementan como lo es la zona del Centro de Día y la de Residencia para adultos mayores. Por lo tanto, se obtienen dos volúmenes y en cada uno se desarrolla una actividad, sin embargo, logran unirse por unos puentes superiores y un gran patio central que conecta todo el proyecto. 
7.4.Programa arquitectónico.

El proyecto tiene las funciones de Residencia y Centro de Día para personas de la tercera edad, lo que genera dos flujos de usuarios distintos que comparten las mismas actividades, pero que llegan desde lugares distintos. Esto nos lleva a pensar en los recorridos que cada uno de estos dos grupos debe realizar para mantener su día activo y como resultado de eso generar el proyecto que se explicará a continuación.

El acceso principal se da en el cruce de las Calle José Olaya y Malecón Grau a través de un patio público ubicado en la parte izquierda del ingreso, y que remata en una Capilla a la que pueden asistir los adultos mayores usuarios y los vecinos de la zona. Como límite del área publica y el centro se trabaja con un espejo de agua que solo permite la conexión visual hacia el interior.

Figura 7.4.1: Análisis programa en planta.

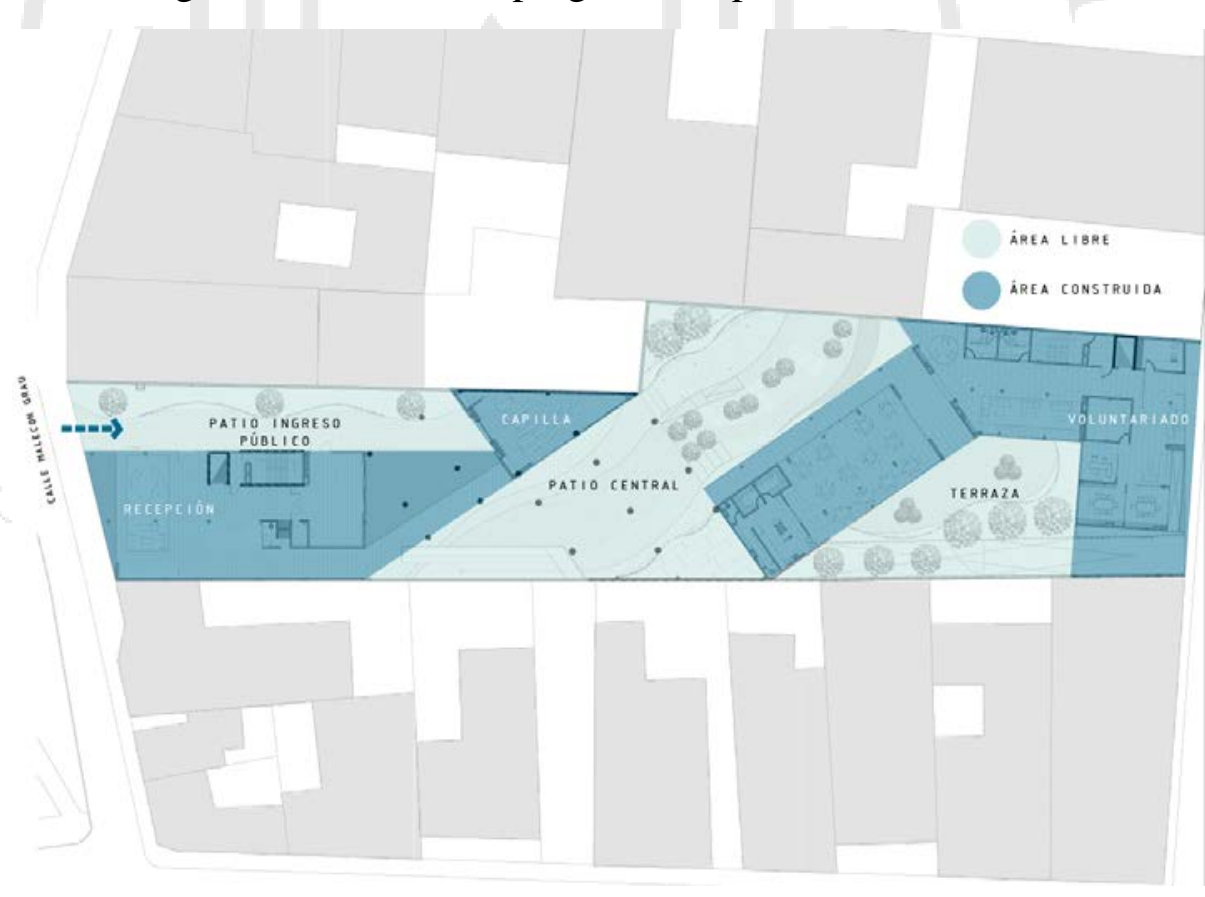

Fuente: Elaborado por autor.

Paralelo al patio se ubica en el siguiente orden desde el ingreso: Una amplia recepción, que permite el ingreso de las personas mayores a los diversos servicios que brinda el centro, luego se ubica la zona de servicios y 
circulación, y finalmente un SUM con ingreso a través del patio público y la recepción, esto con la finalidad que el SUM pueda ser utilizado tanto como por los usuarios como por un público exterior en la oportunidad requerida. Continuando con el recorrido se observa una rampa que conecta la primera con la segunda planta, más adelante el proyecto se abre al núcleo que conecta los dos volúmenes. Es un patio central que tiene distintas características a lo largo de su recorrido, inicia con una pequeña plaza como complemento de la rampa que se amplía llegando a un centro de doble y triple altura, posterior a esto hay un desnivel para ingresar a una zona jardín paralelo al siguiente volumen. En esta nueva área se ubica la cocina, el comedor y una sala de estar que es utilizado por los ancianos de la residencia y centro de día, este bloque tiene acceso a un tercer patio-terraza ubicado en la parte posterior del proyecto. Finalmente, en el primer nivel de este bloque se ubica el centro de voluntariado dirigido a jóvenes, este ambiente da a la calle Santa Teresa y actúa como filtro entre el exterior y la residencia.

En el segundo nivel los bloques están separados por la doble altura del patio central. Al subir por la rampa se llega a la zona administrativa del centro, continuando el recorrido el usuario se topa de nuevo con el núcleo de servicios y circulación para finalmente llegar a los 3 salones en los que se desarrollarán actividades artísticas, culturales y de entretenimiento para los ancianos. Estos 3 ambientes dan a la fachada principal y tienen la vista privilegiada de todo el malecón y el mar. Por otro lado, el bloque posterior tiene fachada en la Calle Santa Rita, se ubica el primer grupo de habitaciones para los residentes, en este nivel hay 20 dormitorios individuales con baño incluido, todos estos se ubican en un corredor central a lo largo del volumen y tienen vista a cada uno de los patios posteriores. En la parte central del bloque se encuentra el núcleo de servicios y circulación, además, también se ubica una estación de enfermeras y una sala de estar con vista a la calle.

En el tercer nivel, ambos bloques se conectan mediante un puente que funciona como sala de estar, cada uno de estos bloques contiene habitaciones. Al igual que en el segundo nivel, las habitaciones están ubicadas a lo largo de cada volumen y divididas por un corredor central, en 
este nivel hay 32 plazas con habitaciones para 1 y 2 personas. Este nivel es el último en el bloque que da a la Calle Santa Rita, por lo cual, en todo el corredor centra se trabaja con teatinas que ayudan a la iluminación y ventilación.

En el cuarto nivel del volumen con fachada en la Calle Malecón Grau, se ubica toda la zona de terraza alta, un ambiente que se trabajará con mucha vegetación. Saliendo del núcleo de circulación se puede observar al frente el área de terapias; en la zona que da a la fachada principal, se ubica una biblioteca y un estar con balcón; en la zona posterior se encuentra el gimnasio y termina el recorrido con un gran vivero ubicado el cuarto nivel de la parte central del proyecto.

Por último, el ingreso al sótano se da por la Calle Santa Teresa a través de una rampa que dirige a los vehículos al estacionamiento que cuenta con 11 espacios. En este nivel subterráneo también se ubica la zona de trabajadores que cuenta con lavandería, baños, vestidores y un salón de estar; así mismo, se ubican los espacios complementarios como depósitos, cuarto de bombas, cuarto de tableros, cuarto de basura, etc. El acceso peatonal a este piso es a través del núcleo de circulaciones del bloque posterior. 
Figura 7.4.2: Elevación principal del proyecto - Calle Malecón Grau.

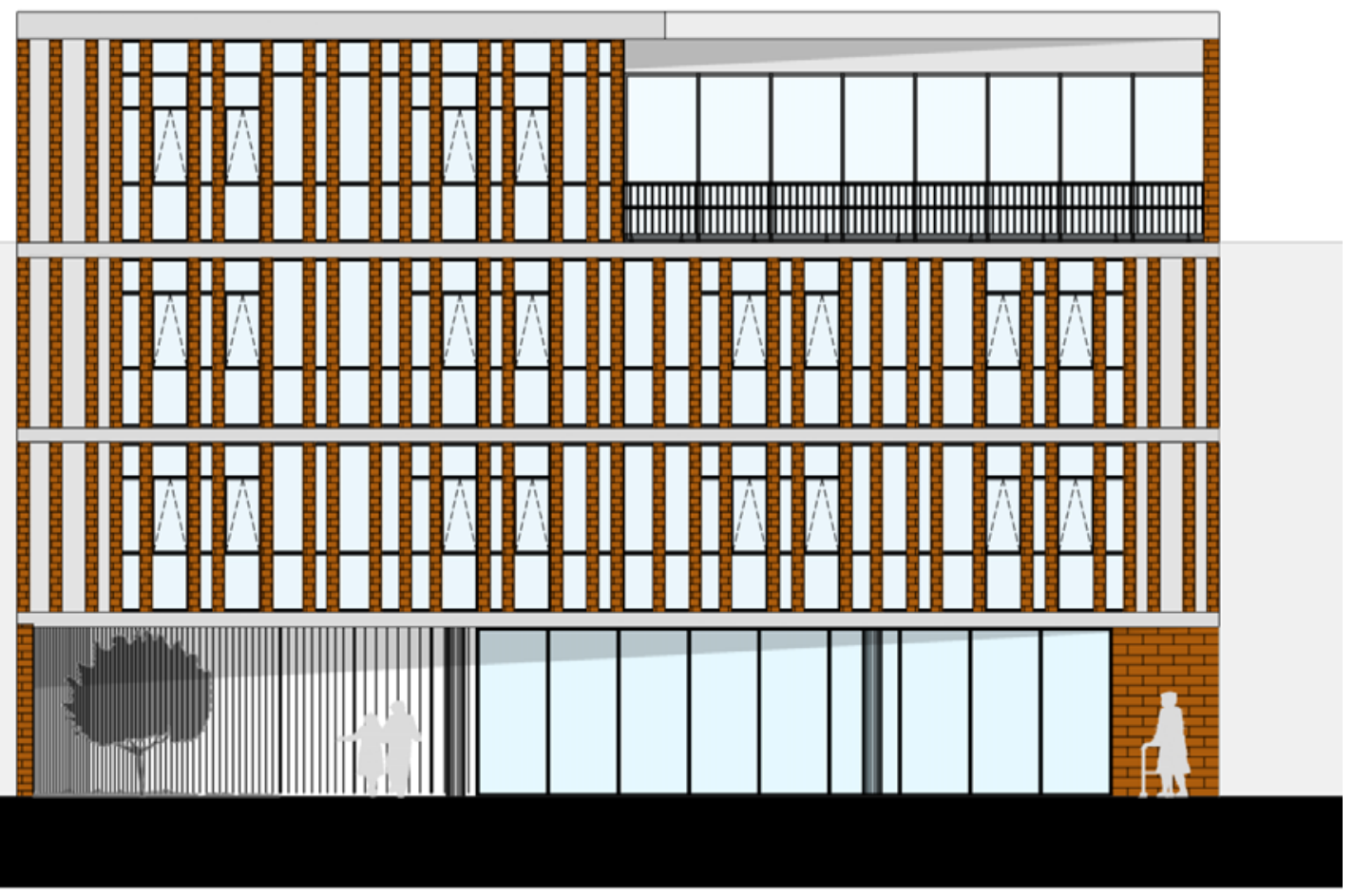

Fuente: Elaborado por autor

Figura 7.4.3: Elevación posterior del proyecto - Calle Santa Teresa.

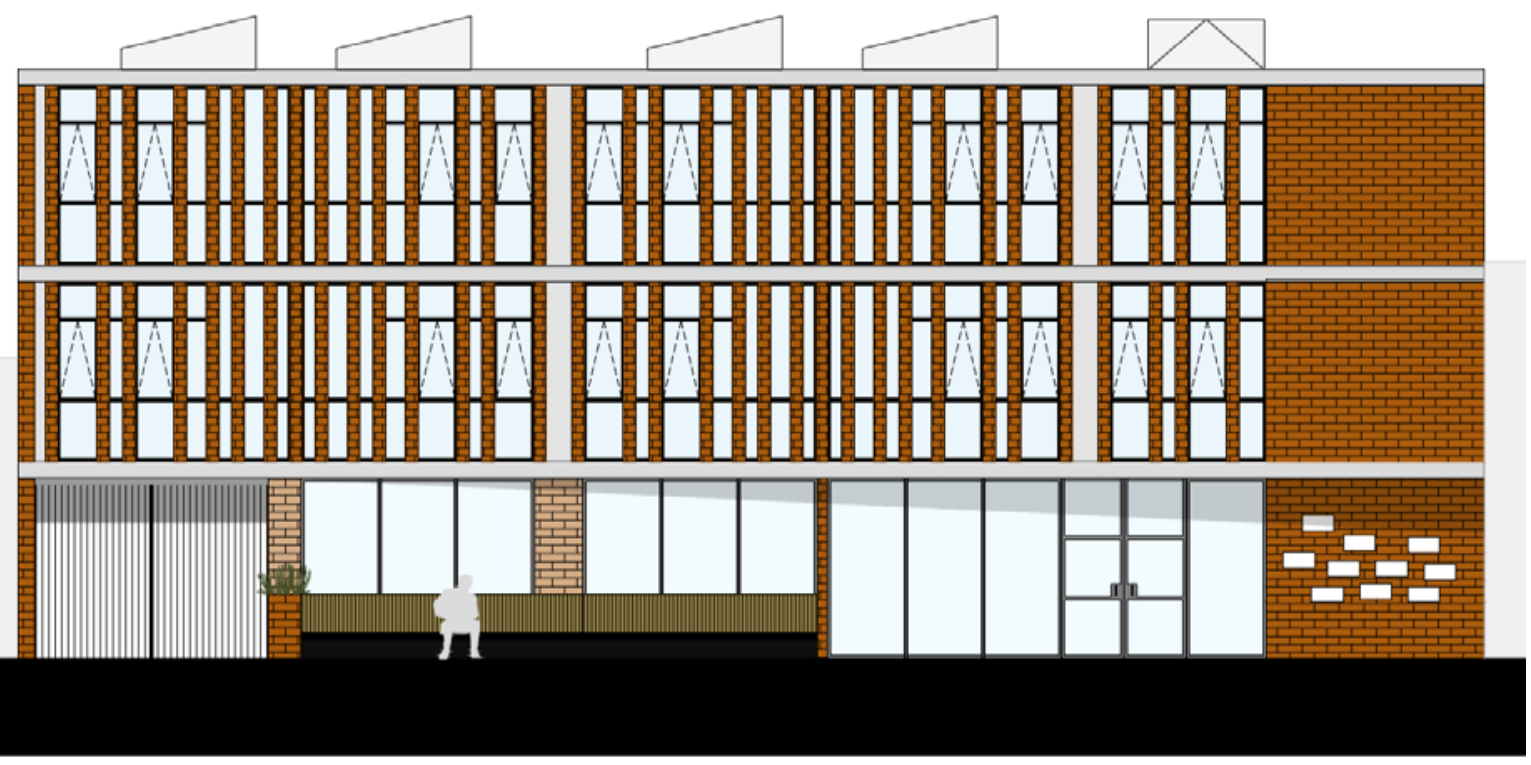

Fuente: Elaborado por autor 
Figura 7.4.4.: Corte del proyecto.

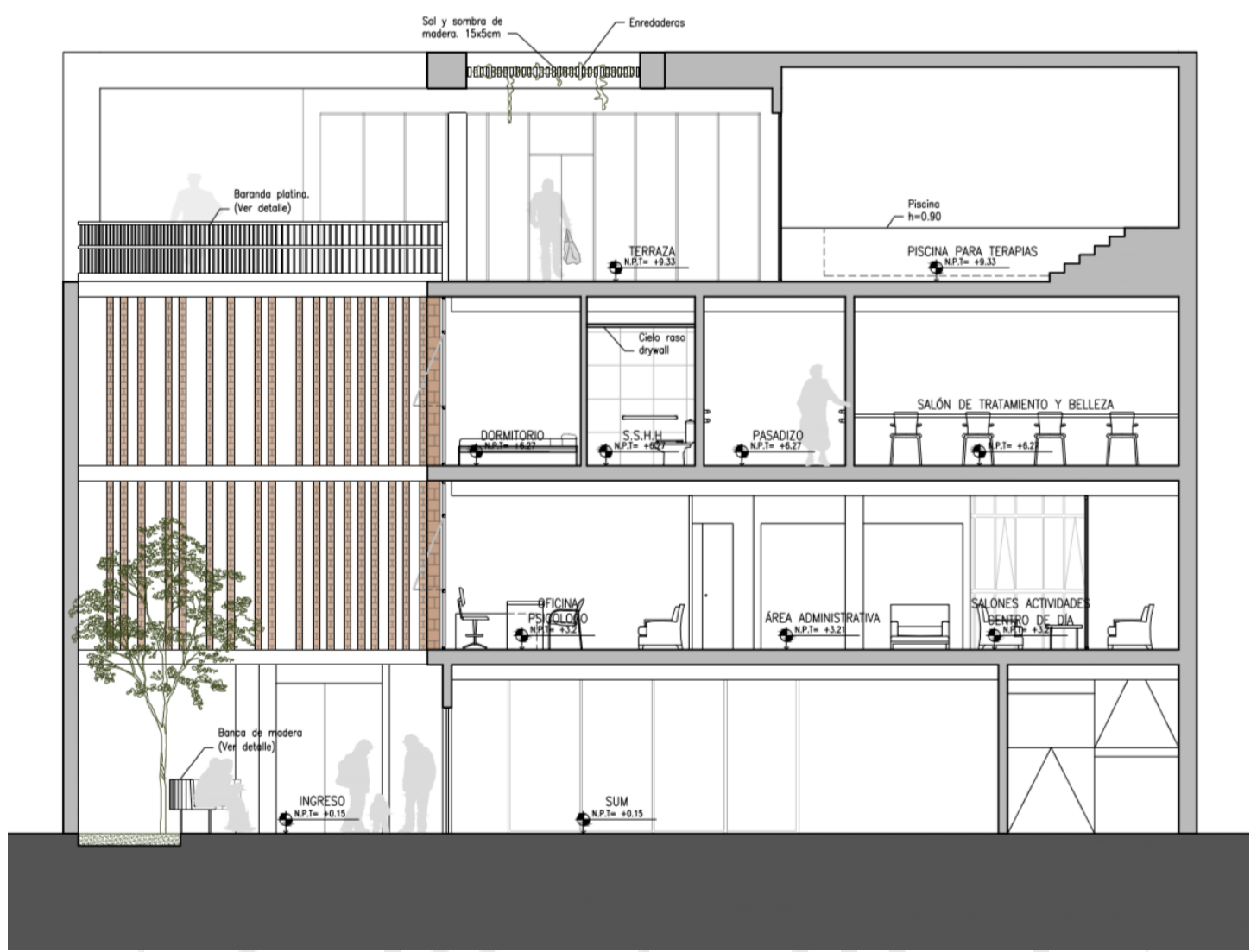

Fuente: Elaborado por autor

Figura 7.4.5: Corte del proyecto.

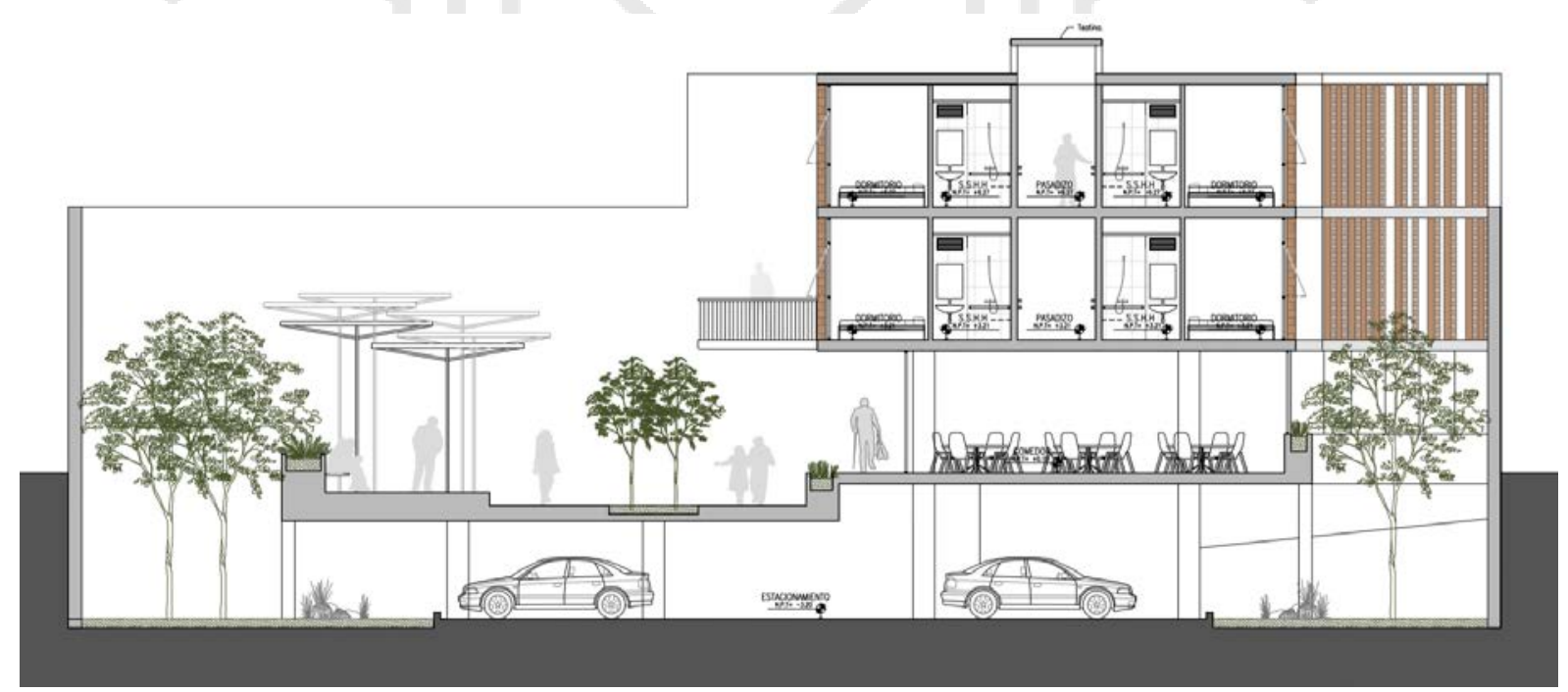

Fuente: Elaborado por autor 
Figura 7.4.6: Corte del proyecto.

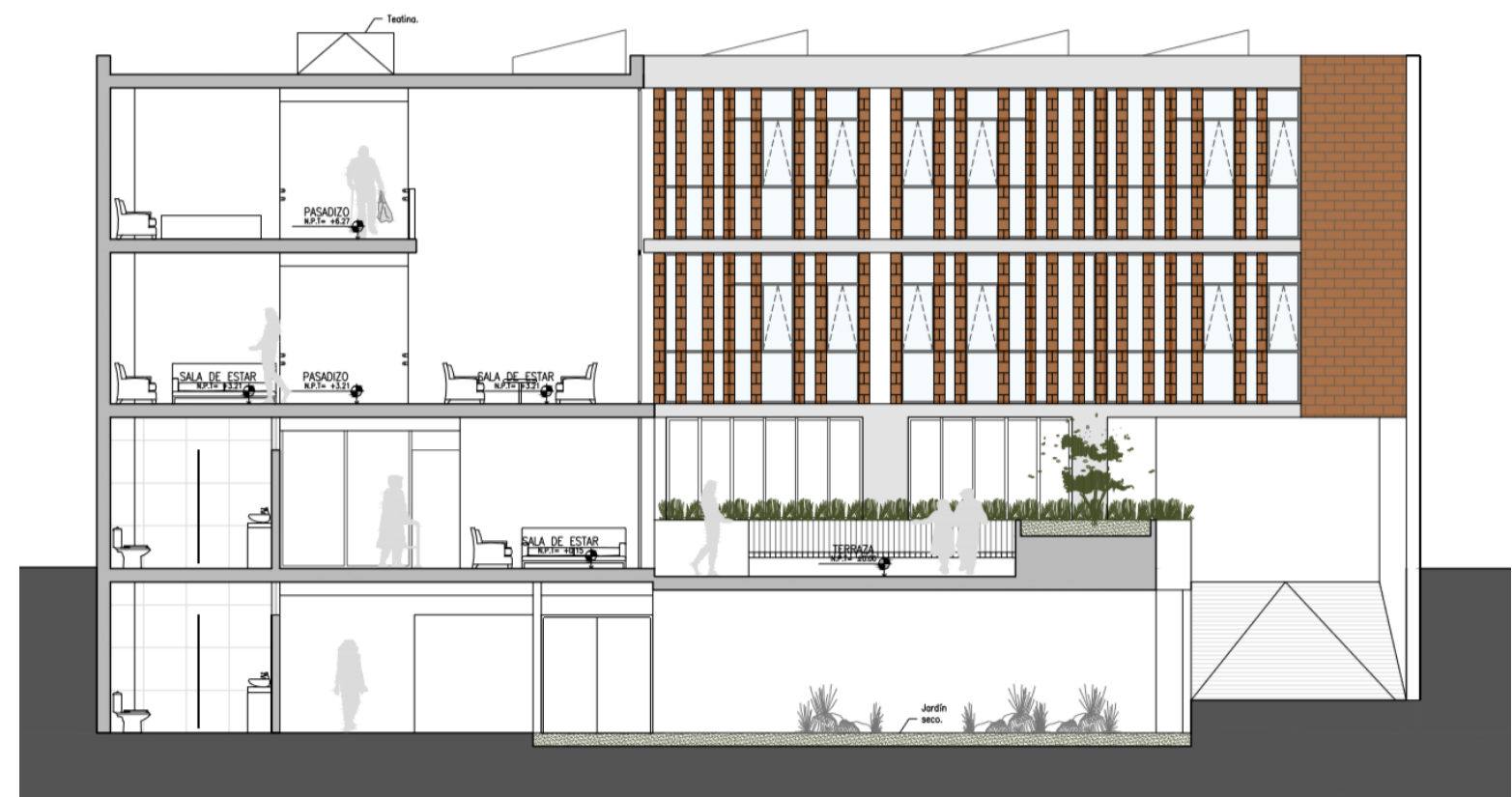

Fuente: Elaborado por autor

Figura 7.4.7: Planta de habitación típica.

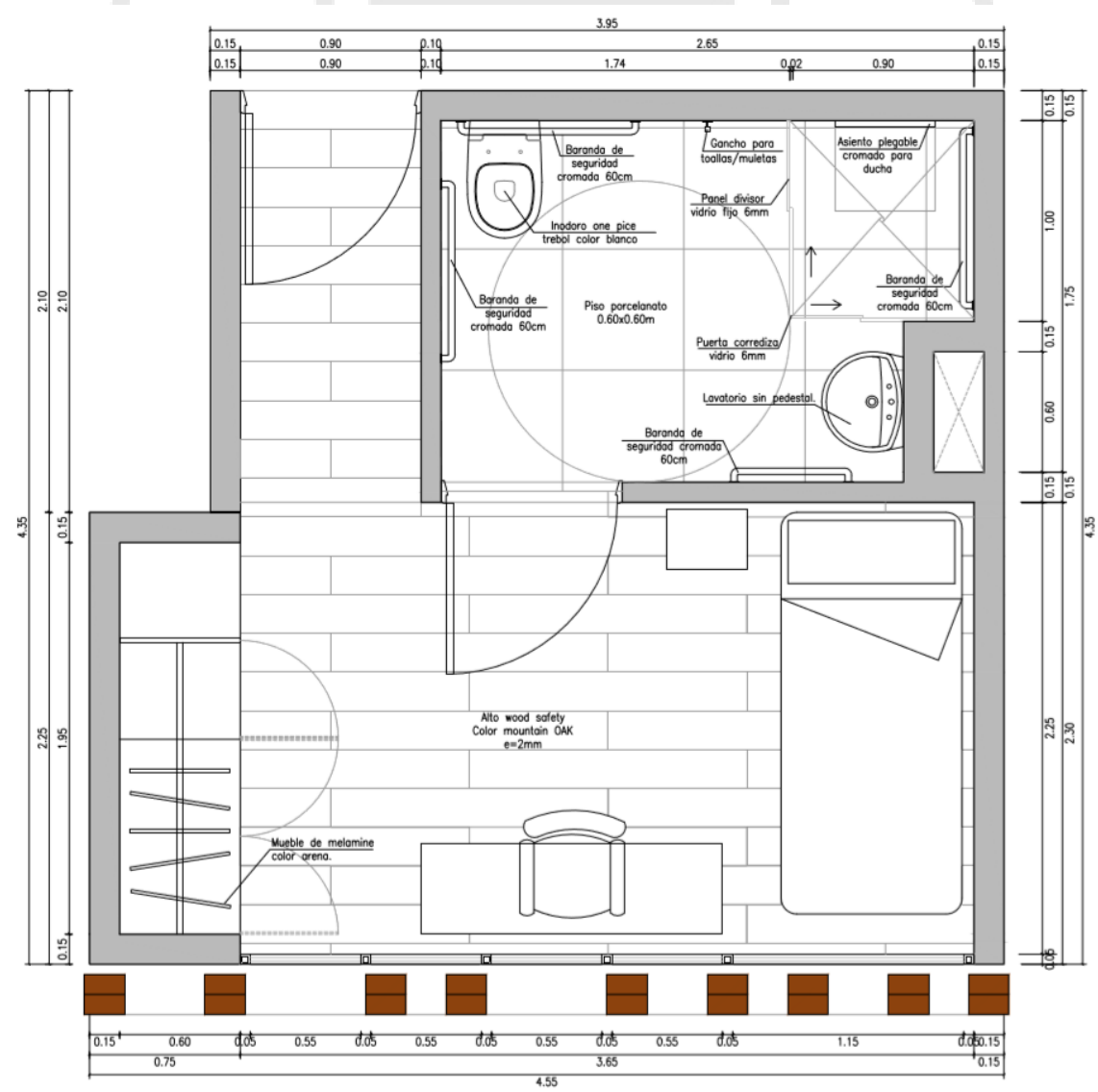

Fuente: Elaborado por autor 
La Residencia y Centro de Dia se enfoca en generar distintos ambientes que le resulten confortables al usuario, uno de los más importantes es la habitación. En este proyecto, las habitaciones son personales y dobles, y cada habitación cuenta con baño propio con las medidas reglamentarias, que permiten que el anciano se pueda desplazar de forma cómoda y segura.

En las áreas exteriores, se busca que el adulto mayor pueda utilizar a lo largo del día los diversos patios, salas y terrazas; los cuales se relacionan entre sí y que por su diseño generan contacto con la naturaleza. Además, busca generar un recorrido dinámico para los usuarios que, conforme realizan su rutina diaria se encuentran con espacios de distintas características.

Tabla 7.4.1: Cuadro de áreas.

\section{Residencia y Centro de Día para Adultos Mayores de Chorrillos y Alto Perú}

\begin{tabular}{|c|c|c|c|c|c|c|}
\hline \multicolumn{7}{|c|}{ Área techada } \\
\hline Piso & & Ambiente & Área & $\mathrm{u}$. & Porcentaje & u. \\
\hline \multirow{19}{*}{$\begin{array}{l}\text { Primer } \\
\text { nivel }\end{array}$} & \multirow{7}{*}{$\begin{array}{l}\text { Área de uso } \\
\text { comunal }\end{array}$} & Hall de ingreso & 136.65 & $\mathrm{~m} 2$ & 2.77 & $\mathrm{~m} 2$ \\
\hline & & SS.HH Mujeres & 3.00 & $\mathrm{~m} 2$ & 0.06 & $\mathrm{~m} 2$ \\
\hline & & SS.HH Hombres & 3.00 & $\mathrm{~m} 2$ & 0.06 & $\mathrm{~m} 2$ \\
\hline & & $\begin{array}{l}\text { SS.HH } \\
\text { Discapacitados }\end{array}$ & 3.17 & $\mathrm{~m} 2$ & 0.06 & $\mathrm{~m} 2$ \\
\hline & & $\begin{array}{l}\text { SS.HH } \\
\text { Empleados }\end{array}$ & 3.36 & $\mathrm{~m} 2$ & 0.07 & $\mathrm{~m} 2$ \\
\hline & & SUM & 54.1 & $\mathrm{~m} 2$ & 1.10 & $\mathrm{~m} 2$ \\
\hline & & Capilla & 72.33 & $\mathrm{~m} 2$ & 1.46 & $\mathrm{~m} 2$ \\
\hline & \multirow{12}{*}{$\begin{array}{l}\text { Área de uso } \\
\text { mixto } \\
\text { (Residencia y } \\
\text { Centro de día) }\end{array}$} & Closets & 2.04 & $\mathrm{~m} 2$ & 0.04 & $\mathrm{~m} 2$ \\
\hline & & Depósitos & 3.84 & $\mathrm{~m} 2$ & 0.08 & $\mathrm{~m} 2$ \\
\hline & & $\begin{array}{l}\text { Área de } \\
\text { circulación. }\end{array}$ & 27.15 & $\mathrm{~m} 2$ & 0.55 & $\mathrm{~m} 2$ \\
\hline & & Pasadizo & 86.98 & $\mathrm{~m} 2$ & 1.76 & $\mathrm{~m} 2$ \\
\hline & & Rampa & 57.62 & $\mathrm{~m} 2$ & 1.17 & $\mathrm{~m} 2$ \\
\hline & & Cocina & 41.98 & $\mathrm{~m} 2$ & 0.85 & $\mathrm{~m} 2$ \\
\hline & & SS.HH cocina & 2.74 & $\mathrm{~m} 2$ & 0.06 & $\mathrm{~m} 2$ \\
\hline & & $\begin{array}{l}\text { Entrega de } \\
\text { alimentos }\end{array}$ & 8.63 & $\mathrm{~m} 2$ & 0.17 & $\mathrm{~m} 2$ \\
\hline & & Comedor & 120.6 & $\mathrm{~m} 2$ & 2.44 & $\mathrm{~m} 2$ \\
\hline & & Sala de estar 2 & 115.16 & $\mathrm{~m} 2$ & 2.33 & $\mathrm{~m} 2$ \\
\hline & & $\begin{array}{l}\text { SS.HH Sala de } \\
\text { estar }\end{array}$ & 18.71 & $\mathrm{~m} 2$ & 0.38 & $\mathrm{~m} 2$ \\
\hline & & Pasadizo & 80.09 & $\mathrm{~m} 2$ & 1.62 & $\mathrm{~m} 2$ \\
\hline
\end{tabular}




\begin{tabular}{|c|c|c|c|c|c|c|}
\hline & \multirow{3}{*}{ Voluntariado } & $\begin{array}{l}\text { Área de } \\
\text { voluntariado }\end{array}$ & 127.4 & $\mathrm{~m} 2$ & 2.58 & $\mathrm{~m} 2$ \\
\hline & & Seguridad & 13.28 & $\mathrm{~m} 2$ & 0.27 & $\mathrm{~m} 2$ \\
\hline & & $\begin{array}{l}\text { Área de } \\
\text { Circulación } 2\end{array}$ & 30.86 & $\mathrm{~m} 2$ & 0.62 & $\mathrm{~m} 2$ \\
\hline \multirow{24}{*}{$\begin{array}{l}\text { Segundo } \\
\text { nivel }\end{array}$} & \multirow{7}{*}{$\begin{array}{l}\text { Área de uso } \\
\text { mixto } \\
\text { (Residencia y } \\
\text { Centro de día) }\end{array}$} & $\begin{array}{l}\text { Salón de } \\
\text { actividades } 1\end{array}$ & 83.32 & $\mathrm{~m} 2$ & 1.69 & $\mathrm{~m} 2$ \\
\hline & & $\begin{array}{l}\text { Salón de } \\
\text { actividades } 2\end{array}$ & 58.58 & $\mathrm{~m} 2$ & 1.19 & $\mathrm{~m} 2$ \\
\hline & & $\begin{array}{l}\text { Salón de } \\
\text { actividades } 3\end{array}$ & 49.15 & $\mathrm{~m} 2$ & 0.99 & $\mathrm{~m} 2$ \\
\hline & & SS.HH Mujeres & 3.00 & $\mathrm{~m} 2$ & 0.06 & $\mathrm{~m} 2$ \\
\hline & & SS.HH Hombres & 3.00 & $\mathrm{~m} 2$ & 0.06 & $\mathrm{~m} 2$ \\
\hline & & $\begin{array}{l}\text { SS.HH } \\
\text { Discapacitados }\end{array}$ & 3.17 & $\mathrm{~m} 2$ & 0.06 & $\mathrm{~m} 2$ \\
\hline & & $\begin{array}{l}\text { Área de } \\
\text { circulación. }\end{array}$ & 27.15 & $\mathrm{~m} 2$ & 0.55 & $\mathrm{~m} 2$ \\
\hline & \multirow{10}{*}{ administrativa } & $\begin{array}{l}\text { Hall área } \\
\text { administrativa }\end{array}$ & 98.69 & $\mathrm{~m} 2$ & 2.00 & $\mathrm{~m} 2$ \\
\hline & & Of. Psicólogo & 14.53 & $\mathrm{~m} 2$ & 0.29 & $\mathrm{~m} 2$ \\
\hline & & $\begin{array}{l}\text { Sala de } \\
\text { reuniones }\end{array}$ & 15.27 & $\mathrm{~m} 2$ & 0.31 & $\mathrm{~m} 2$ \\
\hline & & $\begin{array}{l}\text { Of. Asistente } \\
\text { social }\end{array}$ & 15.56 & $\mathrm{~m} 2$ & 0.31 & $\mathrm{~m} 2$ \\
\hline & & Archivo & 9.44 & $\mathrm{~m} 2$ & 0.19 & $\mathrm{~m} 2$ \\
\hline & & Kitchenette & 12.07 & $\mathrm{~m} 2$ & 0.24 & $\mathrm{~m} 2$ \\
\hline & & $\begin{array}{l}\text { SS.HH } \\
\text { administración }\end{array}$ & 1.98 & $\mathrm{~m} 2$ & 0.04 & $\mathrm{~m} 2$ \\
\hline & & $\begin{array}{l}\text { Director de } \\
\text { centro }\end{array}$ & 23.73 & $\mathrm{~m} 2$ & 0.48 & $\mathrm{~m} 2$ \\
\hline & & $\begin{array}{l}\text { SS.HH Director } \\
\text { de centro }\end{array}$ & 2.36 & $\mathrm{~m} 2$ & 0.05 & $\mathrm{~m} 2$ \\
\hline & & $\begin{array}{l}\text { Of. } \\
\text { Administrador }\end{array}$ & 17.02 & $\mathrm{~m} 2$ & 0.34 & $\mathrm{~m} 2$ \\
\hline & \multirow{7}{*}{$\begin{array}{c}\text { Zona de } \\
\text { Residencia }\end{array}$} & $\begin{array}{l}\text { Hab. adultos } \\
\text { mayores }\end{array}$ & 377.81 & $\mathrm{~m} 2$ & 7.65 & $\mathrm{~m} 2$ \\
\hline & & $\begin{array}{l}\text { Estación de } \\
\text { enfermeras } 1\end{array}$ & 7.94 & $\mathrm{~m} 2$ & 0.16 & $\mathrm{~m} 2$ \\
\hline & & Archivo 1 & 4.67 & $\mathrm{~m} 2$ & 0.09 & $\mathrm{~m} 2$ \\
\hline & & $\begin{array}{l}\text { SS.HH } \\
\text { Enfermeras } 1\end{array}$ & 3.86 & $\mathrm{~m} 2$ & 0.08 & $\mathrm{~m} 2$ \\
\hline & & $\begin{array}{l}\text { Área de } \\
\text { Circulación } 2\end{array}$ & 30.86 & $\mathrm{~m} 2$ & 0.62 & $\mathrm{~m} 2$ \\
\hline & & Salas de estar & 105.6 & $\mathrm{~m} 2$ & 2.14 & $\mathrm{~m} 2$ \\
\hline & & Pasadizo & 72.91 & $\mathrm{~m} 2$ & 1.48 & $\mathrm{~m} 2$ \\
\hline $\begin{array}{c}\text { Tercer } \\
\text { nivel }\end{array}$ & $\begin{array}{c}\text { Zona de } \\
\text { Residencia }\end{array}$ & $\begin{array}{l}\text { Hab. adultos } \\
\text { mayores }\end{array}$ & 646.09 & $\mathrm{~m} 2$ & 13.08 & $\mathrm{~m} 2$ \\
\hline
\end{tabular}




\begin{tabular}{|c|c|c|c|c|c|c|}
\hline & & Sala de estar 1 & 117.75 & $\mathrm{~m} 2$ & 2.38 & $\mathrm{~m} 2$ \\
\hline & & Tópico 1 & 22.56 & $\mathrm{~m} 2$ & 0.46 & $\mathrm{~m} 2$ \\
\hline & & Closet & 4.68 & $\mathrm{~m} 2$ & 0.09 & $\mathrm{~m} 2$ \\
\hline & & Archivo & 4.68 & $\mathrm{~m} 2$ & 0.09 & $\mathrm{~m} 2$ \\
\hline & & $\begin{array}{l}\text { SS.HH } \\
\text { enfermeras }\end{array}$ & 2.96 & $\mathrm{~m} 2$ & 0.06 & $\mathrm{~m} 2$ \\
\hline & & $\begin{array}{l}\text { Estación de } \\
\text { enfermeras } 1\end{array}$ & 19.71 & $\mathrm{~m} 2$ & 0.40 & $\mathrm{~m} 2$ \\
\hline & & $\begin{array}{l}\text { Área de } \\
\text { circulación. }\end{array}$ & 27.15 & $\mathrm{~m} 2$ & 0.55 & $\mathrm{~m} 2$ \\
\hline & & Pasadizo & 199.56 & $\mathrm{~m} 2$ & 4.04 & $\mathrm{~m} 2$ \\
\hline & & $\begin{array}{l}\text { Sala de estar } \\
\text { central }\end{array}$ & 230.57 & $\mathrm{~m} 2$ & 4.67 & $\mathrm{~m} 2$ \\
\hline & & $\begin{array}{l}\text { Estación de } \\
\text { enfermeras } 2\end{array}$ & 7.94 & $\mathrm{~m} 2$ & 0.16 & $\mathrm{~m} 2$ \\
\hline & & Archivo 2 & 4.67 & $\mathrm{~m} 2$ & 0.09 & $\mathrm{~m} 2$ \\
\hline & & $\begin{array}{l}\text { SS.HH } \\
\text { Enfermeras } 2 \\
\end{array}$ & 3.86 & $\mathrm{~m} 2$ & 0.08 & $\mathrm{~m} 2$ \\
\hline & & Sala de estar 2 & 31.01 & $\mathrm{~m} 2$ & 0.63 & $\mathrm{~m} 2$ \\
\hline & & $\begin{array}{l}\text { Área de } \\
\text { Circulación } 2 \\
\end{array}$ & 30.86 & $\mathrm{~m} 2$ & 0.62 & $\mathrm{~m} 2$ \\
\hline & & Sala de lectura & 117.84 & $\mathrm{~m} 2$ & 2.39 & $\mathrm{~m} 2$ \\
\hline & & Terraza techada & 66.49 & $\mathrm{~m} 2$ & 1.35 & $\mathrm{~m} 2$ \\
\hline & & $\begin{array}{l}\text { Terraza sin } \\
\text { techar }\end{array}$ & 24.96 & $\mathrm{~m} 2$ & 0.51 & $\mathrm{~m} 2$ \\
\hline & & $\begin{array}{l}\text { Área de } \\
\text { circulación. }\end{array}$ & 27.15 & $\mathrm{~m} 2$ & 0.55 & $\mathrm{~m} 2$ \\
\hline & & SS.HH Mujeres & 3.00 & $\mathrm{~m} 2$ & 0.06 & $\mathrm{~m} 2$ \\
\hline & & SS.HH Hombres & 3.00 & $\mathrm{~m} 2$ & 0.06 & $\mathrm{~m} 2$ \\
\hline $\begin{array}{l}\text { Cuarto } \\
\text { nivel }\end{array}$ & $\begin{array}{c}\text { mixto } \\
\text { (Residencia y } \\
\text { Centro de día) }\end{array}$ & $\begin{array}{l}\text { SS.HH } \\
\text { Discapacitados }\end{array}$ & 3.17 & $\mathrm{~m} 2$ & 0.06 & $\mathrm{~m} 2$ \\
\hline & Centro de ala) & $\begin{array}{l}\text { Consultorio } \\
\text { terapia física }\end{array}$ & 19.06 & $\mathrm{~m} 2$ & 0.39 & $\mathrm{~m} 2$ \\
\hline & & Piscina & 51.29 & $\mathrm{~m} 2$ & 1.04 & $\mathrm{~m} 2$ \\
\hline & & $\begin{array}{l}\text { Gimnasio y } \\
\text { terapia física }\end{array}$ & 93.41 & $\mathrm{~m} 2$ & 1.89 & $\mathrm{~m} 2$ \\
\hline & & Vivero & 222.79 & $\mathrm{~m} 2$ & 4.51 & $\mathrm{~m} 2$ \\
\hline & & Pasadizo & 126.18 & $\mathrm{~m} 2$ & 2.55 & $\mathrm{~m} 2$ \\
\hline & & Lavandería & 49.98 & $\mathrm{~m} 2$ & 1.01 & $\mathrm{~m} 2$ \\
\hline & & $\begin{array}{l}\text { SS.HH-vestidor } \\
\text { caballeros }\end{array}$ & 31.13 & $\mathrm{~m} 2$ & 0.63 & $\mathrm{~m} 2$ \\
\hline Sótano & & $\begin{array}{l}\text { SS.HH-vestidor } \\
\text { damas }\end{array}$ & 30.19 & $\mathrm{~m} 2$ & 0.61 & $\mathrm{~m} 2$ \\
\hline & & $\begin{array}{l}\text { Sala para } \\
\text { trabajadores }\end{array}$ & 72.79 & $\mathrm{~m} 2$ & 1.47 & $\mathrm{~m} 2$ \\
\hline & & $\begin{array}{l}\text { Terraza } \\
\text { trabajadores }\end{array}$ & 16.19 & $\mathrm{~m} 2$ & 0.33 & $\mathrm{~m} 2$ \\
\hline
\end{tabular}




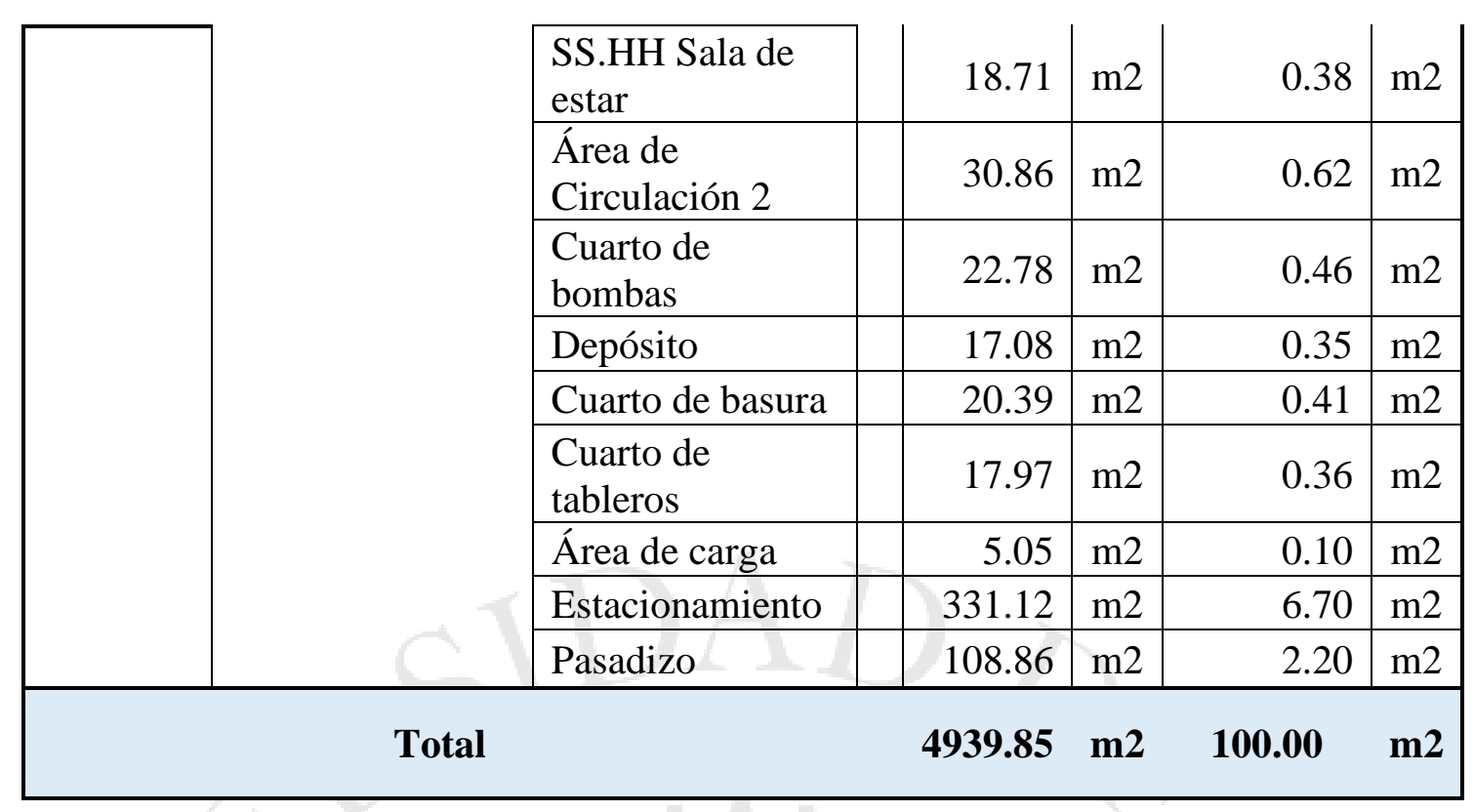

Fuente: Elaborado por autor

7.5.Usuario y aforo permitido.

En el siguiente gráfico se muestra el aforo máximo permitido en cada ambiente por cada área libre o funcional, y en base al Reglamento Nacional de Edificaciones (RNE) y de acuerdo a los diversos capítulos relacionados con los servicios brindados al interior de los edificios que forman parte del proyecto. Por otro lado, es importante resaltar que existen actividades que pueden ser realizadas en los patios y áreas libres del proyecto como yoga, taichí, baile, etc.

Tabla 7.5.1: Aforo

Residencia y Centro de Día para Adultos Mayores de Chorrillos y Alto Perú

\begin{tabular}{|c|c|c|c|c|c|c|}
\hline \multicolumn{7}{|c|}{ Área techada } \\
\hline Piso & & Ambiente & $\begin{array}{l}\text { Área } \\
\text { (m2) }\end{array}$ & \multicolumn{2}{|c|}{ Ratio } & Aforo \\
\hline \multirow{4}{*}{$\begin{array}{c}\text { Primer } \\
\text { nivel }\end{array}$} & \multirow{2}{*}{$\begin{array}{l}\text { Área de uso } \\
\text { comunal }\end{array}$} & SUM & 54.1 & 1 & $\begin{array}{r}\mathrm{m} 2 \mathrm{x} \\
\text { persona }\end{array}$ & 54.1 \\
\hline & & Capilla & 72.33 & 1 & $\begin{array}{r}\mathrm{m} 2 \mathrm{x} \\
\text { persona }\end{array}$ & 72.3 \\
\hline & \multirow{2}{*}{$\begin{array}{l}\text { Área de uso mixto } \\
\text { (Residencia y Centro de } \\
\text { día) }\end{array}$} & Cocina & 44.72 & 9.3 & $\begin{array}{r}\mathrm{m} 2 \mathrm{x} \\
\text { persona }\end{array}$ & 4.8 \\
\hline & & $\begin{array}{l}\text { Entrega de } \\
\text { alimentos }\end{array}$ & 8.63 & 4 & $\begin{array}{r}\mathrm{m} 2 \mathrm{x} \\
\text { persona }\end{array}$ & 2.2 \\
\hline
\end{tabular}




\begin{tabular}{|c|c|c|c|c|c|c|}
\hline & & Comedor & 120.6 & 1.5 & $\begin{array}{r}\mathrm{m} 2 \mathrm{x} \\
\text { persona }\end{array}$ & 80.4 \\
\hline & \multirow{2}{*}{ Voluntariado } & $\begin{array}{l}\text { Área de } \\
\text { voluntariado }\end{array}$ & 127.4 & 10 & $\begin{array}{r}\mathrm{m} 2 \mathrm{x} \\
\text { persona }\end{array}$ & 12.7 \\
\hline & & Seguridad & 13.28 & 10 & $\begin{array}{r}\mathrm{m} 2 \mathrm{x} \\
\text { persona }\end{array}$ & 1.3 \\
\hline \multirow{11}{*}{$\begin{array}{c}\text { Segundo } \\
\text { nivel }\end{array}$} & \multirow{3}{*}{$\begin{array}{l}\text { Área de uso mixto } \\
\text { (Residencia y Centro de } \\
\text { día) }\end{array}$} & $\begin{array}{l}\text { Salón de } \\
\text { actividades } 1\end{array}$ & 83.32 & 4 & $\begin{array}{r}\mathrm{m} 2 \mathrm{x} \\
\text { persona }\end{array}$ & 20.8 \\
\hline & & $\begin{array}{l}\text { Salón de } \\
\text { actividades } 2\end{array}$ & 58.58 & 4 & $\begin{array}{r}\mathrm{m} 2 \mathrm{x} \\
\text { persona }\end{array}$ & 14.6 \\
\hline & & $\begin{array}{l}\text { Salón de } \\
\text { actividades } 3 \\
\end{array}$ & 49.15 & 1.5 & $\begin{array}{r}\mathrm{m} 2 \mathrm{x} \\
\text { persona }\end{array}$ & 32.8 \\
\hline & & Of. Psicólogo & 14.53 & 10 & $\begin{array}{r}\mathrm{m} 2 \mathrm{x} \\
\text { persona }\end{array}$ & 1.5 \\
\hline & & $\begin{array}{l}\text { Sala de } \\
\text { reuniones }\end{array}$ & 15.27 & 1.5 & $\begin{array}{r}\mathrm{m} 2 \mathrm{x} \\
\text { persona }\end{array}$ & 10.2 \\
\hline & & $\begin{array}{l}\text { Of. Asistente } \\
\text { social }\end{array}$ & 15.56 & 10 & $\begin{array}{r}\mathrm{m} 2 \mathrm{x} \\
\text { persona }\end{array}$ & 1.6 \\
\hline & & Kitchenette & 12.07 & 5 & $\begin{array}{r}\mathrm{m} 2 \mathrm{x} \\
\text { persona }\end{array}$ & 2.4 \\
\hline & & $\begin{array}{l}\text { Director de } \\
\text { centro }\end{array}$ & 23.73 & 10 & $\begin{array}{r}\mathrm{m} 2 \mathrm{x} \\
\text { persona }\end{array}$ & 2.4 \\
\hline & & $\begin{array}{l}\text { Of. } \\
\text { Administrador }\end{array}$ & 17.02 & 10 & $\begin{array}{r}\mathrm{m} 2 \mathrm{x} \\
\text { persona }\end{array}$ & 1.7 \\
\hline & encia & $\begin{array}{l}\text { Hab. adultos } \\
\text { mayores }\end{array}$ & 377.81 & & 20 hab. & 20.0 \\
\hline & Hencid & $\begin{array}{l}\text { Estación de } \\
\text { enfermeras } 1\end{array}$ & 7.94 & 5 & $\begin{array}{r}\mathrm{m} 2 \mathrm{x} \\
\text { persona } \\
\end{array}$ & 1.6 \\
\hline & & $\begin{array}{l}\text { Hab. adultos } \\
\text { mayores }\end{array}$ & 646.09 & 8 & 32 hab. & 35.0 \\
\hline Tercer & & Tópico 1 & 22.56 & 5 & $\begin{array}{r}\mathrm{m} 2 \mathrm{x} \\
\text { persona } \\
\end{array}$ & 4.5 \\
\hline nivel & 201 & $\begin{array}{l}\text { Estación de } \\
\text { enfermeras } 1\end{array}$ & 19.71 & 5 & $\begin{array}{r}\mathrm{m} 2 \mathrm{x} \\
\text { persona }\end{array}$ & 3.9 \\
\hline & & $\begin{array}{l}\text { Estación de } \\
\text { enfermeras } 2\end{array}$ & 7.94 & 5 & $\begin{array}{r}\mathrm{m} 2 \mathrm{x} \\
\text { persona } \\
\end{array}$ & 1.6 \\
\hline & & Sala de lectura & 117.84 & 10 & $\begin{array}{r}\mathrm{m} 2 \mathrm{x} \\
\text { persona } \\
\end{array}$ & 11.8 \\
\hline & & Terraza techada & 66.49 & 4.5 & $\begin{array}{r}\mathrm{m} 2 \mathrm{x} \\
\text { persona }\end{array}$ & 14.8 \\
\hline Cuarto & $\begin{array}{l}\text { Área de uso mixto } \\
\text { (Residencia v }\end{array}$ & $\begin{array}{l}\text { Consultorio } \\
\text { terapia física }\end{array}$ & 19.06 & 10 & $\begin{array}{r}\mathrm{m} 2 \mathrm{x} \\
\text { persona }\end{array}$ & 1.9 \\
\hline nivel & Centro de día) & Piscina & 51.29 & 4 & $\begin{array}{r}\mathrm{m} 2 \mathrm{x} \\
\text { persona }\end{array}$ & 12.8 \\
\hline & & $\begin{array}{l}\text { Gimnasio y } \\
\text { terapia física }\end{array}$ & 93.41 & 5 & $\begin{array}{r}\mathrm{m} 2 \mathrm{x} \\
\text { persona } \\
\end{array}$ & 18.7 \\
\hline & & Vivero & 222.79 & 5 & $\begin{array}{r}\mathrm{m} 2 \mathrm{x} \\
\text { persona } \\
\end{array}$ & 44.6 \\
\hline
\end{tabular}




\begin{tabular}{|c|c|c|c|c|c|c|}
\hline \multirow{4}{*}{ Sótano } & \multirow{4}{*}{ Área de servicios } & Lavandería & 49.98 & 10 & $\begin{array}{r}\mathrm{m} 2 \mathrm{x} \\
\text { persona }\end{array}$ & 5.0 \\
\hline & & $\begin{array}{l}\text { SS.HH-vestidor } \\
\text { hombre }\end{array}$ & 31.13 & 3 & $\begin{array}{r}\mathrm{m} 2 \mathrm{x} \\
\text { persona }\end{array}$ & 10.4 \\
\hline & & $\begin{array}{l}\text { SS.HH-vestidor } \\
\text { damas }\end{array}$ & 30.19 & 3 & $\begin{array}{r}\mathrm{m} 2 \mathrm{x} \\
\text { persona }\end{array}$ & 10.1 \\
\hline & & $\begin{array}{l}\text { Sala para } \\
\text { trabajadores }\end{array}$ & 72.79 & 1.5 & $\begin{array}{r}\mathrm{m} 2 \mathrm{x} \\
\text { persona }\end{array}$ & 48.5 \\
\hline \multicolumn{3}{|c|}{ Total } & & & & 560.91 \\
\hline
\end{tabular}

Fuente: Elaborado por autor

7.6. Análisis del lugar y usuario.

El distrito de Chorrillos tiene una Casa para el Adulto Mayor que cuenta con 3 niveles y fue inaugurada en el año 2009. Sin embargo, desde el año 2016, los dos últimos niveles del centro son utilizados por el Poder Judicial del Perú para atender a los distritos de Lima Sur.

Este nuevo uso del centro llevó a reducir el aforo permitido de personas de la tercera de edad, y actualmente, es perjudicial para los pocos ancianos que continúan asistiendo ya que no tienen un lugar propio para desarrollar sus actividades debido a que estas se ven interrumpidas por el movimiento y los flujos que genera el funcionamiento de las oficinas del Poder Judicial.

Figura 7.6.1: Centro del Adulto Mayor - Poder Judicial

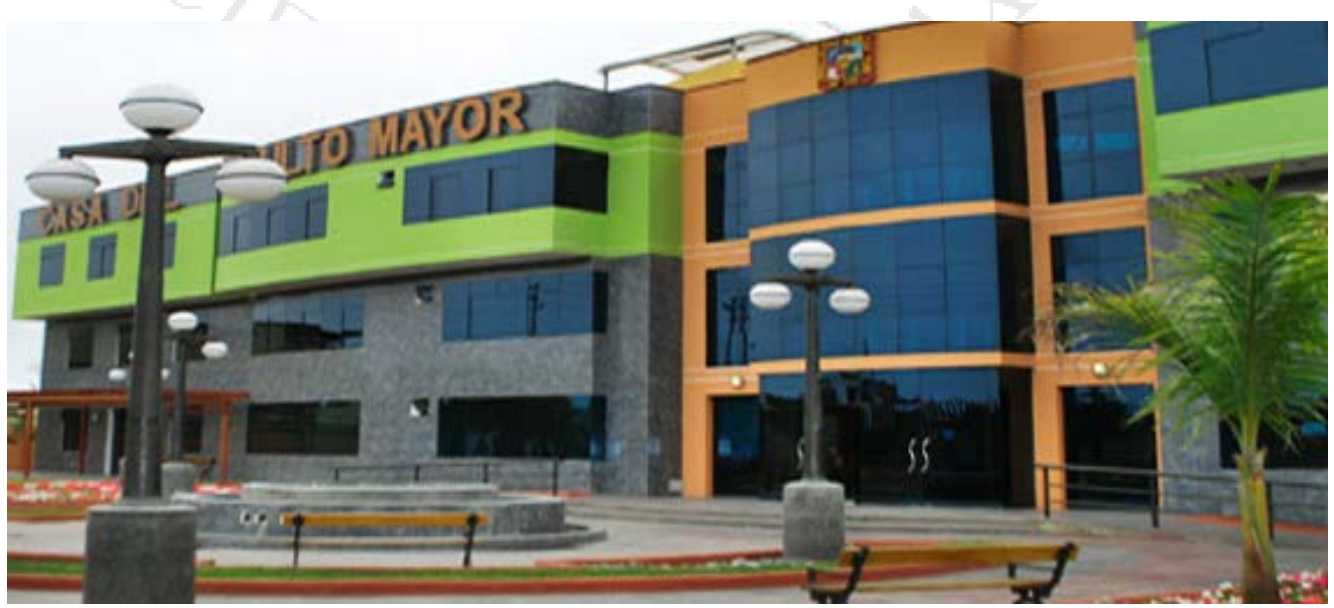

Fuente: (Municipalidad Chorrillos, s.f.) 
Figura 7.6.2: Centro del Adulto Mayor - Poder Judicial

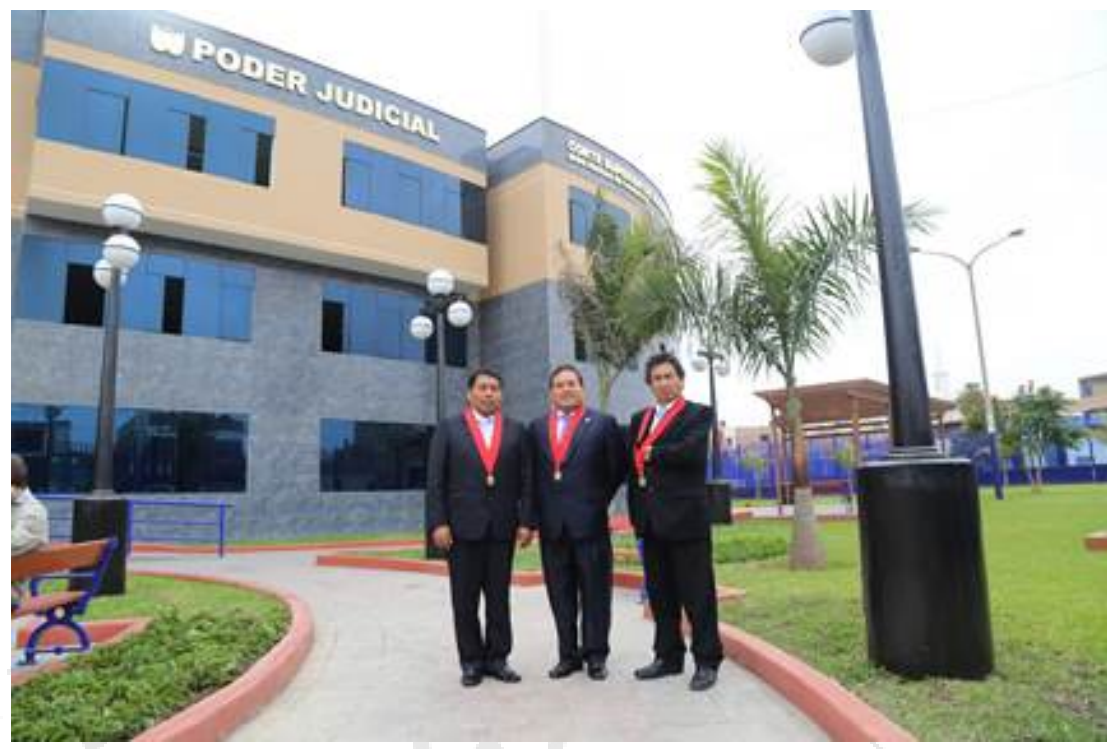

Fuente: (Poder Judicial, 2014)

7.7.Panorama general del proyecto.

Para La ley $\mathrm{N}^{\circ} 29230$ y el Decreto legislativo 1238 y sus correspondientes reglamentos regulan en el Perú la modalidad de inversión denominada” Obras por Impuestos-OXI”, son normas creadas para beneficiar a nuestro país haciendo más eficientes las ejecuciones de obras públicas. Consiste en permitirle a alguna (s) empresa (s) privada(s) financiar y ejecutar proyectos prioritarios para el Estado con el fin de agilizar el beneficio a los ciudadanos. Además, se les permite recuperar la inversión a través de un certificado para el pago del impuesto a la renta de las empresas que participan. Por tal motivo, se utilizará este mecanismo o modalidad de inversión para beneficiar a un grupo vulnerable de la sociedad y de gran importancia y prioridad del estado peruano, que son las personas de la tercera edad.

El terreno donde se desarrollará el proyecto "Residencia y Centro de Día para el Adulto Mayor de Chorrillos y Alto Perú” le pertenece al Arzobispado de Lima, esta institución forma parte de la Iglesia Católica y busca velar por el bien de las personas, por lo cual, el estado de salud de las poblaciones vulnerables, como los adultos mayores, están dentro de sus prioridades. Por este motivo, la institución realizará la donación del terreno ubicado en el distrito de Chorrillos para construir el presente proyecto, además, ellos apoyarían en el funcionamiento y operatividad del mismo. 
Por lo tanto, para que el proyecto pueda desarrollarse, se realizaran dos (2) importantes Convenios entre actores públicos y privados, .Para la elaboración de los estudios y construcción de la Residencia y Centro de Día para el Adulto Mayor se realizara el primer convenio para el financiamiento bajo la modalidad de inversión denominada Obras por Impuesto - OxI, entre la empresa privada y el Ministerio de la Mujer y Poblaciones Vulnerables MIMP- INABIF, y para, la operatividad, mantenimiento y sostenibilidad de este proyecto se realizará un segundo convenio entre el MIMP-INABIF y el Arzobispado de Lima.

Figura 7.7.1:

Pirámide de Maslow

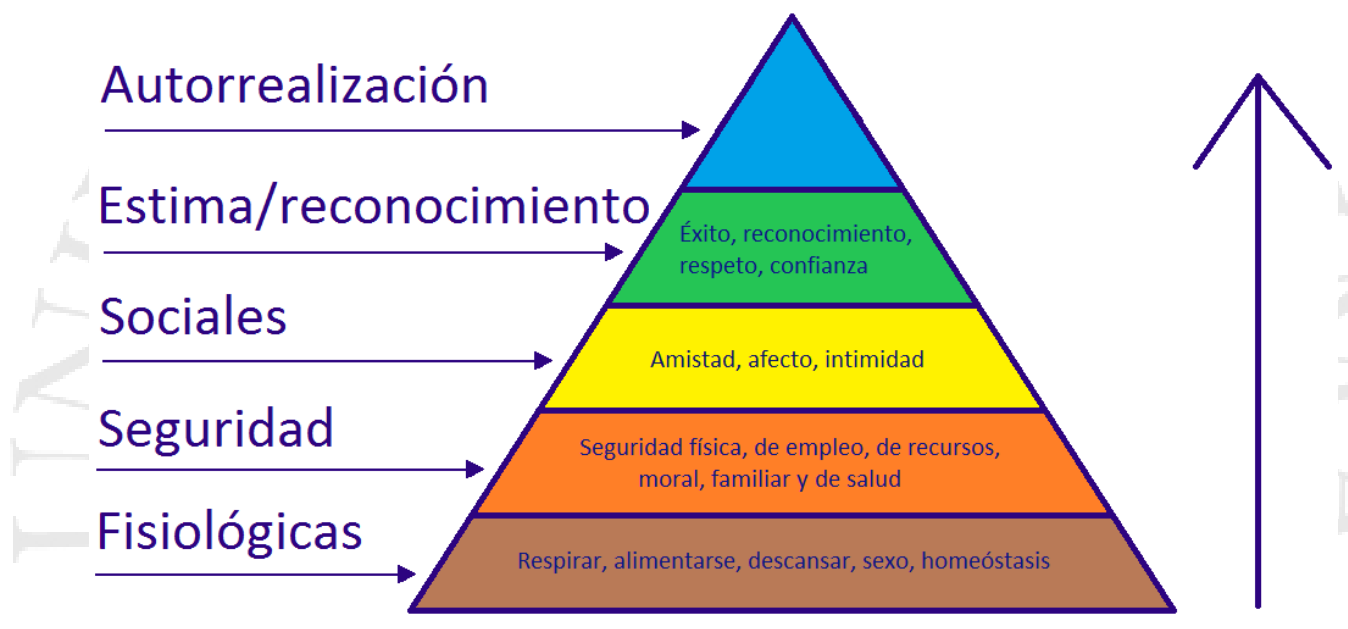

Fuente: (Sevilla Arias, 2017)

Según Maslow, el proyecto se ubica en el campo de las necesidades fisiológicas debido a que busca satisfacer las necesidades básicas como: alimentación, descanso y abrigo, es decir, salud y calidad de vida para un sector vulnerable. Por lo tanto, dada las características eminentemente sociales del proyecto, este no puede ser evaluado desde la perspectiva social del costo beneficio monetario directo, sino, con una evaluación social de costo-efectividad dado que los beneficios a lograr como salud, calidad de vida, impacto que puede lograrse en la familia y en los barrios, etc., no se pueden valorar. Por ejemplo, para los usuarios no se puede medir la recurrencia de enfermedades que originen mayores gastos monetarios en salud; para los familiares se reduce la preocupación de dejar a los adultos mayores solos en casa y con riesgo de accidentes, además, de contar con un nuevo espacio en el cual puedan compartir; así mismo, el barrio se activa al 
existir un nuevo lugar que genera dinamismo en el entorno y reduce la sensación de peligro.

Finalmente, para la 2da etapa relacionada a la operatividad y mantenimiento de la “Residencia y Centro de Día para el Adulto Mayor de Chorrillos y Alto Perú” los recursos financieros o presupuestales requeridos se generarán de dos (2) fuentes de financiamiento denominadas: 1) Recursos Directamente Recaudados-RDR, que se generaran de los ingresos propios del mismo proyecto; 2) Recursos Ordinarios asignados por la Unidad Ejecutora "INABIF" perteneciente al Ministerio de la Mujer y Poblaciones Vulnerables-MIMP, quienes tienen la finalidad de " Contribuir con el desarrollo integral de las familias en situación de vulnerabilidad y riesgo social, con énfasis en niños, niñas, adolescentes, personas adultas mayores y personas con discapacidad en situación de abandono, y propiciar su inclusión en la sociedad y el ejercicio pleno de sus derechos” (Ministerio de la Mujer y Poblaciones Vulnerables - INABIF, 2012, pág. 5) además, se contará con el apoyo de personal voluntario por parte del Arzobispado. Los detalles de esto se explican más adelante.

7.8.Viabilidad, sostenibilidad y tecnología del proyecto.

7.8.1. Viabilidad.

El proyecto se da como resultado de la investigación que identifica la falta de interés que existe por los adultos mayores, quienes son un grupo vulnerable de la población. Así mismo, según un análisis realizado con los datos del MINSA por la Comisión Económica para América Latina y el Caribe (CEPAL, 2016) en nuestro país existen 1,840 centros que brindan atención solo a 43,885 de los 3,011,050 de adultos mayores que viven en la actualidad. Por lo tanto, existe un déficit de atención de más de 2 millones 900 mil ancianos, cifra que puede incrementarse si no se les da la importancia y prioridad necesaria. Además, las actuales condiciones de las residencias y centros de días para los adultos mayores que son de mayor accesibilidad no gozan de las características ni implementación necesaria para garantizar el bienestar de los ancianos.

En el distrito de Chorrillos viven 39,065 adultos mayores, de los cuales aproximadamente 28,517 tienen un estrato medio, medio bajo y bajo; de este grupo aproximadamente 1836 viven en hogares con ingresos per cápita menor a S/. 575.63, 
esto quiere decir que el 4.7 \% no cuenta con los ingresos básicos para vivir de manera estable. (Instituto Nacional de Estadisticas e Informática, 2016). Por otro lado, según los propios pobladores, actualmente hay 47 adultos mayores residen en el AA.HH Alto Perú, zona del distrito con alto índice de peligro, como se explicó en párrafos anteriores, por lo tanto, son un sector de población con mayor vulnerabilidad debido a que viven expuestos a situaciones que comprometen su integridad y estabilidad emocional y física.

Por tal motivo, el objetivo principal del proyecto es generar un nuevo lugar que ayude a acoger y dar cobertura a una mayor cantidad de adultos mayores, lograr que vivan establemente en un lugar seguro en el cual puedan lograr desarrollar sus capacidades y mejorar su calidad de vida. Finalmente, se desea ser un referente para los futuros centros de asistencia que se desarrollen para las personas de la tercera edad que se desarrollara.

\subsubsection{Sostenibilidad.}

La "Residencia y Centro de día para el Adulto Mayor de Chorrillos y Alto Perú” pretende ser un proyecto con carácter social que beneficie a una población vulnerable. Es importante mencionar que, para llevar a cabo la construcción y el desarrollo de este proyecto, se trabajara con dos mecanismos o modalidades distintas. Para el financiamiento de la construcción se utilizará la modalidad de Obra por Impuesto-OxI, debido a que, por sus características, el tipo de proyecto es de gran prioridad para el gobierno peruano por tener como beneficiario a un grupo excluido de población que se considera de alto riesgo.

Debido a que el terreno le pertenece al Arzobispado de Lima, institución que tiene como fin la ayuda a los más necesitados, esta también se hará presente en el funcionamiento del proyecto apoyando con personal voluntario que ayude a la organización y cuidado de los adultos mayores. Este personal pertenecerá a los “Hnos. Franciscanos Capuchinos”, comunidad que se ubica a pocos metros del proyecto.

Por otro lado, para asegurar la sostenibilidad del proyecto a través del tiempo se formará una alianza entre el arzobispado y el Sector Público para cubrir los gastos de mantenimiento y operativos. Los cuales se darán de la siguiente manera. 
- El área de residencia del centro cuenta con una capacidad de 58 plazas, de las cuales, 47 serán gratuitas para los adultos mayores del A.A.H.H Alto Perú y 11 tendrán un costo mínimo mensual para cubrir necesidades básicas.

- Las actividades de centro de día tendrán un costo mínimo de S/. 5.00 diarios para que los adultos mayores puedan ingresar a las diversas actividades. Se formarán 3 grupos de trabajo intercalando días, con esto se brindará mayores opciones a los adultos mayores.

o Grupo A: Lunes-Jueves

o Grupo B: Martes - Viernes

o Grupo C: Miércoles - Sábado.

o Libre: Domingos.

- Como resultado de los trabajos realizados en los diversos talleres, se organizará trimestralmente una feria de exposición y venta de los productos aprendidos en cada uno de estos talleres.

- Alquiler del SUM y aulas para el dictado de cursos y conferencias, así como para el desarrollo de talleres y actividades externas en los horarios de no funcionamiento del Centro de Día.

- La capilla es un espacio de culto gratuito y abierto al público, sin embargo, para actividades específicas como bautizos, matrimonios, etc., se fijará una donación mínima para gastos administrativos

Tabla 7.8.1:

Cuadro de ingresos mensuales y anuales "Residencia y Centro de Día para el Adulto Mayor de Chorrillos y Alto Perú”.

\begin{tabular}{l} 
Ingresos "Residencia y Centro de Día para el Adulto Mayor de Chorrillos y Alto Perú" \\
\hline
\end{tabular}


Tabla 7.8.2:

Cuadro de presupuesto de operación y mantenimiento del Proyecto "Residencia y Centro de Día para el Adulto Mayor de Chorrillos y Alto Perú” para el horizonte de 10 años.

\begin{tabular}{|c|c|c|c|c|c|c|c|c|c|c|}
\hline \multicolumn{11}{|c|}{ Presupuesto de operación y mantenimiento "Residencia y Centro de Día para el Adulto mayor de Chorrillos y Alto Perú" } \\
\hline & Año 1 & Año 2 & Año 3 & Año 4 & Año 5 & Año 6 & Año 7 & Año 8 & Año 9 & Año 10 \\
\hline Personal & \begin{tabular}{|l}
$\mathrm{S} / 1,202,400$. \\
00
\end{tabular} & $\begin{array}{l}\mathrm{S} / 1,202,400 . \\
00\end{array}$ & $\begin{array}{l}\mathrm{S} / 1,202,400 . \\
00\end{array}$ & $\begin{array}{l}\mathrm{S} / 1,202,400 . \\
00\end{array}$ & $\begin{array}{l}\mathrm{S} / 1,202,400 . \\
00\end{array}$ & $\begin{array}{l}\mathrm{S} / 1,202,400 . \\
00\end{array}$ & $\begin{array}{l}\mathrm{S} / 1,202,400 . \\
00\end{array}$ & $\begin{array}{l}\mathrm{S} / 1,202,400 . \\
00\end{array}$ & $\begin{array}{l}\mathrm{S} / 1,202,400 . \\
00\end{array}$ & $\begin{array}{l}\mathrm{S} / 1,202,400 . \\
00\end{array}$ \\
\hline Consumibles oficinas & $\mathrm{S} / 3,600.00$ & $\mathrm{~S} / 3,600.00$ & $\mathrm{~S} / 3,600.00$ & $\mathrm{~S} / 3,600.00$ & $\mathrm{~S} / 3,600.00$ & $\mathrm{~S} / 3,600.00$ & $\mathrm{~S} / 3,600.00$ & $\mathrm{~S} / 3,600.00$ & $\mathrm{~S} / 3,600.00$ & $\mathrm{~S} / 3,600.00$ \\
\hline Seguridad & $\mathrm{S} / 32,400.00$ & $\mathrm{~S} / 32,400.00$ & $\mathrm{~S} / 32,400.00$ & $\mathrm{~S} / 32,400.00$ & $\mathrm{~S} / 32,400.00$ & $\mathrm{~S} / 32,400.00$ & $\mathrm{~S} / 32,400.00$ & $\mathrm{~S} / 32,400.00$ & $\mathrm{~S} / 32,400.00$ & $\mathrm{~S} / 32,400.00$ \\
\hline $\begin{array}{l}\text { Mantenimiento de } \\
\text { equipos }\end{array}$ & $\mathrm{S} / 12,000.00$ & $\mathrm{~S} / 12,000.00$ & $\mathrm{~S} / 12,000.00$ & $\mathrm{~S} / 12,000.00$ & $\mathrm{~S} / 30,000.00$ & $\mathrm{~S} / 12,000.00$ & $\mathrm{~S} / 12,000.00$ & $\mathrm{~S} / 12,000.00$ & S/12,000.00 & $\mathrm{S} / 30,000.00$ \\
\hline Ornato y limpieza & $\mathrm{S} / 12,000.00$ & $\mathrm{~S} / 12,000.00$ & $\mathrm{~S} / 12,000.00$ & $\mathrm{~S} / 12,000.00$ & $\mathrm{~S} / 12,000.00$ & $\mathrm{~S} / 12,000.00$ & $\mathrm{~S} / 12,000.00$ & $\mathrm{~S} / 12,000.00$ & $\mathrm{~S} / 12,000.00$ & $\mathrm{~S} / 12,000.00$ \\
\hline $\begin{array}{l}\text { Alimentaciones } \\
\text { residentes }\end{array}$ & $\mathrm{S} / 20,880.00$ & $\mathrm{~S} / 20,880.00$ & $\mathrm{~S} / 20,880.00$ & $\mathrm{~S} / 20,880.00$ & $\mathrm{~S} / 20,880.00$ & S/20,880.00 & $\mathrm{S} / 20,880.00$ & $\mathrm{~S} / 20,880.00$ & $\mathrm{~S} / 20,880.00$ & $\mathrm{~S} / 20,880.00$ \\
\hline Agua & S/41,760.00 & S/41,760.00 & S/41,760.00 & $\mathrm{S} / 41,760.00$ & S/41,760.00 & S/41,760.00 & $\mathrm{S} / 41,760.00$ & $\mathrm{~S} / 41,760.00$ & S/41,760.00 & $\mathrm{S} / 41,760.00$ \\
\hline Luz & S/41,760.00 & $\mathrm{S} / 41,760.00$ & S/41,760.00 & $\mathrm{S} / 41,760.00$ & $\mathrm{~S} / 41,760.00$ & S/41,760.00 & $\mathrm{S} / 41,760.00$ & $\mathrm{~S} / 41,760.00$ & S/41,760.00 & $\mathrm{S} / 41,760.00$ \\
\hline Gas & S/6,790.00 & $\mathrm{S} / 6,790.00$ & $\mathrm{~S} / 6,790.00$ & $\mathrm{~S} / 6,790.00$ & $\mathrm{~S} / 6,790.00$ & $\mathrm{~S} / 6,790.00$ & $\mathrm{~S} / 6,790.00$ & $\mathrm{~S} / 6,790.00$ & $\mathrm{~S} / 6,790.00$ & $\mathrm{~S} / 6,790.00$ \\
\hline $\begin{array}{l}\text { Teléfono, internet, } \\
\text { cable. }\end{array}$ & S/10,800.00 & S/10,800.00 & S/10,800.00 & $\mathrm{S} / 10,800.00$ & S/10,800.00 & S/10,800.00 & S/10,800.00 & $\mathrm{S} / 10,800.00$ & S/10,800.00 & $\mathrm{S} / 10,800.00$ \\
\hline $\begin{array}{l}\text { Publicidad y } \\
\text { propaganda }\end{array}$ & $\mathrm{S} / 1,000.00$ & $\mathrm{~S} / 1,000.00$ & $\mathrm{~S} / 1,000.00$ & $\mathrm{~S} / 1,000.00$ & $\mathrm{~S} / 1,000.00$ & $\mathrm{~S} / 1,000.00$ & $\mathrm{~S} / 1,000.00$ & $\mathrm{~S} / 1,000.00$ & $\mathrm{~S} / 1,000.00$ & $\mathrm{~S} / 1,000.00$ \\
\hline & & & & $M \cap$ & & & & & & \\
\hline TOTAL & $\mathrm{S} / \mathbf{1}, 385,390.00$ & $\mathrm{~S} / \mathbf{1}, 385,390.00$ & $\mathrm{~S} / \mathbf{1}, 385,390.00$ & $\mathrm{~S} / \mathbf{1}, 385,390.00$ & $\mathrm{~S} / \mathbf{1}, \mathbf{4 0 3 , 3 9 0 . 0 0}$ & $\mathrm{S} / \mathbf{1}, \mathbf{3 8 5}, \mathbf{3 9 0 . 0 0}$ & $\mathrm{S} / \mathbf{1}, \mathbf{3 8 5}, \mathbf{3 9 0 . 0 0}$ & $\mathrm{S} / \mathbf{1}, \mathbf{3 8 5}, \mathbf{3 9 0 . 0 0}$ & S/1,385,390.00 & $\mathrm{S} / \mathbf{1}, \mathbf{4 0 3 , 3 9 0 . 0 0}$ \\
\hline
\end{tabular}

Fuente: Elaborado por autor 


\subsubsection{Tecnología.}

El proyecto, a pesar de estar ubicado en la ciudad, busca una conexión con la naturaleza, por lo tanto, es importante generar visuales, sensaciones, iluminación y ventilación que hagan de este un lugar confortable.

Por tal motivo, la forma del Centro optimiza la ventilación y los ingresos de luz natural al interior del inmueble mediante la orientación y el trabajo de ingresos de luz empleando teatinas, sol y sombra, y una fachada dinámica.

\subsection{Gestión económica financiera.}

La "Residencia y Centro de día para el Adulto Mayor de Chorrillos y Alto Perú” es un proyecto que tiene $2336.37 \mathrm{~m} 2$ de terreno y en el que el $34 \%$ es área libre y el 66\% es área construida, esta está dividida en dos bloques de 3 y 4 niveles que en su totalidad suman 4939.85m2. En el siguiente cuadro se puede observar el costo del proyecto en dos etapas.

Tabla 7.9.1:

Tabla de costos.

\begin{tabular}{|c|c|c|c|c|}
\hline \multicolumn{5}{|c|}{ Residencia y Centro de Día para el Adulto Mayor de Chorrillos y Alto Perú } \\
\hline ITEM & Descripción & Metrado & Precio (S/.) & Parcial (S/.) \\
\hline \multirow[t]{7}{*}{1} & Primera fase & & & \\
\hline & Habilitación de terreno & 2336.37 & $\mathrm{~S} / 580.00$ & $\mathrm{~S} / \mathbf{1}, 355,094.60$ \\
\hline & Gastos notariales y registrales & +1 & 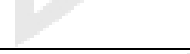 & $\mathrm{C}$ \\
\hline & Estudio topográfico & 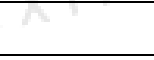 & & +2 \\
\hline & Movimiento de tierras & & 要 & 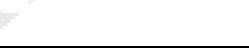 \\
\hline & Trabajos preliminares & & 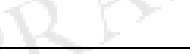 & \\
\hline & Patios y jardinería & & $x$ & \\
\hline \multirow[t]{7}{*}{2} & Segunda fase & & & \\
\hline & Edificación & 4939.85 & $\mathrm{~S} / 3,465.00$ & $\mathrm{~S} / \mathbf{1 7}, \mathbf{1 1 6 , 5 8 0 . 2 5}$ \\
\hline & Cimentación y estructuras & & $\mathrm{S} / 1,650.00$ & \\
\hline & Instalaciones Sanitarias y eléctricas & & $\mathrm{S} / 693.00$ & \\
\hline & Arquitectura y acabados & & $\mathrm{S} / 1,122.00$ & \\
\hline & & & & \\
\hline & COSTO TOTAL S/. & & & $\mathrm{S} / \mathbf{1 8 , 4 7 1 , 6 7 4 . 8 5}$ \\
\hline
\end{tabular}

Fuente: Elaborado por autor 
Cronograma de proyecto "Residencia y Centro de Día para el Adulto Mayor de Chorrillos y Alto Perú"

\begin{tabular}{|c|c|c|c|c|c|c|c|c|c|c|c|c|c|c|c|c|c|c|c|}
\hline & & $\begin{array}{c}\text { Mes } \\
1 \\
\end{array}$ & $\begin{array}{c}\text { Mes } \\
2 \\
\end{array}$ & $\begin{array}{c}\text { Mes } \\
3 \\
\end{array}$ & $\begin{array}{c}\text { Mes } \\
4 \\
\end{array}$ & $\begin{array}{c}\text { Mes } \\
5 \\
\end{array}$ & $\begin{array}{c}\text { Mes } \\
6 \\
\end{array}$ & $\begin{array}{c}\text { Mes } \\
7 \\
\end{array}$ & $\begin{array}{c}\text { Mes } \\
8 \\
\end{array}$ & $\begin{array}{c}\text { Mes } \\
9 \\
\end{array}$ & $\begin{array}{c}\text { Mes } \\
10 \\
\end{array}$ & $\begin{array}{c}\text { Mes } \\
11 \\
\end{array}$ & $\begin{array}{l}\text { Mes } \\
12 \\
\end{array}$ & $\begin{array}{c}\text { Mes } \\
13 \\
\end{array}$ & $\begin{array}{c}\text { Mes } \\
14\end{array}$ & $\begin{array}{c}\text { Mes } \\
15 \\
\end{array}$ & $\begin{array}{c}\text { Mes } \\
16 \\
\end{array}$ & $\begin{array}{c}\text { Mes } \\
17 \\
\end{array}$ & $\begin{array}{c}\text { Mes } \\
18 \\
\end{array}$ \\
\hline \multirow{2}{*}{ Diseño } & Anteproyecto & & & & & & 1 & + & & & 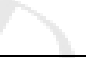 & & & & & & & & \\
\hline & Proyecto & & & & & & & & & 4 & $\pi$ & 2 & & & & & & & \\
\hline \multirow{2}{*}{$\begin{array}{l}\text { Habilit } \\
\text { ación } \\
\text { de } \\
\text { terreno }\end{array}$} & $\begin{array}{l}\text { Inicio de proyecto y entrega } \\
\text { de terreno. }\end{array}$ & & & 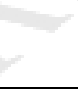 & & & & 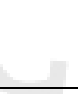 & & & & & & & & & & & \\
\hline & $\begin{array}{l}\text { Habilitación de terreno y } \\
\text { excavación. }\end{array}$ & & & & & & 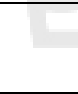 & +1 & & & & & A & & & & & & \\
\hline \multirow{9}{*}{$\begin{array}{l}\text { Constru } \\
\text { cción }\end{array}$} & $\begin{array}{l}\text { Cimentación sótano, } \\
\text { tabiquería e instalaciones. }\end{array}$ & 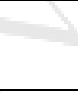 & & & & & + & 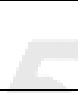 & & & & & & & & & & & \\
\hline & $\begin{array}{l}\text { Casco nivel } 1+ \\
\text { especialidades (volumen } 1 \text { y } \\
\text { 2) }\end{array}$ & $\gamma$ & & & & & 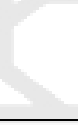 & & & & & & & & & & & & \\
\hline & $\begin{array}{l}\text { Casco nivel } 2+ \\
\text { especialidades (volumen } 1 \text { y } \\
\text { 2) }\end{array}$ & 4 & & & & & & & & & & & & & & & & & \\
\hline & $\begin{array}{l}\text { Casco nivel } 3+ \\
\text { especialidades (volumen } 1 \text { y } \\
\text { 2) }\end{array}$ & 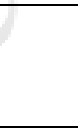 & & & & & . & & 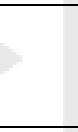 & & & & & & & & & & \\
\hline & $\begin{array}{l}\text { Casco nivel } 4+ \\
\text { especialidades. }\end{array}$ & & & & & & & & & & & & & & & & & & \\
\hline & Tabiquería nivel 1 & & & & & & 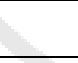 & & & & & & & & & & & & \\
\hline & Tabiquería nivel 2 & & & & & & 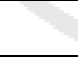 & P & & & Pre & & & & & & & & \\
\hline & Tabiquería nivel 3 & & & & & & & & & & & & & & & & & & \\
\hline & Tabiquería nivel 4 & & & & & 7 & $\mathrm{CH}$ & $1 \times$ & 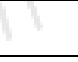 & 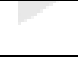 & & va & & & & & & & \\
\hline \multirow{4}{*}{$\begin{array}{l}\text { Acabad } \\
\text { os }\end{array}$} & Acabados interiores nivel 1 & & & $\lambda$ & & & & & & & 61 & 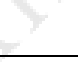 & & & & & & & \\
\hline & Acabados interiores nivel 2 & & & 4 & X & & & & & 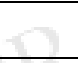 & 8 & & & & & & & & \\
\hline & Acabados interiores nivel 3 & & & & V & 17 & $\Lambda$ & $r_{r}$ & & Le & & & & & & & & & \\
\hline & Acabados interiores nivel & & & & & & L & 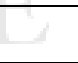 & & & & & & & & & & & \\
\hline
\end{tabular}




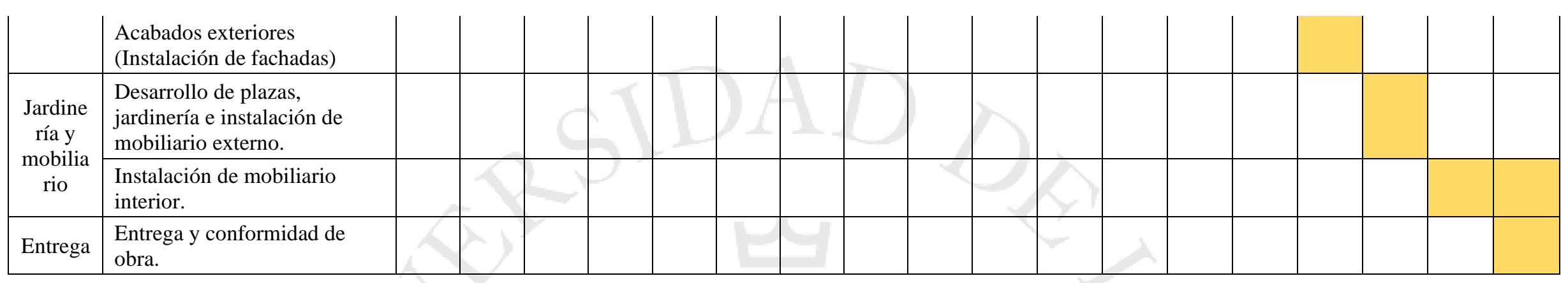

Tabla 7.9.2: Cronograma de proyecto

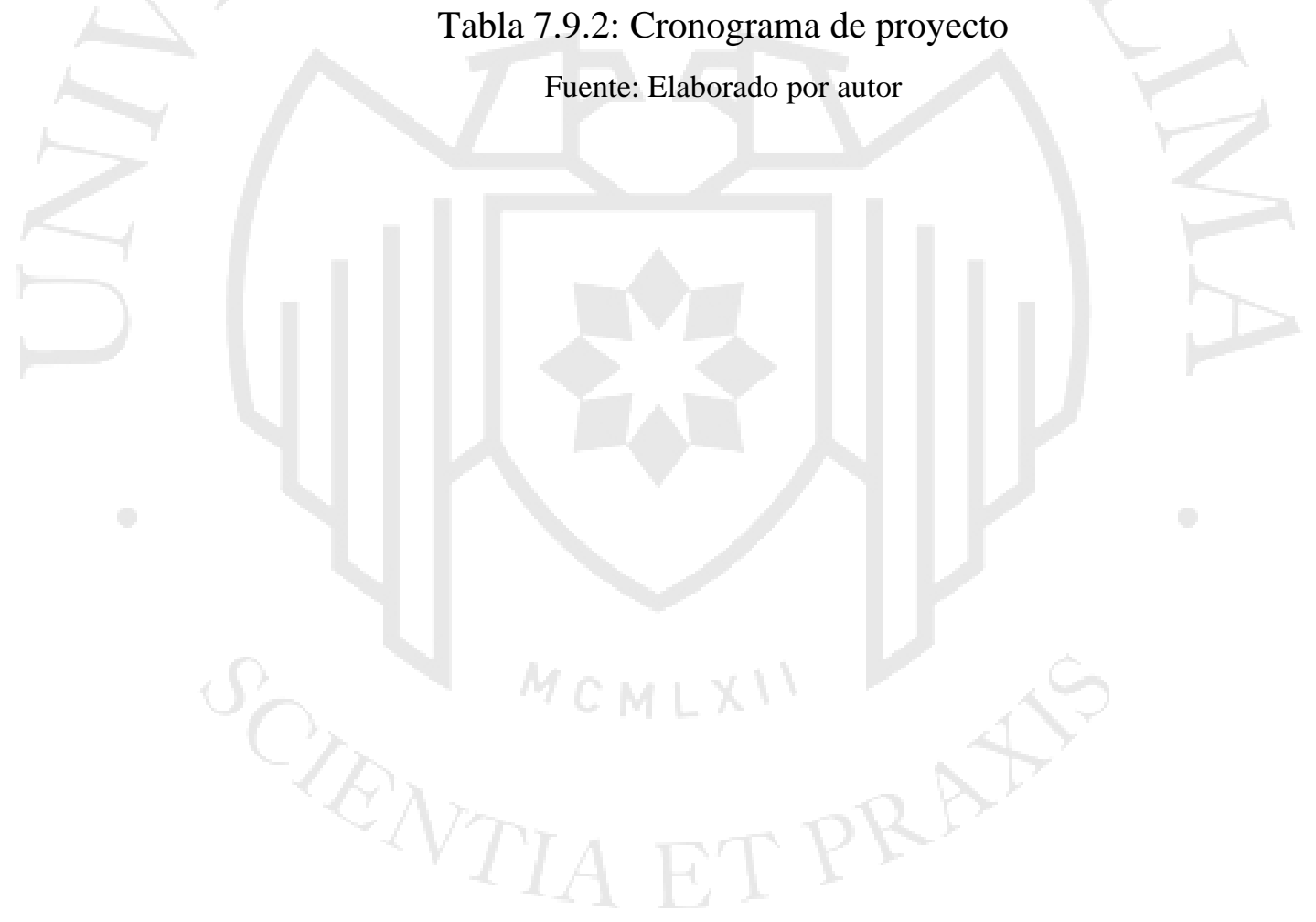




\subsection{Especialidades}

- Estructuras:

El proyecto se divide en 2 volúmenes unidos por un puente suspendido en los niveles $+3 \mathrm{y}+4$ del proyecto. Estos volúmenes se dividen en dos estructuras en la zona de quiebre del volumen, cada una de estas trabajan de forma independiente con un sistema aporticado con luces de $6 \mathrm{mts}$ aproximadamente con vigas de $25 \mathrm{~cm}$ de peralte. Las columnas son redondas o rectangulares dependiendo la ubicación de esta y sus dimensiones son de 30cm de diámetro y 30x25 o 50x25. Finalmente, el tipo de losas es aligeradas de $25 \mathrm{~cm}$ en todos los casos.

- Instalaciones Sanitarias:

El proyecto cuenta con una conexión independiente de agua desde la red pública la cual llega a la cisterna general y distribuye a todas las redes del proyecto. El cálculo de dotación de agua se realizó en base al RNE norma IS 010.

El proyecto tiene en cuenta las actividades que se realizan al interior del proyecto como: SS. HH por cada habitación, SS. HH generales, SS. HH de personal, lavandería, piscina para terapia, sistema de riego para jardines, sistema de circulación en espejos de agua.

Para las áreas verdes se utilizará un económico sistema de regadío por manguera con puntos ubicados estratégicamente para que no interfiera con la estética del proyecto, y para los espejos de agua se implementará un sistema de rebose que permitirá la propia recirculación de este.

Cálculo de dotación de agua: 48’796 litros/día.

- Instalaciones Eléctricas:

Con respecto a las instalaciones eléctricas, el proyecto cuenta con un tablero general y un tablero independiente en cada volumen y/o piso. Además, para este proyecto es necesario el uso de grupo electrógeno en caso de emergencias. 


\section{ANEXO:}

a. Cuadro comparativo entre SNP y SPP.

\begin{tabular}{|c|c|c|}
\hline \multicolumn{3}{|c|}{ DIFERENCIAS ENTRE SNP y SPP. } \\
\hline & SNP & SPP \\
\hline $\begin{array}{l}\text { Propiedad de } \\
\text { aportes }\end{array}$ & $\begin{array}{l}\text { El fondo es común, no es } \\
\text { personal }\end{array}$ & $\begin{array}{l}\text { Tú eres el único dueño de tu } \\
\text { fondo a través de tu Cuenta } \\
\text { Individual. }\end{array}$ \\
\hline $\begin{array}{l}\text { Derecho a servicios } \\
\text { de salud } \\
\text { (ESSALUD) }\end{array}$ & $\begin{array}{l}\text { Como trabajador activo y } \\
\text { también una vez pensionado, } \\
\text { puedes acceder a los servicios de } \\
\text { salud. }\end{array}$ & $\begin{array}{l}\text { Como trabajador activo y } \\
\text { también una vez pensionado, } \\
\text { puedes acceder a los servicios de } \\
\text { salud. }\end{array}$ \\
\hline Pensión Máxima & $\begin{array}{l}\text { Limitada. Hasta el } 100 \% \text { de la } \\
\text { remuneración de referencia y } \\
\text { actualmente hasta un monto } \\
\text { máximo de S/. 857.36; acceso } \\
\text { sujeto a un mínimo de años de } \\
\text { aportación. }\end{array}$ & $\begin{array}{l}\text { Sin límite. El monto de la } \\
\text { pensión resultará del tamaño de } \\
\text { fondo acumulado, el mismo que } \\
\text { crecerá según el valor de los } \\
\text { aportes y de la rentabilidad que } \\
\text { sobre estos se obtenga. }\end{array}$ \\
\hline Pensión Mínima & $\begin{array}{l}\text { A partir de los } 65 \text { años y sólo si } \\
\text { aportas } 20 \text { años como mínimo; } \\
\text { recibes catorce pagos al año de } \\
\text { S/.415. }\end{array}$ & $\begin{array}{l}\text { A partir de los } 65 \text { años y según } \\
\text { los requisitos de ley; recibes } \\
\text { doce pagos al año de } S / .484 .17 \text { o } \\
14 \text { pagos igual al SNP. }\end{array}$ \\
\hline $\begin{array}{l}\text { Aportes } \\
\text { Obligatorios }\end{array}$ & $\begin{array}{l}\text { Descuento del } 13 \% \text { de tu } \\
\text { remuneración mensual. }\end{array}$ & $\begin{array}{l}\text { Descuento del } 10 \% \text { de tu } \\
\text { Remuneración Mensual por } \\
\text { Aporte obligatorio al Fondo, más } \\
\text { la Prima de Seguro y la comisión } \\
\text { de la AFP. }\end{array}$ \\
\hline Aportes Voluntarios & No existen. & $\begin{array}{l}\text { Puedes realizas Aportes } \\
\text { Voluntarios con Fin Previsional } \\
\text { (desde el momento de la } \\
\text { afiliación) y Sin Fin Previsional } \\
\text { (Al cumplir } 5 \text { años de } \\
\text { incorporación al SPP) }\end{array}$ \\
\hline $\begin{array}{l}\text { Pensión por } \\
\text { Discapacidad }\end{array}$ & $\begin{array}{l}\text { Se otorga el } 50 \% \text { de la } \\
\text { remuneración de referencia. }\end{array}$ & $\begin{array}{l}\text { Profuturo otorga el } 50 \% \text { o } 70 \% \\
\text { del promedio de tus } \\
\text { remuneraciones percibidas en los } \\
48 \text { meses anteriores al siniestro, } \\
\text { reajustadas de acuerdo al Índice } \\
\text { de Precios al Consumidor (IPC). }\end{array}$ \\
\hline Gastos de Sepelio & Monto fijo. & $\begin{array}{l}\text { Profuturo otorga un reembolso } \\
\text { de gastos de sepelio, hasta por el } \\
\text { tope máximo reajustable cada }\end{array}$ \\
\hline
\end{tabular}




\begin{tabular}{|c|c|c|}
\hline & & $\begin{array}{l}\text { tres meses por el Índice de } \\
\text { Precios al Consumidor (IPC), } \\
\text { vigente a la fecha de } \\
\text { fallecimiento del afiliado. } \\
\text { Requisitos documentarios: } \\
\text { Gastos de sepelio }\end{array}$ \\
\hline $\begin{array}{l}\text { Pensión de } \\
\text { Sobrevivencia }\end{array}$ & $\begin{array}{l}\text { Se calcula sobre un porcentaje de } \\
\text { la remuneración de referencia } \\
\text { (cónyuge, concubino o } \\
\text { concubina, hijos sanos hasta los } \\
18 \text { años, hijos con discapacidad y } \\
\text { padres). }\end{array}$ & $\begin{array}{l}\text { En caso de fallecimiento, } \\
\text { Profuturo otorga una pensión a tu } \\
\text { cónyuge o concubino, hijos } \\
\text { menores de } 18 \text { años extensible si } \\
\text { continúen sus estudios } \\
\text { ininterrumpidamente hasta } \\
\text { máximo los } 28 \text { años de edad, } \\
\text { hijos con discapacidad total y } \\
\text { permanente, padre (mínimo } 60 \\
\text { años) y madre (mínimo } 55 \text { años) } \\
\text { considerando el devengue a } \\
\text { partir de agosto de 2013. La } \\
\text { pensión se obtiene producto de } \\
\text { calcular el promedio de las } 48 \\
\text { remuneraciones anteriores a la } \\
\text { fecha de siniestro reajustadas con } \\
\text { el Índice de Precios al } \\
\text { Consumidor (IPC). } \\
\text { Requisitos documentarios: } \\
\text { Sobrevivencia de pensionistas } \\
\text { Sobrevivencia (no pensionistas) }\end{array}$ \\
\hline $\begin{array}{l}\text { Informes sobre tus } \\
\text { aportes }\end{array}$ & $\begin{array}{l}\text { El asegurado puede solicitar un } \\
\text { reporte de sus aportes cada } 5 \\
\text { años }\end{array}$ & $\begin{array}{l}\text { De manera permanente a través } \\
\text { de tu estado de cuenta, que } \\
\text { recibirás mensualmente por } \\
\text { correo electrónico o estará } \\
\text { visible en tu zona privada de la } \\
\text { WEB de Profuturo AFP. }\end{array}$ \\
\hline Rentabilidad & $\begin{array}{l}\text { No aplica para el asegurado, es } \\
\text { solo para el Fondo (es común, no } \\
\text { personal) }\end{array}$ & $\begin{array}{l}\text { En Profuturo, tu cuenta } \\
\text { Individual obtiene un } \\
\text { rendimiento producto de la } \\
\text { inversión efectuada con el Fondo } \\
\text { de Pensiones. }\end{array}$ \\
\hline $\begin{array}{l}\text { Tiempo mínimo de } \\
\text { aportes para } \\
\text { jubilación. }\end{array}$ & $\begin{array}{l}\text { Es imprescindible contar con } 20 \\
\text { años de aporte. }\end{array}$ & $\begin{array}{l}\text { En Profuturo, no existe tiempo } \\
\text { mínimo de aportes para recibir } \\
\text { una pensión de jubilación. }\end{array}$ \\
\hline $\begin{array}{l}\text { Edad de Jubilación } \\
\text { Legal }\end{array}$ & 65 años (hombres y mujeres) & 65 años (hombres y mujeres) \\
\hline
\end{tabular}




\begin{tabular}{|c|c|c|}
\hline $\begin{array}{l}\text { Jubilación } \\
\text { Anticipada. }\end{array}$ & $\begin{array}{l}\text { Condiciones según edad y años } \\
\text { de aportes. }\end{array}$ & $\begin{array}{l}\text { Puede ser a cualquier edad antes } \\
\text { de cumplir } 65 \text { años, si el monto } \\
\text { de tu Cuenta Individual así lo } \\
\text { permite, y bajo determinadas } \\
\text { condiciones de la ley del Sistema } \\
\text { Privado de Pensiones (SPP) } \\
\text { podrás acceder a la Jubilación } \\
\text { Anticipada Ordinaria o a la } \\
\text { Jubilación por Desempleo } \\
\text { (REJA). }\end{array}$ \\
\hline $\begin{array}{l}\text { Unidad monetaria } \\
\text { para tu pensión. }\end{array}$ & Nue & $\begin{array}{l}\text { Tú eliges: en Nuevos Soles } \\
\text { (nominales, ajustados o } \\
\text { indexados) o en Dólares de los } \\
\text { E.U.A. (Estados Unidos de } \\
\text { América) ajustados. }\end{array}$ \\
\hline $\begin{array}{l}\text { Bono de } \\
\text { Reconocimiento. }\end{array}$ & No a & $\begin{array}{l}\text { Tienes derecho al Bono de } \\
\text { Reconocimiento si cumples con } \\
\text { los requisitos de ley. Este bono } \\
\text { reconoce los aportes que has } \\
\text { realizado en el Sistema Nacional } \\
\text { de Pensiones (SNP). }\end{array}$ \\
\hline $\begin{array}{l}\text { Modalidades de } \\
\text { Pensión. }\end{array}$ & $M C$ & $\begin{array}{l}\text { Puedes elegir la modalidad de } \\
\text { pensión que más te convenga, } \\
\text { con o sin Gratificación: Retiro } \\
\text { Programado, Renta Vitalicia } \\
\text { Familiar, Renta Temporal con } \\
\text { Vitalicia Diferida, Renta Mixta, } \\
\text { Renta Combinada o Renta } \\
\text { Vitalicia Bimoneda; } \\
\text { adicionalmente, podrás contratar } \\
\text { en el caso de la Renta Vitalicia } \\
\text { Familiar - Inmediata o Diferida - } \\
\text { un periodo garantizado como } \\
\text { producto complementario } \\
\text { (excepto en la Renta Vitalicia } \\
\text { Bimoneda). }\end{array}$ \\
\hline Retiro de su Fondo. & No es posible. & $\begin{array}{l}\text { Existe la posibilidad de retirar } \\
\text { parte de tu Cuenta Individual, } \\
\text { siempre y cuando cumplas con } \\
\text { las condiciones establecidas para } \\
\text { la Pensión de Régimen Especial } \\
\text { de Jubilación Anticipada (REJA) } \\
\text { por desempleo (vigente hasta el } \\
31 \text { de diciembre de 2018) o para } \\
\text { el Retiro del Excedente de } \\
\text { Pensión. }\end{array}$ \\
\hline & & \\
\hline
\end{tabular}




\begin{tabular}{|c|c|c|}
\hline $\begin{array}{l}\text { Puedes mejorar tu } \\
\text { pensión. }\end{array}$ & $\begin{array}{l}\text { No puedes mejorarla, salvo que } \\
\text { el afiliado postergue el momento } \\
\text { de su jubilación para incrementar } \\
\text { el tiempo de aportación. }\end{array}$ & $\begin{array}{l}\text { Si es posible; Profuturo te brinda } \\
\text { la asesoría necesaria para obtener } \\
\text { una pensión de acuerdo a tus } \\
\text { expectativas. }\end{array}$ \\
\hline $\begin{array}{l}\text { Si eres jubilado, } \\
\text { ¿puedes volver a } \\
\text { trabajar? }\end{array}$ & $\begin{array}{l}\text { Sí, sin embargo, es necesario } \\
\text { comunicar este hecho a la ONP, } \\
\text { quien suspenderá el pago de tu } \\
\text { pensión en curso; al concluir tu } \\
\text { nueva relación laboral, el tiempo } \\
\text { aportado se considerará en un } \\
\text { proceso de recalculo del monto } \\
\text { de la pensión. Si la pensión } \\
\text { percibida más la remuneración } \\
\text { del trabajador es menor que el } \\
50 \% \text { de una UIT, no se suspende } \\
\text { el pago de la pensión }\end{array}$ & $\begin{array}{l}\text { Si eres jubilado del Sistema } \\
\text { Privado de Pensiones (SPP), } \\
\text { puedes volver a trabajar sin dejar } \\
\text { de percibir tu pensión de } \\
\text { jubilación y también optar por la } \\
\text { jubilación sin dejar de trabajar; } \\
\text { además, mantienes el derecho a } \\
\text { realizar Aportes Voluntarios con } \\
\text { Fin Previsional (solo bajo un } \\
\text { Retiro programado) y Aportes } \\
\text { Voluntarios sin Fin Previsional. } \\
\text { No tienes el deber de realizar } \\
\text { Aportes Obligatorios. }\end{array}$ \\
\hline Herencia & $\begin{array}{l}\text { Al no haber propiedad sobre los } \\
\text { aportes, no existe herencia de los } \\
\text { mismos. }\end{array}$ & $\begin{array}{l}\text { Puede existir herencia de los } \\
\text { saldos no usados en el pago de } \\
\text { pensión, si no hay beneficiarios y } \\
\text { el causante fallecido es un } \\
\text { afiliado activo o pasivo en Retiro } \\
\text { Programado, Renta Temporal o } \\
\text { Periodo Garantizado. }\end{array}$ \\
\hline $\begin{array}{l}\text { Transferencia de } \\
\text { Fondos al Exterior }\end{array}$ & $\begin{array}{l}\text { No existe posibilidad alguna de } \\
\text { transferir el aporte efectuado por } \\
\text { el trabajador. }\end{array}$ & $\begin{array}{l}\text { Si cumples con los requisitos de } \\
\text { la normativa, se puede transferir } \\
\text { tu fondo al exterior, incluido el } \\
\text { valor del Bono de } \\
\text { Reconocimiento, en caso de que } \\
\text { ya exista, pagado por la Oficina } \\
\text { de Normalización Previsional } \\
\text { (ONP). }\end{array}$ \\
\hline Tipo de Fondo. & Único. & $\begin{array}{l}\text { Esquema Multifondos. Son } \\
\text { cuatro tipos de fondos: } \\
\text { Tipo } 0 \text { - Protección de Capital. } \\
\text { Tipo } 1 \text { - Preservación de Capital. } \\
\text { Tipo } 2 \text { - Mixto o Balanceado. } \\
\text { Tipo } 3 \text { - Apreciación de Capital. } \\
\text { Tú eliges el que más se ajuste a } \\
\text { tu perfil y objetivos. }\end{array}$ \\
\hline $\begin{array}{l}\text { Reajuste de la } \\
\text { Pensión. }\end{array}$ & $\begin{array}{l}\text { Sujeto a disponibilidad de } \\
\text { recursos del Estado. }\end{array}$ & $\begin{array}{l}\text { Las pensiones vitalicias en } \\
\text { nuevos soles se reajustan } \\
\text { trimestralmente con el Î́ndice de } \\
\text { Precios al Consumidor (IPC) o la } \\
\text { tasa de ajuste pactada. La } \\
\text { Pensión bajo Retiro Programado }\end{array}$ \\
\hline
\end{tabular}




\begin{tabular}{|l|l|l|} 
& & $\begin{array}{l}\text { se recalcula cada año, incluyendo } \\
\text { los rendimientos obtenidos. }\end{array}$ \\
\hline $\begin{array}{l}\text { Devolución de } \\
\text { saldo. }\end{array}$ & No disponible & $\begin{array}{l}\text { El afiliado que cuente con } 65 \\
\text { años o más podrá solicitar la } \\
\text { entrega de hasta el 95.5\% del } \\
\text { saldo disponible de su cuenta }\end{array}$ \\
\hline
\end{tabular}

Fuente: (PROFUTURO, s.f.) 


\section{Bibliografía}

Acevedo Alemán, J., Trujillo Perez, M., \& López Saucedo, M. (2012). Envejeciendo Dignamente: Una mirada hacia las condiciones de vida del Adulto Mayor. Mexico D.F: Plaza y Valdéz.

Acolle.org. (2018). ACOLLE. Obtenido de ACOLLE: http://www.acolle.org/centrosasociados/residencia-padre-rubinos/

Archdaily. (20 de Enero de 2012). Archdaily. Obtenido de Archdaily: https://www.archdaily.pe/pe/02-132203/residencia-para-mayores-en-mota-delcuervo-cuenca-geed-arquitectos

Archdaily. (14 de 09 de 2014). Archdaily. Obtenido de Archdaily: https://www.archdaily.pe/pe/627503/padre-rubinos-elsa-urquijo-arquitectos

Arquitectos Jaliscienses. (2014). Arquitectos Jaliscienses. Obtenido de Arquitectos Jaliscienses.:

http://quijote.biblio.iteso.mx/arquitectos/julio_de_la_pena/planos/agencias_de_a utos/

Asociación UNACEM. (22 de Octubre de 2014). UNACEM. Obtenido de UNACEM: http://www.asociacionunacem.org/tag/adulto-mayor/

Atlantico.net. (04 de Setiembre de 2014). atlantico.net. Obtenido de atlantico.net: http://www.atlantico.net/articulo/galicia/institucion-padre-rubinos-ejemploatencion-social/20140904105923433653.html

Ayundamiento Mota del Cuervo. (16 de Diciembre de 2015). Ayundamiento Mota del Cuervo. Obtenido de Ayundamiento Mota del Cuervo: https://www.motadelcuervo.es/

Banco Mundial. (2016). http://www.bancomundial.org/. Recuperado el 2018, de http://www.bancomundial.org/: https://datos.bancomundial.org/indicador/SP.DYN.LE00.IN?end=2016\&start=1 960\&view $=$ chart

Caritas del Perú. (s.f.). Caritas del Perú. Obtenido de Caritas del Perú: http://www.caritas.org.pe/

Castilla - La Mancha. (2016). Castilla - La Mancha. Obtenido de Castilla - La Mancha: http://www.castillalamancha.es/node/79372

Central Informativa del Adulto Mayor. (10 de 08 de 2016). Central Informativa del Adulto Mayor. Obtenido de Central Informativa del Adulto Mayor: https://www.redadultomayor.org/actividades-para-adultos-mayores-de-hogargeriatrico/

CEPAL. (2016). Cepal. (J. Irving, Editor) Recuperado el Noviembre de 2018, de Cepal: https://www.cepal.org/celade/noticias/paginas/7/53017/IrvingJaime.pdf

Conferencia Episcopal Peruana. (15 de Mayo de 2009). Iglesia Catolica.org. Obtenido de Iglesia Catolica.org:

http://www.iglesiacatolica.org.pe/cep_prensa/archivo_2009/desarrolloinformaci on_150509.htm

Congregación Religiosas de Las Hijas de Nuestra Señora de la Piedad. (2016). Casa Hogar "La Piedad". Casa Hogar "La Piedad". Lima.

Congreso de la República. (1973). Decreto Legistlativo Nº19990. Lima.

Congreso de la República. (12 de Junio de 2006). Ministerio de la Mujer y Poblaciones Vulnerables. Obtenido de http://www.mimp.gob.pe/files/direcciones/dgfc/diapam/Ley_28803_Ley_del_A dulto_Mayor.pdf

Congreso de la República. (9 de Mayo de 2010). Congreso de la República. Obtenido de 
http://www2.congreso.gob.pe/Sicr/RelatAgenda/proapro.nsf/ProyectosAprobado sPortal/96B160FDACE4B1A00525774A0076CFE5/\$FILE/1898AdultoMayor.p $\mathrm{df}$

Congreso de la República. (20 de Marzo de 2015). Congreso de la República. Obtenido de

http://www2.congreso.gob.pe/Sicr/TraDocEstProc/Contdoc03_2011.nsf/d99575 da99ebfbe305256f2e006d1cf0/7082a31ea66fdcaf05257e0e006ad41e/\$FILE/PL 04339200315.pdf

Di Véroli, D., \& Schmunis, E. (2008). Arquitectura y Envejecimiento - Hacia un Hábitat inclusivo. Buenos Aires, Argentina: Nobuko. Recuperado el 19 de Mayo de 2016

Diario Gestión. (09 de 12 de 2013). Arcadia: Una opción de lujo entre 340 residencias geriátricas informales en Lima. Diario Gestión. Obtenido de https://gestion.pe/economia/empresas/arcadia-opcion-lujo-340-residenciasgeriatricas-informales-lima-54401

Diario Gestión. (2016). Diario Gestión. Obtenido de Diario Gestión: https://gestion.pe/economia/distritos-perifericos-lima-seran-afectados-sismogran-magnitud-118259

Dulce Estacia Hogar para Personas Mayores. (2018). Dulce Estacia Hogar para Personas Mayores. Obtenido de Dulce Estacia Hogar para Personas Mayores: http://dulceestancia.com/

El Comercio. (06 de Julio de 2017). El Comercio. Obtenido de El Comercio: https://elcomercio.pe/somos/tatiana-mora-joven-promesa-peruana-muay-thai440088 ?foto $=4$

Elsa Urquijo Arquitectos. (2018). Elsa Urquijo Arquitectos. Obtenido de Elsa Urquijo Arquitectos: http://www.elsaurquijo.com/

ESSALUD. (s.f.). Seguro Social de Salud del Perú, CAM. Obtenido de Seguro Social de Salud del Perú, CAM.: http://www.essalud.gob.pe/adulto-mayor/

For Handicap Travelers. (2018). For Handicap Travelers. Obtenido de For Handicap Travelers: http://www.herramientasparaturismoespecial.com/adaptatuhotel.htm

Franco, J. (06 de mayo de 2014). ArchDaily. Obtenido de ArchDaily: https://www.archdaily.pe/pe/02-358786/en-detalle-espacios-dormitorio

González, J. (2018 de Enero de 2014). Salamanca al día. Obtenido de Salamanca al día.: www.salamancartvaldia.es

Google Maps . (s.f.). Google Maps. Obtenido de https://www.google.com/maps

Herrera S., F., Romero A., A., Gonzales J., E., \& Guillen Q., L. (2008). Percepción de los Ancianos sobre los Centros de Desarrollo Integral para el Adulto Mayor. Revista IIPSI - UNMSM, 11(1), 129 - 136.

Ibeas, M. V. (2006). El Fenómeno del Envejecimiento. En J. G. Miranda, Envejecimiento activo, envejecimiento en positivo (págs. 37-64). España: Biblioteca de investigación.

INADEF. (2014). INADEF. Obtenido de INADEF: https://www.gob.mx/cms/uploads/attachment/file/105396/Tomo2_Accesibilidad .pdf

INEI. (2013). Instituto Nacional de Estadísticas e Informática. Recuperado el Mayo de 2016, de https://www.inei.gob.pe:

https://www.inei.gob.pe/media/MenuRecursivo/publicaciones_digitales/Est/Lib1 169/cap06.pdf 
INEI. (25 de 08 de 2015). Instituto Nacional de Estadística e Informática. Recuperado el 2018, de https://www.inei.gob.pe/prensa/noticias/en-el-peru-viven-mas-de-3millones-de-adultos-mayores-8570/

INEI. (10 de 11 de 2015). Www.inei.gob.pe. Obtenido de www.inei.gob.pe: https://www.inei.gob.pe/prensa/noticias/esperanza-de-vida-de-poblacionperuana-aumento-en-15-anos-en-las-ultimas-cuatro-decadas-8723/

INEI. (Marzo de 2016). www.inei.gob.p. Obtenido de www.inei.gob.p: https://www.inei.gob.pe/media/MenuRecursivo/boletines/informetecnico_poblacion-adulta-mayor-oct-nov-dic2015.pdf

INEI, I. N. (30 de Junio de 2015). www.inei.gob.pe. Obtenido de www.inei.gob.pe: https://www.inei.gob.pe/estadisticas/indice-tematico/poblacion-y-vivienda/

Inmaculada de la Serna, P. (2003). La Vejez Desconocida: Una Mirada desde la Biología de la Cultura. España: Ediciones Díaz de Santos S.A.

Instituto Nacional de Estadisticas e Informática. (Noviembre de 2016). Instituto Nacional de Estadisticas e Informática. Obtenido de Instituto Nacional de Estadisticas e Informática:

https://www.inei.gob.pe/media/MenuRecursivo/publicaciones_digitales/Est/Lib1 403/index.html

Interempresas.net. (13 de Febrero de 2018). Interempresas.net. Obtenido de Interempresas.net:

https://www.interempresas.net/Instaladores/Articulos/208759-Climatizacionradiante-por-energia-geotermica-en-Instituto-Benefico-Social-PadreRubinos.html

Ito, T. (2000). Escritos. Valencia, España: ARTES GRÁFICAS SOLER, S. L.

Jiménez, J. J. (1992). La jubilación: opción o imposición social. Reis: Revista española de investigaciones sociológicas, 91-126.

Jones, T. (Mayo de 2015). Replacing and Redefining the Nursing Home Archetype: Integration into Communities. Savannah, Georgia: Degree of Masters of Architecture at Savannah College of Art and Design.

Jones, T.-M. (Mayo de 2015). Replacing and Redefining the Nursing Home Archetype: Integration into Communities. Thesis degree of Masters of Architectura. Savannah, Georgia, EEUU: Faculty of the School of Building Arts.

Mansilla, L., \& Tuñon, E. (2013). Circo - Permeabilidad. Obtenido de http://www.mansilla-tunon.com/circo/epoca8/pdf/2013_193.pdf

Mar del Sur. (s.f.). Mar del Sur. Obtenido de Mar del Sur: https://www.mardelsur.com.pe/historia-de-chorrillos/

Mayores de hoy. (31 de Enero de 2013). Mayores de hoy. Obtenido de Mayores de hoy: https://mayoresdehoy.com/2013/02/09/silla-de-ruedas-y-recamara-que-medidasy-espacios-deben-de-existir/captura-de-pantalla-2013-01-31-a-las-19-04-14/

Milan Celenti, J. C. (2006). Principios de geriatría y gerontología. España: McGrawHill España.

MIMP. (2005). Ministerio de la Mujere y Poblaciones Vulnerables. Obtenido de www.mimp.gob.p:

http://www.mimp.gob.pe/files/programas_nacionales/pncvfs/mimdes_adultos_m ayores_libros.pdf

MIMP. (s.f.). Ministerio de la Mujer y Poblaciones Vulnerables. Obtenido de Ministerio de la Mujer y Poblaciones Vulnerables:

https://www.mimp.gob.pe/contigo/ 
Ministerio de la Mujer y Desarrollo Social. (Diciembre de 2009). www.mimp.gob.pe.

Recuperado el 2018, de www.mimp.gob.pe:

https://www.mimp.gob.pe/adultomayor/archivos/CIAM_boletin.pdf

Ministerio de la Mujer y Poblaciones Vulnerables - INABIF. (20 de Noviembre de 2012). INABIF. Obtenido de INABIF:

https://www.inabif.gob.pe/portalweb/documentos/RM_315_2012_MIMP.pdf

Ministerio de Vivienda. (15 de Agosto de 2019). Programa nuestras ciudades.

Montibeller, M. (3 de Diciembre de 2010). La situación del adulto mayor en el Perú prehispánico y en el Perú moderno. Revista Peruana de Epidemiología., 14, 63.

Montibeller, M. (Diciembre de 2010). La situación del adulto mayor en el Perú prehispánico y en el Perú moderno. Revista Peruana de Epidemología, 12(3), 12.

Municipalidad Ancon, Lima. (s.f.). Municipalidad Ancon, Lima. Obtenido de http://muniancon.gob.pe/portal/noticia521

Municipalidad Chorrillos. (s.f.). MuniChorrillos. Obtenido de MuniChorrillos: http://www.munichorrillos.gob.pe/

Municipalidad de La Molina. (20 de Junio de 2018). Munimolina. Obtenido de Munimolina: http://www.munimolina.gob.pe/index.php/servicios/programasmunicipales/ciam

Municipalidad de Lima. (Agosto de 2017). MunLima. Obtenido de MunLima: http://www.munlima.gob.pe/noticias/item/35019-adultos-mayores-celebran-sud\%C3\%ADa-con-variadas-actividades-en-establecimientos-de-la-mml

Municipalidad de Lima. (s.f.). Municipalidad de Lima, Centro Integral de Atención al Adulto Mayor - CIAM. Obtenido de Municipalidad de Lima, Centro Integral de Atención al Adulto Mayor - CIAM: http://www.munlima.gob.pe/centrointegral-de-atencion-al-adulto-mayor-ciam\#sede-lima

Municipalidad La Arena, Piura. (2015). Municipalidad La Arena. Obtenido de http://www.munilaarena.gob.pe/noticia.php?cod_noticia=316

Oficina de Normalización Previsional. (s.f.). ONP. Obtenido de https://www.onp.gob.pe/Servicios/quiero_afiliarme_snp/tipos_regimenes_pensio narios_prestaciones/inf/pension_jubilacion_19990

OMS - Organización Mundial de la Salud. (22 de Abril de 2016). Acción multisectorial para un envejecimiento saludable basado en el ciclo de vida. Obtenido de 69.a Asamblea Mundial de la Salud: http://apps.who.int/gb/ebwha/pdf_files/WHA69/A69_17-sp.pdf

OMS. (1 de Enero de 2016). Organización Mundial de la Salud. Obtenido de Organización Mundial de la Salud: http://www.who.int/ageing/es/

ONU. (13 de Agosto de 2019). World Population Prospects 2019. Obtenido de https://population.un.org/wpp/graphs/

Organización Mundial de la Salud (OMS). (1 de Enero de 2016). Organización Mundial de la Salud. Obtenido de Organización Mundial de la Salud: http://www.who.int/ageing/es/

Orosco, C. (7 de Julio de 2015). Depresión y autoestima en adultos mayores institucionalizados y no institucionalizados en la ciudad de Lima. Persona, revista de Psicología de la Universidad de Lima(18), 91-104. Obtenido de http://revistas.ulima.edu.pe/index.php/Persona/article/view/500/474

Padre Rubinos. (2018). Institución Benéfico Social Padre Rubinos. Obtenido de Institución Benéfico Social Padre Rubinos: http://www.padrerubinos.org/ 
Pensión 65. (5 de Mayo de 2015). Pensión 65. Obtenido de Pensión 65:

http://www.pension65.gob.pe/2015/05/adultos-mayores-usuarios-de-pension-65empezaron-a-cobrar-su-segundo-pago-del-ano/

Peru.com. (s.f.). Peru.com. Recuperado el 2018, de Peru.com: https://peru.com/retro/peru/chorrillos-decada-1940-noticia-447528

Peru21. (15 de 09 de 2012). Peru 21. Obtenido de Peru 21: https://peru21.pe/lima/aprueban-programa-rescatar-adultos-mayores-abandono46106

Pinazo, S., \& Sanchez, M. (2005). Gerontología. Actualización, innovación y propuestas. En S. Pinazo, \& M. Sanchez, Anuario de Psicología (págs. 339347). Barcelona, España: Universidad de Barcelona, Facultat de Psicología. Obtenido de https://www.raco.cat/index.php/anuariopsicologia/article/viewFile/101326/1273 54

Poder Judicial. (21 de Octubre de 2014). PJ. Obtenido de PJ: www.pj.gob.pe PROFUTURO. (s.f.). PROFUTURO AFP del grupo Scotiabank. Recuperado el Marzo de 2018, de PROFUTURO AFP del grupo Scotiabank: https://www.profuturo.com.pe/Personas/Tu-Aportes/Conociendo-el-SistemaPrivado-de-Pensiones/diferencias-entre-el-snp-y-el-spp

Quintanar Olguín, F. (2000). Atención a los Ancianos en los Asilos y Casas Hogar en la Ciudad de México. (1 ed.). México DF, México: Plaza y Valdez S.A.

Residence-Sthelier. (s.f.). residence-sthelier. Obtenido de residence-sthelier: www.residence-sthelier.fr

RNE. (21 de Junio de 2006). Reglamento Nacional de Edificacines - Norma A.120. Obtenido de Reglamento Nacional de Edificacines - Norma A.120: http://www.construccion.org/normas/rne2012/rne2006.htm

Ronie Bautista Gonzales. (20 de Agosto de 2015). La Mula.pe. Obtenido de La Mula.pe: https://redaccion.lamula.pe/2015/08/20/albergues-para-ancianosreclaman-millonaria-deuda-al-mimp-por-cuidado-de-beneficiarios-de-vidadigna/rbautista/

Sáez, C. (3 de Mayo de 2014). En Casa. Obtenido de https://cristinasaez.files.wordpress.com/2014/05/edificios-con-neuronas.pdf

Salazar Sanches, S. (s.f.). Urbanistas Perú. Recuperado el 2018, de Urbanistas Perú: http://www.urbanistasperu.org/limalahorrible/malecon\%20a\%20la\%20chorrillan a.htm

Santa Cruz, W. (2007). Abuelos y Abuelas en la Lucha: Génesis, desarrollo y acciones del movimiento de tercera edad sin cobertura social. Guatemala: Facultad Latinoamericana de Ciencias Sociales (FLACSO).

Sevilla Arias, P. (Agosto de 2017). Economipedia. Obtenido de Economipedia: http://economipedia.com/definiciones/piramide-de-maslow.html

Sirlin, C. (Julio - Setiembre de 2007). Insituto de Seguridad Social. Recuperado el 2016, de Insituto de Seguridad Social: http://www.bps.gub.uy/bps/file/1671/1/lajubilacion-como-situacion-de-cambio.-c.--sirlin.pdf

Zapata Frías, H. (2001). Adulto Mayor: Participación e indentidad. Revistas de Psicología, X, 189 - 197. Obtenido de http://www.redalyc.org/articulo.oa? 